Portland State University

PDXScholar

Fall 12-17-2013

\title{
The Dynamics of Creating Strong Democracy in Portland, Oregon : 1974 to 2013
}

\author{
Paul Roland Leistner \\ Portland State University
}

Follow this and additional works at: https://pdxscholar.library.pdx.edu/open_access_etds

Part of the American Politics Commons, and the Political History Commons Let us know how access to this document benefits you.

\section{Recommended Citation}

Leistner, Paul Roland, "The Dynamics of Creating Strong Democracy in Portland, Oregon : 1974 to 2013" (2013). Dissertations and Theses. Paper 1521.

https://doi.org/10.15760/etd.1520

This Dissertation is brought to you for free and open access. It has been accepted for inclusion in Dissertations and Theses by an authorized administrator of PDXScholar. Please contact us if we can make this document more accessible: pdxscholar@pdx.edu. 
The Dynamics of Creating Strong Democracy in Portland, Oregon - 1974 to 2013

by

Paul Roland Leistner

A dissertation submitted in partial fulfillment of the requirements for the degree of

\author{
Doctor of Philosophy \\ in \\ Urban Studies
}

Dissertation Committee:

Sy Adler, Chair

Carl Abbott

Charles Heying

David Johnson

Richard White

Portland State University

2013 
(C) 2013 Paul Roland Leistner 


\begin{abstract}
Communities across the United States are experiencing a "civic revival" that is reconnecting community members with local decision-making and civic life in their communities. Since the 1980s, academic researchers and local governance reformers have advocated for a shift away from the traditional top-down, expert-driven approach to governance and toward a governance model in which government leaders and staff and community members work as partners to shape the community and make local decisions.

Portland, Oregon, since the 1970s, has been known nationally and internationally as a city with a tradition of strong community involvement. Portland's successes and failures offer a valuable case study into what it takes to develop, implement, and sustain policies, structures, and programs that encourage greater participatory democracy.

This dissertation reviews the evolution of Portland's community and neighborhood system from its creation in the 1970s through 2013 through an examination of the many reviews of the system over the years supplemented by reviews of newspaper accounts and informal, unstructured interviews with individuals who were involved in different processes and programs. This dissertation investigates which elements are important to the success of a city-wide community and neighborhood involvement system, the factors that help or hinder the adoption and implementation of system reforms, and strategies that help embed system advances to prevent them from being eroded or undone.
\end{abstract}

This dissertation argues that a community that wants to move toward much greater participatory democracy and community governance must develop and implement 
a comprehensive strategy that accomplishes three goals: involving many more people in the civic life in their community, building community capacity to organize and be involved in local decision making, and significantly improving the willingness and ability of city leaders and staff to work in partnership with community members and organizations. This dissertation also argues that community and neighborhood involvement systems need to include not only traditional geographic-based neighborhood associations but also communities of people who find their community through shared identity. 


\section{DEDICATION}

To all the thousands of Portlanders who have volunteered their time in neighborhood associations and other community-based groups over the past forty years and who have helped make Portland the great city it is. 


\section{ACKNOWLEDGEMENTS}

I would not have been able to complete my dissertation without the ongoing guidance of my dissertation committee members, the support of my co-workers at the City of Portland Office of Neighborhood Involvement, valuable input from many Portland neighborhood and community activists, and years of support from my family.

I would like to thank my dissertation committee chair, Sy Adler, for remaining calm and always helping me find a way to keep moving forward, and my dissertation committee members, Carl Abbott, Charles Heying, David Johnson, and Richard White, for sticking with me and remaining enthusiastic even when the chapters got long.

I would not have been able to complete this project without strong and ongoing support from my co-workers at the City of Portland Office of Neighborhood Involvement. They shared their experiences of working within the system with me, helped me track down information, covered for me during the extended time I took off to finish writing, and always cheered me on. I particularly want to thank Amalia Alarcón de Morris, Brian Hoop, Jeri Williams, Afifa Ahmed-Shafi, Nickole Cheron, Amy Archer, and Mike Kersting.

I also would like to thank the many neighborhood and community activists who shared their memories, frustrations, hopes, and ideas with me and the many city staff people who also shared their experiences and helped me track down informationespecially the staff at the City of Portland City Archives office. 
Finally, I want to express my deep gratitude to my wife, Amy, and my daughter, Alexa, for their patience and support throughout this long process, for Amy's proofreading, and for Alexa's unflagging belief that I could get this project done. 
TABLE OF CONTENTS

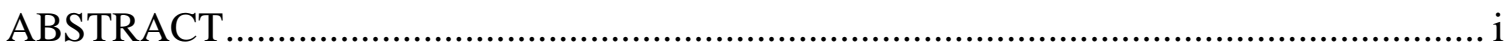

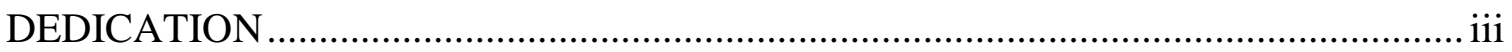

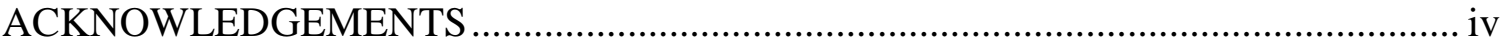

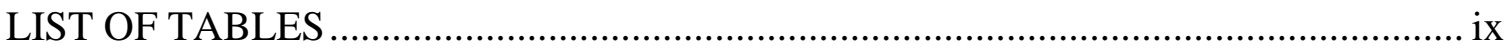

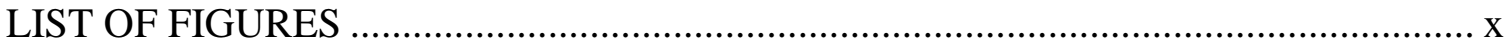

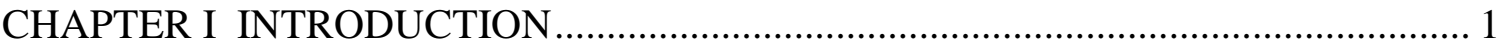

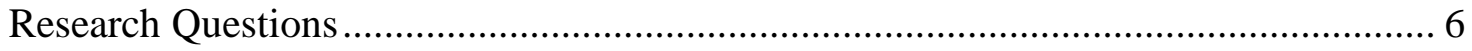

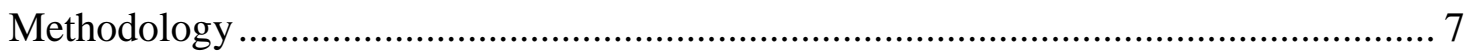

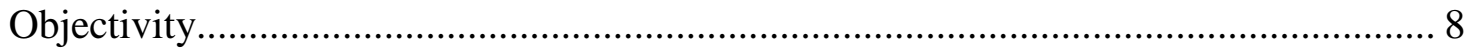

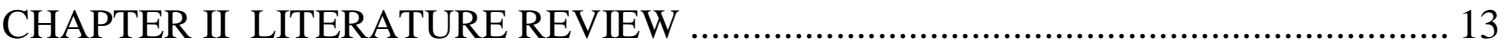

What's the Problem to be Solved?....................................................................... 13

Terms Used to Describe the Goal of a Civic Revival................................................. 17

What will Get Us There?-Elements of Successful City-wide Community Involvement Systems …................................................................................................ 29

Social Capital and Community Building ……………............................................ 39

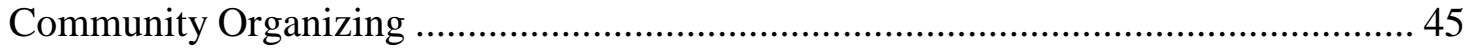

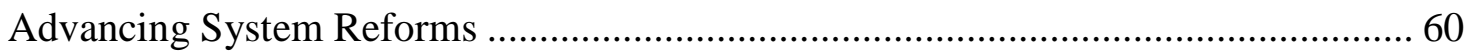

Embedding Change-Sustaining Progress Toward Participatory Democracy............. 64

Literature Specific to Portland ............................................................................. 80

What do I Expect to See in My Case Study of Portland's Citywide Community Involvement System?.......................................................................................... 140

CHAPTER III ORIGINS AND EARLY YEARS_-1970s ............................................ 146

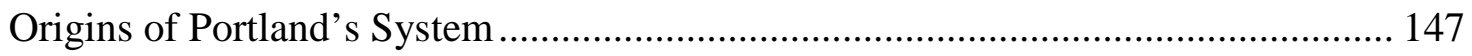

The Birth of Portland's Neighborhood System ………............................................... 148

1971 Planning Commission Proposal for District Planning ....................................... 150

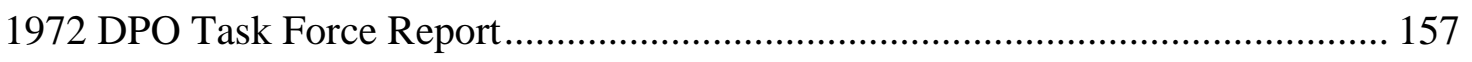

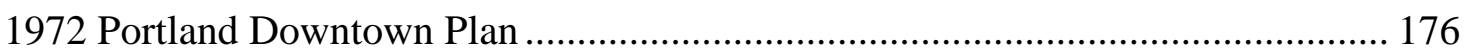

Neighborhood System Structure and Requirements--City Ordinances (1974-1975) . 178

Summary of Key Elements of 1975 Ordinance .......................................................... 185 


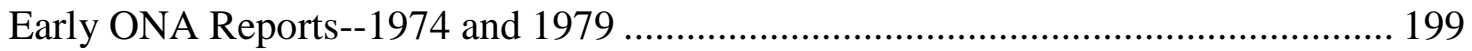

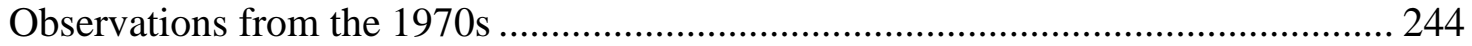

CHAPTER IV EXPANSION AND INSTITUTIONALIZATION-1980s................. 260

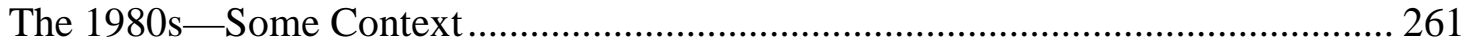

1980 ONA Review Committee ........................................................................... 269

Association of Portland Neighborhoods - 1984-1986 ......................................... 280

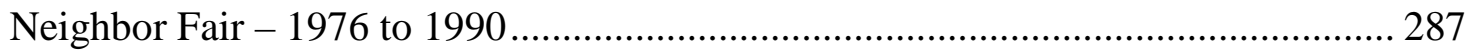

Mayor Bud Clark—Community and Neighborhood Celebration and Recognition ... 292

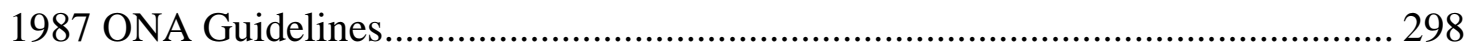

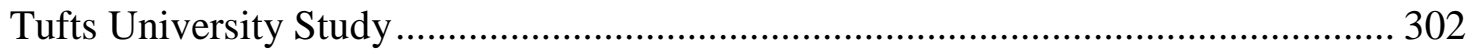

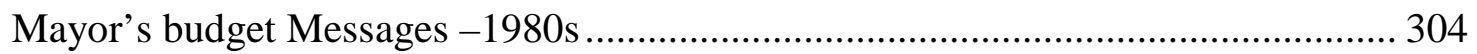

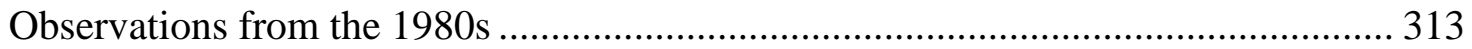

CHAPTER V SOUL SEARCHING AND DECLINE-1990s.................................. 315

1990 Portland Future Focus .................................................................................... 317

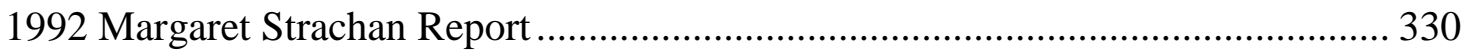

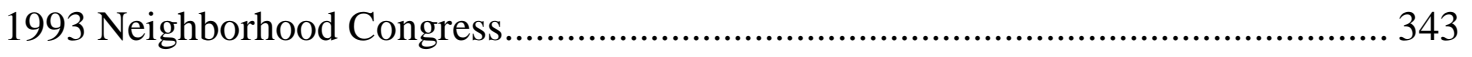

1995-96 Neighborhood Involvement Task Force ................................................ 356

1998 ONI Standards and formal name change from ONA to ONI.......................... 397

1998 - Lee Perlman statement to Neighborhoods USA Conference......................... 398

Mayor's Budget Messages_Katz-1993 to 1999 .................................................. 403

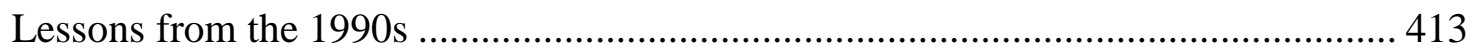

CHAPTER VI DEEPER ANALYSIS AND CONFLICT-2000-2004..................... 417

Southwest Community Plan $-1994-2000$.......................................................... 420

Citywide Administrative Services Review (ASR) - 2000-2001 ............................. 423

Post ASR -Attempts to Centralize Community Involvement Services .................... 444

Commissioner Attempts to Improve the Neighborhood System ............................. 452

Communities Beyond Neighborhood Boundaries_-Reaching Beyond Traditional Neighborhood Associations ......................................................................... 472

Southeast Uplift Neighborhood Coalition--DRC and DCL ................................... 496

Public Involvement Task Force--“A Strategic Plan for Improving Public Involvement

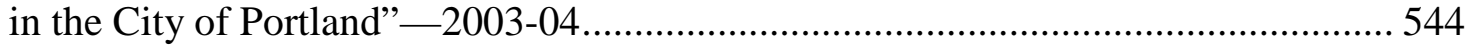

Budget Outreach Study Group_-2004-05 ......................................................... 580

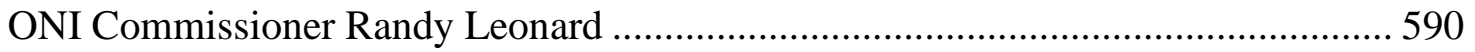


Seltzer Sharpe Strachan Proposal-November 11, 2003 ....................................... 597

2004 Election and Tom Potter-A Turning Point ................................................... 603

Mayor's Budget Messages - Vera Katz - FY 2000-01 to 2004-05 .......................... 615

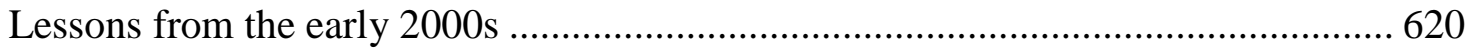

CHAPTER VII REFORM AND REJUVENATION_2005 to 2013 .......................... 633

Neighborhood Coalition Leaders' Strategic Assessment-December 2004 ............. 636

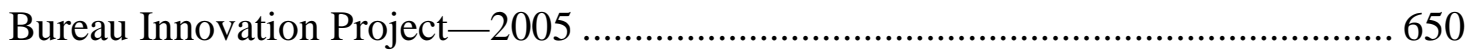

Bureau Innovation Project 9- “Develop Improved Public Engagement Procedures"670

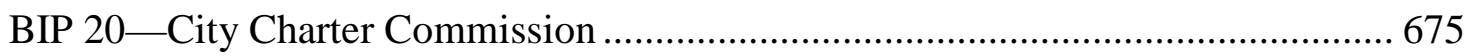

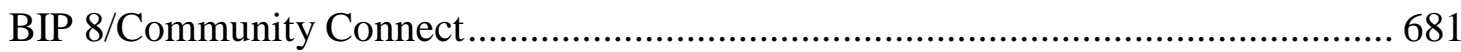

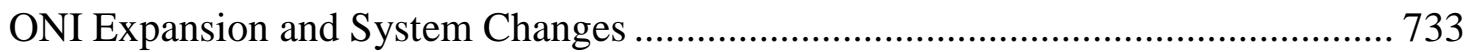

Mayor's Budget Messages - Tom Potter - 2005-06 to 2008-09 .............................. 772

Citywide Policy Bodies--Citywide Land Use Group and Citywide Parks Team ....... 782

Mayor Sam Adams and ONI Commissioner Amanda Fritz (2009-2012) ................. 791

Public Involvement Advisory Council (PIAC) (2008 to present) ............................. 809

Office of Equity and Human Rights ............................................................... 843

Title II ADA and Title VI Civil Rights Program................................................ 847

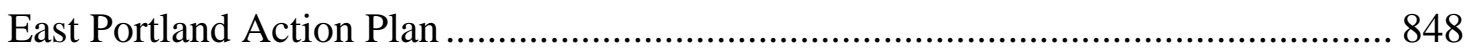

Mayor's Budget Messages - Sam Adams - 2009-10 to 2012-13........................... 870

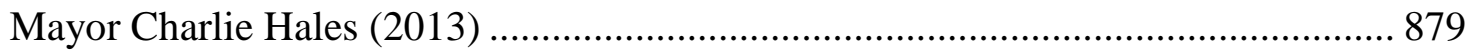

Looking to the Future - What Comes Next? ....................................................... 893

Lessons of the Potter and Post Potter era - 2005 to 2013 ....................................... 902

CHAPTER VIII ANALYSIS ............................................................................ 912

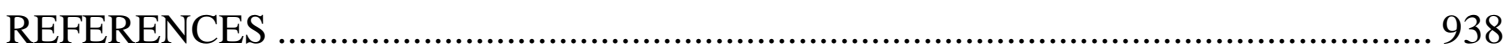

APPENDIX PORTLAND MAYORS, ONA/ONI COMMISSIONERS IN CHARGE,

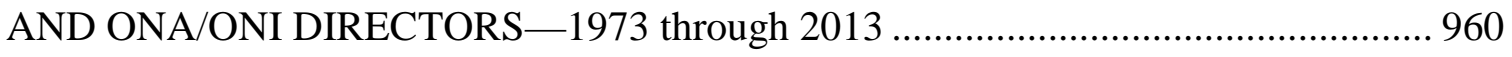




\section{LIST OF TABLES}

Table 1: Portland Community and Neighborhood Involvement System, Major Studies,

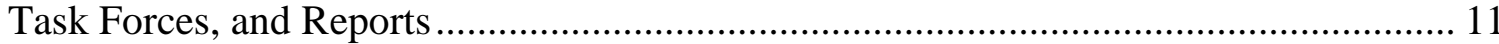
Table 2: Major New Funding for ONI under Mayor Potter (FY 2006-07, 2007-08, 200809) 


\section{LIST OF FIGURES}

Figure 1: Critical Elements of Strong Participation................................................. 21

Figure 2: Eight Core Principles of Collaborative Governance and Policy Design........... 27

Figure 3: Portland Public Involvement Principles, 1996 ............................................ 391

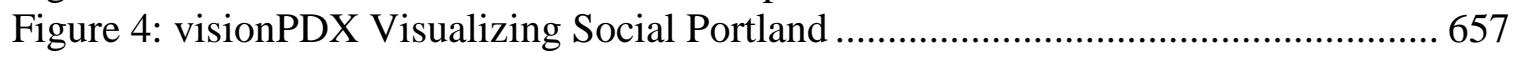

Figure 5: Office of Neighborhood Involvement Mission/Goals/Values....................... 739

Figure 6: City of Portland Financial Impact and Public Involvement Statement (FIPIS) -

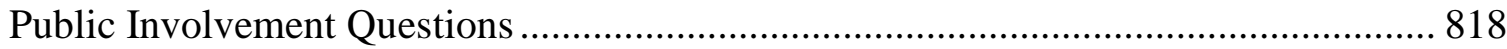




\section{CHAPTER I}

\section{INTRODUCTION}

In this dissertation, I examine the evolution of Portland, Oregon's nationally recognized community and neighborhood involvement system with a special focus on identifying the system elements and dynamics that have helped advance and sustain Portland's progress toward achieving a "strong democracy" culture and governance partnership between city government and the community.

Communities across the United States are experiencing a "civic revival" that is reconnecting community members with local decision-making and civic life in their communities. Over the past decades, researchers have studied many aspects of this "revival" in an effort to better understand the origins and key elements that lead to success or failure.

Since the 1980s, academic researchers and local governance reformers have advocated for a shift away from the traditional top-down, expert-driven approach to governance and toward a governance model in which government leaders and staff and community members work more as partners in shaping the community and in local decision making. Many communities have tried and are trying different approaches to give community members a stronger voice in local decision making and that engage more people in the civic life of their community.

Portland is known nationally and internationally as a city with a tradition of strong community involvement. Portlanders have learned a lot about what works and 
what does not over the forty years since the Portland City Council first created community and neighborhood involvement system. Portland's experience offers a valuable case study of what it takes to develop, implement, and sustain a strong democracy system and culture.

Fortunately, for this study, Portlanders are not shy about studying their city and recommending how it could be improved. Since the 1970s, Portlanders repeatedly have reviewed and examined different aspects of Portland's community and neighborhood involvement system. The reports and materials that document these reviews and the formal policy documents that implemented changes in the system offer interesting insights into what Portlanders believed was needed for the system to effectively engage community members in civic live and local decision making. The story of the evolution of Portland's community and neighborhood involvement system also offers important insights into the dynamics of how system improvements are proposed and adopted or ignored and into what it takes to sustain reforms and advances once they are in place.

Many academic researchers have explored different aspects of what it takes to achieve and sustain "stronger democracy" or "participatory democracy." Their work establishes what we would expect to see over the four decades of the evolution of Portland's community and neighborhood involvement system. Chapter Two reviews this academic literature. The chapter first examines the many different terms researchers have used to describe what they identify as the goals of a civic revival and the elements of stronger participatory democracy. The chapter continues by exploring the literature in some specific thematic areas including what research has identified as the elements of 
successful city-wide community engagement systems, social capital and community building, community organizing, public agenda setting, and achieving and sustaining government policy and organizational change. The chapter concludes by reviewing previous research, focused specially on Portland and the evolution of Portland's community and neighborhood involvement system.

Chapters Three through Seven tell the story of the 40-year evolution of Portland's community and neighborhood involvement system (from the 1970s to 2013). These chapters examine the many evaluations of the system completed over the years as well as the major policy and structure changes implemented during that time.

Chapter Three reviews the founding and early years of the system in the 1970s. This chapter examines early proposals that set the stage for the creation of Portland's community and neighborhood involvement system, city council ordinances that established the initial formal policy framework for the system, and reports that describe the system's early programs, successes, and challenges.

Chapter Four reviews the 1980s, a time during which the system continued to expand and became increasingly institutionalized. The chapter examines a system review from 1980 that was done in response to early concerns about the transparency and accountability of some neighborhood associations and reviews the first formal guidelines for Portland's neighborhood system adopted in 1987. The chapter also reviews efforts by neighborhood activists to create city wide bodies to analyze and respond to broader policy issues and mechanisms to formally recognize and Mayor Bud Clark creation of mechanisms to celebrate neighborhood achievements. The chapter closes with a review 
of the system elements, strengths and weaknesses identified by a research team from Tufts University in the late 1980s.

Chapter Five covers the 1990s a time during which critics of the system repeatedly called for the system to involve a broader range of community members and an increase in the willingness and ability of city government leaders and staff to work with the community. A number of programs that had been identified as key strengths of the system were discontinued. System funding stagnated and conflicts between neighborhood and community activists and city leaders and staff increased. Different system reforms efforts were attempted, but most were not very successful. This chapter reviews these evaluations and reform attempts. The chapter also describes in more detail efforts to broaden participation in the system beyond traditional geographic neighborhood associations to include-particularly, communities of color and immigrants and refugees - and increased efforts to change the culture of city government and increase the quality and consistency of community involvement by city leaders and staff.

Chapter Six covers the early to mid 2000s and describes attempts to shift the focus of the system away from community empowerment and toward the provision of city services, while at the same certain projects and task forces were exploring how to broaden participation in the system especially by historically under-represented communities in Portland. The growing number and intensity of clashes between Portland city government and neighborhood and community activists led to an in-depth study by the Public Involvement Task Force of how to improve the quality and consistency of community involvement across city government. The increasing conflict also set the 
stage for former Portland Police Chief Tom Potter's successful run for mayor on a platform of reconnecting the community with city government.

Chapter Seven reviews the significant expansion and reform of Portland's community and neighborhood involvement system initiated under Mayor Potter (20052009) and the fate of these changes under two subsequent Portland mayors. The chapter describes a comprehensive review of the system, initiated by Potter, called "Community Connect" and the resulting "Five-year Plan to Increase Community Involvement" in Portland. The Community Connect goals set a new strategic course for Portland's system the included involving more people in civic life, building capacity in the community for greater involvement, and changing the culture and practices of city government to ensure that community members can have an impact. Community Connect recognized that many people find their sense of community outside traditional geographic neighborhoods and led to the creation of new city programs to support community organizing and capacity building in non-geographic communities. Chapter VII also examines the creation of City of Portland Public Involvement Advisory Committee (PIAC) and its innovative work to develop new citywide standards for community involvement and embed them in city government policies and practices. The chapter concludes with a review of proposed next steps for the system, beyond 2013, generated by the City of Portland Office of Neighborhood Involvement and its neighborhood and community organization partners.

Chapter Eight analyses the Portland experience in light of the theories and expectations established in the academic literature and this study's primary research questions, presents findings, and recommends areas for future research. 
Table 1 below presents a list of major studies, task forces, and reports completed that helped shape Portland's community and neighborhood involvement system over the past forty years.

\section{$\underline{\text { Research Questions }}$}

Thomson (2001) poses what he says is a central question for academics and practitioners who are seeking to bolster civic society: "[W]hat forms of organizations and activities have the potential to bridge the yawning gap between citizens and their governments....” (Thomson 2001 2).

Portland's experience not only provides insight into the structures and programs that encourage and support greater participatory democracy in a community, but it also provides insights into the dynamics by which system reforms are proposed and implemented and the strategies and mechanisms to sustain these advances once they are in place.

This study seeks to answer the following primary research questions:

1. What structures, program elements, policies, and practices did Portlanders find over time are necessary to encourage and support greater community involvement in local decision making and civic life?

2. What dynamics helped or hindered the evolution of Portland's community and neighborhood involvement system?

3. What does the Portland experience tell us about what it takes to sustain and preserve the advances toward greater participatory democracy? 


\section{$\underline{\text { Methodology }}$}

This study draws on the many formal reviews and evaluations of Portland's community and neighborhood involvement system and major policy changes from the 1970s to 2013 to identify the evolving understanding in Portland of what it takes to advance and sustain progress toward an effective city wide community and neighborhood involvement system and thereby move toward stronger participatory democracy.

This study uses qualitative research methods to review existing sources of information to prepare a case study of the Portland experience and to identify common themes and trends over time.

The principle data sources for this study include:

- Documents that present the findings of the many different reviews and evaluations of Portland's community and neighborhood involvement system produced by government-initiated task forces and community organizations;

- Government policy documents, including city council ordinances and resolutions that enacted system structures and requirements and formal policy guidelines and standards adopted by the Portland City Council.

- City of Portland annual city budget documents, from 1974 to 2013, which provide valuable information about the changing mission, programs, priorities, and funding of the City of Portland Office of Neighborhood Associations/Office of Neighborhood Involvement (ONA/ONI). 
- Mayor's budget messages that accompany each annual city budget document (from 1973 to the present) and which provide insights into each mayor's priorities and their view of the role of community involvement in decision making.

- Newspaper articles from the Oregonian archives available online through the Multnomah County Library website, which provide valuable historical details, context, and insights into the views and opinions of people at different times in the history of the system.

- Unstructured informal interviews and conservations with city staff and community members to fill in historical facts and provide insights into the motivations and thinking of people involved in the processes.

\section{Objectivity}

I have participated in a number of the efforts to review and improve Portland's community and neighborhood involvement system, both as a neighborhood association activist since the mid-1990s and as an employee of the City of Portland Office of Neighborhood Involvement (ONI) since 2009. While my activities as a neighborhood volunteer and ONI employee give me useful knowledge of the progression of events, awareness of and access to existing documentation, and access to people who were involved in the processes that are the focus of this study, they also can pose a challenge to the objectivity of my research and analysis.

In response, I have chosen primarily to draw on existing historical and policy documents supplemented by unstructured interviews with other participants for my research, rather than drawing on my own experiences, perceptions, and opinions. In the 
interest of transparency, I also briefly describe my involvement as a neighborhood activist and ONI employee.

I have participated actively as a volunteer neighborhood association volunteer and leader in Portland's neighborhood association system since 1995. I began attending meetings of my neighborhood association in Portland in 1995. I have been a volunteer board member of my neighborhood association from 1996 to the present and served as president of the neighborhood association from 1998 to 2003. I also have served as a volunteer board member of the Southeast Uplift Neighborhood Coalition—one of Portland's seven neighborhood district coalitions-since 2004 and served as the board chair for two years from 2005 to 2007.

I participated in a number of the reviews of Portland's community and neighborhood involvement system including: Public Involvement Task Force 2003-2004, the City Budget Study Group (2005), and Community Connect (2005 to 2008).

I also was one of a group of neighborhood activists who joined forces and ran against City Commissioner Randy Leonard in the 2004 city council election. I also was very involved, as volunteer, on Tom Potter's 2004 mayoral campaign.

I began working at ONI in 2009 as a "neighborhood program coordinator" with responsibility to support to Portland's neighborhood association system. In this role I provide training, technical assistance, conflict resolution support, and help develop best practices materials. I administer ONI's grants to Portland's seven neighborhood coalitions and consult with city agencies on their community and neighborhood involvement strategies and projects. I also serve, as an ONI employee, on the City of 
Portland Public Involvement Advisory Council and the ONI Bureau/Budget Advisory Committee. 
Table 1: Portland Community and Neighborhood Involvement System, Major Studies, Task Forces, and Reports

\begin{tabular}{|c|c|c|}
\hline Date & Name & Originator \\
\hline \multicolumn{3}{|l|}{ 1970s } \\
\hline 1971 & $\begin{array}{l}\text { Portland Planning Commission } \\
\text { Proposal }\end{array}$ & Planning Commission \\
\hline 1972 & $\begin{array}{l}\text { District Planning Organization (DPO) } \\
\text { Task Force Report }\end{array}$ & City Council \\
\hline 1974 & 1974 Ordinance & City Council \\
\hline 1974 & ONA $1^{\text {st }}$ Year Report & ONA (Director Mary Pedersen) \\
\hline 1975 & 1975 Ordinance & City Council \\
\hline 1979 & ONA $5^{\text {th }}$ Year Report & ONA (Director Mary Pedersen) \\
\hline \multicolumn{3}{|l|}{ 1980s } \\
\hline 1980 & ONA Review Committee Report & ONA Commissioner (Charles Jordan) \\
\hline 1987 & $1^{\text {st }}$ ONA Guidelines & ONA \\
\hline & Tufts University research team & Tufts University \\
\hline \multicolumn{3}{|l|}{ 1990s } \\
\hline 1991 & Portland Future Focus & Mayor Bud Clark \\
\hline 1992 & $2^{\text {nd }}$ ONA Guidelines & ONA \\
\hline 1992 & Strachan Focus Group Report & $\begin{array}{l}\text { ONA Commissioner } \\
\text { (Kafoury)/Strachan }\end{array}$ \\
\hline 1993 & 1993 Neighborhood Congress & Neighborhood Activists \\
\hline 1995 & $\begin{array}{l}\text { Task Force on Neighborhood } \\
\text { Involvement (TFNI) }\end{array}$ & ONA Commissioner (Hales) \\
\hline 1998 & $3^{\text {rd }}$ ONI Guidelines & ONA \\
\hline \multicolumn{3}{|l|}{$2000 \mathrm{~s}$} \\
\hline 2000 & $\begin{array}{l}\text { SW Community Plan-Citizen } \\
\text { Involvement goal and objectives }\end{array}$ & $\begin{array}{l}\text { Bureau of Planning/SW community } \\
\text { activists }\end{array}$ \\
\hline 2000 & $\begin{array}{l}\text { Administrative Services Review } \\
\text { (ASR) }\end{array}$ & Mayor Katz \\
\hline 2001-03 & Interwoven Tapestry & ONI/IRCO \\
\hline 2001-05 & $\begin{array}{l}\text { Southeast Uplift Diversity and } \\
\text { Representation Committee }\end{array}$ & Southeast Uplift \\
\hline 2004-05 & $\begin{array}{l}\text { Southeast Uplift Diversity and Civic } \\
\text { Leadership Committee }\end{array}$ & Southeast Uplift \\
\hline 2003-04 & $\begin{array}{l}\text { Public Involvement Task Force } \\
\text { (PITF) }\end{array}$ & $\begin{array}{l}\text { ONI Commissioners (Francesconi, } \\
\text { Saltzman and Leonard) }\end{array}$ \\
\hline $\begin{array}{l}2004 \\
\text { (Dec.) }\end{array}$ & $\begin{array}{l}\text { Neighborhood Coalition Leaders } \\
\text { report }\end{array}$ & Neighborhood coalition leaders \\
\hline 2005 & $4^{\text {th }}$ ONI Standards & ONI \\
\hline 2005-07 & BIP 1—visionPDX & Mayor Potter \\
\hline 2005-08 & BIP 8-Community Connect & Mayor Potter \\
\hline
\end{tabular}




\begin{tabular}{lll}
\multicolumn{1}{c}{ Date } & \multicolumn{1}{c}{$\begin{array}{c}\text { Name } \\
\text { 2005-06 }\end{array}$} & $\begin{array}{l}\text { Originator } \\
\text { BIP 9-Public Involvement }\end{array}$ \\
Assessment Toolkit & Mayor Potter \\
2005-07 & BIP 20-Charter Commission & Mayor Potter \\
2010s & & \\
2007-12 & Portland Plan & Mayor Adams \\
2012- & Portland Comprehensive Plan Update & Mayor Adams \\
2014 & & \\
2013 & Title VI - Civil Rights Plan & City Council
\end{tabular}




\section{CHAPTER II}

\section{LITERATURE REVIEW}

Communities across the United States are experiencing a "civic revival" that is reconnecting community members with local decision-making and civic life in their communities. Over the past decades, researchers have studied many aspects of this "revival" in an effort to better understand the origins and key elements that lead to success or failure.

This chapter reviews the academic literature and what scholars have discovered about the nature of the "civic" problem that needs to be solved, the many terms they use to talk about this work, common elements researchers have found advance participatory democracy in a community, and the processes by which such reforms are adopted and embedded in the culture and practices of a community and local government. This chapter also reviews the research on the evolution of Portland, Oregon's internationally recognized neighborhood and community involvement system.

\section{What's the Problem to be Solved?}

Since the 1960s, many researchers have warned of a decline in democracy in the United States. They cite declines in traditional forms of political involvement, such as voting and participation in traditional political parties. They warn of the growth in singleissue interest groups that focus on "check-book" participation in which individual "members" participate primarily by contributing funds rather than engaging in hands-on and face-to-face interactions with other members (Sirianni and Friedland, Civic Dictionary. [no date]). 
They write about the increase in the "professionalization of politics" in which a "politics" is carried out by politicians, professional lobbyists, and experts and is separate from the civic activities carried out by the general citizenry in local communities (Barber 1984, Boyte 2004, Mathews, 1999). “Citizens have become increasingly disengaged and cynical about politics because they see it as an exclusive game for professionals and experts, such as politicians, campaign managers, lobbyists, pollsters, journalists, talking heads." "Technocratic approaches within public administration exacerbate this sense of the displaced citizen" (Sirianni and Friedland, Civic Dictionary. [no date]).

Political discourse also has become more simplistic. Sirianni and Friedland warn of the growth of "Direct Plebecitary Democracy" - the ..."ascendancy of opinion polls, talk show democracy, referendums, and primaries" lead to policy questions becoming “oversimplified and stylized, and our capacity to solve increasingly complex public problems declines" (Sirianni and Friedland, Civic Dictionary. [no date]).

Community members not only have been disengaging from governance and politics, they also have been disengaging from each other. De Tocqueville highlighted the extensive use of voluntary associations by Americans to get things done in their communities. This web of voluntary associations provided a ..."mechanism for combining the relative weakness of individuals in an egalitarian society into aggregations of power that could effectively solve problems, asset needs and preferences, and engage government...." also " these associations were the training grounds for citizenship and civic competence" (Cooper 2006 77). 
Putnam has documented a national pattern of decline in these collective practices and structures across the county. This decline in "social capital"- the "social networks and the norms of reciprocity and trustworthiness that arise from them"-further reduces the capacity of community members to work together to develop the skills to work together and the connections needed to get things done (Putnam 2000 19).

Americans have grown increasing alienated from government and trust in government institutions has fallen steadily. Although the "Tea Party" and "Occupy" movements that arose during the late 2000s and early 2010s tend to be at different ends of the political spectrum, they share a distrust of large institutions and the belief that powerful interests drive policies in this country that serve their interests over the interests of the general community.

Smock argues that while democratic participation has ebbed and flowed for some groups in our society, significant social and economic inequalities in our society also have ensured “a significant portion of our nation's population has always been excluded from meaningful participation in the democratic arena." "In the United States, disparities in financial resources, social status, education, and other resources confer political advantages on the most privileged and effectively exclude a sizeable portion of our populace from meaningful public participation." Traditional channels for civic participation in policy making frequently are "dominated by an economic and political elite." Smock writes that "as our society becomes more economically and socially stratified, this pattern has only worsened" (Smock 2004 5). 
The alienation and exclusion of many community members from politics and governance is exacerbated by a long-standing cultural tradition among public agency leaders and staff who view the public as having a fairly limited role in policy development and the day-to-day operations of government (Cooper 2011). This tradition is rooted in the reforms of the Progressive Reform movement of the early $20^{\text {th }}$ Century that sought to ground public administration in "norms of professionalism, efficiency, scientific management, and administrative management" and which led to the creation of "barriers against the influence of the citizenry on the day-to-day administration of government (239-240). While the "de facto power of the bureaucracy" has increased dramatically since the Progressive reform era, this "professionalization of administration" has established "formidable barriers" to meaningful civic engagement by community members in governance.

More recently, this traditional expert-driven public administration culture has faced increasing resistance from community members. Leighninger has written that elected officials and administrators are finding it more difficult to govern. The public has grow alienated from the government as a tool of collective action. Community members trust government less than in the past. They are less willing to pay to support government services. Also, many of the problems facing communities today are complex.

Government leaders and administrators find they need to leverage community resource to solve them- "government can't do it on it alone" (Leighninger 2006).

Leighninger writes that “...citizens seem better at governing, and worse at being governed...." Many community members resent what they see as an "adult-child" 
relationship between government and the community. Local leaders who try to make decision in this old way often "are faced with angry, informed, articulate citizens" who are more able to oppose government actions. Leighninger found that" local leaders are becoming tired of confrontation and desperate for resources" (Leighninger 2006 1-2).

Terms Used to Describe the Goal of a Civic Revival

Researchers have used a variety of terms to characterize the democratic governance approaches they believe are needed to remedy many of the problems they see plaguing civic life and governance in our nation and our local communities. Some of the prevalent terms used in recent years include:

- Citizen Politics (Boyte 2004)

- Citizen-driven Administration (Cooper 2011)

- Collaborative Governance (Sirianni 2009)

- Community Governance (Somerville 2005)

- Deliberative Democracy (Gastil and Levine 2005)

- Democratic Governance (Leighninger 2006; National League of Cities)

- Local Democracy (Leighninger and Mann 2011)

- Neighborhood Governance (Chaskin 2003)

- Participatory Democracy (Berry, Portney and Thomson 1993)

- Public Work (Boyte 2011)

- Shared Governance (Leighninger 2006)

- Strong Democracy (Barber 1984; Berry, Portney and Thomson, 1993; Thomson 2001) 
- "We the People" politics (Boyte 2011)

- Empowered Participatory Governance (Fung 2004)

These terms embody some key themes, governance orientations and values. Some focus on specific approaches and methods—others focus on capacity building in the community or in government. Commons themes that emerge across these terms include:

- Broadening the concepts of "politics" and "governance"

- Ensuring broad and deep participation

- Governance as a "partnership"

- Deliberative decision making

- Building strong capacity in the community to engage in governance

- Government willingness and ability to partner with the community

Broadening the concepts of "politics" and "governance": Barber, Boyte, and the Kettering Foundation believe that the definition of politics should be expanded to include the practical decisions and active work community members engage in to shape their communities. The work community members do is important and needs to be seen to be so by traditional decisions makers and by community members themselves. Chaskin suggests that the conception of governance shift from the traditional focus on "governmental decision making and the wielding of political authority." to include the structures and process that define relations between civil society (including the private sector, community organizations, and social movements) and the state (Chaskin 162). Boyte defines "citizen politics" as "ordinary people of different views and interests working together to define and to solve problems...” (Boyte 2004 xiii). 
Ensuring broad and deep participation: When Berry, Portney and Thomson undertook their study of citywide community involvement programs across the nation, they noted that efforts to expand the public role in democratic processes at that time focused mostly on increasing voting. The authors wrote that "Voting does little to build a sense of community." "Rebuilding citizenship in America means that reform must move beyond getting more people in private voting booths to getting more people to public forums where they can work with their neighbors to solve the problems of their community" (Berry, Portney and Thomson 2).

The authors argued that "strong democracy" would include strong participatory structures that ideally would include: (1) the ability of community members to develop and propose alternatives in the participation process; (2) that all individuals would have identical information; (3) that every citizen would express their preferences among alternatives considered in the participation process; (4) that the choice of each individual would be given identical weight, (5) that the alternative with the greatest support would be chosen and (6) that it displace other alternatives with less support, and (7) that the chosen policy be implemented, and (8) that implementation decision hold true to the outcome of the process or that new decisions go through the stages of the process again (Berry, Portney and Thomson 53-54).

Based on these criteria, Berry et al suggest two broad parameters by which to evaluate practical community participation efforts_-breadth (elements 1 through 3 ) and depth (elements 5 through 8). "The breadth of a participation effort is the extent to which an opportunity is offered to every community member to participate at every stage of the 
policy making process." "The depth of a participation effort is the extent to which the citizens who choose to participate have the opportunity to determine the final policy outcome by means of the participation process" (54-55).

Berry, Portney and Thomson set out the "critical elements of strong participation" in Figure 1 below. 
Figure 1: Critical Elements of Strong Participation

\begin{tabular}{|c|c|c|}
\hline & Structure & Desired outcome \\
\hline Breadth & $\begin{array}{l}\text { Outreach effort } \\
\text {-Open access } \\
\text {-Full information flow } \\
\text { - Realistic opportunities to } \\
\quad \text { participate }\end{array}$ & $\begin{array}{l}\text { Increase numbers of people } \\
\text { who participate } \\
\text { Improve representativeness } \\
\text { of participants } \\
\text { Include all citizen concerns } \\
\text { on decision making } \\
\text { agenda }\end{array}$ \\
\hline Depth & $\begin{array}{l}\text { Decision making process } \\
\text { —Equal consideration of } \\
\text { ideas } \\
\text {-Direct translation of } \\
\text { citizen preferences } \\
\text { into policy decisions } \\
\text { Effective implementation of } \\
\text { participatory } \\
\text { decisions }\end{array}$ & $\begin{array}{l}\text { Improve match between } \\
\text { policy outcomes and } \\
\text { participants' final } \\
\text { choices } \\
\text { Improve match between } \\
\text { policy outcomes and } \\
\text { needs of all population } \\
\text { arguments. }\end{array}$ \\
\hline
\end{tabular}

(Berry, Portney, and Thomson 1993 55).

Smock's research additionally stresses that broad involvement must include portions of communities that always have been "excluded from meaningful participation in the democratic arena" (Smock 5).

Deliberative Decision-making Processes: Many researchers maintain that "expanding opportunities for community members to deliberate" is necessary to increase "meaningful involvement in political discourse and decision-making" and to strengthen democracy and expand governance partnerships.

Sirianni and Friedland write that "Deliberative democracy rests on the core notion of citizens and their representatives deliberating about public problems and solutions under conditions that are conducive to reasoned reflection and refined public judgment; a mutual willingness to understand the values, perspectives, and interests of others; and the possibility of reframing their interests and perspectives in light of a joint search for 
common interests and mutually acceptable solutions" (Sirianni and Friedland, Civic Dictionary. [no date]).

The Kettering Foundation argues that "deliberative democratic practices and community decision-making processes" are important factors in helping "democracy work as well as it should." Phil Stewart describes six "democratic practices" that the Kettering Foundation maintains "enable citizens to gain a significant measure of control over their lives" (Stewart 2008 25).

- Naming: "'naming' issues so that citizens can see themselves implicated in them"

- Framing: “'framing' approaches and alternatives in ways that enable citizens to recognize the tensions among things held valuable that must be resolved to enable community action"

- Public Deliberation: "making choices through 'public deliberation,' which enables citizens, through listening to diverse perspectives, to work through the inherent tensions in serious issues and come to some form of public judgment;"

- Covenants: "Once a community comes to judgment regarding a course of action, citizens make 'covenants' with each other, most often informal and tacit, but sometimes formal and explicit, regarding actions to be taken, singly or collectively;",

- Mutually Complementary Public Acting: "These covenants lead to "mutually complementary public acting' on the collectively agreed change or course of action;" and 
- Learning: "In the final step of this 'citizens political process,' 'citizens learn' from their experience, and the cycle begins again."

Many organizations have developed formal process models that include deliberative elements, including the Kettering Foundation's National Issues Forums, Everyday Democracy's Study Circles, and the large group deliberative processes organized by American Speaks.

Governance as a "partnership": Many researchers argue that more democratic governance would include a more equal partnership between government and the community in which community members play an active role in governance and both sides recognize that they other can bring important knowledge, skills, and resources to solving the problems of the community.

Many researchers argue that the role of community members needs to shift from being passive recipients of the work and services of "government" to being active participants in "governance" (Barber 117). Leighninger characterizes this as a shift away from the currently more prevalent top-down, expert-driven, "adult-child" relationship between government and the community to an "adult-adult relationship" (Leighninger 2006 3). Sirianni writes that in "collaborative governance, "policy design aims to "empower, enlighten, and engage citizens in the process of self-government"" (Sirianni 2009 39) and should enable the "work of citizens themselves in coproducing public goods." (42). 
In a governance partnership, community members actively would participate in defining problems, helping set government priorities, and in the development and monitoring of government policies, programs, and projects.

\section{Government Openness and Ability to Partner with the Community:}

Achieving an effective "governance partnership" between government and the community requires that both sides need to have the capacity and ability to work together. Some researchers focus on one or the other of these.

The National League of Cities (NLC) recognizes that a "fundamental shift" is underway "in the way that citizens and government work together." The NLC notes that "many local leaders have put a new emphasis on mobilizing citizens in order to make decisions, overcome conflicts, and solve critical public problems. The NLC actively encourages and supports this shift through its Democratic Governance project. The NLC defines "democratic governance" as "The art of governing a community in participatory, deliberative, and collaborative ways" (National League of Cities [no date] 1).

The National League of Cities recognizes that the shift to democratic governance will require a shift in the attitudes of local government officials and public employees. Many officials ran for office with the expectation that they would be the decision makers, and the role of community members would be limited to evaluating their performance at the next election. NLC writes that "Ensuring the effective governance of the community—rather than simply running the local government—requires different skills and attitudes than the ones taught in most public administration schools." NLC quotes a city manager who says: "You have to be able to frame issues in language that brings 
people of different perspectives to the same table." NLC quotes another local official who said: "You also have to make it clear to citizens that you aren't just asking for their input: you want them to contribute their own time and effort to solving problems in their neighborhood and community" (4).

Cooper, Bryer and Meek write that traditional public administration culture and practices act as major barriers to effective community involvement in the work of government. Reforms in public administration instituted during the Progressive Reform Era of the early 1900s, transformed "administrative institutions of government based on the norms of professionalism, efficiency, scientific management, and administrative management (Cooper, Bryer and Meek 77). These institutional reforms resulted in "the creation of barriers against the influence of the citizenry on the day-to-day administration of government." Citizens were to vote for representatives, "but otherwise leave the administration of government services to the professional experts and their 'scientific' methods" (Cooper 2011 240). As the "defacto power of the bureaucracy" increased dramatically, "citizens were increasingly confronted by a technical professional role definition of the administrator that precluded the need for their lay input." This "professionalism of administrated established formidable barriers to anything like sustained civic engagement.”

Gibson says that a shift to more "citizen-based approaches" will need to focus "primarily on culture change, rather than on short-term outcomes, issues, or victories, and include a cross-section of entire communities, rather than parts of them" (Gibson 2006 2). 
Any effort to shift government culture toward greater participatory democracy will need to change the willingness and ability of both elected and appointed officials and public employees to work collaboratively with community members.

Strong Governance Capacity in the Community: Sirianni writes that in “collaborative governance, policy design aims to 'empower, enlighten and engage citizens in the process of self-government.'" Sirianni states that he drew on civic engagement and collaborative governance literature and empirical analyses literature and eight case studies he developed to "extract eight core principles of collaborative governance" (Sirianni 2009 39). These core principles are presented in Figure 2 below: 
Figure 2: Eight Core Principles of Collaborative Governance and Policy Design

\begin{tabular}{|c|c|}
\hline Core principle & Policy design \\
\hline $\begin{array}{l}\text { Coproduce public } \\
\text { goods }\end{array}$ & $\begin{array}{l}\text { Policy should enable the work of citizens themselves in } \\
\text { coproducing public goods. }\end{array}$ \\
\hline $\begin{array}{l}\text { Mobilize community } \\
\text { assets }\end{array}$ & $\begin{array}{l}\text { Policy should enable communities to mobilize their own assets } \\
\text { for problem solving and development. }\end{array}$ \\
\hline $\begin{array}{l}\text { Share professional } \\
\text { expertise }\end{array}$ & $\begin{array}{l}\text { Policy should mobilize expert knowledge to enlighten and } \\
\text { empower everyday citizens and to use citizens' own local } \\
\text { knowledge. }\end{array}$ \\
\hline $\begin{array}{r}\text { Enable public } \\
\text { deliberation }\end{array}$ & $\begin{array}{l}\text { Policy should enable and expect citizens to engage in the public } \\
\text { reasoning upon which good policy choices, democratic } \\
\text { legitimacy, and effective implementation depend. }\end{array}$ \\
\hline $\begin{array}{l}\text { Promote sustainable } \\
\text { partnerships }\end{array}$ & $\begin{array}{l}\text { Policy should promote collaborative work and partnerships } \\
\text { among citizens, organized stakeholders, and public agencies. }\end{array}$ \\
\hline $\begin{array}{l}\text { Build fields and } \\
\text { governance } \\
\text { networks } \\
\text { strategically }\end{array}$ & $\begin{array}{l}\text { Policy should mobilize field-building assets strategically to } \\
\text { enable citizens, civic associations, and broader governance } \\
\text { networks to work effectively together. }\end{array}$ \\
\hline $\begin{array}{l}\text { Transform } \\
\text { institutional cultures }\end{array}$ & $\begin{array}{l}\text { Policy should catalyze public and nonprofit agencies to become } \\
\text { learning organizations for community empowerment and civic } \\
\text { problem solving and draw market actors into civic } \\
\text { partnerships and culture change as well. }\end{array}$ \\
\hline $\begin{array}{l}\text { Ensure reciprocal } \\
\text { accountability }\end{array}$ & $\begin{array}{l}\text { Policy should promote mutual accountability for collaborative } \\
\text { work among the broad range of democratic actors and } \\
\text { partners. }\end{array}$ \\
\hline
\end{tabular}

(Sirianni 2009 42).

Phil Stewart of the Kettering Foundation writes that "At the heart of selforganizing systems are networks of interaction." "The most influential organizations in citizens politics often will not be formal, nor will they be highly visible. Rather, they tend 
to be those informal networks, with changing and overlapping "membership" (Stewart 2008 26).

Boyte quotes Jonathan Sacks "In today's liberal democracies, it is not that we are too much together but that we are too much alone and seek to learn again how to connect with others in lasting and rewarding ways" (Boyte 2008 4). Boyte writes about an emerging citizen movement that is "beginning to overcome people's feelings of powerlessness and hopelessness about the large problems facing us" (3). Boyte emphasizes the importance of building community strength," mediating institutions, and building the skills of individuals.

Putnam and Feldstein state that increasing social capital is vital to expanding local democracy. They argue that, in the community building efforts they studied “...interpersonal connections and civic engagement among ordinary citizens were essential to making participatory democracy work" (Putnam and Feldstein 274). They also note that “.... a society that has only bonding social capital will”...."be segregated into mutually hostile camps." "So a pluralist democracy requires lots of bridging social capital, not just the bonding variety" (3).America's communities have experienced a trend in which community members are "no longer building the dense webs of encounter and participation so vital to the health of ourselves, our families, and our polities." The authors maintain that local leaders need to reweave social webs "through the sometimes slow, frequently fractious, and profoundly transformative route of social-capital building" and need to "create new spaces for recognition, reconnection, conversation, and debate" (294). 
Chaskin defines "neighborhood governance" as "...the engagement of neighborhood-level mechanisms and processes to guide civic participation, planning, decision making, coordination, and implementation of activities within the neighborhood, to represent neighborhood interests to actors beyond it, and to identify and organize accountability and responsibility for action undertaken." Chaskin defines "governance" as a broader conception of governance than traditional "governmental decision making and the wielding of political authority" (162). Chaskin defines governance broadly to include the structures and process that define relations between civil society (including the private sector, community organizations, and social movements) and the state (162 referring to McCarney, Mohamed, \& Rodriguez, 1995).

Researchers have identified the importance of building and sustaining community capacity to engage in civic life and local decision making. So what happens next? Thomson states that "A central question in the civil society debate... is what forms of organizations and activities have the potential to bridge the yawning gap between citizens and their governments" (Thomson 2)?

What will Get Us There?-Elements of Successful City-wide Community Involvement Systems

Researchers have found that expanding participatory democracy requires establishing activities and structures that build capacity in a community for community members and government to work together in the shaping their community and in local decision making. Many communities have tried different approaches and strategies to create these structures and build this capacity. 
Leighninger has found that democratic governance efforts have taken two main forms: "temporary organizing efforts and permanent neighborhood structures." Leighninger writes that the temporary efforts include a wide variety of one-time processes often referred to as "citizen involvement" and "public engagement" processes-what Leighninger suggests should be called "democratic organizing." Examples include visioning processes, community budgeting, deliberative dialogues on different topics and policy issues, advisory groups created for specific policy and program development projects, etc. The most prominent examples of permanent community involvement systems are the formal, ongoing city-wide systems of neighborhood associations and neighborhood councils that have been created in some U.S. cities since the 1970s (Leighninger 2006 3-4).

This section identifies some of the key elements researchers have found exist in city-wide systems and examines other important community organizing concepts.

Leighninger argues that the best examples of both temporary and permanent structures embody four principles: (1) broad recruitment of participants through groups and organizations in the community to assemble a "large and diverse 'critical mass' of citizens;" (2) involvement of participants in a combination of small and large-group facilitated meetings that allow them to identify shared conclusions and move to action; (3) the opportunity for participants to "compare values and experiences, and to consider a range of views and policy options;" and (4) an effect on change by "applying citizen input to policy and planning decisions, by encouraging change within organizations and 
institutions, by creating teams to work on particular action ideas, by inspiring and connecting individual volunteers, or all of the above" (Leighninger 20063 ).

Leighninger notes that some of the common weaknesses of the permanent neighborhood structures appear when participants see themselves as representing their community as opposed to involving their community. Other typical weaknesses include low turnout and high burnout (4).

Berry, Portney and Thomson completed the most comprehensive national study of city-wide neighborhood council/association systems in the late 1980s. They studied four cities with city-wide "joint citizen-government participation" neighborhood council/association systems—Portland, Oregon, Dayton, Ohio, Birmingham, Alabama, and St. Paul, Minnesota. They also examined the Industrial Areas Foundation COPS (Communities Organized for Public Service) organization in San Antonio. Like the programs in the other four cities, "citizen demands for participation were the energy" for the COPS organizing efforts. The initiation of the COPS initiative, unlike in the other four cities, was not supported in any way by city government (52).

Berry, Portney and Thomson found that cities must meet three important conditions to have a good chance of their citizen participation systems becoming an integral part of city government:

- "Exclusive powers must be turned over to the citizen participation structures." The primary participation structures "must have authority to allocate some significant goods and services in their communities." 
- The structural changes must be accompanied by "an administrative plan that creates sanctions and rewards for city hall administrators who must interact with the neighborhood groups."

- "Citizen participation systems must be citywide in nature" (295).

Other structural features that also will contribute to the success of citizen participation programs include:

- Control over funds: "Ideal neighborhood-based public involvement programs should have control over some significant discretionary financial resources." Nothing will make neighborhood organizations more credible to residents than the right to appropriate funds as the organizations see fit.

- $\quad$ Resources for communication: "The city should provide financial support to enable the neighborhood associations to communicate with every household within their boundaries at least a couple of times a year."

- $\quad$ Feeders to other participation structures: "Neighborhood associations should be feeders to other citizen participation structures in the city. If there are citywide bodies that include public representatives, the neighborhood associations should be a primary source for recruitment."

- Early warning system: "An early warning system should be built into the administrative structure of city government to provide notice to neighborhoods of pending city activities that will affect them." 
- Term limits: "Terms of office for volunteers leading the neighborhood associations should be relatively short to work against the development of oligarchies."

- Non-partisan: "Neighborhood associations should be prohibited from involvement in electoral activity. They should be nonpartisan organizations in all respects" (296).

Ken Thomson developed his own independent analysis from the Tufts University team's research and identified a number of elements required for the practical development of participatory democracy (Thomson 2001). Thomson identified three essential components: "The Core"- "Small, face-to-face decision-making bodies that he says "are the fundamental structures of any participatory endeavor;" "The Link to the Community"- "Energetic outreach by the core groups is essential to keep participatory opportunity alive for all members of the community;" and "The Link to Government Policymaking"- "To create participatory democracy, the core groups must have political impact" (Thomson 20015 ).

Thomson also identified a number of important sub-elements, including:

- Participatory Core: "five propositions about the internal requirements for the core groups of a participatory democracy" (50)

- Communitywide Representation: "To the maximum extent possible, the network of participation organizations should represent every segment of the community on an equal footing" (50). 
○ Multi-Issue Responsiveness: "Within the context of a continuously evolving set of priorities determined by participants, the organization should tackle any and all issues that are brought before it" (59).

○ Internal Democracy: "To the maximum extent possible, the activities and operations of such organizations should take place in a democratic, deliberative manner" (63).

○ Openness: "To the maximum extent possible, the organizations should be continuously open and responsive to new participants" (67).

○ Network Maintenance: “The group should have a strong, ongoing relationship with a support network that can help it to maintain these characteristics over time."

- Aggressive Outreach

○ Interpersonal Relationships: "A structure of involvement is needed that enables the development of an extensive set of interpersonal relationships" (77).

○ Timely Information: “The outreach process must provide timely information to all community members about the issues at stake, and the opportunity to be involved (78)."

○ Information Flow from the Community: "The outreach process must ensure a constant flow of perceptions, concerns and reactions from community members to the participation groups and citywide decision makers" (79). 
○ Crisis Preparedness: "Additional mechanisms to fold in the involvement of much larger number than usual are needed when controversies arise and the public interest peaks" (80).

○ Broadening the Base: "Ongoing efforts to broaden the base of participation among the lowest-income members of the community are crucial to prevent the exclusion of their interests by default" (81).

\section{- $\quad$ The Policy Link}

○ Collective Decisions: "The participation core groups need to be able to reach collective decisions on public policy" (95).

○ Inter-Group Dialogue: "A dialogue needs to be maintained among the participation core groups to identify common ground and work out differences" (96).

○ Multi-Group Decision Making: "The network of participation core groups needs to be able to reach decisions on the priority issues that emerge from the individual groups" (98).

○ Legitimacy: "The core groups, the decision-making process, and its outcomes need to be recognized and accepted by policymakers, administrators, and the public as a whole" (101)"

○ Oversight: "Once a decision is made and accepted, the participation core groups need to be able to oversee policy implementation" (103).

○ Thinking Big, Thinking Whole: "The big issues need to be confronted, and parochialism overcome" (104). 
○ Standing Up: "The process needs to be able to withstand the dual threats of cooptation by the bureaucracy and alienation from the bureaucracy" (105).

○ Democratic Connections: "Constructive relationships between the participation group process and existing forms of representation need to be developed and maintained" (107).

Warren added to the understanding of the Industrial Areas Foundation COPS program in San Antonio with his 2001 book, Dry Bones Rattling. Warren framed the broader problem in the United States as an erosion in social capital in communities and a disconnection between people and the political system. He argues that "the key to reinvigorating democracy in the United States can be found in efforts to engage people in politics through their participation in the stable institutions of community life" (15). "Revitalizing democracy, then, requires community building, but also something more: creating institutional links between stronger communities and our political system" (19).

Warren presents four-part framework to help 'specify the necessary components of the process of building social capital to revitalize democracy."

- "First, the process of building social capital needs to start with the institutional life that still exists in local communities."

- "Second, since these institutions and the social fabric of communities are weak, an effective strategy is needed to develop cooperative ties and enhance the leadership capacity of community members." 
- "Third, strong local communities can be isolated, inward looking, even antidemocratic. In order to develop broader identities and a commitment to the common good, we need a strategy to bridge social capital across communities, especially those divided by race."

- "Finally, building strong communities with diverse connections may not matter if they lack the power to shape their own development. Effective power requires mediating institutions capable of intervening successfully in politics and government" (19-20).

Sirianni, in his book Investing in Democracy (2009), explores "ways government can serve as a critical enabler of productive engagement and collaborative problem solving among ordinary citizens, civic associations, and stakeholder groups-and how public policy and administration can be designed to support this involvement" (1). Sirianni used his "eight core principles of collaborative governance and policy design"(presented earlier in this paper) to analyze Seattle's citywide neighborhood empowerment and neighborhood planning system. Sirianni found that "Seattle's neighborhood system of district councils, matching funds, community gardens, and neighborhood planning embodies the core principles of civic policy design...." (106).

Sirianni reports that the City of Seattle "took its first steps in creating a system of formal neighborhood representation in 1987-88 when it established twelve district councils to represent independently organized 'community councils,' the preferred term for neighborhood associations...." (Sirianni 2009 66). The City created the system in response to rising neighborhood "activism and outright resistance to unchecked 
development and top-down, zone-by-zone planning." The Seattle Planning Commission investigated neighborhood representation systems in other cities (including Portland, Oregon and St. Paul, Minnesota), and in 1988 created the Seattle Department of Neighborhoods to support the system. Jim Diers was hired to be the first director of the Department of Neighborhoods and served in that capacity for the next thirteen years, during which the scope of the department's activities grew.

Significant elements of the Seattle system include: Neighborhood Service Centers, District Councils, Leadership Development, Neighborhood Matching Fund, PPatch Program, and Neighborhood Planning, which emphasizes asset based community development approaches.

Sirianni identified key ideas that led to the success of the Seattle program:

- Involvement and empowerment of community members;

- A strong focus on relationship building;

- Emphasis on facilitating culture change in city agencies; and

- Support for wide range of community organizing.

Sirianni also identified key challenges for Seattle's system, which include:

- Ensuring diverse involvement not domination by white middle class participants;

- Turnover in mayors and a loss of political support at the top-a new mayor was not invested in community governance and instead focused on centralizing power vs. empowering community members; 
- Disinvestment by the city in the neighborhood program overtime, illustrated by the loss of the leadership training program, the elimination of neighborhood planners, and a reduction in the number of district coordinators; and

- The need for ongoing support to sustain community involvement and capacity and the willingness of government leaders and staff to work with the community. Turnover among city leaders and staff and among community activists without new training and relationship building will erode advances.

Jim Diers, in own his book, Neighborhood Power: Building Community the Seattle Way (2004), describes his experience helping to develop and lead the Seattle Department of Neighborhoods. Diers identifies three forms of "participatory democracy" that he says have emerged over the past third of century that he finds especially promising: "asset-based community development, formal participation structures, and community organizing" (8).

\section{Social Capital and Community Building}

Community building is a vital part of giving individuals the capacity to join together to shape their community.

In a follow up to Robert Putnam's book, Bowling Alone (2000), Putnam and Feldstein sought out examples of effective social capital and community building across the country. They identified key characteristics of these examples in their book, Better Together (2003). The authors maintained that the stories in the book show "the positive effects of social capital, the ways that people in relationship can reach goals that would 
have been far beyond the grasp of individuals in solution" (2) and argued that interpersonal "connections and civic engagement among ordinary citizens" is "essential to making participatory democracy work" (274).

Some of the authors' key findings were that effective social capital building is a local phenomenon "because it is defined by connections among people who know one another" and "trust relationships and resilient communities generally form through local personal contact." People also come together and develop social capital "in pursuit of a particular goal or set of goals and not for its own sake. Creating "robust social capital takes time and effort." The authors state that "For the most part, it develops through extensive and time-consuming face-to-face conversation between two individuals or among small groups of people" (9-10).

The authors also found that smaller organizational structures are better for creating bonds of trust and reciprocity, and bigger structures are better for extending the power and reach of social networks (9-10). Listening and trusting are easier in smaller settings" as is the ability to "discover unexpected mutuality even in the face of difference" Smaller groups are more likely to share assumptions and easier tacit communication. Smaller settings "offer easier footholds for initial steps," and people are more likely to feel individual responsibility for maintaining the group. Smaller settings also allow the one-on-on, face-to-face communication that is more effective at building relationships and creating empathy and understanding" rather than remote, impersonal communication. The density of interaction matters as well as the small size of the setting. Redundancy of contact is needed to "foster virtuous circles of mutual responsibility." The 
authors found that larger settings are better for developing "critical mass, power, and diversity" (276-277) and for developing the power needed to achieve objectives. They found that creating bridging capital in large organizations is a challenge (10).

Putnam and Feldstein identified a number of characteristics of the successful community-building examples they studied.

- Networks of networks: Nesting smaller groups within larger more encompassing ones" (10) facilitates both "mixing" and "bridging" among the small groups that can "harness the benefits of both intimacy and breadth." and responds to the need to and importance of "building horizontal ties among local groups" (278-279).

- Protagonists and enabling structural conditions: The author's found that "Building social capital depends both on the actions of protagonists" and on "key enabling structural conditions in the broader environment, many of which are immutable in the short run (though not in the long run)." Support from large, private foundations was important in one example. Education often is the most powerful predictor of high levels of social capital. Educated people and educated communities have skills and resources that enable them to form and exploit social networks more readily, whereas less educated communities have to struggle harder to do so." Urban sprawl and people's complex lives and the resulting demands on their time can inhibit social capital creation (271-272). Government policies can encourage or destroy community (e.g. the destruction of communities by urban renewal). Political 
actors who maintain commitment to and support for local participation are important. The authors found that it "helps to be blessed with 'true believers' in positions of power" who are "committed to grassroots participation" and will "follow the social-capital route through all its apparent meanderings" (274).

- $\quad$ Shared common space: Shared commons spaces are important mechanisms that bring people together across social boundaries and encourage shared activities that "bridge ethnic, gender, class, and age distinctions" (281), "build in redundancy of contact" (291) and create intergenerational and interethnic bonds. Commons spaces can enable people to have informal interactions in a number of different settings which helps strengthen social capital through building "multi-stranded relationships, for example encountering the "same person at the market and the ball field and a political rally..." (291). Common spaces can be physical spaces such as plazas and parks. Communication technology also can create commons spaces, such as through a local newspaper and other technologies that ..."provide a forum for exchange among editors, reporters, readers and residents". The authors also found that new communications technologies support and stimulate" longstanding forms of community" but did not believe that computer-based technologies on their own could create, rather than as instigators of radically new 'virtual communities'....”. They suggest that computer-based technologies matter not because they can create some new and separate forms 
of virtual communities, but because they can "broaden and deepen and strengthen our physical communities (292-293). ${ }^{1}$

- Successful community organizing: The authors found that successful community organizing was an important element in social capital building efforts. They found that "Organizing is about transforming private aches and pains into a shared vision of collective action." While they found the successful organizing sometimes is achieved through a single leader, more often it is a "process of 'interest' articulation' and 'interest aggregation"' that emerges "from carefully nurtured conversations among ordinary folks" (282). Putnam and Feldstein found that organizers need to help members "find their own voice" and "take the lead on their own projects." Effective community organizing recognizes community members "interests and needs (including their need for fun and fellowship), not just their ideals" and has more staying power if it starts with "what people care about, not some external agenda." A strong emphasis on having people tell their stories helps people "acknowledge and recognize their interests," provides easy entry for integrating new members into an organization and helps people find their commonalities (283284). Building on existing networks is an important strategy especially for communities that do not have a lot of social capital (227-228). The authors found that people are more likely to get involved through "preexisting

\footnotetext{
${ }^{1}$ The authors based their findings on partly on their examination of Craigslist in the early 2000s. Recent examples of community organizing in the Occupy Wall Street movement and the Arab Spring's use of Twitter and Facebook and other social media offer interesting tests of the authors' conclusions.
} 
friendship networks" than through "ideological commitment and objective self-interest." Building on existing networks complement with a "strategy for encouraging 'walk-ins' and for reaching out to the social disconnected. Acknowledging and celebrating successes also is important. The author's found that "Success breeds success". It's important to show residents what they can "accomplish by working together" and lay "the groundwork for bolder efforts" (289).

- Sustain and embed success: Success in building social capital also needs to be sustained as conditions and circumstances change over time. Successful organizing can change a community — as in the case of gentrification. Political champions can move on as can founding community leaders and early enthusiasts. The authors found that it is important to embed opportunities for involvement in government decisions making processes, community organizations and community culture (289-290).

In 2007, Putnam recognized that "Ethnic diversity is increasing in most advanced countries, driven mostly by sharp increases in immigration." He wrote that while, "In the long run immigration and diversity are likely to have important cultural, economic, fiscal, and developmental benefits," in the short turn "immigration and ethnic diversity challenge social solidarity and inhibit social capital" (Putnam 2007 137-138). Putnam suggests that residents in ethnically diverse neighborhoods tend to "hunker down." (137). He asserts that "Diversity does not produce 'bad race relations' or ethnically-defined group hostility" but rather that: 
"inhabitants of diverse communities tend to withdraw from collective life, to distrust their neighbors, regardless of colour of their skin, to withdraw even from close friends, to expect the worst from their community and its leaders, to volunteer less, give less to charity and work on community projects less often, to register to vote less, to agitate for social reform more, but have less faith that they can actually make a difference, and to huddle unhappily in front of the television" $(150-151)$

Putnam writes that in the "medium to long run" "successful immigrant societies create new forms of social solidarity and dampen the negative effects of diversity by constructing new, more encompassing identities" (138-139). Putnam asserts that the "central challenge for modern, diversifying societies is to create a new, broader sense of "we"” (139).

Putnam identifies the need for policies that foster "a sense of shared citizenship." He called for more opportunities for "meaningful interaction across ethnic lines where Americans (new and old) work, learn, recreate, and live" to strengthen "shared identities. He advocates for expanded "public support for English-language training, especially in settings that encourage ties among immigrants and natives of diverse ethnic backgrounds," "national aid to affected localities," and "locally based programs" that "reach out to new immigrant communities" as "a powerful tool for mutual learning" (164).

\section{Community Organizing}

The citywide community involvement systems commonly depend on some form of neighborhood council or neighborhood association system as their main model for neighborhood organizing. Some researchers have focused on understanding better the 
strengths and weaknesses of the neighborhood association model as compared to other community organizing models.

Smock, while agreeing with other authors about the importance of community organizing for achieving broader local democracy, believes that neighborhood associations/councils are unlikely to achieve this end by themselves. She argues that that a variety of community organizing mechanisms are needed to help ordinary people, especially the most disenfranchised, directly participate in public decision making and impact the social and economic conditions that affect them.

Smock identifies some core features that characterize effective urban community organizing initiatives:

- Building individual capacity-developing local leaders

- Building community capacity—networks and social capital

- Building a community governance structure (democratic governance structures that allow members of a community to make collective decisions)

- Diagnosing and framing the community's problems

- Taking collective action for community change (Smock 6).

Smock writes that, in some cases, "organizing also goes beyond its communitybased focus to contribute to broader social structural change... by building the foundational infrastructure for broader movement building and by providing the spaces for residents to reflect on their experiences and develop a collective vision for society" (7). 
Smock studied community organizing efforts in Chicago and Portland, Oregon and, from this research, identified five models of organizing. Her book describes examples of these five models (Civic, Power-based, Community-building, Womencentered, and Transformative) and identifies their particular strengths and tradeoffs.

Smock maintains that no one model can fills all objectives of community organizing in complex urban environments. She argues that it take the coexistence of many different organizations representing different models different organizations in a neighborhood to promote broader civic participation. She suggests that it is best to create cooperative relationships between these organizations versus a hodge-podge of unconnected activity.

Smock shows that each model has distinctive advantages and tradeoffs. Community organizers need to think strategically about what niche each model can fill in response to particular factors in a community, such as neighborhood population, the type of neighborhood problems, the political climate, etc. She warns that community organizers and their support networks need to avoid narrow dogmatism and turf battles among different models.

Civic Model: Smock's civic-organizing model represents the relatively unstructured and informal form of traditional neighborhood associations. Smock writes that the civic model focuses on "protecting the neighborhood's public order," which often is threatened by "the absence of shared behavioral norms and ineffective monitoring of the neighborhood's public spaces" (21). Civic organizations "sponsor informal gatherings and unstructured meetings where residents can share news and information, voice 
concerns, and develop strategies for tackling local problems. These strategies typically involve the use of organized peer pressure and hands-on voluntary activities to shore up the neighborhood's public order."

Smock found that Civic Model organizations are "easy to implement" and help connect residents to city services. She writes that these organizations are the "simplest to create and sustain," typically “operate as all-volunteer groups with little to no funding," and are the "most informal and unstructured of all the groups." "As long as there are enough residents in the neighborhood with the basic skills necessary for keeping the organizations running, civic organizations can operate with minimal investment of time and resources" (248).

She writes that "Civic organizations link residents to the city's established mechanisms for solving local problems. They provide residents with information about how the city services system works, and they give residents an opportunity to communicate directly with the city services personnel assigned to address specific problems in their neighborhood. By giving residents clear information about city laws and ordinances and direct access to the bureaucracy, civic organizations help to democratize the provision of city services" (248).

Smock identified the weaknesses of the civic model in its limited capacity, its tendency to become a forum for the middle class, its potential for insularity and exclusion, and its "emphasis on stability and control rather than proactive change" (248249). 
Smock writes that "lack of paid staff or formally designated leaders" requires civic model organizations to rely on the "personal initiative and individual discretion of each participant to get anything done." The absence of effective mechanisms for internal accountability hinders the ability of these organizations to "perform the necessary behind-the-scenes work to move their projects and campaigns forward." Civic organizations lack 'formal mechanisms for recruiting and training local leaders" and have to rely on residents who already have "leadership skills and experience." As a result, these organizations often are "dominated by the neighborhood's most privileged residents, particularly landlords, business owners, and middle-class professionals." The unstructured nature of these organizations does not "provide a way to ensure that the interest and perspectives of all the participants are heard' and they offer "few opportunities for less experienced residents to become involved in community life" (248249).

Civic model organizations tend to have homogeneous membership which, combined with their limited size, can foster "insularity and exclusivity." "The organizations' members do not typically reach out to other populations or social groups outside of their immediate clique, and they rarely work in cooperation with other institutions or organizations." This leads them to define problems in ways that "tend to ignore the interests and perspectives of other social groups within the community," which can "exacerbate social division in the neighborhood and limit the community's overall problem solving capacity." The model's emphasis on "stability and control rather than proactive change" and its "orientation to the public sphere," while helping "residents 
obtain information about" city services, "they do little to increase residents' influence within the public sphere or to alter the way that government operates" (249).

Smock's analysis of the traditional neighborhood association model is particularly valuable given that many researchers encourage the development of citywide neighborhood structures as an important strategy for increasing participatory democracy in a community.

Power Model: Smock's identifies the power-based model being rooted in traditional Saul Alinksy-style community organizing, which she writes has at its core the belief that "urban problems stem from residents' lack of power within the public sphere." Proponents of this model believe "urban residents must be organized into large, well disciplined 'people's organizations' and need to have "both the opportunity to formulate their program... and a medium through which to express and achieve" it. Community members then engage in "public confrontation with power holders in order to win a seat at the negotiating table." Paid staff often lead the organizing effort and focus on recruiting and building individual leaders in the community (14).

Power-based organizations tend to build strong organizations that have an impact on public decision making. They involve large numbers of residents by "recruiting and agitating residents around their most immediate concerns.” Hierarchical organizations and majority voting allow the organizations to "identify neighborhood priorities and develop strategic campaigns quickly and efficiently (249). Extensive "leadership training and logistical support" helps "create a skilled and disciplined base of leaders. Powerbased organizations "are able to alter the balance of power in urban neighborhoods" 
through "a well-developed repertoire of techniques" and "engage large numbers of inexperienced residents in collective action" (250).

The reliance of power-based organizations on majority voting can "undermine full inclusion of all members voices." The "imperative to develop winnable strategies through a quick and efficient decision-making process can lead to manipulation of the members and oversimplification of the issues," and sometimes framing of the political process in polarizing and one-dimensional ways leaves little "possibility for engaging members in genuine deliberations over public priorities." While "strengthening residents' influence at the public bargaining table" these organizations are "able to alter the distribution of public resources, but they have little impact on the overall structure of local government or the public sphere" (250).

Community-Building Model: The community-building model "focuses on strengthening the internal social and economic fabric of the neighborhood. This model uses an "asset-based" approach—similar to that championed by Kretzman and McKnight—-to "build collaborative partnerships among the neighborhood's stakeholders..." "Every institution and organization with a stake in the neighborhood...is seen as a potential source of assets and resources..." Communitybuilding organizations "develop a shared vision among these groups" by engaging in "a comprehensive planning process to assess the overall assets and needs of the community," and, based on this plan, "develop a holistic plan for rebuilding the community's economic base and social infrastructure." Smock writes that proponents of this model argue that "urban neighborhoods must develop consensual working 
partnerships with government officials and policymakers...to leverage the resources and support necessary to achieve the community's goals" (18).

Smock finds that community-building organizations build a community's institutional capacity to address its problems and can develop comprehensive plans to respond to the needs and concerns of the community as a whole. Smock found that the community-building model "is most at risk of leaving individual residents who are not the staff and leaders of local institutions and associations out of the organizing process." "The emphasis on comprehensive planning and technical expertise privileges the involvement of community-based professionals and administrators..." Also, "the pressure to reach consensus among institutions with widely varying interests can limit the potential scope of the organizations' work." Community building organizations also require "substantial external resources and support" to "implement their comprehensive plans," which "creates a dependence on government funding and assistance that forces them to frame much of their work to fit within existing governmental priorities." This makes the organizations "vulnerable to manipulation and cooptation by political leaders who may not share their substantive goals" (250-252).

Women-centered model: Smock argues that the most disenfranchised groups often need special community organizing mechanisms to bring them together, build their confidence and skills, and help them see the public policy aspects to the challenges they face in their daily lives.

Smock suggests that Women-centered model is the "most effective at engaging society's most disenfranchised members in public life." This model creates "a fluid 
connection between the personal and public spheres," and provides for "mutual sharing and support" that enables "participants to overcome personal obstacles and build collective leadership," which allows them to "work on broader community issues." This model also "promotes a highly democratic and inclusive process for decision-making about local priorities and goals."

The Women-centered model approach limits the "organizations' size as well as the breadth of their networks" and impact, and the "emphasis on building face-to-face relationships within local institutions, one person at a time, typically limits their ability to gain meaningful influence over the public decision-making process" (252-253).

Transformative Model: Smock argues that most community organizing models focus primarily on helping community members have a greater voice in getting their needs met within an existing power system. Smock writes that achieving a broader and lasting community voice in shaping communities requires transforming the dominant system. The transformative model strongly focuses on challenging dominant ideological frameworks and seeks to build the foundation for social change. The common weakness of these organizations is their limited capacity to engage community members, the difficulty of achieving concrete results, and the tension between educating community members and mobilizing them to take action.

Smock maintains that knowing the strengths and weaknesses of different models allows people to "make strategic decisions about which approach to organizing will be most effective in a given situation." "The effectiveness of a particular model can vary in response to a wide variety of different factors - the distinct composition of the 
neighborhood's population, the specific nature of the neighborhood's problems, the political climate, and the primary focus of the organization's goals" (255).

For instance, Smock argues that the traditional informal neighborhood association model "is uniquely suited for neighborhoods that have a predominately middle-class, homogeneous population and relatively few social problems. The model provides meaningful leadership opportunities for primarily middle-class residents with preexisting leadership skills and experience, but it does little to include low-income, disenfranchised residents in community life." The civic model can "provide an easy way for residents of middle-class neighborhoods to get involved in public life, learn about city government, and solve small problems as they arise" but" is not capable of addressing complex community issues" (255-6).

Smock suggests the "creation of complementary relationships among organizations implementing different models provides a way to maximize the models' distinctive strengths while avoid their limitations." Smock refers to Fisher and Taafe study of the organizational structure of one Texas neighborhood (Fisher and Taafe 1997) and asserts that “in a 'postmodern' society with multiple identify and interest groups, the coexistence of many different organizations in a single neighborhood promotes broader civic participation." She also suggests that "hybrid organizations" could be developed that would incorporate "elements of more than one model within a single organizational structure" (257-258).

Smock notes that "...some scholars and activists" have concluded "that community-based organizing is incapable of contributing to long-term social change." 
She clarifies that she believes that "community organizing can provide an essential building block for achieving broader structural change" (225). She cautions, however, that "In an increasingly globalized world, however, not all problems can be addressed at the community level. The problems experienced by urban residents are typically rooted in political and economic structures that are anything but local in their origins" (222). Smock argues that "History suggests that if we want to transform the social and economic arrangements underlying contemporary urban problems, we must build a broad-based social justice movement" (225).

Smock argues that community organizing "actually provides one of the most effective (and realistic) starting points for movement formation" because "local neighborhoods remain the center of most people's lived experience;" and “...people experience contemporary social problems as they are manifested at a local level." Smock suggested that “...the most effective way to get people involved in social action of any kind is by engaging them in struggles that related directly to their everyday experiences...." She finds that "Local based organizing thus provides an essential mechanism for getting ordinary people—particularly America's most disenfranchised residents—involved with public life" (226).

Smock argues that local organizing can help engage residents and develop their skills and capacities as public actors, can generate the stability and hope "necessary to enable them to participate in long-term campaigns for social change; raise their awareness of "the limitations of an entirely locally-based strategy," and creating the momentum "necessary to propel residents to engage in broader movement work" (227). 
Smock argues that to contribute to long-term social structural change, community organizing must be able to both build upon and transcend its neighborhood focus. She says that this requires the creation of a "supra-local infrastructure of well-networked organizations" and "an overarching ideological framework that challenges society's dominant economic and political arrangements" (227).

Taafe and Fisher propose that "community organization models need to consider that highly diverse and often contentious community efforts within a single community represent well the context of life in contemporary heterogeneous urban neighborhoods." “... a highly diverse and often fragmented public life has been developing at the grassroots. The disparate aims of different community groups in a single neighborhood reflect a movement towards organizing based on communities of interestracial/ethnic/political—as well as organizing based on communities of place" (31-32).

Grossman and Gumz found that "Neighborhood organizing has been an important aspect of community organization over the last 50 years. However, as individuals identify less with geographic communities and community organizing efforts become issue-as opposed to locality-based, the viability of neighborhood-focused organizing efforts becomes more uncertain" (47).

Chaskin studied community organizations in Portland (Oregon), Boston, Baltimore. The intent of his study was to "call attention to, define, and provide an analysis of the broader ecology of organizations and processes that constitute neighborhood governance systems - to synthesize and make explicit the systemic nature 
of such relations - across the different cities, and to provide some framework for considering how these patterns may play out in particular (other) contexts" (163).

Chaskin encouraged organizations that seek to work within community not to focus just on one organization. He encouraged them to recognize that individual neighborhood associations or other community-based organizations "operate within a local ecology of organizations and inter-organizational relationships that help define and condition their work and influence." He found that often community organizations operate "in a context that is often already well populated with a range of associations, organizations, and crafted coalitions that would also claim-in particular cases or around particular issues - to speak for and act on behalf of the neighborhood and its members" (163).

An increasing number of communities are creating city government sponsored "citizens academies" as a way to increase the ability of community members to engage effectively with their local governments. Morse (2012) studied citizen academies in North Carolina and elsewhere in the country to learn more about their purposes and goals, content, and other characteristics.

Morse (2012) emphasizes that the "increasing emphasis on collaborative governance and citizen engagement in local government" raises the issue of "how communities can build capacity for collaboration and engagement." He goes on to say that "Local government leaders may have a strong commitment to citizen engagement and collaboration, but success, ultimately, is dependent upon the capability and willingness of citizens, groups, and organizations to be engaged partners in the governance process" 
[emphasis in the original] (79). Morse suggests that "The issue of civic capacity may be one answer to why the practice of citizen engagement is not as widespread as its acceptance as an ideal" (82).

Morse differentiates citizen academies from two other forms of local training programs: citizen police academies and community leadership programs. Morse describes "citizen police academies" as opportunities offered by police departments of local governments "to inform citizens of police operations, create opportunities for positive citizen-officer interactions" and to "develop a relationship of trust and cooperation between the police and citizens" (85). "Community leadership programs" "exist for the purpose of developing active and informed citizen leaders who can collaborate with other individuals and groups to solve community-based problems." These training programs focus broadly--not just on a single local government—and promote leadership skills and community networking. Community leadership programs usually are sponsored by a chamber of commerce, a local United Way or some other nonprofit organization (86).

Citizen academies commonly are sponsored by a single local jurisdiction and focus on activities of and issues relevant to the government enterprise. Like citizen police academies "they are civic education programs for local citizens, conducted by local government," and like community leadership programs "they cover a broad range of topics and seek to develop civic capacity through the civic education of citizens" (86).

Morse found that the purposes and goals of the citizen academies he studied were fairly consistent. They usually focus on: improving “participants' knowledge of local 
government;" increasing the involvement of citizens in local government, for example through service on local boards, commissions, and committees; and improving community relations by helping community members to get to know local officials and to open lines of communication between local officials and staff and community members. Morse found that the program he studied varied in their focus from a more basic emphasis on public relations to a more advanced and substantive focus on "building community capacity for citizen engagement." For example, some programs focused more on a one-way transfer of information from city staff to community members, while others incorporated dialogue opportunities that allowed two-way information sharing and learning between city leaders and staff and community members.

Morse's key observations about "citizens academies and capacity building" from his research included:

- "Citizens academies can improve the skills and knowledge of citizens with respect to engaging in community affairs."

- "The more citizens academies emphasize avenues and opportunities for participation, the greater impact they will have on developing leadership and active participation among citizens."

- "The more citizens academies facilitate community-building and dialogue, the more impact they will have on developing the social capital and 'space for dialogue and collective action' dimensions of civic capacity" (95).

Morse concluded that "As local governments look to promote more citizen engagement and collaboration, they will need to simultaneously work to build the 
capacity of citizens to do so." He also encouraged local government staff members who develop these programs to "(re)consider to what extent they capture the more advanced, capacity-building potential inherent in the citizens academy concept" (96).

\section{$\underline{\text { Advancing System Reforms }}$}

We have explored the basic characteristics of participatory democracy and the elements different researchers have suggested are needed for a community to move toward greater participatory democracy. Another important aspect is the process by which communities adopt and implement the policies and programs to move down this path. What does it take to develop and enact these participatory democracy reforms in a community?

Kingdon's "multiple streams" theory offers a useful model to explain how participatory democracy reforms are likely to get on a local government agenda and be acted on (Kingdon 1995). While Kingdon's research focused primarily on the federal government level, the theory may be a good fit for agenda setting at the local level with some minor adjustments.

Kingdon suggests that three separate "streams" flow through the governmental agenda-setting system, each with its own dynamics and rules. He identifies the three streams as: problems, policies, and politics.

- Problems: The process by which decision-makers learn about conditions and the ways in which conditions are defined as "problems" that government should address. Problems can be identified through indicators, a focusing event "such as a disaster, crisis, personal experience or powerful symbol," or feedback about "the 
operation of existing programs." Conditions also can be re-defined as problems when people "in and around government" see that important values are violated, or see that other jurisdictions have chosen to address a similar problem, or people re-categorize a condition increasing its priority—such as when a service delivery problem is refined as a civil rights issue.

- Policies: The process by which proposals are developed and by which "the list of potential alternatives for public policy choices [is] narrowed to the ones that actually receive serious consideration...." Potential alternatives often are raised, tested, and refined by "loosely knit communities of specialists" in an issue or problem area. These communities often include "academics, researchers, consultants," long-time government staff, interest group analysts." Kingdon notes that policy proposals often go through a long process of "softening up" the system before they move forward (200-201).

- Politics: A problem can move up on a government agenda with the arrival of a new administration or a change in the national or community mood. Participants in the political stream "recognize problems or settle on certain proposals in the policy stream..." (199). Participants often include both "visible" and "hidden" players. Visible participants often include prominent politicians, high-level appointees, the media, and other political players, such as political parties and campaigners. Hidden participants often include "academic specialists, career bureaucrats, and congressional staffers" (199). 
Kingdon found that these three separate streams sometimes come together, increasing the chance that a problem will be addressed or a proposal moved forward. The "complete joining of all three streams dramatically enhances the odds that a subject will become firmly fixed," not only on "government agendas" (the "lists of subjects to which governmental officials are paying serious attention”) but also on a government's "decision agenda" ("a list of subjects that is moving into position for an authoritative decision....”) (202).

Kingdon identified "policy entrepreneurs"...individuals who "broker people and ideas" as being crucial to the agenda setting process (201). Policy entrepreneurs are "people willing to invest their resources in return for future policies they favor" (204). Policy entrepreneurs can include: elected officials, career civil servants, lobbyists, academics, and journalists (205). Policy entrepreneurs play a major role in drawing attention to and defining problems. They seek to push "their concerns about certain problems higher on the agenda," push their "pet proposals during" the process to soften up the system, and coupling streams together-e.g. problems to policy opportunities. Policy entrepreneurs especially seek to couple streams at critical times when "open windows" open up that would allow them to draw attention to problems that concern them and get policy proposals on the government decision making agenda. Kingdon defines "open windows" as "an opportunity for advocates to push their pet solutions or to push attention to their special problems." Windows can open either in the "problem stream"- - such as the emergence of a new problem to which policy solutions 
can be attached, or the "political stream"- -such as the election of a new administration, a swing in national or community mood, or vigorous lobbying (203).

Kingdon maintains that "Elected officials and their appointees turn out to be more important than career civil servants or participants outside government." He notes that his research into the roles of various participants in agenda setting has found that "a fairly straightforward top-down model, with elected officials at the top, comes surprisingly close to the truth." Given this, we would expect a strong role for local elected officials, especially the mayor (199).

Kingdon's "multiple streams" theory would lead us to look for certain patterns in the path by which participatory democracy policies and programs get on the local government agenda and are adopted, especially in the three "streams" of problems, policies, and politics.

We would expect to see reforms move forward when general agreement among decision-makers that a problem exists that needs to be solved through the adoption of greater participatory democracy elements. We would also expect to see both "visible" and "hidden" participants who develop reform proposals and advocate for them-most likely over many years. Major advances would be most likely when a political champion-most likely a mayor at the city government level—supports the effort, and when crises or studies draw attention to an issue. Policy entrepreneurs would be likely to play a crucial role in advancing coupling of the three streams-problems, policies, and politics--especially during "policy windows." 
Embedding Change_-Sustaining Progress Toward Participatory Democracy

Gibson argues that "Citizen-based approaches" to governance focus "primarily on culture change, rather than on short-term outcomes, issues, or victories, and include a cross-section of entire communities, rather than parts of them" (Gibson 2). She says the challenge is to inculcate a "deeper and more firmly entrenched cultural ethos of civic engagement - an ethos that helps give people a sense of public purpose and a belief that their voice matters in larger issues" [emphasis in the original] (5).

Fagotto and Fung (2009) studied the embedding of deliberative practices in communities. They found that "A community that has embedded deliberation in its practices of public reflection and action (i) utilizes methods of organized-more or less formal—deliberation (ii) to consider a range of public issues or problems (iii) over a period of several years. Often public deliberation is (iv) linked to a range of communitybased or governmental organizations in ways that affect the decisions, resources, or policies of those bodies."

Stone (1998), in his research on urban regime theory and public education reform, notes that many public policy arenas largely are controlled by "semiautonomous subsystems." "The most active players tend to be the ones most directly affected... and are most likely to "direct the day-to-day activities of these subsystems" (6-7). Stone argues that the goal is to alter the subsystem relations and to establish an "institutional legacy" to ensure that the changes are lasting. Fundamental reform requires sustained mobilization and the institutionalization of new practices and relationships. Stone argues 
that the inner core of a subsystem rarely reforms itself and that some form of civic mobilization is needed to achieve and sustain reform (8).

Fung, in his 2004 book Empowered Participation, studied community participation structures created by the Chicago Police Department and Chicago Public Schools in the 1990s to see whether these types of institutional mechanisms can help further participatory democracy "even in the most depressed areas and for the poorest people" (ix). Fung's study identifies a number of elements that can assist in the success of these types of participatory mechanisms.

Fung reports that both the Chicago Police Department and Chicago Public Schools "reorganized to create new channels through which residents could exercise their collective voice and influence. Extensive powers were devolved from their headquarters out to the neighborhoods" through neighborhood "beat" meetings and local school councils (3). Fung believed that these reforms "advance the central tenet of participatory democracy: that people should have substantial and equal opportunities to participate directly in decisions that affect them" (3-4).

Fung wrote that these reforms represent a type of participatory democracy that can be appropriately referred to as "Empowered Participatory Governance" because it is "participatory," "empowered," and "deliberative":

- "participatory" because CPS and CPD invited "ordinary individuals to take part in crucial governance decisions about the goals, priorities, and strategies of policing and public education." 
- "empowered" because "unlike the case with regard to many advisory panels, public hearings, and discussion groups, decisions generated by these processes determine the actions of officials and their agencies."

- "deliberative" because "members of Local School Councils and beat meetings make decisions through a process of structured reasoning in which they offer proposals and arguments to one another" (4).

Fung recognizes common criticisms of participatory democracy, including that the "scale, technical complexity, and intricate division of labor of government, and the privatization of public life" cannot adequately be responded to by traditional participatory democracy mechanisms, and that the devolution of decision making authority will not be able to overcome social tensions in the community (4).

Fung states that his core argument is that "troubled public agencies such as urban police departments and school systems can become more responsive, fair, innovative and effective by incorporating empowerment participation and deliberation into their governance structures" (4).

Fung advocates for blending devolution of decision making authority with some centralized support and oversight, which he calls "Accountable Autonomy." He contrasts this approach with traditional, top-down government decision making, the marketinfluenced, choice approach to public management, and complete devolution of decisionmaking to the community. Fung suggests that:

- "Decentralization, by contrast, allows localities to formulate solutions tailored to their particular needs or preferences" (reference to Tiebout 1956) (4). 
- "Devolution can also free residents, teachers, and police officers to imagine and implement innovations that depart from conventional wisdom and routine, and are therefore unlikely to come from the central office."

- " residents and officials may have local knowledge that can usefully inform policy strategies but that may not be systematically available to or easily usable by centralized organizations."

- "citizens who depend on these public services have strong motivations to contribute to their improvement through civic engagement. Given opportunities to participate in school governance or community policing, they can contribute distinctive resources and expertise...." “...they also can use these opportunities to hold principals and police officers accountable when they shirk, lie, or act incompetently" (5).

Fung also notes that scholars who study participatory small-group decision processes have identified some common dangers of these process. They have found that these processes often are no more fair than other kinds of governance and decisionmaking (reference to Mansbridge 1980; Gastil 1993; Sanders 1997) (5). Some of the common dangers include:

- "Voices of minority, less educated, diffident, or culturally subordinate participants are often drowned out by those who are wealthy, confident, accustomed to management, or otherwise privileged." 
- "Liabilities such as parochialism, lack of expertise, and resource constraints may impair the problem-solving and administrative capabilities of local organizations relative to centralized forms" (5-6).

Fung also warns that "groups may lack the wherewithal, goodwill, or motivation to come together" (7). Two particular threats to democratic values in small group processes include:

- Internal divisions: Internal divisions "among participants, for example, between factions of residents or between residents and officials" that "may paralyze the group or allow some to dominate."

- Lethargy: "even in the absence of conflict, groups may be unmotivated to utilize local discretion to innovate and advance public ends through problem solving."

Fung argues that the problems of devolution of decision making to the community are more dependent on institutional design rather than innate to participatory democracy. He suggests that "a judicious allocation of power, function, and responsibility between central authorities and local bodies can mitigate these pathologies of inequality, parochialism, and group-think and so better realize the ideals of empowered deliberation and participation." "Centralized authority in 'accountable autonomy' can reduce these internal obstacles through mechanisms to safeguard both local processes and substantive outcomes" (6-7). 
Fung argues that "Support and accountability are two pillars of a reconstructed relationship between central power and neighborhood action that can reinforce local autonomy" (6). He found that achieving this requires:

- "Successful local action, especially in depressed urban contexts, frequently requires external support." This support can include "financing, other direct resources, expertise or cooperation from larger entities." Fung found that CPS and CPD organized themselves "to provide quite systemic forms of assistance for local planning and problem-solving" that included:

○ "Extensive training for both participating residents and street-level officials"

○ "Changes in the legal and regulatory environment of these efforts"

○ "The pooling of knowledge and experience"

○ "Provision of technical assistance" (6-7).

- Increased discretion for street-level officials and flexibility in centralized rules and oversight, while providing "bottom-up" accountability, both internally and externally, through citizen participation to "assure that street-level officials utilize their irreducible discretion to advance public ends.” Internal accountability happens when citizens are "invited to deliberate with streetlevel officials, in forums like beat meeting and local school councils, on how public power and resources should be deployed.” External accountability comes when "these group deliberations, subsequent actions, and the results of those actions" are "fully documented and available to the wider public" (20). 
- External reviews and audits "check domination and faction": "...external reviews and audits can verify the integrity of local decision-making processes and intervene when procedures seem suspect." For example, CPS and CPD "require local groups to document and justify their missions, agendas, strategies, and particular actions and then subject these plans to supervisory review." "To assure that local groups utilize their discretionary latitude constructively, outside bodies monitor the relevant outcomes — through student test scores, truancy rates, incidents of crime, and more discerning measures - to detect trends of improvement, stasis, or decline in performance." Fung argues that substantive accountability requires “developing sensitive performance metrics and judiciously associating observed performance with internal effort..." (7-8).

Fung also argues that "community organizations and civic associations" can play "crucial roles in designing and establishing these deliberative and participatory reforms..." These groups can contribute their own expertise in the policy issues being address, be strong champions to ensure the process achieves a stronger voice for community members, mobilize neighborhood participants to participate in civic engagement opportunities, mobilize broad city-wide constituencies to support their positions, and act as "watchdogs of public accountability" and hold "officials responsible for the implementation and development of participatory and deliberative reforms." These community organizations can play an important role by "raising awareness, providing training and technical assistance, and trying to give ordinary parents and 
residents the confidence and presence of mind to deal as equals with their street-level public servants in forums such as community beat meetings and [local school council] sessions" (228-229).

Cooper (2011) advocates that local public agencies use a "citizen-centered" approach to working with community members. He agrees with Gibson (2006) that this approach needs further development that includes moving away from an emphasis on "particular participatory techniques, specific projects, and particular problems" and toward a broader "citizen-centered approach to civic engagement" that would focus primarily on:

- "Cultural change instead of short-term solutions and outcomes." Numerous engagement techniques are available, but often an adequate culture of engagement does not exist to "sustain and effectively employ them. "

- "Providing opportunities for "people to form and promote their own decisions, build capacities for self-government, and promote open-ended civic processes." Cooper refers to Gibson's contrasting of this with "offering specific focused opportunities for citizens to 'plug into' projects, events, techniques, and exercises 'driven by outside experts, professionals, organizations, or those external to the community."'

- "Approaches that are "pluralistic and nonpartisan." Cooper argues that "building a culture of engagement requires interaction with diverse people holding a variety of beliefs and political perspectives." Techniques that create collaboration across various divides is "required to ground a culture of 
engagement." Cooper suggests that practice with this type of approach can "support all kinds of problem solving."

- "Transcending ideological silos." Citizen-centered civic engagement should be "oriented toward the needs and concerns of citizens rather than the advancement of a partisan agenda."

- "Going beyond "the perennial and wearisome debate over which is more important or lacking_-'service or politics'—-that tends to dominate public discussions about civic engagement in the United States.”

- "Doing more than just talking" about deliberation and pursuing deliberation that leads to "tangible results."

- "Understanding that citizen-centered approaches 'do not replace politics or other democratic processes"” (249).

Cooper examined Los Angeles governance reforms in 1999 which sought to apply "neighborhood-level civic engagement institutions" to a larger-scale urban area. Cooper maintains that Los Angeles was the first major metropolis "that attempted to create formal links to communities intended primarily for participation in governance rather than the decentralized delivery of services." Voters adopted city charter reforms in 1999 that mandated "that a citywide system of neighborhood councils be organized from the grass roots up, allowing for considerable variation in form, structure, and size of the councils." The system required "people in each community" to "identify their own boundaries, design their own bylaws, adopt their own systems of financial accountability, and then request certification from the city Board of Neighborhood Commissioners." The 
system requires neighborhood councils to involve all of the neighborhoods stakeholders. The City initially provided $\$ 50,000$ annually to each neighborhood council to support its work (Cooper notes that the City Council later reduced this amount to $\$ 45,000$ ).

Cooper has studied many aspects of Los Angeles's neighborhood council system through his work with the Civic Engagement Initiative at the University of Southern California (USC). Cooper refers to a major summary of research on Los Angeles's system titled "Toward Community Engagement in City Governance: Evaluating Neighborhood Council Reform in Los Angeles" (Musso et al. 2007). Cooper reports major findings of the report include:

- "A citywide system of operating neighborhood councils" was successfully established "in the five years since the Los Angeles Department of Neighborhood Empowerment was fully functioning...." "Contrary to the myth that the people are apathetic and uninterested in participation" Los Angelenos "were eager to engage in the difficult process of organizing neighborhood councils..." "Unfortunately, the city was much less forthcoming with its support, staff and funding to assist those volunteers in accomplishing such an enormous task" (245).

- "Based on surveys of the boards, it is clear that most of those participating in the organizing process are not newcomers to civic activity but people who have been relatively active in community and political life in their areas and the city. The report found that board members are "'more likely 
than neighborhood residents to be white, wealthy, highly educated, and homeowners"", (245)

- "The focus on the complex certification and board election processes may have drained energy away from outreach to the communities the councils represent, thus producing the lack of adequate representation" on the councils. The report also notes a tendency to confuse "outreach" with “organizing." The report defines"outreach" as involving “distribution of information through flyers, e-mail, posters in prominent locations, notices in community newspaper, and similar means of notifying people of the new councils." The report defines "organizing" as requiring "personal contact in addition to the dissemination of information to persuade people to participate and to create social capital by establishing bonds of trust." "In the early years there was insufficient organizing and too much reliance on outreach" which, in some cases, "has created a deficit in social capital that can be invested in the governance process" (245).

- The "political leadership of the city " assumed that the councils would provide a "way of more effectively connecting the people to the governance process..." This anticipated interaction between the councils and city officials "was slow getting started." "This was mainly because the city was slow initiating some of the mechanisms that would encourage this interaction, such as the early notification system to let people know of planned city activity in their communities and the participatory budget 
mechanisms to involve citizens in the development of the annual city budget." "Also, some elected officials had not fully embraced the neighborhood councils and tended to keep them at arm's length." Engagement with the city bureaucracy also was hampered because "most of those agencies were still dominated by personnel with the old Progressive-era technical professional role identities. They tended to see the new councils not as assets, but rather as annoying distractions from their main work" (246).

- "The people of Los Angeles appear to have felt empowered by the creation of the neighborhood council system within a relatively short time, even though the city's performance had actually changed little" (246).

Cooper also notes that "several formal and informal elements of the system have helped in building the capacity of the councils for collective action, sharing of information, and engaging the administrative agencies of the city. " These include the development of regional and citywide networks, including the "Citywide Alliance of Neighborhood Councils," similar regional alliance organizations, and "other issue- or identify-oriented networks" (246-247).

Many researchers have found that changing the culture of local government is a key factor in truly advancing more collaborative working relationships between government and community. Fernandez and Rainy (2006) reviewed the literature on organizational culture change in the public sector. They found "remarkable similarities" among the models and frameworks for organizational change that they reviewed. 
Fernandez and Rainey identified eight factors that they suggested "change leaders and change to which participants" should pay special attention. These eight factors are described below.

Factor 1: Ensure the Need. "Managerial leaders must verify and persuasively communicate the need for change." People have to be convinced of the need for change and suggest beginning by "crafting a compelling vision for it" that is "easy to communicate," "appealing," "provides overall direction for the change process" and "serves as the foundation from which to develop specific strategies for arriving at a future end state." Fernandez and Rainey found that some research shows "it is easier to convince individuals of the need for change when leaders craft a vision that offers the hope of relief from stress or discomfort." Researchers found that public sector leaders can take advantage of “mandates," 'political windows of opportunity,' and 'external influences" to verify and communicate the need for change (169).

Factor 2: Provide a Plan. "Managerial leaders must develop a course of action or strategy for implementing change." The vision for change needs to be transformed into a "strategy with goals and a plan for achieving it." The strategy should offer "direction on how to arrive at the preferred end state," identify obstacles, and propose measures for overcoming these obstacles. Specific goals will limit "the ability of implementing officials to change the policy objectives" and provide "a standard of accountability"(169170).

\section{Factor 3: Build Internal Support for Change and Overcome Resistance.}

"Managerial leaders must build internal support for change and reduce resistance to it 
through widespread participation in the change process and other means" (170).

Fernandez and Rainey write that a "crisis, shock, or strong external challenge"—real or manufactured-“can help reduce resistance to change." They caution that managers run the risk of "playing it too safe" if the urgency rate is not pumped up enough. "

Wide-spread, effective and ethical participation" can support change and lower resistance. Effective approaches managers can employ include: “persuasion, inducements and rewards, compromises and bargaining, guarantees against personal loss, psychological support, employee participation, ceremonies and other efforts to build loyalty, recognition of the appropriateness and legitimacy of past practices, and gradual and flexible implementation of change. Fernandez and Rainey write that "participation is particularly important in the public sector." "...career civil servants...can use the frequent turnover among top political appointees to their advantage by simply resisting new initiatives until a new administration comes into power"..."their participation in the stages of change can help reduce this kind of resistance."

Successful implementation of organizational change often resembles a hybrid of "lower-level participation" and "direction from top management." In addition to widespread participation, leaders must "take participation seriously, commit time and effort to it, and manage it properly" (170-171).

Factor 4: Ensure Top-Management Support and Commitment. “An individual or group within the organization should champion the cause for change." Some studies stress the importance of having a single change agent or 'idea champion' lead the transformation." Others stress the need for a "guiding coalition" of individuals 
"who lend legitimacy to the effort and marshal the resources and emotional support required to induce organizational members to change." "Successful reform requires "leadership continuity and stability," which is a particular challenge in the public sector because of "frequent and rapid turnover of many executives in government agencies." Because of this, career civil servants often lead significant government reforms (171).

Factor 5: Build External Support. "Managerial leaders must develop support from political overseers and key external stakeholders..." partly because of the ability of these players to: "impose statutory changes" and "control the flow of vital resources to public organizations." Political overseers can influence reform efforts by "creating and conveying a vision that explains the need for change" as well as selecting political appointees who are "sympathetic to the change" and "have the knowledge and skills required for managing the transformation" (171).

Factor 6: Provide Resources. "Successful change usually requires sufficient resources to support the process.” Fernandez and Rainey maintain that "...change is not cheap or without trade-offs." "Planned organizational change involves a redeployment or redirection of scarce organizational resources toward a host of new activities," including:

- "developing a plan or strategy for implementing the change"

- "communicating the need for change"

- "training employees"

- "developing new processes and practices"

- "restructuring and reorganizing the organization" and

- "testing and experimenting with innovations." 
"Ample funding is necessary to staff implementation agencies and provide them with the administrative and technical capacity to ensure that they achieve statutory objectives" (712).

Factor 7: Institutionalize Change. "Managers and employees must effectively institutionalize and embed changes." "Virtually all organizational changes involve changes in the behavior of organizational members." For changes to endure, "members of the organization must incorporate the new policies or innovations into their daily routines." "Employees must learn and routinize these behaviors in the short term and leaders must institutionalize them over the long haul so that new patterns of behavior displace old ones."

Fernandez and Rainey cite one model for "reinforcing and institutionalizing change,", developed by Armenakis, Harris, and Field (1999), under which leaders can:

- "modify formal structure, procedures, and human resource management practices;"

- "employ rites and ceremonies"

- "diffuse the innovation through trial runs and pilot projects"

- "collect data to track the progress of and commitment to change" and

- "engage employees in active participation tactics that foster 'learning by doing"” (172).

The collection of data and monitoring of the implementation process can help "keep managers aware of the extent to which organizational members have adopted the 
change" and "should continue even after the change is fully adopted to ensure that organizational members do not lapse into old patterns of behavior" (172-173).

Factor 8: Pursue Comprehensive Change. "Managerial leaders must develop an integrative, comprehensive approach to change that achieves subsystem congruence." Similar to Stone, Fernandez and Rainey argue that systemic changes are needed to the subsystems of an organization and "must be aligned with the desired end state." "Changing one or two subsystems will not generate sufficient force to bring about organizational transformation." Fernandez and Rainy note that "subsystem congruence may be more difficult to achieve in the public than the private sector because change agents in the public sector exercise less discretion than their private sector counterparts" (173).

$\underline{\text { Literature Specific to Portland }}$

A number of scholars have studied different aspects of Portland's neighborhood system since the early 1980s. This section reviews their research and findings.

Abbott (1983): Abbott documented the origins and early development of Portland citizen participation system as part of his broader examination of how Portland came to be seen-by both residents and outside evaluators - as one of the best planned and most livable cities in the nation in the late 1970s and early 1980s.

In Chapter 9, Abbott describes the origins of Portland's "neighborhood planning revolution" and the founding and early years of Portland's formal city-wide neighborhood system. 
Abbott found that, prior to the mid-1960, Portland city planners generally did not involve community members in their planning activities. They saw older inner neighborhoods had outlived their usefulness as residential areas. They proposed that these neighborhoods be redeveloped to support the "growing downtown office district," light industry, warehousing, and "expanding institutions, such as hospitals, the state university, and shopping centers" (186-187). Community activists began to organization in these inner neighborhoods to oppose city government land use and urban renewal proposals and to advocate for revitalization, rather than replacement, of their neighborhoods.

Abbott found that planning in Portland underwent "startling changes" from 1966 to 1972 that included:

- "the emergence of active and often angry neighborhood association organizations" that "made local residents the actors rather than the objects in neighborhood decisions"

- "a change of generations on the Portland City Council in 1969-70" that brought on leaders who "were more willing to respond to neighborhood requests" as well as Neil Goldschmidt, who was a strong champion of increased neighborhood involvement in city governance and who, as mayor, oversaw the creation of Portland's neighborhood system.

- Strong requirements by the federal government for citizen participation in city policy and spending decisions through the Community Action Program of the Office of Economic Opportunity, the Model Cities program, and the Housing and Community Development program. (190-91). 
Abbott writes that by "1971 and 1972, active neighborhood associations and planning committees were a presence that politicians and planning administrators could not ignore" and together constituted a citywide "neighborhood movement" (192).

The Portland Planning Commission with input from community activists began to explore the "definition of a formal role for neighborhood groups in city decision making." In 1971, the City Council established a District Planning Organization (DPO) Taskforce to "define the role for neighborhood groups in planning decisions, establish criteria for their recognition, identify funding needs, and describe channels of communication between neighborhoods and the council" (199).

The DPO Task Force's report recommended a two-tier system of self identified existing and future neighborhood associations and the creation of district planning organizations defined by the Planning Commission that would have full-time staff "to assist neighborhood access to city bureaucrats." Neighborhood associations would have access to city planning staff who could help them develop neighborhood comprehensive plans (200).

The City Council created Portland's formal neighborhood system in 1974 by ordinance, which included the creation of a new city agency, the Office of Neighborhood Associations (ONA), dedicated to supporting the creation of the new neighborhood system and supporting citizen input and participation into government decision making.

The City Council dropped the proposal to create district planning offices in response to strong opposition from neighborhood activists who feared that these offices 
would introduce a new layer between neighborhoods and city leaders that would serve the interests of city government over the interests of the neighborhoods.

Abbott wrote that ONA's essential function was to "assist neighborhood organizations through a central office and five area offices." ONA' purpose was "to provide standards and procedures whereby organized groups of citizens seeking to communicate with city officials and city bureaus on matters concerning neighborhood livability may obtain assistance from staff... and to provide certain minimum standards for said organizations." Neighborhood associations were required to have open membership and to record minority as well as majority opinions.

Abbott noted that ONA coordinated a new Neighborhood Needs program that allowed neighborhood associations to communicate their priorities for capital improvements in their neighborhoods. Planning staff also began to notify neighborhood associations of zoning change requests and began to work with "individual communities on down-zoning and district plans." Abbott found that the number of active neighborhood associations doubled between 1974 and 1979 (from 30 to 60) (200-201). ONA staff also quickly reintroduced the strategy of providing services to neighborhood associations through district level, community-controlled organizations by contracting with community organizations to serve as field offices for ONA.

Abbott recognized that many of forces that led to the "neighborhood revolution" in Portland mirrored similar calls for greater citizen participation across the nation. He noted that "Portland provided a receptive environment for a new style of neighborhood planning." City council member and then Mayor Neil Goldschmidt was "able to lead and 
to personify a major change in local politics." Goldschmidt also "attracted and supported a new generation of city employees who worked to alter the direction of Portland Planning" (206).

Berry, Portney and Thomson (1993): In the later 1980s, a research team from Tufts University identified Portland's citizen participation system as one of the best examples of participatory democracy in the country. The team investigated participation systems in a number of cities and identified a number of elements important for citizen participation system to advance participatory democracy (discussed earlier in this paper).

Berry, Portney, and Thomson identified Portland as a city that is democratic and had made had made an impressive commitment to the idea of participatory democracy." The authors maintained that increased people participation in government required to have "the foundation on which to build a true participatory democracy" (1). They found that Portland was a city that had decentralized decision making and that relied "on structures of strong democracy to provide a high level of neighborhood government" (283).

The authors found that what made the five cities, including Portland, that they studied different included: groups were "organized in every neighborhood of the city and therefore cover all the population," "regular two-way channels to and from city hall," “comparatively extensive support staff, training opportunities, technical assistance, and neighborhood offices...," neighborhood groups were "empowered to act on behalf of the residents and local businesses, and "Access, support, and a recognized, ongoing mission-these factors add up to impact on local policy" (46-47). 
Berry et al examined the Portland system against the "breadth" and "depth" criteria they had identified as the critical elements for strong participation:

\section{Breadth:}

Access of Citizens to the System: The authors recognized the strong tradition of independence of Portland's neighborhood associations. Many neighborhood associations predated the creation of the City of Portland's formal neighborhood system. From the founding of Portland's Office of Neighborhood Associations, individual neighborhood associations also had "fought any sign of structure or control by city hall." Also, fourteen years after the founding of the neighborhood system went by before neighborhoods accepted the development and adoption of written guidelines for neighborhood associations, such as requirements that neighborhood membership be open to all residents and that minority points of view be reported, and clarification of the the responsibilities of neighborhood association for the use of city funds.

The authors particularly singled out the independence of the neighborhood district coalitions "with boards made up entirely of neighborhood association representatives" that "help support neighborhood outreach and advocacy activities and provide the day-today link to city hall."

"Individual neighborhoods are also encouraged to work directly with city agencies and with the city council, and many additional participation opportunities, such as they citywide Budget Advisory Committees, are open to individuals in the city without regard to neighborhood affiliation." 
Berry et al found that neighborhood-based organizations in all five study cities provided "a clear means of access" and found that citizens are likely to know where to go to have a voice on issues covered by the system.

The authors cautioned that, in Portland, " a proliferation of committees and formal participation opportunities tends to undercut the claim of either neighborhood groups or district coalitions to be the voice of the citizens" (Berry, Portney, and Thomson 59-60).

Information and Outreach to Citizens: Berry et al stated that "Citizens cannot participate without early and adequate information about the participation process, the times and places they can become involved, and the potential impacts of the issues upon their lives" (60). They found that the City of Portland supported direct communications by neighborhood associations and district coalition with citizens by providing "a specific amount of city funds" for "the printing and postage of at least one neighborhood newsletter for every household." The City also required district coalitions to support neighborhood communications in the City's contract with the district coalitions.

Neighborhood associations that found ways to cut costs could use their allotment to produce more newsletters.

Berry et al found that "The sum of these efforts—-providing open access, maintaining an extensive information flow, and establishing a long-term commitment of city resources to the participation process-represents a serious attempt to offer realistic participation opportunities, continuously, to every resident of the city" (62).

Depth:

Opportunity to Affect Citywide Budget Priorities: Berry et al maintained that

"One of the most direct measures of the depth of a participation system is its ability to 
grapple realistically with the city budget." "In Portland, the Budget Advisory Committees perform this role to some degree, but actual ability to affect budgets varies greatly from one committee to the next" (64).

Opportunity to Affect Neighborhood Allocations: The authors determined that the ability of neighborhood associations to influence the allocation of city spending in their neighborhood, is an important element of strong participatory democracy. They found that in "Portland, the process of defining neighborhood needs highlights the neighborhoods' priorities." They also found that "small projects are handled well, but larger projects tend to remain attached to the traditional city development systems with little input from citizen groups" (65).

Ability to Define the Decision Making Process: The authors determined that having more public involvement opportunities is not always better and can lead to confusion. Competing public involvement options can lead to uncertainty about who truly speaks on behalf of a neighborhood or a group of citizens.

The authors found that "Portland offers a good example of multiple participation opportunities and uncertainty in representation." City administrators emphasize the openness of city government and provide many different avenues for public involvement and take citizen input seriously. Individual citizens can meet with agency administrators. Dozens of special citizen advisory committees existed. Neighborhood association representatives had the opportunity to speak before the city council, district coalition boards, and the City's Office of Neighborhood Involvement. Special participation efforts, such as the Central City Plan planning process at the time, brought in thousands of 
responses from targeted outreach efforts. The authors found that these many avenues for input into decision making had had many positive effects.

Berry et al noted, however, that despite all this "relative levels of dissatisfaction and distrust of city government appear to be higher among participants in Portland than in some of the other cities. The citizen interviews revealed considerably more hostility among neighborhoods and between neighborhoods and city hall than elsewhere. “

They also suggested that "the uncertainty about who is speaking for whom may be one factor that left Portland's neighborhood associations vulnerable to the charge of being "unrepresentative" of their neighborhoods" during a particular land use controversy of the time. The authors noted, in contrast, that in St. Paul ...."district councils clearly speak for residents in their area and form the majority in most citywide citizen bodies" (66).

Strength of Administrator Involvement: Berry et al determined that the "access that citizens have to line administrators during the participation process has a major impact on their ability to affect services and programs. They noted that in most cities, administrators only go to neighborhood meetings during some sort of a crisis.

The authors found that Portland had extensive mechanisms to provide "regular, ongoing contact between administrators and citizens. They particular lauded the Budget Advisory Committees (BACs) that each major department had that included neighborhood associations representatives and other interested citizens. The BACs "act as a sounding board for administrative initiatives throughout the year, particularly at budget preparation time." "They do not allow for widespread contact between citizens 
and administrators on routine issues but do give a few citizens the opportunity to grapple with agency problems in depth and to bring fresh perspectives to the departments." "Recruitment and initial training for the BACs is handled by the central Office of Neighborhood Associations." "In addition, the 'big BAC,' or Bureau Advisory Coordinating Committee, brings together representatives from all the individual BACs to consider citywide administrative policies" (67-68).

Control of Staff: Berry et al wrote that "[p]aid staff supply the administrative support and organizational abilities that citizen participants often cannot devote to volunteer work."..."staff also provide the cohesion that keeps the organization together year after year, through the ups and downs of volunteer leadership energy and attention." The authors recognized that in Portland the district coalitions had the power to hire and fire and direct their staff free of control by the City even though the city provided the core of the district coalition funding (68-69).

Controlling the Public Agenda: Berry et al explored the extent to which neighborhood associations are able to get items on or keep them off the public agenda. They looked particularly at the institutionalized role of neighborhood associations in "transmitting the demands, preferences and complaints of their constituents to various administrative agencies." The authors cited Portland's formal Neighborhood Needs process as an important vehicle to channel "complaints from citizens to a central office that, in turn sends them on to the relevant administrative agency" (110-111).

They identified value in community members having an existing network of organized neighborhood associations in place. "Would-be policy initiators know that 
residents do not have to overcome inertia to organize to stop something they disapprove of. Each community is already organized...." Administrators were somewhat selfregulating as well. "The anticipation of what will pass muster at the neighborhood level is augmented by agency rules and norms designed to keep administrators from trying to escape or minimize neighborhood review" (112).

The authors also identified the bureau Budget Advisory Committees as important vehicles by which community members could affect agency agendas. They found that each administrative agency had a Budget Advisory Committee and selected members for the committee from names provided by neighborhood associations. "The BACs tackle a wide range of issues from the geographic distribution of expenditures in a development agency to the need for a new computer system in a personnel office." "In many cases, citizens on these committees respond to specific questions and issues raised by agency personnel, but in other cases the citizens themselves are raising previously unrecognized concerns and developing initiatives for change that would otherwise never have been raised." Portland's Office of Neighborhood Associations coordinated the program and provided training and support to citizens serving on the BACs. "The BACs are not focused on the neighborhoods, but they provide an unusual opportunity for citizens to become directly involved in the nitty-gritty of city policymaking" (113).

Berry et al also found that the influence of the neighborhood associations over the agenda-building process is also magnified by the planning processes" in Portland. "Whenever...Portland does any planning, it is participatory planning. The neighborhood associations are always involved, and in neighborhood-level zoning decisions they are 
dominant." They noted that in "Portland...neighborhood plans commissioned by the city are done by the neighborhood associations. Most of them have land use committees and some even have a land use specialist on their staff." City planners also selected community members to participate in the formal Central City Plan process from lists provided by the neighborhood associations. "All development proposals are made within a set of constraints established by plans in which neighborhood associations have participated" (113).

The authors do recognize that "not all business-related decisions are created equal," however. They found that "on the most critical development issues, the development side almost always wins" (142). "On other important but smaller projects and proposals, business is quite vulnerable" to neighborhood input and advocacy.

The authors summarized that "More than anything else, the neighborhood associations give an institutionalized voice to residents at the early stages of the policymaking process when ideas are being formulated into proposals" (Berry, Portney, and Thomson 114).

Adler and Blake (1990): Adler and Blake, in their 1990 article, discuss the "evolution and dynamics of citizen participation in planning" in Portland and reviewed patterns of neighborhood participation across the city related to land use regulation by analyzing the ways neighborhood associations responded to notifications of zone changes and conditional use permit applications. They focused especially on the evolution of the role of the district level neighborhood offices in supporting this participation. (These district offices were independent organizations governed by their constituent 
neighborhood associations that the city funded through contracts to provide citizen participation and community organizing support to their neighborhoods.)

Adler and Blake noted that the "structural, program, and operational aspects of the Portland system" embodied several important recommendations made by advocates of more effective citizen participation, including:

- "city government funding for operation of neighborhood associations, so these organizations can gain access to community organizers and publish newsletters;"

- "establishing nonprofit, tax-exempt status for neighborhood organizations to allow them to seek additional sources of financial support;"

- "developing pre-service and in-service training for neighborhood activists;"

- "establishing an early notification process, whereby neighborhood organizations are brought into the planning of city actions at the earliest possible stage; and"

- "assuring the active cooperation and support of local government officials, particularly top agency officials" (37).

They found that Portland's system of citizen participation, as "facilitated by the district-level organizations" appeared to be effective in equalizing "across the city the capacity to participate in the land-use decision-making process" (42). Neighborhood association response rates (with the exception of one district) did not vary a great deal and were "not strongly influenced by either socioeconomic and demographic characteristics of residents or the volume of challenges confronting a neighborhood." 
Adler and Blake suggested that the "main question confronting the future of the Portland participation system is whether city hall and the neighborhood associations can sustain the creative tension that is embodied in the set of district-level organizations“" (43).

The authors note that the district organizations, despite receiving much of their funding from city government, "adamantly maintain their autonomy from city hall." The district organizations increasingly, at the time, "translate city agency initiatives into locally oriented terms. Because the district organizations are shaped by and responding to the needs and direction of their constituent neighborhood associations they vary in the way they operate and their capacities.

The authors found that city hall "had been working to boost the managerial capabilities" of the district offices to "create more operational uniformity" and that city agencies increasingly were using the "office to rationalize their own participation programs." They found that these pressures challenge "the autonomy of the district-level organizations and their responsiveness to constituent neighborhood associations."

The authors conclude by writing that the "success of the Portland participation system — rooted precisely in autonomy and responsiveness-intensified tendencies to routinize the system, particularly during the administration of a neighborhood-oriented mayor. This has been the case in Portland since 1985. Continued success of the system depends on the capacity of volunteer activists to balance these tendencies, maintaining the focus of district offices on neighborhood concerns" (43). 
Witt 2000: Witt's dissertation provides the most detailed description available of the evolution of Portland's neighborhood association system from the 1970s to 1999. Witt contends that Portland's commitment to citizen participation has been lasting and significant and also conflicted (39).

Witt criticizes the Tufts University study for failing to "adequately theorize control" issues in Portland's neighborhood system as well as issues of "co-optation." He further argues that the Tufts researchers "failed to theorize the manner in which incentive frameworks shape interest groups processes at the neighborhood association and district coalition levels" (40). A significant flaw in the Tufts study, according to Witt, "was the omission of any systematic examination of how District Coalition Boards of Directors (DCBs) work on a day-to-day basis" even though the "DCB level of activity is integral to the overall working of Portland's NA system" (3-4).

In addition to exploring these issues across the evolution of Portland's neighborhood program, Witt also describes in detail internal conflicts in two of the previously independent, community-governed neighborhood district offices that led to the dissolution of these organizations and the takeover of the management of those offices by the City's Office of Neighborhood Associations.

Witt notes that the Tufts University study claim that "citizens have a real and ongoing capacity not only to influence but also to shape policy outcomes in accordance with their stated preferences through participation in their respective neighborhood associations" pre-dated some key shifts in the Portland program, including: the dissolution of city's Bureau Advisory Committee program and the Neighborhood Needs 
process in the 1990s—-both programs identified by Berry et al as important examples of participatory democracy elements; the break up of two of the independent district coalition offices and takeover of the management of these offices by the city's Office of Neighborhood Associations; and the shift in focus of the city's formal citizen participation program away from a neighborhood-centric structure "towards an assimilation of other interest groups and agendas" (40).

Witt identifies a number of phases of the evolution of Portland's neighborhood involvement system. These phases and Witt's assessment of their key events and themes are presented below.

Capacity Building-1974-83: Witt writes that the first ONA director Mary Pedersen 'faced significant obstacles in launching" the neighborhood program. She was "forced to operate within a climate of two-pronged distrust." She needed to "dispel the suspicions of existing neighborhood groups that ONA was a front for downtown control," while at the same time demonstrating to "City council that the program she sought to foster had sufficient support in the community to warrant Council's ongoing support" (101). Witt reports that Pederson drew on her faith in a participatory ethos and worked diligently to make neighborhood concerns visible to City Council. Her "capacity building" approach emphasized that "neighborhood-based action could serve as a catalyst for community building" (102).

The next ONA director Pattie Jacobsen focused on building "the capacity of District Coalition staff as well as the leadership skills of NA participants. She also focused on building trust with City Council and city bureaus "after [their] often-times 
stormy relations with Mary Pederson" and her advocacy for neighborhood associations (110). Jacobsen tried to get more reporting from the neighborhoods to demonstrate to city council and bureaus that the program was "able to function smoothly and accountably," but Jacobsen told Witt, "Getting information from neighborhood coordinators at first was like pulling teeth" (110). As the number of neighborhood associations grew, "ONA needed to build District Coalition capacity in order to help spread the burden of accountability in the program" and to show city council that the "two-tiered, sovereignty model" (independent neighborhood associations served by independent district coalition offices) was viable. This was difficult. Neighborhood activists "remained leery that ONA sought to subordinate them to the downtown bureaucracy" (109). Neighborhood association and district coalition leadership often viewed ONA contract dollars "as entitlement funding" and often were indignant about ONA request for greater accountability (111-112).

Jacobsen paid special attention to downtown city administrators. Some city council members and some city administrators feared "losing control of City agenda setting" to neighborhood activists. In response, Jacobsen "sponsored workshops for downtown staff covering the skills necessary for successfully communicating with neighborhood activists.” The Tuft research team's selection of Portland's neighborhood involvement system as one of the best examples of strong participatory democracy in the country also helped city administrators hold Portland's system in higher esteem (113).

Despite neighborhood and coalition suspicion of ONA, Jacobsen successfully organized the community in 1983 to fend off conservative Mayor Frank Ivancie's attempt 
to cut district coalition funding from "residual skepticism and fear that the [district coalition] level would detract authority from City Council” (115).

During the mid 1980s, the ONA program also expanded to incorporation community-based crime prevention services and the city's neighborhood mediation program (114) .

Institution Building-1984-89: Sarah Newhall became the next ONA director at about the same time that neighborhood and community activist Bud Clark was elected as Portland mayor. This time period was marked by a severe economic recession in Portland in the early 1980s and by the beginning of Portland's contentious process to annex the unincorporated land east of the city. ONA also starting wrestling with North Portland activists who had developed a strong district structure without strong neighborhood involvement. Newhall also focused on standardizing relationships within the program and rulemaking to fortify "the program against political exigencies and inherent vulnerabilities" (121).

By 1987, ONA also was “increasingly enmeshed in the City’s budget planning process" through its coordination of citizen participation through the city's Bureau Advisory Committee program (132). Previous ONA Director Jacobsen had initiated the Budget Advisory Coordinating Committee which tied together the individual BAC's and gave citizens a stronger voice in the development of the overall city budget (121).

Portland's neighborhood system faced some long-standing dilemmas. One was the question of the basis for the legitimacy of neighborhood associations. Did they have legitimacy "by virtue of their representativeness of neighborhood-wide viewpoints, or 
through participation of those who choose to be involved" (124-5)? Another was the role of ONA. Was it to "advocate for neighborhood-based mobilization against development threats, or was it merely a general contractor for citizen involvement services, obliged to remain neutral with respect to development politics" [emphasis in original] (125)? City Council and ONA sometimes challenged DCB and NA authority saying these bodies were not representative and "noting lack of participation and new membership." DCB and NA responded by accusing City Council and ONA of "sham maneuvers meant to end-run the citizen participation process" (125-126).

The pressure to provide greater structure and rules for the neighborhood system continued. Witt describes a number of processes convened to review the workings of the system and to propose guidelines and rules. In 1980, City Commissioner Charles Jordan "empanelled an ONA Review Committee"” whose charge was to "assess the entire ONA program to test the extent to which the problems indicated by allegations" made by neighborhood activists against one of the district coalitions "were apparent elsewhere in the City" (133). In 1985, Newhall appointed a "policies and procedures review committee," that included a move that just ten years previously" "would have been unthinkable, as the City's NAs jealously guarded their various, and largely self-defined prerogatives, and fervently resisted the formulation of District Coalition Boards" (123). Newhall's committee included DCB representatives from across the city, as well as DCB and ONA staff (122). The committee produced the first set of "Guidelines for Neighborhood Associations, District Coalition Boards, and the Office of Neighborhood Associations," which "set out in painstaking detaile the various types of relationships and 
responsibilities that the ONA program encompassed" (135). It essentially formalized the conventions at the time, but it also represented an end of an era. Witt argues that the new Guidelines "heralded a shift in focus from a relationship building ethos dependent upon close ties between ONA and neighborhood associations, to the full enfranchisement of the District Coalition model—a model the City Council, and many activist, had found so problematic at the outset of the program" (136). The Guidelines were followed by a rewrite of the 1975 ONA ordinance that eliminated reference to the NA role in city planning and to the NA role in providing recommendations on zoning (137).

The Guidelines required the DCBs to develop annual work plans and to submit mid-year progress reports. The Guidelines also "stressed the important of full NA involvement at the DCB level" (138). Witt writes that the logic of the Guidelines was that “DCBs derive their legitimacy from NA involvement and vice versa...." (143). Some critics saw the provisions of the Guidelines as too bureaucratic (139) or as an effort to undermine the influence of the district coalitions, particularly the district coalition in North Portland and the former county-established Community Planning Groups in East Portland, by creating and strengthening independent neighborhood associations (142).

Witt argues that, with the Guidelines process, Newhall had called a bluff that was foundational to the program: that everyone could continue defining for himself or herself what the program stood for" (Witt 149).

The role of ONA continued to shift in the 1980s with the addition of new functions. In 1983, the City of Portland and Multnomah County adopted Resolution A which divided duties among the two jurisdictions-human services went to the county, 
while the city focused more on services related to the city's physical infrastructure. Witt reports that in 1986, Newhall began discussions with city staff and the City Council about integrating some of the City's human services functions "with its citizen participation program" (Witt 146). Newhall suggested that "neighborhoods are in fact becoming the 'people's safety net'” (Witt 147). As a result, in 1989, ONA assumes responsibility for three bodies formerly supported by the City's Bureau of Human resources:

- Portland Multnomah Commission on Aging

- Metropolitan Human Rights Commission

- Youth Commission.

DCB and NA activists feared that ONA incorporation of these programs "signaled a trend away from support for NA activism."

Retrenchment-1989-93: Witt identifies this period as one of the most difficult in ONA's history. Neighborhood leaders continued to be suspicious of Rachel Jacky--the ONA director during that time period--partly because of her previous position as director of the city's Bureau of Human Services. They feared that the transfer of the three commissions to ONA "signaled a drift in the ONA mission away from its historic role of NA support towards an emphasis on human services delivery" (157). Instead of responding to calls from neighborhood leaders for more support from the City, the City Council instead cut funding for the neighborhood system after voters approved a property tax limitation ballot measure in 1991. ONA and leaders of the northwest coalition office locked horns repeatedly over their negotiations of the terms of ONA's contract with the district coalition office. Jacky attempted to include requirements in the contract that 
would have removed the DCB control over the crime prevention programming, given ONA the ability to request DCB staff to meet with ONA on ONA request, not just quarterly, and required "that DCB members and staff actively encourage citizens to attend training and orientation sessions sponsored by ONA, as well as related activities set by city bureaus; and would have reduced DCB control over office staff salaries" (161).

DCB leaders were unhappy but signed the contracts, except for the northwest coalition office. ONA and the northwest district coalition negotiated changes that removed some of these requirements, and these changes were applied to the other district coalition contracts as well (162). Similar issues arose in contract negotiations in subsequent years.

City Commissioner Gretchen Kafoury was given responsibility for ONA in the early 1990s. She was an ardent social service and affordable housing advocate. Witt reports that "her zeal to mobilize an agenda for assisting disenfranchised groups would set her at loggerheads with key NA leadership" when she and Jacky tried to "harness the NA program” to serve Kafoury’s social service efforts “(167-168). Witt reports that none of Jacky's initiatives originated with DCB leadership (170).

Kafoury and Jacky also worked to incorporate neighborhood association activity into Mayor Bud Clark's Portland Future Focus (PFF) citywide strategic planning process. The PFF process identified 25 strategic goals, some of which related directly to ONA programs, Including crime prevention, tolerance for diversity, and leadership development (171). Some of the PFF action items including "an elaborate schedule for 
evaluating neighborhood association activity", the establishment of a "mentoring program for new and emerging leaders using" neighborhood association leadership; and a logo contest for kicking off a public relations campaign on diversity issues." The ONI [Bureau Advisory Committee (BAC)] said the goals were laudatory, but opposed imposing any new priorities on the neighborhood system without additional funding (172).

In response to Commissioner Kafoury's push to establish a city government and ONA-initiated agenda for the neighborhood system, "DCB activists from around the City came together, on their own terms, to define for themselves why they existed" [emphasis in original] (172). DCB leaders pressured ONA to support a survey of the district coalitions and a retreat in February 1992. The survey results showed that district coalitions said their relationships with city bureaus "tended to be reactive and adversarial" (175). They also complained that ONA was not providing enough technical assistance to the district coalitions and focused too much time on fiscal and performance oversight of the coalitions. Jacky responded that most of ONA's time was spent on technical assistance to neighborhood associations and citizens, and ONA spent little time on fiscal and performance oversight of the district coalitions. She maintained that ONA had a legitimate role to play in overseeing performance because ONA's primary function with regard to the district coalitions was contract compliance oversight (176).

In 1992, Commissioner Kafoury hired Margaret Strahan, former NW activist and city commissioner, to set up focus groups to "assess the suitability of adapting NA efforts to fit with the Future Focus agenda." "Strachan reached out to neighborhood association 
participants, current and past district coalition staff people, "neighborhood business interests, representatives from community-based organizations, and City bureau personnel" (Witt 177). One theme Strachan's work identified was that “organizations other than NAs and DCBs were needed to broaden the base of citizen participation in Portland." Another was that neighborhood associations 'were being burdened with too many tasks from ONA.” Strachan's findings “echoed DCB disgruntlement about Kafoury's 'agenda'”. She found that: "Neighborhood Associations must maintain their grassroots orientation. The city cannot use them as another service delivery network without risking co-optation of their independence, credibility, and ability to get things done by pulling neighbors together and speaking with an independent voice" (quoted by Witt, 178).

Witt reports that Strachan made "another notable observation." She noted the "suggestion that gained strong support" and which proposed "more personal intervention and fewer legalistic approaches to problem-solving with neighborhoods and between the City and neighborhoods" (178). Witt suggested that this suggestion should be "taken as implicating all NA stakeholder groups" including neighborhood associations and district coalitions. Witt notes that both had been criticized for garnering coercive powers through the Guidelines "as well as through procedural innovations (including the sometimes heavy-handed use of Roberts Rules of Order), had drawn "accusations about power cliques taking control over agenda setting, especially at the DCB level” (178). ONA's increasingly rule-based approach to controlling the neighborhood system also provoked resentment. 
Strachan went on to work with neighborhood and district coalition leaders to plan a three-day gathering of that became known as "Portland's Neighborhood Congress." Strachan "pushed hard to frame the Congress effort as a citizen-led charge to revitalize Portland's commitment to neighborhood-based citizen involvement" (179). The Congress took place over a weekend in October 1993. Participants identified and voted on a number of resolutions. "Congress planners hoped to establish a mandate for revamping the NA program" (180-181). Witt reports that, while the City Council and ONA did not adopt the resolutions produced by the Congress, "the Congress was a significant historic marker for Portland, for it demonstrated that there still existed fervent interest in sustaining and renewing the NA program" (182).

Also during the early 1990's internal conflicts and actions by ONA led to the first dissolution of an independent district coalition--the district coalition in north Portland-and the ultimate takeover of staffing responsibilities for the office by ONA.

Witt contends that "collective action problems" were "chronic among all of Portland's" neighborhood associations (215). He suggests that collective action problems are more like to occur in poor and rich neighborhoods than middle class neighborhood. Witt maintains that "Portland's NA program was never devoted to mobilizing working and lower-class interests" (216). Witt says the implosion of the north Portland district coalition raises questions about the Tufts conclusions "that claimed NA's typically host hospitable venues for constructive dialogue" (219). Witt poses the question of whether the implosion of the north Portland district coalition was an "anomalous event" or "more 
endemic to Portland's NA program than we might otherwise expect." Was the experience in north Portland just "more externalized" (219)?

Recapturing, Recasting_1993-1999: Diane Linn served as ONA director from 1993 to 1998 . Key events during her tenure included the implosion of the East Portland District Coalition because of internal strife-similar to the demise of the north Portland district coalition-followed by an ONA takeover of the staffing of the office, and another major review of Portland's neighborhood system, the 1995 ONA Task Force on Neighborhood Involvement (TFNI).

Witt suggests that the 1985-87 Policies and Procedures Review Committee and the 1995 TFNI were "triggered by crises confronting the NA institution" (Witt 222). Witt reports that Linn faced two years of various disputes in East Portland, "continuing drift in the program and on-going DCB disgruntlement and intransigence stemming from the unresolved bouts with Jacky and Kafoury" as well as the "uneasy acceptance for longtime NA activists of the North Portland" city-run district office model. Also, antagonisms had arisen between the Portland Police and the DCBs over who controlled the City's Community Policing program” since its inception in 1990.

Witt also reports that “... steady and clear signals of new alignments between downtown policy makers and development interests beginning around 1991 (and continuing throughout the decade) signaled NA and DCB activists that their role in the land use development review process was becoming less clear and certain” (Witt 222). Linn "under significant guidance from" City Commissioner Charles Hales, who had been given responsibility over ONA, attempted to rein in and recast the neighborhood program 
institution by enlarging “ONA's purview, by codifying new stakeholder interests and redefining the terms for engagement...." (223).

The TFNI membership included representatives from neighborhood associations, district coalitions, business associations, community-based organizations "representing various civic and ethnic interests," as well as district coalition staff, the police, and staff from the county chair's office (224). Commissioner Hales gave the TFNI a broad mandate that included, but was not limited to:

- "'...a thorough examination of the structure, effectiveness, funding needs, and distribution of the citizen involvement system; and the identification of options for enhancing citizen participation and citizen/government communication"” (quoted in Witt, 224-5).

Hales later expanded the scope also to include:

- An examination of the NA/DC/ONA structure regarding citizen involvement with city government and other government agencies

- A look "beyond the current ONA structure to find opportunities to broaden citizen involvement and to encourage participation by the full diversity of our communities;" and

- A look "for opportunities to make significant improvement in citizen participation." (225).

The TFNI gathered input from neighborhood association and district coalition representatives, key City agency staff, representatives from other government entities, 
and from the general public. The TFNI also reviewed the "ONA Guidelines, ordinances, budgets and contracts" and citizen involvement models from other U.S. cities (227).

The TFNI report and recommendations reaffirmed the important role that citizen and neighborhood involvement plays in the life of all Portlanders and in "promoting an effective and responsive government" (228). Rather than focusing on involvement by neighborhood associations, the TFNI stated that "The highest level of involvement is participation of the full diversity of neighbors sitting face to face with those planning and implementing public policy/action" (229).

The TFNI report articulated new language for the purpose of neighborhood associations: "to promote community, not just to communicate with government" (230). Witt notes that "nowhere in past ONA documents is such an explicit description of NA's rendered." Witt suggests that "This language is clearly intended to establish a seamless correspondence between NAs and other stakeholder groups the Task Force was charged to accommodate." Witt maintains that this represented a major shift in how NAs were being talked about." He suggests that a statement that NAs should "promote community" "would never have been tolerated previously" and would have been "taken as a burden (or prerogative) left for each NA to define for itself" (231).

The TFNI recommended that neighborhood associations be allowed to consider "alternative structures" to the traditional district coalition model, which Witt suggests was a challenge to the district coalitions and opened the door for their replacement by alternative models, like the city-run district office model (231). 
The TFNI also recommended that Portland's formal neighborhood involvement system be expanded to include business associations and "communities beyond neighborhood boundaries, " defined by the TFNI as "Ethnically-based community organizations whose members face unique differences, particularly in the areas of language and cultural adjustment" (247). In recognition of this expanded focus, the TFNI recommended that the name of ONA be changed to the Office of Neighborhood Involvement (ONI). The TFNI also envisioned ONI again serving as the central agency for "coordinating the efforts of the Bureau to reach out to citizen/neighbors to involve them in key planning and implementation efforts" (223-224). Over time, many major bureaus had developed their own internal capacity to reach out to and involve the public. Witt describes and discusses the many other TFNI recommendations.

The TFNI marked another turning point in the evolution of Portland's neighborhood involvement system. By 1995, Witt argues, "not even the staunchest advocate of NAs could refute serious claims made against the institution" (250). The time had come for some major adjustments.

Witt's research provides valuable insights beyond the basic structure and programs of Portland's neighborhood involvement system and looks at how the system functions and the control issues that Witt argues shape much of the interaction between the City Council, ONA/ONI, the district coalitions, and the neighborhood associations. The 1995 TFNI formally introduced the need to consider whether neighborhood associations and district coalitions alone are sufficient vehicles to promote participatory democracy or whether Portland's renowned neighborhood system needed to expand its 
mechanisms and structures to ensure that other groups not well served within the neighborhood association system have a strong voice in public decisions making and in shaping their communities. Witt also questioned the stability of the DCB model-Would it survive the City's takeover of the two formally independent district offices in north and east Portland?

Johnson (2002): Johnson's 2002 study examined the evolution of civic life and civic organizations in Portland, Oregon between 1960 and 1999. His research challenges Putnam's contention that civic life in the United States has declined since the 1950s. Johnson argues that while traditional civic organizations did decline significantly in Portland after 1960, these civic organizations were displace and replaced by "advocacy oriented organizations: identity interest groups, neighborhood associations, citizen interest organizations, and social service organizations that advocated for causes" (Johnson 1). Johnson's research found that the civic infrastructure in Portland by 1999 was "a complex one that facilitates civic engagement by a broader cross section of citizens, utilizing a far richer repertoire of civic actions than were available in the 1950s" (7).

Johnson disagrees “with Putnam and Skocpol's declaration that civic life has declined in America." He argues "that civic life has changed for the better because it now involves a broader cross section of citizens and incorporates more open and democratic processes" (34).

Johnson identifies and examines "four discernible periods" in the "history of civic life in Portland from 1960 to 1999," which include: 
- "Traditional civic life" (1960s): Johnson writes that this "should be what Putnam (2000) defines as the height of post World War II civic life, dominated by the 'long generation'...."

- “Civic reconstruction period" (1968 to 1974): This is when "social movements of the 1960s were institutionalized through new organizations and practices, and traditional civic life began to unravel."

- "Populist pluralist period" (1975 to 1990): During this period "new institutions and practices took hold" and "the growth of new organizations and civic practices was most prevalent." This is when civic life in Portland "incorporated the broadest cross section of citizens in public policy deliberation, and the most extensive array of new civic actions and into common practice."

- "Civic innovation period" (1990s): Johnson found that this period saw "continued growth of new civic organizations and civic practices, a withdrawal from some of the broadening democratic principles and actions from the previous period, and the emergence of civic innovations that focused on building consensus across interest communities" (4-5).

Johnson argues that "that the new civic organizations, and civic engagement processes established by local government citizen participation programs, blend the democratic virtues of effective participation in democratic institutions with social capital engendering activities." He suggests that, in Portland, the "potential undemocratic voices of single issue interest groups have been tempered with the development of: 
1. “direct, or face-to-face, democratic venues such as neighborhood associations,"

2. "an expanding arena of representative civic bodies, especially citizen advisory committees,"

3. "many and varied citizen participation programs," and

4. "the creation of innovative civic engagement processes that facilitate both civic engagement opportunities along with social interaction” (3).

Johnson found "that in Portland, civic life evolved since 1960 from a fairly limited array of civic organizations, a narrow cross section of citizens, and limited repertoire of civic actions, all operating within an informal and closed political system, and evolved into a system with a more diverse and innovative range of civic organizations, a broader cross section of citizens, and a more structured, open and democratic political system" (13-14).

While "traditional civic life was defined by charity and community service" "a new more democratic civic life is defined by collaborative decision making through more open democratic processes. Bridging interest representation is not done within organizations so much as it is between organizations." Johnson also argues that "traditional civic organizations failed to provide a forum for a broader cross section of citizens" and "did not incorporate the new civic players-in particular, women, minorities, and a new cohort of citizen activists." Johnson maintains that today citizens learn "essential skills for civic participation through interest groups, neighborhood associations, citizen advisory groups, and publicly sponsored citizen participation 
processes" (13-14). The new civic organizations also expanded the repertoires of civic actions that are important to and used by civic organization to maintain a "strong civic life" (26).

Johnson suggests that while the research done on Portland by Berry et al (1993) and Witt (2000) "provide in-depth analysis of a particular democratic institutional arrangement," his study "provides an analysis that is based more on how the entire body of the civic infrastructure and its repertoires of civic actions, influence the capacity of the community to maintain a strong civic life." Johnson maintains that his study "provides a more sweeping view of changes in Portland's civic life" by not only including "the direct democratic venues of the neighborhood system," but also examining "representative or appointed forms of citizen involvement through civic bodies...." (31).

Johnson states that he focuses on "civic infrastructure itself as a key variable" instead of focusing on "individual civic attitudes and behaviors...." as Putnam did. "Notable differences in levels of civic action, or even changes in civic attitudes, may not be the cause of individual preferences as much as the availability of structures, practices, and opportunities that facilitate civic engagement" (34).

In his review of each of the four periods, the largest growth in the number of nontraditional civic associations occurred in 1972 to 1985, which included significant growth in the number of neighborhood associations and the number of citizen advisory committees (as opposed to more traditional city boards and commissions). "Neighborhood activism was at an all-time high. Citizen participation through civic bodies was also at an all time high. Both trends indicate Portland's expansion of civic 
involvement processes had peaked" (118). "Membership on all citizen advisory committees increased. In the 1980 s there were almost twice as many appointments to citizen advisory committees and task forces as there were to city commissions and boards" (129).

Johnson suggests that "it seems likely that the increased activity in civic engagement processes that were recognized by the City of Portland slowed down the growth of outside advocacy organizations, as activists become more involved in the formal civic structures." "Likewise, neighborhood activists who in the 1970s may have operated on their own through informal networks by the 1980s had City-sanctioned associations operating under the umbrella of the City's Office of Neighborhood Associations" (128).

The 1990s, the last period of the study, was "marked by continued growth of advocacy and social service organizations, accompanied by a small decline in the City of Portland's investment in the direct democratic structure of neighborhood involvement and representative democratic structures of civic bodies." Civic innovations emerged "in the public and nonprofit sectors to respond to the complexity of empowered citizen groups," as did a "need to re-establish community consensus about a common vision for the community" (130).

"Overall the growth of civic bodies in Portland was stagnant between the 1980s and 1990s. In fact, the total number of bodies decreased slightly." "The number of citizen advisory committees and commissions stayed the same, while boards and task forces decreased. There were 51 fewer citizen advisory committees working on social issues in 
the 1990 s than in the 1980 s. Some committees were created in the 1980 s to focus on social issues, such as rising crime rates" (155-156).

Johnson also examines the news coverage of civic associations across the four periods. News coverage of "the actions of neighborhood associations and civic bodies" increased significantly between 1972 and 1985 (128). "News about advocacy organizations in 1999 accounted for $60 \%$ of all the news, up $10 \%$ since. 1985" (134). “From 1985 to 1999, news about advocacy organizations changed dramatically in several ways. The most notable change was a 50\% drop in news about neighborhood groups and civic bodies." "Reports of neighborhood actions were down from 1985 levels, and the news tended to be more negative than positive as some of the City's formal civic planning processes turned contentious" (155).

Johnson deduces from the "decrease in positive news about neighborhood actions and changes in policy about involving citizens on bureau advisory committees, that the City of Portland pulled back from its wholehearted endorsement of direct democratic processes and the representative form of civic engagement citizen advisory committees" (155-156).

Johnson found in the 1990s a trend of forming new organizations and processes to accommodate multiple-interest communities and stakeholders" (156). The City formed the Taskforce on Neighborhood Involvement to re-examine Portland's neighborhood involvement system. The Portland Future Focus strategic visioning forum "was created to bring together a cross section of leaders and citizens to create consensus about a vision for the community." "The Coalition for a Livable Future was created to bridge 
progressive interest groups concerned about urban growth management under one umbrella." "The Johnson Creek Watershed Council, and others like it in the region, were created to bring together citizens, organized groups, and government agencies to build consensus and work together to solve difficult environmental issues" (156).

Johnson summaries his research by concluding that during the study period "the City of Portland greatly increased the opportunities for a broader cross section of citizens to be involved in public affairs through civic bodies.... In the 1960s, the predominant civic bodies commissions and boards. Starting in the 1970s, citizen advisory committees became more dominant." Johnson argues "that this change represents a broadening of civic engagement in terms of opportunities and the diversity of citizens involved" (165).

Johnson found that by 1999, "three times as many citizens" were "involved through citizen advisory committees as there were in 1960 . On the other hand, there were fewer citizens involved in civic life through city commissions and boards" (166).

Johnson notes "that there was a peak of civic engagement during the 1980s represented by the number of citizen advisory committees and the high number of appointees to all bodies, but especially citizen advisory committees. Johnson recognizes that this corresponds to Witt's (2000) findings that the City of Portland's political and monetary investment in its neighborhood involvement program peaked at about this same time, and then declined" (169).

Johnson found that the "City continued large-scale citizen involvement processes into the 1990s (such as the Albina Community Planning Process) and others in outer southeast and southwest Portland, but they were fraught with more contention." The City 
also recognized that the neighborhood system was in need of evaluation in the early 1990s when it convened the Neighborhood Involvement Taskforce. "Since that time, the City has allowed individual bureaus more discretion to decide how to involve citizens, especially neighborhood associations." "City bureaus continue to draw upon citizen resources, but the more widely used civic structure is the stakeholder committee. While these types of committees still draw upon citizens at large, they are more likely to be populated by established interest groups and professional citizen activists" (169-170).

Johnson finally concludes that "It is difficult to see from this vantage point if the diminished important of face-to-face democratic deliberation through the neighborhood involvement process and the narrowing of representative democracy through citizen advisory committees is a short-term or long-term trend. It is most likely the reflection of a civic infrastructure in need of repair or innovation. With a more diverse population and more empowered citizens and citizen interest groups, finding innovative and democratic institutional arrangement and civic actions is critical for a healthy civic life" (Johnson 170).

Putnam and Feldstein (2003): Putnam and Feldstein include a chapter in their book, Better Together (2003), in which they look for an explanation for Portland's strong local tradition of neighborhood activism and civic participation.

Their research showed that in the early 1970s, Portlanders "were no more or less civically engaged than any other Americans" (Putnam and Feldstein 241-242) "but twenty years later, Portlanders of all walks of life were three or four times more likely to be involved in civic life as their counterparts elsewhere in America" (243-244). 
The authors ask why Portland became so different than other cities in the 1970s and 1980s. They attribute the difference to: “...institutional innovations that began in the Goldschmidt era;" “...those institutions (epitomized by the Office of Neighborhood Associations) [that] helped sustain and encourage the sort of civic activism that bubbled up from the grass roots in the 1960s in Portland....," and that "Goldschmidt and his successors in local government seem to have been unusually effective at working with (and struggling with) activists to create innovative channels of access and a new spirit of openness that enabled the community to reach a new level of civic participation" (252253).

Putnam and Feldstein give a lot of credit to Portland Mayor Neil Goldschmidt who was elected mayor in 1972 and championed the creation of Portland's formal neighborhood association system. The authors write that Goldschmidt's administration "developed structures that not only supported citizen activism but embedded it in the government's decision-making processes. The most dramatic step in that direction was the creation of the Office of Neighborhood Associations, in 1974." The ordinance that established ONA "spelled out the direct active role of the citizen groups in the process of planning and carrying out government policy..." and gave neighborhood associations the power to " to recommend an action, a policy, or a comprehensive plan to the city and to any city agency on any matter affecting livability of the neighborhood...." (247).

Goldschmidt also incorporated existing neighborhood association that had been created by community members rather than imposing a city-created system. 
The creation of ONA and the neighborhood system "legitimized activism and built it into the official life of the city" (247) “...the city's unusual engagement with citizens' groups and the fact that citizen participation is a central feature of how government works have helped civic engagement flourish" (248). They found that “...the willingness of those in power to open the door to citizen influence rather than protect their 'turf' is a critical elements of the social-capital story" (248).

Putnam and Feldstein note that Abbott and others have suggested that Portland's "modest size" and "history of slow growth" made the city "seem manageable and 'imageable' as a whole." They also recognized that Portland was "fairly homogeneous racially and economically" making it easier for "many resident to think of themselves as members of one community and to avoid divisions along lines of race, income, and innercity-versus suburb that have hindered efforts to unify other cities" (251).

The authors argue that " $[\mathrm{t}]$ wo things stand out about the Portland experience: "first, the skill, persistence, and reach of Portland's activist community, and "second, the evolving capacity of public officials and government to respond and adapt."

"Where they might have viewed such citizen initiatives as challenges to their competence and authority, stonewalled attempts to make changes, and vilified and dismissed their critics, in Portland government officials have evolved a culture of adaptation and accommodation" (249).

"Just as citizens honed their civic skills and vociferously pressed their views, government developed a culture of responding to and learning from, rather than rejecting, many grassroots initiatives" (249). 
"From this 'call and response' evolved a pattern of citizen initiatives and government responses, with less of the acrimony, paralysis, and stasis that defeated change and discouraged activists in other cities" (49) Putnam and Feldstein also refer to this as a "virtuous circle" and suggest that, for the most part "the civic dialectic in Portland has led to positive feedback: more grassroots activism has (often through conflict) led to more responsive public institutions, and more response institutions have in turn evoked more activist" (262).

Putnam and Feldstein also found that "a critical mass of citizens is involved in Portland, which has helped make citizen participation the "norm." The authors write that "it is clear that people participate because that is what many people do in Portland." They suggest that success breeds success and quote local community activist Mike Roach who said "You see people being successful at it, you have visible proof that it can be done" (255). They also quote a former ONA employee who suggests that, of the 90 neighborhood associations "'thirty of them are very active, thirty somewhat active, and thirty 'moribund."' Putnam and Feldstein attribute this partly to the "normal ebb and flow of galvanizing issue and the life cycles of organizations run by volunteers." They also suggest that the extent to which activity in neighborhood associations in Portland may be decreasing may also "signal a shift toward membership in special-interest groups" as documented by Johnson (2002).

Looking ahead, Putnam and Feldstein identify some challenges for Portland's participatory democracy system. They found that while people "who have been deeply involved in civic affairs know one another and are comfortable contacting one another to 
a greater degree there than in larger and more divided cities," some people in Portland are not, such as East Portland residents and other minority and outlying neighborhoods "are not part of that community of mutual acquaintance." Making these civic connections is particularly challenging for "a low-income, ethnically diverse population not usually included in the process" (263-264). Putnam and Feldstein quote another Portland community activist who reports that, in his experience, people who are persistent about showing up and finding out who the decision makers are, are likely to find Portland's community to be remarkably open. People who are less outgoing and determined may find that the system seems "closed or actually is closed." He notes that having a voice in regional issues that can affect a neighborhood can be challenging and "requires sustained community involvement in lengthy city processes." He suggested that, in these cases, often "access is a smaller problem for citizens than finding the stamina to stay engaged in multiple issues" for the time span required to have an impact (264).

The authors quote another long-time neighborhood activists who says that she and others have been fighting "to redefine what citizen participation means" in Portland. She said that while neighborhood associations have had some "success in getting a required meeting with developers at the beginning of the process," "We at the neighborhood level need to be more sophisticated." "It's not enough just to say, 'Don't do it."' She suggests that the blame for problems in citizen involvement is divided between "a city government inclined toward pro forma consultation" and "residents who need to participate more energetically and constructively in the process." She said she sees "politicians failing to live up to earlier ideals of participation: 'Goldschmidt wasn't afraid of the people. He 
knew if you explain what you want to do, people will allow you to do it. I don't think we've got leadership like that now" (264-265).

Putnam and Feldstein argue that while many things are going right about citizen participation in Portland, people who do not share the dominant progressive, "shared vision of a livable city in a healthy environment" "tend to be marginalized (and sometimes marginalize themselves)." They argue that the "process of widening the circle of engagement beyond homogeneous 'small-town' Portland has a way to go." Other challenges include "an influx of new immigrants who may not share the values of the 1970s and early 1980s" and increasing conflict over neighborhoods that are being changed by increased housing density as a consequence of the Portland area's Urban Growth Boundary and growth management policies (265).

Other tensions that have sprung up partly "from the success of the last thirty years that have made [Portland] an attractive place to live" include increasing housing prices that make affordable housing harder to find; and the gentrification of some neighborhoods that has made it "difficult for low-income residents, and principally renters, to stay in their homes." This has led to "some migration of lower-income Portlanders to the east and north" of the city. "They have been joined there by new immigrants to the area, many Southeast Asian and, recently Hispanic, sometimes with a limited grasp of English." Putnam and Feldstein write that Portland "is still at an early stage of dealing with its relatively new diversity issues" (266-267).

Putnam and Feldstein also recognized a real shift in Portland's neighborhood politics. They refer to Johnson's (2002) analysis of news stories about local issues in 
1985 and 1999. "In 1985, 75\% of the news about neighborhood action was positive. Neighborhood associations were described as saving neighborhoods, hosting block parties, and involved in positive encounters with government through sanctioned planning processes." "In the 1999 news, the opposite was true" (267-268).

Putnam and Feldstein conclude their review of Portland's experience by stating that the "greatest danger for Portland may be a new 'tipping point,' where privatism and skepticism about the responsiveness of government become the norm and positive reinforcement of the habits of participation and cooperation begins to diminish." "If Portland is to maintain its uncommon level of citizen engagement, its officials and civicminded activists cannot simply decry the forces of privatism; they need to find a way to bring into 'the process' more of the people who are antitax and antigovernment but are nevertheless citizens of Portland. Whatever the outcome, the future of civic engagement in Portland, like that of its past thirty years, will be well worth watching" (268).

Public Participation and Planning in Portland: Hovey (2003) and Irazábal (2005) both studied specific aspects of community involvement in land use planning in Portland.

Hovey (2003) explores how Portland developed its "deserved reputation for good city planning and strong citizen participation." To discover how Portland was "able to combine strong planning with strong citizen participation to create a better city?" Hovey examines the process and dynamics of the development of the Northwest District Plan (1969-77) and the Southwest Community Plan (1994-2001). Hovey suggests that Portland's achievements in and structure for planning and participation are the "cultural 
product of the concerted mobilization of meaning through the use of language in planning, organizing, democratizing, and institutionalizing these practices" (140). His research provides interesting insights into the formation of Portland's community and neighborhood involvement system and into the tensions that arise between community members and city planners when they try to work together to shape local planning policies.

Hovey recognizes that "Portland has constructed an extensive system of citizen participation, in all aspects of governance but especially in planning" and that "Portland has a dense and active citywide system of neighborhood associations on which citizens rely and city government supports." Hovey found that Portlanders have a pervasive "expectation that citizens will be involved in full and fair discussion about decisions that affect their city and their neighborhoods" and that this expectation "conditions a political life that is, in relative terms at least, open and deliberative" (140). Hovey asserts that the two processes he examines and the "stories of citizens and planners in Portland" show that Portlanders "made their city by talking" and by their collective participation in many different planning processes (141).

NW District Plan (1969-77): Hovey asserts that the process that created the Northwest District Plan significantly shaped both Portland's approach to urban planning and helped lay the foundation for Portland's community and neighborhood involvement system.

Hovey reports that in the late 1960s city planners proposed clearing 16 blocks of an older, mixed neighborhood in northwest Portland around Good Samaritan Hospital. 
Community activists quickly organized to oppose this plan and, in 1969, formed the Northwest District Association (NWDA), which was to become one of Portland's early and most influential neighborhood associations.

Community activists, working through the NWDA, convinced the City Council to authorize a process to develop a plan for the larger neighborhood before any smaller plan should go forward. NWDA activists, with help from "sympathetic planning staffers," proceeded to develop their own plan for their neighborhood. Community members and city planners together used many of the tools of professional planning and community outreach, including "conducting research, holding community meetings, formulating goals, crafting policy language, drafting a full plan, distributing thousands of copies, and vetting it with the community at large" (143).

Hovey says the records of the NW District Plan process "tell the story of a concerted critique of orthodox ideas in planning, the assertion of democratic rights for neighborhood territories, the challenge to professional prerogatives in planning, and ultimately the formulation of a new set of orthodoxies about what makes a good city." In opposition to the urban renewal thinking of the time, the Northwest District Plan developed and celebrated ideas, "vocabulary and concepts" that have "permeated Portland planning since then." "The importance of mixed uses, the possibility of mixed incomes, the importance of transit, the need for walkable streets and local retail services, the importance of density, the value of older buildings, and perhaps most important of all, the importance of strong citizen participation-all of these ideas gained local currency in Northwest and went forward in practice, policy, and rule" (147). Community members 
and city planning staff released the proposed Northwest District Plan in 1972. The City

Council adopted the community-generated plan for the neighborhood in 1972.

Hovey asserts that the legacy of the work of community activists and city

planners on the NW District Plan "is multifold." "They helped produce new ideas about city planning." "They forced city leaders and planning bureaucrats to accommodate neighborhood plans within the structure of municipal law and administrative practices." "They also contributed greatly to the creation of a permanent citywide structure of citizen participation through neighborhood associations" $(146) .^{23}$

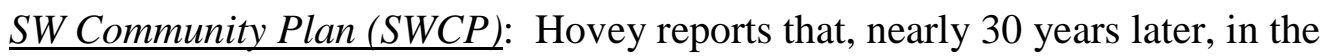
mid 1990s, the Southwest Community Plan became the "apogee" of the trend in the late 1980s and early 1990s toward greater friction between city planners and community activists "over the imposition of regulation stemming from the evolving growth management policy" for the Portland region (142).

In the early 1990s, community activists concerned about "the impact of unplanned growth on Southwest Portland" had convinced the City Council to initiate a district-wide

\footnotetext{
${ }^{2}$ City planning staff cited the success of the Northwest District planning effort to help support their proposal to the Planning Commission, in 1971, to create a citywide system of community-based district planning organizations. This proposal then led to a subsequent task force report that proposed the creation of ONA and Portland's neighborhood association system. (Portland. Planning Commission. Proposal for a City Policy Statement on District Planning. April 14, 1971.)

${ }^{3}$ Hovey also notes that a number of individuals who were involved in community activism in northwest Portland and the NWDA in the 1960s and 1970s went on to play influential roles in shaping Portland. Ogden Beeman chaired the 1972 DPO Task Force that proposed the structure for Portland's neighborhood system. Mary Pedersen served as the executive director of the NWDA, and, in 1973, was hired to lead the effort to develop the 1974 Ordinance that create ONA and the Portland's formal neighborhood system, and served as the first ONA director from 1973 to 1979. Margaret Strachan was a founding staffer of the NWDA and went on to serve as a city council member. Bud Clark and Vera Katz both went on to serve as mayors of Portland (Hovey 2003 146).
} 
planning process for Southwest Portland. ${ }^{4}$ City planners began to collect "base data and began an extensive process of public outreach.” In 1995 and 1996 "planning staff worked with neighborhood associations, one at a time, to create neighborhood plans." Hovey argues that planners were working to implement the regional growth management policy framework, which sought to achieve a "denser, busier, more urban Southwest" Portland. Hovey says this ran up against the "citizens prevailing vision" for southwest Portland that "was very similar to what Southwest already was: an ordinary postwar suburb made bucolic by steep hills and tall conifers."

In the summer of 1996, city planners "produced a 'Draft Discussion Map' that translated prevailing policies and growth concepts into a proposed zoning map for all of Southwest" (149). In response, "Five hundred angry residents showed up to a high school cafeteria that fall and turned a scheduled 'workshop' into a protest rally." Community pressure forced city planners to negotiate a new process "with neighborhood association representatives under which residents would be allowed to propose their own zoning and that promised them "no surprises"” (150).

In 1998, community members submitted their "vision, policies, zoning map and action items." City planners reviewed these products and proposed hundreds of amendments. Hovey says the "planners saw themselves simply as doing their job of interpreting adopted policy," but "Citizens saw them as reneging on a deal." "In the anger and confusion that followed, the Planning Commission voted to suspend the plan." Community members wanted to finish the plan "if for no other reasons than that the

\footnotetext{
${ }^{4}$ The Southwest Community Plan was the fourth in a series of community plans (the early community plans were the Central City Plan, Albina Plan, Outer SE Plan) that city planners were using as their approach to updating Portland's Comprehensive Plan.
} 
Comprehensive Plan already in place allowed for higher housing densities than they wanted.” However, "battered planning staff," an "exhausted Planning Commission,” and 'wary City Council” members resisted resuming the process (151).

In late 1998, community members regrouped under the auspices of the southwest neighborhood district coalition (Southwest Neighborhoods, Inc. (SWNI)). They "reined in their most militant members, and refined their list of demands to include only issues of the greatest importance" (151). It took a year to negotiate a new planning process with the City. Hovey notes that the "political context and policy ground had shifted beneath the SWCP." The planning director had stepped down and Mayor Katz had taken over responsibility for the Planning Bureau. The City also was under pressure from the federal Endangered Species Act (ESA) to protect fish that spawned in streams in southwest Portland. Oregon voters also had approved a statewide "property takings" ballot measure (Measure 7) that required local jurisdictions to pay land owners or waive regulations that reduced property values. The "city moved quickly to close the deal with Southwest." The new zoning map for southwest Portland included "little up-zoning or residential density and some down-zoning in environmentally sensitive areas." "[N]early seven and a half years after they had begun—the plan was adopted by City Council” (151).

Hovey asserts that "It might be fair to say that the SWCP had a major impact on the Portland way of planning — it was the bureau's 'Vietnam'—but just as fair to say that the impact was absorbed." He said city planners seemed to have "learned some lessons about the limits of administration and the persistence of politics" (153). The City of Portland's approach to involving the community in planning changed significantly after 
the SWCP. City planners ended the program to work with neighborhood associations to create/update neighborhood plans. City planners also decided not to do any more community district plans. Instead they focused their efforts on planning projects for specific target areas and in areas where they were wanted by the community.

Hovey notes that, like the community activists in northwest Portland in the late 1960s and early 1970s, community activists in southeast Portland used a wide variety of policy, analysis and community organizing tools and strategies to challenge city planning policies and to craft "alternative policy language that detailed their emerging vision at the same time as it exposed the flaws of logic in what the city present" (151).

Hovey found that community members had "been very adept at constructing the kind of discursive spaces necessary to conduct their public conversation about the character of the city. Hovey asserts that strong democracy requires places for public discourse. "Contesting the terms of a dominant order" require the conditions and protocols for discourse" and "places for the conduct of what Barber called "strong democratic talk." Hovey states that without "some place to gather, some way to come together, some means to communicate, there is effectively, no public at all" (160). Hovey describes how in both the NW District Plan and the SWCP, community members made very good use of a number of different forums and strategies to create discursive spaces, including: public hearings, community committee meetings, house meetings, 'neighborhood public meetings," neighborhood associations (162-163), community newspapers, and email listservs (164-166). 
Hovey also notes that the citywide, formal system of recognized neighborhood associations provided community activists with ready-made organizing vehicles for which they did "not have to demand recognition or create the protocols by which they would participate" (164). He asserts that "The neighborhood association and all the discursive practices it supports are nothing if not structural. They are more or less a permanent part of the civic architecture of Portland, and they were created from the ground up" (162-163).

Hovey cautions that "The dilemma of institutionalization is inescapable. Without institutional foundations, any movement may wither. Given institutional support, any movement may ossify" (164). Hovey observes that after the SWCP, some people "charged that neighborhood associations have too much power in Portland. They say they bring a parochial and fragmentary perspective to policy making and give too much emphasis to homeowner issues to the neglect of broader environmental or social justice concerns" (163). Hovey maintains, however, that in Portland "there is an established time, place, and protocol for discussing issues of concern to residents" and there also is "a structure for aggregating those concerns to the citywide level when necessary." He adds that "there are organs of communication as well as forms of deliberation" which ensure that "there is always some kind of clearly defined 'space' for these discussions to take place" (164).

Hovey recognizes that "While professional and citizen work have often gone hand in hand in Portland, there has also been great tension between the two." "On the ground in Portland, the tension can be felt in the interactions of elected policy makers, 
professional planners, and active citizens" (166). Hovey says these tensions are not simple. "They can be felt in the ongoing relationship between established policy and current planning activity, in the contest between rationality based in the professions and reason grounded in the polity at large, and in the disputes over the relative legitimacy of the status of office holders, bureaucrats, and citizens as participants in a public process and as representatives of others" (166).

Hovey identifies the center of the tension as "a conflict between planning and policy." He asserts that community members "have privileged planning over policy because planning tends to offer democratic control over decisions that will apply here and now and in the immediate future." In contrast, he asserts that "Planners prefer policy, and its stepchild regulation, because they promise the general application of favored principles predictably over time and space" (148). Hovey states that "Both planning and policy have derived from participation but planning is fluid and favors current participants. Policy, by comparison, is solid and fixed and gives more weight to past participants." "The professionals prefer planning as the application of established policy." "Citizens want to plan their neighborhood the way they want it to be, taking into consideration local circumstances and expressing community values" (149).

Another "axis of tension," according to Hovey, are "competing claims to legitimacy from representatives of various sorts versus citizens participating directly in planning and policy making" (168). Community members, Hovey says, they have a "relative advantage...in establishing their legitimacy" over the "poor planning bureaucrat." When a community member speaks out "it is clear to listeners that there may 
be others who share their views." When "they testify on issues in their own neighborhood, they implicitly claim to speak about things they know and care about more than people from some other part of the city." Hovey says many people already had low opinions of elected officials. City staff maintained that they were just implementing existing policy and claimed to represent the "broader public interest." City staff believed those policies "had a stronger claim to their loyalty than the seemingly more transient impulses generated by some citizens in a single planning process" (168).

Another tension identified by Hovey was over the very different role of city planners in working with the community on the SWCP versus the Northwest District Plan. Planners who worked on the SWCP had claimed "to represent special knowledge and skill in decision making" and maintained that "the tough technical work involving data collection and analysis, alternatives generation and evaluation, and especially mapping and zoning was reserved for the professionals." This contrasted with the planners who worked with community members on the Northwest District Plan. "[T]heir own philosophical commitment was to democratize and demystify planning knowledge." Hovey says they also "considered themselves working for the neighborhood and its desires, not the city and its policies" (169).

Tensions also arose over "who really represented the neighborhood." City commissioners and city planners challenged neighborhood association activists with this question both the Northwest District Plan and the SWCP processes. Hovey noted that the "NWDA in 1969 was an ad hoc assembly of certainly fewer than a hundred active members" and the neighborhood associations that fought the SWCP "were no bigger" 
although they were claiming to represent "neighborhoods with populations of two to five or ten thousand people." Hovey says that when city leaders and staff asked "'How do we know you represent the entire neighborhood?" community activists responded in effect, “'How do you know we don't"” (169)?

Citizen advisory committees were another source of tension identified by Hovey. Portland city commissioners commonly appoint "citizen advisory committees" to advise the City on issues and projects. City leaders and planning staff in Portland used community advisory committees for many planning projects. In cases, like the SWCP, "citizen advisory committees became the target for activist opposition." Community activists charged that the "members of such bodies were not representative of the community" but rather "were representatives of the elected officials that appointed them." Southwest community activists "insisted that the only true representatives would be ones chosen by the neighborhood, not by the [city] commissioner." Hovey reports that the SWCP Citizen Advisory Committee set up by the City ultimately was "hounded out of existence." Community activists created their own "Summit Group of neighborhood associations as the ostensibly true representative body of the district." Community involvement policies finally adopted by the City Council as part of the SWCP "stipulated that neighborhood associations would have more to say in the constitution of such bodies in the future" $(169-170) .^{5}$

\footnotetext{
${ }^{5}$ The final SWCP included a number of policies related to community involvement that specifically respond to problems, tensions, and conflict that occurred during the SWCP process. These policies are described in more detail in the chapter below that discusses increasing conflict between neighborhood and community activists and city leaders and staff in the late 1990s and early 2000s.
} 
Hovey answers his initial research question—-How had Portland "been able to combine strong planning with strong citizen participation to create a better city? —by first recognizing that Portland "had a highly educated middle-class population, few minorities and little racial conflict, a beautiful natural environment surrounding [the] city, and a Progressive political culture unsullied by Eastern-style machines." He also accepts that the "analysis of interest, the alignment of power blocs, or the machinations of political entrepreneurs" can explain to some extent how Portland urban planning and community involvement evolved and led to the "legend" of Portland planning.

Hovey, however, argues that the real answer is that Portlanders actively created their urban planning and community involvement culture through "continuing and repetitive acts of agency on the part of thousands of the inhabitants of Portland" (172173).

Hovey concludes by saying:

"This is what makes the Portland regime so sturdy and adaptable. It is built from the ground up in the meanings of place, community, democracy, and planning. It is mobilized in discrete practices of public deliberation, policy making, planning, and regulation. It is perpetuated through organizations, public and private, that carry out these practices over time, like machines that produce the underlying meanings of the regime going forward. And it is installed in the city, providing a constant reminder of what the regime has created and what it stands for. Yet what permeates the entire structure, and what is at the root of all the attempts to change it, is what the people have to say" (173).

Irazábal (2005) chose to study Portland and Curitiba because "both cities are considered successful in the management of urban growth, the design of urban form, and the improvement of urban livability," "both play crucial roles in the development of their metropolitan areas", and "both seem to have achieved those goals using very different 
means" (3). Irazábal, like Hovey, studied the Southwest Community Plan process. She considers the question of whether Portland has too much public process and concludes that rather than too much process, city planners did not do a good job of administering their efforts to involve the community in the SWCP. Irazábal offers a useful assessment of some of the strengths and weaknesses of the efforts of city planners to involve the community in decision making and identifies some important challenges for future planning and community involvement in Portland.

Irazábal argues that "visionary, broad-based, and continuous leadership; comprehensive, coordinated, and enforced urban policies and plans; and empowering, inclusive, and sustained citizen involvement" generate a "unique synergy" (3). She found that both Curitiba and Portland "have had strong leadership and effective urban policies and plans (governing agendas)." "Yet these cities have had some problems at the level of citizen involvement - either by deficit or excess of it, respectively, or by the mismanagement of those participatory processes — which have tampered with some of their planning experiences or have put their models of governance at risk" (4).

Irazábal argues that "citizen participation is considered an imperative for good governance in democratic societies, ensuring an open and legitimate relationship between civil society and the state." She claims, however, "that there is an adequate level of citizen involvement that better promotes effective democratic planning-too much can entangle the process of decision-making and implementation, and too little can delegitimize the planning process" (136). 
She warns, however, that "a rapid examination of certain planning processes in Portland may deceptively lead one to argue that the city has become an example of the former extreme. Indeed, there have been instances in which extensive, confrontational citizen participation has made significantly more difficult, or has altogether caused the demise of, some planning initiatives." Irazábal argues that "the causes of planning entanglements in the city have been subtler and more complex than the ones derived from the mere scale of the participatory process (quantitative issue), to encompass the appropriate management of citizen involvement and power struggles among different stakeholders (qualitative issues)" (136).

Irazábal describes the evolution of Portland's neighborhood involvement system and notes that the relationship between the city and its neighborhoods was "marked by alienation on both sides in the late 1990s." She quotes City Commissioner Dan Saltzman who acknowledged in a newspaper interview at the time that 'from a neighborhood perspective, a lot of them feel that the city isn't listening to them. On the internal, city side, the perception is that all they [neighborhood groups] are is against something; they're seen as more of an obstacle than an ally"' (158).

Like Hovey, Irazábal also examines — the Southwest Community Plan (SWCP) process and the siting process for the Southwest Community Center (SWCC)--“as emblematic examples at both the city and the neighborhood levels of the planning and architectural scales of the recent difficulties that participatory planning has faced in Portland." She finds that these processes challenge both the "urban programs and the trust among all planning stakeholders in the city" (159). 
Irazábal found that these cases "demonstrate that the critical planning problems occurred not because there was too much citizen involvement, but because there was an inappropriate administration of the processes for citizen participation that alienated trust and hindered collaboration among stakeholders, and promoted the adversarial, counterproductive planning climate I have described" (169).

Irazábal found that the response of Portland city leaders and planners showed their willingness to listen to the community and adjust their processes. The SWCP experience also yielded positive citywide impacts. "First and most importantly, it prompted a reevaluation of planning processes in the city and the role of all stakeholders within a participatory decision-making model." Portland's Planning Bureau abandoned large-scale community planning after the difficult experience with the SWCP. Mayor Vera Katz asked for an update of Portland's 9-year-old strategic plan warning that "the city's push to contain sprawl through higher housing density was alienating too many neighborhoods." Former Mayor Neil Goldschmidt, an important champion of downtown revitalization and neighborhood involvement in the 1970s, said Portland needed to put the vision back into planning. Irazábal quotes Goldschmidt saying that "the goal should be to move toward 'a unifying theology, a distilled and acute sense of what the fundamentals are"”(170-171).

Some of the issues raised by community members during the SWCP process had citywide and regional relevance, and city and regional planners responded by undertaking a number of initiatives to address stormwater management, tree preservation and 
planting, accessory dwelling units, urban land standards, and system development charges for transportation and parks" (169).

Irazábal identified some of the factors she believed were causing difficulties and conflict in planning processes in Portland. She noted that Portland's population had grown and was changing. More young people were moving to Portland, educational attainment was up, and more significantly, "the population is also diversifying in racial and ethnic terms." She suggested that neighborhood disputes could be "an indirect reflection" of the psychological impacts on people of increase density and other changes in their community (173-174).

Irazábal suggests that the "ability to build and maintain consensus about the future becomes more challenging as Portland continues to attract a more ethnically and economically varied population, and urbanizable land becomes scarcer" (175). She notes that "Until today, the majority of new residents in Portland have been middle-class whites who move to the area for its environmental and urban benefits. This homogeneity has contributed to easing the way for building agreements" (175).

The author also found that "In Portland, the increasing diversity of the population poses challenges of maintaining equity in the region" (175). "Equity concerns in Portland include alleviating and deconcentrating poverty, redressing disparities of resource allocation among jurisdictions within the region, improving access to jobs, economic opportunities, training, education, health, and affordable housing" (176).

Irazábal recommends that "If Portland is to move towards a physical and social environment of equity, planning will have to tackle several important challenges. These 
include the ability to maintain a long-term planning vision and the development of an ethos of solidarity in the region, a commitment to address disparities among regions in the state and metropolitan areas, and the development of a regional economic and community development strategy." She suggested that "Those who administer the planning process need to have the ability to create, recreate, and not lose sight of a longterm planning vision and the development of an ethos of solidarity in the region" (178179).

Irazábal notes that “...the role of citizens has been substantial in pressuring leaders to include their values and concerns into the plans, giving feedback on how the process was developing and evidencing flaws and strengths (through participation in committees, meetings, surveys, workshops, etc.), supporting in elections and demonstrations, and through the sheet appropriation of the city's public spaces" (180).

Irazábal states that the "balancing interaction "between leaders and citizens, however imperfect, has continually managed to forge the required levels of support for the programs to proceed, even if through unstable consensus." She notes that the SWCP, "one of the most ambitious planning projects since the central city plan," was delayed because city planners gave citizen input "less attention than it deserved." She says this experience "suggests, on the one hand, that Portlanders have become very empowered agents of planning, to the point of having the capacity to halt a major plan it they feel it is not appropriate; on the other hand, Portlanders have become very sophisticated at discerning and selecting the adequate treatment and consideration they aspire for in their 
participations. The experience also demonstrates that city planners and elected officials in Portland have shown good will at learning and adjusting through the process" (183-184).

Irazábal illustrates some of the challenges for community involvement in planning in Portland by quoting Tasha Harmon, a housing affordability activist in Portland. Harmon grants that the "planning experience in Portland is a lot better than the experience in a lot of other communities." Harmon cautions, however, that "it's still very top down, and very bureaucratic in a lot of ways....and there is never enough time given to building trust, building communication, and allowing people to talk to each other about what their conflicts are." Equity issues "often get left out of the equation," according to Harmon, "until somebody comes screaming about it, and then it doesn't get resolved in the way in which we would like it to" (184).

Irazábal finds that, fortunately, "city and planning officials have recognized their responsibility in the inappropriate management of some of these processes, and have shown a will to rectify and make efforts to reverse stagnant and adversarial citizen involvement in the future." She believes that citizens, for their part, will have to keep on making efforts to engage in meaningful participation, overcome selfish NIMBY attitudes, collaborate in the construction of a metropolitan vision, and recuperate the passion and trust that for decades had characterized their participation in planning processes" (184).

Finally Irazábal suggests that planning officials and institutions "will have to share a balance of power with citizens," and should "humbly but wisely (re)locate themselves, both mentally and practically, as facilitators rather than experts in planning processes, and fully and respectfully accept and incorporate the community at the highest 
levels of participation—-the 'power' level (as expressed in Arnstein's “Ladder of Citizen Participation"). They should avoid manipulation or alienation of citizens and groups."

She also identifies a need to "develop strategies to ensure and strengthen the continuation of the participatory process." She suggests that one immediate challenge is the encouragement of "under-represented citizens to be involved in existing civic forums and help create new ones as necessary" (184-185).

What do I Expect to See in My Case Study of Portland's Citywide Community Involvement System?

My research will examine the forty-year history of Portland community and neighborhood involvement system from the early 1970 s to 2013 . I will continue the work of Abbott, Witt, and Johnson by adding documentation and analysis of the evolution of Portland's system from 2000 to 2013. I will draw on the many system evaluations and reviews that occurred during that period as well as the substance and dynamics of major policy changes implemented. I believe that, over time, these sources provide a good indicator of what Portlanders believe are the important factors required to move their community toward greater participatory democracy .

My review of the general literature around participatory democracy as well as the Portland-specific literature helps define what I might expect to find in my review of Portland's more recent history with neighborhood and community involvement.

I expect to find continued support for basic elements identified by Berry, Portney and Thomson and others, including: 
- Existence of citywide structure of independent neighborhood and community organizations that serve as standing, available organizing vehicles for community members.

- Early warning and notification programs to ensure earlier involvement of community members in city decision making.

- Structural sanctions and rewards for city administrators who work with neighborhood groups.

- Control over some funding resources - through direct funding or grant programs.

- Resources to support broad communication and outreach by community organizations to community residents.

- Leadership training and skill building

- Technical support and organizational support

- Dispute resolution services

- Mechanisms to channel evolving and existing community activists into other city government participation structures.

I expect to see community interest in greater involvement in the City budget process and neighborhood planning activities--two areas of decision-making that have a great impact on the community, as well as other mechanisms by which community members can express their priorities to city government officials and staff.

I anticipate a continued need for paid staffing in the community to be able to support neighborhood associations and other community groups in developing the 
capacity to be effective at identifying and pursuing their own goals in the community and in working effectively in city government decision-making processes. Witt poses the question of whether the independent, community-governed, district coalition model will survive that takeover of two of the district offices. The future of this model is not clear from the past research. Part of the answer will depend on how ONI and city government treat the district coalitions and part will turn on the capacity and interest of community members in making these bodies function effectively.

I anticipate that my research will support the importance of incorporating into Portland's neighborhood and community involvement efforts Smock's core features of urban community organizing initiatives:

- Building individual capacity-developing local leaders

- Building community capacity—networks and social capital

- Building a community governance structure (democratic governance structures that allow members of a community to make collective decisions)

- Diagnosing and framing the community's problems

- Taking collective action for community change (Smock 6)

I also expect that the strengths and weaknesses of the neighborhood association model, as identified by Smock, will be validated. A key question is whether ONI and the district coalitions can work together to compensate for the weaknesses and help ensure that neighborhood associations can avoid the dangers identified by Fung, who found that the complexities of some issues overwhelm community groups and that social conflict, 
internal factions, and lethargy can undermine their effectiveness and ability to operate in democratic and fair ways.

I also expect to see neighborhood associations and other community groups having more power over citywide policies if they band together in the "nested structures" Putnam and Feldstein describe or through the creation of a "supra-local infrastructure of well-networked organizations" and "an overarching ideological framework that challenges society's dominant economic and political arrangements" as recommended by Smock. I expect that any opportunities for community leaders to come together and build relationships and discuss issues will help magnify community power-similar to the value of bringing community organizers together as described by Smock and the citywide neighborhood and community alliances in Los Angeles as described by Cooper. Portland's population continues to grow more diverse. I anticipate ever greater demands from people who are not well-integrated into Portland's traditional neighborhood system for expansion of the system to better serve their needs and interests and increase the equity of access by all Portlanders to economic opportunity, education, housing, and the opportunity to shape their community and influence local decision making — a move already anticipated by the 1995 Task Force for Neighborhood Involvement. This transition would be in line with the research by Chaskin, Smock, and others that suggests that effective community organizing and involvement needs to recognize that communities are made up of a fabric of different types of organizations and are better served by an acceptance of this rather than the older style approach that anticipated that most people's needs could be served through the traditional 
neighborhood association model. Putnam and Feldstein argue that people are more likely to get involved in groups that include people they have something in common with and feel comfortable with (bonding social capital). Putnam and Felstein emphasize, however, that community groups need to develop relationships across boundaries between them to leverage the bridging social capital that generates greater political power and efficacy. I also expect to see that the more diverse communities in Portland become, the more challenging it will be to bring people in those diverse communities together to build both bonding and bridging social capital.

I also expect to see Kingdon's theories about public agenda setting supported by the Portland experience in successfully advancing needed reforms--or in the lack of progress. I expect to see continued strong connections between the presence of a strong political champion and the ability to enact reforms. I also expect to see policy entrepreneurs — both in the community and within government - play a valuable role in laying the groundwork for reforms by raising, developing, and championing policy proposals in anticipation of a "policy window" opening given them the chance to move their ideas forward. I also expect to see perceived crises and studies used to highlight the need for reforms and playing an important role in getting participatory democracy reforms on the public agenda.

As suggested by Gibson, Cooper, Stone, and Fernandez and Rainey, I also anticipate that meaningful progress toward participatory democracy will require a change in the willingness and ability of city leaders and staff to work collaboratively with the community. As many researchers have suggested, this likely will take a major and 
intentional effort to change the culture of city government. I assume, as in Los Angeles and elsewhere, that most city leaders and staff will continue to be more comfortable with a top-down orientation to carrying out their duties. I anticipate that little progress will be made at changing the culture of local government without a clear vision, strategy, mechanisms, and political support in place to make it this happen. 


\section{CHAPTER III}

\section{ORIGINS AND EARLY YEARS-1970s}

Portland's internationally-known citywide neighborhood and community involvement system is nearly 40 years old. Over that time, the system has evolved and changed to meet new community needs and changing political priorities. Many of the early goals, purposes, and key elements and challenges established during the founding of the system continue to be part of the system today. Additional elements and programs were added over time. Some endured and others did not. Some recommendations for improvements have been made many times, but still have not been implemented. Other changes were implemented and have strengthened and improved the system.

This section describes studies and documents that provide insights into the original thinking that shaped the origin and early years of the system. These early documents include a formal proposal by the Portland Planning Commission for the creation of community district planning organizations supported by city planning staff that would develop district plans for different parts of the City. The City Council responded to this proposal by created a District Planning Organization Task Force to study and make recommendations for a citywide neighborhood association system. In 1974, the Portland City Council adopted the first ordinance establishing Portland's formal neighborhood association system and the Office of Neighborhood Associations to support the system. A year later the City Council adopted a revised ordinance that eased some of the requirements of the 1974 ordinance. Mary Pedersen, the first director of ONA, prepared two reports on ONA and the neighborhood system-one in 1974 after the first 
year of the new system and in 1979 as she was leaving her position as ONA director and a new Portland mayor was coming in. This chapter closes with a review of Portland Mayor Neil Goldschmidt's mayor's budget messages that accompanied the seven city budgets during his time in office and through which he stated his goals and priorities related to community involvement and city governance.

\section{Origins of Portland's System}

Before the 1970s, Portland's governance culture was very similar to that in other cities. Community members had little involvement or say in governance decisions. Reforms instituted during the 1970s set the stage for a dramatic expansion of community involvement in local decision making. Many of those early reforms and structures continue to shape Portland's system today.

In 2013, Portland has a vibrant downtown surrounded by older neighborhoods that are full of life, activity and character and strong housing values. Portland regularly tops national lists of desirable and livable cities. Portland was a very different city in the 1960s. The city at that time had a lot of older housing in need of repair, especially in Portland's older inner neighborhoods. Abbott (1983) writes that professional planners at the time took for granted that these inner neighborhoods were in decline and should be cleared and redeveloped rather than preserved and revitalized.

Abbott writes that "Changes in public tastes, political leadership, federal programs, and the housing market all combined to convince citizens, planners, and politicians that neighborhood change is not necessarily a one-way street leading to urban blight" (186). Neighborhood planning between 1957 and 1967, according to Abbott, 
made "no reference to neighborhood groups or citizen involvement." Plans were “prepared by city employees for their colleagues in city hall” (188).

Portland planning underwent startling changes from 1966 to 1972. Abbott credits the changes to "the emergence of active and often angry neighborhood organizations" that "made local residents the actors rather than the objects in neighborhood decisions." Neighborhood activists had different values than Planning Commission members and staff and they were able to alter both the process and content of neighborhood planning in Portland. Abbott also credits a "change of generations on the Portland City Council in 1969-70." New city leaders were "less committed to old policies and personnel" and while most did not "initiate the neighborhood revolution" they were "willing to respond to neighborhood requests." The Federal government also had an impact through its demands that community members be included in city spending decisions through the Community Action program of the Office of Economic Opportunity, the Model Cities program, and the Housing and Community Development program (190-191).

The Birth of Portland's Neighborhood System

Portland city planners, in the late 1960s and early 1970s, faced increasing opposition from neighborhood activists who organized groups to oppose urban renewal and other city planning projects.

In the late 1960s and early 1970s, community activists in northwest Portland had organized to oppose an urban renewal plan to clear 16 blocks of northwest Portland to allow expansion of Good Samaritan Hospital. Community activists, in 1969, quickly organized themselves and created the Northwest District Association, one of Portland's 
early organized neighborhood associations Hovey (2003). describes how these activists were able to convince the city council to allow the development of a plan for the larger neighborhood. Community activists worked with sympathetic city planners and other community members to create the Northwest District Plan, which the City Council adopted in the early 1970s. Hovey writes that the early community organizing and neighborhood planning by the NWDA set the stage both for Portland's subsequent style of urban planning and the creation of Portland's community and neighborhood involvement system.

Community activists in other parts of the city also were organizing to oppose City urban renewal and other redevelopment projects and to advocate for their own approach to revitalization of their neighborhoods. City planners determined that a major reason neighborhood activists were organizing to oppose change was that "they have not been given the opportunity to become fully involved in affecting change" in their neighborhoods (Portland. Planning Commission 1971 1). City planners also found that their efforts to involve residents in neighborhood and district planning were hampered because they did not have "staff who could stimulate and coordinate the citizen participation" as did the staff of the Model Cities program in northeast Portland.

City planners responded by proposing the creation of a formal district planning program that included the formation of District Planning Organizations in the community similar to programs developed in other cities at the time (i.e. San Diego and Fort Worth) (Pedersen 1974 2). The Portland City Planning Commission approved the planners' proposal in April 1971 and forwarded it on to the City Council. 
The City Council supported the idea and appointed the District Planning Organization (DPO) Task Force in January 1972 to review the proposal and recommend steps to implement the proposal. The DPO Task Force submitted its report to City Council in December 1972.

Together these two proposals shaped much of the early thinking that influenced the purpose, scope, and structure of Portland's neighborhood involvement system. Many of these original elements still exist today—40 years later-while others have been altered or dropped.

\section{Planning Commission Proposal for District Planning}

City planners and Planning Commissioners recognized an increasing ability and inclination of neighborhood activists to oppose and block land use planning and urban renewal projects in Portland. Planners hoped a district planning program would channel neighborhood opposition into more constructive involvement and begin to give community members a greater voice in shaping their communities.

Planners had had some experience and success at the time involving citizens in developing plans in the Model Cities Program area in northeast Portland and some other parts of Portland. Planners had found that residents and independent neighborhood associations had the capacity to play a constructive and meaningful role in local planning projects. Hovey asserts that the experience of city planners working with the Northwest District Association (NWDA) to develop the Northwest District Plan significantly shaped planners thinking about the potential for broader involvement in land use planning in Portland. 
In April 1971, the Portland Planning Commission approved a proposal, developed by city planners, to create a formal city district planning policy and program. The essence of the proposal was the creation of district planning organizations (DPOs) that would represent community interests and provide a formal vehicle by which community members and city government leaders and staff could work together to develop comprehensive plans for districts across the city. The proposal also represented a significant shift of decision making responsibility and authority away from City staff and agencies to the community — at least on issues with a local versus citywide impact.

The Planning Commission Proposal for District Planning asserted that:

"Recent years have seen an increasing awareness on the part of the citizens of Portland concerning the issues that are affecting the environment of their city and specifically their districts and neighborhoods. Too often this concern has been expressed by opposition to some governmental action or opposition to planning that had been developed without their participation. Groups have formed spontaneously to oppose change because they have not been given the opportunity to become fully involved in affecting change. It should be apparent that if the City is to prepare itself for the changes that must be made, it must redirect the powerful force of citizen involvement from its present role of opposition to the much more meaningful task of creation" (Portland. Planning Commission 1971 1).

City planners and Planning Commissioners hoped that the district planning program would encourage citizen participation in the planning process, clearly define the City's role and commitment to the community, and allow "growth and change" to "take place in a logical and orderly manner" (Portland. Planning Commission 1971 2-3). The primary focus for each DPO in the proposal was to develop a comprehensive plan for the DPO's district. (The City of Portland did not have a formal city-wide comprehensive plan 
at the time. The Oregon State Legislature passed SB 100 in 1973, which required every city to develop a comprehensive plan.)

Key elements of the 1971 proposal included:

Creation of community-based district planning organizations (DPOs):

Neighborhood groups in an area could choose to request that the Planning Commission and City Council approve the creation of a formal DPO for their district. The initiative to create a DPO lay with the neighborhood groups rather than the City unilaterally establishing DPOs across the city.

A DPO proposed by neighborhood groups would need to meet specific standards to receive City Council approval:

- "the organization is representative of the district" (3-4)

- The organization "evidences stability"

- The district boundaries are "logical"

- The district needs planning assistance, and

- The City is able to "budget to meet this need for planning...." (5).

Clarification of roles, responsibility, and authority: The proposal identifies four key players in the development of district comprehensive plans: the DPOs, city planners, the Planning Commission and the City Council. The proposal emphasizes that "each is reliant on the other three" in the planning process (2) and expresses the hope that a clear understanding of this interdependency "will build bridges between government and the citizens" and "discourage conflict for authority...." The planners who prepared the 
proposal also expressed the hope that a better understanding by the DPOs of what the "City can and what it cannot implement" will help discourage "unrealistic demands" (2).

The proposal recommends a significant decentralization of some land use planning decision-making from city planners and officials to the community. The DPOs were to be the source of opinions and ideas for the planning process and to act as "district organizers" and a community forum to develop opinions and ideas within their districts. The proposal explicitly states that City planners were to serve as facilitators and advisors but not decision makers.

A significant element in this proposed shift of decision making power was that issues and conflicts that primarily affected the area within the district should be resolved "among those who are immediately affected by the decision"—-not by City leaders and staff. City Council and the Planning Commission often had found themselves "arbitrating issues that are purely local in nature." The proposal maintained that Community members are much more likely to understand potential costs and benefits for themselves and their community and to help achieve compromises and resolve trade-offs if they are included in the decision making process. The report suggested that community members that are not included in this process likely will focus only on perceived costs to themselves. The proposal recommended that "planning issues that do not cross district lines or that have little or no city-wide implications should, whenever possible, be resolved within the district before reaching the Planning Commission and City Council” (2).

Development of district comprehensive plans and city staff support: The primary focus of the DPO's activities would be to work with the City to develop a comprehensive 
plan for the district. The city would commit to provide "a specified amount of technical planning assistance to the DPO" (4), which would include "basic data on population, social factors, land use, building conditions, and neighborhood facilities" and would conduct "other field surveys normally associated with a district plan" (5). City planners also would help the DPO develop "goals and objectives" and "specific plan proposals for the district" and would propose "alternatives to the DPO and call their attention to emerging problems and conflicts" (4) and act as a liaison with other city agencies to test ideas and get their feedback on the proposed plan. The proposal clearly states that city planners would act in the role of "technical advisor" but that "plan decisions are always made by the DPO" [emphasis in the original].

The DPO would be responsible for communicating regularly with the Planning Commission and City Council during the development of the district plan, and would be responsible for reaching out to the community, especially to distribute the draft plan widely in the community before the DPO formally approves it and forwards it on to the Planning Commission.

The Planning Commission would review the plan based on the following criteria:

- "Is it desirable from the standpoint of implementation over a reasonable period of time?" (4)

- "Is it truly representative of district needs and desires?"

- "Is it in harmony with city-wide plans?"

City commitment to implement and follow district plans: The proposal suggests that a district plan developed by the DPO and approved by the Planning Commission and 
City Council would serve as a "guideline for district development" and will include "a list of priorities and a timetable for implementation." The City would make a "firm commitment to implement the plan in accordance with the" established "priorities and timetable...." in the plan (3).

The proposal suggests further assurance that a formally adopted district plan would become the "City's development plan for the district" and that "[n]o city action can be taken contrary to the plan or purposes of the plan unless the plan is formally amended at a public hearing" (5).

In exchange, the City would expect that the DPO would support the City's efforts to implement the plan (3).

The 1971 Planning Commission proposal embodied some very important values and principles that would become key features of Portland's future community and neighborhood involvement system. One of the most significant was the proposed shift of significant decision making power from City government to the community. City planners had recognized that neighborhood activists had the capacity to participate effectively in city government decision making processes-and the ability to block city government driven projects. City planners also recognized that community members could bring value to government decision making. They maintained that community members had the best understanding of the needs in their community and the implications of different policy and program alternatives. They also recognized that more lasting (and implementable) decisions would be made if representatives of different interests in the district worked together to identify their interests, identify and explore alternative 
approaches, wrestle with tradeoffs, and work out agreements on solutions-rather than having the Planning Commission or City Council try to impose a solution on the district that had no common buy-in within the district. The DPOs also would take on the responsibility for convening and engaging their community members and soliciting community input into the process. As part of this shift of decision making power, city planners recast their role from acting as "professional experts" planning for the community to being "facilitators" who would help convene and support a communitydriven decision making process.

City planners also recognized the importance of only supporting the creation of DPOs where community members showed they had the interest and energy to participate in them rather than trying to impose a citywide system all at once. DPOs only would be created where community members wanted them and would participate in developing a comprehensive plan. While City planners proposed that the DPOs focus primarily on the task of developing a comprehensive plan, Hovey (2003) has shown that neighborhood association comprehensive plans at that time could include a wide range of community revitalization and development strategies and activities.

City planners also recognized that, in order to attract community members to volunteer the significant amount of time and effort that would be required to develop a comprehensive plan and maintain a cooperative relationship with community activists, the City needed to commit to taking the input of community members seriously and complying with and following the resulting comprehensive plan. 
City planners also recognized the importance of establishing basic standards that DPOs would need to meet in exchange for the formal decision making power and the city staff support they would receive. These basic standards included being representative of the community, having the organizational capacity to function as a "stable" organization over time, and that having "logical" boundaries. The need for basic standards, representation of the community, organizational capacity, and relevant boundaries would continue to be important and recurring issues throughout the history of Portland's community and neighborhood involvement system.

\section{DPO Task Force Report}

City Council adopted the Planning Commission proposal to create and support a system of district planning organizations in April 1971. In January 1972, the City Council created the "DPO Task Force" to develop more detailed recommendations for the creation of a formal neighborhood involvement structure and system. The Oregonian reported that the DPO Task Force members included representatives of "the Planning Commission, Housing Authority of Portland, Portland Development Commission, neighborhood organizations and the general public" ("Schrunk appoints 16 to aid area plans," January 27, 1972).

While the Planning Commission's 1971 proposal had recommended the creation of a system of district planning organizations to facilitate comprehensive land use planning across the city, Mayor Terry Schrunk asked the 1972 DPO Task Force to look more broadly and to make recommendations for the creation of a citywide system of formally recognized neighborhood associations. 
As part of his broader charge, Mayor Shrunk asked task force members to define the purpose of neighborhood associations, identify the scope of activities they would undertake, the means for financing neighborhood organizations and source for funding neighborhood projects and activities, criteria and procedures for recognition of neighborhood organizations, and methods to ensure communication between neighborhoods and the City Council (Portland. District Planning Organization Task Force. Task Force Report. 1972 Attachment Number Two).

The creation of the DPO task force took place during a time of major changes in Portland. New city council members like Neil Goldschmidt, a young lawyer with a history of working with community groups ${ }^{6}$, came into office with big ideas to revitalize downtown and the neighborhoods, involve community members in government decision making, and to reform local and regional governance structures. Goldschmidt and others also campaigned for a variety of major governance structure changes in Portland and the region, including consolidation of city and county services and the merger of the City of Portland and Multnomah County. ${ }^{7}$

\footnotetext{
${ }^{6}$ The Oregonian, in its endorsement of Goldschmidt for mayor in 1972, noted that "Mr. Goldschmidt certainly is understanding of and empathetic with the problems of youth, the poor, the minorities, among whom he worked for several years as a lawyer and head of the Albina legal Aid office" ("Neil Goldschmidt for Portland's mayor." Editorial. Oregonian 7 May 1972).

${ }^{7}$ While, city-county consolidation was never implemented, the city and county did divide up many local services, with the county taking on most of the responsibility for human services in Portland and city government taking on responsibility for physical infrastructure such as streets, water, sewer, and parks. In 1978, Oregon voters approved Measure 6 which replaced the Columbia Region Association of Governments (CRAG) with an elected regional government called Metro. In 1983, the City of Portland and Multnomah County agreed to divide up the services each government provided to their overlapping jurisdictions, according to the strengths of each jurisdiction, as a way to use their limited resources most efficiently. The agreement allowed the City of Portland to provide urban services (e.g. sewer and water) to urbanizing areas in unincorporated Multnomah County and allowed Multnomah County ease its financial problem by cutting services that the City already was providing within the City limits. The County agreed to take the lead on human and health services, justice services, libraries, assessment and taxation, elections, corrections. The City agreed to focus on police, neighborhood parks, land use planning, transportation,
} 
At the state level, the Oregon Legislative Assembly passed Senate Bill 100 in 1973, and in 1974 the new state Land Use and Conservation Commission (LCDC) adopted statewide planning goals to guide the new state planning system. "Goal 1 Citizen Participation" set ambitious goals for community involvement and required local governments to involve community members "in all phases of the planning process." Portland's formal system of neighborhood associations would become a key element of Portland's strategy for meeting the community involvement requirements of Goal 1.

The DPO Task Force started work in May 1972. The task force members created five working committees and met 37 times in meetings open to the public. Task force members also "held 11 open meetings throughout the city," which they advertised through "posters and mailings to community groups, people who attended meetings, and those requesting information" (Portland. District Planning Organization Task Force. Attachment Number Five).

The task force members adopted some basic principles to guide their work. These principles included:

(1) “Citizens' organizations of this community have the ability and willingness to deal responsibly and constructively with issues affecting the livability of the city." Task force members emphasized that any meaningful effort to create a formal structure to involve community members in government decision making must be grounded in the assumption that citizens have "the ability and willingness...to play an important role in the working of their government...." They noted that the historical involvement of 
community members in state governance and the more recent involvement of "citizen initiated neighborhood associations" in Portland gave evidence that community members were willing and able to participate (Portland. District Planning Organization Task Force. 2).

The task force defined "livability" as "the quality of the physical environment as well as the range of opportunities for employment, recreation, education, health care, social services and cultural activity" (2).

(2) "A formalized structure established for citizen or neighborhood involvement must encompass both community development (physical factors) and personal development (social factors)." Task force members noted that community members and individual task force members repeatedly had emphasized that physical and social factors are interrelated and to separate them "at the basic level of citizen or neighborhood involvement is a mistake" (2).

\section{(3) "To be most effective, a two-tiered structure for citizen or neighborhood}

involvement is the optimum condition." The task force members believed that the best structure would include both strong neighborhood associations and that these neighborhood associations would join together to form and participate in strong district organizations. The task force members envisioned that "neighborhood associations will deal with local issues and districts will handle broader issues and add 'clout' when appropriate" (3).

(4) "Given a two-tiered system, the larger areas (districts) should be pre-defined and the smaller areas (neighborhoods) should be defined by citizens in that area." They 
lauded the "initiative taken by citizens in forming their own groups based on neighborhood interests and common concern" and insisted that government should not discourage this development by imposing a new structure "for its own convenience" (3).

Task force members reemphasized the point argued by the 1971 Planning Commission report stated that "Many matters of purely local concern and impact can best be considered and studied by those immediately affected" (3).

They also recognized that "city agencies and government" needed a "functional structure to deal with multi-neighborhood problems and needs." To meet this need, task force members envisioned "the organization of committees or task forces by the groups directly involved to handle inter-neighborhood and inter-district problems, thus insuring maximum inter-group cooperation while preserving the identity of the neighborhood or district organizations" (3). Task force members recommended that community members would set neighborhood boundaries, but that city planners would set district boundaries.

(5) "Any structure recommended should take maximum advantage of existing groups and associations and be capable of fitting into present or changed structuring of local government." Task force members recognized that a number of groups and associations had formed in recent years to serve the "interests of their neighborhoods." They recommended that "any new plan adopted by City Council" should enable these existing groups to continue to function constructively, to the extent possible (3).

(6) District and neighborhood planning organizations must be delegated the proper authority by City Council to enable meaningful participation at all levels.." Task force members argued that the City Council needed to grant district and neighborhood 
organizations "more than token authority" to ensure the viability of participation by grassroots organizations. "Much of the quality in neighborhood participation can be lost if that participation is reduced to 'after the fact' reaction" (3-4).

The DPO Task Force members submitted their final report in December 1972. Their report responded to the questions posed by Mayor Schrunk and recommended the creation of a two tiered formal structure that would include neighborhood level organizations that would focus on local issues and district level organizations that would respond to issues that crossed neighborhood lines. The task force members also suggested that some sort of third tier "Council of Districts" be established to provide the City Council with input on multi-district or citywide issues.

The DPO Task Force members structured their recommendations to respond to Mayor Schrunk's original questions to the group. The recommendations included the following:

Purpose of Neighborhood Organizations: Task force members recommended that the purpose of neighborhood organizations include three elements: "To preserve and enhance the livability of Portland through planned, coordinated community development, "to enhance the lives of area citizens by optimizing the quality, availability and delivery of community services and to do this while protecting the rights of all citizens" [emphasis added] (4).

They proposed that a formal structure for neighborhood associations could meet the needs of citizens, city agencies, and the City Council in a number of ways. Citizens would use the structure as a forum for and vehicle to work together to express and discuss 
“their opinions, needs and desires that will have an impact on their community's development and services." City agencies would have a vehicle to receive "opinions, needs, desires, and recommendations" from citizens and community groups that would help city agencies carry out their assigned missions "in a way most beneficial to the community." City Council would have "an improved method for decision-making and assignment of priorities for all programs affecting community development and personal development of citizens."

Scope of Activities for Neighborhood Organizations: Task force members emphasized that the scope of activities for neighborhood organizations should extend beyond a role in land use and comprehensive planning — as recommended by the 1971 Planning Commission proposal. Task force members recommended a scope that included three primary areas of activity for the proposed NPOs. NPOs would develop a comprehensive plan "for their neighborhood"--that would include "physical, social and economic planning"-with assistance from "city agencies involving the NPO and DPO." Once the City Council adopted a neighborhood comprehensive plan, it would become "the basis for City and neighborhood action programs." The plan would be updated by a similar collaborative process from time to time. NPOs also would work on behalf of their neighborhoods with "all governmental and private agencies" on any matters of interest to the neighborhood. NPOs also could identify areas of neighborhood interest and need and work to meet them using resources available within the neighborhood (4-5).

Sources of funding for NPO activities: Task force members recognized that "one of the frustrations that neighborhoods encounter is the unavailability of resources 
for needed programs." Task force members suggested that neighborhoods seek funding from federal, state and local government agencies, apply for grants from foundations, and access volunteers (e.g., VISTA and professional pro bono assistance) as well as leadership training offered by different organizations in the Portland area (Attachment Number Six).

\section{Formal criteria and procedures by which the City would recognize}

neighborhood organizations: Task force members proposed the following approval critieria and process for formal recognition of neighborhood organizations:

Community initiated: The task force members recommended that the recognition process should be activated either by a "group of citizens" in an area, or by the DPO, if it "recognizes the need for an additional NPO to make plans for an unorganized area in their district (6).

Community involvement in NPO creation: Whether the process would be initiated by community members in an area or by a DPO, open meetings would held to discuss the proposed creation of a new NPO. The meetings would be "well advertised" and "all eligible groups should be notified" (6).

Open membership: NPO members must be open at least to any resident, property owners, and licensed business in the area, as well as a representative from "any nonprofit organization located in the area" (6).

NPO establishes own governing process: Community members would establish their own governance structure and operating policies for the NPO. 
NPO sets own boundaries: Community members would establish the boundaries for the NPO, however, "only one NPO should exist in any geographic area"-no overlapping boundaries (6). Task force members included in their final report very detailed guidance for community members on how to establish the boundaries of a new neighborhood association (Attachment Number Seven).

Proposed NPO submitted to DPO and City Council: By means of "a minimum of three open meetings" community members would adopt policies and boundaries for the proposed NPO. They then would forward this information on to their local DPO, which then would recommend that City Council recognize the new NPO. If no DPO had been created for the area, community members would take their proposal to create a new NPO directly to City Council (7).

Annual Report on each NPO: Task force members recommended that the coordinator for a DPO file a "brief annual report to City agencies and City Council to keep them aware of the activities of each NPO" (7).

Annual elections to ensure NPO representativeness and accountability: Task force members recognized the need to "ensure representation" by each NPO of the various views of people in the neighborhood and that the NPO was accomplishing the purposes identified by community members. They maintained that a requirement for "annual free and open elections" of the leadership of the NPOs would "serve as effective citizen tools" to meet these goals (7).

Funding to support basic NPO operating expenses: Task force members recognized that NPOs would need funding support to carry out basic functions including: 
“organizing effectively," notifying "all segments of their community," and preparing a comprehensive plan for the neighborhood. To ensure adequate funding support, the task force recommended:

Communications support: City funding for the DPO headquarters would provide "the coordinator, supplies, machinery, mailing expenses and secretary to aid the NPOs in communication with residents, property owners, and businesses;"

Planning support: Task force members recommended that every NPO have the right to "planning staff assistance from the City and the DPO coordinator to develop a neighborhood comprehensive plan" (8).

Task force members recognized that "many neighborhoods will want to do more" than just the communications and planning activities. NPOs can pursue funding and resources from other sources (government agency, foundation, volunteer, etc.). Task force members also noted that "any neighborhood which desires to completely fund itself"- and not take any City funds_-"has the option to do so" (8).

NPO Authority - mandatory involvement in plans and programs: Task force members recommended that-once the City Council has recognized an NPO or DPO--no city or private agency shall write physical, social, or economic plans or programs for the neighborhood or district without first involving the planning organizations involved" (8). They also recommended that the City Council and city agencies not fund or approve plans or proposals "that do not have the approval of the neighborhood or district involved." 
Protection of minority viewpoints and conflict resolution: Task force members asserted that, at any level of involvement of NPOs or DPOs with City Council and city agencies regarding the development of plans, programs, and proposals, "the rights of the minority views present must be protected." They further assert that minority viewpoints "should be heard and considered" and that people expressing these views "shall have the right of appeal to the appropriate body" (9).

Task force members maintained that this process would serve as a "viable method for conflict resolution" because it would assure that "all views will be heard by the neighborhood, district, and city agencies" and "guarantees that the rights of the individual shall not be bypassed" (9).

DPO purpose, structure, and governance: Task force members recommended that DPOs be formed by the neighborhood associations within a district boundary. Each DPO would be governed by a board made up of representatives from and elected by each neighborhood association in the district. Neighborhood associations would have an equal number of representatives on the DPO board (7).

Planning Commission staff would establish the district boundaries within which DPOs could be established. Task force members suggested that each district be reasonably similar in "terrain, land use, and population" and include between 30,000 and 40,000 people. District boundaries should follow "natural and man-made barriers whenever feasible" and consider existing neighborhood organization boundaries. Task force members suggested that the new district boundaries could influence future 
redrawing of legislative district boundaries, especially if the city-county consolidation (proposed in the 1970s) were to proceed (Attachment Number Seven 5) ${ }^{89}$

Task force members recommended that DPO's be responsible for reviewing and forwarding to City Council proposals for new NPOs in the district and organize, communicate, and coordinate neighborhood activities within a district. City agencies were to use district boundaries for district planning when feasible.

Each DPO would have a headquarters office funded by the City. The DPO board would hire a full-time DPO coordinator and a part-time or full-time secretary. The secretary would provide clerical support, answer the telephone, and type correspondence, minutes, fliers, etc., for neighborhood associations and the DPO. The DPO coordinator's duties would include: Communication support: Task force members viewed the role of the DPO coordinator mainly to support the flow of communications throughout in the

\footnotetext{
${ }^{8}$ Portland's population in 1970 was 382,619. Based on this number and following the DPO Task Force proposal, Planning Commission staff would have created between 9 and 13 districts in Portland in the early 1970s. Applying the same district population criteria to Portland's 2010 population would result in the creation of 15 to 20 districts. Instead, Portland's formal neighborhood associations have been grouped into seven neighborhood districts that range significantly in size from Central Northeast Neighbors (CNN) with a population of 45,423 (2010 U.S. Census) and eight neighborhood associations to Southeast Uplift Neighborhood Coalition with a population of 151,183 (2010 U.S. Census) and 20 neighborhood associations.

[Portland Population 2010: 583,776 (Source. U.S. Census 2010; http://quickfacts.census.gov/qfd/states/41/4159000.html ]; this population data, divided up by neighborhood association and neighborhood district coalition is available on the ONI website at: http://www.portlandoregon.gov/oni/28387 )

[Portland Population 1970: 382,619 [Source U.S. Census 1970; http://www.census.gov/population/www/documentation/twps0027/tab20.txt

${ }^{9}$ Rethinking the size and distribution of Portland's NAs and District Coalitions: Over the 40-year history of Portland's neighborhood system, neighborhood activists, coalition leaders and other community members, periodically have questioned whether the number of neighborhood for each coalition should be made more even and whether large coalitions should be split into more than one coalition. The idea of making the number of neighborhood associations per coalition more equal runs up against the fact that under Portland's current system neighborhood associations themselves choose the coalition with which they want to affiliate. Only neighborhood associations that border a different coalition could make the move under the current rules. Changing the number and size of district coalitions would be a significant change to Portland's current system.
} 
system (11); Information and referral for city staff and neighborhood: "liaison between the neighborhood and city staff by serving as an information source;" Local planning: "Primary function of the coordinator is to involve NPO and DPO with agencies' staff to expedite plans/programs on a local level;" Neighborhood organizing: "Aid neighborhood people in organizing;" Training: "Hold workshops at the community's request to teach them skills;" and Conflict Resolution/Forum: "Be a forum to the community by helping them use conflict creatively" (Attachment Number Eight).

Each DPO headquarters would be located in a facility in the community, preferably selected by the DPO board members. The headquarters facility should be easily accessible by community members (e.g. centrally located and “...preferably on a bus line"). The headquarters should be equipped with “...with telephone, space for secretary and coordinator, supplies, maps,...." and “...if feasible, a meeting hall” (Attachment Number Eight).

\section{City-wide "third tier" of community involvement to address multi-}

district/city wide issues: The task force members considered the need for a "third tier" (in addition to the neighborhood and district tiers) to advise City Council and individual city agencies on citywide or multidistrict issues. They affirmed that issues should be dealt with by community members and the City at their level of impact—e.g., neighborhood issues at the neighborhood level and district issues at the district level. They considered whether another organizational level was needed to provide similar community input on city-wide issues. However, task force members were not able to agree on whether to 
include a formal "third tier" in the formal involvement system or what approach would be best. The DPO Task Force report presents some of the different ideas task force members suggested and discussed but does not recommend a particular course of action. The possible methods of addressing multi-district issues considered by the task force members included:

City Council: City Council deals with multi-district issues by "setting priorities for city-wide expenditures and formulating policy guidelines for city-wide social, physical and economic planning" after "receiving recommendations from all DPOs." Under this option, existing appointed city commissions would continue to make recommendations to City Council on multi-district/citywide issues in additional to input from the DPOs. Task force members also discussed an alternative that would eliminate all the existing commissions and rely instead on input primarily from the DPOs (9-10). ${ }^{10}$

\section{City Council advised by expanded city commission system and DPO}

appointments: This alternative envisioned an expansion over time of appointments of community members to city boards and commission (such as the Planning Commission). Task force members expected that many of these community members would have gained valuable expertise from participation in their neighborhood organization's planning activities. DPOs were expected to play a major role in either appointing community members directly to serve on boards and commissions or by recommending appointments to the City Council. DPOs would forward proposals to these city boards and commission, which would review them "before recommending priorities and policies

\footnotetext{
${ }^{10}$ The idea of eliminating city boards and commissions and relying on input from DPOs instead shows the high expectations some people had for the role that DPOs could play in providing community input on a very broad array of policy issues.
} 
for city-wide issues to the City Council. City agency staff would assist the members of the boards and commissions in developing these recommendations (10).

City Council advised by Council of Districts: DPOs would appoint community members to serve on a new "Council of Districts." This new "third tier" (in addition to neighborhood and district tiers) body would be solely responsible for advising the "City Council on questions of city-wide priorities and policies." The Council of Districts could be spurred to give this advice either upon a request from the City Council or from two or more DPOs. Task force members considered that the development of such a city-wide community council might "evolve naturally through cooperative efforts of various DPO's"'(10).

The task force members reported that they had split on whether to recommend the creation of a third-tier District Council (60 percent for and 40 percent against). Other task force members and members of the public had suggested that the alternative of expanding the membership of community members on city boards and commissions through DPO appointments or recommendations might also be possible in the future (10).

\section{Communication is central to the system-different forms and methods:}

Effective communication within the community and between city government and the community was an important focus in Mayor Schrunk's charge to the DPO Task Force. Task Force members determined that communication and coordination was needed between a number of different elements and levels of the system. Task force members also recommended ways in which these flows of communication could be achieved. They identified needed flows of communications that included communication between: 
- Neighborhood residents and their neighborhood organizations

- Neighborhood associations (one to another)

- Neighborhood residents and organizations and their DPO board

- Neighborhoods and DPOs and city agencies.

- Neighborhoods and City Council.

Task force members viewed the role of the DPO coordinator mainly to support the flow of communications throughout in the system (11).

Task force members suggested that neighborhood residents and their neighborhood association could communicate through "mass mailing of minutes, flyers advertising meetings, open meetings," and a district newsletter. The DPO and DPO staff would help cover the cost of and assist neighborhoods in these communications on request (11).

Task force members expected neighborhood representatives on DPO boards to be responsible for keeping their neighborhood association informed on district activities. They suggested that a district newsletter would help with this communication (11).

The DPO coordinator would facilitate communication between neighborhoods and districts and city agencies by providing city agency staff involved in "plans or programs for a neighborhood" with contacts in the neighborhood and helping neighborhood residents identify whom to contact in city agencies and the process to use to "resolve a problem or concern the neighborhood may have" (11).

Task force members recommended that communication between neighborhoods and districts and City Council could be supported if City Council members were to assign 
staff to act as liaisons with DPO coordinators and neighborhood and district boards (12). They suggested that the need for communication between City Council and neighborhoods might be minimal "if agencies, departments, and Council respond satisfactorily to neighborhoods' planning." They anticipated that neighborhood representatives and residents naturally would be drawn to City Council meeting by issues of special interest to their neighborhoods (12).

Task force members also asserted that "As citizens become involved 'before the facts," there will be fewer protestors reacting against changes planned without their knowledge and consent, and a more creative role will be played by neighborhood organizations" (12).

The 1972 DPO Task Force report asserted some key principles that members believed were essential to the success of a citywide community involvement system. One was the premise that community members are willing and able to participate with city staff in planning, program development and decision making. Others were that community members should be allowed to work on any issues that they believe affect the livability of their community, that an effective formal neighborhood association system should have both strong neighborhood associations and strong district level organizations, and that these neighborhood and district organizations also need to have some real power and influence.

The task force members established that the purpose of a formal system of neighborhood associations should include giving community members the ability to enhance the livability of their communities (as they define it), to help express community 
needs to city government leaders and staff to improve city services to the community, and to protect the rights of all citizens.

Task force members also maintained that the system should include basic critieria and a clear process by which the city formally would recognize neighborhood associations. They recommended that proposals for the recognition of neighborhood associations-or Neighborhood Planning Organizations_-should be initiated by community members. They recommended that groups forming a new neighborhood association involve their community members in the design and approval of the neighborhood association's governance process, policies, and boundaries. Task force members also recommended that membership in neighborhood associations be open and that only one neighborhood association be allowed in a particular area-no overlapping boundaries. They also recommended that neighborhood associations hold regular elections to ensure that they are representative of and accountable to the people in their neighborhood.

Task force members recommended that neighborhood associations be allowed to form District Planning Organizations (within boundaries set by Planning Commission staff) to help neighborhood associations address issues that cross neighborhood boundaries and to give city agencies a structure to work with for planning and program development. They proposed that DPOs would be governed by representatives of the neighborhood associations in the district, but that the City provide funding to establish and staff a district office in the community for each DPO. The district office staff would include a coordinator and clerical support position who would provide an array of support 
services to community members and neighborhood associations to ensure their ability to be involved. A primary focus of the district staff would be to support communications within and between community members, NPOs, and DPOs, and city leaders and staff. Other services would include information and referral for community members, support for NPO and DPO involvement in city agency planning and programs, neighborhood organizing, training and skill building for community members, and conflict resolution. City planning staff would be available to help NPOs and DPOs develop comprehensive plans for their neighborhoods and districts.

Task force members maintained that NPOs and DPOs needed to have real power. They recommended that city and private agencies be required to involve NPOs and DPOs in the development of plans or programs that affect their neighborhoods or districts and that the City Council and city agencies not fund or approve plans or programs that did not have the approval of affected NPOs or DPOs.

Task force members also emphasized the need to protect the rights community members with minority viewpoints to be heard and to have their ideas considered in the system and to have a right of appeal of NPO and DPO decisions. They believed that these protections would help resolve conflicts and guarantee the rights of individuals.

Task force members recognized the possible need for a third tier in the structure to give community members a mechanism to consider and provide input on multi-district or citywide issues, but they could not agree on how this should happen.

The City Council adopted the DPO Task Force report and soon moved to implement the Task Force members' recommendations. 


\section{Portland Downtown Plan}

At the same time that Portlanders were beginning to design a new neighborhood association structure, they also were helping rethink the future of Portland's downtown. Abbott reports that the 1972 Downtown Plan represented a turning point in city planning in Portland and in the involvement of community members in determining the future of the city. Abbott reports that "Businessmen, planners, and citizens collaborated to develop a new downtown plan between 1969 and 1972" that represented a "new orthodoxy" that reversed much of the City's earlier vision for urban planning. The process also was unusual in that a Citizen's Advisory Committee set the basic goals for the plan rather than "outside experts." These goals approached "the downtown area in terms of pedestrian uses and needs"- as a "people's place" rather than early visions that focused strongly on automobile movement into and out of the downtown (Abbott 208).

Abbott writes that "planners with the engineering firm $\mathrm{CH} 2 \mathrm{M}-\mathrm{Hill} . .$. actually conceived the downtown planning process and brought the participants together in 1969 and 1970." Lloyd Anderson, who served as CH2M-Hill's “chief planner from 1964 until his appointment to the city council in 1969" and a few other key individuals transformed what initially had been proposed as a parking study for downtown into a proposal to "study the future functions of downtown Portland and to explore ways to accommodate them." In the fall of 1970, the "Urban Studies Center of Portland State University prepared an analysis of downtown's regional economic role" and developed "lists of problems and maps defining the blocks with significant opportunities for new development." They also "drafted preliminary goals and explored the implications of 
different overall strategies". Abbott reports that this list of goals "became the raw material for the Citizens' Advisory Committee (CAC) that was finally appointed in May 1971” (Abbott 218-219).

Abbott reports that $\mathrm{CH} 2 \mathrm{M}-\mathrm{Hill}$ 's "overall work program” for the project “promised substantial citizen input." After a "group of community activists and the local AIA chapter" complained to Mayor Terry Shrunk about delays in appointing a citizen committee, City Commissioner Frank Ivancie responded by appointing an "Interim Committee on Public Participation" to recommend "how to organize a full Citizen's Advisory Committee." The Interim Committee recommended that the CAC include "representation from neighborhood groups, downtown users, and civic and professional organizations" and recommended a list of individuals to serve on the CAC. Ivancie "accepted most of the names" and "passed them on to the Mayor for appointment" (Abbott 219).

Abbot asserts that the 'invaluable contribution of the Citizen' Advisory Committee was to rewrite and legitimize the list of fundamental downtown values." The CAC quickly established its independence in the process and "defended its own prerogatives against incursions by the professional staff." The CAC members also "gathered input from more than a thousand Portlanders with town hall forums, neighborhood meetings, and questionnaires printed in the newspapers." The final version of the CAC's goals "became a set of moral principles" that set the overall character and direction of the downtown plan (Abbott 219). 
The City Council approved the Downtown Plan in 1972. The plan included four main parts, including the "statement of the citizens' goals" for the kind of downtown Portlanders wanted, the "planning concept and the policy guidelines," recommendations for project for the first phase, and a list of next steps for the process. Abbott observed that the "plan responded to the overwhelming sentiment from public meetings and questionnaires by trying to create a pedestrian atmosphere with interesting and active streets" (Abbott 220).

Abbott reports that "Neil Goldschmidt took office as mayor four days after the city council approved the Downtown Plan." Abbott writes that the timing presented Goldschmidt “with a politician's dream—a detailed agenda of projects for which there was wide approval and deep support and to which most of the opposition had been neutralized." Abbott maintains that the Downtown Plan meshed with Goldschmidt's "goals for neighborhood revitalization and regional planning as part of an overall growth strategy." It also "appealed to his established supporters among neighborhood associations and civic activists" and allowed Goldschmidt to "develop new ties with Portland businessmen." Abbott writes that "In return, Goldschmidt contributed his extraordinary political sense for picking the best sequence of projects and finding the means for implementation" (Abbott 223).

Neighborhood System Structure and Requirements--City Ordinances (1974-1975) Mayor Neil Goldschmidt took the first step toward implementing the 1972 DPO Task Force report in April 1973 when he set aside $\$ 104,000$ in the city budget to create a "Bureau of Neighborhood Organizations" to help coordinate the implementation of the 
report's recommendations. Mayor Goldschmidt assigned responsibility for overseeing the creation of the neighborhood system to City Commissioner Mildred Schwab. In September 1973, Commissioner Schwab hired Mary Pedersen, former director of the Northwest District Association (NWDA) — the influential neighborhood association in northwest Portland - to facilitate the development of an ordinance to establish the formal neighborhood system. Pedersen went on to serve as the first director of the City's Office of Neighborhood Associations (ONA).

Pedersen describes the development of the 1974 Ordinance in her report on the ONA's first year of operation. She reports that the first draft of the ordinance "was based on the Task Force Report, but was more explicit and added provisions for the proposed bureau" (Pedersen 1974 4). The draft "specifically required citizen participation in all city projects and programs affecting neighborhood livability." A section on district planning organizations described how they would be formed by neighborhoods and "stipulated that any matter affecting the livability of more than one neighborhood would be considered by the DPO" while "matters affecting the livability of just one neighborhood would be considered" by the appropriate neighborhood planning organization (NPO). The draft included a formal process for recognizing neighborhood associations (modeled on a process used in Eugene, Oregon), and established the functions of a city agency that would support the neighborhood system. The draft also included a map of proposed district boundaries. Pedersen took the draft out into the community for discussion and comment at over 30 community meetings (4). 
Pedersen reports that the first draft of the ordinance "raised a storm of questions." Neighborhood association leaders worried that DPOs "could turn out to be 'another layer of bureaucracy' between neighborhood associations and City Council" and would "usurp" neighborhood association "review of issues" and reduce neighborhood association "influence at City hearings." Critics also thought the role of the city bureau that would support the system was too strong. They also criticized the proposed district boundaries because they were based on census tracts, and could constrain the ability of neighborhood associations to establish boundaries that made sense for their communities. Neighborhood leaders wanted neighborhood associations to be the primary focus of the new system, not DPOs. Pedersen revised the draft ordinance based on this feedback (4).

Pedersen reported that the second draft of the ordinance responded to many of the criticisms. The revised draft "began by setting out the process for recognizing neighborhood associations, and spelling out their functions." Recognized neighborhood associations were given more control over the formation of a DPO board and what functions it would take on. ONA's role "changed from one of conducting citizen participation to coordinating the effort" (5). Pedersen reports that a "whole new section on accountability was added" that required neighborhood association to include "clauses in their bylaws to guarantee the rights of both non-participants and participants who expressed points of view dissenting from the majority." The draft also stated clearly that "no one would be denied the right to participate directly in the decision-making process of the Council” (5). Neighborhood associations also were given a voice in DPO "administrative decisions, such as the hiring and firing of staff and the disbursement of 
funds" through a requirement that affected neighborhood associations and the city commissioner in charge of ONA would have to both agree with these decisions (5).

Pedersen reported that the "second draft included so many ideas garnered from the citizen review that it met most objections of most citizens." City Council held a couple public hearings on the proposed ordinance and made additional changes before adopting the final version. At the hearings, City commissioners prohibited overlapping neighborhood association boundaries to ensure clarity about which organization represented an area ("Council modifies neighborhood association law." Oregonian January 25, 1974). City commissioners also insisted that language be added to ensure that "applicants for zone changes would be notified of neighborhood meetings" at which their proposals would be reviewed.

Another significant change was the elimination of the entire section on DPO's. Commissioner Frank Ivancie proposed this change "in a surprise move" at the city council hearing to approve the ordinance. Pedersen reports that the proposed deletion "'struck a chord in the hearts of the other commissioners"”..." for now." Pedersen wrote that because citizen input already had led to a shift in emphasis away from the DPOs and to the neighborhood associations, this change "could be absorbed with only minor changes to finish off the language of the ordinance" (Pedersen 1974 5-6).

The Portland City Council adopted the ordinance on February 7, 1974, and Portland's neighborhood system and the Office of Neighborhood Associations were born (Portland. City Council. Ordinance 137816, Feb. 7, 1974.). 
Calls for Greater Flexibility: During the first year implementation of Portland's new neighborhood system, some neighborhood leaders and groups complained that the requirements for neighborhood associations to achieve formal city recognition were too difficult for volunteer community organizations to meet. They asked the City Council to revise the 1974 ordinance to reduce the number of requirements and include greater flexibility, especially in the provisions that set out the formal "recognition" process for neighborhood associations including guidelines for the organization's bylaws. Some groups suggested modifications while others suggested eliminating this section of the ordinance. They also raised concerns about the ordinance language on "membership, dues, and boundary delineations" (Goetze. Oregonian, November 9, 1975).

Some community members called for ONA to be abolished. They raised concerns that ONA Director Mary Pedersen was creating a self-perpetuating bureaucracy with too much power. Some said they wanted to continue receiving community support from the City through existing programs, including Portland Action Committees Together (PACT) — which had led the fight against the Mt. Hood Freeway in SE Portland and the Portland Development Commission (PDC). The Oregonian reported that federal decisions and funding changes were shifting PDC's focus away from PDC's previous support for community involvement to "physical improvements." The Oregonian also reported and that "During its 1972-73 peak year, PDC's project field services included about two-dozen staff members, pared to 17 for the 1975-76 fiscal year." PDC had provided "Southeast Uplift (SEUL) with $\$ 23,000$ to coordinate its groups and [had] five district offices—one each in North Portland and Southeast and three in Northeast." The 
paper reported that "PACT, with activities directed at low-income groups only, has three staff slots and about $\$ 26,000$ for community organization activities in a half-dozen neighborhoods (Goetze. Oregonian, November 9, 1975)..

At a city budget hearing, City Commissioner Connie McCready, who had questioned ONA's role and structure from the beginning, moved to abolish ONA and proposed an entirely new structure. McCready proposed the creation of "a coordinator of citizen participation with five district offices staffed by a minimum number of city employees in order to encourage volunteer efforts." The Oregonian reported that McCready explained that her proposal sought to provide "equal access and information to as many people as possible, regardless of group affiliation. The Oregonian quotes McCready saying, "We are unfairly expecting neighborhood associations to express the views of all in an area." She opposed city funding for neighborhood associations because she believed "that would call for city regulation." McCready suggested that opposition to the City hiring staff in district offices indicated "a negative assumption about city actions or motives. The Oregonian quotes McCready as saying: "'If this is so bad, then we'd better change the system, not find loopholes in it."' ONA Director Pedersen responded that "staff hired through a neighborhood contract, reviewed by the City Council [would] provide more citizen control over district offices and activities than direct city appointment" (Goetze. Oregonian, November 9, 1975)..

Some City Commissioners argued for modifying instead of rolling back Portland's new formal neighborhood system and advocated for specific changes to address their concerns. City Commissioners Frank Ivancie and Charles Jordan requested 
that the ordinance include "a statement of non-discriminatory membership and elimination of the 'recognition' section" that many neighborhood groups had objected to. Ivancie also advocated for language in the ordinance that would establish policy in neighborhood associations to protect dissenting opinions and provide for a formal grievance process. Jordan proposed substituting "minimum standards" for "requirements" and proposed referring to neighborhood associations as "'eligible' rather than recognized"” (Goetze. Oregonian, November, 14 1975). ${ }^{11}$

The Portland City Council adopted a revised ordinance on November 26, 1975 that provided more flexibility to community members organizing their neighborhood associations and responded to particular concerns raised by City Council members (Portland. City Council. Ordinance 140905, November 26, 1975).

The formal policies and structure established by this 1975 ordinance remained unchanged for 13 years (until the adoption of the first ONA Guidelines in 1987) and significantly shaped the form and activities of Portland's new community and neighborhood involvement system. Many of the elements in the 1975 ordinance continue to exist and guide Portland's community and neighborhood involvement system 40 years later. $^{12}$

\footnotetext{
${ }^{11}$ In another example of the rocky beginnings for ONA, the Oregonian reported that a majority of city council members (not including Neil Goldschmidt and Mildred Schwab) voted on November 13, 1975 to remove ONA's status as a separate city "bureau" and incorporate ONA staff in with the staff members in one of the city commissioners offices. Despite this attempt to demote ONA's status, ONA/ONI would continue to function as a distinct city agency throughout its 40-year history. Although Portland city government, in 2013, continues to include city agencies that are referred to as "offices" and as "bureaus," the Portland City Charter and City Code do not establish any formal distinction between a "bureau" and other "divisions, or other administrative units" of city government (Portland City Charter Sec. 2-301 and Portland City Code Sec. 3.06.020).

${ }^{12}$ The formal structure and aspects of Portland's community and neighborhood involvement system can be found in Portland City Code 3.96-Office of Neighborhood Involvement.
} 
Some elements included in the 1974 Ordinance but dropped from the 1975

Ordinance—such as minimum requirements for neighborhood association bylaws and boundaries and district level bodies - would reappear later in either revisions to the City Code or in the ONA/ONI Standards (first adopted in 1987). The following section identifies major elements established by the 1975 ordinance and discusses some of the primary changes from the 1974 ordinance to the 1975 ordinance.

\section{Summary of Key Elements of 1975 Ordinance}

This section describes the major elements of the 1975 ordinance and the significant changes from the 1974 ordinance (Portland. City Council. Ordinance 140905, November 26, 1975).

Need for ONA and a formal neighborhood system: The City Council formally justified the creation of ONA and the neighborhood association system based on the need to "assist and broaden channels of communication between the people of Portland and City officials on matters of neighborhood livability...." In the 1975 ordinance, the City Council recognized that the "eligibility requirements" for neighborhood associations to receive city assistance included in the 1974 ordinance had been "too rigid and inflexible." The City Council stated that the 1975 ordinance contained "less stringent requirements for organized groups seeking to obtain city assistance in communicating with city government."

Purpose: The 1975 Ordinance stated that its purpose was to "provide standards and procedures whereby organized groups of citizens seeking to communicate with city officials and city bureaus on matters concerning neighborhood livability may obtain 
assistance from staff in so communicating and to provide certain minimum standards for said organizations in order to insure that the broadest possible means for citizens' organizations to communicate with city government may exist."

Both the 1974 and 1975 Ordinances sought to ensure that neighborhood associations would not prevent individuals or groups from making their views known in City decision making processes. Both ordinances included the statement: "Nothing in this chapter shall limit the right of any person or group to participate directly in the decision making process of the city council or any city agency."

Minimum Standards: The 1975 Ordinance defined "neighborhood association" as "any group of people organized for the purpose of considering and acting upon any of a broad range of issues affecting the livability of their neighborhood" (3.96.020). To receive city support, a neighborhood association was required to: not limit membership “ by race, creed, color, sex, national origin or income;" not charge membership dues; to have and follow a written procedure "by which dissenting views on any issue considered by the neighborhood association" would be "recorded and transmitted" along with any recommendations to the City; to have and follow a written grievance procedure through which "persons may request the association to reconsider a decision which adversely affects the person or causes some grievance;" and to keep a current copy of the neighborhood association's bylaws on file with ONA (3.96.020 and 3.96.030).

Any neighborhood association that met the minimum standards could request assistance from ONA and would be eligible to carry out all the functions of a neighborhood association listed in the ordinance. ONA also would include the 
neighborhood association and its contact information on the formal list of neighborhood associations which was used by city agencies for notice and community outreach purposes (3.96.080).

Accountability of NAs: The 1975 Ordinance attempted to ensure that neighborhood associations would be open to and reflect a diversity of opinions in the community by requiring neighborhood associations to "follow a written procedure by which dissenting views on any issue considered by the neighborhood association shall be recorded and transmitted along with any recommendations made by the association to the city." The ordinance attempted to ensure some transparency and credibility for neighborhood association decision making process by requiring that neighborhood associations include with their formal recommendations to the City, "a record of meetings held including a record of attendance and results of any vote." The ordinance also required neighborhood associations to provide notice of their elections and neighborhood planning efforts and to follow state open meetings and public records laws.

Functions of NAs: Neighborhood associations that met the minimum standards in the ordinance would be eligible to": Recommend actions, policies, or a comprehensive plan for the neighborhood to the "city and to any city agency on any matter affecting the livability of the neighborhood...." The ordinance reinforced the broad scope of this function by affirming that neighborhood associations could make recommendations on topic areas that included, but were not limited to, "land use, zoning, housing, community facilities, human resources, social and recreational programs, traffic and transportation, environmental quality, open space and parks." 
The ordinance also gave eligible neighborhood associations a formal role "in determining priority needs of the neighborhoods," and in reviewing "items for inclusion in the city budget" making "recommendations relating to budget items for neighborhood improvement." (These provisions provided the basis for ONA's development of the Neighborhood Needs process and the bureau Budget Advisory Committee (BAC) program.)

The ordinance also gave eligible neighborhood associations the opportunity to enter into contracts with city bureaus to manage projects in the community (3.96.040).

Responsibilities of NAs: The ordinance sought to ensure that neighborhood associations would be open and transparent to their community members, would give community members the opportunity to get involved, and would consider, record, and report dissenting views from within their communities to the City.

The ordinance required neighborhood associations to notify affected individuals and groups of neighborhood associations elections and of any neighborhood association "planning efforts as they are about to begin." The ordinance also required neighborhood association meetings and records to be open to the public and required them to comply with state open meetings and public records laws.

The ordinance required neighborhood associations to work collaboratively with city agencies when appropriate. It required neighborhood associations to work with affected city agencies when neighborhood associations engaged in planning activities that affected the livability of their neighborhood, and to cooperate with city agencies "in 
seeking outside sources of funding for neighborhood projects affecting neighborhood livability" (3.96.050).

Responsibilities of City Agencies: The ordinance similarly required City agencies to provide notice to neighborhood associations and to work collaborative with these community organizations. The ordinance required City agencies to notify a neighborhood association of and involve it in all planning efforts that would affect the neighborhood.

The ordinance also established an "early warning" provision that required city agencies to notify affected neighborhood associations when the city agency planned to make a policy decision that would affect the neighborhood's livability. The ordinance required that the city agency provide notice "30 days prior" to the decision, unless waiting 30 days would injure "public health or safety " or cause a "significant financial loss to the City or to the public." In these cases, the ordinance required city agencies to provide "as much notice as possible."

The ordinance also required the City and city agencies to hold a public hearing in a timely fashion when a neighborhood association submitted a neighborhood-associationdeveloped comprehensive plan for its neighborhood. The ordinance required the City to send any proposed amendments to neighborhood comprehensive plans to the "affected neighborhood association for consideration and for a response before final action is taken." 
The ordinance also required City agencies to cooperate with neighborhood associations "in seeking outside sources of funding for neighborhood projects" (3.96.060).

ONA Functions: The ordinance established ONA and authorized the hiring of a director and other employees approved by the City Council. ${ }^{13}$ The ordinance directed ONA to "assist Neighborhood Associations, or individuals" in a number of ways, when requested, "to facilitate citizen participation and improve communications." ONA's specific functions were established to include:

- Event notification: "Notify interested persons of meetings, hearings, elections and other events;"

- Information clearinghouse: "Provide for the sharing of information and maintain a list of reports, studies, data sources and other available information;"

- Referral services: "Provide referral services to individuals, neighborhood associations, city agencies and other public agencies;"

- $\quad$ Neighborhood contact list: "Keep an up-to-date list of neighborhood associations and their principal officers;"

- $\quad$ Project coordination assistance: "Assist neighborhood volunteers in coordinating projects on behalf of neighborhood livability;"

\footnotetext{
${ }^{13}$ At the time the City Council approved the 1975 Ordinance, the Oregonian reported that ONA full-time staffing included the director (Mary Pedersen) and a secretary. ONA also employed two other individuals half time. Two temporary positions were funded through "federal public employment funds" (Goetze. Oregonian, 6 November 1975).
} 
- $\quad$ Promotion of involvement with neighborhood associations: "Encourage individuals to work with existing neighborhood associations where possible;

- $\quad$ Printing and mailing: "Assist in reproducing and mailing newsletters and other printed matter when written material is supplied by a neighborhood association;"

- Liaison: "Act as a liaison while a neighborhood association and city agencies work out processes for citizen involvement;"

- $\quad$ Referral to city agencies: "Assist in contacts with city agencies on behalf of neighborhood associations or other interested individuals;" and

- Education regarding citizen participation: “Assist in educational efforts relating to citizen participation in city government" (Portland. City Council. Ordinance 140905, November 26, 1975 3.96.070).

The ordinance gave the Commissioner-in-charge of ONA responsibility for the administrative management of ONA.

Although the 1975 ordinance did not restore a formal district level tier to the neighborhood system, the ordinance did authorize ONA to disburse funds to "any district office which may be established with city funding" but required that ONA only engage in "the hiring and firing of staff in the district offices" and similar administrative matters related to any district office "only after consultation between the neighborhood associations affected by these decisions and with the approval of the commissioner in charge (3.96.070). 
Enforcement of Minimum Standards for NAs: The ordinance stated that, if a neighborhood association violated the minimum standards a person in that neighborhood or the commissioner in charge of ONA could ask ONA to "suspend any assistance to the Neighborhood Association." ONA was responsible for "initiating a mediation process" to resolve the problem that was to continue for 30 days. If at the end of that time "satisfactory resolution of the problem" was not achieved, the ordinance gave the commissioner in charge of ONA the authority to make a final decision in the matter (3.96.080).

ONA Accountability: The ordinance stated that ONA recommendations and actions were subject to the approval of the commissioner in charge of ONA. Any individual directly affected by an ONA recommendation or action was allowed to appeal to the city council by filing a written notice of their appeal "with the city auditor within 14 days after receiving written notification of the Commissioner's decision" (3.96.090). The 1975 Ordinance dropped some items from the 1974 Ordinance that community members had found difficult to comply with. Some of these requirements, although not included in the 1975 ordinance, over time, would be found to be important and would reappear in future versions of the Portland City Code and formal guidelines and standards for the neighborhood system. This section describes some of the primary changes from the 1974 to the 1975 Ordinances.

Membership: Both the 1974 and 1975 Ordinances envisioned that membership in neighborhood associations would be open and inclusive. The 1974 Ordinance declared that the membership neighborhood associations must be "open to residents, property 
owners, business licenses and representatives of nonprofit organizations located within the neighborhood boundaries." The 1975 Ordinance replaced this language and instead prohibited neighborhood associations from limiting membership based on "race, creed, color, sex, national origin or income." (Later revisions to the City Code and formal guidelines for neighborhood associations would define who should be eligible to be a member of a neighborhood association and would require neighborhood associations not to discriminate in any of their actions or activities.) Both the 1974 and 1975 Ordinances prohibited neighborhood associations from charging membership dues.

Boundaries: The 1974 Ordinance included a number of provisions related to neighborhood association boundaries. Boundaries were to be set by each neighborhood association (not by the City) and were to "reflect the common identify or social communication of the people in the area." The ordinance prohibited overlapping boundaries and required neighborhood associations to seek help from an arbiter and the commissioner in charge of ONA to resolve boundary disputes. The 1975 Ordinance dropped any mentioned of neighborhood association boundaries. Requirements related to neighborhood boundaries would reappear in City Code and formal guidelines for neighborhood associations in the future.

Community support: The 1974 Ordinance required a neighborhood association seeking recognition from the City to show that it had developed "goals, bylaws and procedures for notification," circulated these "throughout the neighborhood" and that people eligible for membership in the neighborhood association found them acceptable. The 1975 Ordinance dropped this specific requirement, but continued to require that each 
neighborhood association have formal bylaws on file with ONA, and to provide notice to the community of neighborhood association elections, meetings, and planning efforts. The 1975 Ordinance no longer required neighborhood associations to reach out to their community and get support for their initial goals and governance structure and processes.

Recognition letter: The 1974 Ordinance established a formal process by which the commissioner-in-charge of ONA would send a neighborhood association a formal letter when the City recognized the organization. The 1975 Ordinance dropped this language and instead stated that neighborhood associations that met the minimum requirements could ask for city assistance and could carry out the functions listed in the ordinance.

NA accountability: The 1974 Ordinance stated that "Neighborhood associations shall be accountable to their people of the neighborhood they represent" and are "responsible for seeking the views of the people affected by proposed policies or actions before adopting any recommendations." The City Council dropped this language from the 1975 Ordinance, but retained requirements that neighborhood associations notify the community of its meetings, elections, and actions, record and transmit dissenting views and have a written policy by which people could file grievances with the neighborhood association. Tension would continue to exist throughout the history of Portland's neighborhood system between expectations (by city leaders and staff and some community members) that neighborhood associations should reach out to and solicit and reflect the views of their community members and the limited capacity and/or willingness of neighborhood associations leaders to do so. 
Enforcement: The 1974 Ordinance allowed people or entities eligible for membership in the neighborhood association, or other neighborhood associations to recommend that the City suspend recognition of a neighbor association that "consistently violates its own bylaws" "until new officers can be elected or until the problem is otherwise resolved.” The 1975 Ordinance redirected enforcement action to from violations of a neighborhood association's bylaws to violations of the "minimum standards" and only allowed "a person from that neighborhood or the Commission-inCharge" to request suspension (3.96.080). The 1975 Ordinance added a requirement that ONA immediately initiate a mediation process to try to resolve the problem. (In future years, a formal grievance process would evolve that would include opportunities to file a grievance and appeal grievance decisions at the neighborhood, district, and ONA levels. The grievance process would become the primary trigger for ONA/ONI to consider enforcement action against a neighborhood association or district coalition.)

Future City Code revisions and formal guidelines and standards adopted by ONA/ONI (starting in 1987) would build on and expand the requirements and guidance for the neighborhood system. These future policies would include definitions of who is eligible to be a member of a neighborhood association and reinstate requirements related to neighborhood boundaries. While establishment of a formal district-level organizational tier was dropped from the 1974 ordinance and not included in the 1975 ordinance, ONA moved ahead to contract with community controlled organizations as one of its major mechanisms to deliver support services to neighborhood associations. ${ }^{14}$

\footnotetext{
${ }^{14}$ The City Council would approve the establishment of a formal district-level tier of organizations in the neighborhood system in the future.
} 
The 1975 Ordinance also softened or dropped some of the 1974 Ordinance's language and requirements that neighborhood associations reach out to and involve and be accountable to their community members. However, the question of how representative neighborhood associations should be or could be has continued to be an issue throughout the history of Portland's community and neighborhood involvement system.

The 1974 and 1975 ordinances set the initial framework and culture for Portland's community and neighborhood involvement system. This early framework incorporated many important elements needed to encourage greater participatory democracy.

The system preserved the independence of neighborhood associations from city government. City government would have no control over what neighborhood associations chose to work on, the positions they took, and decisions they made. Neighborhood associations were free to challenge and oppose city proposals and decisions if they chose to. The ordinances empowered neighborhood associations to work with the city on any issues they determined affected the "livability" of their community.

The ordinances also codified a formal exchange agreement between city government and the community. Neighborhood associations agreed to meet minimum requirements for openness, non-discrimination, and protection of the rights of community members. In exchange, city government agreed to recognize and treat them as formal partners in decision making. City government agreed to open its doors to neighborhood associations and to notify them of and invite them to participate in planning and decision making processes that could affect their neighborhood. City government also committed 
to reviewing and responding to neighborhood-association-initiated plans and project proposals. City government went even further by offering active support to help build the capacity of neighborhood associations to reach out to and involve their community members and to interact with city government in constructive and meaningful ways.

Given the history of both conflict and collaboration between city agencies and neighborhood organizations in the late 1960s and early 1970s, the ordinances sought to encourage more cooperative interactions and relationships between neighborhood and city agencies by requiring them to let each other know when they are engaging in planning or projects relevant to the other and cooperating on efforts to raise additional resources from outside sources.

The system also created a city agency—ONA—dedicated to supporting — not controlling — the activities of neighborhood associations. ONA's focus was on community empowerment, not on serving the community involvement needs of particular city elected officials or city agencies. ONA's role was to provide a wide range of support services intended to help community members get involved and to empower them to make a difference in their communities. ONA served as a bridge to help city government and community members work together more effectively—not to do community involvement for city agencies.

The ordinances recognized the potential for a group of people with one point of view to dominate a neighborhood association, even though other people in the neighborhood may feel differently. The ordinances made a special effort to protect dissenting viewpoints and make sure they are heard in decision making processes. The 
ordinances also attempt to ensure that community members would be notified of what the neighborhood association was doing in their name and of opportunities to participate in discussions and elections.

The ordinances sought to ensure that city agencies would provide meaningful opportunities for community members to get involved and have an impact on decisions made that affected their communities. Some of the key elements included notification and early warning (30-day advance notice) requirements intended to let neighborhood associations know about upcoming city decisions and actions, and requirements that city agencies consider community-driven recommendations and proposals and respond to them in a timely fashion.

The ordinances also sought to ensure community involvement in some very important decision streams in city government, including the identification of neighborhood needs in capital project planning and program priority setting, development of the city budget, and the development of neighborhood and district comprehensive plans. To ensure that community input would be respected, the ordinances required the city to follow any comprehensive plans developed with the community and involving the community in any proposed changes to the plans.

District level bodies_a major element of the 1971 Planning Commission proposal, the 1972 DPO report, and the original draft of the 1974 ordinance-were not included as a formal tier in this initial structure, partly in deference to neighborhood association concerns that district bodies would dilute the neighborhood association voice and influence in decision making. However, some people continued to believe that 
district bodies could play an important role in supporting community organizing and involvement on the front lines in the neighborhoods and could serve as valuable forums for community members to convene and discuss issues that transcended neighborhood boundaries. Portland had experience with district level support offices through the community offices set up under the Model Cities program and PDC's community support activities (for example, the PDC-supported Southeast Uplift office in inner southeast Portland). While the ordinances did not establish a formal district-level tier, the 1975 ordinance did authorize ONA to create, fund, and staff district offices and required ONA to consult with the neighborhood associations in a district on any administrative (particularly staffing) decisions related to their district office. Mary Pedersen, ONA's first director, moved quickly to begin to fund community-governed district offices to deliver community involvement support services in different parts of Portland. The City of Portland has continued to provide the bulk of its support for neighborhood associations through city-funded community-governed district coalition offices since that time.

While, the 1974 and 1975 ordinances set the basic structure and direction for Portland's new community and neighborhood involvement system, ONA's implementation of these ordinances helped bring the system to life. The next section reviews the contents of two reports that describe the system's early activities, programs, successes, and challenges.

\section{Early ONA Reports--1974 and 1979}

Mary Pedersen, ONA's first director, provides valuable insights into the initial years of Portland's community and neighborhood involvement system in two reports she 
prepared—one which she completed in 1974 after the first year operation of the program and the other in 1979, as she was leaving as ONA director and in anticipation of a new mayor taking office.

Pedersen reported that significant neighborhood organizing by community members in the 1960s and early 1970s in different areas of Portland and the distrust that existed between neighborhood activists and city officials during that time significantly shaped the initial focus and structure of the system. Pedersen reported that neighborhood activists and community members were concerned that the city officials and staff would choose and control staff assigned to support neighborhood associations and possibly exploit community volunteers for the City's own objectives. Community members questioned whether citizen participation would be "token or manipulative." City officials questioned neighborhood activists' intentions. "Were neighborhoods really going to be political?" "Was the City funding its own revolution?" Would neighborhoods use funds "efficiently and accountably?" "Would neighborhoods try to take over City policy making?" (Pedersen 1979 11).

The City Council members ultimately identified the overall objective of the system as improving "communications among citizens and between citizens and City officials on matters affecting neighborhood livability." They also set objectives for ONA that include establishing "a circle of neighborhood offices around the city," assisting "neighborhood groups to organize where they do not already exist" and "providing technical assistance to them," and coordinating "the new budget advisory committees" (Pedersen 1979 11). 
Pedersen reported that during the first five years of the program Portland "acquired a national reputation for having a successful program for citizen participation." She notes, however, that the limitations of the system "are more easily visible here" (Pedersen 1979 3).

From its creation, ONA's focus was on empowering the community and community organizations versus directing or controlling them. Strong advocacy by neighborhood activists shifted ONA's role from the latter to the former during the development of the 1974 Ordinance. Pedersen says it "changed from one of conducting citizen participation to coordinating the effort" (Pedersen 1974 5).

Program Elements and Philosophy: In her 1979 report, Pedersen identified the major activities of Portland's broader community involvement program as:

City government consultation with neighborhood associations: The City of Portland consults neighborhood associations "on policy matters or planning which will affect the livability of their area" (Pedersen 1979 3).

City Budget Process: ONA recruits community members to serve on "citizen budget advisory committees" (BACs) and provide input that helps city agencies develop their budget proposals to the city council. ONA staff help coordinate the work of the BACs. City Council appoints the BAC members (Pedersen 1979 4).

Neighborhood Needs Process: ONA coordinates a "neighborhood needs process" that gives neighborhood associations the opportunity to forward requests for projects and services to city agencies. 
Neighborhood outreach to the community: Neighborhood associations are reaching out to communicate and consult with their community members "on important issues and projects."

Neighborhood self-help projects: Some neighborhood associations have initiated innovative "self-help projects," including creation of a "credit union, several tool banks, and a nonprofit housing corporation" (Pedersen 1979 4).

Pedersen stressed that the variety of approaches included in Portland's diversified involvement system gave "opportunities for participation to more citizens." The combination of "neighborhood based and citywide efforts was believed to be more stable and more complete." Pedersen notes the strength of having standing neighborhood associations in place and "organized and ready to respond to needs as they arise" versus community members having to create a new organization each time an issue arises. Pedersen writes that the citizen budget advisory committees were important because the BAC members became "well informed about bureau activities and goals" and, thus, were able to provide meaningful input as they review proposed agency budgets. She stressed that neighborhood associations and budget committees need "lead time" and "coordination" and support. She also noted that "volunteers are more effective when they have at least a minimum of staff support" and when they have a physical "home base", such as "an office supplied with phones, maps, reference materials, files and conference space...." (i.e., a district office) (Pedersen 1979 4).

Pedersen reports that a shared governance philosophy guided Portland's community and neighborhood involvement system at its creation. This philosophy 
maintained that "both volunteer citizens and City staff have much to contribute to the process of making neighborhoods more livable." City staff bring their "technical capacity" and ability to access resources, while their key limitation often is that they focus only on one policy area. Neighborhood volunteers bring "their familiarity with the overall neighborhood systems as they actually work, their contacts, and their willingness to help." City council members bring their "overall citywide view" that crosses the needs of any particular neighborhood or group of neighborhoods, as well as their ability to make "important decisions about funding and goals". Pedersen said ONA staff saw a need to help citizens and city staff develop a spirit of partnership by putting them in "contact with each other, developing communications" and "mediating where necessary" (Pedersen 1979 5).

ONA program services and activities: The central ONA office and its five to six staff people provided a number of services that supported the formation and effective operation of neighborhood associations. Pedersen reported that the number of neighborhood associations formally recognized by the City doubled between 1974 and 1979, from 30 to 60. Pedersen wrote that, as ONA Director, she consulted with neighborhood groups on organizational development issues and shared information from other neighborhood associations and their rights under the new system. Each neighborhood group then established "its own structure and procedures for notification of meeting and other events" (Pedersen 1974 6).

In addition to ONA's primary activities, described in more detail below, ONA also maintained a list of neighborhood association contact people to assist city agency 
community involvement efforts and provided information and referral service to “agencies, neighborhood associations and other nonpartisan groups...” (Pedersen 1974 6).

ONA' primary activities included supporting a wide array of communications and notification efforts, coordinating the City's new budget advisory committee program and Neighborhood Needs program, and negotiating and administering contract agreements with district offices.

Communication: Communication between community members, and between community members and city government, was a primary purpose for the creation of Portland's neighborhood and community involvement system. Pedersen reported that, during its first five years, ONA worked to improve ways for "citizens to consult with each other on their concerns; express these concerns to the City;" and "for City bureaus to communicate to and work with citizen volunteers" (Pedersen 1979 13). Examples included:

Citywide newsletter: ONA helped community members find out about involvement opportunities by producing a monthly newsletter, "Neighborhood Intercomm," which included a "calendar of major public hearings" and brief descriptions of "current programs at the city" (Pedersen 1974 6).

Communication within the community: ONA also assisted neighborhood groups in communicating with their residents and community members. Neighborhood associations used a variety of methods to get the word out to their community members and to learn about their opinions, including flyers or newsletters distributed door to door, mailing newsletters to interested people, door-to-door surveys hand delivered or mailed, 
regular neighborhood association meetings, and special planning conferences, meetings and workshops to encourage information sharing and dialogue among community members (Pedersen 1979 13-14). ONA supported these efforts primarily by helping neighborhood associations print and mail newsletters and fliers. ONA reimbursed neighborhood associations "for hand distribution at the same rate as a non-profit mailing" (Pedersen 1979 13).

Neighborhood communications did not necessarily reach all the residents in a neighborhood. Pedersen reported that, in 1974, only a few neighborhood associations had "prepared mailing lists including 18-20\% of neighborhood households and businesses." “Most neighborhood associations' mailing lists, however, include several hundred addresses."

Local news media also helped get the word out into the community. In 1978, the major daily Portland newspaper, the Oregonian, "included one page of neighborhood news three days a week." Local newspapers also have printed a "neighborhood meeting calendar" "for the past three years." "Special events have been covered by the television stations" (Pedersen 1979 18).

Communication from the community to city government: Pedersen reported that Portland's city government continued to provide traditional opportunities for public comment—public hearings, individual or group testimony, and letters to city council. Community members could submit petitions to create a local improvement district (LID). Some city agencies used postcard surveys to assess public opinion. In 1978 and 1979, the City funded studies of citizen opinions of City bureau performances. The 1978 study 
included "an exercise where citizens could practice budget cuts according to their own values. ${ }^{15}$ City agencies used different combinations of mailings and town hall meetings or hearings to engage with the community on specific planning and other governance issues.

Notification of city government actions: Notification or "early warning" by the city government to neighborhood groups was intended as an important tool to alert these groups to proposed actions that might affect their communities and to give community members a chance to get involved and voice their opinions and preferences.

The 1975 ordinance required city agencies to notify "all neighborhood associations affected by planning efforts that are about to begin." The ordinance also required city agencies to give neighborhood associations 30-days notice of "pending policy decisions affecting neighborhood livability.” The ordinance waived the 30-day notice requirement in cases in which 30 day notice might "injure the public health or safety, or would result in a significant financial loss to the city or to the public," but required city agencies to provide "as much notice as possible..." (Portland. City Council. Ordinance 140905, November 26, 1975 3.96.060). In response, the Portland Planning Commission took formal action to revise the procedures by which city agencies notified neighborhood associations of zoning matters to ensure "longer notice time" (Pedersen $19746)$.

Pedersen identified some important strengths and weaknesses in the newlycreated formal notification process. She wrote that the City sent "legal notices of zone

\footnotetext{
${ }^{15}$ The Portland City Auditor continues to commission an annual survey to assess community member opinions on city government performance.
} 
change requests and conditional use permits" to property "owners within 400 feet of the property in question, "two weeks before hearings are held." Property owners also received "notices of variance requests for minor changes in regulations"- such as requests for changes to fence setback requirements—if they live "within 150 feet one week before the hearings." Pedersen remarked that non-owner residents (e.g., renters) did not necessarily receive these notices, which indicated that a significant segment of the community was not included in this outreach. Neighborhood associations and their district offices also received these notices, and Pedersen reported that "[B]usinesses and other civic groups, and sometimes renters and the general public hear of these proposals" through their neighborhood associations and district offices (Pedersen 1979 16).

Pedersen noted that neighborhood groups continued to complain that notice periods were too short and did not give adequate time to respond. Even thirty-days notice was not enough for neighborhood associations that met only once a month. Pedersen wrote that this notice process periodically is "criticized because neighborhood associations often do not have time to call a meeting to review the proposals." She noted that hearing officers regularly grant "a one-month delay if a neighborhood board or office can justify the need for more time."

Pedersen reported that the Bureau of Planning, at one time, agreed to send neighborhood offices notices of "pre-application meetings" on major proposals. Notice of this early stage of the development process, sometimes gave "the applicant and a neighborhood group" time "to begin rational discussions" (Pedersen 1979 17). 
Pedersen reports that neighborhood associations had asked that "the neighborhood office and two officers of the neighborhood group be notified...to provide a back-up system, in case of leadership turnover or vacations." She writes that the "Auditor's Office, which mails legal notices, has been reluctant" to make this change. Pedersen notes that additional notices would be a "good investment" because "lack of notice can lead to delays in hearings or startup of projects" (Pedersen 1979 17). ${ }^{16}$

Collaboration between City agencies and neighborhood groups: Pedersen reported that some city agencies worked with neighborhood groups to get the word out into the community about agencies programs and opportunities. City agencies sometimes paid the printing and distribution costs for neighborhood newsletters that included city agency outreach information. Pedersen wrote that neighborhood associations could help city agencies save money and time and increase the effectiveness of their outreach by arranging meetings with citizens and often coordinating the work of volunteers. She reported that some city/neighborhood association projects included: neighborhood cleanups, mapping current land uses in a neighborhood, signing up neighborhoods to take care of street trees, fund raising to purchase park land and pay for park facilities and improvements, neighborhood-hosted crime prevention meetings (Pedersen 1979 18).

City Agency Budget Advisory Committees: Mayor Goldschmidt began to require city agencies to involve budget advisory committees (BACs) as soon as he took office in 1973. Witt writes that the Budget Advisory Committee (BAC) program, established "in

\footnotetext{
${ }^{16}$ Neighborhood leaders and community members voice many of the same criticisms of Portland's formal notification system in 2013. A number of studies have called on the city to expand its notification strategy to include more affected and interested people to give people more time to understand and respond to the notices.
} 
1975 with initial support and backing from Goldschmidt," "was intended to offer citizens direct and unprecedented access to what had historically been the exclusive province of City Council members. This feature of Portland's citizen involvement program served to complete the City's pledge to more fully incorporate direct citizen participation in the City's agenda making process." ONA was charged with supporting the BAC program (Witt 2000, Appendix B 378).

Witt describes the BAC program as follows:

The BACs were to consist of citizens drawn from a pool of applicants screened by the ONA and reviewed for final selection by City Commissioners following consultation with their operating bureaus. The BAC makeup was to include minority representation, a diversity of viewpoints, incorporate geographic diversity among its members as well as special occupational knowledge. City employees could not serve as members on any BAC, and care was taken to insure BACs were not captured by special interest groups. Each BAC received staffing support from an "in-bureau liaison" made available to answer questions and provide background information as well as to provide facilitation in BAC deliberations. Keeping track of correspondence, minute taking and photocopying were also to be carried out by the bureau liaison (Witt 2000, Appendix B 378-379).

In 1973, Mayor Goldschmidt "appointed citizens to review the budgets of four City bureaus" under his administrative control. During the 1974-75 budget process, Goldschmidt required every City department and "every major bureau" to create a budget advisory committee with community member participation. ONA staff were "charged with coordinating the appointments, orientation and activities of the Budget Advisory Committees" (Portland. Office of Neighborhood Associations. BAC information sheet [no date-appears to be from the mid 1980s]). 
In 1979, Pedersen reported that the BACs “...have experienced some difficulties, but intelligent suggestions have been made by committee members, saving tax dollars or getting more returns for each dollar spent" (Pedersen 1979 12). "In 1980, the City Council adopted a resolution formalizing the Citizens' Budget Advisory Committee process and a set of guidelines" that defined and clarified the BACs functions and responsibilities (Portland. Office of Neighborhood Associations. BAC information sheet [no date—appears to be from the mid 1980s]).

Neighborhood Needs: Mayor Goldschmidt also initiated a pilot program shortly after he took office in 1973 by which neighborhood associations could identify their needs for capital improvement and city agencies were required to consider whether they could meet the requests. One of ONA's early objectives was to assist this process, and subsequently ONA staff took over coordination of the program. In 1975, ONA expanded the process to include any type of need, not just capital improvement needs (Pedersen 1979 12).

By 1979, Pedersen reported that "The need report process has stabilized with approximately $3 / 4$ of the neighborhoods reporting needs each year. The percent of Need Reports lost in the process has been reduced from 16\% in 1975 to 2\% in 1979" (Pedersen 1979 12-13).

Neighborhood Field Offices: Neighborhood activists had rejected the idea of cityrun and staffed district offices proposed in 1971 by the Planning Commission and in 1972 by the DPO Task Force. The City Council did not establish a formal district-level tier of organizations in the 1974 or 1975 ordinances, but did authorize ONA to fund district 
offices to help it carry out its mission and provide support services in the community to neighborhood associations.

After the City Council created ONA in 1974, Pedersen reported that the "City Council approved a plan to try out field offices in three areas of the city, where staff resources from federal or other funds" - such as the federally-funded Model Cities program office in northeast Portland and the similar PDC-funded Southeast Uplift office in southeast Portland—-were not available. Pedersen moved forward to establish district offices that would be controlled by neighborhood associations but funded by the City. Pedersen reported that she used a contract-for-services model for these offices that followed a similar model used by Multnomah County to contract with community nonprofits to provide human services to community members. ONA began with two contracts with neighborhood associations for district offices in North Portland and in West-Northwest Portland (Pedersen 1979 12).

During 1974, Pedersen worked with neighborhood association representatives to set up these decentralized offices. She reported that "at least two of the three offices will be established by a contract for services, where the City will pay an agreed sum to the neighborhood associations in an area in return for services in citizen participation". Neighborhood representatives were to hire a "staff person and part-time secretary to perform the functions stipulated in the contract...." The Commissioner in charge of ONA was required to approve the hires (Pedersen 1974 7).

Pedersen (1974) notes that government contracting out of service delivery to nonprofit organizations in the community was not new. What was new was "contracting with 
incorporated neighborhood groups to provide services in citizen participation." The city let neighborhood association representatives take the lead in setting up the district office and hiring staff, with "mutual agreement" from the ONA commissioner in charge (8).

ONA negotiated the contracts with representatives of the neighborhood associations in a district and then submitted the contracts to the City Council for approval (Pedersen 1979 12). Either the neighborhood district review board or ONA could terminate the contract if they thought the conditions of the contract were not being met. The annual review built into the contract provided a natural time for ONA or the district review board to renegotiate and change the terms of the agreement if needed (Pedersen 1974 9). The guidelines established in the "contracts became the foundation for developing a partnership" between ONA and the district review boards and district offices.

“[N]eighborhood review boards, composed of representatives from each neighborhood served in area," hired the district office staff. The Commissioner in Charge of ONA retained the authority to review and approve or disapprove these hiring decisions. Pedersen reported in 1979 that neither of ONA's commissioners in charge had vetoed any of the "neighborhood staff selections" (Pedersen 1979 12).

Under the contract model, district staff did not need to be civil service employees. Pedersen suggested that the responsiveness of district employees to the needs of the neighborhoods was likely to be greater than if they had been city employees, because neighborhood representatives had an equal say in hiring and firing decisions (Pedersen $19749)$. 
By 1979, Pedersen reported that five neighborhood district offices were operating. ONA had contracts with four district offices in North, West/Northwest, Southeast (the former PDC-run Southeast Uplift office) and Southwest Portland. At the neighborhood district office in Northeast Portland, the Model Cities Program employees were "still covered by their civil service status, as requested by the neighborhoods" (Pedersen 1979 12).

Pedersen noted that the formal relationship between the city and neighborhood associations regarding the district offices expressed "the understanding that the neighborhood associations and the City are coequal partners in this effort" (Pedersen 1974 8). If either party refused to cooperate, "the experiment would fail." She noted that "the two parties need each other's assistance" and, therefore, "must share the responsibility and the authority" (8-9). This partnership was illustrated by the need for neighborhood and the city to agree on hiring and budget matters to be able to act (9).

The district offices represented an early priority for pushing resources out into the community rather than concentrating staff and activity in the central ONA office downtown. The focus of the district offices was intended to be on outreach and community capacity building, not political activity. The ONA contract did not allow district offices to use city funds to support or oppose candidates or ballot measures (Pedersen 1974 7).

ONA staff left advocacy to community members, rather than advocating for the community on issues before city agencies and decision makers. Neighborhood activists had made it clear that they did "not want to have to convince [ONA] staff of their point of 
view" nor did they wish to leave representation of their views to ONA staff. They wanted to speak directly to city leaders and staff without ONA or any district bodies acting as filters or gatekeepers (Pedersen 1974 6).

Pedersen emphasized that neighborhood associations were different than other types of community groups that often focused on a specific policy area or on delivering certain services to the community. Neighborhood associations are general purpose organizations committed to serving the interests of the people in a particular geographic area and can respond to the full spectrum of the community's experience. Each neighborhood association can define "neighborhood livability" in its own way according to the needs and priorities of its community members. The "neighborhood is the one place where an integrated pattern of living and working occurs" (Pedersen 1974 11).

System Strengths/Successes: Pedersen reported that the City's new citizen involvement program was leading more people to get involved and have a voice in civic life in Portland. Neighborhood associations were involved in many different projects and activities that increased the livability of their neighborhoods. The BAC program, for the first time in Portland's history, was giving community members a voice in shaping the city's budget priorities. The Neighborhood Needs process was giving community members a way to get city agencies to consider projects that were high priorities in the neighborhoods. The city was sending city resources out to support community-directed neighborhood district offices that provided a wide range of communications and other organizing and organizational support to neighborhood organizations. Neighborhood associations also were experiencing higher levels of involvement in land use planning, 
new planning efforts were beginning to "open a long-term role for neighborhood participation (Pedersen 1974 11).

Pedersen wrote that "Neighborhood associations are beginning to work out more constructive roles for themselves." She noted that protest may still be needed in some cases, but that "protest alone cannot tackle all the problem facing a neighborhood." She also found that many problems are addressed better at the community level, and that citizen action often can respond to community needs more swiftly than city government. Pedersen cited a wide range of examples of programs neighborhood associations had started including: recycling centers, tool-lending cooperatives, community gardens, a community tree-planting program, youth service centers, new parks and mini-parks, and housing rehabilitation (Pedersen 1974 11-12).

Challenges: Pedersen also noted several challenges:

Capital improvement planning: Pedersen said the city's commitment to community involvement would be tested as the city moved forward with its capital improvement planning and further developed the new Neighborhood Needs process.

New state land use planning law: Oregon's 1973 state land use planning law required local jurisdictions to develop comprehensive plans and comply with a number of state planning goals established by the state's Land Conservation and Development Commission (LCDC). Oregon State Planning "Goal 1: Citizen Involvement" required local jurisdictions to ensure that community members had the opportunity to "be involved in all phases of the planning process" and to "adopt and publicize a program for citizen involvement that clearly defines the procedures by which the general public will be 
involved in the on-going land-use planning process" (Oregon. Statewide Planning Goals and Guidelines, Goal 1: Citizen Involvement, 1974). Portland's neighborhood associations provided a ready-made structure to involve community members in Portland's mandated comprehensive planning process.

Representativeness: An ongoing critique of volunteer neighborhood associations is the degree to which they truly "represent" the priorities and views of their community members. Pedersen noted that "Neighborhood organizations are often challenged by questioning how representative they are." She argues that "Neighborhood associations can represent citizen opinion, but the degree of representativeness depends on the quality and depth of participation" [emphasis added]. Pedersen suggested that the requirement that neighborhood associations present both majority and dissenting views would help encourage more balance, She also noted that a "wider range of viewpoints will reach City Council" if majority and dissenting views and "if neighborhood associations receive staff aid necessary to reach more citizens" (Pedersen 1974 10).

Limited capacity of community members to participate: Pedersen cautioned that the City's new enthusiasm for involving community members in many different local government decision making process could exceed the capacity of community volunteers to participate (Pedersen 1974 7).

Level of participation should fit the decision to be made: Pedersen asserts that the "amount and quality of participation depends on the importance of the decision to be made, and the degree to which the participation is ultimately effective." 
Goal of better decision making: Pedersen argues that one of the major goals of increased community involvement was "more informed decisions based on more participatory process." She also identified the need for coordinated city-wide planning efforts in capital improvements, housing rehabilitation, an arterial street study, transit planning projects, and cable television service (Pedersen 1974 13).

Recommendations for ONA: Pedersen also reported on program criticisms and suggestions shared by "budget advisory committees and other close observers of the neighborhood program" (Pedersen 1979 26). These recommendations included:

Performance Measurement: Community members recommend that a process be developed to review the effectiveness of neighborhood staff in the district offices. Pedersen reported that ONA had developed, but not yet implemented a tracking system to compare requests for services by neighborhoods and the percent of services delivered (Pedersen 1979 26).

Tracking Savings to the City: Pedersen identified the need for a method to measure the savings to the City from funding the neighborhood and community involvement program. She noted that this question "rises each spring at budget hearings." This question most likely was raised by City Council members (Pedersen 1979 26).

Neighborhood Needs: Pedersen noted that city agencies reported that they agreed to perform the work requested by 40 percent of the needs reports submitted by neighborhood associations. Pedersen suggested that additional investigation was needed to determine how often city agencies followed through and completed the work and how long this took (Pedersen 1979 26). 
Training Program: Pedersen strongly advocated for the development of a leadership training program. "What [ONA's] program lacks is a consistent, strong program for training new neighborhood leaders." She noted that the 1978-79 ONA budget had included a small amount for a training program, but that half the funds were "frozen by budget constraints" and the other half was spent instead on a "citywide conference on economic development for the neighborhoods." She said reduced funding in the 1979-80 ONA budget made it unlikely the training program would be developed in the near future. ONA had responded to suggestions from a "committee on citizen participation" and had prepared written materials, including "an information packet for neighborhood leaders," "an updated list of neighborhood accomplishments," and "a file of neighborhood leaders especially skilled in dealing with recurring problems or projects" who could consult with and advise other neighborhood leaders (Pedersen 1979 26-27).

Creation of an additional district office: Pedersen recommended a community organizing effort and the creation of a new district office to support neighborhoods in far northeast Portland (Pedersen 1979 27). ${ }^{17}$

Annual or Biennial Goal Setting: Pedersen recommended the establishment of an "annual or biennial process for goal setting" for ONA and the neighborhood and citizen involvement program. She noted that ONA largely had accomplished the initial objectives set by the City Council for the program. This regular process would help ONA "keep a perspective on neighborhood organizational needs" (Pedersen 1979 27).

\footnotetext{
${ }^{17}$ This additional, sixth neighborhood district office—-known as Central Northeast Neighbors—was funded by the City Council in June 1984 and opened for business in January 1985 in an old city fire station ("Open house drill welcomes neighborhood associations to firehouse offices.” Oregonian 9 April 1985).
} 
Guidelines for BACs: Pedersen reported that guidelines for the BACs had never been "written into a city ordinance." She described a recommendation that a study be done to determine whether the BACs "really do save the City money." If the study finds they do, the BACs should be "legitimized by passing the appropriate legislation or council resolution" (Pedersen 1979 27). ${ }^{18}$

Recommendations for Neighborhood Associations: Pedersen reported that "several criticisms are heard of the neighborhood associations themselves...," and she described a number of recommendations for improvements (Pedersen 1979 27-28). She writes that "Perhaps the most frequent criticisms of neighborhood associations are that they are not representative" (31-32). She argues that neighborhood associations "opinions on some subjects may be representative, but this is hard to prove." She cites data that shows that the alternatives neighborhood associations "developed for the [citywide] comprehensive plan were in fact supported by opinion polls filled out by people who chose to do so, but the sample was a small one." She notes that "it is generally concluded that a quicker and but reliable method is needed" (32).

Pedersen described some specific recommendations, including:

Soliciting neighborhood opinions: Pedersen notes that neighborhood associations have a hard time "sounding neighborhood opinion" on "important issues." She describes a number of possible strategies neighborhood associations could use to improve their outreach, including door knob surveys, telephone surveys-as an alternative to going door to door, polls by city government or inclusion of additional questions to polls

\footnotetext{
${ }^{18}$ The City Council adopted a resolution in 1980 that formalized the Citizens' Budget Advisory Committee process and a set of guidelines that defined and clarified the functions and responsibilities of the BACs. (Portland. Office of Neighborhood Involvement. ONA Files. ONA BAC information sheet, no date).
} 
conducted by city agencies; and inclusion of a few questions in the regular market surveys done by marketing firms (Pedersen 1979 28).

Pedersen suggests that some form of "'interactive' cable television system may eventually be the best method." Her description of how the system might work gives insight into the role she thought neighborhood associations and community members could play in civic discourse and decisions making. The interactive system she described would allow "watchers to vote their opinion and see an immediate tally." She suggested that such a system could play a vital role in helping community members communicate with each other and with government about important issues. She recommends that neighborhood association board members and other community groups could help prepare materials and develop questions to which community members would respond. Neighborhood leaders could be in the studio preparing materials based on the input coming in that could be used to develop testimony to present to government bodies. "Neighborhood associations can also work with cable companies to set up locations where people can meet, discuss the issues and vote, whether or not their homes are hooked up to the cable." She recognizes that such interactive systems take several years to develop, but encouraged community members to think about how they would use such a system (Pedersen 1979 32). ${ }^{19}$

\section{Community involvement in neighborhood association elections: Pedersen reports} that neighborhood associations used a wide range of approaches to elect their board

\footnotetext{
${ }^{19}$ In 2013, neighborhood associations are still talking about ways people can participate in community meetings without having to physically attend. One suggestion people are thinking about is allowing people to participate via Skype - a much lower cost method of remote interactive participation but still similar to the interactive cable TV concept described by Pedersen.
} 
members and officers. A one end of the spectrum were elections "held at locations throughout [a neighborhood] for a week or at least one weekend." At the other end of the spectrum were neighborhood association elections held "at sparsely attending meetings." This very limited involvement of the community in a neighborhood association's election "leaves the association open to the criticism that they are a "small clique.", One recommendation was to include neighborhood association elections on regular local election ballots. Pedersen comments that this would not work because local elections occur every two years, while neighborhood elections occur annually "to compensate for high turnover and 'burnout'” of volunteers (Pedersen 1979 28).

A city-wide forum for neighborhood presidents: "Neighborhood leaders have consistently seen the need for a city wide forum for neighborhood presidents" to share information and discuss issues related to the functioning of the neighborhood and community involvement system. Pedersen writes that "City commissioners or bureau chiefs may be concerned about the direction of such a forum" but notes that "citywide forums exist in many cities and are actually useful to assist in rumor control and to give advance notice of new opportunities for participation." Pedersen remarks that a group called the "Portland Alliance of Neighborhoods" functioned for a while in Portland but was "issue oriented rather than program-oriented" and "never involved a majority of the neighborhood presidents."

Pedersen reported that attempts to reach a citywide audience were complicated by the diffused nature of Portland's system with its many neighborhood associations and district offices. Pedersen explained that most association meeting "agendas are crowded 
with neighborhood or district concerns" and getting time on the agenda can be difficult. Also neighborhood association presidents are volunteers with a lot of demands on their time already. Pedersen suggested that "perhaps it would be a better job for neighborhood vice presidents." Pedersen also suggested combined citywide meetings with social activities to help neighborhood officers "come to know each other better" and develop familiarity with each other that "might go a long way to building cooperation among neighborhoods" (Pedersen 1979 29).

Looking to the future: Pedersen closed her fifth-year report by noting that most neighborhood associations in Portland had evolved "well beyond the stage of merely reacting to city proposals." Their closeness to the grass roots of their neighborhoods allows them often to be "aware of individual needs, sometimes before they become an observable pattern." She argued that neighborhood associations also are able to refine solutions to fit "the specific nature of the problem as it occurs in their area." She suggested that public officials could hope that citizen involvement would lead the public to support "their thinking" and them "at the polls" (Pedersen 1974 13).

Pedersen saw that neighborhood associations were "beginning to work collectively on smaller scale projects to satisfy other needs." Neighborhoods are using town meetings as forums for assessing the needs and assets of their areas. They then are using public and private efforts to "begin programs which give hope for Portland's future" (Pedersen 1974 13). $\underline{1970 \text { s - Mayor's Budget Messages }}$ 
One of the focuses of this study is to examine the dynamics that helped or hindered the evolution of Portland's community and neighborhood involvement system. Portland mayors, under Portland's commission form of government, while they do not lead the administration of all city government agencies (as under the traditional strong mayor system), do significantly influence the development of the City's annual budget. The City's budget is a powerful policy tool that reflects the goals and priorities that the city council members are willing to back up with resources (not just rhetoric). Since 1973, Portland city mayors have included a "mayor's budget message" with each annual City budget. In these "messages," a mayor can state his or her goals and priorities for the city and highlight how he or she believes the funding choices in the budget help achieve these goals. Whether or not a mayor mentions the role of community members in decision making and comments on strategies to involve the community may indicate the importance that mayor places on community involvement and their willingness to use their influence to champion the cause of increasing and sustaining community involvement in city decision making. This section reviews the content of Mayor Neil Goldschmidt's seven mayor's budget messages during the 1970s.

The tradition of Portland mayors introducing the annual city budget with a “mayor's budget message” was started by Mayor Neil Goldschmidt with his first city budget as mayor in 1973. Prior to 1973, City of Portland annual budget documents were pages of numbers with little additional explanation or context to make government priorities and the decision making process transparent and accessible to the public. Goldschmidt instituted a new practice (which continues through the present in 2013) of 
preparing a city budget with introductory materials that include a budget review committee statement, mayor's message, and a citizen's guide to the budget. Some subsequent Portland mayors have chosen to include extensive comments in their mayor's budget messages, while others kept their comments fairly brief.

This section reviews the budget messages Mayor Goldschmidt included with the seven city budgets adopted during his time in office in the 1970s (January 1973 to September 1979). His messages vary in length from eight to fourteen pages, and include statements about overall goals, challenges facing the City, his priorities and strategies, comments on the city budget process, individual bureau highlights, and some concluding remarks. ${ }^{20}$

Goldschmidt was very consistent in the themes and priorities he stressed in his first six mayor's budget messages. In these first six messages, he emphasized his strong support for neighborhood revitalization, community involvement in decision making, and more effective management of city government as the primary solutions to the city's challenges.

Challenges: Portland faced major challenges throughout the 1970s. Goldschmidt stated that the City's livability was being threatened by "grave problems" that constituted "an inter-connected pattern of decay and neglect." At the end of his first term as mayor, Goldschmidt reminded Portlanders that in 1973, Portland faced "threats to the health of the City" including: "Our most productive citizens were steadily abandoning the City for

\footnotetext{
${ }^{20}$ Goldschmidt wrote the longest mayor's budget messages on average (10.6 pages). The average length of mayor's budget messages for all Portland mayor's from the 1970s to 2013 are: Goldschmidt --10.6 pages, Mcready--9 pages, Ivancie-- 2 pages, Clark-- 3 pages, Katz-9.75 pages, Potter-6.5 pages, Adams— 5 pages, and Hales -4 pages.
} 
the suburbs; our residential neighborhoods faced uncertain and unstable futures; downtown was declining as the economic center of the region; and increasing air pollution was creating a health hazard and threatening to prevent economic growth" (Portland. “Mayor’s Budget Message.” City Budget 1976-77 7).

Goldschmidt warned that the 1970 U.S. Census showed that "those persons most generally committed to making our neighborhoods fit for vital urban life are leaving the City. Families with children, families that participate in the life of our City and do things for themselves, make up a smaller portion of our population than ever before. They are being replaced by the young and the very old" (Portland. "Mayor's Budget Message." City Budget. FY 1973-74 5).

Portland's vitality also was challenged by the economic conditions of the time. Goldschmidt repeatedly warned of the "darkening revenue picture" and a bleak "longterm financial picture" as the economy moved "into a deepening recession," intensifying the "need for many City services." Throughout the 1970s, Goldschmidt warned repeatedly that high inflation was eroding city government's purchasing power every year at the same time that community members were increasingly interested in and demanding services (Portland. “Mayor's Budget Message.” City Budget. FY 1974-75 I-4 and FY 1976-77 7).

Goldschmidt writes that his first budget as mayor came "at a time of rapidly growing City responsibilities," and he predicted that the "City's functions will continue to expand dramatically." Some of the areas he identified for expanded city involvement 
and action included "economic development, a healthy environment, employment and social services” (Portland. “Mayor’s Budget Message.” City Budget. FY 1973-74 3).

Goldschmidt also warned that that Portland "City government's ability to face these problems squarely and to provide leadership in solving them was seriously in question.” In the early 1970s, while City government was "able to deliver traditional services dependably, [it] was ill-prepared and ill-equipped to deal with the multiplying and complex problems of the future" (Portland. "Mayor's Budget Message." City Budget. FY 1973-74 7). Goldschmidt writes that the problems in city government included management and organizational, fiscal, and personnel weaknesses, a lack of "long-range planning tools to identify problems before they could become crises," and "poor communications with our own citizens" (Portland. "Mayor's Budget Message." City Budget. FY 1976-77 7).

In 1973, Goldschmidt stated that the question was not "'whether we will face new problems; rather it is whether we will be able to deal with them effectively"' (Portland. “Mayor’s Budget Message." City Budget. FY 1976-77 7).

Major Strategies/Priorities: Goldschmidt strongly committed to not allowing Portland to succumb to the same financial pressures and trends afflicting cities across the country. Goldschmidt recognized that "Many American cities are experiencing severe financial distress," usually caused by "a loss of middle income, taxpaying families to the suburbs and a resulting population imbalance in the city between those who are the most in need of services and those who are most able to afford them" and lack of attention to "expensive capital investments in the city" including "housing stock, parks, streets, and 
roads, and so on...." He asserted that "We in Portland are committed to the principle that the hard experiences of other cities need not be ours" (Portland. "Mayor's Budget Message.” City Budget. FY 1977-78 5).

Goldschmidt led off his first mayor's budget message with strong statements arguing for the need for "neighborhood improvement" and "vitality" and devoted nearly half of the eight pages of his first mayor's budget to discussing his ideas for how to support community participation in neighborhood revitalization and local decision making and how to increase city services to respond to neighborhood needs and priorities (Portland. “Mayor's Budget Message.” City Budget. FY 1973-74). In subsequent City budgets, Goldschmidt maintained his focus on "a concentrated program of neighborhood stabilization" to "preserve and protect the livability of Portland's neighborhoods so that the families we now have in the city and those we would hope to attract will choose to make Portland their home" (Portland. "Mayor's Budget Message." City Budget. FY 1977-78 6).

Goldschmidt, in one budget message, stated that his overall strategy was "designed to accomplish one major goal: to ensure the people of Portland that they will have the opportunity, capability and confidence to decide their own future" (Portland. “Mayor’s Budget Message.” City Budget. FY 1976-77 7).

Goldschmidt's vision included a strategy of city investments to encourage Portlanders to get involved and invest their own resources in their neighborhoods and the community at large. Goldschmidt wrote:

"Of course we cannot begin to meet all the needs or solve all the problems confronting the residents of the City's neighborhoods. But at the 
very least, the budget can stimulate our citizens to take action themselves to create the viable, healthy neighborhoods on which the future of Portland depends. This budget, then, represents "opportunity dollars" for our neighborhood residents. It tells them clearly that their government is committed to joining them in the tremendous effort required to assure that our City and its neighborhoods not only survive, but ultimately flourish" (Portland. "Mayor's Budget Message." City Budget. FY 1973-74 5).

Goldschmidt identified the creation of Portland's new "concerted neighborhood improvement program" as an important step toward establishing "a structure in which citizens can plan their own neighborhoods and can more effectively seek and receive a response from their City Government." He noted that "It is the first step in what we all hope will become a more participatory decision making structure which gives neighborhoods the leverage to shape their own environment" (Portland. "Mayor's Budget Message." City Budget. FY 1973-74 6).

Goldschmidt also argued that that "this concept of neighborhood organization will never work without adequate support" and recommended funding for the Planning Bureau to hire "five additional planners to work on plans in specific neighborhoods of the City and two planners to respond to the increasing demand for solution of zoning and other land -use problems" and to work on an "expanded effort to develop a comprehensive plan" for the city, especially in the areas of housing and transportation (Portland. “Mayor's Budget Message.” City Budget. FY 1973-74 6).

Goldschmidt recognized that "planning itself is not enough" and that "concerned citizens must find ways to make existing conditions more bearable by changing the quality of the environment" of their neighborhoods "by removing abandoned cars, enforcing building codes, eliminating nuisances and repairing streets and sidewalks." $\mathrm{He}$ 
noted that community members "attempting to make government respond to these problems often have trouble dealing with the City's fragmented structure." Goldschmidt created the "Bureau of Neighborhood Environment" to take on these issues and the city's existing Nuisance Abatement function as well as noise abatement services. This new bureau was intended to develop "working agreements with other City bureaus" to help solve a neighborhood's problems "swiftly" and to eliminate "excessive delay" (Portland. “Mayor’s Budget Message.” City Budget. FY 1973-74 6).

Goldschmidt stressed that "To ensure neighborhood survival, our City Government must demonstrate that it will respond when neighborhood residents call, that it will reward participation and involvement" (Portland. "Mayor's Budget Message." City Budget. FY 1973-74 5). He asserted that City government needed to "focus its attention on the services actually reaching our citizens, to assure that citizen priorities govern the allocation of resources to programs and that service quality rather than quantity be the measure of our effectiveness as a government" [emphasis in the original] (7). Under Goldschmidt, the City's Office of Planning and Development (OPD) continued to review and comment on community project requests and "prepared information on all requested projects and distributed this material to interested neighborhood organizations" through ONA. OPD reviewed comments from neighborhood groups and incorporated community input into its review of capital project requests (Portland. "Mayor's Budget Message." City Budget. FY 1974-75 I-4). Goldschmidt continued to support ongoing strengthening of the Neighborhood Needs process and other efforts by city agencies to identify and respond to community-identified needs. 
Goldschmidt also expanded the City's role in providing human services in the community. He reported that federal revenue sharing funds, first available to Portland in 1973, brought with them "the responsibility for the development of realistic human resources services." Goldschmidt states that "We thus have an obligation to the disadvantaged citizens of our community to protect their interests. Planning for the youth and aged and revitalizing our neighborhood are now within the reach of these resources" (Portland. “Mayor's Budget Message.” City Budget. FY 1973-74 5). In 1973, Goldschmidt created a new "Bureau of Human Resources" (BHR) that would establish "youth service centers throughout the City which will provide recreation, counseling and social activities to local youth" and a "youth employment program aimed at providing job opportunities for the poor and disadvantaged" (7).

Crime prevention also became an important element of Goldschmidt's neighborhood revitalization strategy. In 1973, Goldschmidt added "more than thirty additional [police] officers, primarily for patrolling our neighborhoods"... (Portland. “Mayor's Budget Message.” City Budget. FY 1973-74 7). Future budget messages referred to the value of federally-funded crime prevention activities which funded a "program of neighborhood meetings and public information to help citizens avoid becoming victims of burglary and robbery" (Portland. "Mayor's Budget Message." City Budget. FY 1974-75 I-7 - I-8). The BHR Youth Diversion Program also attempted to offer young people attractive options to getting involved in criminal behavior in their communities. 
Goldschmidt saw the involvement of community members in the City's budget development as a very important part of his strategy to ensure that the City was serving the needs of the community. He also saw it as an important tool to help modernize the management of city government and to save money "through efficiency proposals initiated by the City's managers in a budget process where all City programs are thoroughly scrutinized and must be justified to dedicated citizen participants" (Portland. “Mayor's Budget Message.” City Budget. FY 1975-76 5).

City Budget Process: Goldschmidt, for the first time, opened up and involved the community in Portland's annual process to develop the city budget. Goldschmidt noted that the City budget traditionally had been a "bookkeeping process that resulted in a thick document containing endless columns of numbers, unrelated to the concerns of our citizens." He argued that "In truth, it is a process of deciding how the City will spend its time, talents and dollars, in support of what we value and need." Goldschmidt asserted that the City budget "has to be comprehensible to citizens, for the budget represents a means to a series of shared ends: to maintain vital City services at a high level; to involve citizens in the decisions that affect their lives" and to protect the City's fiscal integrity, prepare for future problems, take advantage of opportunities and manage these efforts constructively [emphasis added] (Portland. "Mayor's Budget Message." City Budget. FY 1976-77 8).

Goldschmidt wrote that the City budget needs to be grounded in "preserving this community's basic values" and identifies five critical elements of his budget strategy, including: 
1. "Good citizens are the riches of the City.' That quotation from the base of the Skidmore Fountain [in the Old Town area of downtown Portland] reminds us that government cannot solve problems without the active, informed, continuing involvement of large number of our citizens. With such involvement we cannot fail." [emphasis added]

2. "Healthy neighborhoods are essential to the success of the City."

3. "Public programs and money should be carefully used to stimulate and reinforce the investment by our citizens of their private actions and money" (Portland. “Mayor's Budget Message.” City Budget. FY 1976-77 8).

Other elements focused on the improving the capacity of City management staff and systems and the conservation of financial resources "against and uncertain future" (8).

Goldschmidt, in his mayor's budget messages, year after year, celebrated the opening up of the City's budget process "to increasing citizen participation" and noted that the process "has evolved into a tool for greater citizen input and management review” (Portland. “Mayor's Budget Message.” City Budget. FY 1977-78 7) .Goldschmidt asserted that "the increased involvement of our citizens" in the budget process is equally important to the application of effective "budgetary and management techniques” (Portland. “Mayor’s Budget Message.” City Budget. FY 1978-79).

City agency "budget advisory committees" (BACs) were a central tool of Goldschmidt's strategy to open up the city budget process and to improve decision making and accountability to the community. In 1973, Goldschmidt initiated the first five 
BACs to help their respective bureaus "formulate their goals and objectives" (Portland. “Mayor's Budget Message.” City Budget. FY 1973-74 4). The next year, Goldschmidt reported that the use of bureau "budget advisory committees" expanded and had an impact. All the city commissioners had established "citizen task forces" [BACs] to assist in the city budget process. "After a period of orientation regarding the agencies' operations, the task forces met to review each bureau's objectives and work activities prior to reviewing their budget submissions. In some agencies, task force comments resulted in substantially revised budget requests" (Portland. "Mayor's Budget Message." City Budget. FY 1974-75 I-4).

Goldschmidt also created a citywide budget review committee to review the input from the BACs and "all budget requests" and advise him on the development of his recommended budget for the city. The membership of this citywide committee included the director of the new Office of Management Services, one of Goldschmidt's assistants, assistants from each of the other city commissioners, and two (later three) community members. This committee also held public hearings on the city budget (Portland. “Mayor's Budget Message.” City Budget. FY 1973-74 4). Goldschmidt repeatedly reported that the committee's recommendations helped him with the difficult task of balancing the budget and enhanced the "thoroughness" of his recommendations (Portland. “Mayor's Budget Message.” City Budget. FY 1974-75 I-4).

In 1975, Goldschmidt reported that the "1976-76 budget process has been particularly gratifying for me. In particular, the citizen participation process which was begun two years ago as part of the budget process has demonstrated its value in opening a 
two-way communication between the bureaucracy and concerned members of the public." He noted that City Commissioners appointed "nine citizen participation task forces" in the late fall (Portland. "Mayor's Budget Message." City Budget. FY 1975-76). "These nine task forces spent long hours reviewing bureau programs, plans, and priorities with bureau managers as indicted in their budget request submissions. Eight of the nine task forces produced written reports outlining specific programs which they recommended for funding as well as those activities in which staff reductions could occur" (Portland. "Mayor's Budget Message." City Budget. FY 1975-76 6).

Goldschmidt said that he "carefully reviewed each of these reports" and that they played an important role in shaping his final budget recommendations (Portland. "Mayor's Budget Message." City Budget. FY 1975-76 6). By the time he resigned as Portland's mayor, ten BACs were operating as part of the city budget process.

In 1975, Goldschmidt wrote that "I am pleased that most of the task forces reported that our [City] managers had taken great pains to assist the citizens in their work." He noted that "A major recommendation of the task forces was the establishment of task forces on a year-round basis to guarantee a better informed project." Goldschmidt wrote that he strongly supported "this proposal as another step in improving the value of the citizen task forces" (Portland. "Mayor's Budget Message." City Budget. FY 1975-76 7).

In 1977, Goldschmidt's enthusiasm for the BACs continued:

"Our Citizen Budget Advisory Committees have been actively involved in the budget process, discussing bureau goals and priorities, and reviewing bureau budget submissions in light of those goals. I have had the opportunity to meet with the Task Forces for those agencies within the 
Department of Finance and Administration and am extremely impressed with the efforts they have made. Many of their recommendations are reflected in this Proposed Budget, and I am looking forward to hearing representatives from each of the Task Forces during the April budget hearings" (Portland. "Mayor's Budget Message." City Budget. FY 1977$787)$.

Goldschmidt continually emphasized the importance of the city budget and its role not only as a "basic resource and expenditure control tool" but also as a "key management tool for the City to outline its policies, plans, goals and objectives" (Portland. “Mayor's Budget Message.” City Budget. FY 1978-79 9).

Bureau Highlights: Goldschmidt, in his mayor's budget messages, also chose to draw attention to specific budget actions related to individual city bureaus. Goldschmidt included a number of community involvement and neighborhood revitalization elements in his list of budget highlights.

Goldschmidt reported on the creation of the "program to support staff and other expenses for neighborhood associations" and the creation of ONA and procedures by which ONA would provide assistance to neighborhood associations, including the funding of district offices and "a central office, serving neighborhoods throughout the city” (Portland. "Mayor's Budget Message.” City Budget. FY 1974-75 I-6). In 1975, Goldschmidt reported that ONA would take over the role of providing "neighborhood assistance in the area formerly served by the Model Cities Community Participation Program.” He said community input in the Capital Improvement Program process [i.e. the Neighborhood Needs program] would be continued. He wrote that "Intensive review of the capital programs of the City has demonstrated its effectiveness and responsiveness to citizen input and long-range planning programs. Duplication of agency efforts has 
been reduced and citizen participation in the planning process has been increased" (Portland. “Mayor's Budget Message.” City Budget. FY 1975-76 9). He also highlighted ONA successful implementation of district offices in the community "which are providing additional resources and information to citizens to enable improved and increased citizen input into City decision making" (Portland. "Mayor's Budget Message." City Budget. FY 1975-76 14-15). Goldschmidt also singled out the inclusion of particular capital improvements projects specifically to serve elders and youth, including "reimbursements to senior citizens for sidewalk and driveway repairs;" "neighborhood street drainage assistance;" "sidewalks for schools;" and "street paving and LID incentive projects...” (Portland. “Mayor’s Budget Message.” City Budget. FY 1974-75 I-6). In 1978, Goldschmidt reported that the ONA coordinator position for the BACs "will become a full-time position with responsibilities that extend to coordination of the budget task forces and follow-through work on the Neighborhood Needs Assessment Program" (Portland. “Mayor’s Budget Message.” City Budget. FY 1978-79 14).

Goldschmidt also reported that initially the Bureau of Neighborhood Environment was funded to expand its "complaint inspection program during the summer months." Additional inspectors had been transferred to the bureau from other parts of city government to help "consolidate various inspection functions to simplify citizen contacts and increase efficiency" (Portland. "Mayor's Budget Message." City Budget. FY 1974-75 I-7). Over a number of budget years, the Bureau of Neighborhood Environment also received funds to continue the "implementation of the noise control program...." In 1978, the Bureau of Neighborhood Environment was funded to develop a comprehensive 
system of "neighborhood condition standards" (Portland. "Mayor's Budget Message." City Budget. FY 1978-79 14).

The Metropolitan Human Relations Commission (50 percent funded by Multnomah County) developed a neighbor-to-neighbor conflict resolution and mediation program (Portland. "Mayor's Budget Message.” City Budget. FY 1977-78 11). and later expanded its "involvement in the areas of education, housing and equal justice" (Portland. “Mayor's Budget Message.” City Budget. FY 1978-79 14).

City crime prevention programs continued to support the provision of "safe home and neighborhood environments" for youth. The Bureau of Human Resources received federal funding to support its Youth Diversion Program, and the city budget added funding to support a total of four youth diversion centers around the city. The City also created a "Youth Work Experience Program" to "provide constructive public employment to unemployed youth" and provided funds to "ensure that jobs are available to Portland's children, regardless of family income—but according to local priorities" (Portland. “Mayor's Budget Message.” City Budget. FY 1974-75 I-7 - I-8).

Youth continued to be served by the Bureau of Human Resources through its four youth service centers. These centers provided services to "juveniles" who otherwise would have "entered the criminal justice system as offenders." The work of the BHR was coordinated with those of the Portland Police Bureau Youth Division which supported the youth service centers, schools, and parks. The City and County continued to support a joint "comprehensive program of services to the aging" and people with disabilities. Employment assistance and training and service programs in the community continued 
through the City's participation in the federal Comprehensive Employment and Training Program (CETA). These funds also helped support other neighborhood improvements including ten miles of road paving and the installation of 900 additional curb ramps (Portland. “Mayor’s Budget Message.” City Budget. FY 1975-76 8).

In 1976, Goldschmidt identified the need for the City to work more closely with the Portland Public Schools "so that each jurisdiction makes the most of its facilities and programs to increase the attractiveness and stability of our neighborhoods“ (Portland. “Mayor’s Budget Message.” City Budget. FY 1976-77 19). The next year, Goldschmidt included "coordination with our public schools" as one of the "major critical issues of my second term” (Portland. "Mayor’s Budget Message.” City Budget. FY 1977-78 5). In 1978, he reported, "Approval by the City and the School Board to create a joint commission to target resources on the interrelationship between stable neighborhoods and good schools” (Portland. “Mayor’s Budget Message.” City Budget. FY 1978-79 7).

Summary Themes: In 1976, Goldschmidt reviewed some of the accomplishments of his first term as mayor. Goldschmidt said that in 1973 the City budget got a boost from the first year of federal revenue sharing. He wrote that "That year, we directed increased resources into citizen participation, neighborhood capital improvements, and management improvements," and the new Bureau of Human Resources began to assist "youth and senior citizens." Goldschmidt emphasized that "workable social programs can reinforce other City efforts, for stable and secure neighborhoods, sounds schools, and reduced crime" (Portland. "Mayor's Budget Message.” City Budget. FY 1976-77 8). 
Goldschmidt reported that, since 1973, "we continued to invest in management, citizen participation, and neighborhoods...." He maintained that "our emphasis on citizen review of the budget and management improvement began to pay off" through the identified of reductions in city staff positions without "any significant reduction in services provided to Portlanders" (Portland. "Mayor's Budget Message." City Budget. FY 1976-77 9).

Goldschmidt claimed that his overall strategy during his first term "has paid off." "Citizen activity is greater than ever; our air is cleaner; the rise in crime has been halted; urban neighborhoods are increasingly livable and secure; downtown business and investment are booming; best of all, people are returning to live and work in the City" (Portland. “Mayor's Budget Message.” City Budget. FY 1976-77 9).

Goldschmidt identified "public safety" as the highest priority for the 1976-77 City budget, but emphasized his belief that the overall city budget continued the City's "emphasis on citizen involvement and neighborhoods, the essential ingredients of the City’s future” (Portland. “Mayor's Budget Message.” City Budget. FY 1976-77 10). Goldschmidt also continued to laud the efforts and impact of the "Citizen Budget Task Forces" (BACs) (14).

Portland voters elected Goldschmidt to a second term as mayor in November 1976. In his first mayor's budget message of his second term, Goldschmidt listed the "major critical issues of my second term" the first of which was: "Implementing a neighborhood stabilization strategy to attract families back into our city and keep the ones who are here." He also listed "Improving our housing stock through comprehensive 
programs of inspection, rehabilitation, and new construction; "continued economic development through partnerships with the private sector; improved City "coordination with our public schools; " the maintenance of basic services without new taxes or major fee increases; and the maintenance of "the fiscal integrity of our City government..." (Portland. “Mayor’s Budget Message.” City Budget. FY 1977-78 5).

In 1975, Goldschmidt emphasized his view of city governance as a shared responsibility between City leaders and staff and community members and shared his confidence that the City will be able to meet the challenges of the economic downturn and inflation "only by continued support of sound modern management practice and continued openness and dialogue with our citizens at every level of our activities (Portland. "Mayor's Budget Message.” City Budget. FY 1975-76 16).

In 1976, he celebrated the "hard budget decisions" over his first term that produced a City government that "is leaner, better managed, and in better touch with its citizens" and closes by stating that "While the problems still before us are immense, so are the opportunities. The unselfish commitment of Portlanders to work together over the past four years in pursuit of common goals has forged a reborn confidence" (Portland. “Mayor’s Budget Message.” City Budget. FY 1976-77 20).

In 1977, Goldschmidt asserted that this city budget "represents our commitment to a neighborhood stabilization initiative" and claims that "Its basic thrust is to assure Portland's future livability by encouraging a balanced city population, a population of families who choose to invest their futures in this City. Goldschmidt warns that inflation continues to reduce the City's purchasing power even as the City has saved millions of 
dollars through staff reductions and efficiencies. Given the lack of growth in the City's tax base, Goldschmidt said that a proposal for revenue sharing by state government offers the best way to end the City's financial uncertainty (Portland. "Mayor's Budget Message." City Budget. FY 1977-78).

In 1978, Goldschmidt reaffirmed that the City's primary objective is to "target our resources to preserve Portland's quality of life and to avert the urban ills that have plagued so many of our country's largest cities." He maintained that Portland is "finally on the threshold of achieving this objective." He said that while "inflationary increases in costs continue to outstrip increases in revenues, the new State Revenue Sharing Program now enables a 'hold the line' budget with few major program cuts and a limited number of new activities” (Portland. “Mayor's Budget Message.” City Budget. FY 1978-79 6).

Goldschmidt proposed to continue his commitment to "target resources to the goal of protecting Portland's quality of life..." and iterated the same six "critical issues" that he identified in his previous year's mayor's budget message (Portland. "Mayor's Budget Message." City Budget. FY 1978-79 6-7).

Goldschmidt reprised his familiar theme of identifying the "City's fiscal condition" as a "major constraint toward achieving our full potential," but notes that this fiscal year "will be the first year in the last four that major reduction in personnel and service levels will not be necessary..." While Goldschmidt states that "Today our City is winning in a fight, not only for her livability, but for her life. It is not a fight that is over; it is too early to proclaim victory. There is still work enough for all of us - to safeguard the gains that have been made and to carry on with the job of creating a future for 
Portland that we want for ourselves and for our children" (Portland. "Mayor's Budget Message." City Budget. FY 1978-79 16).

Goldschmidt's last mayor's budget message—1979-80: Goldschmidt submitted his last mayor's budget message in March 1979, a few months before he resigned to take a position in the Carter Administration as U.S. Secretary of Transportation. This message reads very differently than Goldschmidt's other mayor's budget messages.

Goldschmidt does not refer to community involvement in the budget process or city decision making anywhere in this budget message. The difference is evident right from the first sentence, which, instead of talking about the need to revitalize Portland neighborhoods or preserving Portland's livability, states that "Legally, Portland must have a balanced budget." The introduction goes on to say that the City has a dual responsibility to be a steward of "the public's resources" while at the same time serving "the public good and the public's needs." The introduction mentions the "shared commitment of the City Government and the citizens to preserve Portland" and states that “'Portland' has come to represent nationally not just another name of another city, but a way of life and a civic culture which others can envy" (Portland. "Mayor's Budget Message." City Budget. FY 1979-80 4). Instead of emphasizing the strong need for community revitalization—as in his previous six messages—-he instead talks about the need to manage and control anticipated growth and change in Portland.

Goldschmidt reports signs of "what restored health to our downtown and in our neighborhoods means" and warns that Portlanders must not "let our success consume us." Goldschmidt cautions that while "enormous new investments have been proposed, 
investments which will change the face of the City, bring us housing, jobs, and new economic vitality," Portlanders "must have the capacity to control and guide the forces released by those investments so that they become part of Portland rather than Portland becoming part of them." Part of the challenge "as we seek to accommodate those who would come here" is to "not destroy our neighborhoods" and to maintain strong basics services to serve all community members (Portland. "Mayor's Budget Message." City Budget. FY 1979-80 4-5).

Goldschmidt emphasizes that "The goal of the budget is the same goal that has driven me since I became Mayor: to preserve those qualities and values which make Portland a special place to live. It is a budget which works hard to recognize the strong attachments we have for our city. It is a budget which seeks to manage the changes taking place in our community, to a shared better life for all Portlanders" (Portland. "Mayor's Budget Message." City Budget. FY 1979-80 5).

Goldschmidt states that his budget highlights "represent my view of the overriding responsibilities of City government and the priority needs of our citizens." He grouped his primary budget highlights under the headings of jobs, maintenance of city service levels, emergency services, and energy supply. The only mention of community or neighborhood involvement is Goldschmidt's report of new General Fund support for "one of the three neighborhood mediation centers currently staffed by three CETA positions and funded in the Metropolitan Human Relations Commission budget" to help remove "day-to-day neighborhood conflict resolution from the workload of our police patrolmen" and to "serve on a City-wide basis" (Portland. "Mayor's Budget Message." 
City Budget. FY 1979-80 10). Goldschmidt also announces that the City will "develop its own information referral mechanism" and will fund a position in the Office of General Services to serve as a central information referral point for citizens." 21

Overall, Goldschmidt's mayor's budget messages show him to be a mayor who strongly and consistently supported community involvement in city government decision as an important element in his strategy to revitalize Portland neighborhoods and to preserve and enhance the livability of Portland overall. He opened up the city budget development process to include and then expand community input and supported the creation of city agencies and programs to support community involvement and to improve the quality of and services in Portland's neighborhoods.

\section{Observations from the 1970 s}

Portland's community and neighborhood involvement system was created in the 1970s during a time of great enthusiasm, challenge, and change in Portland. City leaders and neighborhood activists found common cause in the revitalization of Portland's deteriorating neighborhoods and downtown. Portland's leaders were open to decentralizing local decision making and implemented major new policies, structures, and programs intended to give community members a meaningful voice in shaping the livability of their communities. This section summarizes some of the insights of the this chapter related to the three main research questions of this study.

System Elements: During the 1970s, Portlanders thought a lot about the policies, structures, and programs that most would encourage greater participatory democracy in

\footnotetext{
${ }^{21}$ This function later became a program within ONA/ONI.
} 
Portland. Many of the system elements implemented during this time continue as major parts of the system forty years later.

Some important values and assumptions shaped the system's effectiveness at promoting greater participatory democracy. Community members were seen as willing and able to participate in local decision making and program development, and both community members and city leaders and staff were seen as being able to bring important value to the work of city government. It was recognized that community members often have the best understanding of local needs and the implications of different possible government policies, programs, and actions for their part of the city. Also, government policies and programs often are more effective and sustainable when their development includes people representing different interests in the community coming together to identify and reconcile their interests and priorities.

A number of city leaders and staff during the 1970s were open to decentralizing some local decision making away from Portland's tradition of top-down decision making prior to the 1970s. The city planners and Planning Commission members who developed the 1971 proposal for district planning organizations believed that a system of neighborhood organizations with a meaningful voice in local planning would help create better plans and would reduce the likelihood of the kind of conflict and unpredictability that was a regular feature of urban renewal, land use, and transportation planning efforts in Portland during the 1960s and early 1970s. Goldschmidt believed that involving community members in city government decisions and priority setting not only would 
help revitalize Portland's neighborhoods and downtown, but also would help improve the efficiency and effectiveness of city government.

Many people recognized that community members and neighborhood organizations need to have some real power and impact to attract strong community participation. They also recognized that, to have an impact, community members need to be involved early in the development of plans, policies, and programs, not "after the fact" when most important decisions already have been made.

An effective decision-making partnership between government and community organizations and members also requires good communication. In the 1974 and 1975 Ordinances, the City Council declared that the primary purpose for creating a formal citywide system of ongoing neighborhood associations was to create a vehicle to facilitate communication between community and government. The scope of the needed communication later was described by Pedersen as including two-way communication within and between all parts of the system: neighborhood associations with their community members; between neighborhood associations, between neighborhood associations and neighborhood districts, between the community and city government agencies and leaders, and within city government.

System designers also saw the value and importance of developing a city-wide system of neighborhood associations recognized by city government that would be available on an ongoing basis to community members who decided to organize themselves to work on a particular issue or problem. Community members would not need to take the time to create a new organization for every effort. 
Independence and community control of neighborhood associations also was seen as an important feature of the system. Community members were most likely to participate in organizations that they had a voice in shaping, and neighborhood activists aggressively advocated to protect the independence of neighborhood associations in the system as it developed. The importance of community ownership in the system also was reflected in the decision to extensively involve neighborhood and community activists in the development of the system. Neighborhood association independence also was reflected in the ultimate scope of what neighborhood associations could work on. While the initial 1971 Planning Commission proposal suggested that neighborhood associations and district planning organizations would focus primarily on developing neighborhood plans, the scope for the neighborhood system quickly grew to empower community members to use their neighborhood associations to work on anything that they felt affected the livability of their neighborhoods.

As a counterpoint to the need for neighborhood organization independence, many city leaders and staff, and some community members as well, saw the need for the system to ensure the protection of the rights of all citizens and that a variety of viewpoints would be welcomed and heard—not just those of the people who controlled a particular neighborhood at the time. This led to a formal exchange agreement—formal recognition, benefits and support for neighborhood associations in exchange for neighborhood association agreeing to structure and manage themselves in ways that were open and accountable to the city and the community. The system required neighborhood associations not to discriminate against individuals and to record and pass on to city 
decision makers any minority opinions as well as the majority opinions or recommendations of their neighborhood association. The system also required neighborhood associations to hold regular elections, provide formal notice of their neighborhood meetings, and to have a formal process to resolve complaints.

Many individuals involved in the early development of the system recognized that, while neighborhood associations needed to be independent, effective community organizing and involvement requires support—community volunteers only can do so much on their own. The system recognized that assistance from paid staff would increase the effectiveness of organizing, communication, capacity building. ONA was created to provide a broad array of support to neighborhood organizing and communication efforts. Other city staff also were tasked with helping community members to be involvedincluding city planners who supported for neighborhood planning efforts and city staff who supported the individual city agency BACs and the Neighborhood Needs process. It also was important that community members controlled the staff in the ONA-funded neighborhood district offices to ensure that the top priority of these staff members would be the needs of the community. District offices also provided a community-controlled physical space in the community to serve a welcoming place for community members to "call home," discuss issues, and work together.

Multi-tiered structure: A number of the reviews of the proposed and implemented system during the 1970s recognized the advantages of a multi-tiered system of neighborhood associations, district-level bodies, and some sort of a citywide body for community members. Neighborhood associations were envisioned to be the ideal places 
to discuss and work on issues that affected a particular neighborhood. District level bodies were seen as an effective way to bring neighborhoods together to share ideas and resources and to discuss issues that affected more than one neighborhood in the district. A citywide body would offer the opportunity to broaden information and resource sharing even further and to give community members the opportunity to discuss and organize action on issues of citywide impact and importance. Some neighborhood activists initially opposed the development of a district-level tier of organizations out of concern that another layer in the system would dilute the clout of the neighborhood associations. District level bodies evolved anyway, largely because of ONA's decision under Pedersen to contract with district level bodies to deliver community involvement support services to their neighborhood associations. The formal role of district coalition boards later would be formalized in the 1987 ONA Guidelines. Witt documents that tensions continued to exist between neighborhood associations and their district coalition boards around the city to varying degrees for many years. Over the history of Portland's community and neighborhood involvement system, community members periodically would attempt to create a city-wide body for neighborhood activists and community members-usually only with short term success.

The system structure also included the creation of a city agency - the Office of Neighborhood Associations (ONA) — to help support and coordinate the system. Early on, the decision was made for ONA to play a supportive, rather than directive, role. ONA would provide organizing, communications and other support to neighborhood associations, but would not control them. ONA also would provide some assistance to 
help city agencies work constructively with neighborhood associations and community members, but would not do the community involvement work for city agencies.

Formalization of Roles and Responsibilities: The formalization of the roles and responsibilities of neighborhood associations, city agencies, and ONA through the 1974 and 1975 ordinances also was an important element of the system's early development.

Despite the strong advocacy by neighborhood activists that neighborhood associations be independent of city control, city leaders and staff (and many neighborhood activists) saw the need for neighborhood associations to agree to some basic requirements in exchange for the benefits of formal recognition and support from city government. The 1974 and 1975 ordinances set out minimum requirements that neighborhood associations needed to meet to be recognized formally by the city, as well the benefits and service they then could receive and the roles and responsibilities of city agencies and the new Office of Neighborhood Association (ONA) in supporting community involvement.

Neighborhood associations were required to have open membership, not charge dues, not to discriminate, and to file their bylaws with ONA. Neighborhood association were to be held accountable to their community members and the city through the requirement of regular neighborhood association elections, notification of elections and neighborhood meetings, compliance with open meetings and public records requirements, and the recording and transmittal to the city of discussion, minority viewpoints, and votes at neighborhood meetings when the organization took formal positions or adopted formal recommendations. Neighborhood associations also were required to have a formal 
process to respond to complaints and grievances. (Some requirements discussed early on, such as requirements related to neighborhood boundaries, were dropped from the initial ordinances but would reappear in the 1987 ONA Guidelines.)

In exchange for meeting the minimum requirements, neighborhood associations became eligible for a range of benefits, including formal notification of city government policies, programs, and land use actions that might affect the livability of the neighborhood, support for neighborhood planning efforts, involvement in the city budget process, the ability to share neighborhood priorities for city projects, and a wide range of support services from ONA.

On the city government side, the system required city agencies to provide neighborhood associations with formal notice - at least 30 days when possible--of actions that would affect the livability of the neighborhood, formally involve neighborhood associations in any planning efforts that affected their neighborhood, and to following the provisions of any formally adopted neighborhood plan adopted by the City.

ONA's role was to support community involvement and the organizing and effective functioning of neighborhood associations-not to control neighborhood associations. ONA also helped city agencies work with neighborhood associations, but did not take on the responsibility of doing community involvement work for city agencies or city leaders. ONA's support for neighborhood associations included: communications support_-including printing and mailing assistance, information and referral, leadership and skill training, organizing support, conflict resolution, assistance to help neighborhood associations work with city agencies effectively, and help organizing neighborhood 
projects. ONA acted as an information clearing house, maintained the list of neighborhood association contacts, promoted involvement in neighborhood associations and public education about community involvement, assisted in conflict resolution, and enforced the minimum standards for neighborhood associations. ONA also managed the BAC program and the Neighborhood Needs Process and contracted with community-run district offices to provide assistance and support to neighborhood association in those districts.

Challenges: Some issues emerged early in the system's development that would continue to pose challenges to achieving an effective community and neighborhood involvement system for many years.

A major early (and ongoing) challenge was the expectation by city leaders and staff — and many community members — that neighborhood associations should be "representative" of their communities. Many city leaders and staff seemed to hope that the new neighborhood associations would become a "one-stop" source of information about what the people in a neighborhood wanted and cared about. Many neighborhood leaders_-all volunteers_-found it difficult to meet this expectation. Not all neighborhood leaders and their board members necessarily came into their leadership positions with the skills, time and energy, or even the desire to develop and implement effective outreach and involvement efforts in their communities. Most neighborhood associations also had limited resources and support to reach out and involve their community members.

Effective communication and outreach capacity clearly was a critical factor in a neighborhood association's ability to claim to involve and "represent" the views and 
wishes of the people in their neighborhood. The City Council recognized that effective communication was a central task for the neighborhood system. In the early years of the system, ONA saw communication support as one of its major functions and provided some level of assistance to neighborhood associations with designing flyers, notices, and newsletters, and provided printing and mailing support. ONA also distributed its own newsletter about community involvement activities and opportunities. The Oregonian and local community newspapers also played a role in getting information out about community issues and events. Pedersen discussed in her ONA reports the desire to find innovative ways to involve more people more easily in neighborhood association elections, meetings and activities - one of these was the idea of establishing an interactive cable television system. The need for better outreach by neighborhood associations would continue to be a major challenge throughout the history of the system.

Adequate training for community volunteers was another challenge. Portland's new community and neighborhood engagement system depended very heavily on the ability of community volunteers to step up to create and then lead and manage neighborhood organizations, to analyze and advocate for issues, and to participate effectively in city decision making processes. Pedersen quickly recognized the strong need for ongoing leadership and skill training for community members and called for ONA to develop an ongoing training program for new neighborhood leaders.

Increasing numbers of city staff also began to try to engage community members on a wide range of projects and processes. Many needed to understand that community members have a limited capacity — in time, energy, and interest—to participate in the 
rapidly growing number of city decision making processes that were looking for community input. City staff needed to have the skills and willingness to ensure that community involvement efforts were well thought out, well designed and supported, and reflected the true scope and needs a particular decision making process and its relevance to community members. The extent to which city staff received training and support in doing this is not clear.

Different reviews also identified the need for some sort of citywide tier or body that would bring community members together to share information and learn about and advocate together on issues that had citywide impact. Portland's initial system did not include a formal citywide tier. The next chapter describes some independent, community lead efforts to create citywide bodies in the 1970s and 1980s.

Reform Process: Many factors and individual players helped set the stage for the early development and implementation of Portland's community and neighborhood involvement system. Abbott reports that "startling changes" from 1966 to 1972, included "the emergence of active and often angry neighborhood association organizations" that "made local residents the actors rather than the objects in neighborhood decisions;" strong requirements by the federal government for citizen participation in city policy and spending decisions through the Community Action Program of the Office of Economic Opportunity, the Model Cities program, and the Housing and Community Development program (190-91), and "a change of generations on the Portland City Council in 196970" that brought on leaders who "were more willing to respond to neighborhood requests.” Abbott (1983) writes that by "1971 and 1972, active neighborhood 
associations and planning committees were a presence that politicians and planning administrators could not ignore" and together constituted a citywide "neighborhood movement" (192).

The 1970s also were a time when Portland city leaders were thinking in new ways about local governance roles and structures. Goldschmidt and other leaders championed revitalization of neighborhoods and downtown, increased community involvement in local decision making, city/county consolidation, and new approaches to regional governance. In Salem, the Oregon Legislative Assembly passed Oregon's land use planning law which required Portland and other local jurisdictions to develop comprehensive plans.

Policy entrepreneurs played an important role in the development of the ideas and proposals that led to the creation of Portland's community and neighborhood involvement system. Hovey (2003) cites the role sympathetic city planners-who had worked with neighborhood activists on planning projects, such as the Northwest District Plan-played in advocating for a more formal role for neighborhood associations in city planning. City planners and Planning Commission members then developed the 1971 proposal to create the district planning organization system. This proposal then led Mayor Schrunk and the City Council to create the DPO Task Force which fleshed out a much more detailed set of recommendations for the creation of a city-wide neighborhood association system. Mary Pedersen, who was hired in 1973, worked with the community to develop the 1974 and 1975 ordinances and helped shape ONA's early focus and 
programs. Neighborhood activists, organized strong neighborhood association and pushed for greater involvement in local decision making.

Political champions also played a role. Mayor Terry Shrunk and City Commissioner Lloyd Anderson supported the creation of the DPO Task Force and the subsequent move to create the neighborhood system. Mayor Goldschmidt made neighborhood revitalization and citizen involvement in government decision making a major element of his strategy to save Portland from decline. Hovey reminds us that Portland's community and neighborhood involvement system grew out of a "broad based... nascent movement" that involved hundreds of community members and that Mayor Neil Goldschmidt did not create Portland's neighborhood association and land use planning systems on his own, but did serve a valuable role "as the avatar of a new public narrative about Portland, what it was becoming, and what it meant to live there." Goldschmidt's mayor's budget messages that accompanied the annual city budget indicate that involving community members in city decision making and the creation of a system of strong neighborhood associations were central to his plans to revitalize Portland. Goldschmidt used his political skills and power in the city budget process to support his vision by creating administrative structures (e.g., ONA, Bureau of Neighborhood Environment, Bureau of Human Services, etc.) and programs (e.g., Budget Advisory Committees Program, Neighborhood Needs Process), and by sending a strong message that he expected these structures to be effective and ongoing.

Embedding: One of this study's primary research questions is how reforms that advance toward greater participatory democracy can be sustained over time. Portland city 
government's emerging openness to working with the community in the 1970s represented a dramatic departure from the City's previous top-down culture of governance. The literature suggests that achieving and sustaining a major culture change like this depends on a number of factors, some of which were enacted in Portland in the 1970s and others that were not.

Gibson emphasizes that "citizen-based approaches" to governance need to focus on lasting culture change within government (Gibson 2). Stone argues that many policy arenas are controlled by "semiautonomous subsystems" and that the day-to-day activities of these subsystems need to be altered to establish an "institutional legacy" to ensure that the changes are lasting. Stone asserts that fundamental reform requires sustained mobilization and the institutionalization of new practices and relationships. He argues that sub-systems rarely reform themselves and require some sort of external civic mobilization to achieve lasting change (Stone 6-8).

Fernandez and Rainy (2006) identified a number of common factors that together advance lasting organizational culture change in the public sector. ${ }^{22}$ They argue that resources need to be dedicated to support the change process and to support developing a strategy for change, communicating the need for change, "training employees," "developing new processes and practices," "restructuring and reorganizing the organization," and "testing and experimenting with innovations" (712).

\footnotetext{
${ }^{22}$ Fernandez and Rainey identified eight factors to achieve local government organizational culture change, which include: "Ensure the Need;" "Provide a Plan;" "Build Internal Support for Change and Overcome Resistance;" "Ensure Top-Management Support and Commitment;" "Build External Support;" "Provide Resources;" "Institutionalize Change;" and "Pursue Comprehensive Change."
} 
The City Council's adoption of the 1974 and 1975 ordinances, which created ONA and Portland's community and neighborhood involvement system, placed the new system into city code, thereby creating an expectation that the system would be ongoing rather than a temporary experiment or pilot project. The ordinances also codified a formal statement of the need for and purpose of the system and laid out expectations, roles, and responsibilities for neighborhood associations, city agencies, and ONA.

The ordinances also mandated changes to city practices and procedures, including the introduction of formal notification requirements, the 30-day early warning requirement for city policies and projects that affected neighborhood livability, and community involvement in neighborhood planning, the city budget process, and identifying neighborhood needs related to capital and other city projects and services.

The City Council's creation and funding of ONA helped support the development of important community involvement capacity and infrastructure in the community. The ordinances established an incentive for community members to organize communitybased neighborhood associations and to apply for formal recognition for their neighborhood associations to be eligible for the status, services, and support that came with formal recognition. The creation of these ongoing vehicles for community organizing and action created a citywide infrastructure to support greater community involvement. ONA's increased the level of organizing and capacity building by helping neighborhood organizations get organized, reach out to and involve their community members, along with a wide range of other support services. The increase in the number of community members and organizations also increased public expectations and 
expanded the constituency that would advocate for city government to continue to involve the community in local decision making. ONA also provided support to city agencies to help them reach out to and work with neighborhood associations and community members.

Pedersen notes that a number of City staff people initially were enthusiastic about increasing the involvement of community members, but it is not clear how widely this enthusiasm existed through city government or how the extent to which city staff had the training, skills, and support needed to work effectively with community members. As the years would go by, community members repeatedly would complain that city leaders and staff were not really listening to the community or working with community member early enough and in ways that would be most meaningful.

The embeddedness of many of these early elements of Portland's community and neighborhood involvement system would be challenged and tested by changing leadership on the city council, success and frustrations with existing programs and structures, and evolving understanding of what constitutes a meaningful governance partnership between community organizations and members and city government. 


\section{CHAPTER IV EXPANSION AND INSTITUTIONALIZATION—1980s}

Portland's community and neighborhood involvement system continued to expand and evolve during the 1980s. Witt (2000) characterized the mid to latter 1980s as a time of "institution building" for the system. He also described many of the power dynamics that shaped the system as it moved from the initial, more open creative phase to greater normalization and standardization. This chapter reviews a number of major system developments during the 1980s.

This chapter begins by offering some context for the system initiatives and changes implemented under the two ONA directors during the 1980s, Patty Jacobsen and Sarah Newhall. The chapter reviews concerns raised about the openness and democratic practice of neighborhood associations and 1980 ONA Review Committees review and assessment of the system that was initiated in response to these concerns. The chapter also reviews the creation, by neighborhood activists of a citywide body to allow neighborhood associations to work on city wide issues - the Association of Portland Neighborhoods. The chapter describes events that celebrated neighborhood associations and recognized the work of neighborhood volunteers through an examination of Neighborfair (1976-1990 and Bud Clark's establishment of Neighborhood Recognition Week and the Spirit of Portland Awards.

Despite the finding by the 1980 ONA Review Committee that formal standards for neighborhood associations were not needed, by the mid 1980s, a number of conflicts 
within the system and concerns about openness and stability of neighborhood associations and the role of the neighborhood district coalitions led to the development of the first set of citywide guidelines for the neighborhood system. This chapter describes the more significant elements of the guidelines and perspectives on the guidelines from proponents and opponents.

The chapter closes with a brief review of the findings of the Tufts University research team that studied Portland's system in the late 1980s, a review of the formal mayor's budget messages that accompanied city budgets during the decade, and observations about the evolution of Portland's community and neighborhood involvement system during related to this study's three research questions.

\section{The 1980s-Some Context}

Portland's community and neighborhood involvement system continued to grow and change during the 1980s. ONA struggled to clarify its role after the end of the Goldschmidt and Pedersen era, and the City Council assigned new programs and functions to ONA. Witt notes that, under the leadership of ONA directors Patty Jacobsen and Sarah Newhall during the 1980s, ONA moved to formalize and regularize the system.

During the 1980s, ONA wrestled with questions about its role. Was its role to support or control the system and to what extent should ONA actively advocate for neighborhood issues and concerns versus staying neutral? Witt provided interesting descriptions of different conflicts and power struggles between ONA and the 
neighborhood districts, between the districts and neighborhood associations, and between neighborhood associations and ONA during this time.

The mayor's led Portland during the 1980s. City Commissioner Connie McCready finished out Goldschmidt's term. City Commissioner Frank Ivancie won election to succeed McCready as mayor and served for one term. Community and neighborhood activist Bud Clark defeated Ivancie in the 1984 mayoral election and served for two terms. Neither McCready nor Ivancie had been supporters of community involvement. Clark, once in office, moved quickly to reestablish the City's commitment to community and neighborhood involvement and initiated a number of projects to raise the visibility and stature of neighborhood associations and community input in City decision making. While in office, Clark also championed the development of Portland's community policing program.

The 1980s also saw the beginning of major annexations by the City of Portland of unincorporated areas of Multnomah County east of Portland. These annexations would lead to the creation of many new neighborhood associations and two new neighborhood district coalition offices and also generate significant controversy for Portland's neighborhood system (described in more detail in the next chapter).

New programs added to ONA: The City Council expanded the number and type of programs at ONA during the 1980s. The City Budget for FY 1982-83 reported the development of a new crime prevention program at ONA (Portland. City Budget FY 1982-83 118). In 1983, the City of Portland and Multnomah County agreed to divide up responsibility for different types of urban services in an effort to "ensure the efficient use 
of limited local resources by having each jurisdiction deliver those services that drew on their respective strengths" (Portland. Office of the City Auditor. Urban Services Policy and Resolution A, March 2013). ${ }^{23}$ This division of services led the City to dissolve the Bureau of Human Resources and shifted some of this bureau's functions to ONA. The ONA budget for FY 1983-84 announced the transfer of the Neighborhood Mediation Program, and its four full-time positions, from the Metropolitan Human Relations Commission to ONA (Portland. City Budget FY 1983-84 127). In FY 1987-88, a position that supported public safety services for immigrant and refugee communities was transferred from the Bureau of Human Resources to ONA (Portland. City Budget FY 1987-88 129). In FY 1988-89, the City Council transferred three programs from the Bureau of Human Resources to ONA - " the Metropolitan Youth Commission, the Metropolitan Human Relations Commission and the City/County Commission on Aging." The City Budget reported that: "These programs join the existing ONA programs of Citizen Participation, Crime Prevention and Mediation. The youth, aging and human rights constituencies are a natural complement to the neighborhood network in that they serve as a vehicle for citizen participation and advocacy on social issues of concern to neighborhoods. The agendas of both programs will be enhanced by integration into one bureau" (Portland. City Budget FY 1988-89 167-170).

\footnotetext{
${ }^{23}$ This agreement was driven in part by the fact that the City was better able to provide urban services to people living in un-incorporated areas of Multnomah County to the east of the City of Portland (much of this area was annexed into Portland during the 1980s and 1990s), and by the County's revenue short fall at the time. The County agreed to focus on its core services of assessment and taxation, elections, corrections, libraries, and health services. The City focused on police services, neighborhood parks, and land use planning, which allowed the County to reduce its spending in these areas (City of Portland, Office of the City Auditor 2013 3).
} 
ONA Directors Patti Jacobsen (1979-84) and Sarah Newhall (1984-1989):

Pattie Jacobsen became the new ONA director in October 1979 after the departure of ONA's first director, Mary Pedersen. Witt reported that Jacobsen had worked at ONA under Pedersen and "would build on the program's initial accomplishments, maintaining a capacity building ethos while consolidating ONA's stature vis-à-vis" city government agencies (Witt 108). Witt noted that Jacobsen focused on "fostering greater administrative capacity among the District Coalition offices..." at the same time that some neighborhood activists remained leery of ONA control. Witt argued that Jacobsen needed to show the City Council and "ardently conservative" Mayor Frank Ivancie, that the neighborhood system could function "smoothly and accountably" (Witt 109)."District Coalition volunteers typically did not identify themselves with an administrative role" and viewed with suspicion ONA efforts to build ties with District staff and to shift administrative responsibilities and neighborhood association support functions ONA to the neighborhood district coalitions. Witt reported that, under Pedersen, ONA's primary focus had been on organizing new neighborhood associations and ONA picked up the "slack in administrative work, and [forgave] breaches in accountability among District Coalition boards and staff as a means for leveraging trust in ONA (Witt 110-111). As the number of recognized neighborhood associations grew "ONA needed to build District Coalition capacity in order to help spread the burden of accountability in the program." Witt maintains that building capacity among the District Coalition Boards also was needed to show the "City Council that the two-tiered, sovereignty model of neighborhood association governance was viable." 
Witt reports that "shoring up faith in the neighborhood association ethos required that more attention be paid to downtown administrators as well." He writes that "Jacobsen worked diligently to establish trust between ONA and other bureaus, especially the Bureau of Planning and the Department of Transportation. Under her administration, ONA sponsored workshops for downtown staff covering the skills necessary for successfully communicating with neighborhood activists." Witt gave Jacobsen's efforts a large part of the credit for the "esteem with which Portland [City] administrators would hold the neighborhood program by the time the Tufts [University] team held is first round of interviews in 1986..." (Witt 113). Jacobsen also oversaw the incorporation of two new programs into ONA - the crime prevention and neighborhood mediation programs.

The Crime Prevention program, had been a separate program, initially funded by federal dollars. Witt reports that district coalition board directors and staff had often "bristled "at the programs mandates. The City took over administration of the crime prevention program in 1984 and housed it within ONA. Witt reports that "crime prevention staff associated with ONA," who were trained in community outreach, “cultivated an outlook distinctively separate from crime prevention efforts operating out of the Bureau of Police." While the police focused on "'target hardening' workshops and school-aged programming," ONA's crime prevention efforts "focused on assisting neighborhood residents [to identify] crime and public safety issues, setting up block watches, and providing training in spotting and addressing neighborhood crime trends." Staff "served as a bridge between beat officers and their police precincts, and 
neighborhood activists." Witt reported that the "neighborhood mediation program had been functioning under the Metropolitan Human Relations Commission.” The mediation program "focused on resolving disputes between neighbors that otherwise might have escalated to confrontation and legal proceedings" (Witt 113-114).

Witt wrote that Jacobsen and her staff achieved many of the priorities established when she became ONA director. Witt reports that one example of the strengthened credibility of Portland's community and neighborhood involvement system was ONA's successful effort to rally ONA supporters to lobby against "a proposal by Mayor Ivancie to cut the district coalition program in 1983." Witt writes that Ivancie's effort to cut the district coalition program "stemmed from residual skepticism and fear that the [neighborhood district coalition] level would detract authority from City Council" (Witt 115). Witt reports that one priority that Jacobsen was not able to achieve was to "codify the role of the Budget Advisory Committees through Council ordinance." Although the BAC program was "expanded and in some ways strengthened under Jacobsen's successor, Sarah Newhall," the BAC program never would receive the formal stature of being established through ordinance. Witt reports that the City Council would recognize the program through a City Council resolution and that subsequent formal ONA "Guidelines" would refer to the program, as well (Witt 115-116).

Witt concludes that Pattie Jacobsen's tenure as ONA director primarily was focused on consolidating the early gains of the Portland's new community and neighborhood involvement system. He argues that "the contradictions and embedded conflicts the program embodied were contained during ONA's first decade" partly 
because "few were willing to publicly gainsay the program during its infancy" out of a sense of "fair play"" that "necessitated that it be given a chance." Witt also cited the importance of the still strong memory of the impact of urban renewal in Portland and role of the ONA program in "signaling the City Council's good faith never again to impose a unilateral will upon the City's struggling neighborhoods." Another factor, Witt identified, is the deft management of Pedersen and Jacobsen in building "stakeholder investment in the program, thereby capturing insurgent dissent" and Goldschmidt's role in leaving in "strong legacy of activist leadership" in Portland and a "halo effect" the "citizen participation" would retain "for the next several years" because of Goldschmidt's "political presence throughout the 1970s" and his "close affiliation with the NA program, and vice versa" (Witt 116-117). Witt states that, "In sum, Portland wasn't quite sure what it had done by creating an NA program; but whatever it was, or was to become, it had something in it for everyone" (117).

Witt reports that "forces were in motion that would have a lasting impact on the NA program," including: an economic recession that started around 1982; Portland's push to annex large areas of unincorporated Multnomah County east of the city limits and ONA's involvement in trying to bring existing neighborhood organizations and structure in this area in the ONA system; and clashes within the North Portland district board that would lead to an ONA takeover of the management of that district office (Witt 117-118).

Sarah Newhall became ONA's third director about the same time that northwest Portland populist tavern owner and community activist Bud Clark defeated incumbent 
Frank Ivancie in the mayoral race in 1984. Witt reported that Newhall pursued several initiatives that would decisively shift ONA's focus (Witt 119-120).

Witt characterized Ivancie's defeat as the end of the City's "old boy's club" that the Portland's “1970s activist vanguard,” including Goldschmidt, had mobilized against. Witt reports that Clark's decisive victory over Ivancie showed that "liberal populist sentiment was still alive in Portland despite the "conservative backlash" in many communities across the country during the Reagan administration (Witt 199). Berry, Portney and Thomson (1993) reported that when the Reagan administration took office in 1981, it quickly classified "citizen participation" "as part of the liberal agenda that it was elected to undo" and supported the dismantling of many community involvement programs across the country (40). In contrast, the Oregonian reported that Portland historian E. Kimbark MacColl said that “Clark’s victory as a political novice is unprecedented in mayoral races in this century" and represented a "return to a trend toward neighborhood power" that began in the Goldschmidt administration (Painter. Oregonian 17 May 1984).

Witt reported that the major shifts under Newhall were driven in part by a number of intense conflicts within the neighborhood system during her tenure as ONA director. Newhall responded to these challenges by focusing on formalizing ONA/DCB relations through rule making processes (Witt 121). Newhall also would strengthen the BAC program. Witt wrote that "linked together, the BAC program and routinization of ONA/DCB relations would garner for ONA a fully manifest institutional profile in city politics" (122). Witt reported that, in 1988, Newhall also "would have to head off a 
budget battle which, as with the Ivancie effort in 1983, threatened to halve the ONA program by doing away with the District Coalition offices" (120).

Witt also asserted that the shift of programs from the Bureau of Human Services to ONA, represented a shift in thinking by ONA Director Sarah Newhall and subsequent ONA Director Rachel Jacky about the purpose of the neighborhood system. Witt reported that, in the face of "continuing cutbacks in funding for social programs," City leaders saw neighborhoods becoming "the 'people's safety net"” and that "Neighborhood groups are being drawn, sometimes in spite of themselves, into a wider range of self-help problems than has been customary." Witt reported that, even though ONA BAC approved the move of programs from the Bureau of Human Resources to ONA, the move "elicited strong reaction from some [neighborhood district coalition] and [neighborhood association] activists fearful this move signaled a trend away from support for [neighborhood association] activism" (Witt 146-147).

\section{ONA Review Committee}

By the late 1970s, concerns had started to arise in the community that some neighborhood associations were not operating in open and democratic ways and were being dominated by small groups of people. In 1979, ONA's Commissioner-in-Charge Charles Jordan impaneled a special citizens committee-the ONA Review Committee--to review aspects of the operation of ONA and neighborhood associations. He initiated this review partly in response to the concerns of a community member about "the quality of citizen participation and the conduct of neighborhood associations," particularly the Northwest District Association. The central focus of the community member's concerns 
was the lack of adequate mechanisms to ensure that neighborhood associations would be accountable to their communities and would operate in an open and democratic manner. The committee gathered information during the fall of 1979 and submitted its report to Commissioner Jordan and the City Council in April 1980. This report offered interesting insights into how well Portland's neighborhood system was meeting the needs of some community members and included recommendations for system improvements.

The community member who had filed the formal complaint expressed concern that the City's standards for formally recognized neighborhood associations were inadequate and that the standards in the 1975 Ordinance and ONA's contracts with the district offices were too vague to hold neighborhoods accountable to their communities.

In a letter to the community member, Commissioner Jordan said he shared this view that the City should require the procedures and practices of recognized neighborhood associations to "encourage broad participation, the expression of diverse views, open decision-making, and the recording of minority positions." Jordan agreed that "any citizen participation process sanctioned by the City must be fundamentally democratic." Jordan disagreed with the community member about the "propriety and desirability of City control of the programmatic and policy directions of neighborhood associations." He stated that his opinion was that "the vitality of the City depends in part on a diversity of neighborhood interests, perspectives and organizational models" and that the City Council was responsible for fashioning "City-wide policies in full awareness of such diversity" (Portland. City Commissioner Charles Jordan. Letter to Robert Butler 2 August 1979.) 
Jordan charged the ONA Review Committee members with developing recommendations in response to the following questions:

- $\quad$ "The adequacy of and the need for process standards in the ONA ordinance including but not limited to: bylaws, membership, elections, minutes, financial statements, meeting notifications, grievances, communications with the City, and conflicts of interest."

- "The adequacy of performance requirements in the neighborhood office contracts, including but not limited to fiscal and work accountability to the City."

- "An assessment of the public benefits and liabilities of contract and Civic Service employment arrangements for neighborhood office staff." (At the time, of the five neighborhood district offices, only the office in northeast Portland still had civil service employees)

Jordan asked the committee members to confer with a city-wide sample of community members that represented businesses, neighborhood associations, the five area review boards, and the broader community.

Committee members began their work in the fall of 1979. They gathered information through "face-to-face interviews, a mailed questionnaire and a public hearing" (Portland. City Commission Charles Jordon. Memo from Peter Engbretson. January 28,1980$)$. The committee sent questionnaires to neighborhood association chairs and designated contact people and interviewed neighborhood activists, representatives of neighborhood business associations, Patty Jacobsen, the ONA director, and present and 
past ONA staff members, City Council members, and the area coordinators from the district offices (Portland. Office of Neighborhood Associations. ONA Review Committee Hearing November, 7, 1979, meeting notes 3-4; from Carl Abbott personal file; and notes from Jacobsen interview and meeting with area coordinators).

November 1979 Hearing: Notes from a public hearing held by the committee in November 1979 reveal the nature of some of the concerns being raised at the time about neighborhood associations. Robert Butler, the original complainant, asked who was responsible for investigating and correcting a situation in which a neighborhood association was being controlled by "a specific interest group" that did not reflect the opinions and priorities of the broader neighborhood? Butler said he agreed with the committee's view "that the City should require that recognized neighborhood associations' procedures and practices encourage broad participation, expression of diverse views, open decision-making, and recording of minority positions." He then asked how "neighborhood associations can be made sure of being democratic." He then asked who would determine when a "specific interest group exists and controls a neighborhood association" and how would such a circumstance be corrected (Portland. Office of Neighborhood Associations. ONA Review Committee Hearing November, 7, 1979 , meeting notes 1$)$ ?

Butler recounted his frustrations with the City's response to his complaints about the NWDA. Butler had gone to ONA in 1978 with a complaint that the NWDA was being controlled by "a special interest group." ONA said that NWDA was an independent contractor and was not controlled by ONA. Butler got a similar response when he took 
his concerns to the Commissioner in Charge of ONA. He then took his complaint to the City Council asking that the NWDA be investigated and that the organization's city funding be revoked because it had violated the 1975 Ordinance. While supporting the need for and value of neighborhood associations to the City, Butler argued that given that the "City funds neighborhood associations" and that the City, therefore, had the "right to ask for standards, standards pertaining to quorum size, minute-taking, and public hearings" (2).

Butler specifically suggested that "[s]ome neighborhood associations are not democratic with their minutes." He recommended the adoption of citywide standards for neighborhood association minutes. He reported that ONA staff had told him that ONA did not want to require neighborhood associations to submit their minutes to ONA to avoid the impression that ONA was trying to "wiggle into their organization and make a City bureaucracy out of it" (2). Butler argued that neighborhood associations should be required to make their minutes public to provide a formal record when neighborhood association make decisions. One participant argued that making minutes public might subject neighborhood association members who make motions subject to personal retaliation (3).

Other hearing participants agreed with Butler. One said that standards are very important. "Lump groups of two or three people can control entire neighborhoods, just because people don't go to meetings, quorums aren't required, minutes aren't read and filed." He said the impression was that City government had "abdicated its responsibility" over "variances and condition use requirements" and had "dumped them 
onto the neighborhoods." Another participant charged that the NWDA often appeared to have made decisions in advance with fully reviewing and considering proposals before them and exercised its authority in very subjective ways-denying most land use process requests, but approving proposals submitted by a clients of the chair and a board member (5). Some participants charged that some neighborhood association leaders were abusing their power and acting in undemocratic ways. Another individual said that "Neighborhood associations have a lot of political clout. That's ok only if those organizations are run with standards on a democratic basis" (5).

The committee chair noted participants concerns that some neighborhood association processes were not open and appeared to prejudge issues brought before them. He recognized that one suggestion was "quorum requirements for that kind of decision-making committee" (6).

One neighborhood leader reported that not all neighborhood associations handled land use issues the way NWDA was being accused of doing. He said when his neighborhood association gets a conditional use permit request "we poll [the] area about it, put out 100 forms, get [them] back, break down the response into majority and minority report $[\mathrm{s}] . .$. " He said the neighborhood association included space on the form for "people to say why they voted the way they did." Another participant suggested a "meeting of chairmen of neighborhood associations" to share outreach and inputgathering tools that work well (6).

Another testifier suggested that neighborhood associations sometimes are and sometimes are not representative, "because it depends on who's willing to come. When 
the issue is of wide interest, [a] really big crowd comes" and they get a fair opportunity to share their opinions. "Most of the time, day in and day out, [the] same people show up. That's representative, because people are aware of [the] meeting." If they come, "they are represented. If they don't come, they are not represented. If you have a special interest, you can possibly stack the deck" (7).

The committee chair noted that the 1974 Ordinance had established a formal process for official City Council recognition of neighborhood association and approval of their bylaws. Objections from neighborhood association activists lead the City Council to delete the City's recognition of neighborhood association bylaws in the 1975 Ordinance. Thus, the City currently did not require neighborhoods to record dissenting votes, record types of meetings at which issues were considered, and attendance (7).

ONA Review Committee Findings and Recommendations: The ONA Review Committee submitted its final report to Commissioner Jordan in February 1980. The committee found that people involved in neighborhood associations had high levels of support and/or satisfaction with ONA and that citizens increasingly supported neighborhood involvement citywide as they became "familiar with ONA and neighborhood associations." They also found a "strong consensus" that any ONA structure must be designed to serve neighborhood interests and agendas, and that leadership must rest with neighborhood associations and not city staff." The committee urged that the impact of citizen participation not be "measured simply by the number of people who attend meetings," but in the impact of "the entire process of neighborhood associations," which "raises issues," "facilitates formal and informal discussion," and 
helps to train "large numbers of citizens in ways to influence city government," not just in the "number of people who attend meetings" (Portland. Office of Neighborhood Associations. ONA Review Committee. Final Report. February 25, 1980 1).

The committee found "almost unanimous support" for the present contract approach between ONA and the four area offices. ONA staff, City Council members, and the citizens interviewed strongly supported neighborhood control of area coordinators. Committee members reported that they found a strong belief "ONA structures should be responsible to the associations and not the other way around" (Portland. Office of Neighborhood Associations. ONA Review Committee 1).

The committee recommended that the city "continue the contract arrangement with area review boards for the employment of staff for areas offices..." and that the central ONA office “develop a system for setting and monitoring work goals and objectives in cooperation with area coordinators." The committee members clarified that their intention was that the central ONA office would assist the coordinators of the district offices "in self management of their time," not "establish work program and priorities" for the district offices (1).

The committee did not support the adoption of more formal guidelines for neighborhood association recognition — such as those recommended by some of the participants at the November 1979 hearing-but rather recognized and supported the "trend in the evolution of ONA" which the committee noted had been, throughout the system's early history, "away from specific structural requirements for neighborhood associations and toward looser performance guidelines and standards." The committee 
found that the current performance standards for the system were adequate "to assure democratic procedures if these standards are conscientiously followed" (2). ${ }^{24}$

ONA Organizational Capacity Building: The committee identified a number of ways ONA could assist neighborhood associations. The committee recommended that ONA develop a standard reporting form that neighborhood association could use to report "the results of neighborhood decisions to city bureaus, including data on the vote, attendance, character of meeting, and the like" and one or two templates for standard bylaws that neighborhood associations could "adopt or modify as they please" (3).

The committee recommended that ONA review neighborhood association bylaws and point out any violations of the 1975 Ordinance language that established eligibility requirements for formal recognition of neighborhood associations (these included: nondiscrimination in membership and no dues, a formal process to document and transmit dissenting view, a formal grievance process, and filing of the neighborhood association bylaws with ONA (3.96.030)) (2).

The committee also recommended that ONA "educate" new neighborhood leaders "about their responsibilities to their neighborhood and to the city" and hold workshops for neighborhood leaders on techniques to solicit a broad range of public opinion (e.g. neighborhood polling) and procedures for neighborhood association elections that would expand participation in elections beyond those who regularly attend neighborhood meetings (2).

\footnotetext{
${ }^{24}$ It is interesting to note that calls for more formal standards continued to be heard, and led to the creation of the first version of the ONA Guidelines in 1987 (described below). Formal guidelines (later called "standards") have continued to be an important element of Portland's neighborhood system. Revisions of the 1987 Guidelines were adopted in 1992, 1998, and 2005. In 2013, ONI and the neighborhood coalition leaders again are preparing to initiate a formal process to review and update the ONI Standards.
} 
Communication: The committee also recommended "a substantial increase in the ONA budget for printing and distribution of newsletters and other notification materials." The committee found neighborhood associations depended on ONA assistance to produce and distribute "newsletters and notifications" and that communications could be "significantly strengthened at relatively small cost." The committee members argued that "ongoing facilitation of intra-neighborhood and city-neighborhood communication is the most positive way to deal with the question of representativeness" of neighborhood associations (2).

Although the committee did not recommend formalizing additional requirements for neighborhood recognition, the committee did suggested that ONA "encourage neighborhood associations to include agendas and minutes of previous actions in their meeting notifications" and "encourage neighborhood associations to develop publicity and membership campaigns oriented to the needs and character of each neighborhood" (3).

Increase ONA assistance capacity: The committee recommended that ONA increase the capacity of ONA staff to provide organizational and technical assistance to neighborhood associations. Key areas for assistance included: communication, block organization, neighborhood surveys, retention of neighborhood association members, and technical advice on land use, economic development, the creation of community cooperatives, and local service provision. The committee urged ONA to make workshops "an ongoing part of ONA activities" and to develop a peer support system through which 
"neighborhoods can borrow expertise from each other and from other voluntary sources through regular workshops and project consultation" (3).

The committee also suggested that ONA establish a "technical assistance fund" of about $\$ 10,000$ to $\$ 15,000$ to pay for technical assistance to neighborhood associations. The committee envisioned that the central office would administer this fund, "which area boards and perhaps individual neighborhood associations can use for short-term technical advice on questions of planning, law, economic development, and self help" (3).

Neighborhood Needs Process: The committee recognized that ONA already monitored and reported on city bureau responses to formal Neighborhood Needs Program requests from neighborhoods, but recommended that if would be useful for ONA also to report on the "actual implementation of these requests" by city bureaus (3).

ONA orientation-service to neighborhoods vs. city agencies: The committee raised a concern about the focus of ONA's work, noting that ONA assistance to city bureaus could divert ONA's attention away from ONA's service to the neighborhoods. The committee recognized that ONA work with neighborhoods and citizens greatly eased the work of city bureaus. The committee cited citizen participation functions "performed for the Planning Bureau, the Neighborhood Needs process, which "several bureaus now rely on in their budget-making," and "individual referral and assistance, which should property be a function of a general city information and service system" (3). The committee cautioned these activities and similar service to city bureaus could "absorb such a large portion of ONA staff time and money," that they agency would not be able to "properly assist the activities of the neighborhood associations themselves" (3). 
The ONI Review Committee examined issues of the accountability and openness of neighborhood associations and instead of formal standards what neighborhood associations needed was more support—-training, funding for communications, and organizational support. The Committee also emphasized the importance of ONA remaining primarily focused on providing services to neighborhood associations not City bureaus. Many of these same issues would continue to come up throughout the history of Portland's community and neighborhood involvement system.

\section{Association of Portland Neighborhoods - 1984-1986}

The 1972 DPO Task Force report discussed the value of having some sort of citywide body that would allow neighborhood association leaders to discuss and act on citywide issues. The task force members were not able to agree on a particular approach to recommend. In the 1970s, the Portland Association of Neighborhoods (PAN) organized a short-lived effort to convene neighborhood leaders from across the city to take action on city wide issues. In March 1984, a number of neighborhood association representatives met and founded a new city-wide neighborhood body that they named the Association of Portland Neighborhoods (APN). The Oregonian reported that the group's interim purpose statement said "the organization is intended to promote stronger neighborhood associations and provide a structure for communication among neighborhood associations."

Meeting participants discussed different citywide issues the group might work on. They agreed that when special-interest groups already were working on an issue the APN would work "with the existing groups rather than duplicate their work." Some of the 
issues identified by the group included: "budgeting for the [ONA] budget, transportation concerns, sign code enforcement, notification on land use issues to neighborhood associations, annexation, and development along the Willamette River" ("Citywide group ‘official.'” Oregonian 30 March 1984).

The Oregonian ran an editorial criticizing the creation of the group and warned that the group could shift the "direction of issues and advocacy" from the "grass roots up" to a more top-down model. The Oregonian said the group's promotion of a citywide organization for neighborhood associations “could end up diluting Portland's growing and enthusiastic neighborhoods effort and support." The editorial argued that the city's grass-roots neighborhood program was "set up to be participatory, not representative." “The City Council is representative" while "citizens serving on neighborhood associations are obliged to involve their neighbors in the issues that affect their neighborhoods, not purport to represent them on a citywide panel."

The editorial also said the new group would shift emphasis away from "internal communication" between neighbors to "external communication" between neighborhood associations. Rather than creating a new citywide body, the Oregonian supported continued sharing of information by individual neighborhood associations "with members of other groups and through" ONA. The editorial also advocated for the restoration of "ONA sponsored citywide conferences, which offered additional opportunities for discussing mutual problems and sharing ideas for solutions." The editorial noted that "City budget cuts ended those conferences." The Oregonian supported continued funding for the ONA and "the local groups themselves," but 
opposed additional city funding to fund a new citywide group. The editorial recognized that "no such request for money" had been made, but argued that "organizations tend to want staff and, thus. New bureaucracies are established."

The Oregonian concluded that "Citizens concerned about maintaining and improving their city and their neighborhoods have the tools at hand now: their personal energy and commitment, their neighborhood associations, the elected City Council, County Commission and regional Metro Council, and state and national governments. They do not need another structure — another layer of organization" ("Maintain neighborhood focus.” Editorial. Oregonian 28 March 1984).

A few weeks later, John Werneken, a representative of the Association of Portland Neighborhoods, responded to the Oregonian editorial in an "in my opinion" piece. Werneken chided the Oregonian for opposing the new group and argued that the new organization's "primary goal is to promote stronger neighborhood associations" not to weaken them. He argued that the group would accomplish this by "providing a structure for communication and information sharing" that would "help community volunteers throughout the city" and would give "an opportunity to citizen volunteers from throughout the region to get to know each other face to face...." Werneken maintained that the "association is participatory and in no way another layer of organization."

Werneken argued that the group specifically was working to "avoid duplication of effort" and the creation of "a cumbersome bureaucratic structure" and "seeks no city funds." He maintained that group members "care about issues of city-wide concern, such as adequate public notice about upcoming hearings and decisions. It intends to pursue 
these issues by providing a forum for citizens to work together on issue research and by providing a means of quickly informing all neighborhoods of research findings."

Werneken further argued that neighborhood associations should continue to focus on their neighborhoods but that "citizen volunteers acting together to research and report on issues can provide more effective support for neighborhoods than citywide conferences held at public expense." Werneken wrote that the group would complement the efforts of the district coalition boards and ONA to foster citizen participation, helping community members express their opinions, and to mobilize "volunteer energy to accomplish tasks which otherwise might have to be done by the city itself." He argued that the new forums would work with ONA and build on "a system that works efficiently and effectively today at the area board level."

Werneken concluded that the Association of Portland Neighborhoods would enhance citizen participation by "supporting neighborhood associations" and working “with [ONA] as the associations do with the city agency's field offices." He maintained that the "new association will be building more support for the heart and soul of all neighborhood associations: the concerned citizen who is willing to contribute his or her energies to the better met of the community" (Werneken, John. "In my opinion: Association to serve neighborhood groups.” Oregonian 24 April 1984).

Over the next two years, newspaper articles show that the APN held regular meetings at which its members discussed a wide range of issues, including: citywide public transit issues, noise issues, enforcement of outdoor sign regulations ("Community Calendar." Oregonian 26 June 1984) and zoning code revisions, annexations and urban 
services policies, "nuclear waste processing by the Portland of Portland, and other citywide neighborhood concerns" (Oliver. Oregonian 26 September 1984).

In August 1984, the APN co-sponsored the city's second annual citywide neighborhood picnic along with ONA, the City Council, the Neighborhood Mediation Center, the Police Bureau crime prevention unit and the five district neighborhood offices. The event was intended to be a gathering of neighborhood volunteers and “anyone interested in meeting people." The event included a wide range of entertainment and activities, including "a volleyball tournament featuring city commissioners on each of four teams...." (“Citywide neighborhood picnic on tap.” Oregonian 21 August 1984).

The APN also was called on to play a role in local elections. The Oregonian reported on an effort by community members to get the APN and ONA to join the League of Women Voters in sponsoring a public forum for candidates seeking to fill the city council seat being vacated by City Commissioner Charles Jordan, the long-time commissioner-in-charge of ONA. ONA Director Sarah Newhall said "she did not think it was proper for her agency to sponsor such an event" but thought the APN "would be an appropriate sponsor." It's not clear whether the APN did go ahead and co-sponsor this event, but the request from the community appears to show an interest in having a citywide neighborhood body have a voice in local politics (Painter. Oregonian 7 September 1984).

An interesting example of how APN saw its role occurred when the APN "tiptoed...into the volatile debate over a proposed Fred Meyer store" in northeast Portland in 1985, which was being challenged by nine neighborhood associations. The 
APN maintained that it did not "take stands on specific neighborhood issues" and, instead, chose to “produce a statement generally supporting the city's comprehensive plan and arterial street designation" and affirming "that neighborhood associations represent Portland's citizens and support economic development...." The APN also chose to "send a summary of the evening's discussion of the Fred Meyer proposal to the city's 80 neighborhood associations, asking them to consider taking a stand on issues raised by the controversy."

The APN's major policy achievement was in 1986 when it got the City's Bureau of Planning to research, develop, and adopt regulations for conveniences stores in Portland-regulations that remain in effect nearly 30 years later. During the 1980s, neighborhood activists became alarmed by what they perceived as "a serious epidemic" of convenience doors being located in their neighborhoods. Neighborhood representatives charged that the stores degraded neighborhood livability. Key concerns included "traffic, noise, litter, loitering, crime, density, hours of operation, liquor sales, and community relations" (Bailey. Oregonian 27 August 1986). The APN's effort led the City's Bureau of Planning to create a citizens advisory committee, which studied the issue and recommended new regulations for the convenience store industry. These "good neighbor standards" required convenience store developers to "meet with delegates from interested neighborhood association before apply[ing] for city land use and business permits." The standards also provided for the development of a good neighborhood agreement between "store operators and neighborhood groups on the issues of crime, alcohol sales, noise, little, building appearance and maintenance, loitering and lighting." The new regulations 
also included provisions for "long-term communication between neighborhood associations and convenience store operators to monitor and enforce the good neighbor agreement..." (Oliver. Oregonian 24 September 1986).

The APN did not appear in newspaper accounts after the adoption of the new convenience store standards. Lee Perlman, long-time community journalist and former ONA employee, reported that he had volunteered with the APN and had helped them get out their mailings. He remembered that after the major effort on the convenience store regulations, the APN members "ran out of steam." Perlman also noted that the group did not have any formal staff support putting all the burden of managing the organization and carrying out its activities on the members. Perlman noted that most APN members already were active in their neighborhood associations and neighborhood district coalition bodies and that this additional level of activity became too much for most of them.

Perlman also commented that he thought the inability of both the Portland Alliance of Neighborhoods in the 1970s and and the Association of Portland Neighborhoods 1980s to sustain their efforts was due in part to the fact that Portland neighborhoods already had some voice through the formal neighborhood system. Perlman suggested that similar citywide organizations in other cities had persisted because community activists saw them as critically important to protecting their communities. Perlman said that, in his opinion, neighborhood activists in Portland saw the PAN and the APN as something that was "nice but not essential." The activists involved say these bodies as "a few priorities down from priority one." Also "the same 
people got kind of burned out" and there was "not enough replacement, so after a while they petered out" (Perlman. Conversation with Leistner. February 13, 2013).

The APN experience illustrates both the advantages of having some sort of citywide body to give neighborhood associations visibility and a voice in broader policy issues but also the difficulty of maintaining such a body without formal staffing support. Volunteers in such effort get stretched thin because they usually already are active with their neighborhood association and neighborhood district levels—involvement that grounds them in the issues of the neighborhood. However, volunteers find it difficult to sustain this high level of involvement over time, especially if they have other vehicles available to pursue their goals.

Neighbor Fair - 1976 to 1990

Neighborhood celebrations and festivals are an important way that community members engage in civic life and become aware of community involvement opportunities. Portland's largest citywide celebrations of neighborhoodsNeighborfair—occurred during the early years of Portland community and neighborhood involvement system. Neighborfair was an annual event organized by KGW Radio and held for the first time in downtown Portland in July 1976 on the city's newly reclaimed riverfront. ${ }^{25}$ The event showcased local neighborhood associations, ethnic groups, and

\footnotetext{
${ }^{25}$ In 1976, the first Neighborfair was held on riverfront land in downtown Portland that had recently been reclaimed to build a public park after the decommissioning and demolition of the Harbor Drive freeway. The Congress for New Urbanism identified this project as the first major freeway removal in the U.S. Harbor Drive was closed in 1974 and the new 37-acre Waterfront Park was opened in its place in 1978 (Congress for the New Urbanism website, http://www.cnu.org/highways/portland, downloaded on 09/07/13ed). In 1976, ONA Director Mary Pedersen told the Oregonian that she thought "Neighborfair vindicated all those people who worked so long on getting that park down there" and clearly responded to
} 
other community organizations. The event grew each year and drew more people, organizations, and entertainment. By the early 1980s, however, the event had grown so big that most neighborhood associations had stopped participating. KGW finally cancelled the event in 1990.

First Neighborfair was held in 1976. The event originated with KGW Channel 8 staffer, Joan Biggs, who had been had been "working on a series of news reports about Portland communities." During her research she had learned about the many community organizations and program in Portland at the time. Biggs told the Oregonian that she thought “'Wouldn't it be nice if all these people could come together at the waterfront some Sunday and display what they have to offer?'” (Stickel. Oregonian 20 July 1981.) The event was combined with the already planned Portland Folkfest, which was organized by ethnic and cultural organizations in Portland to intended to showcase their “cultural, historical and folk life traditions" (Pihl. Oregonian 25 July 1976).

Neighborfair included a wide range of activities including ethnic food booths, musical performances, booths and activities sponsored by neighborhood and community groups, speeches from politicians including Portland mayors and city council members and Oregon's governors and often closed with an evening concert and fireworks. ${ }^{26}$ In

people who had raised questions about "who would use a waterfront park and why anyone would want to go there..." (Goetze. Oregonian 1 August 1976).

${ }^{26}$ Neighborfair in 1979 featured the first release of what would become the world famous "Expose Yourself to Art" in which Bud Clark, community activist, local bar owner, and co-founded of the Northwest Neighbor community newspaper, appeared from the back to be wearing only a trench coat and was exposing himself to a statue of a nude woman on Portland's bus mall. The photo was taken by Northwest Neighbor staffer Mike Ryerson and was sold at Neighborfair in 1979 to raise funds for the newspaper. By 1984, when Portlander's elected Bud Clark as their new mayor, Ryerson reported that over 250,000 copies of the poster been sold to people all over the country (Hayakawa. Oregonian 17 May 1984; Wikipedia article, "Expose Yourself to Art," downloaded on 09/07/13). 
1977, the Oregonian described Neighborfair as a "chance to stroll, munch, hum and meet your neighbors," listen to "music from every land on three stages," and enjoy "folk dances, gospel singers, clowns, jugglers and circus stunts." The paper noted that "Everywhere there was dancing: Belly dances, African hat dances, Swedish, Norwegian, Greek and Oriental dances." "Visitors could take a Cook's Tour of the world" sample food from many different countries and cultures (Ruble and Leverett. Oregonian 18 July 1977.)

Neighborfair was very popular, and attendance grew each year. Between 50,000 and 75, 000 people participated in the first Neighborfair In 1976, according to the Oregonian (Olmos. Oregonian 19 July 1976). In 1980, the Oregonian reported that 250,000 people attended the event (Goetze. Oregonian 17 July 1981). In 1981, the Oregonian referred to Neighborfair as the "country's biggest block party" and noted that 250 non-profit organizations participated, including "Neighborhood associations, scout troops, school organizations, church groups, and social service agencies (Goetze. Oregonian. 17 July 1981). In 1982, the Oregonian anticipated that 500,000 people would attend, which, the paper noted, would qualify Neighborfair as the "biggest city in Oregon" for the day (Hortsch. Oregonian 16 July 1982).

In the early years, many neighborhood associations participated and had booths from which they "offered information about their organizations and activities for fairgoers" (Goetze. Oregonian 20 July 1979). In 1979, the Oregonian reported that at least eighteen neighborhood associations were among the more than 200 organizations expected to participate in Neighborfair that year. Neighborhood associations booths 
offered activities that included: "a bean bag toss—with caricatures of city commissioners as targets," "face painting and a balloon dart game," "arts and crafts and peanuts," and beer gardens, and offered "fruit drinks and sausage," "lemonade... and jogging maps," "hot dogs and coffee," and "watermelon slices." Some neighborhood associations sold tshirts with their logos, while another neighborhood association operated a dunk tank for local leaders and celebrities as a fund raiser (Goetze. Oregonian 19 July 1979). ONA had a booth and gave out bumper stickers that read: "Neighborhoods: A Renewable Resource" (Goetze. Oregonian 20 June 1979).

Neighborhood association participation in Neighborfair began to drop off in the early 1980 s as the event got much bigger and the focus on neighborhoods was overshadowed by all the other activities at the event. Neighborhood associations said they stopped participating because the cost of having a booth were too high for many neighborhood associations and because the large size of the fair made it difficult for neighborhood associations to compete for visibility with all the other activities and commercial food sales at the fair. Some neighborhood leaders said the high amount of volunteer effort required for them to participate in the event was not worth it. Many other community non-profit organizations continued to participate in Neighborfair and used the event as a major fundraising opportunity.

By 1990, KGW decided to cancel Neighborfair because the cost to the station of producing the event had risen dramatically over the years and neighborhood associations—one of the original focuses of the event—had stopped participating. Also, while Neighborfair originally had been the "only festival of its kind held in Portland's 
riverside park," by 1990, the event was competing with a number of other similar events and was no longer unique (Gilbert. Oregonian 3 February 1990).

The Oregonian reported that an ONA representative said that the "neighborhood flavor of the fair and its benefit to neighborhood groups" had been "lost years ago." She said that neighborhood associations believed that "their efforts are better spent organizing their communities around issues that affect them in their own back yards and prefer to organize their own smaller festivals...." "It outgrew itself as a neighborhood event. It just got too big." ONA had dropped out of the "fair after finding that the event was "not a good place to recruit volunteers or deal with issues" (Gilbert. Oregonian 3 February 1990).

A number of neighborhood associations and neighborhood district coalitions focused instead on developing community festivals at the neighborhood or neighborhood district level. One neighborhood district coalition that refocused its efforts on a local district festival was Southeast Uplift. In 1981, Southeast Uplift decided to hold its own district festival in August-The Southeast Summer Festival. Several community and neighborhood organizations participated. One of the event coordinators told the Oregonian that "The festival is planned 'to generate revenue for the community associations and to be an information exchange between people who ought to work together..." The event is "patterned after the downtown Neighborfair...." "The event will have good and information booths, a beer and wine area, as well as softball and volleyball events." The Oregonian reported that "The idea for the festival started with the Buckman neighborhood, which has sponsored a flea market in past years...." Other 
organizations involved included "the Mount Tabor, South Tabor, Kerns and Richmond neighborhood associations and the Southeast Uplift office.” Other organizations that signed up to have information booths include: "Responsible Urban Neighborhood Technology (RUNT), the Oregon State University Extension Service and Sunflower Recycling..." The southeast Portland community organizing group PACT hired a PSU work-study student to coordinate the event. She told the Oregonian that "one of the purposes of bringing social action groups together with neighborhood associations is to promote the idea of solving problems on a neighborhood or personal level." "We have been trying to get an emphasis on self-reliance; neighborhood self-reliance is basically the theme." She asserted that the "Southeast Summer Festival will help neighbors meet each other." "It's a good idea in these days and times to get to know your neighbors....It's like turning a big city into a bunch of small towns. It gets people out of their houses and lets them explore food-buying clubs, recycling, solar energy, tool banks and crime prevention"(Dolan. Oregonian 25 August 1981).

While, no citywide neighborhood festival has been held in Portland since the cancellation of Neighborfair, a number of individual neighborhood associations and neighborhood district have continued to organized and host community festivals in their own areas of Portland.

Mayor Bud Clark-Community and Neighborhood Celebration and Recognition Mayor Bud Clark, populist candidate and long-time community and neighborhood activist took office in January 1985. Clark had a strong reputation for having fun and focused on bringing the community together to celebrate and to recognize the work of 
community volunteers and community organizations. Clark hosted a number of community recognition events during this time in office, which are described below.

Bud's Ball: Clark invited the entire community to his inaugural ball, which became known as Bud's Ball and was billed as "Portland's biggest party." The event included 28 bands playing an eclectic mix of "everything from big band swing to new wave to reggae to Dixieland to honky-tonk tunes," a "Bud's Beer and Shooter booth" and an "international food fair." Oregon Symphony Director James DePriest served as master of ceremonies for the first half of the event, followed by Darcelle, Portland's well-known female impersonator, who hosted the second half. The finale included a fireworks display from the Steel Bridge. The proceeds from the party went to help retired Clark's campaign debt (Painter. Oregonian 3 January 1985). Clark continued to host "Bud's Ball” in subsequent years. The events continued to serve as big community parties and, in later years, as fund raisers for the Oregon Food Bank and other organizations. In 1986, the Oregonian announced Bud's Ball for that year and quoted Clark as saying: "Life is more meaningful if you're having fun" (Tomlinson. Oregonian 8 February 1986).

Neighborhood Recognition Week: Soon after taking office, Mayor Bud Clark had his staff begin working with a committee that included representatives from the mayor's office "and each Commissioner's office, [ONA], and many volunteers" to plan a series of activities for what he called "Neighborhood Recognition Week." In a March 1985 memo to city agency directors, Clark announced that the week's activities would include his presentation of "the first annual 'Spirit of Portland' Awards to twelve outstanding citizens...selected by a committee appointed by the City Council with 
recommendations from Neighborhood Area Boards." The awards were to be presented at a City Council hearing on May 9, 1985, followed by a City Council hosted reception for the award recipients. Neighborhood Recognition Week also would include "'The City Listens' a one-day gathering of neighborhood representatives and city personnel." Clark reported that the purpose of this event was to "strengthen communication and develop greater understanding between Portland government and its citizens." He asserted that the "information obtained from this session will be utilized for developing a format aimed at improving services." Clark invited bureau directors and their staff to "participate in the 'City Listens' by facilitating workshops, making presentations, providing tours of city buildings/offices to assist citizens in getting better acquainted with us and the services we provide" (Portland. Office of the Mayor. Memo from Bud Clark to Bureau Managers. “RE: Neighborhood Recognition Week May 6-10, 1985" 8 March 1985). The Oregonian reported that the "City Listens" program would be the primary event for Neighborhood Recognition Week and would allow "neighborhood representatives, city personnel and interested residents" to open "channels for two-way communication." The Oregonian reported that "Mayor Bud Clark, [ONA], and numerous citizen volunteers" were using the event to "develop a hearing aid for city government...one they need residents to speak into if citizens are to play a greater role in determining the future of Portland in coming years" (“Learn to talk to your city.” Editorial. Oregonian 25 April 1985).

Clark continued to host annual "neighborhood recognition weeks" for at least two more years. In 1986, the Oregonian reported that Neighborhood Recognition Week and the "City Listens" program included the Spirit of Portland awards and reception, and a 
series of workshops "on seven topics of community concern" including: "neighborhood traffic management; communicating with City Council; land-use planning; the Portland Development Commission and small business; neighborhood nuisances; police and crime prevention issues; and neighborhood associations.” The week's activities also included informal meetings between commissioners and citizens in which groups of community members met with individual city commissioners or the mayor. The Oregonian reported that Clark said that, in 1985, community members had "emphasized improved communications and understanding of land-use planning." Clark had reported that "communications between the city and citizens had improved" and that the "Planning Bureau developed a training program for neighborhood groups and added a neighborhood planner position” (“Citizen concerns object of 'City Listens' program.” Editorial. Oregonian 29 April 1986). In 1987, Neighborhood Recognition Week, included the third awarding of Spirit of Portland Awards followed by a dessert reception with the City Council, the first time city offices held open houses "to acquaint citizens with bureaus," and a parade of community members, led by Mayor Clark and the city commissioners, from City Hall to Pioneer Courthouse Square for a brown bag lunch and dessert and musical entertainment (“Council ceremony to honor volunteers." Oregonian 10 May 1987).

The Spirit of Portland Awards have become an annual tradition in Portland since Clark initiated the first award ceremony in 1985 . This city-wide recognition process continues to honor community members and community organizations that have made exceptional contributions to the community. Many of the neighborhood district coalitions 
have recognized the importance of awards ceremonies in encouraging and support community and neighborhood activist and volunteerism and hold their own awards ceremonies in their districts as well.

Neighborhood Flag Project: Staring in 1984, Clark also supported the “Neighborhood Flag Project.” This project encouraged each of Portland's neighborhood associations to design and produce its own neighborhood flag. Two women from Portland, on a trip to Sienna, Italy, had “observed that each of the city's 17 political districts" had its own flag. They came back to Portland and proposed that each Portland neighborhood be invited to design and display its own flag. Mayor Clark agreed to support their effort, and ONA, the Junior League of Portland, and the Historic Preservation League of Oregon signed on as co-sponsors for what came to be known as the Neighborhood Flag Project."ONA coordinated the project and sought funds to help neighborhoods "unable to finance a flag." The Oregonian reported that the sponsors believed "the flags will symbolize the uniqueness of each of the city's neighborhoods" (“Neighborhood groups sew up banner designs." Oregonian 26 November 1984). Clark said he intended to "display the banners at his office on a rotating basis" ("Neighborhood banners." Oregonian 2 March 1985).

More than 35 neighborhood associations took advantage of the project to produce their own flags. The flags all had original designs. Some were "created by volunteer artists within the neighborhoods or by hired professionals. Some neighborhoods held flag-design contests in local schools." Nike donated "50 yards of nylon taffeta in four different colors." Kitty Wheeler, originator of the project, said "each of the flags has a 
design that reflects something unique to or of historical interest in the particular neighborhood." "Some designs are silk-screened and some are appliquéd." One neighborhood painted their flag with outdoor point, while another needle pointed their neighborhood name on their flag. All flags were 2.5" by 3.”. ONA Director Sarah Newhall said the "flag project was intended to build neighborhood pride." She envisioned them "being used to brighten business districts and neighborhood parades, hang at City Hall when neighborhood residents visit the City Council, and fly at neighborhood fairs and other special events (Falk. Oregonian 2 May 1985).

Neighborhood flags were displayed in the foyer of City Hall during Neighborhood Recognition week in May 1985 (Falk. Oregonian 2 May 1985) and were flown again at Pioneer Courthouse Square (the "living room" of Portland) in August after a "special flag-unfurling celebration (Oregonian 23 August 1985). Some neighborhood associations mass produced and sold their flags and some printed their flag designs on Tshirts (Falk. Oregonian 9 May 1985).

Mayor Bud Clark marched in the Rose Festival Star Light Parade—in both 1985 and 1986 - and was followed in the parade by community members carrying flags from the Neighborhood Flag Project. (Oregonian 31 May 1985, and Oregonian, 29 May 1986). During the summer of 1986, the Portland neighborhood flags flew at the Multnomah County Fair at Portland's Expo Center (Erickson. Oregonian 23 July 1986).

The practice of unfurling the neighborhood flags at City Hall along with the Spirit of Portland Awards ceremony in the spring continued until 1992. In 1993, both the awards ceremony and the neighborhood flag unfurling was moved to the fall to coincide 
with the 1993 Neighborhood Congress. ONA Director Diane Linn remarked that "some people really like the awards and flag ceremony in the City Council Chambers" and noted that the events got better press and generally more attention being located there (Portland. Office of Neighborhood Associations. Memo from Diane Linn to Sam Adams 18 February 1994).

The neighborhood flags were removed from City Hall when the building closed in 1996 for an extensive renovation. Long-time ONI Staff person Brian Hoop, reported that the flags went into boxes, and later ONI Staff send them back to the neighborhood associations. The neighborhood flags have not been flown together since that time (Hoop. Conversation with Leistner. December 3, 2012).

\section{ONA Guidelines}

Witt noted that the 1980 ONA Review Committee had supported "the historical trend in the evolution of ONA" "away from specific structural requirements for neighborhood associations and toward looser performance guidelines and standards." Witt reported that this view had "shifted dramatically by 1987 when the City Council approved the first ONA Guidelines for the neighborhood system." Witt noted that the 1987 Guidelines formalized “conventions that had guided Portland's NA program until that time" and did so during a time when "several threats were challenging and eroding the institution" (Witt 135). Witt noted that "from another perspective, the Guidelines process signaled the end of the era captured in the 1980 ONA Review Committee report" and "heralded a shift in focus from a relationship building ethos dependent upon close ties between ONA and neighborhood associations, to the full enfranchisement of the 
District Coalition model—a feature the City Council, and many activists, had found so problematic at the outset of the program" (Witt 136).

Witt reports that the 1987 ONA Guidelines "set out in painstaking detail the various types of relationships and responsibilities" of neighborhood associations district coalition boards and ONA (Witt 135). The 1987 Guidelines included requirements for neighborhood associations to receive formal recognition from ONA and to be eligible to receive services from ONA and neighborhood district coalitions. The 1987 Guidelines also established formal roles and responsibilities for neighborhood district coalitions (“district coalition boards" or "DCBs") and ONA. The 1987 Guidelines also established specific guidelines for designating and resolving disputes over neighborhood boundaries, grievance procedures, neighborhood newsletter policies, and the process for future amendments of the ONA Guidelines.

Witt argued that the 1987 Guidelines "signified more than merely formalizing relationships among ONA participants already in operation at the time." He wrote that "Several provisions of the Guidelines significantly altered the terms for engagement within the NA edifice," primarily "the explicit delineation of District Coalition Board functions." Witt noted that duties assigned to neighborhood coalitions included requirements established by ONA that neighborhood coalitions developed annual work plans and submit mid-year progress reports to ONA. Witt emphasized that these provisions "quite clearly laid down the need for [neighborhood associations] to establish a basic consensus in order to acquire yearly contracts that would pay for district staff and office resources" (137-138). Witt noted that the 1987 Guidelines also "stressed the 
importance of full NA involvement at the DCB level" by including, in the section on requirements for neighborhood association recognition, the statement that:

To have a voice in setting goals and priorities for a District

Coalition board, and to determine the allocation of that DCBs resources, a

Neighborhood Association must participate as a member of its District

Coalition Board (Portland. Office of Neighborhood Involvement.

Guidelines for Neighborhood Associations. 1987 2).

While the 1987 Guidelines allowed neighborhood associations not to participate in a neighborhood district coalition, the document clearly established a preference for neighborhood associations to actively participate in their neighborhood coalition. The 1987 Guidelines also shifted administrative responsibilities from ONA to neighborhood district coalitions, including responsibility for orienting neighborhood association and neighborhood coalition members on the operations and procedures of the system. The formal grievance process requirements in the 1987 Guidelines also shifted formal dispute resolution responsibilities away from ONA and out into the community. Neighborhood associations and neighborhood district coalitions needed to sort out disputes "amongst themselves." ONA only was to be involved in grievances that pertained to a violation of the 1987 Guidelines. This was a major departure from the early system in which ONA could be involved helping to resolve a wide range of disputes and in which grievants could appeal "beyond ONA to the Commissioner-in-charge" and then to City Council (140). Additional provisions in the 1987 Guidelines responded directly to conflicts that 
had arisen in the mid-1980s including provisions for "resolving neighborhood boundary disputes" and the establishment of explicit neighborhood association newsletter policies.

Witt asserted that the "substantive and symbolic effects" of the 1987 Guidelines process "constituted a major turning point for Portland's NA program." Supporters of the new guidelines saw them as beneficial and a necessary standardization of roles and responsibilities in response to stresses in the system at the time. They saw that the 1987 Guidelines "could serve to buffer the institution from scattershot and disabling claims made against its legitimacy" rising out of "squabbles and contention" within the system (140-1). Critics of the 1987 Guidelines saw them as a challenge to existing practices and power dynamics between neighborhood associations and neighborhood district coalitions in areas of the city, especially in north Portland and east Portland (141-143). While proponents of the 1987 Guidelines saw the shift in administrative responsibilities and direct support from ONA to the neighborhood district coalitions as a necessary shift as the number of neighborhood association had grow, critics were suspicious that ONA Director Sarah Newhall was attempting to "insulate ONA by off-loading administrative duties onto DCBs for which they were ill-equipped to deal" (144).

Witt reported that proponents of the new guidelines hailed "the process as a brilliant resolution to the problems that the program" had been facing, including "several forces threatening to pull the neighborhood association program apart from different directions." Witt noted that the 1987 Guidelines stalled "criticism that the NAs were unaccountable and prone to self-destruction," and that the codification "of the DCB structure" "purchased for ONA a new lease on consolidating a legacy of NA 
involvement" in Portland. Stronger neighborhood district coalitions would allow capacity building at the neighborhood association level "with minimal intrusion from downtown." Witt noted that proponents of the 1987 Guidelines hoped they would "finally head off suspicions that ONA was prone to pitting [neighborhood associations] against one another," and that "a strong DCB network would enable ONA to mobilize and target resources in ways it had been unable to achieve previously." This would free ONA from needing to provide direct administrative support to neighborhood associations, which would allow "ONA to focus its efforts on 'watchdogging' City Council and downtown bureaus to insure citizen involvement would remain a priority" (145-146).

Witt also noted that the City Council, in adopting the 1987 Guidelines, revised the City Code that established ONA and the neighborhood system (Portland. City Council. Ordinance 159928, July 29, 1987). The City Council gave ONA greater authority to enforce the formal requirements for neighborhood associations, but also deleted the reference to the role that neighborhood associations "would play in city planning efforts" and dropped the reference to neighborhood associations roles in "providing recommendations regarding zoning" (Witt 137).

\section{Tufts University Study}

In the later 1980s, a research team from Tufts University-led by Jeffrey Berry, Kent Portney, and Ken Thomson—studied Portland's citizen participation system and identified it as one of the best examples of participatory democracy in the country. The researchers happened to be studying Portland's system during one of the high points in its 
functioning. The strengths of and challenges for the system that they identified are summarized below. ${ }^{27}$

Berry et al examined both the "breadth" and "depth" of Portland's system. Under "breadth" the authors noted the strong independence of Portland's neighborhood associations and neighborhood district coalitions (Berry Portney and Thomson 59-60) and the value to community members of having an existing network of organized neighborhood associations in place (112). They found that the City encouraged neighborhood associations to work directly with city bureaus and the city council, and that individuals also had the opportunity to participate on bureau budget advisory committees and many other communities. They also recognized that the City of Portland provided funding to neighborhood associations and neighborhood district coalitions to communication directly with community members.

Under "depth," the researchers noted that "One of the most direct measures of the depth of a participation system is its ability to grapple realistically with the city budget." They noted the opportunity for community members to have some impact on the city budget through the bureau budget advisory committees, but also recognized that the "actual ability to affect budgets varies greatly from one committee to the next" (64). The researchers found that the Neighborhood Needs Process allowed neighborhoods to community their priorities to city agencies, but found that neighborhood groups were more likely to have an impact on small projects, rather than larger projects (65). They

\footnotetext{
${ }^{27}$ Berry, Portney, and Thomson's findings related to Portland's community and neighborhood involvement system are described in more detail in Chapter II.
} 
also noted very high levels of "participatory planning" and community involvement in neighborhood planning and in larger planning processes.

Berry et al cautioned that, while Portland city government was very open and provided many avenues for community input and took the input seriously, providing more community involvement opportunities is not always better and can lead to confusion and uncertainty about who truly speaks for a neighborhood or group of citizens. They also noted that, despite high levels of community involvement in Portland, they had found more hostility between neighborhoods and city hall that in other communities (66). This suggested that expanding community involvement opportunities can raise expectations in the community that all city government decision making processes should involve community members in effective and meaningful ways.

The researchers recognized that even though "on the most critical development issues, the development side almost always wins" (142), on other "important but smaller projects and proposals, business is quite vulnerable" to neighborhood input and advocacy. They concluded that "More than anything else, the neighborhood associations give an institutionalized voice to residents at the early stages of the policymaking process when ideas are being formulated into proposals" (114).

\section{Mayor's budget Messages -1980s}

Three Portland mayors served during the 1980s, including former city commissioners Connie McCready and Frank Ivancie, and community and neighborhood activist Bud Clark. Neither McCready or Ivancie had been strong supporters of community involvement as city commissioners. Clark, in contrast, was a very strong 
proponent of community involvement in city government decision making. The community involvement references of their annual mayor's budget messages are summarized below.

Mayor Connie McCready: Mayor Connie McCready finished out Goldschmidt's second term and served as mayor for a little over a year. She presided over the development of only one city budget-FY 1980-81. In her nine-page mayor's budget message, McCready noted the continuing challenge of high inflation and identified major priorities for the city as including "our energy, housing, and economic development policies; major capital improvement programs in transportation and parks; major improvements in the way the City manages its resources" (Portland. "Mayor's Message. City Budget FY 1980-81 2).

McCready stated that the city budget is city government's "responsibility to serve the public good"(3). She mentioned the importance of the "integrity" of Portland's neighborhoods, the "economic vitality of downtown," and the "maintenance of basic services." She stated that “These values have been written into the City's future, because this City and its residents have accepted the age-old challenge of self-determination."

McCready did not refer to community involvement in governance decisions or Portland's community and neighborhood involvement system in her introductory remarks. She introduced her "budget highlights" for individual city bureaus by saying that they "represent my view of the City's highest priorities in serving our citizens during the next fiscal year" (5). McCready did not refer to ONA or community involvement in any of her the budget highlights. 
She concluded her mayor's budget message by stating that "This is a budget of public needs, conservative in outlay and mindful of the economic climate. Yet, it is a budget, developed through the partnership of this City with the people, to maintain the quality of life that we Portlanders value so highly. As mayor, I remain committed to that purpose" (10).

Mayor Frank Ivancie: Mayor Frank Ivancie wrote four mayor's budget messages during his one term in office. Ivancie kept his annual communication to the "Citizens of Portland" about the city budget to a brief two pages each. Like McCready, Ivancie focused his budget messages mostly on the delivery of city services. In his last two messages, he did recognize the work of the Budget Advisory Committees (BACS) in helping to prepare the city budget. Ivancie did not make any additional statements about the role of community members in city government decision making or the value of ONA or the community and neighborhood involvement system.

In his first budget message in 1981, Ivancie started out by mentioning that public hearings had provided "valuable input to the decision making process" and recognizing that the "interest and perseverance of City officials and citizens have resulted in a budget which maintains all basic City services, enhances the livability and progress of Portland, plans for the financial future of the City." Ivancie's brief budget highlights do not refer to ONA or community involvement activities (Portland. "Mayor's Message." City Budget FY 1981-82 1).

In his 1982 budget message, Ivancie noted the challenges of the "current recession, combined with reductions in federal and state programs" that impact "many of 
Portland's citizens, as well as "high interest rates and declining [city] revenues." Ivancie stated that city resources must "be concentrated to provide those basic services citizens expect from their City government. He listed traditional city services-police and fire, streets, water, sewer, and parks—and additional services, which he says "are now considered to be basic," including: "land use, transportation planning and control, economic development, preservation of housing stock, support for the City's cultural needs and social services for youth, the elderly and disadvantaged").. Ivancie did not mention ONA or community involvement (Portland. "Mayor's Message." City Budget FY 1982-83 1).

In 1983, Ivancie stated that the city budget "continues to provide Portland citizens with basic services at generally the same level of the FY 82-83" budget. His budget highlights mentioned a plan to consolidate "small offices" in City Hall to reduce clerical support costs. The plan included co-locating the Office of Cable Communications and the Energy Office with the Metropolitan Arts Commission and Metropolitan Human Relations Commission in City Hall to allow them to share clerical support. Ivancie noted that ONA would remain in City Hall and "retain its one clerical position." He also reported the transfer of the Metropolitan Human Relations Commission Mediation Program to ONA to "more efficiently and effectively coordinate like activities" (Portland. City Budget FY 1983-84. Mayor's Budget Message 1). In closing his budget message, Ivancie thanked "the many people_-Budget Advisory Committee members, interested citizens and City staff-who contributed their time and energy in the preparation of this document" (2). 
"Ivancie's last budget message, in 1984, did not include any reference to overall goals and purposes, but did report a special appropriation to support city bureaus involved in the delivery of urban services to areas slated to be annexed to Portland. Ivancie's budget highlights refered to additional funds for the Metropolitan Human Relations Commission for a part-time "typist clerk" and to ONA to support "technical assistance" for neighborhoods. Ivancie again thanked the Budget Advisory Committees, city staff and the other members of the city council for their work on the budget, which, he said, "provides Portland's citizens with quality services, making Portland the most livable City in the nation" (Portland. "Mayor's Message." City Budget FY 1984-85 1-2).

Mayor Bud Clark: Mayor Bud Clark prepared eight mayor's budget messages during his two terms as Portland's mayor. For the first five years, he kept his messages to two pages, and then expanded to four to six pages for his final three city budgets. Unlike Ivancie, Clark did share some of his vision for the community and his priorities beyond basic delivery of city services. During Clark's time as mayor, he supported community involvement in the budget process and civic life in Portland, increased funding for the existing neighborhood coalitions and funded a new district coalition in the newlyannexed areas of east Portland. He also strongly supported the development and implementation of the city's new community policing program and a community visioning process for the city called Portland Future Focus (discussed in the next chapter).

In his first budget message in 1985-86, Clark pledged to the "citizens of Portland" to have an "open, honest administration" and to provide "responsive public safety 
services and increased opportunities for meaningful citizen involvement in the affairs of the government. He also stressed his commitment to "greater levels of team management approaches" in City government to reduce costs, improve efficiency in city government, and explore new sources of revenue. Clark made a point of recognizing the "untiring efforts on the part of citizen advisory communities and City personnel" in helping to develop the city budget (Portland. "Mayor's Message.” City Budget FY 1985-86 1). In 1986, Clark again recognized the "countless hours" "City employees and citizen volunteers" put into the development of the City budget. He notes that the city budget stopped the drawdown of the City's reserves, increased services to Portlanders, and utilized "a consensus-building process which ensures that the budget reflects a citywide view of City priorities." Some of the service highlights Clark mentioned included funding for additional police officers, expanded economic development efforts, “expanded City services to newly-annexed areas, to keep our promises to Portland's newest citizens and ensuring their efficient service delivery," funding for Clark's "program for the homeless and disadvantaged," and "additional counseling and employment services for our city’s youth" (Portland. "Mayor's Message." City Budget FY 1986-87 1-2).

In 1987, Clark's budget message again thanked citizen volunteers and city staff for their work on the city budget. He noted that City revenues had fallen below projections, which required some cuts in City services. He noted that while some city services and programs were cut or deferred, the budget continued to fund increased numbers of police officers, maintained parks summer youth playground programs, and 
ensured that fire and building inspection services would continue to "preserve the safety and well-being of our citizens. Clark described some steps to improve efficiency and reduce costs. He closed by affirming that he will "continue to foster a consensus approach to budget and policy decisions... and to explore and develop strategies to stabilize the City finances so that Portland's citizens can be assured that they will be safe...able to find jobs, and that the services they expect from their City government (12).

In 1988, at the end of his first term as mayor, Clark stated that the city budget for the first time implemented a "program budgeting" program to improve the City's ability to "monitor performance and direct City resources to our priority programs." He identified the city's highest priority as "public safety" and "the fight against crime" and reported the hiring of 22 additional police officers. He also reported the dedication of resources to "the restoration of abandoned housing, which is a critical first step in reclaiming our neighborhoods." He reported the funding of "two more crime prevention coordinators and a street crime coordinator" in ONA. In his budget highlights, he reported increased funding for ONA to provide "operational support for the mid-county neighborhood office" and increased funding for the existing six district offices. Clark closes by thanking the "hundreds of volunteers who contributed to the development of the City's 1988-89 budget, including those who participated on Bureau Advisory Committees and those who took time to testify before the City Council." He stated that their dedication and credibility helped "ensure the tradition of citizen participation that is 
an important part of our city" (Portland. "Mayor's Message.” City Budget FY 1988-89 12).

Clark's first budget message of his second term, in 1989, continued to maintain the primary focus of the budget as "preservation of public safety services." He also reported on the City's ongoing negotiations and cooperation with Multnomah County to implement the division of services between the two jurisdictions across a wide range of public services. He reported the elimination of City funding for the Metropolitan Youth Commission. He closed by thanking "the many citizens who participated in the City's budget process, including those who testified at the hearings, and the hundreds who volunteered on Bureau Advisory Committees." He wrote that their "dedication and insights help ensure that the people's voices are heard" (Portland. "Mayor's Message." City Budget FY 1989-90 1).

Starting in 1990, Clark began to include much more detail in his budget messages about his goals for the City and specific program initiatives. In his 1990 budget message, Clark noted that, for the first time in his service as mayor, the City budget "substantially improves public safety without cutting other city services." He credited this achievement to "tight fiscal management" and "an improved economy." He also notes that, in November 1989, the City Council "adopted a resolution which made public safety, and in particular Community Policing, the City's top priority" (1).

Clark identified four service priorities and budget issues, which included public safety, human development, emergency help for youth at risk, and affirmative action. He reported the full funding of the Phase I implementation of Community Policing, which 
included increased funding for the Police Bureau, ONA, and the Park Bureau. He made the case that the "City must seek to address and abolish the social conditions that have left many of our citizens vulnerable to the scourge of drugs and crime" and encouraged “discussions in our community about a 'human development agenda' for Portland..." and a review of the "policy and service implications of this issue" during "strategic planning discussions" (1-2). The City budget also back-filled cuts in federal funding to support the continuation of summer youth employment programs, "especially gang-affected youth." Clark also reported budget support for "continuing and new programs" to "achieve affirmative action goals" within City government (3).

Clark also noted that "Portland's two most pressing problems in the 1980scrime and a poor economy—have consumed most of the city's attention and energy for a decade." He reported that the City budget included funding for the "completion of the City's first strategic planning effort, 'Portland Future Focus: Bridging to a New Century."" He stated that this "effort will create not only a vision of what our citizens want their community to be like in the next century, but also will identify changes needed to achieve that community vision." He asserted that the "resulting action plan will be a foundation for future budgets and future City Council decisions" (4). He also advocated for more coordination of bureau planning in the face of major City bureau projects such as the development of a "new regional light rail agenda for the city" and proposed increased sewer rates to "meet new federal environmental regulation and capacity demand son the sewer system." 
Clark closed by recognizing that the city budget was developed "with the full involvement and cooperation of every member of the Council, and with the help and advice of the Citizens Budget Coordinating Committee and the individual Bureau Advisory Committees." He also recognized the "time, effort, and insight" of city staff and citizens who participated in the preparation of the budget (5).

\section{Observations from the 1980s}

During the 1980s, Portland's community and neighborhood involvement system shifted from its earlier more open and flexible culture to begin to institutionalize structures, roles and responsibilities and practices for the system. The adoption of the first ONA Guildelines in 1987 helped formalize many of these elements and helped protect the system against charges that neighborhood associations were not open and democratic and were unstable. Many of the system elements identified as important in the 1970s continued to be important, such as a citywide system of independent neighborhood associations and communication and organizational support for neighborhood associations. The role of the neighborhood district coalition offices as forums for discussion and vehicles for supporting neighborhood associations also was firmly established in the system. Bud Clark introduced a formal role for neighborhood association and volunteer celebration and recognition with Neighborhood Recognition Week and the Spirit of Portland Awards.

Change in the system was driven in large part by ONA Directors Jacobsen and Newhall. Studies again played important roles, both with the 1980 ONA Review Committee initially saying formal standards were not needed and then the 1985-87 
Policies and Procedures Review Committee, which developed the 1987 ONA Guidelines. Political leaders also continued to play an important role in threatening and supporting the system. The addition of new programs to ONI, and a shift toward a greater focus on human services, was driven in large part by ONA directors and city council members. Mayor Ivancie was not a strong supporter of community involvement and attempted to defund the district tier in the system. ONA, however, was able to rally neighborhood and community activists and prevent this from happening. The election of Bud Clark as Portland's mayor, brought into office a strong supporter of neighborhood and community activism who refocused city government back toward the willingness to involve the community in city decision making that had started under Goldschmidt. Clark also championed the creation of Portland's community policing program.

The City Council's adoption of the 1987 ONA Guidelines was a major step toward further embedding the neighborhood system in Portland's government structure and practices. 


\section{CHAPTER V \\ SOUL SEARCHING AND DECLINE-1990s}

The 1990s were a time of "soul searching" (Witt) and some decline in Portland's community and neighborhood involvement system. A number of different processes examined the purpose and functioning of the system and recommended ways to expand and strengthen it. At the same time, important community involvement programs, which had been part of the system since it was founded in the 1970s, were ended. Community members increasingly complained that city leaders and staff just gave lip service to community involvement and were not involving community members in ways that would allow them to meaningfully affect city government priorities and decisions.

At the beginning of the decade Bud Clark's community visioning process know as Portland Future Focus (PFF) developed a number of goals and action steps that would influence city government thinking for many years. These included calls to strengthen civic leadership, increase the diversity of people involved in civic life and the neighborhood system, and ensure healthy and vigorous neighborhoods.

In 1992, at the request of ONA Commissioner-in-charge Gretchen Kafoury, former city commissioner Margaret Strachan led a series of focus groups that discussed adapting neighborhood association activities to fit the PFF agenda. Strachan's final report offered a number of recommendations to strengthen the neighborhood system and strengthen community involvement in Portland. Strachan went on to work with other neighborhood activists to create 1993 Neighborhood Congress at which neighborhood leaders identified their own set of priorities for the system. 
A year after the Neighborhood Congress, the City Council created the Task Force on Neighborhood Involvement (TFNI), which undertook the most extensive review of Portland neighborhood involvement system since it was created in the mid 1970s. The TFNI submitted its report to City Council in 1996. The report presented a valuable assessment of what was working well and what was not and recommended many different actions to improve the system. At the same time that the TFNI was doing its work, city bureau staff, neighborhood and community activists, and ONA staff worked together to develop a set of public involvement principles for city government and a community outreach handbook to help city staff more effectively involve the community in the city's work.

In 1998, the City Council adopted a revised set of ONA Guidelines that implemented some of the TFNI recommendations, including changing the name of the Office of Neighborhood Associations (ONA) to the Office of Neighborhood Involvement (ONI).

Despite all the good work of these different review processes to identify how to strengthen and expand the neighborhood and community involvement system, little progress was made during the 1990s to implement many of these recommendations. At the same time these processes were examining how to strengthen community involvement in Portland, some key programs that had given community members a voice in important city government decisions since the founding of the system in the mid 1970s were discontinued, including the Budget Advisory Committees, the Neighborhood Needs 
Process, and City staff and funding support for neighborhoods to create neighborhood plans.

Community members repeatedly complained that city leaders and staff were just giving "lip service" to community involvement and not involving community members in ways in which they could meaningfully affect government priorities and decisions. Longtime neighborhood activist and former ONA employee Lee Perlman was angry enough about what he saw as the deterioration of the neighborhood system to compose a strong critique of the system for the delegates who came from all over the country to Portland for the 1998 Neighborhoods USA conference.

Important themes that emerged from the "soul searching" processes of the 1990s were the need to strengthen support for the existing neighborhood system, the need reach out to and involve a greater diversity of people and community organizations, and the need to improve the willingness and capacity of city leaders and staff to work with the community.

This chapter describes and reviews the processes mentioned above and closes with an overview of the key themes and priorities of Portland Mayor Vera Katz mayor's budget messages from 1993 to 1999 , especially as they relate to community involvement and Portland's community and neighborhood involvement system.

\section{Portland Future Focus}

In his second term, in 1990, Bud Clark initiated a broad and inclusive strategic planning process for Portland called "Portland Future Focus." ${ }^{28}$ A committee of 55

\footnotetext{
${ }^{28}$ Mayor Bud Clark served as the vice chair of Portland Future Focus.
} 
community members led what the group's final report billed as “the city's first community-wide strategic planning process" to plan for Portland's future in the face of the community's changing role in the state and region" (Portland Future Focus 6).

Portland Future Focus had five objectives:

- "Educate the community about what the future holds...unless we change current trends."

- "Create a vision of what Portlanders want their community to be in the next decade. “

- "Identify the major changes needed to achieve our community vision. "

- "Forge partnerships between governments, businesses, community organizations, and other interests to find solutions to common problems. "

- "Build an action plan for the next three to five years to be implemented by the community organizations most suited to accomplish necessary changes" (Portland Future Focus 6).

The Portland Future Focus planning process recognized a number of changing dynamics in Portland-rapid population and economic growth in the region, increasing diversity in Portland's population, including rapid growth in "minority, elderly, and special needs populations," growing concern about protecting quality of life and Portland's livability, high levels of hate crimes and gang crime in Portland, and the need to diversify the local economy and prepare for and attract new jobs in the community (Portland Future Focus 6). 
After 16 months of work and broad community input, the Portland Future Focus committee adopted a final plan that included 25 strategic goals. The goals included reducing crime and violence and better supporting victims, embracing diversity and eliminating bigotry, capitalizing on Portland's Pacific Rim location to increase trade, seeking family-wage jobs and training people for them, graduating all children from high school "with the ability to read, write, compute and reason," and managing regional growth to provide services efficiently, improve the environment and enhance quality of life, and strengthen citizen leadership in Portland (Kiyomura. Oregonian, August 3, 1991).

Portland Future Focus built on a number of different values, some of which related directly to community involvement and Portland's neighborhood involvement system. The plan affirmed that facets of the community need to work together to achieve the community's goals, emphasized the right of all Portlanders to "physical, mental, and emotional wellbeing," and affirmed Portland's civic culture as "a city of healthy, vigorous neighborhoods where residents participate in community life and feel a sense of belonging and involvement" (Portland Future Focus 21).

The PFF Committee issued its final report in August 1991. The committee listed ten community values it had developed from input from a community survey. The three values that relate most directly to this study include:

- Diversity: "We value an open and friendly community that is free from bigotry and intimidation. We value a community that welcomes and respects the individuality, unique talents, and contributions of all people 
regardless of age, race, gender, ethnicity, sexual orientation, religion, physical or mental ability, or financial means" (Portland Future Focus 20).

- Good Government: "We value open, honest government that is responsive to its citizens. We value strong, create leadership by elected officials and private citizens willing to empower and work with the entire community to shape Portland's future. We value cooperative approaches to problems that extend beyond Portland's boundaries."

- Sense of Community: "We value a city of healthy, vigorous neighborhoods where residents participate in community life and feel a sense of belonging and involvement" (21).

The PFF report presented twenty-five strategic goals. The three PFF goals that relate most to this study include:

- "Build stronger, innovative, more responsive elected and citizen leadership. Effective leadership at both grass roots and institutional levels is vital to healthy communities. Leadership talent must be consciously nurtured in community organizations as well as city and regional governments. To do this, civic and political organizations must provide leadership opportunities and training. This training should be an ongoing process that begins in the schools" (30).

- "To embrace and celebrate diversity and eliminate bigotry, enhancing the sense of community. Existing diversity in the people of Portland and continuing changes in the demographic makeup of its work force will 
require that the people who live and work here accept and value the differences in their fellow citizens and workers. It will be important to the economic health of our city for us to get along with one another and to work well together. Our world is increasingly a 'global village.' If we want to adequately prepare our children to operate effectively within that village, we must prepare them to live and work with people different from themselves. To do this, we must make a concerted effort to alter those attitudes about differences which create ill will and conflict. Portland should be known as an open and friendly community that welcomes and respects the individuality, unique talents, and contributions of all people regardless of age, race, gender, ethnicity, sexual orientation, religion, national origin, physical or mental ability, or financial means" (31).

- "Ensure that each neighborhood is healthy and vigorous. The wellbeing of the city starts with the condition of its neighborhoods. City and community leaders should support healthy neighborhoods by promoting safe and decent housing, economic activity that provides well paying jobs, crime prevention and control and community policing, quality schools and children's services, successful small businesses in neighborhood commercial zones, accessible social services for all ages, transportation alternatives to the automobile, recreation opportunities through parks, park programs and open space, diversity of the resident population, and strong neighborhood-based organizations" (33). 
The PFF Committee established action plans for six topic areas-Crime, Diversity, Economy, Education, Leadership and Managing Growth. A number of the action items in these plans specifically were directed to or required action by neighborhood associations, community groups, and ONA. The PFF Committee saw that the successful implementation of the plan would require broad participation and insisted that "Every citizen and group can and should have a meaningful role in implementing the action plans" (30).

Crime Action Plan: The Crime Action Plan recognized that "Crime is a community problem which can best be prevented and reduced by the entire community pooling and coordinating resources." "Neighborhoods and individuals" must be empowered and provided tools" so that communities can "help themselves" (40). "The City and its citizens must enter into a contract under which the citizens are empowered to participate in defining and addressing problems and in helping to develop strategies for solving crime" and develop a "working partnership between citizens and government. " The Crime Action Plan recommended the full implementation of Portland's [at that time new] community policing program, a core element of which was "close cooperation among police, citizens and neighborhoods to identify and prevent potential crime problems" (42).

The Crime Action Plan also recommended that ONA and the neighborhood district coalition boards join with the mayor's office to identify and inventory the factors in each neighborhood that contribute to crime and to "develop a neighborhood plan to deal with those factors." The plan also recommended that neighborhood groups 
participate in a Community Safety Steering Committee that would recommend priorities for the justice system and recommended that all city and county employees receive training to help them understand and appreciate social and cultural differencesSoutheast Uplift neighborhood district office's "Unlearning Racism” training was cited as a model.

Diversity Action Plan: The Diversity Action Plan stressed that the "celebration of diversity should be infused throughout the six action plans. ${ }^{29}$ The action plan recommended that city policies and practices be revised "to make the City of Portland a leader in embracing diversity." Related action items included changing the city government workforce to better reflect the demographics of the community and "aggressively" reaching out "to diverse populations in the community" and including "them in all City activities." Some key objectives of this overall strategy included:

- "Establish an on-going watch dog group to monitor action item[s] of this plan."

- "Examine government policies to determine if they are consistent and fair to all groups."

- "Provide tools for government to evaluate their policies impacts on all populations in Portland."

- "Equip organizations with tools to deal with discrimination and bigotry more effectively" (Portland Future Focus 57).

\footnotetext{
${ }^{29}$ The PFF's finding that the "celebration of diversity" should infuse all six PFF action plans was similar to the determination in another Portland citywide strategic planning process 30 years later, known as the Portland Plan, that asserted that achieving greater "equity" in Portland should be an overarching value and influence all the other elements of that strategic planning effort.
} 
Implementation actions included the establishment of a "Diversity Focus Group" made up of "advocates and members of each diverse community" to "monitor and update" the action tasks; study of the "feasibility of establishing human impact criteria for evaluating program, policy, budget, and comprehensive planning decisions at City Council, commission, and bureau and neighborhood levels;" broadening "mediation training in such community institutions as the Police Bureau, neighborhood offices, businesses, and schools....," implementing "a revised affirmative action" and was to include "guidelines for hiring and appointing all levels of City and County staff and volunteer boards" specially noted were "neighborhood coalitions and organizations" and "citizen steering committees, boards, and commissions" and evaluations of city managers "regarding diversity" (Portland Future Focus 57).

The plan also recommended the expansion of "anti-racism training like that used by Southeast Uplift" and an increase in "awareness of community resources available" to support diversity including sharing and expanding existing "cultural and social diversity training programs" in Portland (Portland Future Focus 58). Other action recommendations included: publishing a resource guide "for and about diverse groups" and encouraging "city ethnic associations and other groups to inform the public of their groups goals and activities," annual progress reports, expansion of the role of the Metropolitan Human Relations Commission to include "documentation of hate crimes, action alerts and education programs," and creation of a "public relations and media campaign to help Portlanders build a strong community that understands and celebrates the diversity of its citizens" (58-59). ONA, neighborhood coalition offices, and 
neighborhood organizations were identified as responsible parties or resources for many of these action items.

Building Leadership Action Plan: The other action plan area that included major roles and responsibilities for ONA and neighborhood organizations was the “Building Leadership Action Plan.” PFF proposed a vision of "strong, accountable leaders" and "innovative partnerships between government, schools, business and community organizations" that would "help the community set priorities and direct limited resources to solve the most pressing problems." This action plan also emphasized that "Portland's leaders will come from all segments of its population" (Portland Future Focus 108).

The Building Leadership Action Plan argued that "Leaders must also recognize that the nature of community decision-making is shifting from a centralized, hierarchical structure to a collective citizen base. Power is widely held in Portland rather than concentrated in a handful of elected or corporate leaders." Without leaders who "understand these realities and possess leadership skills, Portland will struggle with the problems and opportunities it faces in the coming decade" (Portland Future Focus 108). The Plan recognized Portland's history of active community participation in civic and government affairs and stressed that providing "adequate training for and access to leadership" would allow the community to "help ensure a healthy future."

The plan identified critical guiding principles. These include the importance of leaders being "responsive to and accountable to their constituents," "person-to-person interaction" as vital to "accessing and securing diverse citizen participation and 
ownership of a community vision," active involvement in shaping the future as critical source of new leaders, the importance of direct participate of "all socio-economic, cultural, racial and ethnic groups, to the success of a community vision and the need for the vision to "speak to the needs of these groups," and the need for "training, support, and removal of structural barriers to leadership" to empower and encourage new leaders" (Portland Future Focus 108).

The plan also highlighted obstacles that would need to be overcome to achieve the goal of building "stronger, more innovative, more responsive citizen and elected leadership." These included:

- "A reluctance to share power with those who are not currently empower."

- "Cynicism about the ability to affect change."

- "Distrust of those in power."

- "Lack of training, experience and resources to attain positions of leadership" (Portland Future Focus 108).

The Building Leadership Action Plan proposed strategies and actions focused on leadership training, youth involvement, reducing barriers to involvement in leadership in government bodies and neighborhood associations, increased participation in leadership by "ethnic, cultural and social" groups, and the use of community dialogues.

The plan called for a greater awareness of regional coordination of leadership training opportunities, especially for “age groups and populations that aren't typically identified as sources of leaders." The plan recommended that existing training resources—including organizations, individuals and leadership opportunities—in the 
community be inventoried and that a list of leadership trainings offerings be produced semi-annually. The plan also called for the development of stronger "curriculum on local and state government for grades K-12" (Portland Future Focus 110).

A special focus on bringing more young people into leadership included proposed actions such as increased support for involving students on government "advisory boards and commissions," the creation of a "mentor program for new and emerging leaders," scholarships for training programs, and the establishment of "the Youth Leadership Forum to allow people under 30 to become involved in relevant community issues." The action plan emphasized the need to reduce barriers to elected officeincluding the financing of city council campaigns and the city-wide election of council members, but also specifically raised the need to periodically evaluate and improve the outreach by neighborhood and community organizations. The plan called for periodic evaluation of neighborhood associations based on the Standards and Guidelines adopted in 1987 and the original ordinance that created the neighborhood system. The plan recommended that these evaluations focus on:

- "Democratic process of decision making;"

- "Public awareness of neighborhood issues and activities;"

- "Public awareness of other groups involved in neighborhood issues;"

- "Regular disclosure of the results of these evaluations;" and

- Neighborhood association focus on responding to the "needs of residents rather than those of City government" (Portland Future Focus 110). 
The Building Leadership Action Plan also reinforced the Diversity Action Plan recommendations by recognizing a "lack of participation by African-Americans, Hispanics, Asians, native Americans and other ethnic, cultural and social groups in community affairs." The plan maintained that the "community loses by not taking advantage of the full potential, diverse perspectives, and varied approaches to problem solving from all members of the community." Changing demographics made the "need for diverse participation even more important." Barriers cited to this increased participation included "a reluctance among entrenched leaders to share power, racial, ethnic and cultural prejudice; and cynicism of members of minority communities" (Portland Future Focus 111).

The proposed actions included:

- Evaluation of the "extent and effectiveness of outreach to diverse groups by community organizations."

- Promotion of "outreach by organizations that are not successful in gaining diverse participation."

- Encouragement of "businesses, governments, colleges, foundations, and nonprofits" to "appoint members of diverse groups to board and advisory bodies."

- Measurement of the "degree of change in diversity in subsequent years."

- Creation of an "annual award program that recognizes leadership by organizations in social and community issues" (Portland Future Focus 111). This action plan also recognized that increasing participation and building leadership skills in advanced by involving community members in dialogue and 
deliberation processes and building community leadership leaders skills through opportunities to discuss, debate, build consensus and implement a community vision.

Portland Future Focus provided Portlander leaders and activists with an important assessment of challenges and opportunities facing the city. The final report identified particular challenges, strategic goals, and action items related to improving community involvement in civic life and local decision making in Portland. One of the related themes was the need to work toward creating a shared governance culture in Portland with broad involvement in setting priorities, development solutions and leveraging community energy and resources in implementing them. PFF recognized that achieving this would require strengthening the leadership capacity of individuals and organizations across the city through expanded and better coordinated leadership training opportunities. PFF also strongly called for increased recognition of the growing diversity in Portland and the need for special efforts by neighborhood associations and other community organizations and by city government to more effectively reach out to and involve the community as a whole and especially historically underrepresented communities.

While the good work of the PFF committee did not lead to many immediate changes in Portland neighborhood and community involvement system, many of the PFF issues and recommendations were re-identified and validated by future review efforts. The PFF recommendations also helped provide valuable context and direction to two particular review processes—a 1992 focus group analysis by Margaret Strachan and the work of the 1995-1996 Neighborhood Involvement Task Force. 


\section{Margaret Strachan Report}

Following the release of the Portland Future Focus report in 1991, Witt reports that Portland's neighborhood system went through a period of tension and "soul searching" from 1991-1993. Witt describes efforts by City Commissioner Gretchen Kafoury and ONA director Rachel Jacky to establish greater control by ONA over the district coalitions and to redirect the focus of the neighborhood system toward Commissioner Kafoury's and Jacky's agenda of “assisting dis-enfranchised groups” (Witt 167) and implementing the goals of Portland Future Focus related to crime prevention, diversity and leadership.

Witt documents that these efforts met significant resistance from the neighborhood district coalition boards (DCBs). He describes tensions between ONA and the DCBs over contract negotiations in 1991 and 1992 as ONA attempted to centralize ONA's control of the system and to increase the consistency of expectations across the district coalitions and neighborhoods. A particular point of contention related to the DCBs use of their crime prevention staff positions. DCB staff chose to have these positions to support a number of other neighborhood support functions. Portland Police wanted these positions to focus more exclusively on crime prevention (Witt, "Chapter V-Retrenchment").

The ONA Bureau Advisory Committee (BAC) reviewed the Portland Future Focus goals related to the neighborhood system at the request of Commissioner Kafoury. Witt reports that the ONA BAC members said the "PFF goals were laudatory, and that several of them were already being undertaken in accordance with previous and existing 
ONA program objectives, especially those pertaining to crime prevention.” The ONA BAC, however, did not support adding any new priorities that would require shifting fund from existing priorities to implement the PFF goals (Witt 172).

In the winter of 1992, Witt reports that DCB activists from around the city joined together to define for themselves the purpose of the district coalitions within Portland's neighborhood system. Witt writes that ONA Director Jacky, in response to pressure from DCB activists, distributed a survey in January 1992 to the six DCBs then operating. The survey was followed up by a retreat for all DCB Chairs and district coalition directors in February 1992. The survey results showed that DCB activists felt that the DCB relationships with citizens, neighborhood associations, and other community-based organizations were good but that "DCB relationships with City bureaus (other than ONA) 'tended to be reactive and adversarial'" (Witt 175). The survey results showed that DCBs felt that ONA was not providing enough technical assistance to district coalitions at their request and was "spending too much time in 'fiscal oversight of the contracts' and 'performance oversight of (DCB) contract(s) and workplan(s)'” (Witt 176). ONA Director Jacky, who attended the retreat, according to Witt, responded that "ONA spent most of its time providing technical assistance to neighborhood associations and citizens making various requests, whereas relatively little time was spent by the agency on both DCB fiscal and performance oversight." Jacky attributed these perceptions to the fact that "a primary function of the DCB/ONA relationship in fact has to do with contract compliance" (Witt 176). 
Witt reported that it was in this context of discord between the neighborhood district coalitions and ONA that City Commissioner Gretchen Kafoury enlisted the help of her friend Margaret Strachan_-former neighborhood activist, former office coordinator for the West-Northwest District Coalition, and former Portland City Council member-to navigate "between the rock of DCB intransigence and the seeming hard place of Future Focus goals and mandates." Kafoury "hired Strachan on contract to perform focus group research to assess the suitability of adapting NA efforts to fit with the Future Focus agenda" (Witt 177).

Strachan analyzed the "Tufts University report on citizen participation, the Future Focus report, [ONA's[ Guidelines and a summary of the District Coalition Board Chairs' retreat..." Strachan also conducted six focus group sessions that included 32 individuals active in and grouped by "neighborhood associations, representatives of other community-based groups, neighborhood business groups, representatives of city bureaus, and present and former staff from neighborhood offices" (Strachan 1).

Strachan presented her report, "Strengthening Citizen Participation Through Neighborhood Associations: Future Focus Goals," in October 1992. Witt notes that it provided measured support for the Future Focus agenda (Witt 177). The report also provided additional insights into the elements or strategies focus group participants believed were important to and/or were needed to strengthen Portland's community and neighborhood involvement system.

Strachan identified five major themes that emerged from the responses of the focus group participants. These included: 
1. "Neighborhood associations and the neighborhood association system are important assets to the city of Portland and its citizens though there are some concerns."

2. "Other organizations and methods are needed to broaden citizen participation. Neighborhood associations are not and cannot be the only mechanism for participation."

3. "Neighborhoods can provide good opportunities for citizens to gain experience and confidence as leaders."

4. "Improved communications are vital for better citizen participation."

5. "Neighborhood associations must maintain their grassroots orientation. The city cannot use them as another service delivery network without risking cooption of their independence, credibility, and ability to get things done by pulling neighbors together and speaking with an independent voice" (Strachan 1).

Theme 1: Neighborhood Associations and the City. Focus group members consistently recognized that neighborhood associations and the neighborhood system were valuable and important assets to Portlanders and to city government. They also raised concerns about the representativeness of neighborhood association. Many questioned the extent to which it is realistic to expect volunteer neighborhood associations to truly represent every neighborhood resident and interest. Some said that neighborhood associations "are participatory rather than representative organizations." Many felt that "if the membership is open, communications within the neighborhood 
allow easy access to decisions." Clear processes for elections and decisions, and "fair and open rules and good communication" would go "far to reduce this concern about representation" (Strachan 2).

The participants questioned the city's true commitment to meaningful citizen participation. Strachan reported that "most participants feel the city gives lip service to participation and wants it on the city's terms; or worse the city listens but does not pay attention." The focus group members universally recognized the need to "improve cityneighborhood relations" and to implement the Portland Future Focus goals.

Focus group members suggested "more training for bureau staff in how to work with citizens in general and neighborhood associations in particular." They urged that, to be effective, "both city employees and neighborhood people should be involved" in designing the trainings. The trainings should make clear that disagreements are a normal part of participation and "emphasize how disagreements can be resolve." The training also should build respect among city staff for the opinions of citizens, because a perception of respect is "vital to the city's credibility with citizen participants" (Strachan 2).

Participants also stressed the "need for a strong advocate for neighborhoods within the city structure" to help ensure that neighborhood viewpoints would receive "a fair hearing and responsible responses." Strachan reported that "the majority of neighborhood association members feel there is no one in city hall that advocates for their inclusion and the value of the participation except in a cursory way" (Strachan 3). 
Participants felt that, "over time, the Office of Neighborhood Associations has become too inflexible and bureaucratic." They stressed that neighborhood associations at the time had very diverse cultures and capabilities, and that ONA needed to be flexible in working with "such a wide range of individuals and associations." They urged ONA to use "more personal intervention" and fewer legalistic approaches. "Participants recognized that sometimes "no matter how well guidelines and contracts are written, some volunteers may ignore the rules, control their district offices, excluding other neighborhoods, and/or disrupt the flow of neighborhood activities or promote dissension among members." The participants said that "in these cases, personal and informal intervention from ONA staff may be appropriate rather than stringent enforcement of the guidelines and contract or additional rules." They stressed that neighborhood associations should not be allowed to "become captive to a small group of volunteers to the exclusion of a broad neighborhood membership" (Strachan 3).

Theme 2. Broadening Citizen Participation: Participants across the focus groups agreed that citizen involvement in Portland needed to be broadened to include more people and a greater diversity of people and perspectives. They suggested that "too much is being expected of neighborhood associations," and that neighborhood associations cannot be all things to all people. They argued that a number of organizations and avenues of participation were needed that could include a range of options from "neighborhood associations to budget advisory committees to environmental groups and community development corporations." 
Participants reported that neighborhood association volunteers "may organize around a few specific issues," such as land use planning or park development that are important to them, but then "the city may expect them to review and respond to a number of other issues from crime prevention to bureau budgets to providing volunteers for committees." They noted that many residents are not interested in these activities causing these additional responsibilities often to a few neighborhood association board members who then "feel they are being misused by the city."

Neighborhood associations "can provide a forum for dialogue between the city and neighborhood residents" but focus group participants cautioned that they "cannot force participation." They noted that when city staff ask community members for input and community members do not respond, "city employees end up feeling that citizen participation is a waste of time." City staff need to value community participation and recognize that community volunteers "volunteer significant amounts of time and resources to improve their neighborhoods and hence the city." This recognition is "basic to a good relationship between neighbors and staff." Focus group members again recommended that "training for city staff may reduce this problem" (Strachan 4).

Focus group members also recognized the need for neighborhood associations "to recruit a more diverse membership," including people of "all races, ages and income levels.” They suggested special efforts to involve youth in neighborhood associations. They recognized that different areas of Portland differ in the makeup of their residents and recommended that each association "look at the demographics of their area and work to see that the membership reflects the residents." They said this kind of diverse 
membership would broaden "the appeal of neighborhood associations and generate enthusiasm" for broader participation (Strachan 4).

The group also recommended that neighborhood associations incorporate more "events and celebrations" into their activities to "reach out to everyone and keep neighborhood associations lively and fund at least some of the time."

"Working with other groups in a neighborhood" also could help "reduce stress and prevent burnout" and help neighborhood volunteers "achieve more." Participants saw value in community members in a neighborhood creating an "informal group" to represent "all the active community-based non-profits in a area." This "informal network" could help reduce duplication, improve scheduling, and allow for "informationsharing in neighborhoods with a high level of activity" (Strachan 4).

Group members recognized that small businesses also are "an important group in most neighborhoods" and said that "neighborhood associations and small business have many similar goals." Group members suggested that "business representatives need to be involved in the neighborhood association either as individuals or through an organization of their own."

The two individuals who participated in the business association focus group complained that neighborhood associations were not representative of the community and that the city should require neighborhood associations to meet standards as a requirement of formal recognition. They also complained that city processes often ask for input from neighborhood associations but not from business district associations. They recommended that the city provide resources, funding and support to business 
associations as well as neighborhood associations but suggested that ONA was not the appropriate agency to oversee and provide this support. They suggested that the Portland Development Commission, which already had a focus on supporting business districts, should play this role. ${ }^{30}$ These focus group participants also identified the need for greater dialogue between neighborhoods and business associations and suggested that the city should take the lead in facilitating these discussion (Strachan, "Focus Group \#2 summary").

Theme 3: Leadership. Most of the participants said that "neighborhood associations provide a good opportunity to gain experience and confidence.” They believed that "people who become active in neighborhood groups already have the potential to be leaders" and that their leadership skills are honed by "activities requiring decision making, public speaking, mediation, volunteer recruitment and management as well as a knowledge of how local government works" (Strachan 5).

All the focus group participants agreed that training should be a high priority. They said that "training should be available to everyone at minimal or no charge and be easily accessible." Training topics they identified as particularly needed included: "how to run a meeting," "land use concepts and hearing processes," "fund raising," and "organizing techniques." They especially emphasized the need for mediation training. Strachan reports that the participants noted that "as urban life has gotten more complex,

\footnotetext{
${ }^{30}$ It turns out that the assessment of these two business association representatives, in 1992, of the needs and preferences of the business district association community would remain valid over the following twenty years. Despite ONI's subsequent efforts to bring business associations under the ONI umbrella, no business association ever applied for formal recognition offered by ONI. In the 2010s, business district associations ended up being served directly by the Portland Development Commission, as originally suggested by these two focus group participants.
} 
the need for mediation training becomes even more important for both volunteers and staff' (Strachan 5).

Participants urged that trainings be jointly designed "by neighborhood people in conjunction with city employees and professionals in various fields" and that training be provided for both city employees and community members. They suggested that the trainings could be "sponsored by individual neighborhood associations or coordinated in a city-wide conference setting." They recommended "programs designed for neighborhood associations members with a wide range of topics" and suggested that "city-wide conference settings" would "allow for better sharing of skills, ideas and information" (Strachan 5).

Theme 4: Communications. All the participants recognized that communications are "the single most important factor in organizing and maintaining strong, representative associations." They stressed the important of good communications "within a neighborhood organization," "among associations," "between the city and neighborhoods," and "with the general public" (Strachan 5). Participants generally accepted communications "as the best buy for tight budget dollars" (7).

Participants stressed that the content, medium, and the distribution method all are important to successful communication. Regarding the content, they said that "simple, straight-forward information is best" and that it is "crucial that the information be complete." Participants said training is needed "in the art of newsletters, both in terms of content and layout." 
Participants identified a neighborhood newspaper as the ideal method of communicating with residents. They noted that many neighborhood associations were looking for better ways to distribute newsletter, because mailing newsletters, while generally guaranteed to reach the recipient is not always timely and is expensive if a "mass mailing to every household" is planned. Door-to-door delivery of newsletters can be used occasionally "but as a regular system...is too volunteer intensive."

Participants saw potential in "handing out newsletters at neighborhood banks and/or grocery stores" but did not have enough follow-up information to determine whether this method was effective at reaching a broad segment of the community.

Cable television was suggested again (at it had been in previous reviews of the neighborhood system) as worthy of further exploration as a communication method. Participants recognized that community members would need training and access to the necessary equipment but thought cable television had great potential and could be used to broadcast "live neighborhood meetings" and to develop "training tapes for neighborhood activists."

City-community communications, according to the participants, needed to be improved by ensuring "earlier, more complete information from the city, with specific contact people identified for additional information of questions" (Strachan 6).

Participants wanted "more positive press coverage" for neighborhood activities. They said the "media tends to emphasize 'bad' news or controversy" and that "more 'good' news helps create a more favorable climate for neighborhood associations." They suggested a strategy of contacting the media more often through press releases and press 
conferences. They recommended that ONA produce a media contact sheet "listing both news agencies and the appropriate contacts" and distribute this list to neighborhood activists along with the ONA Neighborhood Directory.

Strachan reported that focus group participants suggested that ONA should review and keep neighborhood associations informed about "the use, availability, and cost" of new technologies that neighborhood associations could use "to improve services to their members."

Participants discussed the value of a city wide newsletter focused on neighborhood associations and involvement opportunities with city government. They missed the ONA Newsletter, which ONA no longer produced. They felt it had "provided an informational flow between the city and the associations and also increased communications among neighborhood associations" (Strachan 7).

Theme 5: Grass roots Character and Independence: Strachan reported that the interviewees unanimously expressed "great concern that the neighborhood associations remain grass roots organizations." They were concerned that "the city is coming dangerously close to co-opting the associations" and that tight city budgets increased the temptation for city government "to use neighborhood associations as another service delivery system." Some focus group participants said the city should not place any additional expectations on neighborhood associations and that, while this "brave experiment in democracy" had been largely successful, "that success is threatened by overly restrictive rules and additional responsibilities." They stressed that "to remain effective, neighborhood associations must maintain their independence from the city," 
and 'must not be viewed by Portlanders as another arm of city government."' City programs relying on neighborhood associations, such as crime prevention, "must be curtailed to allow neighborhood associations the freedom to choose the best way in which to serve their constituents" (Strachan 7).

Strachan's report recommended that district coalitions establish working groups around "training, communications, and diversity" to "expand and further refine" the report's suggestions. The report suggested that membership of these working groups not be limited to district coalition and neighborhood association representatives, but also include "other citizens and city employees selected by the district coalition chairs."

Strachan's report raised many issues and recommendations heard in past reviews of Portland's community and neighborhood involvement system. She reported that focus groups members found that Portland's neighborhood system was valuable but needed improvement. The system needed to broaden the diversity of people involved, by reaching out to and including people from different ethnic and income backgrounds, incomes and ages. The system also needed to reach out to and involve other types of community organizations and use different outreach strategies and methods.

Focus group members acknowledged concerns that the membership of many neighborhood associations did not represent the diversity of people in the neighborhood, but they cautioned that people needed to have realistic expectations for what neighborhood volunteer could accomplish. They again emphasized that neighborhood associations are "participatory" not "representative" and cannot be all things to all people. 
Focus group members also again identified communications and early notification and leadership training as very high priorities. They also suggested having more community events and celebrations and way for community organizations to network and share information.

Strachan's report also reported participants' questioning of the city government's commitment to community involvement. Participants stressed that city leaders and staff needed to genuinely want to involve the community and have the skills listen and work with community members, rather than just engaging in "lip-service." Participants suggested offering community involvement training for city staff and possibly including community members in the design and delivery of the training. They also identified the need for a strong political champion and political support for community involvement in city government—which they said was lacking at the time of the report.

Focus group members also again stressed the importance of neighborhood associations being independent from city government. They stressed that community and neighborhood volunteers should focus on the priorities and needs of their community, not work on the priorities of city agencies or act as an arm of city government. They also called on ONA to focus on supporting community organizing and involvement rather than what many saw as ONA's focus at the time on regulation and administration of the system.

\section{Neighborhood Congress}

Margaret Strachan followed up on her 1992 report by joining with other neighborhood activists to plan a two-day citywide gathering called Portland 
Neighborhood Congress, which was held in October 1993. Witt reports that Strachan used "her political contacts to City Hall, including recently elected Mayor Vera Katz" to push "hard to frame the Congress effort as a citizen-led charge to revitalize Portland's commitment to neighborhood-based citizen involvement, and to break the deadlock between ONA and the DCBs that had emerged over the previous years" (Witt 180).

Strachan and other neighborhood activists reached out to other neighborhood activists to identify several themes for the Congress. The plan was that congress participants would gather in subcommittees on these themes and "craft "resolutions" that participants would rank in importance on the last day of the event. The intention was that the "votes would then be tallied and presented to City Council for adoption by resolution. In this way, Congress planners hoped to establish a mandate for revamping the NA program" (Witt 180).

An Oregonian editorial in February 1993 supported the idea of a neighborhood congress that would look at the layers of management that had been added to the Portland's neighborhood system since its founding and "see how close to the ground the grass roots of the city's 89 neighborhood associations really lie." The editorial quotes Strachan as saying "There was a lot more neighborhood-to-neighborhood sharing of problems. We need to get back to those kinds of partnerships." The Oregonian supported "making sure residents have a strong voice" in deciding how city budget cuts affect services and programs in their neighborhoods. The editorial quoted Strachan as saying "I want citizens to quit being the fifth wheel and start being the steering wheel" (Oregonian 10 February 1993) 
Strachan strongly defended the grass-roots, neighborhood driven character of the Congress. When Mayor Katz included a budget note in the city budget expressing support for a "neighborhood congress" "to improve citizen participation in government and to contribute to the "empowerment of neighborhoods," Strachan responded "It shouldn't be in the budget." "We're not asking for anything" from the City. The budget note also directed ONA to "re-examine the missions and goals, and assess the current and future role of ONA and citizen participation" (Ellis. Oregonian 10 April 1993).

An article by Peter Mazza ran in the NW Examiner community paper just prior to the congress with the headline "What's happening to the neighborhood movement?" The article began by stating that "a consensus seems to be emerging that the Portland neighborhood system must change-yet there is little agreement on what shape the 20year-old, city-sanctioned system should take." The article noted that "the most basic of questions are on the table" given that the system was facing "a new mayor [Vera Katz], a new commissioner in charge of neighborhoods [Charlie Hales] and a new director of the Office of Neighborhood Associations [Diane Linn]." The article quotes City Commissioner Charlie Hales as saying "I want to rethink the whole neighborhood system" and reported that Hales was asking questions such as: "'Do we need an office downtown at all? Do we need to put more resources out in the district coalitions? Do we just do grants to each neighborhood and let them spend it has they want? I'm open to any number of options." (Mazza. NW Examiner, October 1993)

Mazza's article said the upcoming Portland Neighborhood Congress would be a "crucial step" toward answering important questions about the system and would 
"provide an unusual opportunity for activists to join in a conversation on the future of the neighborhood movement in Portland." The article said the event was called a "Congress" because the intention was that the participants would develop and agree on resolutions that would influence City Council action on the future of the system.

Mazza highlighted some of the tensions within Portland's neighborhood system and shared some of the critical comments citizen activists made during focus groups aimed at designing the selection of workshops at the event. These comments included:

- "Coalitions are a waste of money for the city to fund...They are bureaucratic and interfere with the functioning of the neighborhood associations."

- "There is not trust between neighborhood associations and the city as well as between neighborhood associations themselves."

- "The Office of Neighborhood Associations was an advocate. Now it is a watch dog that gives little direction except budget constraints.

- "Presently neighborhood associations are frustrating. One troublemaker can destroy an association.”

- "Coalitions are not productive enough to justify their existence and sometimes reinforce unproductive behavior."

- "The Office of Neighborhood Associations serves the city bureaucracy more than the neighborhood associations."

People also had good things to say about neighborhood associations, including that they helped build community and provided a permanent structure that gives people a "means to address issues as they arise, rather than having to organize from scratch." 
Mazza quoted Strachan as citing two major concerns from her 1992 review of the neighborhood system, including concerns about whether neighborhood associations are representative of their residents and the nearly universal questioning of the city's commitment to citizen participation. The article also quotes former ONA director Rachel Jacky at a recent City Council meeting sharing her perception that "there has been too much of a parental relationship between the city and the district coalitions for too long. We have been hearing it from the coalitions for a while."

A companion article in the same issue of the $N W$ Examiner reminded readers that Strachan had been the first coordinator of the West/Northwest neighborhood coalition after it was formed in 1976. In the article, Strachan reflects back on the early years of the neighborhood system, "There was much more communication and exchange of ideas from neighborhood to neighborhood across the city. Everybody viewed themselves as pioneers...You knew who the people were in other neighborhoods without looking it up." "We had citywide events: training sessions for the public and potlucks or other events twice a year. People are hungry for that kind of cross-pollination" (NW Examiner, October 1993).

Mazza also spoke with Ken Thomson, a member of the Tufts University team that had studied Portland's neighborhood system and other similar system in cities across the country in the mid and later 1980s. (Thomson also was the keynote speaker for the Congress.) Thomas said his study looked at concerns about "whether city funding co-opts the independence of coalitions and neighborhood associations." Thomson said while city funding can be a concern, it also can enable the "city to insist that the organizations be 
open" and it can promote "continuous outreach" to the community. Thomson warned that in the absence of pressure for outreach cliques can form in neighborhood associations within a couple years at least. He said if no city money is available, neighborhood groups often will form only in response to a "hot issue" and then "fizzle again in three years or so."

Thomson went on to assert that, whatever the future of ONA, "'There definitely needs to be some people working full time at city hall who act as liaisons between neighborhoods and city hall."' He also said Portland was missing a cutting edge practice in some other cities of having a "citywide coalition of neighborhood associations as a complement to city hall." Thomson said that "such a group would be elected by all neighborhood associations to act as a collective voice for the neighborhood movement on citywide issues." Mazza reported that Thomson saw the neighborhood congress "as a potential starting point toward such a coalition." The article quotes a neighborhood activist representing an organization that was sponsoring the congress as saying that the congress could "be the seed for a citywide association of neighborhood associations." Mazza wrote that congress organizers hoped the event would "begin a profound level of communication among neighborhoods" and serve as the "beginning of an ongoing conversation” (Mazza. October 1993).

A day before the start of the Congress, the Oregonian ran an editorial arguing that the question of the representativeness of neighborhood associations should be high on the Congress agenda. The editorial said that the question of "how board members can best represent neighbors was not answered" back in the 1970s when the system was created 
and still needed to be answered twenty years later. The editorial urged neighborhood board members to not overlook the concerns and possible contributions of less assertive residents. The editorial asserted that if anything came out of the discussions at the Congress it should be a commitment by neighborhood board members "to do a better job of informing and involving more residents" (Oregonian 7 October 1993).

Witt reports that 400 people participated in the Portland Neighborhood Congress. During the event, five workgroup discussed and developed resolutions for the consideration of the larger body. The five workgroup theme areas were:

- "Planning: Land Use, Environment \& Transportation"

- "Neighborhood Associations: Roles, Rules, \& Regulations"

- "Neighborhoods \& Community Policing"

- "Broadening the Base of Citizen Participation \& Diversity"

- "Regional Communications Technology" (Witt 181).

Witt reports that the workgroups developed 39 resolutions. Congress participants voted on their top priorities among the resolutions. The top resolutions they chose offer an interesting look at what neighborhood activists at that time thought were the most pressing issues. (Witt notes that it is interesting that the resolution that Thomson supported that would have instituted a citywide coalition body "received zero votes from program participants"(Witt 181-2).

A list of the top 15 resolutions from the ONA/ONI archives shows that the Congress participants most supported resolutions that involved crime prevention, neighborhood planning, public involvement in capital improvement and land use 
planning processes, broad outreach and diversity, timely and centralized notification, a citizen board to govern ONA, a streamlined process to involved neighborhoods in "E" zone processes, and increased funding for neighborhood communications. Highlights of the most popular resolutions are included below (Portland. Office of Neighborhood Associations. The Top 10 Resolutions from the 1993 ONA Neighborhood Congress. [no date]).

Crime prevention: Crime prevention and community policing topped the list. The top resolution asked the city to make public safety its top priority and to "allow the Police Bureau to fill all vacant positions" and to ensure and maintain crime prevention staff positions in all of the coalition offices. The second most popular resolution supported the creation of a "pro-active community policing program." The ninth most popular resolution ( 75 votes) supported strategies to "improve communications between citizens, crime coordinators and police." ${ }^{31}$

Neighborhood Plans: The third most popular resolution (139 votes) called on the City to "create a process that requires neighborhoods to create their own viable and enforceable neighborhood plans in partnership with the community. These plans shall incorporate land use, transportation, ecosystems, and historical preservation that meet intergovernmental requirements."

Capital Improvement and Land Use Planning: The fourth most popular resolution (134 votes) called for neighborhood associations to be "formally involved in all aspects of capital improvements, current and long range planning." The resolution sought "early and continuing" opportunities for "significant neighborhood participation"

\footnotetext{
${ }^{31}$ The document in the ONA/ONI archives did not list separate vote totals for the top two resolutions.
} 
in "any regulation or regulatory review process..." and supported the retention and full city endorsement of the "neighborhood and community planning process" "as vehicles for planning and city involvement." The resolution also advocated for increased "communication between citizens, local, and state governments and developers."

Broader Outreach and Diversity: The fifth most popular resolution (125 votes) advocated for a "commitment to increase social and cultural diversity within neighborhood associations by extending outreach to our schools, businesses, churches, and other community stakeholders..." The resolution proposed to accomplish this through training in diversity and interpersonal skills; technical support from ONA and the coalitions to help neighborhood associations strengthen their organizations and identify goals; the establishment of "relationships and common goals with liaisons from targeted community groups;" and the facilitation of "information sharing between neighborhood associations, community organizations" and other groups.

\section{Timely and Centralized Notification of City Citizen Involvement}

Opportunities: The sixth most popular resolution (105 votes) sought the development and maintenance of "a cross referenced multi-modal information system (e.g. clearing house) listing timely notices from all agencies/entities seeking citizen involvement from community groups," and the development of two way communications with city agencies that would allow neighborhoods to "set or influence agency agendas and timelines" and not merely react to agency determined actions.

Citizen Board to Govern ONA: The seventh most popular resolution (94 votes) called for the created of a "broad-based citizen board to govern ONA" to "increase the 
neighborhood associations' direct authority, control and management of resources...." The board's role would be to include "re-evaluation of the role and function of district coalitions."

Streamlined E-Zone Approval Process: The eighth most popular resolution (86 votes) called for the City Council to adopt an ordinance that would streamline the process "that mandates sign off on all development applications in 'E' zones" by affected neighborhood associations and coalitions.

The next five resolutions included: increased funding of neighborhood communications (70 votes), formation of an ONA advisory board with neighborhood association representatives — not coalition board members-from each district, redefinition of ONA role to shift more power to neighborhood associations "by offering more support better information, less regulation, and less control” (67 votes); development of a simplified substitute for Roberts Rules of Order for use by “neighborhood associations and other citizens groups (67 votes); ONA promotion of citywide communication within and among neighborhood organizations (63 votes); and recognition by neighborhood associations and district coalitions that they "are a reflection of the community — they are not the community itself" (41 votes).

The resolution to have ONA promote citywide communication suggested examples such as a "citywide newsletter, cable access, training sessions, resource library, e-mail, I\&R.” The resolution advocated a search for solutions to overcome challenges neighborhood associations face to producing and distributing printed communications, such as "affordability, distribution, one way flow, labor intensive." The resolution 
supported finding ways to "promote and foster partnerships with schools, business, and community organizations. It also called for an assessment and identification of currently used communications channels, including "newsletters, cable, and bulletin boards," and "serious" support for "a pilot project in computer, cable, fax, and other electronic communication for citizen involvement."

The resolution that called on neighborhood associations and district coalitions to recognize that they "reflect" but "are not" the community suggested a number of community outreach strategies and ways to make the organizations more open and inclusive. These included:

- "Proving they have contacted all segments of the community."

- "Go to the places where people congregate - develop personal relationships / trust."

- "Honor diverse styles of communication and use them to get in touch."

- "Keep challenging and changing neighborhood associations to accommodate the needs / issues of the people you want to involve."

- "Open up the "definition" of involvement (e.g., contribute talent, \$ $\$$, ideas) how to work together - not just meetings; celebrate together, find small ways people can contribute."

- "Recognize individual and family commitments so all feel valued (reward must be meaningful to the person)."

- "Use incentives (i.e., donated by businesses) to recruit citizens and business." 
- "Find out what's important to various segments of the neighborhood so they will be willing to be involved over something they feel passionate about."

- "Support the events and businesses of other cultures so over time they get to know you and may become willing to support you activities."

- "Link with other organizations to perform services (i.e., AARP, \& district coalitions offer free tax preparation)."

Witt notes that the success of the Congress was limited in part by a "reticence to 'rock the boat' and make major changes to the neighborhood system." As an example, Witt reports that the resolution that could have altered the dynamic of power struggles between ONA and the district coalitions - the creation of a citywide body coalition of neighborhood associations (as suggested by Ken Thomson)--"received zero votes from program participants."

Witt reports that the "more ambitious aspirations of the event—-to induce City Council and ONA to adopt the resolutions produced by the Congress—would not materialize" but asserts that the Congress still served as a "significant historic marker for Portland" because it demonstrated that a "fervent interest in sustaining and renewing the NA program" still existed. The Portland Neighborhood Congress would be referenced only two years later when another major review of the neighborhood system-The Neighborhood Involvement Task Force--was initiated (Witt 182).

The top priorities identified by the Congress participants raised familiar issues. They supported the city making crime prevention and implementation of the City's new community policing program high priorities and supported called additional police 
officers and maintaining crime prevention staff positions at the neighborhood coalition offices. They also called for processes to assist neighborhood associations to develop neighborhood plans and strong community involvement in capital improvement planning and long-term land use planning (all of which had been important elements of Portland's original neighborhood system structure).

Congress participants continued the call for efforts to "increase the social and cultural diversity" of people involved in neighborhood associations and for greater neighborhood association involvement with other community organizations to identify shared goals and to share information. They called for ONA and district coalitions offices to support neighborhood associations in these efforts and in increasing the effectiveness of neighborhood association outreach to the community in general. Participants also called for increase support for neighborhood association and district coalition communications.

Another priority that echoed similar calls since the 1970s was the Congress participants call for timely and centralized notification of City public involvement opportunities. Such a system would allow neighborhood associations to get involved in City projects and decisions early when they could influence agency agendas and timelines instead of just reacting to decisions that already had been made.

While Thomson tried to draw attention to the value of a citywide body of neighborhood associations "to act as a collective voice for the neighborhood movement on citywide issues"-an issue that had come up a number of times during the 1970s and 1980s - Congress participants did not find this to be one of their priorities in 1993. 
1995-96 Neighborhood Involvement Task Force

In October 1994_ one year after the Portland Neighborhood Congress- the Portland City Council directed ONA to launch a new "comprehensive assessment of the neighborhood network/citizen involvement system." The City Council stated that the purpose of the assessment was to "assure continued effective, assertive citizen involvement programs" and should "include but not be limited to a thorough examination of the structure, effectiveness, funding needs and distribution of the citizen involvement system" and that the process identify "options for enhancing citizen participation and citizen/government communication" (Portland. City Council. Resolution 35318. 19 October 1994).

The City Council directed ONA to hire a consultant to help facilitate the process. Community members were to be involved in the process through "regular communication about the progress of the assessment" through methods such as "newsletter, focus groups, key informant contributions" and other opportunities. The City Council anticipated that the assessment would take one year (Portland. City Council. Resolution 35318. 19 October 1994).

The Oregonian reported that several neighborhood activists strongly objected to City Council's grant of the power to select the task force members to Charlie Hales, the City Commissioner in charge of ONA. They feared that Commissioner Hales would "stack the deck" and wanted community groups to be able to select their own representatives on the task force. Hales and other city council members "defended the selection process, saying the task force 'needs to have broad representation from the 
community." The Oregonian reported that despite the sharp criticism, "most neighborhood leaders agree that an objective examination of the neighborhood structured is warranted" (Kiyomura. Oregonian 20 October 1994).

The Oregonian quoted ONA Director Diane Linn who argued that "We have a great system in place. The question now is do we have the guts to make it better." The article also recorded Commissioner Hales, referring to Socrates saying "an unexamined life is not worth living" said "I think an unexamined neighborhood association may not be worth keeping. Let's do this now when we are strong [rather] than at a future time when we would be doing damage control and critical repairs" (Kiyomura. Oregonian 20 October 1994).

One week later, on October 26, 1994, the City Council passed a resolution that appointed twenty-four people to serve on the "Task Force on Neighborhood Involvement" (TFNI). The TFNI final report states that Commissioner Hales' appointments to the TFNI reinforced his desire to broaden the TFNI's review to include perspectives beyond just those of neighborhood activists. The TFNI members included 25 community members from all over the city, from a variety of backgrounds and perspectives, some with "extensive experience working with Neighborhood Associations and District Coalitions" and other with "little or no previous contact with the current neighborhood involvement structures" (Portland. Office of Neighborhood Associations. Report and Recommendations of the Task Force on Neighborhood Involvement. February 7, 1996 3-4). The appointees included eight district coalition representatives and four neighborhood association representatives - together they constituted half of the task force 
membership. The other half of the task force members represented a variety of community interests, including a general community activist, three individuals from culturally diverse communities, and individuals from the non-profit, business, philanthropic communities, and representatives of district coalition staff, business district associations, community development corporations and one city bureau outreach specialist (Portland. City Council. Resolution 35322, 27 October 1994).

The task force members got right to work on what would become the most indepth review and evaluation of Portland's neighborhood association since its founding in the 1970s. After a year of hard work including "hundreds of hours looking at the way Portland's neighborhood association program work," they shared a draft of their report and recommendations with the community in November 1995. The Oregonian reported that the draft was "not a report to scare your socks off. But it is a document demanding attention, at least because most recommendations involve putting more money into the Portland neighborhood association system." The "thoughtful...findings and recommendations" did not "overthrow the current system" but, in addition to calling for an estimate $\$ 1$ million in increased funding, also recommended a number of changes to expand the system and make it more inclusive, responsive, and effective (Christ, Janet. Oregonian, 13 November 1995 and Oregonian, 4 December 1995).

The TFNI's formal charge from City Council and Commissioner Hales was to "Conduct an assessment which includes but is not limited to 'a thorough examination of the structure, effectiveness, funding needs, and distribution of the citizen involvement system; and the identification of options for enhancing citizen participation and 
citizen/government communication." Commissioner Hales and task force members expanded the scope of the TFNI's charge to include responsibility to:

1. "Examine the Neighborhood Association (NA)/District Coalition (DC)/Office of Neighborhood Associations (ONA) structure in relation to citizen involvement with the City of Portland and other governmental entities;" and to

2. "Look beyond the current ONA structure to find opportunities to broaden citizen involvement and to encourage participation by the full diversity of our communities;"

Commissioner Hales asked the TFNI members to "Look for opportunities to make significant improvement in citizen participation" (Portland. Office of Neighborhood Associations. Report and Recommendations of the Task Force on Neighborhood Involvement 1).

TFNI members began by adopting a shared definition of "citizen participation/neighborhood involvement" to guide their work:

"Citizen participation/neighborhood involvement includes efforts by residents, business owners, service providers, and others to improve the quality of life in their shared neighborhood. It includes, but is not limited to efforts to improve air and water quality, transportation, safety, appearance, and overall livability of the neighborhood" (1).

This definition echoed the purpose statements for neighborhood associations in the original 1974 and 1975 ordinances that created Portland's neighborhood system. The 
TFNI members further clarified in their report that their use of the term "citizen" was meant to include all individuals in a community—regardless of their formal citizenship status in the U.S. (1).

The TFNI members also created a framework of principles and characteristics of good community involvement to guide their work. Future reviews of Portland community and neighborhood system also would call for and recommend similar statements of principles and elements to define and guide effective community involvement, both within the neighborhood and community involvement system and by city staff and officials.

The TFNI "Framework for Citizen Involvement" included the following:

1. Promote Problem Solving in an Atmosphere of Mutual Respect

a. Build trust

b. Promote win/win, not win/lose resolutions to issues

c. Reduce adversarial relationships between neighborhoods, City and others

d. Provide opportunities for civil adversaries to deal effectively with differences

e. Bring decision-makers face-to-face with citizens

f. Encourage early participation in development planning

g. Provide ways for neighborhoods to related to other communities

h. Provide base for developing long term solutions

i. Encourage folks working for government to feel part of the community and vice versa

2. Be Responsive and Inclusive

a. Provide a framework for involvement which is visible and understandable to the general public

b. Be welcoming, nurturing, and allow participants to have a good time.

c. Promote active involvement of diverse communities

d. Contribute to a greater sense of community

e. Be representative of communities

f. Overcome apathy

g. Proactively reflect needs/concerns of communities 
3. Be Effective
a. Meet citizen needs quickly and effectively
b. Result in improved livability
c. Build community partnerships
d. Involve minimal waste
e. Be able to impact laws and challenge the status quo
f. Be accountable

4. Develop Leadership Skills of Participants

5. Be Respected and Utilized by the City and Other Governmental Units

a. Build and support government respect for the wishes/values of neighborhoods

b. Be utilized by governments to involve neighborhoods in key decisions

(Portland. Office of Neighborhood Associations. Report and Recommendations of the Task Force on Neighborhood Involvement 3).

Many of these same elements were included in a set of public involvement "guiding principles" for city government, which the City Council adopted at the same time it formally accepted the TFNI report in February 1996.

The TFNI members reached out to the community in many ways. The TFNI report states that TFNI members engaged in a variety of outreach efforts to the district coalitions, neighborhood associations, different parts of the city, and city staff from different bureaus and city officials. They interviewed representatives of business and civic organizations that operated outside the City's neighborhood involvement system. They also examined citizen involvement models from other cities (3-4).

The TFNI members reported a number of findings. They emphasized that the current neighborhood system was working well for many people and was nationally famous as "a model for encouraging citizens to work together to improve their neighborhoods and the city as a whole." They asserted that any changes "must build on the strengths of the current system." They said they heard about many strengths of both 
neighborhood associations and district coalitions. Neighborhood associations were "excellent at receiving and discussing information;" "Getting results on issues neighbors identify;" "Creating a sense of neighborhood and community;" Linking businesses and residents;" and "Supporting diversity in the community." District Coalition were successful in their effort to: "Provide strong support to meet neighborhood needs"; Provide effective advocacy with the City"; "Make good use of limited resources"; "Communicate information throughout their districts through newsletters"; and "Effectively support neighborhood efforts in crime prevention, growth, transportation, and planning issues" (4).

They also reported that they heard about problems and lack of effectiveness in the neighborhood association, district coalition, and ONA system. Some neighborhood associations "Involve a very small portion of the people in their neighborhood;" "Do not reflect the diversity of the residents of their community;" and "Experience conflict and interpersonal communication problems which discourage participation." Some District Coalitions were "More focused on administrative and staff management issues than on [neighborhood association] concerns," "Limited in their effectiveness by difficulty dealing with conflicts," and "Staff driven rather than neighborhood driven" (5).

Many people suggested to the TFNI that inadequate funding was a least partly to blame for the problems. Neighborhood associations did not have the resources to reach all their residents. District coalitions did not have the staff capacity to support the "education and outreach" needed to engage the community. Low pay and benefits led to high turnover rates in some district coalitions (5). 
City bureau managers saw the neighborhood associations and neighborhood district coalitions as valuable avenues by which the City can "engage in dialogue with its citizens," recognized their same limitations listed above, but emphasized the important of "maintaining ongoing structures" that "bring neighbors together to work on issues of mutual interest" (5).

The TFNI members recognized that many challenges impeded the involvement of community members at the neighborhood level. Many "individuals lack the time and energy needed to develop a sense of community." However, what they heard consistently from people was that "the benefits of strong neighborhood involvement are worth the effort" (5).

Overall, the TFNI members did not find that the neighborhood system structure needed major changes. They did find that "additional investment" was needed to increase the effectiveness of the system. This investment "should be directed to improving functioning and building structures which promote greater participation, of a wider diversity of neighbors, with increased citizen satisfaction and a higher success rate...." They wrote that success should be "measured by needs addressed, problems solved, community satisfaction, and cohesiveness" (5).

The TFNI members grouped their recommendations in eight topic areas:

- "Value of Neighborhood Involvement,"

- "Structure for Neighborhood Involvement,"

- "The Role of the Current Office of Neighborhood Associations,"

- "Key Neighborhood Involvement Initiatives," 
- "Collaborative Approach to Accountability,"

- "Operational Recommendations," and

- "Budget Recommendations"

- "Policies and Procedures Needed to Implement Initiatives and Recommendations"

Value of Neighborhood Involvement: TFNI members highlighted the overall benefits of citizen participation and neighborhood involvement and described some of the characteristics and roles that would characterize a strong system. They argued that community involvement "plays a central role in improving the quality of life for all Portlanders and in promoting an effective and responsive government." Portlanders received substantial "public benefit" for the public funds spent to support this involvement. TFNI members stressed that they intended their recommendations to strengthen the existing system and to increase its "openness and effectiveness" and to increase the "already strong City commitment to the value of citizen participation" (6).

The report established a goal of achieving a "participatory government" that "provides a direct link between neighbors and their government." It envisioned the "highest level of involvement" as "the full diversity of neighbors sitting face to face with those planning and implementing public policy" and actions, "participating in decision making" and "allocating resources" (6).

The report stated that neighborhood associations should function as 'forums' for people from common geographical areas and with common interests to "come together to discuss issues of concern, resolve conflicts, achieve consensus, and communicate with 
their government." While TFNI members believed that community involvement structures should give people the opportunity to "participate in government decisions" that "affect their quality of life," they emphasized that the primary purpose of neighborhood associations is to "promote community" not just to "communicate with government." To play this role effectively, the report asserted that neighborhood associations must remain independent and without constraint, but that neighborhood associations that follow basic guidelines should receive support services, if they need them, "to enhance their effectiveness as participatory groups." District coalitions were found to "provide a practical structure to support NA's with training and technical assistance" (6).

Structure for Neighborhood Involvement: TFNI members recognized that neighborhood associations are driven by individuals and their needs and views. Given this they asserted that neighborhood associations "should remain and be revitalized as the cornerstone of Portland's structure for neighborhood involvement." They also supported the value of district coalitions as a structure that allowed the City to fund support for neighborhood associations while they acted as a buffer between the City and neighborhood associations to help preserve their "essential independence" (7).

TFNI members departed from tradition in a major way by recommending that neighborhood associations have the option to ask ONA to create a "neighborhood [district] office" staffed by city staff to provide support services to them instead of the traditional independent non-profit district coalition model. ONA already had created one city-staffed "neighborhood office" in 1992 to serve neighborhood associations in north 
Portland after the north Portland district coalition board (the North Portland Citizens

Committee (NPCC)) had disbanded because of major conflicts between its board members. Under this alternative, ONA would hire the office staff, and the neighborhood associations in the district and ONA mutually would agree on the procedures by which these staff people would support the neighborhood associations. Instead of a non-profit board of directors made up of representatives of the district's neighborhood associations that set policy and directed the office, the neighborhood associations would send "their Chair or designee to regular meeting to discuss common problems and issues and to express needs and priorities for staff assistance." The neighborhood associations "would participate in the hiring, evaluation, and firing of staff including developing the job descriptions for each position." ONA would be accountable to ensure that the office staff members were effective and responsive to the neighborhoods. The TFNI members recommended that ONA consider proposals from NA's for other district structures as well (7). ${ }^{32}$

The TFNI members determined that the ONA Guidelines should be changed to clarify the district structure options and to establish a measured process through which "such proposals for alternative structures" could be examined, but only when the affected communities were in "substantial consensus" in favor of a structural change (8).

\footnotetext{
${ }^{32}$ Witt provides a fascinating and detailed account of the conflict that led to the dissolution of the north Portland district coalition in Chapter V of his dissertation. In Chapter VI, Witt documents similar conflicts on the board of the east Portland district coalition that led ONA (then ONI) to create another city-staffed neighborhood office in east Portland in 1997. Since that time none of the five remaining independent nonprofit district coalitions has shifted to the city-staff neighborhood office model or any other model. While some east Portland neighborhood leaders have advocated for a return to the independent non-profit model, others do not want to take on the work of running a non-profit organization and prefer having a city-staffed neighborhood office.
} 
The TFNI members emphasized that consideration of any alternative district structures should ensure that: neighborhood associations continue to play the central role in involving their community members and continue to provide a structure for community members to communicate with the City and for the City other government entities to community with community members. The TFNI members wrote that "it is extremely important that the City be responsive to the needs and views" of neighborhood associations and respect the "volunteer time and energy of the NA participants" and that the neighborhood associations remain independent. They also re-emphasized an important value held since the founding of the neighborhood system that community members "always have the right to communicate directly with the City," and that neighborhood associations should not "close off opportunities of citizens/neighbors to speak directly with the City when they choose to do so" (8).

The Role and Name of the Current Office of Neighborhood Associations:

The TFNI members also recommended a major expansion of ONA's role. In additional to supporting neighborhood associations, TFNI members recommended that ONI also support "neighborhood Business District Associations and other civic organizations in their efforts to work effectively with neighbors and with the City." In keeping with this expanded role, the TFNI members recommended that the name of ONA be changed to the "Office of Neighborhood Involvement." The TFNI members intended that the name change would eliminate the misperception that neighborhood associations were part of city government rather than independent community organizations. The name change 
also would reflect the broader role that TFNI members recommended that ONA/ONI play in extending its support network to other types of community organizations.

The TFNI members affirmed the importance of and need to continue ONA's existing functions, which included: "recognition and support of NA's"; funding of support for NA's through contracts with district coalition and neighborhood offices; 'training for NA and DC participants;" information and referral services; coordination of and support for the DC crime prevention efforts; coordination of immigrant and refugees services; coordination of City bureau outreach to neighborhood associations and neighborhoods; "promotion of communication and collaboration among NA's, neighborhood Business District Associations, ethnic and civic organizations, major employers, and institutions"; and mediation and facilitation services provided through the Neighborhood Mediation Center (9).

The TFNI members also recommended a major change in the role of ONA in relation to the rest of city government. They recommended that ONA be put in charge of community involvement for all of city government and be given the "responsibility and authority for coordinating the efforts of the Bureaus to reach out to citizens/neighbors to involve them in key planning and implementation efforts" and discussion of "Bureau issues" (9-10).

Key Neighborhood Involvement Initiatives: TFNI members developed and recommended implementation of eight specific initiatives intended to respond to the challenges they identified during their study process. 
Boundaries: TFNI members recommended that ONA complete a study of neighborhood and district coalition boundaries and adopt processes to resolve boundary disputes between neighborhood associations (10).

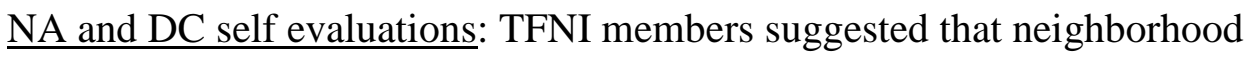
associations and district coalitions consider evaluating their strengths and weaknesses "in meeting the needs of their communities within the criteria" set out in the TFNI Framework for Citizen Involvement. They suggested that neighborhood associations and district coalitions reach out to and solicit the views and preferences "residents, business, ethnic, and civic groups" within their boundaries. They also suggested that district coalitions reach to their neighborhood associations to discuss "the degree to which the DC is meeting the needs of each NA" as part of their self-evaluation. The TFNI member recommended that ONA should fund and support these processes (10-11).

Increased linkages between the neighborhood system and other groups: TFNI members recommended that NAs and DCs be encouraged to pursue communication with and invite participation from "community civic groups (including ethnic organizations) and business associations in their community." They also recommended that the ONA Guidelines be amended to encourage communications between business district associations and DCs. They recommended that ONA should act as a clearinghouse of information on the neighborhood system for business and civic groups and assist NAs and DCs in forming effective relationships with these groups.

$\underline{\text { Recognition and support for business district associations: TFNI members }}$ recommended that ONA facilitate a process with the Alliance of Portland Neighborhood 
Business Associations (APNBA) — the citywide organization of neighborhood business district associations - and neighborhood activists to establish criteria and procedures by which business districts could apply to ONA for formal recognition. Recognized business districts would receive the same City notifications received by neighborhood associations. ONA would provide funding to the district coalitions to support communications by recognized business districts in their areas. Recognized business districts would become the official representative of businesses in their area to the City (11).

Increased Outreach and Inclusiveness: TFNI members emphasized the need for NAs and DCs to "reflect the full diversity of their communities" as they had set out in the TFNI's "Framework for Citizen Involvement." However, they also recognized that achieving this goal would be very challenging, partly because "as volunteers," neighborhood leaders faced many demands on their limited time.

The TFNI members recommended that ONA request additional funding from the City to "assist NA's to increase and enhance their efforts to reach all members of their communities, particularly those segments of their communities which are presently underrepresented in their activities." The TFNI members suggested strategies that including "mailings to all households offering an opportunity for involvement; training in effective outreach and building multicultural organizations; funding for newsletter production and distribution; and support for other initiatives designed and proposed by NA's for approach specifically appropriate for their communities." 
TFNI members also recommended that ONA create a process to formally acknowledge community groups that represented communities that were not tied to particular geography (as were neighborhood associations and business district associations). They referred to these communities as "neighborhoods without boundaries." Much of the task force's thinking on this topic appears to have been driven by Charles Shi, a task force member who presented the Asian Pacific American Alliance of Oregon and the American Burmese Association of Oregon on the task force. Shi' suggested that immigrant and refugee communities be allowed to form their own "nongeographic" organizations and that Portland's neighborhood system be expanded to formally include them. This approach did not expect all residents to work through their neighborhood association, but recognized that people in some communities are more likely to be drawn to join together with people from their own community rather than traditional neighborhood associations. ${ }^{33}$ A fuller description of Shi's proposal below will helps to reveal the origins and original form of his ideas.

\section{Charles Shi's Concept for "Neighborhoods without Borders": TFNI member}

Charles Shi proposed that a new element be added to Portland's neighborhood program that would recognize immigrant and refugee Mutual Assistance Associations (MAAs) as “neighborhoods without borders." He also proposed that ONA develop a program to help

\footnotetext{
${ }^{33}$ Shi's concept continued to generate interest and more community discussion for a number of years, until a variation of his recommendations were implemented in 2006 under Mayor Tom Potter in response to advocacy from the Southeast Uplift Neighborhood Coalition Diversity and Civic Leadership Committee and in conjunction with another in-depth review of Portland's community and neighborhood involvement system known as "Community Connect."
} 
immigrant and non-immigrant neighbors who lived on a particular block work with their related MAAs and their local neighborhood association.

Shi's proposals rose out of his concerns about growing crime within different immigrant and refugee communities. He especially was concerned about youth in these communities who were being drawn into criminal lifestyles and then preying on people in their own communities. Shi noted that immigrant and refugee communities often were isolated from the regular sources of law enforcement and other assistance in the community. This isolation allowed cycles of serious problems, "such as home invasion and ethnic gangsterism" to grow "adding fuel to the growing social disorder and violence that are threatening to us all" (Shi. November 1994).

Shi said these problems were "...not solvable through the usual routine law enforcement action and procedure." No "effective law enforcement action" was being taken "due to lack of crime reporting by the victims." Shi maintained that "victims need to know how to access...the protection and redress provided by the law enforcement system available here" (Shi. December 1994). Shi explained that the social and cultural mismatch between immigrants and refugees and their next door neighbors "is the main cause of living in isolation for the immigrant/refugee families trying to resettle" in "this new homeland." Shi argued that legal immigrants have a right to expect "a safer and crime-free environment" (Shi November 1994).

Shi wrote that many immigrant and refugee communities, while not connected to the larger community, had created Mutual Assistance Associations (MAAs) to assist people within their own communities. These MAAs were not tied to any particular 
geographic area, but were made up of people who were drawn together by their shared language and social and cultural backgrounds. Shi wrote that these new immigrants and refugees "trust and rely on former compatriots for help and support" instead of "nearby neighbors who are so near yet so alien." Shi called these groupings "neighborhoods without borders."

Shi wrote that differences in "the manner of communication and networking" also acted as a barrier between victims and sources of law enforcement and other assistance in the larger community. By involving "various ethnic-based new immigrant associations themselves" they could help develop and improve lines of communication between their community members and the larger community and its resources. He suggested that "many of the ethnic-based organizations, individually or organizationally are more than happy to get involved in this good cause if clear instruction and safety protection are provided" (Shi November 1994).

Shi suggested that an additional "dimension" be added to the "City's Neighborhood Associations Program” by formally recognizing MAAs "as the neighborhood associations" for these communities_-"neighborhoods without borders." He also suggested that "MAAs from [the] same socio-cultural region of the world," such as "Asian/Pacific Islanders" and "East Europeans," could form and be recognized by the City as "coalitions" equivalent to the neighborhood district coalitions (Shi December 1994 and November 1994).

Shi envisioned a system in which "neighborhoods without borders" and traditional geographic neighborhood associations would "interact and work interwovenly 
together without requiring extra law enforcement and other services resources...to fulfill the mission of community policing across the ethnic barrier with flying colors" (Shi November 1994).

Shi also proposed the development of a program of "infra neighborhood structure and inter-ethnic networking" that he called "Operation Community Tapestry." The proposal included:

- Organization of Block Neighborhoods on every street with participation from "neighbors from both sides of the street."

- Identification of one key neighbor in each Block Neighborhood to act as "neighborhood facilitator."

- Outreach by the "neighborhood facilitator" to "all the neighbors within the block" to let them know about this role.

- Facilitation of communication between the block neighborhood and the neighborhood association for the area by the "neighborhood facilitator."

One of the roles of the block neighborhoods would be to "find out the ethnic identity of the immigrant/refugee families residing" on their block. ONA then would help neighborhood facilitators organize "home and/or community place" visits with these families by the appropriate "ethnic MAA." The purpose would be to "establish the vital link between the neighbors within the geographic border and gain access to the normal help and support from the local resources for security and well-being."

Shi envisioned that the Block Neighborhoods would involve as much volunteer participation as possible with support from ONA, and from law enforcement and social 
service agencies, local schools, and neighborhood businesses, banks, and insurance companies.

Shi's proposals got people thinking about whether Portland's neighborhood system should be expanded to include, not only the geographically defined traditional neighborhood associations and business associations, but also communities of Portlanders who share a particular identity, ethnicity, or culture but do not live in one particular geographic area. ${ }^{34}$

Increased Support for Conflict Resolution: TFNI members emphasized that community members "can craft solutions to perceived conflicts" in the community "more effectively than City Bureaus or City Council.” They also recognized that resolving conflicts at the "local level—among neighbors and businesses at the neighborhood level and among neighborhoods at the district level" often required "mediation and facilitation skills" that many community members did not have. Interpersonal conflicts and conflicts over communication problems were two areas identified by TFNI members for particular attention. They stated that effective facilitation of "dialogue and issues resolution" was needed to overcome these problems.

TFNI members recommended that the City and ONA "invest new resources to assist NA's and DC's to develop conflict resolution skills and provide conflict resolution assistance when needed (Portland. Task Force on Neighborhood Involvement 12).

\footnotetext{
${ }^{34}$ Charles Shi's proposal for helping neighborhood association and immigrants and refugees work together better was explored further starting in 2001 through the implementation of a three year project called "Interwoven Tapestry" - part of a national study funded by the federal government and the National Association of State Legislatures. This project is described in more detail in the next chapter.
} 
Improve district coalition staff quality and stability by reducing pay disparities: TFNI members found that differences in salary and pay benefits across the DCs and the city-staffed neighborhood office in North Portland had results in some staff moving "from district to district" for better compensation for "essentially the same levels of responsibility." TFNI members recommended that the ONA contracts with the DCs, "set and fund salary levels" for DC positions "at levels equivalent" to those of the city employees in comparable positions and provide funding to "equalize benefit levels" across the DCs but not require parity with city employee benefits. TFNI members did not recommend setting benefit levels at those of city employees because those levels might not be appropriate for non-profit organizations and the resource to fund these higher benefit levels likely would not become available (12-13).

Increase resources to NAs and to strengthen DC services to NAs: TFNI members presented a number of recommendations for increasing and more equitably distributing the funding and resources available to the neighborhood system. One recommendation was to establish a "Neighborhood Grants Program" that would allow NAs to apply for additional funds to carry out projects and activities in their neighborhood. ${ }^{35}$

TFNI members also sought to give NAs more control over their DCs by requiring DCs to consult with their NAs on the "review of each DC's proposed annual workplan, proposed performance measurements, and annual review of achievements." TFNI recommended that ONA would assist in "problem solving," if a DC's NAs did not support the DC's proposed or actual activities.

\footnotetext{
${ }^{35}$ The creation of a neighborhood grants program was not funded for many years, despite additional attempts to establish the program. Mayor Tom Potter successfully established and funded Portland's "Neighborhood Small Grants Program" in 2006.
} 
Other recommendations sought to tie some of the funding allocation for DCs on the relative demand for services in their district, e.g. "the number of NA's and citizen's served." TFNI members sought to put additional pressure on DCs to listen to their NAs by recommending that that, if a NA was unhappy with the services it was receiving from its DC, the NA be allowed to move to a different DC along with the NA's funding allocation.

The TFNI members recognized that the current allocation per NA was "very low" and recommended additional funding to increase the amount received by each NA. TFNI members sought to ensure that any movement of neighborhoods would not endangered the ability of a DC to provide basic services. They recommended that each DC "receive a core allocation...sufficient to provide basic services" and that funding tied to the number and characteristics of its member neighborhood associations "would be in addition to this core allocation" (13).

The TFNI members recognized that establishing an equitable allocation of funding among the districts was "complex." They recommended that a portion of the TFNI members continue to "work with the ONA BAC to develop an equity funding strategy which considers but is not limited to factors such as population, number of NA's served, and area; and indicators of need such as rate of development, crime, poverty, and education and income levels. ${ }^{, 36}$ The TFNI members also called for standards to be set

\footnotetext{
${ }^{36}$ Soon after the TFNI completed its report, SE Uplift Neighborhood Program, the district coalition for inner SE Portland, approached ONA and made the case that their coalition should receive significantly more funding then the other coalitions because nearly a quarter of the city's population lived in inner SE. ONA subsequently increased SE Uplift's allocation to nearly twice as much as the other district coalitions. While Portland continued to grow and change over the next twenty years, the distribution of resources among the district coalitions did not change, prompting increasing demands for the development of a more equitable funding formula. The strongest push for reworking the funding formula would come from East
} 
within 90 days to guide funding allocations that would be tied directly to the number of residents is a district and related to the delivery of particular services, "such as newsletters and mailings" (13-14).

Collaborative Accountability: TFNI members heard calls for greater accountability with the neighborhood system. Some critics said "NA's should be accountable for being inclusive and representing fairly the views of all participants." Some said that DC's needed to be held accountable — both by their NAs and by the DCs themselves-for supporting NAs as required in their ONA contracts. Some said ONA should do a better job of "enforcing the terms of its contracts" but not in a way that would interfere "with each Coalition's right to set priorities and address community needs" (14).

TFNI members called for the City to "measure the public benefit being achieved through the investment of public dollars in neighborhood involvement" - a call that would be heard periodically over subsequent years in Portland and in other communities as community members and city government leaders sought to justify public expenditures on public involvement activities and systems (14).

The TFNI members stressed that any effort to respond to "problems and dissatisfactions with NA's, DC's and ONA needed to preserve "the independence of the NA's and the DC's from City control" as an "essential element in an effective system of neighborhood involvement." They also found that the City needed to be more responsive to neighborhood concerns and found that "both NA's and citizens" needed effective ways to hold the City accountable (14).

Portland neighborhood leaders. By 2010, the population of east Portland had grown to nearly equal that living in inner SE Portland and represented the greatest population diversity in Portland and therefore some of the greatest challenges to effective community organizing and civic involvement. 
To ensure "mutual accountability," TFNI members recommended a "commitment to a collaborative rather than adversarial approach...." They recommended that participants at all levels of the neighborhood system be encouraged to: "ask for what they want," "explain how they would know if they got it," "not tell each other what not to do," and "address problem in the context of larger goals" (14). TFNI members said that all interactions between parties to "themselves and one another accountable" should include: "focusing on goals," rewarding desired behavior," "training," "modeling desired behavior," "using mediation to resolve conflict," "planning for improvement rather than blaming for past outcomes," and agreeing on "principles rather than developing rules" (14).

TFNI members called on ONA to work collaboratively with the NAs and DCs to develop future contract agreements and "facilitate inclusive evaluation" of progress in meeting the agreed-on goals and lead the way in helping parties to clarify what they want and agree among themselves on the resolution of their path forward. TFNI members suggested some specific approaches:

- Written expectations: “Development by NA's and DC's of written expectations for NA and DC board members;"

- Evaluation guidelines: "Development of guidelines for action plans and performance evaluations, including reference to City, County and State benchmarks, and measureable as well as subjective outcomes;"

- Public access to performance data: "Increased public disclosure of performance indicators;" 
- Enforcement of the ONA Guidelines: "Reassessment of options for enforcement of the Guidelines, including a clearer definition of the role of ONA and the establishment of the Citizen Advisory Committee;" and

- Grievance procedure review: "Reassessment of the Grievance procedure" (15).

Operational Recommendations: TFNI members presented seven additional goals with supporting strategies that provide very useful insights into what TFNI members believed needed to be implemented by ONA, NAs and DCs, and the City to achieve these goals. The goals and summaries of their implementation strategies are presented below.

Goal \#1: Community members should be aware of and understand the work of the NAs, DCs, and ONA and know about the resources available through the neighborhood system. Strategies focused on actions by ONA including:

- Inclusion of elements in the ONA workplan that would "build visibility and understanding" of the neighborhood system.

- ONA development and distribution of "more understandable brochures and materials" about the neighborhood system, ways to get involved in NAs, and "services available from ONA and the DCs" and clarification for community members that the neighborhood system is intended to "help neighbors work together effectively" but not, in any way, to limit "the access of individuals to City officials" (15). 
- Outreach and communication efforts that included a map of NA boundaries, advertisements on buses, utilization of "school, local, and ethnic newspapers", and a pilot project to increase the use of electronic communication (e.g. computer, cable, fax, etc.) "between the City and residents."

- ONA funding to assist NAs and DCs to communicate more effectively "with neighbors within their boundaries" (16).

Goal \#2: Increased involvement in NAs and DCs by "low income residents, $\underline{\text { renters, ethnic minorities, younger people with young children, and other under- }}$ represented groups in NAs and DCs" to strengthen "the neighborhood involvement process" and benefit "individual neighborhoods and the City as a whole." TFNI members recommended that ONA:

- Establish a process to acknowledge "neighborhoods/communities without boundaries" as proposed by Charles Shi (see above).

- Offer ongoing training for NA leaders on strategies to encourage diverse participation.

- Encourage NAs and DCs to work with other community organizations, including "civic groups, ethnic groups, schools, businesses, churches, and other community stakeholders" and strongly encourage NAs to "make proactive efforts to assure participation by the full diversity of their community." 
- Provide language translation and interpretation services to help NAs and DCs overcome language barriers and to encourage NAs and DCs to provide child care at their meetings and events whenever possible.

- Increase accessibility by encouraging general compliance with the Americans with Disabilities Act (ADA) (16).

TFNI members recommended that the City help hold NAs accountable by asking, during decision making processes, whether the NA has a minority report, and how many community members were involved in the neighborhood's decision making process (17).

Goals \#3 and \#4: "NAs and DCs should be welcoming to all members of the community" and people who do not like attending meetings should have other opportunities to get involved in their neighborhood. TFNI members recommended that NAs and DCs be strongly encouraged to:

- "Use a welcoming process at each meeting" and "identify and welcome" new residents to their communities through devices as a "welcome wagon" (e.g. a packet of information and materials about their new neighborhood and how to get involved).

- "Hold meetings at times and locations" that are "convenient to as many neighbors as possible" and to hold meetings at "accessible locations," whenever possible.

- Host fun events and social opportunities, and offer opportunities for community members "to work on projects and activities," all in addition to standard meetings. 
TFNI members recommended that ONA should:

- Offer ongoing training opportunities to NA and DC leaders "in meeting facilitation and effective meeting techniques" with a special focus on promoting the "expression of views by all participants and preventing "more vocal participants" from dominating the meeting time.

- Fund conflict resolution support and assistance to NAs and DCs in "dealing with difficult people" (17).

- Build greater awareness of its "telephone information and referral services."

- Explore how to use electronic communication tools (like the Internet and the library’s data system) to "post information on City plans and provide opportunities for input" and on "NA activities."

Goal \#5: Support the "development of new and continuing leadership at all levels of NA's and DC's." TFNI recommended that ONA should provide continuous leadership development training and support and offer multiple levels of training opportunities to meet the "needs of both more and less experienced activists." TFNI members recommended that NA and DC leaders be encourage strongly to "attend trainings at least once a year" (18).

Goal \#6: Experienced and knowledgeable staff should be available to support community members and NAs at all "District Coalitions and District Offices." TFNI members recommended that ONA "facilitate regular networking meetings" for district staff to help them share strategies and information (18). 
Goal \#7: City bureaus should more productively involve community members and NAs in "developing and implementing policy through more effective, sincere coordinated efforts." TFNI members recommend a long list of actions that City bureaus should take to help improve the quality and effectiveness of their involvement of the community in decision making. These included:

- Educate NAs about and involve them in "real choices" (this echoes the call for "genuine community involvement instead of "lip service" from the 1992 Strachan report).

- Require every city bureau to "allocate staff time to neighborhood education," and then to use these "educated citizens effectively." The TFNI members stressed that "Bureaus should ask NA's for information only when it will be used in a meaningful way."

- Use "neighborhood volunteers to assist" the City in its work "whenever possible."

- Involve NAs early in project planning, "especially when infrastructure improvements are involved."

- Schedule and locate meeting at times and locations convenient "to the maximum number of people" (18).

- Include sign-in sheets at hearings as part of the public record and formally count everyone who attended, not just those who came to speak (to more accurately record the level of public interest). 
- Ensure that the most relevant staff person reaches out to the public and avoid assigning the responsibilities for managing the project and listening to neighbors to different staff people.

- Ensure that high-level bureau staff get out into the community and interact with NAs and DCS more often. More community members likely would come to these meeting because people with the authority to make decisions would be there, and NA's would be more "useful to decision-makers."

- Schedule and advertise bureau outreach activities "at least six weeks in advance" (rather than the 30 day notice required in City Code) as often as possible to allow community groups to get the word out to the public in their newsletters.

- Improve community outreach by using postcards more often because "They're easier to read, recycle, or post," and "phone/email notification of meetings" because it is more efficient and less wasteful.

- Use the "guiding principles and handbook developed by the District Chairs, Bureau outreach staff, and ONA" to "improve City/citizen communication." 37 Budget Recommendations: TFNI members supported expanded funding for the community and neighborhood involvement system to implement the TFNI recommendations. TFNI members highlighted their recommendation that "a four-position

\footnotetext{
${ }^{37}$ The City Council would adopt these principles for public involvement by resolution at the same Feb 1996 hearing at which it accepted the TFNI report. In the following years, while some city staff referred to the principles and the Handbook, developed in 1995, most did not. Continuing community concerns about inconsistent and poor quality community involvement by city bureaus would lead City Council to create the Public Involvement Task Force in 2003 to undertake a major review of city government public involvement. This process is discussed in more detail in the next chapter.
} 
core staff be provided for each DC or District Office" and that at least one of these positions should be devoted to "crime prevention activities."

ONA estimated that implementation of the TFNI recommendation would require a funding increase of $\$ 677,809$ in the 1996-97 fiscal year. The increased funding proposed included:

\begin{tabular}{lc} 
Small Grant Program & $\$ 200,000$ \\
Increased "Linkages and Outreach" & $\$ 142,499$ \\
Neighborhood Association Mediation and Facilitation & $\$ 50,000$ \\
Business District Association Recognition and Support: & $\$ 50,000$ \\
Establishment of Salary Ranges & $\$ 137,005$ \\
Core Staff of 4 & $\$ 98,305$ \\
Working toward equity in the future & $\$ 0$ \\
\hline TOTAL & $\mathbf{\$ 6 7 7 , 8 0 9}$
\end{tabular}

\section{Policies and Procedures Needed to Implement Initiatives and}

Recommendations: TFNI members recommended that, after the City Council adopted the TFNI recommendations, the TFNI should continue to review and develop policy and procedure changes that would support the implementation of the TFNI recommendations. In keeping with the spirit and values of the TFNI report, the TFNI members recommended that a thorough community involvement process be used to consider and develop any changes to City policy and the ONA Guidelines.

\section{Public Involvement Principles and City Employee Outreach Handbook:}

During the time the TFNI was working on its report, community members and city staff were working together on two other products: a set of "Citizen Involvement Principles" to guide public involvement for city government, and an Outreach and Involvement Handbook for City of Portland Bureaus to help city staff improve community involvement and communication practices in their bureaus. 
In February 1996, the City Council adopted Resolution 35494 by which the council formally adopted the new public involvement principles and directed City agencies "to integrate these principles into their programs," and to use the "outreach and Involvement handbook and other resources available to ensure that the City and its citizens reap the benefits of effective, high-quality citizen involvement" (Portland. City Council. Resolution 354947 February 1996). (The full text of the principles is reproduced in Figure 3 below.)

The new public involvement principles stated that the "elected officials and staff of the City of Portland...believe that effective citizen involvement is essential to good governance" and that a "respectful and informed exchange of ideas between the City and citizens will result in the best policies and decisions" The resolution committed the "City of Portland" to "promote and sustain an environment that creates and responds to citizen involvement."

By adopting the resolution, the City Council also committed themselves and city staff to: "value civic involvement," "promote on-going dialogue with citizens," ensure that City "communications and processes are understandable;" reach out to and encourage participation from all of Portland's diverse communities; design citizen involvement process to fit the goals of the particular projects; "seek early involvement of citizens in planning, projects, and policy development;" respond in a timely way to citizen input; coordinate City bureau outreach efforts to best use "citizens time and efforts;" promote ongoing citizens, City officials and staff "in community organizing, networking, and collaboration;" and to "Provide financial and technical support to 
Portland's neighborhood association network as the primary channel for citizen input and involvement."

The Outreach and Involvement Handbook for City of Portland Bureaus (Fall 1995) originally had been developed by a group of city staff and neighborhood and community activists in 1995. The authors characterized it as "a distillation of the collective wisdom of many citizens and City staff with years of experience in citizen involvement." They stated that the Handbook was intended it to "shape how City staff think about, plan and carry out citizen involvement efforts." They said they intended the handbook to be a guide and resource, not a “'cookbook' with hard-and-fast rules." They also stated that the handbook for city staff was intended to be a companion to the "Citizens Handbook" created by ONA to guide community members in organizing and interacting with City government (Portland. Office of Neighborhood Involvement. An Outreach and Involvement Handbook, Fall 1995 1).

The Outreach and Involvement Handbook did a good job of describing many public involvement best practices. It emphasized that effective community involvement strengthens the legitimacy of government and leads to better solutions that can help City staff "implement effective policies and programs for Portland" (2). it also offered a checklist to help City staff scope out a project by asking about the projects goal, who in the community will be impacted most, what information staff need to share with the community, what involvement and/or input staff want from community members, who else in City government might have undertaken a similar project in the same target area, and the resources and time the project will require (3-5). 
The Outreach and Involvement Handbook offered process design tips and emphasizes process design guiding values, such as, "Allow enough time. Communicate openly. Listen carefully." The Outreach and Involvement Handbook offers specific tips that encouraged city staff to: clearly explain to community members the "process, expectation, and time lines up front" [emphasis in the original]; minimize scheduling conflicts with other events and processes; use up to date mailing lists, look for meeting locations "convenient to the people in the impacted neighborhoods;" represent city government not just your bureau (i.e. "be knowledgeable of activities by other bureaus that relate to" your project); actively listen to questions and comments from community members to be able to identify and respond to underlying problems or needs; "Respect both your own and the citizen's' expertise; " explain city policies—don't just quote them; make meeting minutes and other materials available to community members; and document and communicate back to community members the impact community input had on the project.

The Outreach and Involvement Handbook also stressed that City staff need to recognize the impact that each City community involvement process can have on other City community involvement processes. The Outreach and Involvement Handbook stated that "Every involvement effort builds either a bridge or a barrier for the next one." The Handbook stresses that:

"When citizens see that City staff are truly listening to their concerns and working to gain the most benefit from the involvement effort, those citizens are more likely to treat the next involvement effort as credible. Conversely, if citizens believe their time was wasted or disrespected - that the involvement effort was only to put a veneer of 
endorsement on set decision-those citizens are more likely to approach the next involvement effort with suspicion or apathy" (15).

The Outreach and Involvement Handbook notes that citizen activists say that two "most common mistakes the City makes when implementing citizen involvement efforts" are: "Using the 'wrong' approach for the outreach process and not allowing enough time for outreach and development."

The Outreach and Involvement Handbook goes on to describe: different methods to identify and reach out to different groups in the community; technical assistance and support available to City staff from ONA; how to use and support committees effectively; a flow chart of the "typical components of a citizen involvement process;" tips on improving day-to-day contacts with the public; profiles of and tips on working with community members who are effective advocates or angry or apathetic; a profile of an effective city staff person; contact information for neighborhood district offices; and contacts for local media and district coalition and neighborhood association newsletters $(15-20)$.

Together, the public involvement principles and the Outreach and Involvement Handbook did a very good job of capturing values and best practice of community involvement. Many of these same values, strategies and methods would be "rediscovered" by future efforts to identify what good city community involvement should look like and to create best practices guides and support materials for city staff. 
Figure 3: Portland Public Involvement Principles, 1996

\section{City of Portland \\ Citizen Involvement Principles}

As elected officials and staff of the City of Portland, we believe that effective citizen involvement is essential to good governance. We believe a respectful and informed exchange of ideas between the City and citizens will result in the best policies and decisions for all of Portland. To this end, the City of Portland commits itself to promote and sustain an environment that creates and responds to citizen involvement.

We hold that the success of citizen involvement depends on:

- Mutual respect of all parties;

- Broad-based outreach to inform and involve citizens;

- Commitment and skills to effectively facilitate, receive, and respond to citizen input and involvement;

- Coordination of outreach and involvement efforts of all City bureaus.

To carry out our commitment, we adopt these guiding principles of citizen involvement:

1. Value civic involvement as essential to the health of the city.

2. Promote on-going dialogue with citizens by maintaining relationships with neighborhood and community groups.

3. Respect and encourage citizen participation by ensuring that City communications and processes are understandable.

4. Reach out to all our communities to encourage participation which reflects Portland's rich diversity.

5. Think creatively and plan wisely, using citizen involvement processes and techniques to best fit the goals of the particular project.

6. Seek early involvement of citizens in planning, projects, and policy development.

7. Consider and respond to citizen input in a timely manner, respecting all perspectives and insights.

8. Promote the coordination of City bureaus' outreach and involvement activities to make the best use of citizens' time and efforts.

9. Promote ongoing education of citizens in neighborhood and community groups and City officials and staff in community organizing, networking, and collaboration.

10. Provide financial and technical support to Portland's neighborhood association network as the primary channel for citizen input and involvement.

(City of Portland Public Involvement Principles, adopted by the Portland City Council through Resolution 35494, February 7, 1996). 
On February 7, 1996, the TFNI members presented their final report to the City Council along with the proposed Citizen Involvement Principles and the Outreach and Involvement Outreach and Involvement Handbook developed for city bureaus by community members and city staff. Commissioner Hales-the Commissioner in Charge of ONA—noted that these documents "work together." He thanked neighborhood activists and the TFNI members for "helping the City reexamine its successful neighborhood program" which he said was "a national model of how citizen democracy ought to work." Hales said that, rather than resting on its laurels, the City had reviewed its program, recognizing changes in society, to see "if the City is working as effectively as it can with the neighborhood organizations" and to see whether the City "really means it when it says it values citizen participation." The City Council proceeded to consider first the resolution to adopt and public involvement principles and direct city bureaus to use the Outreach and Involvement Handbook and then the "transmittal" of the TFNI report (Portland. City Council. Public hearing minutes, Feb 7, 1996).

It is important to note that the City Council adopted the principles and directed city bureaus to use the Handbook by "resolution" and voted to "accept" the TFNI report-a common practice for this type of task force report. While an "ordinance" passed by the city council "carries the binding force of law," a "resolution" adopted by the City Council is a statement of City policy or values but does not carry the same weight as an "ordinance." City bureau compliance with a "resolution" or an "accepted" report depends much more on the willingness of city staff and managers to follow the policy set out in the resolution or recommendations in the report and willingness of City 
Council members to hold them accountable for doing so. The City Council did not take any formal action to require further action on either the principles, the Handbook, or the TFNI report recommendations (Portland. Office of the City Auditor. Drafting Manual: Ordinances, Resolutions, Reports, May 2013 1-2).

While all the city council members made positive remarks at the hearing about community involvement and the task force report, the most telling comments were made by Mayor Vera Katz, who would have significant influence on whether the many TFNI recommendations that required additional funding would be included in the City budget that would be developed in the coming months. Mayor Katz noted that the city budget note that had prompted the creation of the TFNI had raised the question of "how to organize the community-outreach people found in every bureau." She recognized that the TFNI had not "gotten to the final answer" on this but congratulated the TFNI members for developing their report. ${ }^{38}$ While Mayor Katz said she supported the TFNI report, she maintained that the city council needed to revisit particular recommendations and decide which ones the council wanted to move forward. The hearing minutes record Mayor Katz as adding that "while this is a wonderful report," she did "not know yet how much will actually be acted upon" (Portland. City Council. Public hearing minutes, Feb 7, 1996 15).

The TFNI report included many recommendations and action steps that help illustrate what TFNI members believed were the necessary elements to achieve and support an effective city-wide community and neighborhood involvement system. TFNI

\footnotetext{
${ }^{38}$ The concept of whether city bureau community involvement activities or staff could be somehow consolidated or centrally organized was raised again in 2000 during Mayor Katz's Administrative Services Review (ASR), which looked at opportunities to centralize and consolidate a number of administrative services across city agencies. The ASR is discussed in the next chapter.
} 
member started their larger vision of a creating a "participatory government" in which neighbors and their government are directly linked and in which a "full diversity of neighbors" work face-to-face with city leaders and staff to plan and implement public policy and allocate resources. Many of the TFNI recommendations echo recommendations from earlier reviews of Portland's community and neighborhood involvement system, including more resources to support the system, more training for community members, increased support for communications, outreach and conflict resolution, greater accountability throughout the system, and a genuine commitment by city leaders and staff to value and utilize early involvement and guidance and support to help them do so.

TFNI emphasized the important of some basic values, including the importance of building trust and respect between city leaders and staff and community members, the creation of processes that are transparent and welcoming and that involve and respond to the diversity of people, organizations, and perspectives a neighborhood or community; the need for community involvement to lead to results for the community, the need to strengthen the leadership and other skills of participants, and the need for leaders and staff need to respect the wishes and values of neighborhoods and involve them in making key government decisions.

TFNI found that the neighborhood system was working well and provided significant value, but also could be improved. TFNI members recognized that some neighborhood associations only involved small number of people and often did not reflect the diversity of people in their community. Conflict and interpersonal communication 
problems in neighborhood associations and district coalitions sometimes led to conflict and discouraged participation. TFNI members asserted that additional funding and support for the system could help improve the functioning of the system, promote greater and more diverse participation, and increase the effectiveness of community involvement.

TFNI members recommended allowing alternatives to the non-profit model for district coalitions, including the city-run office in place in north Portland. They recommended expanding the system to support and involve other types of community organizations including business district associations and organizations that represent immigrants and refugees and other historically underrepresented groups in the community. They supported the continuation of ONA's role in providing support to neighborhood associations through the district coalition offices including training, information and referral, coordination of crime prevention efforts, coordination of community outreach by City bureaus, promotion of communication between NAs, DCBs, and other community organizations, and mediation and facilitation services. They also recommended a new, significantly expanded role for ONA, in which ONA would be given the "responsibility and authority" to coordinate the outreach efforts of all city agencies.

TFNI members recommended specific actions and strategies to strengthen the neighborhood system including a study or boundary issues and develop of a process to resolve boundary disputes; self-evaluations by NAs and DCS, increased communications and linkages between the neighborhood system and other community groups and organizations; formal recognition of business district associations; and support to help 
neighborhood association reach out to and involve groups not well represented in their organizations and activities_-such as support for mailings, newsletters, and other outreach tools, training for neighborhood volunteers on effective outreach to these groups and how to create inclusive organizations, and resources to help neighborhood associations provide translation, interpretation, and child care. TFNI member Charles Shi introduced the ultimately very influential concept of formally recognizing nongeographic communities ("neighborhoods without borders") and integrating them into Portland's community and neighborhood involvement system.

Other important recommendations included increase support for conflict resolution, and a reduction in staff pay disparities across neighborhood coalitions and an increase in the amount and equitable distribution of resources among the neighborhood coalitions. TFNI members also called for greater accountability of neighborhood associations to their community members and district coalitions to their member neighborhood associations, including a stronger role for NAs in reviewing the workplans, performance measurements, and annual achievements of the district coalition and an increase in the responsiveness and accountability of the City to neighborhoods and the community. TFNI members also called for a significant increase in leadership training and capacity building and networking among neighborhood volunteers and district coalition staff.

TFNI members recommended a number of approaches and action to increase the quality and effectiveness of City government community involvement efforts, including ensuring that community members can have a real affect on the outcomes of the 
processes, that involvement processes are adequately staffed and are given enough time to be successful, and that city agencies involve neighborhood associations early in project planning. TFNI members recognized that many city staff may need help in learning how to design and implement better community involvement processes and hoped that the new public involvement principles and the Outreach and Involvement Handbook developed by city staff, community and neighborhood activists and ONA staff would provide some of this needed support.

The TFNI also recognized that additional work would be needed after they submitted their report to ensure that their recommendations would lead to changes in City policy and the ONA Guidelines and to changes in practices both in the City and in the neighborhood system.

\section{ONI Standards and formal name change from ONA to ONI}

In January 1998, the City Council adopted Resolution 35667, which formally adopted the 1998 update of the ONA/ONI Guidelines and changed the name of ONA to the Office of Neighborhood Involvement (ONI). Major changes in the 1998 Guidelines included the addition of processes by which business district associations and "ethnicallybased communications" ("Communities Beyond Neighborhood Boundaries" (CBNBs)) that met certain requirements could apply for formal recognition by ONI and become eligible to receive notices, be listed in the ONI Directory, and receive other support from ONI. ${ }^{39}$ The 1998 Guidelines also created the opportunity for district coalitions to choose

\footnotetext{
${ }^{39}$ The next chapter includes a more detailed description of the new provisions in the 1998 Guidelines for the recognition of business districts associations and "communities beyond neighborhood boundaries" and the response of these communities to these new opportunities.
} 
alternative governance models, such as the city-run office model, used by the North Portland Neighborhood Office at that time.

1998 - Lee Perlman statement to Neighborhoods USA Conference

Despite the work of the TFNI, many neighborhood activists continued to be very concerned about what they saw as the shift in ONA away from community empowerment and more toward rule making and administration. They also were alarmed at what they saw as a lack of support—and sometimes active hostility—from City Council members toward Portland's neighborhood system and community involvement in general. A formal statement prepared by one long-time neighborhood activist offers a window into these concerns.

In May 1998, Portland hosted the national conference of Neighborhoods USA. ${ }^{40}$ Lee Perlman, a long-time neighborhood and community activist in Portland prepared an overview of the evolution of Portland's neighborhood association system for the "Neighborhoods U.S.A. delegates," titled "Welcome to Portland, A Neighborhood Unfriendly City." Perlman, who worked as a free lance journalist covering neighborhood news for a number of community newspapers and served as an informal historian of Portland's neighborhood system, criticized the direction the system was taking and particularly criticized Portland Mayor Vera Katz, former ONA Commissioner in Charge

\footnotetext{
${ }^{40}$ According to the Neighborhoods USA website: "Neighborhoods, USA is a national non-profit organization committed to building and strengthening neighborhood organizations. Created in 1975 to share information and experiences toward building stronger communities, NUSA now continues to encourage networking and information sharing to facilitate the development of partnerships between neighborhood organizations, government and the private sector" (NUSA website, http://www.nusa.org/contactus.aspx, downloaded Sept. 23, 2013).
} 
Gretchen Kafoury and current (at the time) ONA/ONI Commissioner Charlie Hales ${ }^{41}$ (Perlman. Welcome to Portland, A Neighborhood Unfriendly City. 1998 1).

In the document, Perlman examines the evolution of Portland's neighborhood system in light of Frances Fox Piven's description of the life cycle of grass roots movements in her book, Poor People's Movements: Why they Succeed, How they Fail (1977). Perlman writes that the ability of grass roots movements to "bring about lasting change is based on the fact that they are outside the system, and have the ability to disrupt it." He notes that "After a time, such movements are offered an 'official' place within the established order," which he says Piven identifies as the "beginning of the end" for the movement. Perlman argued that "official acceptance" comes with limitations on the movement's "actions and obligations that limits its ability to act." The movement takes on "a top-heavy organizational structure, the maintenance of which saps their energy. Their official leadership positions become prizes that the power-hungry fight over. They fade away when they become so weak that no one can pretend they are still relevant." Perlman goes on to suggest that "Portland might well be a case study for much of Piven's theory" (2).

Perlman recounts how neighborhood associations had existed early on in Portland for many years, but that "with the turbulence and problems of the late 1960s and early '70s there were more of them active at one time than there had ever been before, and they because a sort of movement" (3). Perlman notes that "In some cases makeshift

\footnotetext{
${ }^{41}$ Lee Perlman passed away in August 2013. This document was discovered by community volunteers and staff from ONI and the City of Portland City Archives who helped sort through the mountains of papers and documents - spanning the entire forty year history of the neighborhood system-in Lee's house after his passing. It is not clear whether or not Lee distributed this document at the conference. Nevertheless, the document sums up Lee's assessment of Portland's neighborhood system at the time.
} 
government and private support systems were put in place," such as the federally funded organization in North Portland, the PDC supported neighborhood offices in inner northeast and southeast Portland, and the inner southeast non-profit organizing group, Portland Actions Committees Together (PACT).

Perlman said neighborhood associations at the time "tended to be ad hoc organizations, with both the strengths and weaknesses of such groups. They were strong and active during times of crisis, fading away partially or entirely between crises." He wrote that in the 1970s, citizen involvement requirements of many federal assistance programs and the citizen participation requirements of Oregon's new statewide land use planning law led city of Portland officials to see "a need for a stable, dependable system to give citizen feedback to government proposals." Perlman describes how Mary Pedersen, instead of creating a new structure, chose to build on the "existing grass roots neighborhood network" in Portland. He wrote that the system provided grass roots organizations with "enough staff support, and money for printing and mailing to sustain them during the non-crisis periods." ONA provided this support through contracts for services with community-based and governed organizations. Perlman wrote that "The independent contract system was intended to give the city enough control to ensure that its money was used for the intended purpose, yet free local associations, and their staff, from day to day political interference"- “Coordination, but not control” (4).

Perlman relates how some "city leaders were suspicious of the idea" early on, but that over time, "Pedersen and her successor, Patti Jacobsen, won acceptance for the new system within and without city government. City bureaus that previously had refused to 
acknowledge the existence of neighborhood associations now began to actively seek them out" (Perlman 4-5). Perlman asserts that "Neighborhood Associations were never the 'revolution,' but they became a force to be reckoned with" (5).

Perlman writes that the "long downhill slide" for the system began in the mid1980s under ONA Director Sarah Newhall. He notes that "ONA administration took an increasingly heavy hand in regulating the neighborhood [district] offices, their staffs and the local associations." ONA used problems "stemming from struggles for power" in some neighborhoods and district offices and charges that neighborhood organizations were not "'fully representative of their communities"” to impose "increasingly greater control over associations and coalitions..." (6-7). (Perlman notes that if these organizations had been "fully representative of their communities" they would have been the first "activist organizations in history to achieve this distinction.") Perlman noted that, at the same time the City was pressuring neighborhood associations to "attract members of every conceivable special interest group," the City simultaneously was "encouraging business associations and ethnic groups to seek an independent source by offering them “official recognition" (in the ONA Guidelines). Perlman predicted (correctly) that few of these organizations would apply for formal recognition because they would have to comply with many of the same city requirements that applied to neighborhood associations (Perlman 7).

Perlman directed his more intense criticism toward "mayor Vera Katz and commissioner Gretchen Kafoury" who he identified as the "hostesses of this NUSA conference." He noted the irony, as he saw it, of having these two women host the NUSA 
conference when they had "done their best to push local associations out of their positions of influence." Perlman writes:

"Katz, once a neighborhood volunteer herself, plainly does not like people who talk back to her, and neighborhood volunteers are notoriously poor at towing anyone's party line when they think it conflicts with their interests. Kafoury is a staunch advocate of low-income housing a[nd] social service providers - a laudable cause, to be sure, but one she is so single-mindedly devoted to that she judges everything else in relation to it. She seemed at one point to feel neighborhood associations' function was to support her efforts in this regard, and she became annoyed when they didn't seem to get it. Twice she has been given responsibility for ONA, yet she may hold a modern Council record for the fewest neighborhood meetings attended" (7-8).

Perlman charges that, while Katz and Kafoury often opposed each other politically, they shared a dislike of the neighborhood movement. He writes that "Kafoury, who is retiring from electoral politics, no longer feels any need to disguise her dislike for the neighborhood movement. Katz, knowing this, put her in charge of ONA as a way to weaken the neighborhood movement without having to bear responsibility for doing it" (8).

Perlman also criticizes City Commissioner Charlie Hales, the ONI Commissioner in Charge at the time, for manipulating the public process on projects, when the processes did not "match his preconceived conclusions." Perlman also charged that Hales' effort at the time to reorganizing city land use planning and development-known as Blueprint 2000 — was seen by many neighborhood activists as "the latest step in efforts to increase development activity by removing opportunities for citizens to review it."

Perlman notes that, earlier in the neighborhood systems history, "such assaults on the Portland neighborhood system would have mobilized volunteers citywide to deluge 
Council with angry phone calls, letters, and more. That such an outpouring is not taking place is an indication of how impotent and divided the neighborhood movement has become" (Perlman 9). Perlman closes by predicting that "The death of the Portland neighborhood movement as currently conceived is a matter of when, not if' and states that "In some ways, the sooner it happens the better." Perlman states that the demise of the current system would allow "concerned community members" to "begin the work of creating a replacement, which they certainly will do" (9).

Lee Perlman's passionate critique of the neighborhood system likely reflected the frustration many neighborhood activists felt in the later 1990s. Perlman felt the system had lost its way and was being redirected away from its original community empowerment focus at the same time that mechanisms and programs to support involvement were being eliminated or undermined. The lack of support and active hostility toward the neighborhood system that Perlman saw from the city council caused some passionate advocates of neighborhood power to feel little hope for positive change.

\section{Mayor's Budget Messages_Katz-1993 to 1999}

Vera Katz succeeded Bud Clark as Portland's mayor in January 1993. She had early roots in Portland politics as a community activist in NW Portland. She ran for and was elected to the Oregon House of Representatives in 1972 and served in that body until 1990. She was elected as the first woman Oregon Speaker of the House in 1985 and served as Speaker for three sessions. In 1992, Portlanders elected Katz as their mayor.

During Katz's first two terms in the 1990s, Portland's economy was recovering and people from all over the county (and a number of immigrants and refugees as well) 
were moving to the Portland and the region. City government concerns about economic revitalization soon began to compete with the need to effectively manage all the new population growth in the region and in Portland. During the 1990s, additional property tax limitations passed first by the voters and then the state legislature further restricted city revenues.

Katz's budget messages are the longest and most detailed since those of Mayor Goldschmidt. Katz's first budget message, in 1993, sets the tone for all her messages in the 1990s. In her opening paragraph, she establishes her primary focus as the ongoing effort to "make government more efficient, more innovative, more cost effective, more productive and more responsive to the needs of all Portland's citizens." She states that this city budget was "framed to meet the policy objectives set by the Council," which included: “A safe, peaceful community; economic vitality and security; communityoriented city government; a well-planned city with managed/balanced growth; affordable basic services; financial stability; quality urban life; decent, affordable housing; quality education; and families and children" (Portland. "Mayor's Message." City Budget FY 1993-94 i). All of Katz's budget messages include a primary focus on the provision of "high quality city services."

In her 1993 budget message, Katz describes city government as "a large, highly complex public corporation" and states that she and the City Council are "determined to reinvigorate it with a renewed entrepreneurial spirit, and a greater sense of thrift and service" (ii). She talks about a goal of creating "strong and healthy neighborhoods" and building "new partnerships with the community." The examples she uses to illustrate this 
focus include the construction of facilities, increased code enforcement by building inspectors, traffic management and enforcement, job training programs for at-risk youth, and increased access for minority and female-owned businesses to City contracts (ii-iii). Katz also reports that the budget continued funding for the Outer Southeast District Plan and the retention of two planner positions to support "neighborhood planning programs." Katz also mentioned that the budget "includes money for serving those areas of the city we have recently annexed..."(iii).

In the conclusion of her first budget message, Katz states that she wants to see, during her time as mayor, the emergence of "a reinvigorated government for Portland, one that is leaner, more decentralized, more flexible and less hindered by bureaucratic inertia and, most important, one that puts service to the citizen and taxpayer- $\underline{\text { the }}$ customer-first" [emphasis added] (iv).

Public Involvement in the City Budget Process: By 1994, Katz had instituted a new approach to involving the community in the city budget process. Katz created a new process she called "Your City, Your Choice" (YCYC) that used different strategies to ask Portlanders what they "believed to be the most pressing city-wide and neighborhood needs in an extensive public outreach process." Katz asserted that YCYC was "the most comprehensive" outreach to the community related to the city budget "in two decades." She stated that the YCYC process included a questionnaire sent out in FOODday newspaper, "which reaches nearly every household in the city," "eight community forums in the neighborhoods," and a "random-sample telephone survey" (Portland. “Mayor's Message.” City Budget FY 1994-95 i). 
Katz reported that community members had told the City Council their highest priorities were “'quality education' a 'safe, peaceful community,' and a good environment for families and children." She also identified as "vital concerns" of community members as "increased public safety," "effective anti-graffiti programs, better traffic management, and expanded youth recreation programs." Katz wrote that the City Council considered this input in developing the final city budget, making the budget "not only the Mayor's and the Council's budget, but your budget" [emphasis in original] (Portland. “Mayor's Message.” City Budget FY 1994-95 i).

The YCYC process - and the model of using a telephone survey, questionnaires, and community budget meetings—-would become Mayor Katz's primary method for obtaining feedback from community members on their priorities and needs. In 1997 , when further property tax limitations reduced city revenues, Katz used this process to ask community members which government services they would cut. Katz reported that "Citizens told us they wanted their basic service protected as well as the services that support lower-income families." "Economic development, the arts, administration and support, planning, and citizen and neighborhood services were all areas in both the workshops and the survey that citizens thought could be cut" (Portland. "Mayor Message." City Budget FY 1997-98 vi). ${ }^{42}$

\footnotetext{
${ }^{42}$ One of the criticisms of the YCYC process was that community members were asked to identify the city services they valued and which were a lower priority and could be considered for cuts without much context for the role and impact of these services relative to the overall work of city government and the implications of cutting them. For instance, I attended a YCYC community budget meeting in the late 1990s. Community members were asked to break into groups and identify programs and services to cut. At my table, community members voted to cut long-range planning to help save the City-provided fall leaf pick up services that cleared leaves off the streets in neighborhoods with a lot of street trees. They could directly see the value of the leaf pick service up but did not have any sense of the value of long-range planning.
} 
The Budget Advisory Committee program, which had been a major program since the founding of Portland's community and neighborhood involvement system was phased out under Katz. Katz only mentions the BACs once briefly in her 1995 budget message as another source of community input that year in addition to the YCYC process ${ }^{43}$ (Portland. “Mayor's Message. City Budget FY 1995-96 vi).

Visioning and Policy Guidance: Katz, in many of her budget messages, identifies goals set by the city council and the goals of Portland Future Focus as major guides for the city budget. In 1994, Katz identified the City Council's major focuses as "Quality education; public safety; families and children; customer service and government efficiency; economic vitality; and managed growth and livability" (Portland. “Mayor's Message. City Budget FY 1994-96 iii). ${ }^{44}$

In her budget messages in the later 1990s, Katz also referred to the Portland Multnomah Progress Board Benchmarks (the Progress Board was created in 1994 to monitor progress and measure success in meeting the Portland Future Focus goals) and the Metro 2040 regional growth management plan as overarching guides for the city council's budget decisions. In her 1998 budget message, Katz called for a process to

\footnotetext{
${ }^{43}$ Witt, in his description of the overall history of the BAC program, describes the end of the program in the early 1990s as follows: "By 1992, support for the BAC program began to falter. By 1993, Mayor Vera Katz had instituted a biennial budgeting process. This stretching of the budget planning timeline would tax volunteer commitment to the breaking point, and would initiate a spiral of disinterest in maintaining ONA's commitment to staffing the BACC. By 1994, the ONA and the City's Office of Finance and Administration (OFA) agreed to support the BAC program in principle, but ONA would cease staffing the BACC. Without the BACC to serve steering committee functions, the BAC program would fall into disuse over the next few years." He noted that, by the late 1990s, few city agencies still had BACs (Witt Appendix B).

${ }^{44}$ It's interesting to note that Katz never mentions the Portland Future Focus "Good Government" "community value" that called for nurturing strong community leadership by offering ongoing leadership and skill building trainings to community members and that valued "elected officials and private citizens willing to empower and work with the entire community to shape Portland's future" (Portland Future Focus $199120)$.
} 
examine which Portland Future Focus goals had been met and to set new goals, but this process never was implemented (15).

Neighborhood Livability: Katz placed a very high priority on preserving and enhancing neighborhood livability in her budget messages. Her primary focus in this area was ensuring strong city services in the community, especially police, fire, street repair, park facilities, affordable housing, job programs for at-risk youth and other similar services. Katz frequently mentions funding to hire additional police and to support Portland's community policing program (first started under Bud Clark). Katz also placed a high priority on growth management and planning to steer increased density in Portland, as much as possible, to areas designated for growth in the regional Metro 2040 growth management plan-these included designated Town Centers, Main Streets, transit corridors, entirely new neighborhoods (e.g. the very popular Pearl District and the still evolving South Waterfront District), and areas in and around downtown. Katz also stressed the need for good design in infill development. "We are determined not to allow Portland to "grow ugly"” (Portland. City Budget FY 1998-99 13). Katz believed that Portlanders were more likely to accept greater density in their neighborhoods if it was well designed and fit in with the existing character of their neighborhood.

Under Mayor Katz, the City stopped supporting the long time practice of working with community members to develop individual neighborhood plans. The last district planning effort that included neighborhood plans, the East Portland District Plan, was ended in 1997 in the face of budget cuts. Planning efforts shifted to larger district area plans, and then, after the intensive conflict between the City and community activists 
over the Southwest Community Plan in the late 1990s (see Hovey and Irazabal) to targeted planning projects focused on accommodating growth in specific locations.

In 1996, Katz enthusiastically ended her mayor's message by stating "We live in a great city. Together, we can make it even better!" She also quoted "the late San Francisco Supervisor Harvey Milk":

The American Dream starts with the neighborhoods. If we wish to rebuild our cities, we must first rebuild our neighborhoods. And to do that, we must understand that the quality of life is more important than the standard of living. To sit on the front steps... whether it's a veranda in a small town or a concrete stoop in a big city...a[nd] talk to our neighbors is infinitely more important than to huddle on the living-room lounger and watch a make believe world in not so living color (xvi).

ONA and Community Involvement: Katz seldom mentioned ONA or community involvement in her lengthy and detailed budget messages (other than her frequent references to the YCYC process). The few times Katz does refer to ONA/ONI or community involvement it is often with regard to specific funding allocation to support a particular staff position, service, or program.

In her 1995 budget message, Katz reported that "We opened a new centralized information and referral service within the Office of Neighborhood Associations to make it easier for our citizens to communicate with the city [to] get answers to questions."

In her 1996 budget message, Katz refers to an allocation, in response to the TFNI Report, of " $\$ 750,00$ over the next two year to provide neighborhood grants. The purpose of this program is to improve neighborhood safety and quality of life, develop services that respond to the needs identified by the neighborhoods and empower citizens to participate in community life and promote community partnerships" (xiii). Katz later 
redirected this funding to other budget needs that arose after the budget was completed, and the grant program was not implemented.

Also in 1996, in response to another TFNI recommendation, Katz reported the allocation of " $\$ 279,835$ over the next two years that will allow the city to provide additional neighborhood office staffing, reach out to a more diverse group of citizens and to help neighbors with training and assistance in mediation and conflict resolution..." and to "develop a print a citizen's guide to city services" (xv).

In 1997, Katz proposed a list of eight ideas for reorganizing city government to increase efficiency. The list included a proposed reorganization of "crime prevention functions" in ONA and the "Bureau of Police," and the merger of "the functions of the Metropolitan Human Rights Commission with” ONA (xviii).

Katz placed particular emphasis on improving online access for community members to city government. In 1998, Katz highlighted work within city government to move much of City governments work online to offer community members a "' 24 hour City Hall"" that will allow community members to "pay City bills online and to get City information without having to travel downtown and wait in line, or play endless games of phone tag." Katz also described a project to use "Geographical Information Management System (GIS)" technology to "convert City information into an electronic format that will allow Portland to access the information they need from their home computer at any hour." Both projects represented important advances in the transparency of city government and community member access to information and are up, operating, and well used by the public in 2013 (3). 
In 1998 Katz reported that the city budget included funding to restore a crime prevention position in ONI and funding to assist in the transition of the ONI Mediation Center to non-profit status (6). Katz also highlighted city budget support for “strengthening our neighborhood business districts," which included $\$ 200,000$ to start a “neighborhood Business Improvement District program” (12).

In 1999, Katz included a goal to "Promote the inclusion of under-represented neighborhoods and groups in participation in City activities and services." The action items she listed under this goal included: restoration of full funding of ONA's Mediation Center to help community members resolve disputes before the police have to get involved; funding for the city and county to study "problem of homeless youth in Portland;" funding for after school programs and apprentice programs in the City's transportation and parks agencies; and a parks program guide (Portland. City Budget FY 1999-2000, “Mayor's Budget Message” 10).

Key Strengths of Portland: While most of Katz's budget messages are detailed descriptions of specific services and program actions, Katz sometimes refers to what she thinks makes Portland a special place.

In 1993, Katz notes that Portland is no longer a "small city." It has "grown into one of the 30 largest metropolitan areas in the country" and that city government had become a "large, highly complex public corporation" (ii). In 1994, Katz reported that Portland is "recognized nationally and internationally for its vision and good planning" and notes that the city faces different challenges than in the 1960 s when "the health of the entire downtown was threatened" (xiii). 
In 1996, Katz writes that the city budget "honors the past by building on the work of my predecessors who made Portland one of the rare cities in this country filled with excitement, opportunity - a city that enriches and inspires" (v). She stressed the importance of attracting growth in the region into Portland to "enhance the character of our neighborhoods and prevent Portland from becoming a freeway to other destinations in the region" (vi). She also notes that "Portland is well known, even internationally regarded, as one of the best places to live. Its natural beauty, close proximity to recreation opportunities, small-town feel, neighborhoods with individual character, rich artistic endeavors, and short community times, make Portland an ideal place to raise a family, locate a business and enjoy life" (x).

In 1998, Katz stressed the importance of protecting and improving "Portland's quality of life in the face of rapid change and growth—-for those of us who live and work here today-and those who will follow us tomorrow" (1). Katz closed her 1999 budget message by stating that "We are no longer a small city on the edge of the United States somewhere between Washington and California." She noted that Portland is home to "globally recognized companies" and is a leader in "international trade, high technology, creative services, environmental technology, and planning" (Portland. "Mayor's Message." City Budget FY 1999-2000 12).

Katz's characterization of community involvement in her budget messages was a major departure from how Goldschmidt and Clark talked about community involvement. Instead of being portrayed as partners in city government decision making - as in the budget messages of Goldschmidt and Clark—Katz identifies community members almost 
solely as "customers" of city services. The role of community members, in Katz's budget messages, primarily is to tell the city what services they do and do not want. The City's role, in turn, is to provide community members with high quality city services.

When talking about what makes Portland special, Katz, unlike other mayors before her, never mentions Portland's long tradition of strong community involvement in government decision making and civic life. She also does not lay out a vision for a greater governance partnership between city government and the community.

During the 1990s, Katz championed many priorities and initiated many projects, programs, and changes that reshaped the physical character of Portland. She also championed and implemented many innovations in city government organization and management. While Katz focused in great detail on many different subjects in her budget messages, her minimal comments about community involvement appear to indicate that community involvement in government decision making and further advancing the evolution of Portland's community and neighborhood involvement system were not high priorities for her.

\section{Lessons from the 1990s}

The "soul searching" of the 1990s found that Portland's community and neighborhood involvement system had value, but needed further development and improvement to successfully move further toward achieving participatory democracy in Portland. Key themes that surfaced were the need to strengthen support for the existing system; to expand the system to do a better job of reaching out to and involving a greater diversity of people and community organizations in civic life and decision making; and to 
improve the willingness and capacity of city leaders and staff to work with the community.

Many of the elements needed to achieve a strong city-wide community and neighborhood involvement system that advances a community toward greater participatory democracy had been identified in earlier processes in the 1970s and 1980s and were identified again by processes in the 1990s. Some of these included: the important of the independence of neighborhood associations and district coalitions, a central agency that focuses primarily on supporting and empowering rather than controlling the system and acts as a bridge to help city agencies and community and neighborhood organizations work together effectively; funding and technical support to help community and neighborhood volunteers communicate effectively with their communities and government; effective and ongoing leadership and other skills training for community members; conflict resolution assistance; and information and referral. City government leaders and staff also need to have the willingness and ability to engage the community through early involvement, adequate notification, well designed processes that help community members affect outcomes, transparent processes and access to information, and accountability of city leaders and staff to document processes and decisions and communicate them back to the community members.

The 1990s provided additional insights into the process by which policies, programs and projects that would move a community toward greater participatory democracy get on the public decision making agenda and are acted on. The 1990s provided examples of studies that helped frame issues and elevated their visibility and the 
urgency with which decision makers viewed them-examples include Portland Future Focus, Strachan's 1992 report, and the TFNI. The 1990s also illustrated the important role policy entrepreneurs can play in developing and advocating for policy recommendations, such as the role Strachan played in leading the focus group review and then helping organize the 1993 Neighborhood Congress, which refocused neighborhood leaders on some common city wide strategies, and Charles Shi's championing of the concept of "neighborhoods without borders," which would introduce the idea of nongeographic communities and go on to significantly shape the system's evolution.

In contrast with the 1970s and 1980s, when Neil Goldschmidt and Bud Clark used their influence as mayor to actively support and champion community and neighborhood involvement, the experience of the 1990s showed how the lack of a strong political champion can block the adoption and implementation of policies and programs that advance participatory democracy. In Portland's case, the system actually lost ground with the discontinuation of key community involvement programs, such as the BACS, the Neighborhood Needs process, and neighborhood planning. Mayor Katz significantly shaped Portland city government's agenda during the 1990s. The fact that she did not strongly support greater community involvement in city decision making, coupled with the seemingly lack of strong enthusiasm for the existing neighborhood system on the part of the ONA/ONI commissioners in charge during the 1990s and the lack of a strong advocate for community involvement among the other council members appears to have played a role in the lack of substantial advances in implementing the recommends of different review processes during the 1990s. 
Some efforts were made in the 1990s to further embed participatory democracy values and practices into the City's policies and day-to-day operations and in the structure and operation of ONA, the district coalitions, and neighborhood associations. City Council adopted the public involvement principles and directed city agencies to use the Outreach and Involvement Handbook to improve their community involvement. This did raise the stature of community involvement somewhat, but appeared to have little effect on the culture and practices of city leaders and city government. The TFNI members had recognized that additional work would be needed to ensure that their recommendations were implemented in a way that would lead to change, but no vision or strategy for organizational change within city government was developed and implemented. The 1998 ONI Guidelines did embed some structural changes to Portland's community and neighborhood involvement system by allowing formal recognition of business district association and ethnic-based community organizations and allowing alternative governance models for district coalitions, but these changes ended up having little effect.

The next chapter describes some very interesting projects and processes that supported deeper thinking about both the inclusion of non-geographic and historically underrepresented communities in Portland's community and neighborhood involvement system and the policies, strategies, and support that would be needed to achieve a broadbased and lasting improvement in city government community involvement. 


\section{CHAPTER VI \\ DEEPER ANALYSIS AND CONFLICT-2000-2004}

The early 2000s saw Portlanders engage in much deeper and more strategic thinking about how to involve a greater diversity of the community and what it would take to improve city government community involvement. During this time, Mayor Katz assigned ONI to three different city commissioners in fairly rapid succession. Conflicts between city council members and community activists rose dramatically as city commissioners tried to impose changes to "fix" the neighborhood system and city leaders and community members clashed over a number of high-profile planning processes and projects.

This chapter reviews a number of key processes that took place during the early 2000s and describes some of the efforts by city commissioners to shift the focus and practices of ONA and the neighborhood system. It also describes some of the major issues and community involvement themes raised during the 2004 city council and mayoral election.

The chapter begins with a review of the "citizen involvement" goal and objectives included in the Southwest Community Plan in 2000. Community members had developed the language for the goal and objectives to institutionalize the form of community involvement they wanted the City to provide related to planning in southwest Portland. The City Council adopted the goal and objectives by ordinance, technically giving them the force of law. 
The chapter continues with a review of the 2000 Administrative Services Review (ASR), which was charged with finding administrative efficiencies in city government. The ASR committee that reviewed the City's public involvement and public information activities recommended a number of actions to centralize public involvement in ONI and to increase the consistency and effectiveness of City public involvement efforts. The chapter also examines attempts by ONI to implement some of the ASR recommendations and efforts by ONI Commissioner Dan Saltzman to implement some neighborhood system reforms.

The chapter then turns to three very innovative and influential processes that took on the challenge of how to increase the diversity of involvement in Portland's community and neighborhood involvement system. The 2001-2003 Interwoven Tapestry process brought leaders and activists from Portland's growing immigrant and refugee communities together with neighborhood association leaders to find ways they could learn about each other and work together more effectively. This process was very inclusive and modeled many of the values and best practices of community involvement.

Southeast Uplift Neighborhood Coalition followed up on the Interwoven Tapestry experience and created its own Diversity and Representation Committee (DRC). The DRC brought together leaders of communities of color, immigrant and refugee communities and other underrepresented groups in the community with neighborhood leaders to continue to learn about each other and promote greater involvement by historically underrepresented groups in the neighborhood system. The DRC again modeled a process that was very diverse, respectful of all the participants and included a 
strong focus on relationship building. The DRC became the source of a new way of thinking about involving under-represented communities that focused on by helping people organize with their own community members first and building capacity in their own organizations before linking up with neighborhood associations and other community groups.

Southeast Uplift Neighborhood Coalition followed up on the good work of the DRC by creating a Diversity and Civic Leadership Committee (DCLC) to develop and advocate for specific proposals to support leadership training and capacity building among communities of color and other under-represented groups. DCLC members lobbied hard with city council members for City support and funding for their proposals. They finally succeeded during Mayor Potter's administration and ONI's Diversity and Civic Leadership Program was started.

The early 2000s also was a time when very comprehensive and sophisticated thinking occurred about how to improve the willingness and ability of city government leaders and staff to work effectively and in partnership with the community. The ASR had recommended that a follow up process be established to develop guideline and standards for city government public involvement. Increasing conflict between community and city leaders helped convince the three ONI commissioners during the early 2000s to create the Public Involvement Task Force. The PITF developed a new set of public involvement principles and a series of recommendations to change the structural policies of city government, to build capacity for involvement both in city government and in the community, and to ensure good process design, greater accountability and 
transparency of city government processes and regular evaluation of community involvement efforts. After the PITF finished its work, a Budget Outreach Study Committee (BOSG) formed (implementing on one of the PITF recommendations) that studied how to improve community involvement in the city's budget process.

Conflict between city leaders and community activists grew during the early 2000s. This chapter examines the controversial role of City Commission Randy Leonard and the major changes he attempted to implement for ONI and the Portland's neighborhood system and a strong critique of the direction Leonard was taking the system from former City Commissioner Margaret Strachan and others.

The 2004 city council and mayor election became a turning point in the history of community involvement in Portland. This chapter describes an attempt by neighborhood leaders to run against Leonard for his city council seat, and issues and themes of the mayoral race between City Commissioner Jim Francesconi and former Portland Police Chief and creator of Portland's community policing program Tom Potter. Potters election in November 2004 would open the door to significant reform and expansion of Portland's community and neighborhood involvement system.

The chapter closes with a review of Mayor Vera Katz's five final mayor's budget messages.

$\underline{\text { Southwest Community Plan -1994-2000 }}$

The Southwest Community Plan (SWCP) was the focus of intense friction between community activists and city planners during the later 1990s. Hovey (2003) called it the Planning Bureau's "Vietnam" (153) and identified the SWCP as the 
"apogee" of the trend in the late 1980s and early 1990s toward increasing friction between city planners and community activists "over the imposition of regulation stemming from evolving growth management policy" for the Portland region (142). The final version of the SWCP, adopted by ordinance (Portland, City Council. Ordinance 174667, 13 July 2000.) by the City Council in July 2000, included a "Citizen Involvement" policy and nine objectives that had been developed primarily by community members.

The "Citizen Involvement" policy sought to institutionalize community involvement in all phases of the development, amendment, implementation and monitoring of the SWCP, as well as any other City policies or programs that might affect southwest Portland. Because the City Council adopted the SWCP by ordinance, the City was legally required to comply with the goal and objectives. The policy stated:

Ensure that the policies and objectives of the Southwest Community Plan are used to guide the collaborative action so the city and Southwest citizens for the next 20 years. Involve citizens integrally in the Southwest Community Plan from concept through evaluation and revision (Portland. Bureau of Planning. Southwest Community Plan: Vision, Policies, and Objectives. July 2000 19).

The accompanying objectives laid out a vision for what community members believed would be good community involvement by the City.

The "Citizen Involvement" objectives stressed that implementation of the planand the creation, development, and implementation of any other policies and programs that would affect Southwest Portland—should be done through collaborative partnerships of community stakeholders, city officials and staff, and "all implementing bodies." The "roles, rights, responsibilities, and degree of accountability of the participants, including 
city officials, bureau directors, staff, citizen leadership, organization and individuals...." were to be clearly defined. Community concerns and goals were to be "addressed" "during the creation, development, implementation, monitoring, evaluation, and revision" of the SWCP. Communication links "between the Planning Commission, City Council, city staff, and citizens" were to be identified, strengthened, and used throughout the “creation, development and implementation" of the SWCP. Policymakers were called on to respond to community members and to explain the rationale for their decisions.

The "Citizen Involvement" objectives also required that the SWCP policies and objectives be used "to create, develop, implement or evaluate new citywide policies, programs or project proposals to ensure that the concerns of the Southwest community are addressed." The City was called on to "Engage the Southwest community and all relevant stakeholders" in a discussion of the economic and demographic factors the current and future development and business needs related to the implementation of the SWCP. One objective required the City to "Support the activities of recognized organizations when creating, developing, or implementing policies or program for the [SWCP] or Southwest area" (19).

The last two objectives required the City to involve southwest community members in reviewing the progress of the SWCP "through ongoing monitoring and periodic evaluation," and to ask "Southwest neighborhood associations, business associations, and other community-based organizations" to recommend individual to serve on any "citizen advisory committee" related to "any phase or facet of the [SWCP] 
or plan area." The objectives call on the City to "Seek balance and variety on all citizen advisory committees." (20)

The SWCP Citizen Involvement goal and policies stressed broad and ongoing involvement of southwest Portland community organizations and interests in all aspects of the SWCP development and implementation. The goal and policies stressed partnerships between the city and community, clear roles and responsibilities, consideration of community needs and goals, strong and active communication between the City and the community, feedback from the City to the community on outcomes and the rationale behind decisions made, identification of economic and demographic trends in the community, City support to increase the capacity of community organizations, community involvement in monitoring progress of the SWCP, and invitations by the City to community organizations to recommend individuals to serve on any "citizen advisory committee."

Citywide Administrative Services Review (ASR) - 2000-2001

Mayor Katz, during her twelve years in office, strongly pursued efforts to improve customer service and business practices within city government and streamline and increase the accountability of government operations. One priority for Katz was to reorganize and centralize many city government administrative services that were duplicated across different city bureaus. Katz led the effort to create a new position of "Chief Administrative Office" for all of city government and initiated a major review of administrative services in 2000-2001 - known as the "Citywide Administrative Services 
Review" (ASR). One of the areas the ASR investigated was city government "public information and public involvement" activities.

Portland's commission form of government divides administrative responsibility for city agencies among the five city council members. This structure offers few incentives for city agencies to collaborate or for city officials to engage in citygovernment-wide strategic planning. In the late 1990s, most city bureaus received administrative services—-such as human resources, information technology, purchasing, etc.--from units within their own agency rather than through any sort of centralized city government office.

In May 2000, the Portland City Council adopted Ordinance 174410, which reorganized city government administrative functions to increase efficiency and accountability to the City Council. The City Council defined administrative services as "all those functions that provide products, services, and support to city employees and programs that in turn provide direct service to the public." The City Council list of "administrative services" included: "accounting, debt, treasury, clerical, payroll, external and internal communications, training, education, outreach, grant administration and fee collection, risk management, facilities, fleet, human resources, information technology, legal, printing and distribution, public information, and purchasing” (Portland. City Council. Ordinance 1744103 May 2000).

The ordinance created the new position of Chief Administrative Officer (CAO) for city government to lead a new agency called the Office of Management and Finance (OMF)—OMF consolidated the city's existing Office of Finance and Administration, 
Bureau of General Services, and Bureau of Purchases. The CAO would report to the entire city council, not just to one commissioner or the mayor. The City Council also created a number of centralized agencies including: the Bureau of Finance, Bureau of Human Resources, Bureau of Information Technology, Bureau of Risk Management. The City Council gave the $\mathrm{CAO}$ the authority to review and propose improvements for administrative service functions in all city bureaus (Portland. City Council. Ordinance 1744103 May 2000).

In fall 2000, the CAO began a citywide review of administrative services called the "Administrative Services Review" (ASR). The ASR was intended to seek opportunities to reduce costs and increase administrative service efficiency. ASR committees were set up to review fifteen different service areas—one of which was "Public Information/Public Involvement."

The ASR Public Information and Public Involvement (PI/PI) Committee was the first body to look specifically at the city-government side of Portland's community involvement system. While many of the committee's recommendations were not immediately implemented, the committee's work raised important issues that would be taken up by future review and reform efforts.

The ASR PI/PI committee included about fifteen people - a third represented neighborhood and community organizations and the rest represented city bureaus, including ONI. ONI Director Dr. David Lane chaired the group. The ASR PI/PI committee started meeting in September and completed its report by January 2001 
(Portland. Office of Neighborhood Involvement. ASR Team-Public Involvement and Public Information. Meeting Summary 27 September 2000).

The group's final report, dated February 1, 2001, presented findings, four major recommendations that focused on cost reduction and efficiency, and six additional recommendations intended to improve the quality and consistency of city government public involvement (Portland. Citywide Administrative Service Review. Framework Plan: Public Information/Public Involvement 1 February 2001).

The ASR PI/PI report states that the group was charged to:

1. "Improve public involvement and public information for citizens and bureaus. (ONI)"

2. "Look at "new ways of doing business' (OMF)"

3. "Ensure the City is doing these administrative and support functions in the most efficient and cost-effective manner (Council)"

4. "Explore how technology could improve public involvement and public information administration (OMF)"

5. Meet target reductions-about 5.8\% cut (Council)" (Portland. Citywide Administrative Service Review. Framework Plan: Public Information/Public Involvement 6).

The team reviewed PI/PI activities that included "public involvement outreach (both City-supported efforts and outsourced contracts), information and referral functions in ONI, Police Bureau (PPB), and the Bureau of Emergency Communications (BoEC), 
media relations, crime prevention, mediation services through ONI, neighborhood outreach, public information, and public relations" (6).

The team started from the premise that "Public involvement and public information (PI/PI) are central to the City's mission, values, and programs. Citizen participation in civic decisions are at the heart of what makes Portland one of the most livable cities in the world. As city staff and as neighbors, we pride ourselves in the ability to involve our co-workers, neighbors, businesses, and community partners in programs and decisions" (4). ${ }^{45}$

The PI/PI committee members also took the important step of developing definitions that began formally to differentiate "public involvement" from other types of city agency outreach activities. Their definitions included:

- $\quad$ Public Information: "Fact-based educational tool, usually little opportunity for public feedback. Public learns from information they are provided. Purpose is communication, often of specific messages."

- $\quad$ Public Relations: "Marketing tool used to promote public understanding [of] an organization. Shines a positive light and gives company a positive image in the public eye."

\footnotetext{
${ }^{45}$ Despite the PI/PI Team's optimistic statements and the recommendations, community activists in Portland continued to clash with city staff in an increasing number of high profile conflicts over city projects in next few years. The consistent disconnect between what community members and city staff considered good public involvement led three City Commissioners who had been in charge of ONI to create the Public Involvement Task Force in 2003 to establish clear public involvement guidelines and standards for city government.
} 
- $\quad$ Public Education: "Provision of information and programs designed to inform the public, provide background history and information, and increase their knowledge, skills, and abilities to understand a specific situation or topic."

- $\quad$ Public Involvement: "Involves the public by requiring active participation and a feedback loop. Public is encouraged to provide feedback and participate in development and the decision making process. Public involvement is a process whose outcome is shared power."

PI/PI committee members focused on a fundamental concern-shared by both city staff and neighborhood district coalition representatives - that PI/PI activities should not be considered "administrative services" and should not be targeted for cost reduction strategies in the ASR review. They argued instead that PI/PI activities are "direct services" closely tied to the substantive work of different city agencies (7). ${ }^{46}$

PI/PI Team members noted that city agency budgets for public involvement and public information had remained "relatively stable with no major increases, except as dictated by the specific projects of new targeted programs." Some bureaus had increased their public involvement spending for specific projects, and ONI had partnered with some bureaus to help provide public involvement services for some of these projects. The team members recognized that budgets for the neighborhood district coalitions, funded through ONI, had remained flat.

\footnotetext{
${ }^{46}$ The question of whether community involvement should be an integral part of a project's design and implementation or an add-on service — somewhat independent of the substantive elements of the projectwould be discussed again and again in future efforts to improve city government public involvement activities.
} 
The PI/PI Team members noted that while "PI/PI in Portland is central to every bureau's goals and mission," "the administration of PI/PI is very decentralized with very few citywide policies or standards, or direction." Their report identified key obstacles to moving forward, including:

1. "Lack of citywide standards, policies, and procedures for public involvement and public information;

2. Inability to gather data on current services because of a lack of databases to track PTE [professional, technical, and expert services] contracts and to get a clear picture of FTE [full time equivalent] designated to this area; and

3. Lack of clear definition of the role of the Office of Neighborhood Involvement in the city's public involvement and public information administration" (5).

Committee members also identified "key implementation issues for any administrative changes in public involvement and public information," including the need for the City Council to establish "standards, policies, and procedures for public involvement and public information;" the need to clarify "the public involvement and public information role" of ONI; and the need to determine "which parts of public involvement and public information are central administrative services and which are bureau specific direct services" (5).

PI/PI Vision and Core Values: The PI/PI Team members identified a number of core values to guide their own and "future discussion of PI/PI needs and changes. ${ }^{47}$ The

\footnotetext{
${ }^{47}$ It is interesting to note how often groups that have reviewed Portland's community involvement system and activities choose to go through a similar process and develop very similar principles and values-often
} 
team members recognized that the City Council had adopted the 1996 "citizen

involvement principles" but went on to develop their own list of values, which included:

- “Community members will be involved

- Open, fair process

- Input will be utilized

- Consistency in policy and methodology

- Understandable by community

- Opinions and the public role is respected

- Engaging the diversity of Portland's population

- Involvement must be relevant

- Hearing the voice of the community

- Public involvement adds value and improves community

- Customer service mindset

- Every voice should be heard and respected

- Balance the needs of the stakeholders with the context of the system

- Accurate information for the creating [of] sound decisions

- Follow-through/feedback/close the information loop

- Information easy for the public to find

with little formal reference to similar lists developed by other review groups before them. Despite the frequent listing of public involvement core values and principles by these different groups, the lists often appeared to have little impact on changing the behavior of city staff or the nature and character of their interaction with the public. Clearly something else needed to be added to the mix. To learn more about how Portland began to move beyond these repeated but relatively ineffective lists of values, see discussion of the work of the Public Involvement Task Force (PITF) in 2003-04 and the later work of the Public Involvement Advisory Council (PIAC) created in 2008 in the next chapter. 
- Responsive relationship with the media

- Proactive information sharing

- Consistent quality

- Professional quality products

- Appropriate for audience and the internal needs of the organization

- Involvement and information in context with other efforts" (17)

The PI/PI committee members also listed in their report core values established by the International Association of Public Participation (IAP2):

- "The public should have a say in decisions about actions that affect their lives."

- "Public participation includes the promise that the public's contribution will influence the decision."

- The public participation process:

- "communicates the interests and meets the process needs of all participants."

- "seeks out and facilities the involvement of those potentially affected."

- "involves participants in defining how they participate."

- "communicates to participants how their input affected the decision."

- "provides the participants with the information they need to participate in a meaningful way." 
Existing Structures and Proposed Framework: PI/PI committee members reported that, at the time of their review, PI/PI activities in Portland city government were de-centralized—each bureau handled its own public involvement and carried out its public involvement its own way. ONI was seen as a leader in public involvement in city government because of its "guidance and maintenance of recognition of neighborhood associations, coalition contracts, and monitoring of compliance with" the ONA Guidelines. PI/PI committee members also recognized ONI's recent efforts to coordinate citywide PI/PI processes, including supporting networking meetings of city bureau public involvement staff (known as CPIN_-“Citywide Public Involvement Network”), publishing a monthly citywide outreach calendar and a calendar of neighborhood association meetings, and a calendar of citywide bureau events. The PI/PI committee members found that while these efforts were useful and should be continued, "ONI's role in these efforts has not been clearly defined by the City and efforts to coordinate have based on voluntary, time allowed, basis by bureaus resulting in incomplete calendars that are not widely distributed" (21).

The PI/PI committee members recommendations proposed the creation of a new structure in which city bureaus still would "direct their individual PI/PI decisions and processes," and neighborhood district coalitions could continue to "establish direct relationships with bureaus" but also in which ONI would play a much more prominent and centralized role in managing PI/PI contracts, advising bureaus on their public involvement processes, and coordinating bureau PI/PI meetings, training, and public meetings. 
Major Recommendations: PI/PI committee members developed and turned four major recommendations related to: coordination of public involvement PTE contracts, coordination of public involvement meetings, opportunities, and events; consolidation of the City's information and referral services, and creation of a city-wide public information officer position. The committee also developed additional recommendations after turning in its initial four recommendations. These recommendations are described below.

"Improve coordination, monitoring, and dissemination of public involvement professional contract dollars outsourced to consultants." Under this recommendation, ONI would: coordinate public involvement professional services contracts for other city bureaus that choose to participate; develop a request for proposal (RFP) from public involvement practitioners and use the responses to develop a list of prequalified public involvement consultants and invite the neighborhood district coalitions to submit proposals to get on the list. City bureaus who needed to hire a public involvement consultant could select a service provider from ONI's list without having to follow the City's policies that usually would require them to go through their own Request for Proposal (RFP) process. The "bureaus would discuss the scope and plans with ONI" and would consider contracting with ONI to provide the service. Bureaus would have the final say on whether they contracted with ONI, a consultant from ONI's prequalified list, or selected a consultant on their own (31).

The PI/PI committee members believed that implementation of this recommendation would save time and lower costs for bureau staff-who would not have 
to do their own RFP processes - and reduce the time and process needed for bureaus to select consultants and get them on the job. ONI and the neighborhood coalitions might get contracts and earn revenue that would help them support their organizations.

Community members would see better tracking and accountability for city bureau use of public involvement consultants (this information was not being tracked and some city commissioners had expressed concern about the lack of documentation and what they saw as the excessive use of consultants by city bureaus) (32).

"Coordinate administration of the majority of public involvement/public information meetings, trainings, involvement opportunities, and policies in ONI." This recommendation included three major elements:

"Stakeholder identification": ONI would "maintain and administer a central citywide public involvement database that would assist bureaus in identifying and contacting stakeholders" for their projects. ONI would maintain and regularly update the contacts in the database. PI/PI committee members envisioned that ONI would document who received notification of a project and when they received it. ONI also would coordinate both mail and electronic notification services, use GIS to target "specific geographic areas," and target "special interest groups, businesses" and other stakeholder groups as needed.

PI/PI committee members believed that this recommendation would generate the greatest cost savings by reducing duplication and would increase the effectiveness of bureau outreach efforts. This centralized approach also would improve "identification 
and notification of underserved communities" and improve customer satisfaction by helping city bureaus better coordinate their outreach efforts.

“Coordination and dissemination of general announcements, information to stakeholders about an issue, event, proposal etc. “ ONI would coordinate and take on a significant amount of the responsibility of delivering these services. Bureaus would have a one-stop place to go for assistance, and bureau staff time would be freed up to work on other tasks. This sub-recommendation included six separate services described below.

- Develop a citywide PI/PI calendar: This "comprehensive calendar" was intended to "list citywide events and include advisory committees, public meetings, forums, special events, neighborhood meetings etc." The calendar would be "web-based" and accessible to the public. Bureaus would "retain control" over what they listed on the calendar. PI/PI committee members saw this calendar as an extension of the calendar of events that ONI produced on an "'as needed' and 'information-provided' basis. Community members could view the calendar by day or by week and month. The calendar also would include links to the ONI I\&R database to "facilitate communication and outreach" and link to bureau and neighborhood web pages. City bureaus would relay information to ONI about their meetings and events, and ONI would update the calendar daily (38).

The PI/PI committee members intended that this calendar would provide a "centralized location for all public information, notification, and news 
efforts," and would improve coordination between city bureau and neighborhood groups, and reduce duplication and overlap of meetings. Bureaus would increase their ability to disseminate information about their events, and staff time spent on duplicating this calendar service in each bureau would be shifted to ONI. Members of the public would be able to access the calendar from any place where they had access to the web.

\section{Develop flyers to announce meetings and dissemination of meeting}

agendas and meeting minutes: City bureaus could send ONI content to distribute to the public and ONI would format the information "as flyers, postcards, fact sheets, email etc" and "distribute the information." ONI would look for opportunities to combine the outreach efforts of multiple bureaus. The PI/PI committee members noted that bureaus would still send out formal notification (e.g. land use notices) as required by City Code or state requirements. ONI would send out meeting notices, agendas, and meeting minutes for a wide array of city government advisory committees and task forces, city boards and commissions, public information meetings, special events, and public involvement events (39-40).

The PI/PI committee members believed that this centralization would increase collaboration and coordination among city bureaus and increase the professionalism of the layout and effectiveness of outreach materials. Bureau staff would be able to redirect some of their time to "content issues." 
Community members would have a “centralized' one-stop shopping source of information" and less "information overload" and frustration because city bureaus would coordinate their outreach more effectively (40).

- Coordinate public meetings: ONI would help city bureaus schedule many of their advisory committee and board and commission meetings and public meetings and special events. ONI would advise bureaus on the time and location of the meetings, coordinate with other bureau and neighborhood meetings, take care of the meeting logistics, notify the public and stakeholders, and disseminate meeting agendas and minutes (41).

- Coordinate public involvement and education opportunities: ONI would support "increased City efforts to coordinate strategic planning opportunities" to "maximize public involvement and minimize duplication of effort." ONI also would coordinate "public information and education opportunities on specific topics" and create "citywide public information and education opportunities." PI/PI committee members anticipated that this would increase citizen participation "numbers, diversity, representation" and would create multiple opportunities for community members to build their skill and knowledge and capacity to participate effectively (42).

\section{Provide bureaus with consistent citywide public involvement policies and} procedures: ONI would coordinate and support regular meetings of city bureau public information and public involvement staff (i.e. the C-PIN group) 
to allow these staff people to network and learn about new techniques and technologies. ONI would use C-PIN as an advisory group to:

○ "Revise the 'Outreach and Involvement Handbook for City of Portland Bureaus;"

○ Create a PI/PI “'best practices' checklist;"

○ "Provide feedback and evaluation for ONI services;"

- Explore opportunities for additional administrative efficiencies and savings;

○ Coordinate city PI/PI services beyond what ONI would provide; and

○ Host professional "in-service" training opportunities on PI/PI topics.

This recommendation was intended to lead to the development of consistent PI/PI standards and guidelines and to support ongoing skills and capacity building for city bureau staff.

- Provide strategic development services for bureaus: ONI staff would be available to help city bureau project teams to assess the need for PI/PI and to help them design appropriate involvement processes. ONI staff would help a bureau identify and clarify issues, identify potential stakeholders based on the likely impact of the project, identify appropriate outreach methods, develop an initial public involvement project schedule, advise bureaus on "mechanisms for assessment and evaluation of public 
involvement," and consult with bureau staff on any process changes needed during a project. ONI staff also could discuss a bureau's “outreach program, public involvement need," and provide advice to bureau on how to work with "ONI staff, coalitions, or other city-supported staff” as resources for outreach efforts (44).

This recommendation envisioned ONI staff as public participation strategic consultants to City bureaus. ONI staff would use their expertise and connections to help city bureaus design better processes and more effectively reach out to and involve different groups and communities in Portland.

In the third element of recommendation \#2, the PI/PI committee members recommended that "ONI, with cooperation from the bureaus, and with the C-PIN advisory group" "develop an evaluation/feedback mechanism to ensure that the new systems are working as designed and to make any adjustments needed once implemented." "Product and Process Benchmarks" and evaluation forms would be developed and used regularly depending on the frequency with which a city bureau used the services. PI/PI committee members also recommended that ONI report annually to OMF and the City Council "about the PI/PI process including suggestions for other possible administrative improvements and enhancement" (45).

PI/PI committee members recognized that a number of factors could make the successful implementation difficult. Bureau staff would have to devote significant 
amounts of time to work with ONI initially to set up the "database, notification requirements, etc." ONI staff would need to "commit to understanding Bureau needs for public involvement." Bureaus would lose some independence as they gave up doing some of their own public involvement activities and relied on the citywide system instead. ONI would need to be "responsive and available to work on efforts within Bureau timeframes."

PI/PI committee members recognized that having ONI staff take on many public involvement responsibilities for city bureaus would mean that bureaus would not have their own staff doing these activities anymore. ONI staff would not have the same grounding in the substance of the work of the bureau, and bureau program staff would not have the same ability to have regular "face-to-face" meetings with their own PI/PI staff people.

The PI/PI committee members also recognized that its recommendations would significantly increase the amount of staff needed at ONI to take on all these new duties, and would "represent a significant change in the City's 'way of doing business."”

Consolidate and improve City government information and referral services: PI/PI committee members also recommended further consolidation and improvement of city government "information and referral" services—especially relieving the "Police Bureau of some I\&R tasks.” The proposed changes would build on ONI's existing city/county I \& R Program.

Establish a "Citywide Public Information Officer Position:" Communications, like other administrative services in Portland's city government, were managed 
independently by each city bureau. Bureaus followed no consistent citywide standards and generally did not coordinate their communications with other bureaus. No standing capacity existed to manage citywide communication efforts. PI/PI committee members noted that when an unusual situation required a citywide response—-such as "Y2k, weather-related emergencies, legislative support" and city wide celebrations—city leaders would "borrow" public information staff from different bureaus to staff these efforts. "Borrowed staff" achieved results, but had to add these duties to their existing workloads.

The PI/PI committee members explored the question: "How can the City best leverage shared multi-bureau and City media relations and public information opportunities without lessening Bureau-specific information programs" (52)?

PI/PI members found that no one in city government was tasked to "strategize or address the situations where public information efforts would be useful and desirable." They found that media relations were particularly important because "most residents form their understanding and perception of City services based on the information they gain through electronic and print media reporting." They argued that the city needed actively to plan its interactions with the news media, and that this would "offer residents greater access to information," a "better understanding of how the City works, how services are paid for, and how the City responds to the challenges of a more complicated and regulated world to improve residents' quality of life." They maintained that this was "full-time work" that deserved its own dedicated and ongoing staffing (52-53). 
PI/PI committee members recommended that the City Council create a new position of Citywide Public Information Officer. This individual would "develop and manage a central information strategy to provide residents and interested others access to information" and be housed either in OMF or in the City's legislative relations office. In most cases, bureaus would retain their own public information staff.

The Citywide PIO would serve as the primary—but not exclusive—contact with media organizations, centrally coordinate "citywide information, concerns and opportunities," and "serve as a resource to Commissioners, Council offices, Office of Management and Finance, Legislative Office, City Attorney's Office" and city bureaus that did not have strong communication capacity of their own. The Citywide PIO would help develop media strategies, "messaging, news releases, news events, story placement, information gathering and fact finding," and "interview preparation." The Citywide PIO would work with bureaus to develop communications procedures and standards, provide strategic advice, and serve as the City's spokesperson as needed. City Council would hold an annual work session to help set the priorities for the Citywide PIO (53).

Other Recommendations: The PI/PI committee report included six additional recommendations, some of which were addressed to some extent by the four major recommendations. These recommendations did not focus specifically on cost reduction or efficiency but identified actions that would improve the quality and consistency of city government public involvement. The additional recommendations included: improved coordination of public involvement in the City's various capital improvement project identification processes, bureau consultation "with ONI on all public involvement 
processes," invitation to ONI to "bid on all public involvement contracts," ONI coordination of a "citywide discussion to develop common terms understanding and expectations for outreach processes along with standard guidelines," ONI coordination of "a citywide discussion to explore development of a common stakeholder identification database with citywide availability," ONI and Bureau of Information Technology coordination of "a citywide discussion on how bureaus might use information technology to facilitate public involvement and public information."

The ASR PI/PI report was the first in-depth look at how to improve the efficiency and quality of community involvement by Portland's city agencies. The report identified a number of key problems, including the lack of consistent standards for community involvement and the policies, mechanisms, practices, and staff and other resources needed significantly to improve their community involvement.

The PI/PI committee recommendations represented a strong effort by ONI Director David Lane and Commissioner Saltzman to create a new role for ONI and to centralize in ONI many community involvement tasks that, at the time, staff in individual city bureau were doing themselves. PI/PI committee members also hoped that bureaus would shift from hiring outside contractors to do public involvement for them and instead infuse additional revenue and funding into ONI and the neighborhood coalitions by contracting with them for these types of services.

The PI/PI committee also raised an important strategic question about whether public involvement is an "administrative service" that a bureau could farm out easily to a provider outside the bureau, or whether community involvement should be an integral 
part of a city agency's planning and implementation of its service to the community. Later reviews would reject much of the centralization model proposed by ONI City Commissioner Dan Saltzman (Saltzman was the commissioner in charge of ONI at the time of the ASR) and ONI Director Dr. David Lane (and the ASR PI/PI committee) and favor building strong community involvement capacity within each individual city bureau.

The ASR PI/PI committee report, for the first time, identified many important capacity areas city government needed to develop to be able to provide consistent, good quality and effective community involvement. Future reviews of city government public involvement would bring up many of the same issues again.

ONI attempted to implement some of the ASR PI/PI committee recommendations, but the City Council did not provide the significant increase in funding that would have been needed for full implementation. Some ONI staff did reduce their support for community empowerment and support for the neighborhood system so that they could provide community involvement support on some specific bureau projects. Most of ONI's attempts to implement various ASR recommendations ultimately were abandoned. The next section describes some of the post-ASR efforts and their results.

\section{$\underline{\text { Post ASR-Attempts to Centralize Community Involvement Services }}$}

The ASR PI/PI committee laid out a broad plan for major reform of city government community involvement and communications roles and services. David Lane, ONI Director from July 1999 to January 2004, and Brian Hoop, an ONI staff 
person hired by Lane in January 2000, offered some interesting context for ONI at the time and insights into ONI's efforts to implement some of the ASR recommendations.

Dan Saltzman served as the City Commissioner in charge of ONI from Jan 1999 to May 2002. Saltzman hired Dr. David Lane to serve as ONI Director in July 1999. Lane says that when he came in as ONI director ONI was suffering "from long-building angst, frustration, and apathy from City Hall and the Mayor." "Each commissioner...expressed the need to revamp the neighborhood system and make it work better. City Hall staff and neighborhood activists were uniformly frustrated with lack of trust from each direction. Activists were troubled by lack of support for NAs, and lack of 'letting the NAs do their work.' Many city hall insiders saw the NAs and coalitions as out of touch with the real neighborhood issues" and many referred to the neighborhood associations "as "necessary but useless' and not really in touch with the real neighbors. [Neighborhood] Coalitions, of course, saw it differently and felt that many city hall and bureau leaders did not utilize them effectively. Funding was a huge issue, and each year I was there, we had to cut the [ONI] budget" (Lane email to Leistner, July 18, 2008). Hoop recalls that neither Mayor Vera Katz nor the other city council members strongly championed Portland's neighborhood system during the early 2000s.

Lane said that Saltzman's focus during his three years in charge of ONI was to "reactivate the neighborhood system," restructure, and reorganize ONI staff," "support NAs more from ONI Central," "re-energize [the Metropolitan Human Rights Commission]," "Expand the I\&R line with [Multnomah] County," "Initiate the CityCounty Siting program" (to help with the siting of residential service facilities in the 
community), and to “expand ONI's role in [public involvement] for all the City's bureaus."

PTE contracts: The ASR PI/PI report recommended that ONI develop and manage a centralized professional service contract process. Commissioner Saltzman directed ONI staff to develop a process by which consultant firms and community organizations could apply to be included in a city government flexible services contract for public involvement and public information services. The contract would establish a list of providers that bureaus could hire from without having to go through their own RFP process.

Hoop says Lane and Saltzman wanted to build the capacity of the neighborhood coalitions to offer provide public involvement services equal to those of other consultants and contractors. Hoop said Saltzman and Lane hoped to get city bureaus to hire coalitions instead of the private contractors who traditionally had received most of this work (Hoop. Conversation with Leistner, July 11, 2008).

ONI staff proceeded to set up the application process. Hoop reports that ONI staff encouraged all the neighborhood coalitions and also some community of color organizations to apply to be included on the list. Hoop said that some neighborhood coalitions responded with "angst" that taking on public involvement projects for city bureaus would pull their organizations away from the primary role to support and empower neighborhood associations. They also were concerned about potential conflicts of interest that could arise if the interests of neighborhood associations and city bureaus 
diverged. Hoop said coalitions directors reluctantly agreed to apply because they saw it was in their best interest to do so.

ONI staff developed and issued a request for qualifications (RFQ) to provide "public information" and "public information and public involvement" services. A number of consultant firms and community organizations responded. In March 2002, the Portland City Council approved an ordinance that established a two-year "flexibleservices contract" intended to provide city bureaus with "consistent, cost-effective, and fairly determined public involvement and public information services." In addition to many of Portland's traditional public involvement consultants, the ordinance approved a list of providers that included all seven of Portland's neighborhood district coalitions (Portland. City Council. Ordinance 17633620 March 2002). A later ordinance added organizations that worked with communities of color and immigrants and refugees to the list (Portland. City Council. Ordinance 17688412 September 2002).

The program was not successful. Hoop says ONI had intended to spread the work across all the providers on the list by rotating the firms and organizations the offered to bureaus seeking public involvement assistance. While bureaus liked the much easier process of hiring providers from the list, they continued to insist on hiring the consulting firms they had used in the past and already were comfortable with. Some community organizations complained that they never received any business from city bureaus, despite being on the list. The project ultimately was abandoned and bureaus went back to managing their own public involvement services contracts (Hoop. Conversation with Leistner. February 16, 2011). 
CIP Process: The ASR PI/PI committee recommended that ONI help bureaus coordinate community outreach and input on capital improvement project planning. During the summer and fall of 2001, ONI staff worked with the "CIP Oversight Committee" to host a series of four open houses for community members. City Council had created the CIP Oversight Committee to "better integrate Capital Improvement Project planning, funding, public involvement, design, and construction phases." Representatives of all the major city bureaus that planned and implemented capital improvement projects participated. The fall 2001 open houses were one of the committee's "core strategies" for public involvement.

A formal evaluation report on the open houses_-completed shortly after they took place_-stated that "dozens of city workers helped over a six to nine month period with event logistics, web and database design, developing literature, maps and displays.” Eight city bureaus actively sponsored the events and two additional bureaus presented displays at the open houses. After all this effort, only 154 community members participated in the open houses (an average of 39 people per event). The evaluation notes that thousands of other community members "learned about CIP efforts through web site visits, media stories," and presentations at about 50 neighborhood meetings. City bureaus also contracted with four neighborhood district coalitions to help reach out to neighborhood associations to encourage people to come to the events (Portland. Office of Neighborhood Involvement. Evaluation Report: City Wide CIP Open House: Fall 2001 December 2001). 
The open houses included presentations by bureau staff about projects in the planning phase or moving toward implementation. Community members could visit display stations for different bureaus and receive information about that bureaus projects and talk directly to staff people. The open houses also unveiled a new, web-based source of information on capital improvement projects called "PortlandMaps.",48

Positive outcomes recorded in the evaluation report included reports from bureau staff who appreciated the opportunity to build relationships and coordinate across different bureaus and from community members who like the "fair-like atmosphere," getting to learn about "multiple projects at one time, building relationships with project managers, speaking on-on-one with upper level fiscal managers, and picking up lots of handouts" (Portland. Office of Neighborhood Involvement. Evaluation Report. December $20014)$.

Critiques of the open houses included feedback from bureau staff who questioned their value, given the low community attendance and high level of staff time that went into organizing the events (at some of the open houses, more city staff were present than community members). Some community members were frustrated that the events were designed for bureaus to provide information about their projects, but did not include formal opportunities for community members to share their priorities for capital improvement projects or their ideas or concerns about specific projects being planned or implemented.

\footnotetext{
${ }^{48}$ In 2013, PortlandMaps.com continued to be a widely used resource for community members and city staff. Individuals can use the site to access a wide range of information about different property locations, including: permitting, property assessor information, crime statistics, zoning, and a wide array of information about different infrastructure (e.g. roads, sewer, water, parks, etc.) and capital projects in the surrounding area.
} 
Suggestions for improvements in the future included: "organize one large event requiring multiple city staff attendance" instead of multiple citywide events; more focus on training city staff to "make presentations to each neighborhood association;" expanded "use of the web site to provide year-round education and input;" more "localized marketing of open houses to emphasize local neighborhood projects; " and a suggestion to "create a City Fair at Waterfront Park" where community members could come to "learn about all City services," such as "abandoned cards, building codes, etc." that would include other jurisdictions, such as Tri-Met (the regional transit agency) and Multnomah County (4).

The varied community feedback in the evaluation also shows that community members came to the events with a diversity of information needs and ability to provide meaningful feedback to city bureaus. Some people just want to know what was going on, while others wanted to provide much more in-depth input to city staff on their own priorities and on specific projects. This feedback again reaffirmed the need for city government community involvement to be designed for and relevant to different audiences in the community and to provide the opportunity for meaningful community input that could make a difference in city decision-making and project implementation.

Brian Hoop reported that the ONI and city bureaus, after the experience with the 2001 open houses, chose not to try to host similar coordinated citywide capital improvement community outreach events. Hoop says this was in large part due to the "sticker shock" bureaus felt because of the cost of the events and the high amounts of 
staff time required to plan and implement them, especially given the low community participation in the events. $^{49}$

ONI Assistance with Bureau outreach projects: ONI also aggressively pursued opportunities to provide direct community involvement services to other city bureausanother ASR recommendation. ONI staff began to help city bureaus design and implement community involvement activities for a number of specific bureau projects. ONI pursued this work without hiring additional staff. As a result, Hoop says he and the other ONI staff person dedicated to community involvement soon found that nearly all of their time was taken working on a number of very demanding projects for other bureaus city bureaus during the early 2000s. Their work on these bureau projects resulted in their having almost no time to devote to supporting and strengthening the neighborhood system or other community capacity building.

Hoop said that by 2003, ONI started to pull back from this attempt to serve as a community involvement contractor for other city bureaus. At that time, Hoop was the sole ONI employee dedicated to supporting the neighborhood system. Hoop said his major focus became supporting the third round of review and revision of the ONI Standards and another major process to review and improve city government community involvement, known as the 2003-2004 Public Involvement Task Force (described below).

Other ASR recommendations: Other recommendations of the ASR PI/PI Committee were not implemented. The City Council did not create a central PIO position

\footnotetext{
${ }^{49}$ It is interesting to note that community members, since the founding of the Portland's community and neighborhood involvement system in the 1970s, have continued to ask city government leaders and staff to provide opportunities for them to have a voice in determining priorities for the capital improvement projects. They also have asked that city bureaus do a better job of coordinating their projects in the community, and to provide a centralized source of information about city government capital projects.
} 
or pursue the development of a coordinated strategy for city government communications. ONI also did not take on the formal role of reviewing most bureau community involvement plans and advising bureau staff on best practices. Community members and some city staff continued to call for better coordination and consistency of communications across city government as well as the need to improve the quality and consistency of community involvement by city agencies and leaders. Both issues would be a major focus on the Public Involvement Task Force. ${ }^{50}$

As described above, the ONI did try to implement some of the ASR recommendations to centralize public involvement services. Generally, these attempts were not successful and were not continued, in large part because the City Council did not make available the resources that would have been required to implement some of the recommendations. The ASR experiment also surfaced the important question of whether it was better for city agencies and the community to integrate public involvement into their agency's work and develop the internal capacity to plan for and implement community involvement rather than contracting out public involvement services to outside contractors or a centralized public involvement agency.

\section{Commissioner Attempts to Improve the Neighborhood System}

ONI Commissioner Dan Saltzman developed and attempted to implement number of ideas that he thought would improve Portland's neighborhood system. All the ideas ran into opposition from neighborhood district coalition leaders. Commissioner Francesconi,

\footnotetext{
${ }^{50}$ These same issues still would be a subject of reform and improvement efforts ten years later by the City of Portland's Public Involvement Advisory Committee.
} 
when he became the ONI Commissioner, advocated for the implementation of a neighborhood grants program. This section examines each of these efforts.

Re-examine and Reconnect-2001: During the early 2000s, City

Commissioners in charge of ONI would engage in a number of different attempts to "fix" Portland's neighborhood system. In March 2001, City Commissioner Dan Saltzman surprised neighborhood association leaders at the 2001 Neighborhood Summit by announcing his proposal to initiate yet another review of Portland's neighborhood system, which he called "Re-examine and Reconnect." The Oregonian reported that Saltzman told the assembled neighborhood leaders that Re-examine and Reconnect would help broaden participation by neighborhood residents, "especially renters and minorities," in their neighborhood association. The Oregonian quoted Saltzman as saying, "We need to move away from structured connections and the them-or-us attitude that is too often the way we do business." "With people moving around so much, I'd like to see something like a welcome wagon in each neighborhood that would encourage every new renter and homeowner to get involved." The Oregonian reported that many of the neighborhood activists at the summit also said they "wanted to strengthen ties with local business, school and civic organizations" (Fitzgibbon. Oregonian. March 5, 2001).

A press release from Saltzman's office about Re-examine and Reconnect stated that it would be a "focused, systematic look at the neighborhood system." Saltzman said that "Portland's landmark system of 95 neighborhood associations and public involvement system is a leader worldwide," but that "To retain our leadership and to have the best access for neighbors to their city government, we need to periodically take a hard 
look at our system. We have to look at how our resources are spent and ask what can we do to make our system better" (Portland. City Commissioner Dan Saltzman. Press release. "Saltzman Announces New Neighborhood Focus" 7 March 2001).

The press release stated that Re-examine and Reconnect would focus on three key areas, which included: an investigation by ONI of "how best to support neighborhood associations and their connection to the coalitions;" how to "increase the number and representation of neighborhoods in our neighborhood associations; and an effort to “improve partnerships within the City and [an examination of] how to get more resources for neighborhoods and more involvement with neighbors."

Saltzman planned to have ONI reach out to "neighborhood associations, neighbors, and coalitions," "community partners" and "underserved communities" in a "bureau-wide effort to make sure that every aspect of ONI is exploring how to support neighborhoods and neighborhoods." ONI also would reach out to community partners and underserved communities, because, according to Saltzman, "If we want our neighborhood system to continue working, it has to include and represent every Portland neighbor" [emphasis in original]. Saltzman also made a point of mentioning in the press release his desire to establish "a way that neighbors are notified about their neighborhood associations when they move into a neighborhood."

Neighborhood coalition leaders pushed back immediately. One neighborhood coalition director emailed ONI Director David Lane a couple days after the Neighborhood Summit and noted that "Saturday was the first I had heard of this new campaign" and wondered "why this campaign is new news to me" given the long- 
standing assumptions that "the coalition offices are and should be the key support system for neighborhood associations..." The neighborhood coalition director called for a discussion about "the goals of this effort and each party's roles" at the next monthly meeting of the neighborhood coalition directors and ONI. She emphasized that "integral to the neighborhood structure is the notion that the coalitions are free from the constraints of a city bureau and free to serve as advocates for the concerns of the neighborhoods." She urged the city to "consider looking at how it uses the neighborhood system and the role it expects citizens to play. Public involvement is much different than leadership development and organizing. I would love to see ONI get behind supporting the coalitions and neighborhood associations with the kind of resources it takes to develop a truly activist neighborhood association structure" (Portland. Office of Neighborhood Involvement. Email from Elizabeth Kennedy-Wong to David Lane and others, March 5, 2001).

David Lane emailed back right away saying that ONI planned to have neighborhood coalitions "play an integral role in 'Re-Examine and Reconnect"” and that "coalition staffs, their Boards, and their neighborhood associations," "many, many neighbors," ONI staff, other bureau staff, other community partners, and [City] Council offices" all would be involved as well (Portland. Office of Neighborhood Involvement. Email from David Lane to Elizabeth Kennedy-Wong and others, March 5 2001).

In his email, Lane also suggested that Re-examine and Reconnect "complements and fits in well with several efforts (ongoing and soon-to-be-starting) which we've been discussing in the last weeks and months...." He said ONI proposed that the Re-examine 
and Reconnect effort would combine a number of "already planned efforts into a 'focused systematic look" at Portland's neighborhood and public involvement system. Lane identified these other efforts as:

1. Implementation of the Administrative Services Review (“ASR”) recommendations;

2. Review and development of the next iteration of the ONI Guidelines [required by City Code to be completed by 2002];

3. Development of a new coalition funding formula to ensure greater equity in the distribution of resources across the neighborhood system;

4. "[ONI] BAC discussion around funding and ONI programs in general....";

5. "Input from coalitions, boards, coalition staff about the roles of coalitions"; and

6. "Input from coalitions, boards, coalition staff and others about the need to document the purpose, roles, and effectiveness of coalitions and the neighborhood structure."

ONI documents show that ONI staff and the neighborhood coalition leaders began formal discussions about the goals, process, roles and timeline for Re-examine and Reconnect in late march at the monthly meeting of the coalition directors. One document prepared by ONI staff characterized the proposed Re-examine and Reconnect as a "review of how the neighborhood is working" as a complement to the ASR examination of the city government side of public involvement in Portland. 
ONI staff and the neighborhood coalition directors continued to go back and forth about the goals, scope, timeline of Re-examine and Reconnect as well as the composition of the steering or advisory committee that would lead the process. ONI staff maintained that a key catalyst for the process had been "neighbors and neighborhood associations and coalition staff" who had "asked ONI and the coalitions to re-visit the [1996 TFNI Report], look at the role of ONI, look at what neighborhood offices should be doing, and figure out a way to get more money for neighborhood associations" and the ASR review of city public information and public involvement (Portland. Office of Neighborhood Involvement. Joleen Classen, “overview of R\&R spring 2001” [saved June 7, 2001]).

Coalition directors continued to be concerned that ONI was driving the process and not working in a partnership with the coalitions to develop the process. One coalition director argued that the "effort should be led by representatives from each of the affected parties" and noted that the scope of the project still was not clear- "Are we looking at ONI, all of its services and its constituents? Or are we looking exclusively at ONI/Coalition/NA."? She recommended that this "steering committee" should "define the goal of the effort," "define the process," "oversee implementation," and "make recommendations." She asked whether the goal of the project was to look at ways to "implement the recommendations of the 1996 Task Force? Are we looking to overhaul the system entirely? Are we looking to see if there are problems or are we assuming there are problems?"51 She asked for a formal statement from Commissioner Saltzman on his

\footnotetext{
${ }^{51}$ It is somewhat ironic that this same individual a few years later would oversee another major review of Portland neighborhood and community involvement system as a staff person in Mayor Tom Potter's office and would face many of the same questions by neighborhood activists and community members about the lack of clarity regarding the charge, goals and scope of that process. Some important lessons here are that
} 
goals and intentions for the process and what commitments he would be willing to make. She also suggested that the process could be "an excellent opportunity to educate both the city and community about who we are and what we do." She suggested that the process mirror and support the Southeast Uplift neighborhood coalition's outreach and self assessment process for its neighborhood associations, known as the "Healthy Neighborhoods Initiative," and similar efforts by the Metropolitan Human Rights Center and Latino Network (i.e. the 2001-2003 Interwoven Tapestry Project described below) (Portland. Office of Neighborhood Involvement. Elizabeth Kennedy-Wong. Memo to coalition directors and David Lane 2001).

At the same time that ONI staff were trying to work with coalition leaders to develop a process to move forward with Re-examine and Reconnect, Saltzman plunged the parties into further conflict by insisting that the neighborhood coalitions should compete for their traditional ONI contracts in an open bidding process.

\section{Commissioner Saltzman's attempt to require district coalitions to compete}

for their ONI contracts: In the spring of 2001, Saltzman further strained his relationship with the neighborhood district coalitions by declaring that he was going to open up their long-standing ONI contracts to outside bidders and requiring them to compete against other potential providers to receive funding to support the neighborhood associations in their districts. David Lane said that "the coalitions...were uniformly upset" and refused to comply. Lane identified the resulting conflict between Saltzman 
and the neighborhood coalitions as the "biggest controversy" during his time as ONI director (Lane. Email to Leistner, 2008).

Since the founding of Portland's neighborhood system ONA/ONI had contracted with individual neighborhood district coalitions to provide public involvement and capacity building services and support to the neighborhood associations in their districts. ONA/ONI never had submitted the contracts to an open bidding process. David Lane noted that Saltzman became aware that city government regulations required city agencies to go through a Request for Proposals (RFP) process when engaging in contracts over a certain dollar amount. Lane says that "Saltzman wanted to follow city law and thought a competitive RFP would help support the coalitions as realistically few organizations would meet the criteria of the RFP except for the existing coalitions" (Lane 2008).

One current coalition executive director who was in the same role at the time, said that initially the coalitions "took a wait and see what it means approach" as they often did with other city commissioner ideas on how to "fix" the neighborhood system. He said that Saltzman and ONI staff told the coalitions that this is a chance to show their value by bidding for these contracts. This coalition director said that the attitude of the coalitions at the time was "why should we bid for what we are already doing?" They also asked, "Who else could play this role?" given that district coalitions are defined in city code and the ONI Guidelines are governed by a board of representatives of their neighborhood associations. The executive director said that Saltzman stubbornly refused to back down, and coalition representatives began to lobby other city commissioners to block 
implementation of the requirement (Sieber. Phone conversation with Leistner, March 16, 2012).

In mid-April, neighborhood coalitions leaders issued a press release accusing Saltzman of acting hastily and “"radically undermining' the city's 27-year-old neighborhood system." They criticized Saltzman for dictating top-down changes instead of working in partnership with the district coalitions. Saltzman maintained that he wanted "the coalitions to address problems he sees with the neighborhood system, including difficulties between the coalitions and member neighborhood associations, and low involvement of new residents and minorities." The Oregonian quoted Saltzman as saying:

In the two years I've been in charge of this bureau, I've found there are neighborhoods that question whether the coalitions are representing their interests." "I view this as an opportunity to ask the coalitions to make sure they are really representing the neighborhoods, and that to me is their mission in life.

Saltzman suggested that "other nonprofits such as the Urban League could bid on the services" (Learn. Oregonian, 20 April 2001).

Neighborhood coalition leaders argued that the neighborhood coalitions are governed by boards of directors made up of representatives from their member neighborhood associations and receive City funding through ONI to help their neighborhood associations and community members "weigh in on city policies." Some also raised concerns that ONI could use the contract bidding process to remove funding from and punish coalitions that pushed back to hard on the City on controversial issues thereby undermining the independent voice of the neighborhood system. 
Saltzman also decided to require coalitions to submit letters of support from their member neighborhood associations and to require the coalitions to "develop outreach plans to renters, ethnic minorities and new residents" as part of the contract proposal process (Learn. Oregonian 9 May 2001). This in part was an attempt to respond to complaints from neighborhood associations that some coalitions were pursuing their own agendas and not providing adequate attention and service to their neighborhood associations (Learn. Oregonian, 20 April 2001) and an effort to increase the diversity of participation in neighborhood associations.

ONI's deadline for receiving proposals from the district coalitions for their ONI contracts was May 18. By mid-April, no other non-profit organizations had bid for the contracts, and the neighborhood coalitions continued to boycott meetings ONI tried to set up with them to explain the process by which they could submit their proposals (Learn. Oregonian, 20 April 2001).

Saltzman received little support from his fellow city commissioners. Neighborhood coalition leaders had mounted a lobbying campaign to encourage other city council members to oppose Saltzman's proposal. The Oregonian reported that, as of April 20, three of the five city council members (a majority of the city council) had asked Saltzman to withdraw his request that the district coalitions compete for their ONI funding. A article reported that City Commissioner Jim Francesconi said "The system is set up to have the neighborhood associations_-not city officials—control the coalitions." The article quoted Francesconi as saying "The idea that we're going to pick neighborhood leaders from City Hall makes no sense to me." "The neighborhood 
associations need to do more to represent the neighborhoods but this isn't the way to proceed." Another city council member, Erik Sten is quoted as saying "I think Dan has some pretty good points on things that could be improved, but it's not clear how this process is going to accomplish that." The article closed with Saltzman stating that he was "listening to what my colleagues have to say, but at this point I'm still committed to going ahead... and to just trying to de-escalate the situation" (Learn. Oregonian, 20 April 2001).

Neighborhood leaders appeared at the City Council's sole city budget hearing in the community at the end of April and again asked Saltzman to "back off putting neighborhood coalition services up for bid" (Learn. Oregonian 30 April 2001).

A few days later Oregonian columnist, Renee Mitchell (who often championed community causes) blasted Saltzman in her column and accused him of having "made a mockery of the bureau title under his charge: the Office of Neighborhood Involvement. She wrote that "there was no public involvement before Dan decided to tinker with a nationally admired model of citizen participation. No warning given to City Hall. And apparently no foresight into the firestorm this bright idea would generate." She asked “But how's this for a strategy to propose a significant change initiative: Don't ask for advice, don't think about the implications, and don't involve the stakeholders." Mitchell quoted one coalition volunteer leader who noted that the ONI/coalition contract says that ONI will come out and review each coalition's activities and finances. The coalition leader said "That's not been done for two years, and now they want to come out and tell us that we're not doing our job" (Mitchell. Oregonian 2 May 2001)? 
Mitchell did recognize that "Dan's blundering, though, should not be used an excuse to hide from change. He actually does have good intentions despite a flawed process." "Yes, the coalitions need to be more accountable to the residents they were designed to serve. And, yes, they need to make an extra effort to reach out to renters, young families, low-income residents and recent immigrants." She gave Saltzman credit for embarking on the Re-Examine and Reconnect process to "recruit more residents to get involved in the process." But she also made the point that "those are also issues that can easily be negotiated in a yearly contract — tied with a few more dollars to make it happen.” Mitchell closed her column with some lively advice for Saltzman: "Reexamine. Reconnect. Involve your constituents. Get a clue....It's time to cancel this power trip, Dan. Unpack your bags and make new reservations. 'Cause this bull-headed train ride will not take you where you really want to go."

Saltzman, finally bowed to weeks of pressure from neighborhood leaders, and, on May 8, withdrew his proposal to require neighborhood coalitions to complete for their contracts. Saltzman told the Oregonian that he still wanted to "consider bidding out services as part of a larger push to help associations diversify their membership" and wanted to change "this year's contract to ensure that the coalitions are meeting neighborhood needs." Saltzman claimed to have support from other city council members for the changes, but, the Oregonian reported that it was unclear whether coalition leaders who had opposed Saltzman would agree to the changes (Learn. Oregonian 9 May 2001).

ONI staff at the time and others report that they believed Saltzman lost interest in reforming the neighborhood system after his clashes with coalition leaders and turned his 
attention elsewhere. Hoop said that ONI staff soon thereafter dropped the efforts to initiate the Re-examine and Reconnect review process, in part also because the city budget was heading for more cuts and no new funding likely would be available to implement any major recommendations that might come out of the process (Hoop. Email to Leistner, December 2, 2010).

The controversy over Saltzman's efforts to initiate the Reexamine-Reconnect process, require neighborhood coalitions to compete for their ONI contracts, and to impose additional contract requirements illustrate the danger of not following the basic principles of good public involvement (identified in many previous system reviews in Portland), especially within a community involvement system. The importance of city leaders having the interest in and ability to work effectively with the community would be reinforced again in the early 2000s.

\section{City Commissioner Francesconi’s Attempt to Create Neighborhood Grants}

Program: In June 2002, Mayor Katz reassigned responsibility for ONI from City Commissioner Dan Saltzman to City Commissioner Jim Francesconi. Francesconi served as the ONI commissioner for six months, from June 2002 through November 2002. Lane says that Francesconi continued the ONI staff reorganizations begun under Saltzman and oversaw the spinning off of the mediation services long provided by ONI's Neighborhood Mediation Program to the private, non-profit, Resolutions NW (Lane 2008).

One interesting initiative pursued during Francesconi's short tenure in charge of ONI was the attempt to create a neighborhood grants program. The 1996 TFNI report 
recommended the creation of grant program. Brian Hoop, one of the two ONI staff people who worked on developing the proposed grant program said interest in creating a grants program even pre-dated the 1996 TFNI process. He said that in doing the research to create the program proposal he talked with a former ONI employee who had researched the development of a grant program years early and showed him two or three binders of material from that process. Hoop also talked with Sam Adams, who, as Mayor Katz's chief of staff, had researched the creation of a neighborhood grants program back in the early-mid 1990s. ${ }^{52}$

In November 2002, City Council passed a resolution, prepared by ONI staff, that directed ONI to create a neighborhood grants program. The resolution made the case for the grants program by noting that "neighborhoods have a myriad of needs...that, if met would improve the quality of our neighborhoods," and that the City Council "encourages partnerships among neighbors, neighborhoods, businesses, and our City Bureaus" to improve neighborhood livability, and that the neighborhood system and ONI encourage "residents to be active stewards of their neighborhoods and to volunteer their time and resources in their neighborhoods." The resolution also noted that other Cities had small grants programs and, in particular, mentioned the City of Seattle's very successful Neighborhood Matching Fund program, which had given out \$4.5 million over the previous two years to support local projects. The resolution also recognized that “Portland's neighborhoods, businesses, and community groups have a strong history of

\footnotetext{
${ }^{52}$ Adams, later, as a city council member, supported the neighborhood grants program implemented under Mayor Tom Potter and continued to support the program when he himself became Portland's mayor (from 2009 to 2012).
} 
leveraging small funding opportunities into projects of immense community benefit," and that "neighborhood projects involving the community encourage community cohesion, self-reliance, and a sense of place in today's very mobile society. The resolution closed by stated that while "neighborhood groups work very hard to leverage other community resources" they had "very limited access to small grants" like the ones proposed by this grant program. The resolution also recognized that the City Council would realize some saving by contracting out mediation services formerly provided directly by ONI's Mediation Center, which could be used to help fund the grant program. The resolution directed ONI "to develop a neighborhood small grants program that allows neighborhoods to leverage community resources, encourage volunteerism, and carry out local projects," and directed ONI to "craft program guidelines, approval process, and budget recommendations for Council review no later than February 1, 2003..." (Portland. City Council. Resolution 36110 , November 13, 2002). ${ }^{53}$

However, before much progress could be made on moving forward with the grant program, Mayor Katz, in January 2002, reassigned responsibility over ONI to City Commissioner Randy Leonard. Hoop says the neighborhood grants program was not a priority for Leonard, and ONI staff stopped working on the project. Leonard was to bring to his new leadership role over ONI his own ideas for significantly redirecting the focus of ONI and the neighborhood coalitions away from community empowerment and toward using the system to provide city services at the neighborhood level. Leonard's

\footnotetext{
${ }^{53}$ Mayor Katz, in her "mayor's message" that accompanied the FY 1996-97 City Budget reported that $\$ 750,000$ had been allocated, in response to the TFNI Report, to fund a neighborhood grants program. The funding for the grant program would be directed to other city priorities that budget year, and the grant program was not established.
} 
leadership over ONI led to some of the most significant conflicts between the ONI Commission and neighborhood activists since the founding of the neighborhood system.

By the early 2000s, repeated reviews of various aspects of Portland's neighborhood and community involvement system had revealed a fairly consistent assessment of what was and was not working. The clear challenge was how to develop design a process to develop a strategy to identify positive reforms and how to implement it successfully.

On the community side neighborhood associations and other community groups needed more capacity and resources, and needed to do a better job of involving a greater diversity of the their communities. Neighborhood associations and coalitions both needed to find ways to reach out to and be more responsive to their community members and member neighborhood associations, respectively.

On the city government side, city leaders and staff continued to be criticized for not involving the community effectively. People inside city government needed help in seeing the community as an important part of their work and in developing the skills to engage the community collaboratively and constructively in ways that would give community members the opportunity to shape local priorities and decision making.

Both community members and city government leaders and staff appeared not to have a clear sense of how to act on the problems and solutions that had been identified. Many people felt ONI could play a valuable role, but disagreed on what that role should be. At the same time, no one on the city council, acted as a strong political champion for public involvement or provided effective leadership to identify a reasonable path forward 
and the policy and program changes the would be needed and to advocate the resources to develop and implement them.

Saltzman and ONI—under David Lane's leadership—put significant energy in trying to move the agenda forward on both the city government and community sides. Unfortunately their efforts were too "top-down" and did not seem to be grounded adequately in the actual needs and interests of neighborhood activists and community organizations or of city bureau staff.

ONI's effort to improve city government public involvement through centralization of community involvement services in ONI was not successful. City bureaus resisted because they wanted to retain control and preferred the status quo. While they were happy to have ONI take over the administrative work of getting access to public involvement consultants, they were not interested in hiring neighborhood coalitions or community organizations to do the work, preferring to go with the consultants they had used in the past. The City Council did not strongly support the policy changes or funding needed to implement many other ASR PI/PI recommendations, such as having ONI review bureau public involvement plans or a centralized effort to increase the quality and consistency of city communications with the community.

A question also arose over the value of centralizing public involvement service delivery in a single agency in city government and encouraging city bureaus to contract out their public involvement needs versus integrating planning for and implementation of public involvement services as an important part of the substantive work of each bureau. 
Another related question that arose is over the extent to which ONI and the neighborhood coalitions should devote energy to competing to provide direct public involvement services to city bureaus versus focusing their staff and resources on their traditional role of community empowerment, capacity building, and supporting what one coalition director described as a "truly activist neighborhood association structure" with a strong focus on developing leadership capacity and helping community members organize and have a voice in local decision making. community activism.

Saltzman's actions and comments seemed to support David Lane's contention that city council members thought that they had "fixes" that would solve the problems they saw with the neighborhood system. Saltzman's actions and comments give the strong impression that he felt that the coalitions needed to be reined in and redirected. His attempts to impose new requirements on the neighborhood coalitions without involving them were unsuccessful. They instead generated opposition in the community and undermined trust in ONI's intentions. Coalitions used their ability to organize and apply political pressure on other city council members to stop Saltzman's proposed changes.

Other city council members, even though they thought the neighborhood system had problems, had little political incentive to support Saltzman's proposals especially when they had no authority over or direct responsibility for ONI or for fixing the problems. Lane said he was frustrated by the fact that "behind close[d] doors, every city commissioner and the Mayor was VERY critical of the coalitions and NA system and had ideas on how to fix it. Yet when each ONI commissioner tried to openly address the issues, the other commissioners' public stance was vastly different." Lane says that 
during his time with ONI, Mayor Katz and her chief of staff Sam Adams (who later successfully ran for a seat on the city council and then served as Portland's mayor from 2008 to 2012) “were notably silent on virtually all ONI initiatives except for budgetwhich they usually cut or questioned." Lane, in reflecting on his time as ONI director, said he wished, "in hindsight, that I had funds to bring in outside review to facilitate an open dialogue about the function and role of ONI" (Lane 2008).

The lack of city council consensus on and support for any particular strategy for improving the system made it difficult to move forward. Four different city commissioners were responsible for ONI during Mayor Katz's twelve years as mayor. Mayor Katz herself did not articulate any particular vision for the system (her annual budget messages rarely mention community involvement and focused more on community members as "customers" of city services rather than active partners in governance). As Katz shifted responsibility for ONI from one city commissioner to another, each commissioner tried to pursue their own strategy for "fixing" the system, usually with little input from the community. ONI staff provided some continuity and pushed from behind the scenes for more funding for the system and for programs like the neighborhood small grants program.

Portland would continue to struggle with how to improve the neighborhood and community involvement system during the early 2000s. However, some very good deeper thinking began to take place on how to reach out to and involve immigrants and refugees and other groups that historically had been underrepresented in Portland 
community and neighborhood involvement and in local decision making and on how to improve city government public involvement.

From 2001 to 2003, ONI and community members would explore better ways to involve immigrants and refugees through the "Interwoven Tapestry" project. Then Southeast Uplift Neighborhood Coalition would take the lead in initiating and supporting a community discussion about how the neighborhood system could do a better job of involving historically underrepresented communities, especially communities of color and immigrant and refugee communities. On the city government side, community members and city staff would support the creation of a new task force to follow up on the ASR PI/PI report and take a much deeper look at how to improve the quality and consistency of city government public involvement - this new group was known as the Public Involvement Task Force (2003-04).

On the political front, rather than working more collaboratively with neighborhood and community leaders and groups, City Commissioner Randy Leonard took responsibility for ONI in January 2002 with an even more aggressive, top down and un-collaborative approach to imposing his ideas for "fixing" ONI and the neighborhood system. Leonard's heavy handed approach would lead to some of the most intense clashes between city government and neighborhood activists in the system's history and make the need to reconnect the community and city government a driving issue in the 2004 mayoral and city council election. 
Communities Beyond Neighborhood Boundaries_-Reaching Beyond Traditional Neighborhood Associations

Many of the reviews of the Portland neighborhood and community involvement system in the 1990s and early 2000s highlighted the need to increase the diversity of people involved in Portland's neighborhood system and to improve city government's outreach to and involvement of a greater diversity of Portlanders. This section describes some of ONI's structural and programmatic efforts to respond to this need-some were effective and others were not. This section also describes two major efforts to increase the involvement of historically underrepresented groups in civic life in Portland: Interwoven Tapestry and Southeast Uplift Neighborhood Coalition's Diversity and Representation Committee and Diversity and Civic Leadership Committee.

Portland Future Focus (PFF) had called for greater community involvement in local governance and civic life and greater recognition of the growing diversity of people living in Portland. PFF particularly called on ONA, neighborhood associations and neighborhood coalitions to do a much better job of reaching out to and involving historically underrepresented groups in Portland.

The first City Budget adopted after PFF (FY 1991-92), for the first time, formally stated that ONA's responsibilities included involving diverse communities. The document stated that "The overall mission of the Office of Neighborhood Associations is to provide advocacy and direct avenues for citizen participation in local government decision-making processes and to promote neighborhood livability through the involvement of citizens in the life of the community." The budget directed ONA to 
increase the "effectiveness of citizen participation in City government" and to "Increase representation of Portland's diverse communities in ONA programs" and to work with neighborhood and community representatives to develop and implement a plan to "enhance cultural diversity in ONA programs" before the end of the fiscal year (Portland. City Budget FY 1991-92 204).

In 1996, the Neighborhood Involvement Task Force (TFNI) again advocated for broader involvement in the neighborhood system and recommended that a strategy be developed to reach out to and involve "communities beyond neighborhood boundaries"communities in which people found their sense of community, not through a connection with the people in their physical neighborhood, but with people with whom they shared cultural ties. The TFNI particularly highlighted the need to reach out to and involve immigrant and refugee communities.

Changes at ONI: The 1996 TFNI task force established a strategic vision for a Portland's community involvement system that built on Portland's traditional geographic neighborhood system but recognized that the system needed to expand to involve people who defined their community through shared identity rather than geography. In the following years, city commissioners and ONI staff attempted to implement some of the TFNI recommendations.

In 1998, the City Council, implemented an TFNI recommendation and changed ONA's name to the "Office of Neighborhood Involvement" (ONI). The City Council justified the change by stating that ONA's "role in coordinating and facilitating citizen 
participation activities extends beyond the basic foundation of the neighborhood association system” (Portland. City Council. Resolution 35667, January 7, 1998).

The City Council, at the same time, adopted the 1998 revision of the ONA Guidelines. The 1998 revision, in addition to updating rules for neighborhood associations and coalitions also included for the first time mechanisms by which "neighborhood business associations and ethnic communities beyond neighborhood boundaries" could be "acknowledged as important aspects of Portland's neighborhood association system..." (Portland. City Council. Resolution 35667, January 7, 1998).

1998 ONA Guidelines-CBNBs: The 1998 ONA Guidelines defined Communities Beyond Neighborhood Boundaries (CBNBs) as: "ethnically based community organizations whose members face unique differences, particularly in the areas of language and cultural adjustment" (Portland. Office of Neighborhood Involvement. Guidelines for Neighborhood Associations..., 1998 2).

The Guidelines offered CBNBs the opportunity to be "acknowledged" formally by ONI if they met the following requirements:

- Be registered as a nonprofit corporation with the State of Oregon;

- Have bylaws that asserted that no "dues or other contributions or fees" were required to be a member of the organization; and

- Be included on the "data/mailing list maintained by the [ONI] Metropolitan Human Rights Center. (MHRC) in coordination with the [ONI] Refugee Coordinator" (Portland. Office of Neighborhood Involvement. Guidelines for Neighborhood Associations..., 1998 18). 
An acknowledged CBNB was to receive the following benefits and services:

- ONI would help the CBNB receive "public notices and mailings from the bureaus of the City of Portland on livability issues, decision-making processes, and policy development....";

- At the CBNB's request, ONI would send the organization "newsletters and neighborhood information from ONI, the district coalitions/neighborhood offices, and from neighborhood associations...."; and

- ONI would "make every attempt to ensure" that a CBNB organization that requested specific land use notices for a specific geographic area would receive them (18).

The Guidelines encouraged CBNB organizations to communicate with neighborhood associations, district neighborhood bodies, and neighborhood business associations on "pertinent matters and issues of mutual interest" and to seek opportunities to discuss taking action on these issues (19). The 1998 Guidelines also required CBNB organizations to "encourage their members to participate directly in appropriate neighborhood business associations," "work with neighborhood associations to facilitate such participation," and encouraged them to seek mediation assistance if disagreements arose between their organizations and any neighborhood associations, district coalitions, business associations, other CBNB's, or other entities (19).

The Guidelines language appears to view CBNBs as though they were "membership organizations" similar to neighborhood associations and business district associations. The requirements and services offered in the Guidelines was similar to that 
offered to neighborhood associations. The primary benefit ONI offered to CBNB organizations was the receipt of mailings and notices from city bureaus and other organizations in the ONI network.

An interesting clue to the degree to which the neighborhood leaders and ONI were committed to CBNB involvement was that the 1998 Guidelines stated that "Delivery of these services and any others that CBNBs may receive are dependent upon the resources available to ONI, the district coalitions, and neighborhood associations"-a requirement that was not applied to services to neighborhood associations (19). The 1998 Guidelines included a similar caveat with regard to services to business associations (17).

1998 ONA Guidelines-Business Associations: The 1998 ONA Guidelines also offered business associations the opportunity to apply for formal acknowledgement. The Guidelines defined "neighborhood business association" as "an organization within a specific geographic area, often along a commercial strip or in an industrial area, which promotes the general well-being of the business community and neighborhoods in that area" (1).

The requirements and benefits for business associations were more similar to those for neighborhood associations than were the requirements for CBNBs. The 1998 Guidelines required acknowledged business associations to be a registered non-profit corporation, open their membership to any business licensee or commercial property owner in their district, clearly define the association's geographic boundaries in the organizations bylaws, not charge dues, not discriminate against individuals or groups, and file its current bylaws with ONI. The 1998 Guidelines also required that the business 
association bylaws include provisions for "adopting and amending bylaws, establishing a quorum, and setting the agenda," establish a formal grievance resolution process, provide for regular meetings, and follow to the same open meeting and open records requirements that applied to neighborhood associations (15-16).

The 1998 ONA Guidelines encouraged business associations to affiliate with the citywide coalition through which the City coordinated its interactions with business associations (i.e., the non-profit Association for Portland Neighborhood Business Associations (APNBA)) and to "attend and participate in" and communicate with the appropriate neighborhood associations, district coalitions, and CBNB organizations in their area. Business associations were encouraged to seek mediation to resolve disagreements with other community organizations in the ONI system (16-17).

The 1998 ONA Guidelines offered acknowledged business associations a higher level of support than that was offered to acknowledged CBNBs. Like the CBNBs, ONI would include acknowledged business associations in the ONI Neighborhood Directory, which many City bureaus used to mail out notices and information on "livability issues" and decision-making and policy processes. Unlike the CBNBs, the 1998 ONA Guidelines also offered additional support to business associations, including "assistance with general communications, newsletter production and distribution, activity planning, public relations, and general information and referral, with the caveat that ONI only would provide these services if resources were available (17).

Hoop remembers that when David Lane first hired him to work at ONI in 2000, Lane asked him to look into the CBNB issue and see what could be done to move it along 
(Hoop, May 29 2013). In the fall of 2002, Hoop and the committee preparing the next revision of the ONI Guidelines (known as the GREAT Committee (Guidelines Review, Empowerment, and Assessment Taskforce) reviewed the impact of the CBNB acknowledgement provisions in the 1998 ONA Guidelines. They found that no community organizations eligible for CBNB status had applied to ONI for formal acknowledgement.

The GREAT Committee members asked Hoop to reach out to nearly 100 organizations representing communities-of-color and immigrant and refugee groups to raise awareness of and ask for their assessment of the value of this opportunity. ${ }^{54}$ After distributing a survey and directly contacting many of the organizations, Hoop reported back that these organizations were not interested in what ONI was offering-primarily inclusion on the formal on list of community organizations and public notices from city bureaus. Hoop concluded that "there is a growing clarity that the CBNB policy is an ineffectual and insignificant opportunity for expanding public involvement for communities of color." Hoop found that what these organizations did want was to hold "City bureaus accountable to incorporating outreach to people of color in their public involvement strategies" (Portland. Office of Neighborhood Involvement. Interwoven Tapestry Project Monthly Update. December 2002). and funding support from ONIsimilar to the City's funding support for neighborhood coalitions and neighborhood associations (Hoop. Conversation with Leistner. May 29, 2013).

\footnotetext{
${ }^{54}$ The requirements in the 1998 ONA Guidelines really did not fit most of these organizations. Many were more likely to be community advocacy groups and/or groups that provided services to members of the ethnic community they served, rather than "membership" organizations like neighborhood associations.
} 
Members of the Southeast Uplift Diversity and Representation Committee (DRC) (described in more detail below) offered a number of suggestions for language to strengthen the relationship with and opportunities for CBNBs. According to Brian Hoop, the co-chairs of the GREAT Committee did not have a strong interest in or strongly support addressing CBNB's in the ONI Guidelines. Moshe Lenske, one of the co-chairs, talked with the DRC members at one of their meetings in June 2003. He discussed a number of challenges GREAT Committee members had in trying to formalize roles and responsibilities for CBNBs in the ONI Guidelines when no program yet had been established to define the relationship between ONI and the CBNBs, especially given that no CBNB had applied for the formal acknowledgement the 1998 ONA Guidelines offered them.

Ultimately, the GREAT Committee dropped the references to CBNB's from the ONI Guidelines 2005 and instead included language that directed ONI and the neighborhood coalitions to develop action plans to reach out to and involve individual and organizations from under-represented communities.

Business associations also showed little interest in formal acknowledgement by ONI. ${ }^{55}$ Similar to the CBNB's, no business associations ever applied for the ONI acknowledgement offered in 1998 ONI Guidelines. Business associations did not want to have to comply with the ONI requirements (e.g. no dues, open meetings, etc.). They were more interested in advocating with the City for the interests of their local businesses than

\footnotetext{
${ }^{55}$ It's interesting to note that the lack of interest by business association in a relationship with ONI was predicted in 1992 by the two business association focus group participants in Margaret Strachan's report. They had said that business associations thought PDC was a better fit to support business associations.
} 
being part of a broader city-wide community involvement network. Business associations continued to organize through the APNBA and to advocate for additional City funding support. ONI ended up including business associations in the ONI Directory anyway, which allowed them to receive formal notices from city bureaus. The City continued to provide some financial support to the APNBA to support business associations but did so outside the ONI network. ${ }^{56}$

ONI's effort to expand Portland's neighborhood and community involvement system by offering formal acknowledgment to CBNBs and business associations was not successful. No eligible CBNB or business association ever asked to be acknowledged by ONI. Hoop later remembered that neither Mayor Katz nor the other city council members saw engaging CBNBs as a priority. As a result, the committee that reviewed and revised the 1998 ONI Guidelines dropped the CBNB language from the 2005 version of the ONI Standards (Hoop May 29, 2013). The GREAT committee instead included language directing ONI and the neighborhood coalitions to make an effort to reach out to and include a greater diversity of community members. Also, no business association ever applied for formal acknowledgement from ONI. In 2013, as ONI prepares for the next review and update of the ONI Standards, one of the items up for discussion is dropping the business association section that remains in the 2005 ONI Standards.

ONI MHRC and Refugee Coordinator: The 1998 ONI Guidelines required potential CBNB's to be included in the list of organizations maintained by the ONI

\footnotetext{
${ }^{56}$ Under Mayor Sam Adams (2008 to 2012), the City continued to support business associations through the Portland Development Commission which provided financial support to the APNBA (later called Venture Portland), including a significant small grants program that supported individual business association projects.
} 
MHRC and the Refugee Coordinator. Both of these ONI programs already were providing some support and assistance to a wide range of diverse communities and historically under represented communities.

The Refugee/Immigrant Coordinator position at ONI was created in 1980 to "serve the growing refugee and immigrant communities in Portland." For many years, it was part of ONI's Crime Prevention Program and focused on "resolving crime problems involving members of the refugee community" (Portland. City Budget FY 1989-99 168). The FY 99-00 City Budget document identified the position as assisting "Portland's 24 refugee and immigrant communities in their resettlement efforts," and provided "City officials and staff improved access to and understanding of the different communities and individuals" (Portland. City Budget FY 1999-00 502). In the early 2000s, the position was included under the organizational umbrella of the MHRC.

The roots of the MHRC were established in 1950 when "the City of Portland formed the Portland Inter-Group Relations Commission to advise the Mayor on multicultural relations. In 1969, Multnomah County joined Portland, and the Metropolitan Human Relations Commission was created." While the name of the MHRC changed over time (from a "commission" to a "center"), the city-county partnership continued, and the basic mission remained the same: "To foster mutual understanding and respect and to protect the human rights of all persons...regardless of socio-economic status, religion, ethnicity, race, national origin, disability, age, gender, and sexual orientation." In 1979, the Disability Project was added to the MHRC (Portland. City Budget FY 1999-00 504). 
In 1989, the City Council transferred the MHRC and two other entities from the City’s Human Resources Bureau to ONI (the other two were the Metropolitan Youth Commission and the City/County Commission on Aging). The FY 89-99 City Budget justified the move by saying that "The youth, aging and human rights constituencies are a natural complement to the neighborhood network in that they serve as a vehicle for citizen participation and advocacy on social issues of concern to neighborhoods. The agendas of both programs will be enhanced by integration into one bureau. The agendas of both programs will be enhanced by integration into one bureau" (Portland. City Budget FY 1989-90 134).

The FY 91-92 City Budget identified the purpose of the Metropolitan Human Relations Commission as providing "resources for evaluating public programs for nondiscrimination and to promote equal opportunity. The program handles complaints on civil and human rights, facilitates mediation and provides education for the development of improved intergroup relations" and researched "issues of discrimination," disseminated information to the public" and provide advocacy and information and referral support (Portland. City Budget FY 1991-92 204).

Ten years later, the FY 01-02 City Budget described the purpose of the Metropolitan Human Rights Center (MHRC) as reaching out to:

both individuals as they confront their own human rights problems and the community at large as it faces overriding human rights issues. The MHRC maintains a broad base of information and has established a strong capacity to listen to civil rights complaints and troubleshoot the process. The MHRC Disability Project has been a prime mover toward universal access in the city and county for people with disabilities. Likewise, MHRC's free Anti-Bias Training Program, Dynamic Differences, and its Community Dialogues on Race Relations, 
foster a climate of mutual understanding and respect for all members of the community (399).

The same budget document described the Refugee/Immigrant Coordination program as working "to coordinate the information and service needs of Portland's refugee and immigrant communities. Working with organizations as well as individuals, the Refugee and Immigrant Coordinator helps these communities work with law enforcement and other agencies to effectively provide services and resolve problems" (400).

However, the MHRC and Refugee Coordinator positions were on their way out. The FY 03-04 City Budget, eliminated the Refugee and Immigrant Coordinator position (403), and the following year, the City Council effectively eliminated the MHRC "after three years of budget cuts by both the City and Multnomah County.” The MHRC nominally was combined with ONI's Citizen Participation program, which primarily supported the neighborhood system, to create a new Neighborhood Resource Center. The budget document states that "While NRC will retain some human rights-related information and referral and ADA (Americans with Disabilities Act) functions, it will mainly focus on providing support and technical assistance to Portland's neighborhood system" (Portland. City Budget FY 2003-04 410). The MHRC manager, Amalia Alarcón de Morris, became the manager of the new Neighborhood Resource Center, which primarily provided support to the Portland's neighborhood association system.

While the MHRC and Refugee Coordinator provided some services to communities of color and immigrants and refugees, these programs did not focus on 
bringing these groups formally into Portland's neighborhood and community involvement system as envisioned in the TFNI.

In the years after the TFNI report was released, ONI staff worked on and advocated for structure and program changes to better serve historically-underrepresented communities. These efforts were not a priority for Mayor Katz or other city council members. In fact, a number of programs and structures originally intended to engage a greater diversity of people and perspectives in the community were eliminated. The CBNB language in the ONA Guidelines was dropped and the MHRC and Refugee Coordinator programs were discontinued. ${ }^{57}$ The City Council also shifted the Youth Commission out of ONI to Multnomah County and dissolved both the Disabilities Commission and Human Rights Commission. ${ }^{58}$

One initiative that did make a difference was ONI's involvement in the Interwoven Tapestry Project. This three-year project helped lay the foundation that finally led to the formal inclusion and funding of communities of color and immigrant and refugee organizations within the ONI structure.

Interwoven Tapestry: From 2001-2003, ONI's MHRC partnered with the Immigrant and Refugee Community Organization (IRCO) to administer and support an innovative project called "Interwoven Tapestry." The project was intended to help

\footnotetext{
${ }^{57}$ In 2003, the Diversity and Accessibility Workgroup of the City of Portland Public Involvement Task Force noted that City bureaus and ONI had had "minimal success in engaging diverse constituencies traditionally not engaged in City public involvement efforts" and that the defunding of the MHRC led to the loss of a "key resource in the City's ability to build relationships with diverse community leadership and organizations." (Portland. Public Involvement Task Force. Accessibility Workgroup Priority Recommendations November 17, 2003.)

${ }^{58}$ Mayor Tom Potter a few years later would reestablish the Disabilities Commission and the Human Rights Commission. He also created a new Human Relations Office that took up many of the training and awareness raising activities of the MHRC.
} 
immigrants and refugees in Portland and local neighborhood associations learn about each other and facilitate immigrants and refugees becoming more involved in local civic life. ${ }^{59}$.

Interwoven Tapestry was part of a national project lead by the National Conference of State Legislatures (NCSL) and funded primarily by the U.S. Office of Refugee Resettlement called "Building the New American Community" (BNAC). The project sought to explore ways in which "governments and civil society can co-operate to achieve positive integration outcomes." The project focused on building relationships between local organizations and institutions that worked with immigrants and refugees and "receiving communities" to "capitalize on existing resources and opportunities, as well as to foster two-way integration" (Migration Policy Institute. Building the New American Community. Executive Summary 2004 1).

Four principles guided the BNAC initiative's concept of successful integration:"

1. "New Americans should be involved significantly in decision-making processes."

2. "Integration is a two-way process that implicates and benefits both new Americans and receiving community members."

3. Coalitions are among the vehicles that can foster effective and meaningful collaborations in order to tackle the numerous challenges and opportunities associated with socio-economic, cultural and demographic change. These involve public-private partnerships that reach across levels of government and

\footnotetext{
${ }^{59}$ The Portland City Council authorized ONI's participation in the Interwoven Tapestry project through its adoption of Ordinance 176247 on February 6, 2002.
} 
include a broad array of non-governmental organizations, as well as institutions and individuals from many different segments of society;" and

4. "Resources should be devoted to integration-focused interventions, as well as coalition building and training opportunities, which lead to systemic change“ [emphasis in original] (Migration Policy Institute. Building the New American Community. Executive Summary. 2004 1).

Initially, both the ONI MHRC and IRCO independently submitted proposals for funding under this grant. NCSL responded that, while both proposals had value, NCSL only would consider funding one project in Portland and encouraged MHRC and IRCO to join forces on the project—which they did. They called their project "Interwoven Tapestry" ${ }^{60}$ (Alarcón de Morris. Conversation with Leistner. June 3 2013). Ultimately, the NCSL chose to fund projects in three cities: Portland, Oregon; Lowell, Massachusetts; and Nashville, Tennessee (Migration Policy Institute. Building the New American Community. [no date]. Web.

$\langle$ http://www.migrationpolicy.org/news/BNAC_REPT_SUM.pdf $>$. Downloaded on May $28,2013)$.

NCSL required each project to assemble a coalition of partner organizations that would develop and implement a plan for the project. ONI MHRC and IRCO led the coalition of organizations for Portland. The coalition partners represented an array of immigrant and refugee organizations and neighborhood groups including: three neighborhood coalitions (Central Northeast Neighbors, Northeast Coalition of

\footnotetext{
${ }^{60}$ Charles Shi had used a similar term for one of his proposals to serve "communities beyond neighborhood boundaries" during the 1995-1996 TFNI process.
} 
Neighborhoods, and Southeast Uplift Neighborhood Coalition), immigrant and refugee community organizations focused on particular cultural groups (African Refugee and Immigrant network of Oregon (ARINO), Asian Pacific American Network of Oregon (APANO), Latino Network, and Russian Oregon Social Services), and organizations with a broader focus (ONI, Oregon State Refugee Program, Portland Public Schools/ESLBilingual Program, Refugee/Immigrant Consortium of Oregon and Southwest Washington).

Interwoven Tapestry brought together leaders of immigrant and refugee organizations with a strong interest in helping their communities have a greater voice and role in local decision making and civic life and neighborhood coalition leaders and staff interested in building bridges between neighborhood associations and immigrants and refugees who lived in their areas. These individuals met regularly during the course of the project. Together, they conducted a needs assessment and developed an overall strategy and work plan for the project.

Some of the challenges the group identified early on in the process included:

- "Distinguishing between newly-arrived and established immigrant/refugee communities"

- "Distinguishing the various assets/needs of each community"

- "Lack of information about population and demographics"

- "Honoring diversity vs. homogenization"

- "Working with cultural differences (i.e. nuances, gender roles, communication styles, etc.)" 
- "Current outreach strategies do not include all immigrant/refugee communities"

- "Current outreach strategies do not acknowledge existing leadership within immigrant/refugee communities"

- "Not enough participation/representation of diverse communities at all levels"

- "Not enough culturally-specific, culturally-appropriate, culturally-relevant activities"

- [lack of] "Representation in mainstream media" (Portland. Project Interwoven Tapestry. Receiving Community Retreat, Saturday, August 25, 2001, "Tapestry Community Group Recommenations.doc" [saved September 17, 2001]).

The Interwoven Tapestry Advisory Committee members designed and implemented many different actions, events and products to respond to these challenges. Some of the primary activities and products included:

Needs Assessment and Strategic Plan: The Interwoven Tapestry Advisory Committee members worked together to assess the needs in the community and to establish the goals and workplan for the project. They also reviewed what was working and was not and made adjustments to the workplan during the process.

Workshops for emerging immigrant and refugee leaders: The Interwoven Tapestry Advisory Committee designed and hosted a series of workshops for community leaders and members from the immigrant and refugee communities represented by the coalition partners. The workshops helped create "a space for developing a shared analysis 
specific to the challenges facing our communities." Interwoven Tapestry Advisory Committee members based the workshop design on the "popular education model, which encourages participants to work with their own knowledge and experience to develop strategies to improve their situations" (Portland. Project Interwoven Tapestry. Accomplishments 2001-2003,"“Accomplishments 4.10.03.doc” [saved on April 22, 2003]).

Workshops for neighborhood leaders and activists: The Interwoven Tapestry Advisory Committee developed a series of workshop for the "receiving community"targeted primarily at neighborhood association leaders and volunteers. These workshops were "intended to promote awareness of immigrant and refugee issues" and to "improve the readiness of the mainstream community in their struggle to improve immigrant and refugee integration." The workshop topics included: "Immigrant and Refugee Cultural Overview," "Shifting Neighborhood Demographics," "Racism," and "Outreach Strategies to New Neighbors." The workshops were well attended. Participants included "neighborhood activists and mainstream service providers seeking cultural competency training and ways to connect to immigrants in their neighborhoods" (Portland. Project Interwoven Tapestry. Accomplishments 2001-2003 2003).

Conference: In September 2002 Interwoven Tapestry hosted a one-day community conference called "Our Community, Our Voice: Making Change Happen." Over 200 people came to discuss "how immigrant, refugee, and mainstream communities can improve integration through education, advocacy, and policy analysis." Specific discussion topics included: "New federal policies, citizenship, utilizing the media, 
popular education, media literacy, voter education, leadership development, parent involvement, oral history and a three part workshop series targeted to mainstream [e.g. neighborhood association] groups" (Portland. Project Interwoven Tapestry. Accomplishments 2001-2003).

Small Grants Program: The purpose of the small grants program was to "foster integration by funding projects that encourage civic participation and community engagement between refugee and newcomer communities." A project summary stated that "These small grants brought groups of people together [and] built relationships between groups that that haven't existed before. The small grants projects supported understanding and collaboration between New Americans and the main stream through events and projects." "The 2002 grant cycle funded 6 projects for a total of $\$ 11,000$." The 2003 grant cycle gave out $\$ 11,350$ in competitive grants to ten projects and $\$ 10,000$ for one non-competitive project (Portland. Project Interwoven Tapestry. Accomplishments 2001-2003). Some examples of grant projects include "a community garden, a forum with state legislators and participation in local business district and transportation plans" (Migration Policy Institute. Press Release. December 9, 2004).

Other Interwoven Tapestry achievements and products included:

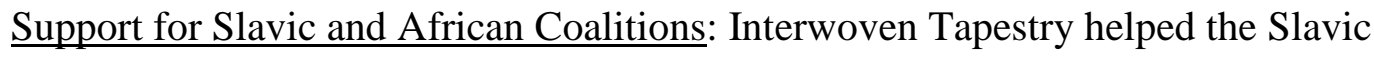
and African communities, which had not been well organized before, become better organized. Interwoven Tapestry supported the coordinators of these groups in their leadership roles and helped organize "events, trainings and meetings for the coalitions...." An Interwoven Tapestry summary document stated that this "support to the 
African and Slavic coalitions has been critical to their development" and increased the self sufficiency of each coalition (Portland. Project Interwoven Tapestry. Accomplishments 2001-2003).

Directory of Immigrant and Refugee resources: ONI staff helped develop a resource directory of immigrant and refugee communities for use by neighborhood associations "and other mainstream organizations" to "better understand how to reach and work with immigrant and refugee groups." The directory listed 250 listed community-based organizations for both immigrants and refugees and for communities of color (Portland. Project Interwoven Tapestry. Accomplishments 2001-2003).

Citizen Involvement Handbook: ONI staff led the effort to develop a handbook, "Making Room at the Table" for neighborhood association leaders. This "how-to manual" was intended to help neighborhood association leaders "build relationships with immigrants and refugee groups" and included "information about how to make meetings more culturally appropriate and accessible to immigrants." The handbook drew on materials developed for the September 2002 conference to help the "mainstream community" "build working relationship with diverse racial and cultural groups" (Portland. Project Interwoven Tapestry. Accomplishments 2001-2003).

Interwoven Tapestry also had other positive effects. Members of the organizing committee and ONI staff successfully advocated that the subsequent Public Involvement Task Force (which would examine how to improve overall community involvement by city government) specifically consider how City bureaus could do a better job of reaching out to and involving immigrant and refugee communities. 
Interwoven Tapestry paid special attention to increasing services to and encouraging youth involvement. Project staff and coalition immigrant and refugee leaders reviewed and provided input "on policy development, planning, and implementation" of Multnomah County's "new policy framework” for 'assessing the County's impact on refugee youth. As a result, the County expanded this policy to recognize that African and Slavic youth need "culturally specific services" (Portland. Project Interwoven Tapestry. Accomplishments 2001-2003).

Critics of Portland's neighborhood and community involvement system for many years had said the system needed to do a better job of reaching out to and involving historically underrepresented communities in Portland. The Interwoven Tapestry Project offered interesting insights into what it would take to achieve and sustain this. Rather than just trying to get more people to neighborhood association meetings, Interwoven Tapestry took a much more sophisticated and multi-layered approach.

Interwoven Tapestry strongly focused on bringing together affected and interested parties and to collaboratively assess and define community needs and then develop and implement an action plan designed to meet them. The project raised awareness and built capacity and skills among both immigrant and refugee communities and neighborhood association leaders and activists. Interwoven Tapestry also stressed the importance of building relationships between individuals as a foundation for future progress. The project also pushed resources out into the community through the grant program and gave people a reason and the means to work together. Funding and strong staff support were vital to the project's success. 
Amalia Alarcón de Morris, who led the Interwoven Tapestry Project for the ONI MHRC later reflected on the Interwoven Tapestry project and its longer-term impacts. Alarcón said Interwoven Tapestry helped reveal that before immigrants and refugees can integrate with main stream structures and processes they first need to organize within their own communities; then they need to build relationships and work with other similar groups; and then they can engage much more effectively with mainstream society.

Alarcón said that Interwoven Tapestry helped immigrant and refugee organizations start working together. When Interwoven Tapestry organizers asked a number of different immigrant groups, at the outset of the process, whether they wanted to work together, the groups said "no." Alarcón said the groups had not worked together in the past and did not trust each other. They did not see that they shared common interests. Alarcón said that by the end of the Interwoven Tapestry process, when these same groups were asked if they wanted to work together, they said "Of course!" (Alarcón de Morris. Conversation with Leistner, March 6, 2011).

Alarcón said that at the outset of the project, neither the Slavic nor the African immigrant communities were well organized. Tensions within these communities between people from different countries and cultures sometimes had made coordinated action difficult. Interwoven Tapestry helped the African community come together, whereas earlier attempts to do so had "imploded." She said the African community coalition continued to evolve and went through couple additional major reorganizations over time, and, in 2013, continues to function. By the end of the project, both communities had stronger leadership and organizational structures and improved 
capacity. One positive impact of the Slavic communities improved organization was that "Multnomah County hired people to work with the Slavic community on health issues."

Alarcón said that neighborhood leaders who participated in Interwoven Tapestry learned about the value of working with immigrant and refugee communities and organizations, the priorities of these communities, and how to approach and engage with these groups more effectively. They also developed contacts with leaders in these communities that made it easier to work together in the future.

Many of the people who participated in Interwoven Tapestry went on to work together in other settings. Some served together on the subsequent Public Involvement Task Force. Relationships formed through Interwoven Tapestry also helped spur Southeast Uplift Neighborhood Coalition to carry on the conversation by creating its Diversity and Representation Committee (DRC) and then its citywide Diversity and Civic Leadership Committee (DCLC). This process led to the creation of the ONI Diversity and Civic Leadership program at ONI under Mayor Tom Potter in 2006.

Many organizations involved in Interwoven Tapestry, such as IRCO and Latino Network, helped create and then formally participated in ONI's DCL program. Kayse Jama, who was organizing Somali Youth during his involvement with Interwoven Tapestry, went to work at Southeast Uplift, and then to create the Center for Intercultural Organizing (CIO), which became a formal ONI community organization partner. Individual neighborhood system representatives and staff who participated in Interwoven Tapestry continued to advocate for greater awareness and cooperation between 
neighborhood associations and immigrant and refugee communities for years after the program.

Alarcón said another very important, broader impact of Interwoven Tapestry was that "It opened the door a crack to people accepting that neighborhood associations can't be all things to all people." It opened up the opportunity for neighborhood associations to work with other organizations to reach different groups in the community instead of “neighborhood associations saying give us money and we'll do it.” Alarcón said that Interwoven Tapestry helped neighborhood leaders begin to see the value of specialization and that it's helpful to work with groups that know different communities rather than advocating for additional funding and staffing for neighborhood associations to reach out to these communities on their own.

Alarcón identified other important lessons learned through the Interwoven Tapestry process. She said the project showed the importance of allowing enough time for people to "identify ideas they share...to build relationships... and to develop common messaging." When people first get together they may have many different viewpoints. Given enough time a group can develop shared ideas and goals. She also emphasized the importance of "having the right people on staff" to support a project. These staff people need to have strong community involvement values and need to have the skills and experience to work with diverse communities and to support effective project planning and implementation. Alarcón said support from ONI director Dr. David Lane and ONI's city commissioner, Commissioner Dan Saltzman, also were important. 
It's important to recognize, however, that Interwoven Tapestry did not lead to widespread increases in cultural awareness and skills across among neighborhood association volunteers in Portland's neighborhood associations. These benefits went mostly to individuals who actively participated in the project.

One very important effect of Interwoven Tapestry was the decision by the executive director of Southeast Uplift Neighborhood Coalition (who had participated in Interwoven Tapestry) to create the Southeast Uplift Diversity and Representation Committee (DRC) to continue the effort to help neighborhood associations and immigrant and refugee organizations and communities of color work together better. This effort was ultimately led to the formal inclusion of these groups in Portland's neighborhood and community involvement system under Mayor Tom Potter.

\section{Southeast Uplift Neighborhood Coalition--DRC and DCL}

After Interwoven Tapestry, the initiative to involve historically underrepresented communities in Portland's neighborhood and community involvement system shifted from ONI and the City to the community. Southeast Uplift_-Portland's largest neighborhood district coalition — built on the awareness gained and relationships built through Interwoven Tapestry and initiated a number of projects to increase the involvement of people from underrepresented communities in neighborhood associations and in civic decision making in Portland. Two of these projects were Southeast Uplift's Diversity and Representation Committee (DRC) and Diversity and Civic Leadership Committee (DCLC). 
Elizabeth Kennedy-Wong started working at Southeast Uplift in 1998 and became the organization's executive director in early 2001. She said her awareness of social justice and equity issues and institutional racism was raised when she and other Southeast Uplift staff and some board members participated in community organizing training at the Western States Center. Once she became the executive director at Southeast Uplift, she recognized that she had an ability to respond and "move this agenda forward" (Kennedy-Wong. Elizabeth. Conversation with Leistner, February 17, 2010).

Southeast Uplift had been an organization partner in the Interwoven Tapestry project, and Kennedy-Wong had participated in the project's committee work and events. She began to have individual conversations with many of the immigrant and refugee and community of color leaders she had met through the project. Kennedy-Wong said she wanted to help initiate a process that would be driven by them-not by neighborhood activists — and would attract and sustain their involvement. Her initial goal was "to get more people of color to participate in neighborhood associations." One of the leaders, Rey España, with the Latino Network, told her that many people from communities of color needed to meet separately first and get organized themselves before they would be interested in interacting with traditional neighborhood associations. Kennedy-Wong said she initially thought that was a bad idea, but over time came to see that this was the right strategy. In May 2001, Kennedy-Wong hired a new Southeast Uplift staff person, Amy Dudley. Kennedy-Wong said she was impressed by Dudley's passion for social justice and working with underrepresented groups. Dudley immediately began to work with a 
group of neighborhood activists and representatives of CBNBs that would become the Southeast Uplift Diversity and Representation Committee (DRC).

In fall 2001, Southeast Uplift, sponsored a "Making Room at the Table" workshop, which included a panel and small group discussion that focused on underrepresented communities in Portland (Southeast Uplift. A Brief History of the DRC [no date]). Linda Nettekoven, a long time and very active neighborhood leader, remembers that this workshop for neighborhood activists, presented data from the 2000 U.S. Census and had participants "answer questions about the makeup of our neighborhoods." Nettekoven said "It helped us see trends and understand how little we knew about who live in our communities." Leaders from different communities of color and immigrant and refugee organizations served on a workshop panel and talked with neighborhood activists about "about some of the misunderstandings in neighborhoods among the groups who lived there..." (Nettekoven. Email to Leistner, June 5, 2013). In early 2002, Dudley followed up on "Making Room at the Table" workshop and contacted neighborhood leaders and representatives of community of color and immigrant and refugee organization and invited them to continue the conversation and work they all had begun at the workshop. Nettekoven says she and a few other neighborhood activists started meeting with Dudley to strategize how to carry on this work.

In May 2002, DRC members identified and discussed "assumptions" they held that would frame their participation in the group. Group members shared the following "assumptions:" 
- "Neighborhoods need to be invested and interested and make this a priority. Currently only 3 of 20 Associations are involved on the [DRC]."

- "There must be cultural change of NAs"

- "System is not in place for dialogue or outreach, but is set up for information from the city, request for input and then output from an association"

- "NAs don't know who is in the neighborhood"

- "A lot of education-community has problems but we are not bringing to associations"

- "We (as white people) need to build personal relationships with people of color and that requires an effort when we live and work with only white people"

- "We also need to build relationships with groups and organizations, not just looking for that one person to go to a meeting. Ex. Churches, Urban League, NAACP."

- "SEUL needs to recruit Board members from organizations that work with people of color and immigrant groups" (Southeast Uplift. Diversity and Representation Committee. Meeting Notes June 25, 2002).

DRC members concluded that "Increasing participation and engagement with underrepresented groups in Neighborhood Associations requires issues to be addressed where decisions are made and change can happen. Ideally change should happen on multiple levels, including: Individual—opportunities for training and dialogue designed to increase awareness on the part of current and new Neighborhood Association leaders; 
organizational—analysis of individual Associations and at a Coalition level; and systemic_-accountability of Neighborhood System" (Southeast Uplift. Diversity and Representation Committee. Meeting Notes June 25, 2002).

The DRC members laid out a workplan for their effort that included: asking the Southeast Uplift board of directors to formally designate the DRC as a committee of the SE Uplift board; training and dialogue events and activities "to increase awareness and support skills and leadership development;" "Ongoing research and education efforts regarding neighborhood demographics and community organizations and institutions that facilitate access to underrepresented community members, leaders and partners;" and "Creation of materials that would assist Neighborhood Associations in considering issues of representation and diversity in their self-assessment" (Southeast Uplift. Diversity and Representation Committee. Meeting Notes June 25, 2002).

In June 2002, the Southeast Uplift board voted to establish the group as the Southeast Uplift Diversity and Representation Committee (DRC). The board charged the group to "play a leadership role in the goal of encouraging Neighborhood Associations to explore what it means to be representative of all neighborhood members" (Southeast Uplift. Board of Directors. Minutes June 3, 2002).

During 2002 and 2003, the DRC meet monthly and scheduled a series of "community dialogues" with different underrepresented groups and hosted some major community workshops that showcased and highlighted the issues of different underrepresented communities in Portland. 
One of the DRCs first "community dialogues" was with residents of Dignity Village (Portland's semi-permanent encampment of people who are homeless). This discussion led Southeast Uplift to create the Homelessness Working Group (HWG). The HWG grew into a major awareness raising and advocacy project. Southeast Uplift staffed the HWG, which included active participation from neighborhood associations and neighborhood activists, service providers and advocacy groups who work with people who are homeless, and a number of individuals experiencing homelessness. The HWG focused on "issues regarding homeless people in the inner southeast neighborhoods of Portland" and sought ways to "address the impact of homelessness." The HWG members participated in over one hundred "community conversations" about homelessness with neighborhood groups and other community-based organizations. The conversations usually included participation by a representative of the homeless community. The conversations were intended to raise awareness in the community and identify community-based solutions. The HWG issued its report in August 2004. ${ }^{61}$ The HWG work helped shape the City of Portland subsequent "ten-year plan to end homelessness" (Portland. Citizens Commission on Homelessness. Home Again: A 10-year plan to end homelessness in Portland and Multnomah County December 2004).

DRC members also engaged with other projects and processes. In late June, DRC members participated in the Interwoven Tapestry "receiving community" workshop. They also began to track the work of the committee that was updating the ONI

\footnotetext{
${ }^{61}$ Southeast Uplift Neighborhood Program, Inc. The Homelessness Work Group: Summary Report August 2004.
} 
Guidelines (the GREAT Committee). DRC members advocated for stronger language in the Guidelines on CBNBs and the inclusion of underrepresented communities.

In late September 2002, DRC members hosted an evening event called "Make Your Voice Heard: Understanding the Neighborhood System and How it Can Work for You." The event goals were to "bring together people who are low-income tenants, homeless, immigrants and people of color to talk about organizing in their communities and the role of Neighborhood Associations," to inform the work of the DRC, and to support the DRC's efforts to continue to build relationships and encourage participation in the DRC by low-income tenants, homeless, immigrants and people of color. The twenty-three people who participated included people of color, people with low income, renters, people who were homeless, and people born outside the United States. The participants together represented 17 different community organizations. Participants shared dinner, introduced themselves, and then talked about what it meant to them to be part of a neighborhood (Southeast Uplift. Diversity and Representation Committee. Make Your Voice Heard! Report October 2002).

In January 2003, the DRC members adopted a set of "guiding principles" for their work that grounded the group in a strong commitment to social justice and to working with and honoring the full diversity of people in the community. The DRC's principles established ambitious goals to promote significant changes in Southeast Uplift, neighborhood associations in southeast Portland, and the broader community. The principles described who should be involved, how the committee members would work together, and established criteria for meaningful involvement in decision making in the 
community. The tone set by these principles were a major reason representatives of nonneighborhood association communities believed it was worth their time to participate on the DRC (España. Conversation with Leistner. June 2013)

The DRC's principles stated that the group was to "include as many groups as are represented in our community, particularly groups who have been historically underrepresented in the neighborhood associations of SE Portland." DRC members committed themselves to modeling the kind of inclusive and power sharing principles they hoped to promote throughout the neighborhood system and in other community organizations. They committed to working "toward a membership that is more than $50 \%$ low-income people, people of color, immigrants and refugees, homeless people, and renters..." and to "employ a trusting, collaborative process that supports the leadership of underrepresented community members, namely low-income people, people of color, immigrants and refugees, homeless people and renters and communities who are underrepresented in decision making" (Southeast Uplift. Diversity and Representation Committee. Guiding Principles January 28, 2003).

DRC members sought to ensure that "all people" would be "effectively engaged in the decisions that affect their lives" and maintained that that "should lead to a more just society, not tokenizing individuals or merely changing the makeup of the group at the table."” The DRC Guiding Principles stated that meaningful engagement in these decisions requires that "everyone receive the same information, be notified early in the process and have access to the decision making process." The DRC recognized that institutional factors often lead to both "conscious and unintentional" exclusion of people 
from underrepresented communities from decision making processes while "other people who benefit from institutional advantages are more able to participate and be heard" (Southeast Uplift. Diversity and Representation Committee. Guiding Principles).

The principles set a broad and ambitious goal for the DRC: to serve "as a nucleus and catalyst for change in Neighborhood Associations, Southeast Uplift," "other community groups and the whole community." The group committed to drawing on the wisdom of group members and other organizations to help it advise others on how to improve their outreach in the community, supporting social justice work by other groups, building relationships, friendship, and trust to encourage mutual support, and to taking the initiative to reach out and build relationships. Each DRC member committee also committed to continuing their own personal growth and increasing their "self-awareness of privilege and oppression." (Southeast Uplift. Diversity and Representation Committee. Guiding Principles).

In March 2003, the DRC hosted four leadership development trainings for low income people. Topics included: "Media, “"Public Speaking and Advocacy," "Introduction to Grant Writing," and "Facilitation and Democratic Group Process."

In April 2003, the DRC hosted two Saturday workshops called "Community Dialogues 2003: Livable for Who?" Publicity for the event described the DRC's purpose as the following:

- "Support the leadership, issues and campaigns of immigrants, people of color, low income, and homeless community members and the organizations they support." 
- "Affirm that immigrants, people of color, low income and homeless people are members of the community that Neighborhood Associations represent."

- "Educate, build understanding and relationships between Neighborhood Association members and traditionally underrepresented community members."

- "Create actions of solidarity that support immigrants, people of color, low income, and homeless people and build relationships with Neighborhood Association allies."

The workshops included a wide array of presentations by individuals and community-based organizations that represented people who are homeless, people with disabilities, day laborers, affordable housing and renter's rights advocates, environmental justice, many different immigrant and refugee groups, including a presentation by IRCO on Project Interwoven Tapestry, and presentations from the African Community Center of Oregon, the Latin American Asia Pacific Youth program of the American Friends Service Committee, the Asian Pacific American Network of Oregon. Portland Impact led a discussion on youth issues, and Elders in Action discussed the "unique needs of the neighborhood's growing aging population."

In February 2004, Southeast Uplift and the DRC hosted "a daylong series of discussions...aimed at getting underrepresented groups more involved in the neighborhoods" called "Building Representative Community Agendas (Chuang. Oregonian. 17 February 2004). Dudley said the event would bring together the immigrant and refugee, low-income and homeless communities with neighborhood association 
activists." Dudley described the DRC as a "cross-class, cross-race and cross-perspective committee" that sought to "reach more people who aren't involved in their neighborhoods already."

The topics of the panel discussions and group dialogues included "Local Democracy," "Immigration and Community Organizing," "Introduction to Neighborhood Democracy: Your Neighborhood Association," "Reaching Out for Leadership and Representation," "Transportation and Environmental Justice: How Long Can I Drive and Breathe?" and "Community Policing and Police Accountability." Presenters included community activists and representatives of community-based groups, the ONI director and ONI staff, and DRC members.

DRC policy proposal: In addition to planning and hosting leadership training and skill building activities, the DRC members also attempted to develop policy and program proposals and to influence other policy development processes. DRC members, led by Rey España, developed a proposal for leadership training and funding to support community projects that bring neighborhood associations and other community groups together. DRC members also tracked and submitted comments and recommendations to the GREAT Committee that was updating the ONI Guidelines and to the Public Involvement Task Force, which had been charged to developed consistent guidelines for public involvement by city government.

In September 2003, DRC member Rey España, submitted a memo to DRC members in which he proposed that the DRC develop and advocate for funding for and 
implementation of a community outreach and capacity building project. ${ }^{62}$ By October 2003, DRC members had adopted España's proposal and forwarded it on to the Southeast Uplift Board.

España grounded his proposal in two principles. He asserted that the project should "Promote active and representative citizen participation so that community members can meaningfully influence decisions that affect their lives;" and "Actively work to increase leadership capacity (skills, confidence, and aspirations) in the community. The overall goal of the project would be to develop "neighborhood capacity to directly involve residents in efforts intended to influence the systems and or institutions, policies, or practices that impact their neighborhood or community." The program also would seek "broader participation of targeted communities in the current neighborhood association system." The objectives of the project would be to help residents get the information they needed, help them learn about and understand the various system in the community that affected their lives, and to review and improve channels of communication for neighborhood association to help them be more inclusive and responsive to the needs and concerns of target communities.

España suggested three strategies for the project. The first was to support for communities to learn about community building. España wanted people to know that anybody can get involved and make a difference - the first steps are the desire to take action and to get more information. The second was to support communities in learning about themselves. España emphasized the importance of building relationships and

\footnotetext{
${ }^{62}$ España's proposal marked the beginning of discussions that, a few years later, would lead ONI to establish a formal, ongoing program to support leadership develop and community organizing among communities of color and immigrant and refugee communities.
} 
"social capital" in a community and building momentum for change by helping people recognize their successes and sharing innovations, experiences, and learning with others. The third, was to help communities learn about opportunities to effect change. España argued that essential to any strategy for change is the need to build the ability and skills of community members to "monitor, research accurately and effectively (to gather and analyze data) on targeted government or private sector institutions, policies, or practices...."

España initially suggested that Southeast Uplift would lead the project and provide funding and staff support. He suggested a one-year pilot and suggested that the project would need about $\$ 6,000$ to $\$ 8,000$ for "trainings, newsletters, mailings, meeting support" and other expenses (Southeast Uplift. Diversity and Representation Committee. Proposal for Community Outreach 8 October 2003).

DRC members shared España's proposal with the Southeast Uplift board and other neighborhood and community organizations. The proposal later would be taken up by a new city-wide advocacy group set up by Southeast Uplift in early 2004-the Diversity and Civic Leadership Committee (DCLC).

DRC Input to the ONI Guidelines Review: DRC members also advocated for the inclusion of strong language supporting CBNBs in the ONI Guidelines. DRC members periodically attended meetings of the GREAT Committee subcommittee that was working on the CBNBs issue and received progress reports from GREAT Committee members and Brian Hoop from ONI who was staffing the GREAT Committee. 
Moshe Lenske, co-chair of the GREAT committee and a board member of the SE Uplift board, came to a DRC meeting in June 2003 and described what he saw as some of the challenges the GREAT subcommittee on CBNBs was facing. Lenske said GREAT Committee members were finding it challenging to draft "useful and appropriate language to describe the roles, responsibilities and mechanisms" for involving these groups and organizations. He said some key questions needed to be answered: "What does term 'representation' mean? How should 'underrepresented' be defined? Do these groups currently participate in City processes and if so, how? Where should language about such groups and about business groups be incorporated within the Guideline language?" He noted that the 1998 ONA Guidelines made support for CBNB organizations contingent on funding being available for this purpose. Lenske asked what the mechanism would be to get these groups more funding when the City budget already was not adequately funding the needs of the established neighborhood association system. He also said ONI's existing system was built on relationships with "groups and not individuals." Lenske asked "Can any individual form a group and gain access to City information/support?" He noted that no CBNB group had applied for acknowledgement from ONI, and asked "What part of the system should handle immigrants and refugees?" (Southeast Uplift. Diversity and Representation Committee. Meeting Notes June 24, 2003).

In October 2003, DRC members sent a formal memo to the GREAT Committee subcommittee on CBNBs with a number of suggestions. They said they felt it was important to "list the types of groups that are traditionally underrepresented in 
neighborhood decision making" to "remind ourselves of those who are often not involved in the neighborhood system" (1).

DRC members also argued that assistance to "neighborhood associations in reaching out to and including all the groups that are represented within their communities" should not be "seen as an optional activity to be taken on only when funding is available." (They were referring to the language in the 1998 Guidelines that said services related to CBNBs were to be provided "subject to the availability of resources.") They explained that elected officials and city staff often dismissed the "recommendations and concerns of neighborhoods by characterizing neighborhood associations as elitist or not representative." They argued that services to support inclusion of CBNBs and underrepresented communities should be at the same level of priority as other ONI services.

DRC members stated their belief that "all people should be effectively engaged in the decisions that affect their lives." They said this requires "that everyone receive the same information, be notified early in the process and have access to the decision making process." They argued that participation by the diversity of the community in neighborhood associations should be of a depth and quality that would "lead to a more just society not merely to the tokenizing of individuals or [merely] to a change in the makeup of the group 'at the table.'

DRC members suggested that language be included in the ONI Guidelines that would: 
- "Maintain an ongoing awareness of the demographic makeup of our neighborhoods and the larger community."

- "Strive to avoid being closed or exclusive by continually engaging in outreach to all groups represented within our communities."

- "Employ processes designed to develop trust and collaboration in order to support the leadership of underrepresented community members."

- "Seek the input of those who are not at the table by always asking, "Are there others affected by these decisions that need to be included in this decision making?"

- "Work to adequately answer that question by maintaining links with other community groups that will help us to understand and access the perspectives of underrepresented communities."

- "Share power within our neighborhood associations as a model for power sharing throughout our community."

- $\quad$ Consider different models for how people might be engaged in neighborhood decision making."

- "Gather and create information about how to make the process open and accessible to all who are part of our neighborhoods" (Southeast Uplift. Diversity and Representation Committee. Memo to GREAT Committee on Communities Beyond Neighborhood Boundaries, October 10, 2003). Ultimately, the new ONI Standards (2005) dropped the language allowing CBNBs to apply formal acknowledgement. Instead, language was included—under the 
heading "inclusion and participation"- that stated the system's interest in responding to the "need for participation and inclusiveness in Neighborhood Associations" and in increased involvement by "Portland's diverse communities." The new ONI Standards also directed neighborhood coalitions and ONI to develop action plans to support this increased involvement.

The ONI Standards (2005) defined “diverse communities" as including "communities of people of color, renters and low-income individuals, working families with children, immigrants and refugees, seniors, students, young adults, people with disabilities, gay, lesbian, bi-sexual and trans-gendered people."

The ONI Standards (2005) required both neighborhood coalitions and ONI to include action steps in their required annual workplans to support increased involvement by “diverse communities." The ONI Standards required neighborhood coalitions to include action steps to:

- Reach out to and build partnerships, a sense of community, and trust with "diverse communities and organizations."

- Help NAs increase their "effectiveness in recruiting, training, and retaining volunteers and leadership from diverse constituencies" and encouraging their participation in neighborhood activities.

- Help NAs make their meetings and communications more accessible and inviting through the use of culturally appropriate strategies, translation, interpretation, childcare, transportation, and accessible meeting locations. 
- Encourage business and BDA representatives to participate on district coalition and neighborhood association boards and in the activities of these organizations (Portland. Office of Neighborhood Involvement. Standards for Neighborhood Associations 2005 16-17).

The ONI Standards (2005) required ONI to develop and adopt action steps to support the district coalitions by:

- Providing technical assistance, including neighborhood demographic data.

- Supporting the development of partnerships with diverse community and organizations, including the development of a database of community organizations.

- Assisting coalitions in their effort to help NAs recruit, train, and retain volunteer leadership from diverse constituencies and encouraging their participate in neighborhood activities.

- Providing resources and assistance to help coalitions assist neighborhood association make their meetings and communications more accessible (Portland. Office of Neighborhood Involvement. Standards for Neighborhood Associations 2005 26-27).

DRC Input to the Public Involvement Task Force: DRC members also tracked the progress of the City's Public Involvement Task Force (PITF). The PITF was developing guidelines and standards for city government public involvement. DRC members advocated for the PITF to follow the a similar representation and coproduction/collaboration approach used by Interwoven Tapestry. DRC members 
recognized that city government public involvement was hampered by a "cultural gap" that caused city bureaus not to understand the cultural perspectives and day-to-day realities of people in historically underrepresented communities. Many people in these communities were not used to dealing with big bureaucracies, and were more used to working with people they know and in smaller social and community systems. City government really did not have any mechanisms to find out what underrepresented groups are concerned about, or have need for, or dream about. Also, language could be a barrier at times (Southeast Uplift. Diversity and Representation Committee. Meeting Notes, August 26, 2003).

The PITF Diversity and Accessibility Workgroup developed a recommendation that incorporated and responded to many of the DRC comments ("Recommendation 2: Initiate popular education and training on how City processes work and advocacy skills for diverse constituencies").

The PITF Workgroup found that "Many individuals from diverse constituency groups are generally unaware of how to work with the City's processes and how to advocate for their issues." The City also was not connecting with diverse community organizations and community leaders who could assist City staff in reaching these communities. The PITF Workgroup found that ONI and "most city bureaus have had minimal success in engaging diverse constituencies traditionally not engaged in City public involvement efforts."

PITF Workgroup members recognized that elected officials and bureau management consistently have "identified lack of diverse participation in public 
involvement efforts as a significant shortcoming of City bureau public involvement programs." Group members suggested that city bureau that partnered with community organizations could help build capacity in the community to get involved. They also found that diverse community organizations, like neighborhood associations, need training to build leadership skills, and that this type of training is a high priority with community leaders of color. Leadership training for underrepresented communities could be coordinated with similar neighborhood association trainings. Workgroup members recognized that more leadership training will require more resources-ONI and most neighborhood coalitions had not had the resources to meet the existing support needs of the traditional neighborhood association system.

Workgroup members recommended that leadership training programs be open to the public. Trainings should use culturally appropriate training models, such as popular education. Topics for the trainings could include "training on how the city operates" and on "City decision-making processes" as well as leadership skills such as parliamentary procedures, organizational development, conflict resolution, how to research an issue, public speaking, and basic land use concepts.

The PITF Workgroup set specific objectives for this recommended training, including the development of partnerships between "culturally-specific community-based organizations" and between the City of Portland and other local agencies that need to reach out to and involve "diverse constituency groups;" culturally-specific leadership trainings; and the development of leadership skills and organizational capacity in 
culturally-specific organizations that would allow them to "provide outreach services to City bureaus" through City contracts.

The PITF Workgroup members also recommended the ongoing funding to “culturally appropriate organizations serving African-American, Latino, American Indian, Asian American, and immigrant/refugee communities," and support for "culturally appropriate skills training for youth [and] people with low-incomes in City public involvement processes."

Rey España-Seeding Change on the Southeast Uplift DRC:_A number of people mentioned the key role Rey España played in shaping the thinking and direction of the DRC and DCLC and the policy and program proposals these groups developed. España's recollected his involvement the DRC and DCLC as follows (España. Conversation with Leistner. June 22, 2013).

España moved to Portland from California in 1990. He had worked with City of Santa Monica and had become familiar with that city's neighborhood system. In Portland, España was hired by Jim McConnell with Multnomah County to do community development and community organizing work within the county's Aging and Disability Services program. Rey later did similar work in other units of county government until $2003^{63}$. During his involvement with the DRC, in addition to working with the county, España was helping to organize the Latino Network in Portland.

España said his experience with neighborhood associations in Santa Monica gave him the idea of trying to work with the neighborhood system in Portland. España

\footnotetext{
${ }^{63}$ España now works as a community development staff person with the Native American Youth and Family Center (NAYA), one of ONI's long-term DCL partner organizations.
} 
discovered that Portland's neighborhood system had a strong history of positive achievements but that it did not engage or represent everyone in the community. The system focused primarily on the traditional system of geographic-based neighborhood associations. España said that people of color he talked with said the system was not responsive to their needs or cultures. España said he believed the neighborhood system needed to grow beyond its traditional roots.

España said he strongly believes in "neighborhood and community based solutions" for people of color, especially those who did not have a lot of resources to help them be engaged and that it is important to align resources to create opportunities for self-empowerment. He said his focus went beyond "participation" and "tokenism" and centered on developing a process to support neighborhood and community engagement through leadership training, skill building, empowerment, advocacy, and preparing people for meaningful roles on boards and decision making bodies.

España said that while Portland had a fairly progressive culture, when it came to substantive policy initiatives and commitment of resources, leaders and decision makers would "tighten up," resist changes, and would "water down" efforts to expand and diversify involvement. España said if he heard people talking about "inclusion" he would say "show me" what you're doing to make it happen. He argued that people needed to "be intentional" and think about how to "operationalize" these efforts. People must "commit resources" and ensure that programs are "not underfunded." These efforts must provide a good "return on investment" and result in "authentic and meaningful engagement." 
España said he learned about Southeast Uplift through his boss at Multnomah County, Jim McConnell, and through Steve Rudman, who managed the community develop program for the City of Portland (Rudman previously had been the executive director at Southeast Uplift).

España read up on Southeast Uplift. He found that the organization had a very open philosophy about representation and engagement and was sincere and genuinely interested in greater inclusion. España said Southeast Uplift was unique in Portland's neighborhood system. He recognized that the organization was "swimming upstream" against the general current of the neighborhood system, which generally was resistant to expanding inclusion. España said Southeast Uplift was willing to challenge and push against this current.

España said he saw an opportunity to improve involvement opportunities and capacity in communities of color by working with Southeast Uplift. "If I could get the neighborhood system to be supportive," together we could influence policy for people of color and "disenfranchised communities" and engage them in creating better policies. By working with allies, such as neighborhood association activists, España said these communities could make better strides in addressing the disparities between their communities and the majority community "that we've all seen in Portland."

España said the early 2000s were interesting times in Portland. Many Portlanders were starting to recognize the growing diversity of people living in Portland, a view supported by data from the recent 2000 U.S. Census. Some neighborhood leaders were starting to understand that traditional neighborhood associations were not working for 
everyone. Also tensions were running high between communities of color and Portland Police. The 2001 shooting by Portland Police of day laborer Jose Mejia Poot in a mental health facility was one in a number of incidents that exacerbated tensions between communities of color and Portland city government.

España said he saw an opportunity, through the DRC, to get the neighborhood system to acknowledge that the traditional approaches were not working for many people and to shift priorities and make a real effort to listen to and engage with people who had been left out.

España remembers that the individuals involved in the DRC played a major role in making the process a positive and rewarding experience for him and other DRC members. España said agreed to participate partly because of the strong neighborhood activists he saw involved with the organization. Neighborhood activist Linda Nettekoven was one of these people. ${ }^{64}$ España said Linda was very strong, progressive, and sincere about engagement, which encouraged him to commit his time and energy to the project. España remembered that "Linda was wonderful from day one." "She typified someone I'd want to spend time with." Her deep commitment to engagement and the respect she showed "touched me personally."

España also fondly remembers Southeast Uplift staff person, Amy Dudley. "She was deeply, deeply committed" to "social justice.” Dudley's manner and approach also showed "respect" for others. España said Dudley was "the model of the ally you need"-

\footnotetext{
${ }^{64}$ In the 1970s, Nettekoven lived in Eugene, Oregon and worked for Lane County helping to organize rural community organization. She moved to Portland in the 1990s and quickly became involved in her neighborhood association in inner southeast Portland and then became involved with Southeast Uplift. Nettekoven has been involved in nearly all of the major policy reviews of Portland's community and neighborhood involvement system during the 2000s and 2010s.
} 
she knew when to contribute and when to support leadership by others. "She was very skilled."

España said he strongly believed in creating "a voice for people who had been silent" and a shared "sense of vision" that encouraged their active engagement and their being part of the solution. España said the DRC provided a vehicle for him to seed his ideas by developing a proposal that laid out principles, goals, strategies, and structure for a program that could move this agenda forward.

España is credited by many for encouraging the shift in thinking among neighborhood leaders away from the traditional approach, which had been to ask for more resources for neighborhood associations to help them do a better job of getting people from underrepresented communities involved in neighborhood meetings and activities. España helped some neighborhood activists begin to see that the system needed to dedicate resources directly to help build strong organizations for people of color that would build leadership and organizing skills and capacity among their own community members.

España believed the emphasis needed to be on building capacity, not trying to get people to go to neighborhood association meetings. "It's not as though people in communities of color were looking for a meeting to attend." España said the 1998 ONA Guidelines language on CBNBs illustrated the City's interest in involving these organizations and communities. However, the City had not funded these efforts. España said he used this existing policy language to bolster his argument that action was needed. 
España said it also was important to recognize that different ethnic and cultural groups in the community were in very different stages of development and organizing. He said they needed to engage in self determination at a pace comfortable for each of those groups. For instance, España said the Latino and Native American communities were just starting to get organized, while the African American community in Portland already had a strong history of organizing and advocacy. Some groups were fairly sophisticated; others were just starting to organize.

España also championed community groups working together. He said that initially the African American community was concerned about other communities becoming more organized and worried that these groups would start competing for the very small pie of resources available at the time. España said he always maintained that having more groups organized and taking collaborative action together would give them all more power. He said he has been glad to see that the different groups "got beyond that" and have worked together on "leadership development," creating a "collective voice," and engaging in "collective advocacy." España said that his view is that "we all need to support all of our children—not one over another."

España said he moved on from his involvement with Southeast Uplift when he saw that the Southeast Uplift DCLC was moving forward with proposals for funding for leadership development and organizing and that a number of good people were involved and going in the right direction.

España remembered that advocating for programs to support leadership training and organizing in communities of color "was a tough sell." He said "there was passive 
resistance on the city council" and council members were only interested in a "slow start." City Council members initially "just threw some funding at it," but it not enough to fully fund the effort. España said "The progress was slow, but that's o.k." The DCLC members were happy to get even "one-time" funding-it was a start. España said the initial one-time nature of the funding made it easier for some decision makers to look at the DCL project as a "special project" that could go away. "It made it less scary and less of a commitment for them."

Mayor Potter soon increased funding for and expanded the DCL program. The program now has become an ongoing element of the ONI system. España remembers that Mayor Potter was a "kind man with a real sense of community." He was "genuinely open, respectful, and supportive" of people in communities of color and immigrants and refugees. Mayor Potter had a "bigger vision" and had "learned a lot about what's important through his community policing work."

Thinking back on his involvement with the DRC, España says he feels "good about those times" and the people he worked with-“They had values I could rely on." España said the DRC process built support in the community-support that the DRC and DCLC and other community organizations could use to push ONI and the City to support and change how it involved the broad diversity of people in the community. At the same time, activists in the community were helping "develop a network of community organizations_like APANO [Asian Pacific American Network of Oregon] — that didn't exist before." "This was great organizing work." "We're all much better together. Remember 'Nothing about me, without me.", 


\section{Southeast Uplift—Diversity and Civic Leadership Committee (DCLC): In}

2004, Southeast Uplift formed a new group — the Diversity and Civic Leadership Committee (DCLC) — to build on the work of the DRC and to develop program proposals and advocate for increased funding from the City Council to further advance the goal of increasing the involvement of under-represented communities in the neighborhood system and in local decision making. The DCLC also built on Southeast Uplift's early efforts to identify neighborhood association priorities and to build support for them across southeast Portland.

In the fall of 2001, Southeast Uplift initiated the "Healthy Neighborhoods Project." SE Uplift staff “worked with neighborhood associations to identify the strengths and challenges present in each association and to determine how [Southeast Uplift] could best support their efforts." SE Uplift staff distilled thousands of comments generated in this process into ten vision statements that represented the needs and objectives identified. SE Uplift staff then reached out to 750 residents who were not involved in their neighborhood associations "to verify how accurate neighborhood associations were in identifying the priorities of its non-affiliated residents-the responses closely tracked the input from the neighborhood associations. The top two priorities of the neighborhood associations were:

- "Neighborhoods want to increase the diversity and involvement in their associations by expanding and improving their outreach," and 
- "Neighborhoods want to reinvent the relationship between themselves and the City" (Southeast Uplift. Kennedy-Wong memo to Mayor Katz, March 24, 2004).

In January 2004, Southeast Uplift convened a meeting of neighborhood association and some community organization representatives—called "Launching Our Community Agendas"- to choose three priorities for Southeast Uplift's 2004 "Neighborhood Agendas Campaign." (Some members of the DRC also participated in this meeting.) Southeast Uplift staff believed that the identification of a few key priorities would allow Southeast Uplift to "marshal its staff and the collective organizing weight and stature of its neighborhoods to advocate for a policy platform with the City" (Hoyt. Email to Leistner, June 6, 2013).

Participants at the event identified three district-wide priorities- - two focused on improving transportation and the design of infill development in southeast Portland. The other was to: "Secure funding from City Council to fund outreach and civic education to increase the diversity of neighborhood associations and build civic leadership among traditionally under-represented Portlanders" (Southeast Uplift. Hoyt memo to DCLC members, April 26, 2004).

Southeast Uplift staff later would remark on what an achievement it was to have neighborhood association representatives identify increasing diversity as a major priority (Hoyt, June 6, 2013). This is especially noteworthy, given that some neighborhood leaders continued to question why Southeast Uplift was putting so much time and effort into serving the needs of under-represented groups-"Why are we supporting special 
interests? We don't have enough resources" to serve the needs of the neighborhood associations (Kennedy-Wong. Conversation with Leistner, February 17, 2010).

Once Southeast Uplift had determined the three district-wide priorities, Southeast Uplift staff began to organize advocacy efforts for each priority. In February 2004, Southeast Uplift Executive Director Elizabeth Kennedy-Wong hired Steve Hoyt to support all three advocacy efforts.

In March 2004, Southeast Uplift convened the first meeting of a new, city-wide "Diversity and Civic Leadership Committee" (DCLC) dedicated to advocating for funding for outreach and civic education to increase the diversity of neighborhood association and to build civic leadership in historically underrepresented communities. Hoyt reported that Southeast Uplift "invited people throughout the city to participate in the DCLC, and for the first year it was a very diverse and large committee." (Hoyt said much of the energy that had been going into the DRC shifted to the DCLC.) ONI staff person Brian Hoop also participated in the DCLC meetings.

The DCLC was constituted as an independent body and not as a committee of Southeast Uplift (Southeast Uplift. Hoyt memo to DCLC members, April 26, 2004). Representatives of about 20 different neighborhood and community organizations participated in the DCLC's weekly meetings. They worked on developing a proposal to submit during the upcoming City budget process. The organizations represented included a few neighborhood associations, most of the neighborhood coalitions, and a number of immigrant and refugee and community of color organizations and community advocacy groups (some of the individuals and organizations had been involved in Interwoven 
Tapestry and had participated in the DRC and/or the DRC "community dialogues" events).

In late March 2004, Kennedy-Wong sent a memo to Mayor Katz that described the DCLC origins, purpose, and participants, and asked that the mayor include $\$ 350,000$ in the city budget to demonstrate the City of Portland's "commitment to a more diverse and inclusive neighborhood system and an enhanced civic life" (The $\$ 350,000$ amount was based on $\$ 50,000$ for each of the seven neighborhood coalitions.) Kennedy-Wong proposed that the funds be allocated across all seven neighborhood coalition areas, and that "any coalition office, organization or group, working with individuals not traditionally participating in the neighborhood system could receive the funds."

Kennedy-Wong identified the purpose of the project as providing "adequate funding for outreach to under-represented groups in the Portland community" and supporting "staffing dedicated to increasing the participation of under-represented individuals in the neighborhood system." Staff would "support and build the leadership skills of under-represented community members and increase their participation in the neighborhood system" and educate community members in the use of city processes, policy analysis, advocacy, and the working of neighborhood coalitions." Kennedy-Wong defined "under-represented groups" as including "people of color, immigrants and refugees, low-income people, renters, and homeless people." "Kennedy-Wong reminded the mayor that ONI had added requirements to its contract with the neighborhood district coalitions that the coalitions do more outreach to underrepresented communities but that ONI never had provided additional funding to support these new activities. 
A later draft proposal from the DCLC asked the City to commit to budgeting $\$ 350,000$ for each of five years "for the purpose of increasing diversity in neighborhood associations and building civic leadership among traditionally under-represented groups." The proposal listed potential project activities that included: "surveys of underrepresented groups," "diversity education or neighborhood associations," resident/citizenship/community training" to help people learn "how the neighborhood association works" and how to reduce "speeding and crime in your neighborhood," "cross-cultural events," and "translation services." The DCLC proposed that ONI administer the funds and that community groups, neighborhood associations, and neighborhood coalition offices could apply for the funding through a competitive grant process (Southeast Uplift. “diversity_project_summ_draft.doc” [saved June 24, 2004]).

DCLC members lobbied heavily for their proposal. They met with all the city commissioners and testified at a community budget hearing. Mayor Katz initially committed to providing $\$ 50,000$ (not the $\$ 350,000$ requested) in funding for the FY 2004-05 budget, but she ended up shifting this money to help pay for a settlement of a police pay dispute.

Mayor Katz did include a budget note in the FY 04-05 budget that read:

"Outreach to Diversify Neighborhood Involvement: The Office of Neighborhood Involvement will develop and present a proposal for a pilot project to increase the involvement of under-represented community members in neighborhood associations. The ONI proposal will include a work scope with measurable deliverables, a budget that identifies matching resources including grants, and an evaluation plan" (Portland. City Budget FY 2004-05 412). 
Hoyt said that, after all the effort DCLC members had put into advocating for their proposal in the City budget process, "there was a fair amount of deflation among the community members on the [DCLC], but [staff] and a smaller group of activists kept on pushing." Over the subsequent years, the DCLC proposals continued to evolve.

ONI followed up on Mayor Katz's budget note by asking the DCLC to lead the development of a pilot project proposal (Southeast Uplift. DCLC working draft proposal. [dcl_pilot_jan_19.doc, saved on January 19, 2005] 2).

In November 2004, Mayor Tom Potter was elected on a platform of reconnecting community and city government and ushering in a new "community governance" culture in Portland. Potter had a strong commitment to supporting communities of color, immigrants and refugees, and other underrepresented groups and to ensuring that they would have a much stronger voice in local decision-making and civic life. Mayor Potter hired Kennedy-Wong to serve on his staff. The Southeast Uplift board of directors hired Cece Hughley Noel to lead the organization. Hughley-Noel continued to push the City to fund some sort of DCLC proposal. ${ }^{65}$

A number of DCLC members, with support from Southeast Uplift staff and ONI staff, continued to meet and worked on developing a "pilot project" proposal to introduce in the next City budget process. In 2005, a DCLC working draft pilot project proposal affirmed the DCLC's commitment to "building and supporting equal access to

\footnotetext{
${ }^{65}$ Hughley-Noel continued SE Uplift's leadership in the neighborhood system and on diversity issues by co-chairing Mayor Potter's comprehensive review of Portland's neighborhood and community involvement system, known as "Community Connect." This process would establish a new vision for Portland community and neighborhood involvement system and a strategic plan for implementing this vision. Community Connect would propose the implementation of a leadership training and organizing capacity building program for communities of color and immigrants and refugees similar to the proposals developed by the DCLC.
} 
participation in the neighborhood system by under-represented groups." The DCLC defined "under-represented groups" as including: "people of color, renters, immigrants, refugees, homeless, low-income individuals, racial minorities, people with physical and mental disabilities, gas, lesbians, trans-gendered individuals, and youth" (Southeast Uplift. DCLC working draft proposal).

The DCLC's objectives for the pilot project included:

- Increase participation of under-represented groups "in Portland's civic society and the neighborhood system;"

- Expand the "knowledge, skills, attitudes and tools for [under-represented group] leaders to effectively organize their constituency, collaborate with neighborhood associations, and advocate before local government;"

- Expand the "knowledge, skills, attitudes and tools of neighborhood association leaders to form and maintain the involvement of [underrepresented groups] by building coalitions with organizations" that represent them;

- Remove "barriers to effective participation of [under-represented groups] in neighborhood association activities;"

- Increase "awareness and ability for [the] neighborhood system to engage and maintain involvement of [under-represented groups] in areas of mutual interest between neighborhood associations and [under-represented groups];" 
- Expand "working relationships and collaborative efforts between neighborhood associations, community-based under-represented organizations and [under-represented groups];”

- Create "a model for the neighborhood system with greater accountability to more fully engage Portlanders from all cultural, social and economic walks of life;"

- Expand "collaboration between [the] neighborhood system, e.g. coalitions, neighborhood associations, community-based organizations, local schools and [under-represented groups]."

The DCLC members considered a number of proposals generated by DCLC members, including:

- People of Color/Racial Minority Leadership Academy: The purpose of the academy was to "prepare natural community leaders of color who desire the advancement of policies to achieve economic and social equity based on the wisdom, voice, and experience of local constituencies." The proposal determined that "leaders of color who understand the needs and assets of community residents and organization will best be able to effectively drive policy efforts" and be aware of issues that affect their communities. The academy curriculum was to include training in "analysis, negotiation, diplomacy and advance" as well as providing tools "to support creative and critical thinking and public speaking; collection management and presentation of information; use of technology; and the development of media and public 
education strategies." The target audience for the academy was to be about twenty leaders from "Communities of Color: Asian and Pacific Islander, African American, Latino and American Indian and Native Alaskan.” The proposal anticipated the funding needed or the academy at $\$ 67,000$ (Southeast Uplift. Project Concept \#1. [people_of_color_acad.doc”, saved February 2, 2005]).

- Community and Neighborhood Engagement Initiative: This proposal sought to "provide leadership opportunities to neighborhood association leaders to engage and build relationships with under-represented groups" through training for neighborhood association board and general members in effective outreach techniques, demographic information about populations in a neighborhood, contacts with leaders from under-represented communities in the neighborhood, efforts to make the neighborhood association's meeting more inviting to these communities, "one-on-one and/or small group discussions between leaders of the neighborhood association and the underrepresented communities, and, if these leaders identify issues of interest to both groups, support in joint organizing the issue or to host an event. The ultimate goal of this proposal continued to be increased participation by member of under-represented communities in neighborhood association and community-sponsored events. This proposal anticipated a two-year commitment of \$50,000 per year (Southeast Uplift. Project Concept \#2. [2_system_imprv.doc, saved April 27, 2005]). 
- Targeted constituency issue-based campaign: This proposal envisioned an “organizing campaign to build working partnerships between Neighborhood Associations with families with K-12 school-age children and existing community-based and government school support organizations with a goal of building stronger involvement with and public support for targeted neighborhood schools." The idea was that members of traditional neighborhood associations and under-represented communities could come together around their shared interested in improving public education for their children. The proposal included "two annual board meetings/retreats for target neighborhood and partnering community organizations to develop issue priorities to work together on;" "one-on-one and/or small group discussions;" the identification and cultivation of new leaders; development of a joint community organizing campaign; a joint communication outreach strategy. The proposal sought to increase participation by under-represented community members in "project meetings with neighborhood associations" and that some of these individuals would hold leadership positions in their neighborhood associations. This proposal also anticipated a two-year commitment of $\$ 50,000$ per year.

- Portland Community Leadership Academy: This proposal was similar to the proposal for a "People of Color/Racial Minority Leadership Academy," but expanded the target audience to include not only communities of color, but also emerging neighborhood association and neighborhood district 
coalition leaders, emerging leaders from the schools communities—including youth, PTA or Site Council members, and "SUN Community School volunteers," low-income housing, welfare and homeless advocates, and other constituencies. The academy curriculum was to include "community building;" "community organizing;" "Diversity: examining white privilege, outreach, being allies with underrepresented groups;" "advocacy;" “communication;" technology;" organizational development, and "public education" strategies and techniques. The program contract funding would be "split between one organization with majority leadership from communities of color and one a neighborhood district coalition.” The program would include "four two-day intensive retreats" over a nine-month period, caucuses for targeted trainings and small group breakouts for communities that request them, mentoring for individual participants b community leaders, and a “ $\$ 2,000$ organizational grant” for each participant for "a project to apply the skills they're learning." The proposed funding for the project was $\$ 310,000$, which included $\$ 60,000$ each for two contracted organizations (Southeast Uplift. Project Concept \#4. [4_Academy_Broad.doc, saved January 20, 2005]).

Mayor Potter choose not to fund any DCLC proposals in his first city budget (FY 2005-06). Amalia Alarcón de Morris remembers that Potter planned to initiate "Community Connect" - a major review of Portland's neighborhood and community involvement system - in the summer of 2006, and he did not want to make any changes 
until he had heard back from that process (Alarcón de Morris. Conversation with Leistner, June 12, 2013).

DCLC members continued to refine their proposals and started working with the members of the ONI Bureau Advisory Committee on a proposal for the FY 2006-07 City Budget. The members of the DCLC and the ONI BAC agreed to advocate for funding for Leadership Academy and NCEI. Mayor Potter funded both the Leadership Academy and NCEI that year as part of a larger $\$ 500,000$ package of new spending at ONI to "support a community governance model" (Portland. City Budget FY 2006-07 412). The budget included \$70,000 for a “Civic Leadership Academy" (split between Latino Network and Oregon Action); and \$45,000 for the "Community Engagement Initiative."

In November 2006, ONI hired Jeri Williams, an experienced and skilled community organizer, former executive director of the Environmental Justice Action Group (EJAG), and Native American woman with strong credibility among communities of color to support the development of and coordinate ONI's Diversity and Civic Leadership Program.

Southeast Uplift Focus on Diversity and Inclusion Winds Down: Southeast Uplift, after a number of years of intensive community organizing and advocacy to broaden diversity in the neighborhood system, and the success in getting the City Council to fund the creation of the DCL program at ONI, disbanded the DCLC and began to wind down the DRC and shift its focus back to providing services to neighborhood associations. Despite all the great work that had been done-as in the case of Interwoven Tapestry-the work of the DRC and DCLC primarily affected the neighborhood 
association activists who actively had participated in their activities. The DRC and DCLC did not have much impact on the awareness or perspectives of most neighborhood associations leaders and activists in Portland. The key staff people at Southeast Uplift who had worked with the DRC and DCLC had moved on. Kennedy-Wong had gone on to work for Mayor Potter. Dudley left to work with the Rural Organizing Project. Steve Hoyt was hired by the Portland Bureau of Transportation.

In summer 2005, Southeast Uplift hired Afifa Ahmed-Shafi and assigned her to help increase diversity in the neighborhood associations. Ahmed-Shafi also came from a strong community organizing and social justice background and was a skilled trainer on issues of diversity, cultural competency, and equity. Ahmed-Shafi staffed the DRC until Southeast Uplift dissolved the group soon thereafter. She also worked with neighborhood associations interested in diversity by providing them with outreach support and helping them network with organizations. Ahmed-Shafi worked with ONI and other neighborhood coalitions on three citywide diversity workshops, which featured panels of people from different cultures (Ahmed-Shafi. Conversation with Leistner, March 15, 2011).

Ahmed-Shafi remembered that she felt that the overall focus of Southeast Uplift and the staff there had begun to shift away from the diversity work she was doing. Afifa did not see a major impact from the DRC/DCLC work in the neighborhood associations. She saw that the other neighborhood coalitions also were not as focused on diversity issues as Southeast Uplift had been. Ahmed-Shafi said the one exception was Central 
Northeast Neighbors $(\mathrm{CNN})$, where CNN staff person Sandra Lefrancois had been part of Interwoven Tapestry project and continued to host panels and workshops on diversity.

Ahmed-Shafi asserted that moving forward on diversity and inclusion faced major capacity and funding issues, especially for neighborhood associations. "They are expected to be utopian societies-representatives as well as volunteer-based." Many neighborhood associations "barely have the capacity to run themselves" let alone actively working to be more inclusive. Ahmed-Shafi said some neighborhood associations were interested in greater diversity, and she would work with them. However, many neighborhood associations were not interested and Ahmed-Shafi said, if she brought it up, she felt as though she was trying to push an outside agenda on the group. This only aggravated the suspicion some neighborhood associations already held that neighborhood coalitions push agendas on neighborhood associations that neighborhood associations do not want and that are unrealistic. "We were asking for something that didn't want to stick...that felt uncomfortable."

Ahmed-Shafi concluded that "It comes down to capacity and leadership." She said it would be good if neighborhood leaders naturally had those skills, however, neighborhood associations have a lot of needs, even without taking on an effort to increase diversity, and adding on a focus on diversity does not seem like a natural fit for many neighborhood associations in Portland. "It's hard when you're working with volunteers." They are unpaid and did not see it as their duty to be more inclusive, however, some did. Ahmed-Shafi said some neighborhood associations did want to work on diversity issues, especially those that had more diversity in their communities. They 
were better able to see the "stark contrast between who's in the neighborhood and who's on the neighborhood association board. It's harder for neighborhoods that don't have higher levels of diversity to move forward on this."

In 2007, ONI hired Ahmed-Shafi to coordinate a new ONI program focused on building the capacity within city government to engage the community. A significant portion of her work included consultation with and training for city bureaus on equity issues and how to work more effectively with historically underrepresented communities. Ahmed-Shafi said that she was able to engage in much higher-level discussions about issues in her new role at ONI.

Ahmed-Shafi would help develop and then coordinate the City of Portland Public Involvement Advisory Council (PIAC). The creation of Ahmed-Shafi's position at ONI and the City Council's creation of PIAC in 2008 both implemented recommendation made by the PITF.

Involving underrepresented communities-some lessons learned: For many years, different reviews of Portland's neighborhood and community involvement system identified the need to involve a greater diversity of the community in the Portland's neighborhood system and in civic life and local decision making in general. Little progress was made at moving beyond "progressive talk" about the problem to actually achieving this goal. The attempt to expand the system and create a formal role for ethnicbased community organizations and business district associations by offering them formal recognition through the 1998 ONA Guidelines, was unsuccessful. The Southeast Uplift DRC and DCLC--building on the Interwoven Tapestry experience-finally 
showed a viable path forward. This section identifies some of the key lessons from the DRC and DCLC.

Leadership: Elizabeth Kennedy-Wong, prompted by her strong commitment to social justice and inclusion, used her authority as executive director of Southeast Uplift to begin to look for a way to bring together representatives of communities of color and other underrepresented groups with neighborhood leaders to find ways to diversify involvement neighborhood associations and to help people in these communities have a stronger voice and power in local decision making. She continued to support the DRC and DCLC throughout the course of their activities.

Relationships and Trust: Kennedy-Wong started the process by reaching out to and building relationships and trust with individual leaders from communities of color and immigrant and refugee communities. España made clear that a major reason he and other representatives of communities of color and immigrant refugee communities participated in the DRC and DCLC was that they believed that Southeast Uplift leaders and staff and the neighborhood association representatives who participated in the DRC and DCLC strongly supported social justice, treated people with honor and respect, and were committed to having a meaningful impact.

Strong Staff Support: Much of the success of the DRC and DCLC was due to strong staff support from Dudley and then Hoyt. Both had a deep commitment to social justice values and had very strong community organizing and group process skills. They were able to help convene the DRC and DCLC members, support them in their discussions and strategizing, and then assist them in planning and implementing their 
outreach activities, workshops, community dialogues and their advocacy campaign to get the city council to support and fund the DCLC proposals.

Neighborhood Allies: The neighborhood leaders and activists who participated on the DRC and DCLC also had strong social justice values, visibly respected the other DRC and DCLC members, and were committed to pursuing meaningful change. Their visible support particularly was valuable in the face of suspicion—and in some cases, hostility—from some neighborhood leaders to the idea of helping underrepresented groups organize outside the traditional neighborhood association system.

Good process principles and design: Good process design and implementation were important strengths of the DRC and DCLC. These processes were designed collaboratively with the participants and, early on, committed themselves to a set of principles that embodied a strong commitment to operating in collaborative and inclusive ways and honoring, respecting, listening to the participants and members of different communities. The DRC and DCLC strategies, products, and activities were co-produced and implemented by the participants. The DRC and DCLC both strived to model community involvement best practices in the way they functioned. ${ }^{66}$

Policy Entrepreneur: España played a valuable role as a "policy entrepreneur" by recognizing Southeast Uplift's willingness to work on inclusion and the creation of the DRC as vehicle to help him move forward his concept of building community capacity and power. España saw that traditional neighborhood system approaches were not

\footnotetext{
${ }^{66}$ Too often in Portland's history, processes that were intended to promote better community involvement have been structured and have functioned in ways that violated many of the basic principles and best practices of good community involvement. Any process established to study and/or promote community involvement offers and important opportunity to model what good community involvement looks like.
} 
working for many people. He brought to the DRC and DCLC processes his strong belief in neighborhood and community based solutions for people of color. He also challenged people who talked about inclusion to show how they were going to help make it happen, including the commitment of resources to ensure that the actions or programs are effective. España's goal was to develop a process to support neighborhood and community engagement through leadership training, skill building, empowerment, advocacy, and preparing people for meaningful roles on boards and decision making bodies. España played a key role in shifting the thinking of many neighborhood leaders away from just trying to get a greater diversity of people to participate in regular neighborhood meeting to supporting people in communities of color and other underrepresented groups to organize themselves and develop capacity in their own communities.

Capacity Building Approach: España championed the idea of recognizing where each community group was in its evolution and then helping them build the capacity to organize themselves and advocate for their issues and priorities. He suggested a strategy that included helping communities learn about community building and their ability to have an impact, supporting communities in learning about themselves and building relationships and social capital, and then helping communities learn about the opportunities by which they can achieve change. España also argued that any strategy for change needs to build the ability and skills of community members to "monitor, research accurately and effectively (to gather and analyze data) on targeted government or private sector institutions, policies, or practices..." 
Partnerships between Organizations: Interwoven Tapestry, DRC, and DCLC showed the advantages of different community groups working together to magnify their power. During the course of these projects, organizations of people of color and immigrants and refugees, went from not seeing an advantage from working togetherand often seeing each other as competitors for limited government and private funding and support - by the end of DCLC were at least willing to work together. ${ }^{67}$ and funding, the outset value showed that power....challenge for URG groups that initially did not work together...getting them to work together and also to join forces with neighborhood leaders...power....had happened in Portland in that way...Politicians who had been criticizing the system for not being inclusive...saw URGs and neighborhood leaders working together-got people's attention. The DRC and DCLC process helped URG groups get beyond their initial differences and work together to advocate for support for leadership development for their community members, the creation of a collective voice, and collaboration on advocacy efforts.

Structural Opportunities that Fit Different Groups: ONI's failed experiment with creating processes to formally recognize $\mathrm{CBNBs}$ and business district associations showed the importance of not using a "one-size-fits-all" approach to incorporating new types of community organizations into Portland's community and neighborhood involvement system. The DRC and DCLC offer a good example of the alternate and much more promising approach championed by España of assessing the capacity of needs

\footnotetext{
${ }^{67}$ Relationships, trust, and collaboration between these groups continued to grow and strengthen through their participation together in ONI's Diversity and Civil Leadership program. ONI, as part of its coordination of the DCL Program, helped coordinate monthly meetings of the community organization partners in the program. These regular meetings supported continued relationship building and cooperation.
} 
of each community and working with representatives of that community to develop an approach that works for them.

\section{Realistic Expectations of Neighborhood Volunteers: The DRC and DCLC}

processes helped many people in the neighborhood system let go of the idea that neighborhood associations were likely to be effective at serving the community organizing and involvement needs of all the groups in the community.

Even though the Interwoven Tapestry, DRC, and DCLC processes had a major effect in shifting thinking about the structure of Portland's community and neighborhood involvement system, they had little effect on the general awareness among neighborhood leaders about the diversity of people in their neighborhoods or on their willingness and capacity to reach out to and work effectively with diverse individuals and groups in their community. Neighborhood associations are made up of volunteers, many of whom get involved with their neighborhood association to work on particular issues or projects that interest them.

Ahmed-Shafi noted that few neighborhood associations have the leadership capacity and skills to actively work to be more inclusive. She said that some neighborhoods were interested-often those in which the diversity of their communities was very visible — she worked to support their efforts. Other neighborhoods were suspicious that Southeast Uplift was trying to force an outside agenda on them. Many neighborhood association leaders and members_-all of whom are unpaid volunteers-did feel it was their duty to take on additional responsibilities for trying to be inclusive, in addition to all the existing neighborhood work they were doing. Any expectations that 
neighborhood associations should become significantly more inclusive and diverse would require all more staff support.

Effective community organizing and advocacy: Another success of the DRC and DCLC processes was the understanding by Kennedy-Wong and others how to use different strategies and vehicles at different stages of the process. The DRC was the right vehicle to help bring together individuals from different communities, primarily in southeast Portland, to learn about each other and to develop a shared set of principles and design and deliver a number of success community outreach events. When it came time to try to seek city council support, Kennedy-Wong helped create a new group, the DCLC, that included representation from organizations from across the city (including many DRC members), with the specific purpose of developing program proposals and advocating with the city council to fund them.

Another success of the DCLC was to persevere in the efforts. Despite the disappointment that many DCLC members felt when the city council did not fund their proposal, group members kept coming back to the council with further evolved proposals. Their ongoing advocacy helped familiarize city council members with the rationale for and nature of their proposals and "softened up" some of the city council's initial resistance. DCLC members also showed strategic flexibility by being willing to accept a smaller amount of funding to get their "foot in the door" and create the opportunity for expanding the program later.

City Agency Allies: ONI staff participated in the DCLC process as part of ONI's ongoing interest in finding way to broaden community involvement in Portland and 
specifically to involve historically underrepresented communities. ONI staff, including Brian Hoop and Amalia Alarcón de Morris were able to provide important guidance and assistance to the DCLC members to help them write up their proposals and strategize about how to lobby effectively for funding during the city budget development process. ${ }^{68}$

\section{Political Champion: Mayor Katz and other city council members did not} particularly support the DCLC recommendations initially. The election of Tom Potter as Portland's new mayor put a much more sympathetic leader in charge. Potter was a strong champion of community involvement and especially a stronger voice in decision making for people or color and immigrants and refugees. Potter ultimately did support and fund a new leadership training and community organizing program similar to the DCLC proposal. Potter continued to support and expanded the program during his time in office. Mayor Potter's role and the resulting DCL program are described in more detail in the next chapter.

The next section focuses back on city government and describes the work of the 2003-2004 Public Involvement Task Force to improve the quality and consistency of city government's community involvement.

$\underline{\text { Public Involvement Task Force--“A Strategic Plan for Improving Public Involvement in }}$ the City of Portland"-2003-04

Community members had been calling for Portland's city government to improve its involvement of the community since the founding of the neighborhood system. A

\footnotetext{
${ }^{68}$ Alarcón de Morris was the project lead on the Interwoven Tapestry project and then became the manager of ONI's Neighborhood Resources Center. She also served as the volunteer chair of the board of the Latino Network in Portland and had long history of working to empower communities of color on health issues. Mayor Tom Potter would appoint Alarcón de Morris as the new Director of ONI in January 2006.
} 
number of high-profile clashes between community members and city government over city projects during the early 2000s increased the political pressure for the City Council to do something to improve city government interaction with the community. City Council members responded by creating a new task force- - the Public Involvement Task Force (PITF)— to develop consistent guidelines and standards for city government community involvement. The PITF process would be Portland's first comprehensive examination of how to improve the city-government side of the community involvement equation. The PITF recommendations would shape a number of follow up efforts to reform and improve city government public involvement, including the creation of the standing City of Portland Public Involvement Advisory Council in 2008.

Relations between city government and neighborhood and community activists deteriorated significantly during the early 2000s. City leaders and staff clashed repeatedly with neighborhood and community activists over projects including the Southwest Community Plan (see Irazabal and Hovey), the Northwest District Plan, the Water Bureau's plan to cover Portland's historical open reservoirs, the aerial tram to OHSU, the siting of off leash dog use areas in city parks, and others. Community members accused city leaders and staff of trying to impose top-down policies and projects with little effort to listen to the community or to consider community needs, priorities, and impacts.

Community members often claimed that city staff did a poor job involving the public and did not followed established public involvement best practices. City staff often claimed that they were doing a good job involving the public. To many community activists, the City Council's adoption of the 1996 public involvement principles and the 
development of a Community Outreach Handbook for city staff appeared to have had little effect. Community members also complained that the quality of public involvement varied significantly from one bureau to the next and even from one project to the next within the same bureau. This disconnect revealed a significant lack of shared understanding of what good public involvement looks like and then how to achieve it.

It was in this context of heightened conflict that, in October 2002, ONI Commissioner-in-Charge Jim Francesoni directed ONI to initiate a process to involve community members and city staff in the development of consistent guidelines and standards for city government community involvement. In a press release, Francesconi stated "The need for consistent standards to involve the public in city discussions and projects has been brought up to me numerous times during my visits with neighborhood activists." He added "I have often heard concerns about inconsistent approaches by bureaus on issues important to community members. For both public involvement and public information, we must look at developing clear guidelines or standards that are applied consistently across the city [government]." Francesoni noted that the ASR had recommended that ONI coordinate a "city-wide discussion" to develop "common terms, understanding and expectations for outreach processes along with standard guidelines for public involvement." Francesconi asserted that "the development of clear, consistent public involvement standards can reaffirm and improve upon Portland's strong history and commitment of involving citizens in decision-making and help us work together to 
ensure that the city continues to be the City that works" ${ }^{69}$ (Portland. Office of City Commissioner Jim Francesconi. Press release. October 30, 2002).

City Commissioners Dan Saltzman and Randy Leonard formally supported Francesoni's effort. (Leonard would take over responsibility for ONI in December 2002.) All three commissioners had clashed with community members over different projects and all three served as the commissioner-in-charge of ONI at different times during the early 2000s. All three commissioners had generated political ill will among neighborhood and community activists, especially Saltzman and Leonard, with their top-down and uncollaborative leadership styles.

In April 2003, the three commissioners issued a joint memo to city bureau directors, city bureau public involvement staff and community members launching the new Public Involvement Task Force. Their memo reiterated the reasons to create the task force stated in Francesconi's October 2002 memo and said the task force's charge was to:

- Review "best practices and current city and bureau policies around public involvement."

- Establish "recommendations for clear, consistent standards to meet the public expectation for public involvement practices across the City," and

- Develop "policy recommendations and public involvement standards for Council adoption" (Portland. Memo from Commissioners Francesconi, Leonard, and Saltzman to City Bureau Directors et al. Citywide Public Involvement Standards Taskforce, April 2, 2003).

\footnotetext{
${ }^{69}$ The City of Portland's motto is: The City that Works.
} 
The three city commissioners affirmed their "hope that the taskforce will provide a set of clear consistent recommendations for Council adoption that will guide City bureaus' public involvement policies for years to come."

ONI staff worked hard to ensure that the PITF participants represented many different perspectives. The PITF members included neighborhood association and coalition activists, city bureau public involvement staff, representatives of communities of color and low income communities, people with disabilities, youth, representatives of business districts associations, public involvement practitioners, academics from Portland State University, and representatives of citizen involvement committees from other local jurisdictions (Portland. Office of Neighborhood Involvement. Public Involvement Task Force. Who is on the Task Force? 2004. Web.

〈www.portlandoregon.gov/oni/article/122082> . [Downloaded October 17, 2013]).

Individuals and ONI staff involved with the Interwoven Tapestry Project (still going at that time) advocated that individuals and groups involved in that process be represented on the PITF and that the PITF pay special attention to the need to the public involvement needs of immigrant and refugee communities.

The three PITF co-chairs represented important points of view on the PITF. Laurel Butman worked in the City of Portland Office of Management and Finance $(\mathrm{OMF})$ and coordinated the mayor's annual community involvement for the city budget process. Butman had helped crate create the 1996 public involvement principles and the city's Community Outreach Handbook. Joanne Bowman was a well known leader in the African American community, a strong community organizer, and an advocate for greater 
police accountability. Julie Odell was a southwest neighborhood activist who had worked on the SW Community Plan and was a doctoral student at PSU with a focus on public involvement.

The PITF began meeting in April 2003 and met monthly through March 2004. In the fall of 2003, PITF members divided up into workgroups. The workgroup subjects give interesting insight into how the PITF members framed their task. The workgroups and their charges included:

- Principles: "Review and update public involvement principles as appropriate. Suggest policy options and opportunities regarding implementation."

- Process Design and Implementation: Ensure "flexibility in designing and implementing [public involvement] efforts to respond to unique characteristics of specific project requirements, geographical and constituent needs, state and federal mandates, etc."

- Diversity and Accessibility: "Develop diverse and accessible public involvement efforts that engage Portland's increasingly diverse demographics, including... culturally appropriate models for engaging low income renters, immigrants/refugees, seniors, youth, and communities of color, etc."

- Accountability and Transparency: "Develop public involvement efforts that are more transparent and ensure accountability measures, expectations for public, bureaus, and staff, access to quality project information, how 
decisions are getting made, who is making them, how the public participates."

- Education and Skills Training: "Provide skill building and leadership training for staff on best practices and for [the] public [on] how the City works and how to be informed advocates for themselves."

- Communication and Access to Information: "Expand coordination efforts for efficiencies and cost reductions. Utilize e-government for each public while acknowledging digital divide issues" (Portland. Office of Neighborhood Involvement. Public Involvement Task Force. Workgroup Descriptions and Documents for Public Involvement Task Force. Web. $<222$.portlandonline.com/oni/index.cfm?c=31198> . Downloaded October 27, 2013).

PITF members also reached out broadly to the community for additional input. They held two community forums, distributed a questionnaire, and held fourteen focus group meetings. The focus groups sought input from particular communities, including: different geographic areas of the city, city public involvement staff, communities of color and immigrants and refugees, business associations, youth, public involvement practitioners, people with disabilities and people with low incomes.

In the winter of 2004, the PITF members adopted the new set of principles developed by the "principles" workgroup. They then regrouped themselves into four workgroups_-“culture," "community," "process," and "accountability and evaluation"to review the over eighty recommendations produced by the workgroups and to 
synthesize the tremendous amount of work these groups had produced into a more focused and effective final report. The PITF members struggled with this task and lost momentum during the spring of 2004 and then stopped meeting without producing a final report (Portland. Office of Neighborhood Involvement. Public Involvement Task Force. Public Involvement Task Force-2003-04. Web.

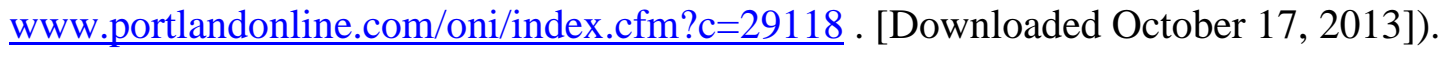
The PITF experienced some internal tension from the outset, in part because the PITF was created during a time of major conflicts between community members and city leaders and staff over a number of controversial projects. In a number of cases, community activists who had been fighting the city over certain projects served on the PITF along with city staff who had played major roles in the public involvement for those projects. As mentioned earlier, many community activists were very critical of the city's public involvement efforts, in contrast to many of the city staff people who felt they had been doing a pretty good job. Some city staff felt attacked and became somewhat defensive and resistant to pressure from community critics. Community members pushed hard for strong requirements and standards, often based in their years of frustration with what they saw as poor public involvement by the city. City staff cautioned against "cookie cutter," "one-size-fits-all" approaches that would impose requirements that did not recognize that different bureaus did very different work and had different needs to engage the public. They also argued that not every city project needed high 4levels of community involvement. Given the limited resources for public involvement in many city bureaus, city staff feared that inappropriately extensive standards would impose 
additional burdens on staff and burn up scare public involvement resources without really improving public involvement.

Some of the key leaders of the PITF effort later explained why they thought the group did not produce a final report. Brian Hoop with ONI, who provided the primary staff support for the PITF, said that the 2004 mayoral election was in full swing, and a number of people wanted to wait to see which of the two main candidates would winCity Commissioner Jim Francesconi or former Portland police chief Tom Potter (Potter was running on a platform of reengaging the city and community in a "community governance" partnership). By waiting to see who won, PITF members could shape the report to fit the political opportunities and priorities of the next mayor. Hoop also reported that he needed to shift the focus of his time to supporting the GREAT Committee, which was completing its nearly five-year process of updating the ONI Standards. Different PITF members said that tensions among the three co-chairs also made it difficult to come to agreement on a final product.

Odell remembers that city staff on some of the workgroups "seemed pretty entrenched in their views" and were "afraid to give new ideas a chance because they weren't sure where it might lead down the road." She also said it was difficult in some cases to build collaborative relationships with city staff because they seemed to expect neighborhood activists to "fight" for "neighborhood issues" rather than seeing that they all were working on a common challenge together. She wondered whether some of the lack of cooperative spirit may have been in part a factor of the personalities and 
perspectives of individual city staff people who participated in the PITF (Odell. Email to Leistner, June 11, 2013).

Butman remembers feeling frustrated that some PITF members did not have a good understanding of the realities of Portland's public involvement system. She also noted that, "on a personal level, having been quite involved with the process that created the original Principles of Public Involvement, I felt that the process and its outcomes were neither understood nor respected by members of the PITF that had not experienced that process." Butman also said that toward the end of the process, Mayor Potter had started up his Bureau Innovation Project \#9 (BIP\#9)—which was to look at ways to improve city government community involvement, and Bureau Innovation Project \#8 (BIP\#8) (later called "Community Connect")—which was a major review of Portland neighborhood and community involvement system). These efforts drew some peoples' energy away from PITF and "caused member burn out" (Butman. Email to Leistner, June 10, 2013). (Both BIP\#9 and BIP\#8 are described in more detail in the next chapter.)

Butman said she believes that sufficient consensus existed in the PITF around the "principles of the recommendation that they could stand as a good start for the next group to take up." She said that in her recollection, PITF members "stumbled when it came down to the fine print." Her assessment was that "this wasn't the group to make some of the timing and refinement decisions. Also, staffing to implement the recommendations was sorely needed and unavailable at the time. I think we always envisioned a new group and added staffing to move things forward." Her sense was that the PITF "had moved as far forward as it could" (Butman 2013). 
The PITF members, even though they collectively were not able to produce a final product, did a tremendous amount of valuable work and laid out a strategic vision and plan for what it would take to significantly improve the quality and consistency of Portland city government public involvement.

In the summer of 2006, it became clear that Mayor Potter's BIP\#9 was going to narrow its focus and produce a public involvement assessment tool for city staff rather than continue the broader work of the PITF. It also appeared that Mayor Potter was open to implementing one of the PITF recommendations, which was to create a standing public involvement advisory commission. PITF co-chair Julie Odell, ONI staff person Brian Hoop, and PITF member Paul Leistner, ${ }^{70}$ not wanting to see the good PITF work forgotten and seeing an opportunity for PITF ideas to influence the new public involvement advisory commission, reached out to former PITF member Elizabeth Kennedy-Wong, who then was serving as Mayor Potter's staff lead on community engagement issues. Kennedy-Wong supported the idea of pulling together a final report on the PITF principles, recommendations and action steps. Odell, Hoop, and Leistner met during the summer and fall, reviewed the PITF recommendations and organized and edited them into a form that could be passed on and would make the PITF work more accessible to future groups. They sent their proposed final report out to PITF members, but made it clear that the report was not a formal product of the full PITF group

\footnotetext{
${ }^{70}$ The author of this study.
} 
(Portland. Office of Neighborhood Involvement. Public Involvement Task Force 20032004). ${ }^{71}$

The PITF principles, recommendations and suggested action steps from the 2006 PITF Report are described below.

PITF-Principles: Similar to other reviews of community involvement in the past, the PITF developed a set of principles to describe the basic values and characteristics of good community involvement. The PITF workgroup members who developed the principles saw them as being similar to the U.S. Constitution's Bill of Rights-the principles would "define what citizens should expect from city elected officials and city government staff" (Portland. Office of Neighborhood Involvement. Public Involvement Task Force Report 2006, v).

The principles began by establishing "governance as partnership" as the overall conceptual framework for the principles. The principles stated that city officials and staff must "joint with citizens to create a partnership in which the public has a real voice in setting the course of the community." The document continued by listing and describing four sets of principles that would help achieve this partnership. These principles focused on basic values and characteristics of good community involvement, building the capacity for involvement in city government and the community, good process design, and government transparency and accountability, and evaluation.

\footnotetext{
${ }^{71}$ In 2008, Mayor Potter and the City Council implemented on of the PITF recommendations by created the ongoing Public Involvement Advisory Council (PIAC) to continue the work of the PITF and develop consistent community involvement guidelines and standards for city government. PIAC members would refer to the PITF report referenced above as one of the source documents they consider in developing the PIAC initial priorities and workplan.
} 
The first set of principles identified the foundation of a governance partnership as requiring: a "culture of listening, hearing, and acting on public input;"the use of collaborative, consensus-seeking, and community-based approaches to identify priorities and create, develop, or implement "public policies" and city government projects, services, and actions; early involvement of the community in the shaping of policies and projects; and outreach to and inclusion of full diversity of community groups and interests in Portland.

The second set of principles focused on ensuring that both the government and community sides of the "governance partnership" had the willingness and ability to work together. One principle states that city leaders and staff "must have the skills and will to support and achieve effective public involvement as set out in these principles." Another focused on building capacity in the community, and identified Portland's "neighborhood and business association system" as a "cornerstone of public involvement and a primary channel for citizen input and involvement" and a central source of skill building opportunities and networking between neighborhood and business district leaders and "other community-based organizations."

The third set of principles focused on good design of community involvement processes. These principles stated that community involvement processes should "fit the scope, character, and impact of the policy or project, and be able to adapt to changing needs and issues as a process moves forward." Other principles recommended that city leaders and staff engage in ongoing "communication and dialogue" with the community, and use "culturally appropriate and effective strategies and techniques' to "reach out to 
and involve constituencies traditionally under-represented in the community." Examples offered of these types of groups included, "people of color, immigrants and refugees, youth, people with low incomes, seniors, and people with disabilities."

The fourth set of principles focused on government accountability and transparency and the need for evaluation of community involvement processes.

The full text of the PITF Principles of Good Public Involvement is presented below. 


\section{PITF Principles of Good Public Involvement}

Core Concept-Governance as Partnership: City elected officials and staff must join with citizens to create a partnership in which the public has a real voice in setting the course of the community. Effective involvement of the public is essential to achieve and sustain this partnership.

The following principles will help achieve this partnership:

\section{FOUNDATIONS OF GOVERNANCE}

1. Culture of listening, hearing, and acting on public input: Public input must be integral to the development and implementation of public policies, public works projects, public services, and other city government actions.

2. Collaborative, consensus-seeking, community-based approach: City government/community partnerships consistently should pursue collaborative, consensusseeking, community-based approaches between all stakeholders when identifying policy priorities, and when creating, developing or implementing public policies, public works projects, public services, and other city government actions.

3. Early Involvement: The public should be involved early when a policy and project is being shaped - not after many important decisions have already been made and little realistic flexibility remains.

4. Inclusiveness: "Community" in Portland is made up of a rich diversity of groups and interests. City elected officials and city bureaus staff should identify, reach out to, and involve the full range of community groups and interests in public dialogue and decisionmaking processes.

\section{BUILDING CAPACITY}

5. Capacity within City Government: City elected officials, decision-makers, and staff must have the skills and will to support and achieve effective public involvement as set out in these principles.

6. Capacity within the Community: Portland's nationally-recognized formal neighborhood and business association system is a cornerstone of public involvement and a primary channel for citizen input and involvement in our City. It should play a pivotal role in creating opportunities for skill building and networking among both neighborhood/business association leaders and leaders of other community-based organizations. 
7. Coordination and Consistency: City bureaus should coordinate their public outreach and involvement resources and activities to make the best use of city resources and public time and efforts.

\section{PROCESS DESIGN}

8. Effective and Flexible Process Design and Implementation: Public involvement processes and techniques should be well-designed, appropriately fit the scope, character, and impact of the policy or project, and be able to adapt to changing needs and issues as a process moves forward.

9. Ongoing Communication and Dialogue: City decision-makers and staff should establish clear, understandable, and ongoing communication and dialogue with the public and with formal groups in the community.

10. Diversity and Accessibility: Culturally appropriate and effective strategies and techniques should be used to reach out to and involve constituencies traditionally underrepresented in the community - for example, people of color, immigrants and refugees, youth, people with low incomes, seniors, and people with disabilities.

\section{GOVERNMENT ACCOUNTABILITY}

11. Accountability: City elected officials, decision-makers and staff must be accountable for following these governance and public involvement principles.

12. Transparency of Governance and Processes: The public policy decisionmaking process should be accessible, open, honest, and understandable. Public participants should receive the information they need to participate effectively.

13. Evaluation: Mechanisms must be in place to allow ongoing monitoring, evaluation, and reporting of how well city elected officials, decision-makers, and staff follow these principles when developing and implementing public policies, projects, and services, and the effectiveness of individual public involvement processes.

(Portland. Portland Office of Neighborhood Involvement. Public Involvement Task Force Report 2006). 
Public Involvement Task Force-Recommendations/Action Items: PITF workgroups formed around topic areas that tied very closely to the PITF principles and developed recommendations that provide what the PITF members intended to be a strategic plan to achieve the "governance partnership" set out in the principles. Many of the recommendations echo similar recommendations made in the ASR, TFNI Report, and other previous reviews of Portland's neighborhood and community involvement system. The recommendations and action items are summarized below.

Foundations of Governance: PITF members recognized the importance of embedding the PITF values and principles in the formal policies and structures of city government to ensure that their enforcement carried more weight and would be more difficult for future city elected officials and city staff to overturn or ignore.

- $\quad$ Adopt the PITF principles: The PITF recommended that the City Council adopt the principles by ordinance to give them force of law. They noted that the city's 1996 Public Involvement Principles had been adopted by non-binding resolution and appeared to have had little effective on the culture and practices of city government (4).

- $\quad$ Rewrite Comp Plan chapter on public involvement: Portland's Comprehensive Plan—required by Oregon's land use planning law—sets formal policy for the City in large of number areas. The Comp Plan governs City land use planning and development activities as well as capital facilities and transportation planning. PITF members recommended that the chapter that sets out requirements for "Citizen Involvement" in the 
Comp Plan should be rewritten to incorporate the PITF principles and process requirements. Including language in the Comp Plan is strategically valuable because h City staff are required to write formal findings to show how their projects meet the Comp Plan goals and policies (4).

- Amend City Charter: PITF members also recommended including in the City Charter language describing and supporting the "governance partnership" model and the principles. The City Charter serves as the "constitution" for City government and carries the force of law. In the early 2000s, the Portland City Charter did not include any language describing the role of community members in city government decision making (4-5).

- Review City's system of boards and commissions: For many decades, Portland's city boards and commissions have acted as a major source of policy guidance for city leaders and agencies. The PITF members recommended a review of the effectiveness of the system at providing community input into and oversight of City decision making and in representing the full diversity of people and perspectives in Portland (5).

- Establish stable funding for community Involvement: PITF members recommended the establishment of a mechanism to ensure stable funding for public involvement processes and to support a citywide public involvement advisory committee that would help implement the PITF recommendations, develop best practices and training materials, and many 
other city government capacity building activities. PITF members suggested funding these activities through an over-head model that would draw funding from each city agency, or by dedicating a certain percentage of a projects budget to support public involvement planning and activities (5). (The ASR also had suggested funding city government community involvement support through an overhead model.)

Building Capacity in City Government: The PITF Report asserted that city officials and staff needed to have the "skills and will to support and achieve effective public involvement" as described in the PITF principles. Recommendations in this area included:

- $\quad$ Review ONI's role and location in city government: PITF members noted the shift in recent years away from ONI's original role of community empowerment and toward supporting city bureau outreach to the community. They called for a better balance of these roles. They also called for a review of the placement of ONI in the structure of city government. PITF members noted that "The current practice of placing a single commissioner over ONI severely limits the agency's ability to advocate for good public involvement in city bureaus that are not under the control of the ONI commissioner." They suggested putting ONI under the Mayor (who has the power to assign city bureaus to individual city commissioners) or under the City Auditor, which they wrote "would 
provide more independence from the City Council, but may decrease [ONI's] ability to influence city bureaus (7).

- Develop education and training programs for City staff: PITF members recognized the need of city staff for ongoing training in and sharing of community involvement best practices and ideas. Suggested training topics included: culturally specific skills for reaching out to and involving diverse communities; electronic media strategies; database development and management; process design; customer service; public information; dealing with difficult people; and conflict resolution. PITF members suggested partnering with institutional training programs (e.g. IAP2, PSU Hatfield School of Government, ODOT, Metro, Tri-Met and county governments) for general skills training and with "diverse communitybased organizations to provide "culturally appropriate skills training" to support outreach to different communities in Portland (7-10).

- Establish a formal networking group for City public involvement staff: PITF members noted that "An informal network of staff has met on and off over the years; however, without a formal structure and dedicated staff support, the group comes and goes." The ASR also recommended the creation of a peer network of City public involvement staff that could help staff share best practices, updates on current public involvement efforts, opportunities to collaborate and share resources, develop web-based tools, and to provide "peer review of bureau public involvement policies" (10). 
Building Capacity in the Community: PITF members recognized that their charge had been to focus on city government, but they also recognized that community members need the capacity to participate, especially to engage in "government priority setting and decision making." They recognized the value of the existing neighborhood and business association system, and noted that "Communities of color and interest-based groups have not always been integrated into the formal system." The PITF members maintained that a high priority for building community capacity "is to create meaningful and collaborative networks between the neighborhood/business association system and other community-based groups." They also reported that "skills-building training" had been "identified as another high priority by neighborhood and business association leaders as well as community leaders of color.” PITF members stated that additional resources would be need to support creating linkages between community organizations and strengthening "the capacity of communities of color to advocate on their own behalf and develop culture-specific training" (10-11). PITF recommendations in this area included:

- "Adequately fund and expand citizen education and training in City processes and advocacy skills:" PITF members recognized that neighborhood leaders and "Leaders from other community-based organizations, particularly those with diverse of minority constituencies" often "find themselves engaged with complex City issues" and may be "unfamiliar or ill equipped to respond in a timely and effect was or to organize others to participate." PITF members recommended the 
development of a "leadership training program, open to the public" that would "cover basic City processes and advocacy skills" to help individuals be informed and effective advocates for their communities. They recommended the development and delivery this training should be adequately funded and expand on existing trainings in the neighborhood system, and partnerships with diverse community-based organizations and existing local institutions (11-13).

- $\quad$ Support the creation of networks between the neighborhood association system and other community-based groups: PITF members argued that "Increased relationships, communication and cooperation between the neighborhood and business association systems" and other groups and interest in the community "will build a stronger and more credible political voice" and will identify broader priorities in the community. PITF members recommended provided additional resources to the neighborhood and business association system to strengthen outreach capacity and providing "leadership training, strategic planning, and networking and relationship building between groups in the community (13-14).

- "Develop a mechanism for identifying and funding community-identified needs: PITF members recognized that, since the discontinuation of the Neighborhood Needs process, "no formal process or funding support is available by which communities can identify their own local spending 
priorities and have these priorities formally considered in the city budget planning process." They recommended that such formal process should be developed. PITF members suggested that a grant program that provided "one-time funding for community-determined projects" or "build organizational capacity for groups to be more effective partners" with the City" might meet the same goals and the Neighborhood Needs process. PITF members noted that "Several Commissioners have expressed strong interest in replicating the Seattle [Neighborhood Matching Fund] model" (14).

Coordination across City Government: PITF members recommended that City bureaus "should coordinate their public outreach and involvement resources and activities to make the best use of city resources and public time and efforts." They offered the following recommendations:

- "Create an internal citywide web-based management system for public involvement contacts:" A central database of stakeholder contacts would help reduce "duplicate, outdated, and deceased persons mailings," "reduce inefficiencies in printing and distribution costs," and reduce duplication of staff effort across different bureaus. Allowing interested stakeholders to filter email notices and messages from the City by "City bureau, project, and geographical region" would prevent "email overload" for individuals in the community (14-15). 
- Coordinate diverse stakeholder contacts and relationship building efforts: PITF members asserted that the City was not "adequately reaching people of color and other underrepresented groups through institutions [they] trust" and "to which they relate." "People do not see City notices in a diverse range of media. Mainstream newspapers do not reach people of color, youth, etc. The Daily Journal of Commerce is not sufficient for official notice.” PITF members recommended that City staff "develop ongoing relationships with diverse community organizations, media, and leadership" and that the City "diversify its base of community contacts" and make them "readily accessible" to City bureaus. PITF suggested a number of specific relationship-building and outreach strategies to accomplish this.

- Coordinate with the City's Office of Affirmative Action on accessibility issues: PITF members suggested that City public involvement staff use the City's Office of Affirmative Action workplan for accessibility and adaptability as a template to evaluate their own public involvement efforts and look to the agency's workplan and 2002 Diversity Development Strategic Initiative for additional ideas. A couple of these ideas included: assessing City bureau public involvement policies to ensure they support accessibility for "diverse constituencies," such as ensuring that "meeting spaces are accessible to people with disabilities," that resources are allocated for "translation or interpretation" and building lists of "diverse 
stakeholders;" and developing strategies to recruit "diverse representation on City Boards, Commissions and Committees." PITF members also recommended the creation of a "Public Involvement Advisory Committee" to "advise City bureaus on developing and implementing citywide and bureau diversity workplans related to public involvement" (16-17).

Process Design: PITF members emphasized the importance of "well-designed" public involvement processes that "appropriately fit the scope, character, and impact" of a policy or project" and that are "able to adapt to changing needs and issues as a process moves forward." They noted that "City bureau public involvement processes can be inconsistent" and called for a "basic framework for developing, implementing, and evaluating public involvement processes." PITF recommendations in this area include:

- $\quad$ Require city bureaus to develop formal written public involvement policies: PITF members recommended that the City Council require, by ordinance, that "every city bureau develop written public involvement policies and strategies that define their vision and goals for how their bureau will be consistent with and implement the public involvement principles." The PITF members recognized that the policies would vary "according to the type of work and needs of individual bureaus" but recommended that the policies describe bureau activities that would require public involvement, list a range of public involvement strategies appropriate to the work of the bureau, provide general guidelines to guide 
bureau staff in developing "project-specific public involvement plans," and "Implementation and evaluation strategies." PITF members stated that the bureau public involvement policies "must be available to the public," and recommended the development of a "model public involvement policy" to guide bureaus in developing their own policies (18-19).

- $\quad$ Refine the city budget outreach process: PITF members argued that community members need "early information" and "involvement" to "provide informed input on decisions about project prioritization, funding, and levels of public involvement in implementation." They identified the city budget process as the "first step for project implementation" and asserted that involvement of community members in the city budget process should go beyond "simply voting on the prioritization of preselected projects." In addition to recommending the refinement of the Your City, Your Choice process, the PITF suggested that a task force of city staff and community members be set up to "research and make recommendations for improving public participation in the City bi-annual budget process." (The Budget Outreach Study Group (BOSG) was created in response to this recommendation. The BOSG's findings and recommendations are described below.) PITF members also suggested that the use of Bureau Advisory Committees (BACS) be re-evaluated and that city bureaus should maintain a calendar, updated annually, that would 
inform community members about "projects that are being funded and the level of public involvement for each project" (19)

- $\quad$ Require written public involvement plans for certain projects: PITF recommended that the City Council require bureaus, by ordinance, to prepare "written formal public involvement plans for certain types of city projects and policies, such as large capital improvement projects, and policies and projects that either involve high levels of public spending or have significant impacts in the community."

- Develop guidelines for bureau public involvement processes: PITF members recommended the development of guidelines for "public involvement plans" for projects that address: conceptual design, technical process design, implementation, feedback to the community, and followup evaluation. PITF members stressed the importance of integrating public involvement up front as part of the overall project design—not after the rest of the project design has been developed. They suggested the development of a "checklist to guide bureaus in evaluating the appropriate level and nature of public involvement processes." (In response to this recommendation, Mayor Tom Potter's, Bureau Innovation Project \#9 would develop such an assessment tool for city bureaus.) PITF members also recommended the development of a "Best Public Involvement Practices Handbook" and a review of the existing "minimum notice requirements" that determine the minimum period of time for public 
notice before a bureau or the City Council acts on a "major policy or capital improvement projects as well as other types of projects." PITF members additionally recommended that "important public involvement documents" be posted on the City's website, that guidelines be developed on how bureaus "should provide feedback to the public after project completion," and that a template be developed to guide bureaus through an evaluation of the public involvement plans, process and outcome" (20-24).

Ongoing Communication and Dialogue: PITF members recommended that "City decision makers and staff should establish clear, understandable and ongoing communication and dialogue with the public and with formal groups in the community. To help accomplish this, PITF members recommended: the creation of a central "Public Information Office" "to coordinate bureau development of citywide communication and media relations (similar to the ASR recommendation); the development of "policies and a system for improving the quality, accessibility and transparency of public information, including addressing the digital divide;" and better utilization of "existing community resources for project outreach." PITF members accompanied each of these recommendations with additional detailed suggestions (24-28).

Diversity and Accessibility: PITF members asserted that "Culturally appropriate and effective strategies and techniques should be used to reach out to and involve constituencies traditionally under-represented in the community-for example, people of color, immigrants and refugees, youth, people with low incomes, seniors and people with disabilities." PITF recommendations in this area include: 
- Improve accessibility of public involvement events to people with disabilities, seniors, and others: PITF members recommended the bureaus commit the resources necessary to ensure broad accessibility of City public involvement events, especially by ensuring that all locations are ADA accessible and to reduce barriers to involvement by providing transportation assistance, language translation and interpretation, and child care support.

- $\quad$ Reduce barriers to participation by "minority, Women and Emergency $\underline{\text { Small Businesses (MWESB)" to City professional services contracts for }}$ public involvement services.

- "Improve accessibility of childcare services at key public involvement $\underline{\text { events to expand participation of families with children in City public }}$ involvement processes.

- "Expand language translation and interpretation accessibility of City information."

- "Engage youth and young adults in civic activities through communitybased service learning."

Government Accountability: PITF members asserted that "City elected officials, decision makers and staff must be accountable for following the [PITF] governance and public involvement principles." They noted that city government, at that time, did not provide bureau directors, managers and staff the "direction or structure needed to encourage" them to "implement the level and character of public involvement" described 
by the PITF principles or to hold "city commissioners and city bureau staff accountable for following public involvement principles and standards.” PITF members presented recommendations in the following areas: Accountability, Transparency, and Evaluation.

The "Accountability" recommendations included:

- Incorporation of public involvement responsibilities into formal bureau employee job descriptions: The formal job descriptions for "bureau directors, a designated bureau manager and at least one bureau staff person" should clearly describe responsibilities for "the development and implementation of public involvement plans" and "public process management." PITF members recommended that language requiring "general support of effective public involvement, should be included for bureau employees at every level to establish a culture of collaboration and partnership between government and the community" (35).

- Include evaluation of "compliance with public involvement principles" in formal personnel reviews for "bureau directors, managers, and staff" (36).

- "Require bureau directors to provide to the City Council annual progress $\underline{\text { reports on their bureau's efforts to improve public involvement }}$ performance and efforts to implement these proposals" (36).

- "Utilize the [City] Ombudsman Office to respond to specific public concerns about public involvement implementation by city bureaus: In Portland city government, the Ombudsman can investigate complaints by community members that a City bureau did not follow established process 
requirements. PITF members noted that if the City Council were to place public involvement standards and requirements in City code, "the Ombudsman could formally investigate complaints that city bureaus did not follow established public involvement requirements. In such a case, the Ombudsman could begin to play a role in helping enforce establish public involvement standards rather than just leaving compliance up to the discretion of each city bureau (36).

- "Require documentation of public involvement actions and outcomes" to accompany all proposed ordinances that go before the City Council: City staff already had to submit certain types of information along with any ordinances they presented to City Council for approval. PITF members recommended requiring city staff to complete a form, as part of this packet of information, that would describe any public involvement done related to the preparation of the subject of the ordinance and any effect public involvement had on shaping the subject of the ordinance. PITF members clarified that the "purpose would be to encourage city staff to think about...public involvement needs" and to "provide the public and elected officials with evidence of the extent to which the public was involved" (36)

- "Establish a standing Public Involvement Advisory Commission to advise bureaus and hold the City accountable to [the] adopted public involvement principles and guidelines," and create a new position to support the 
Commission: PITF members recognized that many of their recommendations were unlikely to be implemented without some sort of ongoing body that would "review and advocate for implementation of the public involvement principles" and the PITF recommendations. They noted that "Many other City policy areas have formal boards or commissions that focus both public and government attention on issues and provide a vehicle to review and comment on related city government activities" (38). (PITF members also noted that Metro and Multnomah County both already had had ongoing "citizen involvement committees" with "similar roles" to that of the proposed commission.)

PITF members recommended that the commission "include both community members and city staff to best facilitate problem-solving efforts" and that a staff person be funded to support the commission's work. PITF members recommended that the commission be charged to: track implementation of the PITF principles; review bureau public involvement policies and plans; establish a baseline measurement and measure annually the "involvement by traditionally underrepresented groups;" institutionalize the role of under-represented groups to ensure they have a voice in holding the City accountable for effectively reaching out to their communities; prepare an annual report on the City's public involvement efforts; and “Work closely with [the City] Auditor's Office 
and Ombudsman Office" to develop "procedures for responding to complaints and recommendations for corrective action" (37-38).

PITF members suggested that the commission also could advise the City on "Culturally appropriate public involvement techniques," "Education and training" needed to "build the capacity of" leaders of neighborhood associations and other community-based organizations; and the use of different public information and communication strategies (37-38).

PITF members stressed that the work of the commission could not be "effective without adequate staff." They argued that, at a minimum, staff support would be needed to prepare "its annual report, scheduling, member recruitment, agendas and minutes." PITF members also supported the inclusion of some "public involvement questions" in the City Auditor's annual survey of community satisfaction—something PITF members noted that the City Auditor and ONI already had been discussing (38).

PITF members asserted that "the workings of government must be transparent, to ensure that community members can be involved meaningfully in the democratic process and the civic life of our community." PITF members identified two types of transparency: "governance/global transparency" related to "how the city operates, coordinates internal 
activities and provides expectations;" and "project-specific transparency" related to "how the city communicates to the public" and the process design of a particular project (39).

PITF members identified basic principles of transparency that included:

- "[T]imely, accessible and understandable information" that is available to the public.

- Easy access for community members to information about current and upcoming city programs and projects including: “The key decisionmaking process; Key decision points, who makes final decisions[s] and when; Factual and legal/policy bases for decisions;" information about which staff are responsible for the project and the organizational structure in which they operate; "Expected budgets, timelines, workplans, schedules; What type and level of public involvement will occur and when, and avenues for appeal/review and deadlines."

- Honest and timely sharing of information, "including presentations of pros and cons and likely costs and impacts of proposed actions."

- Checks and balances that monitor government openness.

- "Policy impact assessments" that provide "a clear r4ational for the project, state why" it is being proposed, and an analysis of the pros and cons of alternatives.

- Identification of the range of public values affected by "each project or process" (39).

PITF “transparency” recommendations included: 
- "Establish consistent policies and processes for responding to formal public records requests" (40).

- 'Develop clear criteria for putting items on the City Council's consent agenda-both routine and 'emergency' ordinances" and prepare and make available to the public "a summary statement and backup information" about the item: PITF members were responding to the common practice, at the time, in which City Commissioners and City bureaus sometimes would bring controversial items to the City Council for action on the council's "consent agenda," which allowed council members to vote on them without any public testimony (40).

- "Develop a more user-friendly system for providing public access to complex policy, planning and capital project-related documentation" (4041).

PITF members asserted that ongoing monitoring, evaluation, and reporting would be needed to determine how well "city elected officials, decision makers and staff" followed the PITF principles in their development and implementation of city policies, projects, and services and to determine the effectiveness of "individual public involvement processes." PITF members noted that Portland city government did not have any such evaluation programs or mechanisms at the time of the PITF study (41). PITF "evaluation" recommendations included:

- "Implement regular evaluation of public involvement process by bureaus" (41). 
- "Review bureau compliance with PI principles and requirements through formal performance and management audits" (41)."

- "Establish peer review of bureau PI Plans by PI staff:" This recommendation referred to review of city bureau proposed public involvement plans by other city public involvement staff people through the city-government-wide peer networking group recommended earlier" (41).

PITF Next Steps: The 2006 PITF Report closed by identifying six “core recommendations" as the highest priority for implementation by then Mayor Tom Potter. These included:

- Adopt, by ordinance, the public involvement principles.

- Direct all city bureaus to develop overall "formal written public involvement policies" for their agencies and develop a "model policy" to serve as a "framework" for this effort.

- Require written PI plans for "certain types of major capital, policy and planning efforts."

- Ensure that city bureaus use "culturally appropriate and effective strategies and techniques" to "reach out to [and] involve" underrepresented communities in Portland.

- "Establish a stable funding mechanism for public involvement processes." 
- "Establish a standing Public Involvement Advisory Commission to advise bureaus and hold the City accountable" for following the adopted public involvement principles, standards and guidelines.

- Create a staff position to support the commission and "issue an annual report, among other duties" (ix).

The PITF, for the first time in Portland, provided a detailed and comprehensive strategy for improving city government public involvement. Other earlier processes had identified the need for principles of public involvement and some of the same recommendations. The PITF was the first process to map out detailed follow up steps to ensure that good community involvement values and practices would become embedded in the City's policy structure and the organization culture of city bureaus and lead to a significant improvement in the quality and consistency of community involvement efforts across city government. The value of the PITF effort would be borne out by the high number of its recommendations that were implemented in the coming years or are still high on the agenda for implementation in 2013.

While the PITF work was winding down in 2004, a small study group formed to review community involvement in the city budget process, implementing one of the many PITF recommendations.

\section{Budget Outreach Study Group_-2004-05}

The city budget is where some of the most important decisions that affect the community are made. The PITF had not been able to focus much attention on community participation in the city budget process. Laurel Butman (PITF co-chair and lead staff 
person on community outreach for the city budget process) and a small group of community members formed the 2004-05 Budget Outreach Study Group (BOSG) to examine the challenges and opportunities for improving community involvement in the city budget process. ${ }^{72}$

BOSG members recognized that Portland's new mayor (Tom Potter, who was elected in November 2004) would take office in January 2005 and that he was likely to want to institute "a new or modified budget outreach process" for the FY 2005-06 budget - an off year for YCYC (Portland. Office of Management and Finance. Budget Outreach Option \& Analysis. September 2005 5). Butman and the other BOSG members saw an opportunity to influence Potter's decision about how to involve the community in the development of the city budget in the future.

The study began by recognizing a "paradox." Community involvement in the City budget process was very important because the city budget served as a primary articulation of the City's values and priorities. At the same time, to participate effectively in the budget process, community members needed to understand the programs being funded and why. Group members noted that the city budget is very complex, as are the city's "financing and accounting processes," and these "are not processes that are accessible or evening interesting to most people" Any process to involve the public in the development of the City budget needs to acknowledge the complexity of the budget process and the uneven civic capacity and limitations of government participation

\footnotetext{
${ }^{72}$ One of the BOSG members was southwest neighborhood activist Amanda Fritz. Fritz also had served on the 1995-96 TFNI. She later would serve on Portland's Planning Commission for many years and then would run for a city council seat under Portland's short-lived publically funded campaigns program. Fritz starting serving on Portland's City Council in 2009 and served as the ONI Commissioner from 2009 through 2012.
} 
processes to involve people in meaningful ways (Portland. Office of Management and Finance. Budget Outreach Option \& Analysis. 2005 3).

Mayor Goldschmidt had required city agencies to create budget advisory committees with community members to help them develop their budget proposals. By the late 1980 s, nearly all of city bureaus had budget advisory committees. In the early 1990s, Mayor Katz had discontinued the program and soon very few bureaus had budget advisory committees. Instead, Katz had instituted the "Your City, Your Choice" program in 1994. The YCYC was conducted every other year and usually included a series of community budget forums prior to Mayor Katz's release of her proposed budget and one or more community surveys. The object of the forums and survey was to "gather information about community priorities for the budget among major service area categories." Sometimes the forums would be coordinated with the City Auditor's release of the "Service Efforts and Accomplishments" report, which reported on the performance of city bureaus and often included comparisons to service provision in other cities (4). The City's Office of Management and Finance (OMF), which was in charge of the city budget process, also had created a website which provided information for community members about the city budget and budget process.

BOSG members found that the YCYC process was good at providing Mayor Katz with some input on general community priorities for services and at providing community members with general information about the budget process. The process was not very effective at providing opportunities for more active stakeholders to become educated and involved in the budget process." Because the forums also took place late in 
the bureau budget development process (which actually starts in the late summer and fall), the YCYC did "not meet some involved stakeholders' desires to be a part of the actual decision making" (6).

BOSG members identified some key factors to improve community involvement in the budget process in the future. These included:

- Integration: BOSG members believed that "people would like to see visioning and planning work tied to the budget in a transparent way. City Council and community priorities in the budget should be clear. The process itself should make people feel invested in the whole system, contributing to the decision making, and feel their priorities are included in the outcome."

- Match Activities to the Audience: A major finding of the BOSG was that different audiences existed in the community and that "these audiences require different levels of information and education to engage them effectively."

- Focus on Outcomes: Good public involvement design requires a "clear focus on the types of outputs and outcomes that are anticipated and desired from any participation process" (6-7).

The BOSG identified four different audiences:

- Expert or Broad Stakeholders: "These are long-term advocates who regularly participate in various City planning and policy-making initiatives, often acting as leaders and advisors in the community...." 
These individuals often are interested and want to be involved in "systemic change" and/or "citywide issues and impacts" (7).

- Focused Stakeholders: "These are community members who focus on a single issue area or geographic area..." They usually want to influence decisions about a particular project or service type or decisions that affect a particular part of the city. They often stay involved with their chosen issue over time (8).

- Casually-involved Stakeholders: “These are community members who may attend City sponsored events that interest them or because a political or livability issue has sparked their interest." If they attend a community budget forum, it "may well be their first meeting on City business." They often are seeking action on a specific project or basic information on how they can get more involved (8).

- The Uninvolved: “These community members rarely, if ever, interact with the City as a local government. They may read about the City and vote, but take a passive rather than active interest in city government projects, initiatives, and policy." Their need is more for basic information about City services in general and opportunities to share their opinions on basic city services (8).

The BOSG's recognition that different audiences have very different levels of interest and capacity to participate in city budget decision-making was a crucial insight for any future effort to improve community involvement in the City's budget process. 
The BOSG found the existing YCYC process was good at providing basic information for individuals in the "casually-involved" and "uninvolved" audiences. The lack of opportunity for more in-depth discussion and analysis and the limited opportunity to have much of an effect on actual decisions about the city budget made YCYC often very frustrating for "focused" or "expert" stakeholders and left them feeling “disenfranchised." A single process, like the YCYC, could not meet the needs of all of these audiences.

BOSG members examined a broad array of strategies and tools by which to improve future community involvement in the budget process and meet the needs of different audiences. They divided these strategies and tools into four broad categories: use of Internet technologies, public input, ongoing education, and community capacity building.

Internet Technologies: The BOSG members recognized that web-based tools offered the opportunity to offer community members a number of opportunities to access information, receive formal notifications, participate in surveys and budget exercises and "games," and pose questions and receive answers, and submit suggestions, comments, and formal testimony. The BOSG members also recognized that not everyone has access to the Internet and that additional strategies need to be developed to reach out to and involve these individuals (11-12).

Public Input: Community surveys and the YCYC community budget forums were good at soliciting general the opinions and priorities of community members related to city services. They did not provide much opportunity for community members to 
identify new needs or to get more deeply involved in understanding and influencing priority setting and decision making by individual bureaus or the city budget as a whole. The BOSG members suggested additional approaches.

One was some sort of a renewed and improved "Neighborhood Needs" process to "link a neighborhood needs process with a finite amount of dedicated funding" rather than just generating a wish list of projects and leaving it to city staff to decide which to pursue (similar to the discontinued Neighborhood Needs process from the 1970s and 1980s). BOSG members suggested the creation of a grant program, similar to Seattle's Neighborhood Matching Program.

BOSG members suggested additional efforts to involve community members in bureau development of their capital project budgets. They recognized that the citywide capital project outreach pilot project in 2001 had not been particularly successful. Some bureaus had created processes to inform the public about their capital projects, such as the PBOT's CIP workshops to "identify critical neighborhood projects" and the Water Bureau's capital project workshops. While these processes did not require the same level of inter-bureau coordination at the 2001 citywide process, these processes still faced the challenge of how to ensure that community members had enough information and understanding to participate in a meaningful way.

One option for responding to the "community capacity" challenge, was to reinstitute some form of bureau "budget advisory committees" and some form of citywide committees with community members participation. The BOSG members recognized that the BAC program in the 1970s and 1980s had been discontinued for a 
number of reasons, including: "committees became too insular (either in support of a bureau or insulated from members' own constituencies); roles and responsibilities [of BAC members and the level of community participation on the BACs] varied across bureaus, resulting in disparate results; the capacity and/or commitment of committee members to interface back to their own publics lagged." While the BOSG members found that BACs could be useful, they cautioned that BAC members needed to reach out to and engage the broader community rather than the $\mathrm{BAC}$ becoming an exclusive vehicle for the community members who served on it.

More elaborate "participatory budgeting" processes, similar to those used in some other cities, were another option. BOSG members recognized that these processes provide a much more structured and far-reaching opportunity to involve the community in priority setting and the development of the City budget. These processes also require higher levels of resources and a much longer time commitment (14-18).

Ongoing Education: General, ongoing education of community members in particular policy areas can help community members develop the civic capacity to participate in complex processes and in complex projects and enable them to provide more meaningful input. BOSG members noted that these types of processes-not being tied to a specific project—often are "difficult activities to justify funding." BOSG members identify one good model as the "PSU Traffic \& Transportation Class" which educated community members on how to advocate for transportation projects in their community. This class had been offered regularly for a number of years at PSU. Similar classes could be developed for other policy areas. Another option was the development of 
a one-time or annual citywide budget forum in the summer or early fall that would help community members understand how to get involved early in the budget development process when they have much more chance to affect the outcome. BOSG also suggested a "brown bag" series of talks that would introduce community members to different aspects of the budget process. The talks could be video-taped and made available on the City's website.

BOSG suggested that, rather than relying only on processes driven by city staff, community groups, such as the neighborhood coalitions, could receive training and then take the lead in training their own board members and neighborhood members on the city budget process. Coalition staff would become important resources for community members and could support community members in identifying and advocating for the budget priorities (18-20).

Community Capacity Building: BOSG members recognized the advantage of "the community taking a lead in its own education" and said these efforts could include "building institutional knowledge from the ground up, to achieving consensus on agendas for influencing government decisions, to ensuring newcomers become rapidly competent at civic engagement activities." The also recognized that the existing power structure in Portland might be threatened by this approach." An "informed and effectively engaged public can pose some threat to the balance of decision making power in government"-"Community capacity is sometimes a challenge to political system." BOSG members identified options including a grassroots, "citizen-run citywide forum" or a process of "community-based development of priorities and proposals" (21). 
In closing, the BOSG members drew attention to the need for city external communications about the budget process to clearly identify the "issues at stake" to encourage greater involvement and to be two-way-both providing education and easily accessible information, and providing closure by letting community members know what affect community input had on the final budget decisions. They also emphasized the "value of relationship building" and the need to invest the "time, resources and education" to "create and maintain long term relationships with people" (22-23).

BOSG members also identified potential "challenges" with existing public involvement in the city budget process that would need to be overcome, including:

- Building partnerships with community-based organizations, churches, and other community groups to build networks and identify potential “spokespeople/leaders.”

- Clearly defining the community audience to be reach, goals for involving them, and identification of what would make their involvement feel successful to them.

- Matching technical information to particular audiences.

- "Acknowledging the important of building relationships and the time that takes" and differentiating between community involvement that is meant to meet a formal requirement and "true 'participation."”

- Following up with community members and "closing the feedback loop" to "let citizens know their comments were heard and that their 
participation was appreciated," and to let them know about "other opportunities for involvement" (22).

While the BOSG members already were looking to the opportunities for improved community involvement symbolized by the election of Tom Potter, it is helpful to step back a moment to understand the context of intensive conflict between city leaders and community members shaped the PITF and BOSG work and that set the stage for Potter's election victory and the strong community expectations for rapid and meaningful improvements in community involvement that came with it.

\section{ONI Commissioner Randy Leonard}

In the early 2000s, Portland's community and neighborhood involvement system had no strong political champion on the city council. Mayor Katz assigned responsibility for ONI to three different commissioners between 2000 and 2004 (i.e. Saltzman, Francesconi, and Leonard). This period was characterized by increasing conflict between neighborhood and community activists and City Hall and the worst relations between City Hall and the community in many years.

Randy Leonard, former Portland fire fighter, president of Firefighters Union, and state legislator from East Portland, was elected to the Portland City Council in 2002. Leonard came into office with strong union support and was seen by many as providing, for the first time, a voice for working class people and others in east Portland, who had felt disenfranchised and ignored by the city council since the City of Portland had annexed their area in the late 1980s and 1990s. 
Leonard long had been known for "aggressiveness toward adversaries" and his willingness to engage in "flare-ups" as a state representative. Shortly after his election as a city commissioner, the Oregonian reported that Leonard "declared that he would tackle 'rude, condescending or hostile behavior' in the city's work force. After a month in office, it's Leonard whose knack for feuds has made some fear him as a rude and hostile inquisitor"-referring to complaints by city staff and bureau directors who already had been targeted by Leonard (Stern. Oregonian, December 24, 2002).

When Mayor Katz assigned the city bureaus to the different city commissioners in December 2002, she assigned ONI to Leonard. Leonard went on to preside over one of the periods of greatest conflict between ONI and the neighborhood system in the history of Portland's neighborhood and community involvement system. Oregonian articles from the time capture some of the intensity and drama of the conflict between Leonard and his critics during his, just over, two years in charge of ONI.

Leonard had big ideas for how to reshape and redirect ONI. In July 2003, he unilaterally announced that he wanted to change ONI's name to the "Neighborhood Services Bureau" and that he was moving twenty-two neighborhood and housing inspectors and noise control staff from the Bureau Development Services (BDS) to ONI. Leonard believed that the move would "give residents one place to turn for problems from abandoned vehicles to loud noise," make these services much more accessible to a broad spectrum of community members, and speed up the city's response to complaints. Leonard also said he planned to "start a year-long pilot project [in] October that would put a senior neighborhood officer, crime prevention specialist and neighborhood 
inspector into the city-staff run north Portland neighborhood office (one of the two neighborhood district offices run by ONI not an independent community board of directors) (Stern. Oregonian, July 22, 2003).

Neighborhood coalition leaders were alarmed. Southeast Uplift leaders told the Oregonian that they feared "the change would dilute [ONI's] commitment to citizen involvement and wrongly shift its focus to services." They also were "unhappy about what they consider to be the lack of citizen involvement in the process." Southeast Uplift representatives said they planned to speak out against the name change and "against the added functions and the way they were presented." The Oregonian quoted Cynthia Peek, the Southeast Uplift board president, as saying "I feel they're trying to cut citizens out of decision-making" (Stern. Oregonian, July 22, 2003).

In September 2003, Leonard clashed with neighborhood activists again over the City Council's decision to allow houses to be built on substandard "skinny" lots in older parts of Portland. Neighborhood activists organized and mounted an aggressive citywide advocacy effort against the policy. They believed creating this exception in the city code would generate a wave of infill development that would damage the character of these older neighborhoods. Portland Planning Commission members agreed, and the City Council voted to reverse the policy. Oregonian columnist Rene Mitchell credited the reversal to "a bit of good luck. An unapologetically bullheaded approach [by neighborhood activists]. And a hesitant link in the ego chain of four stubborn men who all believed they stood on the right side of the truth" (Mitchell. Oregonian, September 12, 2003). 
At the city council hearing at which the council reversed its decision.

Commissioner Erik Sten said "I underestimated the damage to the neighborhoods and how strongly people felt about it." Mayor Katz thanked neighborhood activists and acknowledged that "the neighborhoods were right from the beginning." Commissioner Randy Leonard, "though, maintained his righteously indignant opposition to changing his mind" and was the sole vote on the council not to reverse the city council's earlier decision (Mitchell. Oregonian, September 12, 2003).

In September 2003, ONI Director David Lane announced that he would leave his position to take advantage of an opportunity to move with his partner and their sixmonth-old twins to Hawaii. Lane said his decision to step down had nothing to do with Commissioner Leonard and that he enjoyed working with him. Lane said the move has been in the works for several months (Stern. Oregonian, September 22, 2003). Leonard quickly announced his intention to replace Lane with Jimmy Brown, the manager for the Multnomah County Department of Justice and a childhood friend of Leonard. Leonard did not reach out to the community for any input on Lane's replacement (Stern. Oregonian, September 26, 2003).

Leonard clashed again with neighborhood activists in October 2003 at a community meeting and "pledged to stay as long as needed to explain [to the neighborhood activists] the revolutionary changes he wants for the 30 -year old system of city-financed citizen participation" from "its role as all neighborhoods' voice to City Hall, into City Hall's service centers to neighborhoods." Leonard claimed that his plan to change the focus of ONI was responding to concerns he heard while he was campaigning 
from "residents who don't have the time to attend neighborhood meetings or feel excluded from them." Leonard said his vision was that "residents will use their neighborhood associations as one-stop service centers"..."mini-City Halls”...”to pay traffic tickets, get abandoned cars hauled off or pay utility bills." Leonard told the neighborhood activists at the meeting "You're going to see a level of service people in the neighborhoods have never seen before" (Nkrumah and Stern. Oregonian, October 2, 2003).

The Oregonian reported that "the first-year commissioner's answers [at the community meeting] didn't satisfy many of the questioners, bitter about a growing power struggle between the City Council and longtime supporters of a system that once won national recognition for engaging ordinary citizens in the workings of government." Charles Ford, chairman of the Northeast Coalition of Neighborhoods, said "We are no longer participants....That's not the way we're accustomed to doing business in Portland, Oregon." Leonard also had stirred controversy by deciding, without any community input, to force "longtime neighborhood crime prevention specialists [to] reapply for [their] jobs with expanded duties that include cracking down on problem liquor establishments" (Oregonian, October 2, 2003). ${ }^{73}$

Neighborhood activists critical of Leonard's plan and some of Leonard's fellow city council members were becoming increasingly concerned. Leonard's critics worried

\footnotetext{
73 It's interesting to note that Leonard attempts to unilaterally implement his proposed changes to Portland's neighborhood system, stood in stark contrast to the values and direction of the work of the Southeast Uplift DRC and DCLC — which was looking at really would involve and give a greater voice in decision making to people from under-represented communities in Portland, and the PITF-which was developing very sophisticated and detailed recommendations to improve city government community involvement. Leonard did not consult with any of these groups as he developed his system reform proposals.
} 
that the "trade-off" would be "top-down dictation from the City Council with dissent squashed and neighborhood voice ignored." Mayor Katz (no strong supporter of community involvement herself) said she could not "remember a time in her three terms [as mayor] when relations have been so strained." Katz went on to say "Neighborhoods are feeling a majority of council may not be as sensitive to issues raised before the council....Neighborhoods might feel like they're getting bullied and not being listened to. Are we there now? We're close to being there. I think we're closer now than ever before." The Oregonian reported that "the council's seeming new tack in dealing with neighborhood leaders and their issues has been a rude awakening for activists. This is especially so in a city that long has proudly touted its public involvement process as a model" (Nkrumah and Stern. Oregonian, October 2, 2003).

A number of neighborhood leaders from different districts in the city began speaking out against what they saw as attacks by the city council on the neighborhood system. They asserted that City council members had gone from frequent allies of neighborhood activists to adversaries. One activist stated that the "traditional Portland sense of [shared] governance just doesn't have a lot of meaning for them." Leonard countered by saying "he draws a 'distinction between people active in neighborhood associations and neighborhoods." He complained that "some people...feel they need to sign off on everything we do...Procedural measures are important obviously, but there a point at which I grow impatient by talking. I want to implement." Commissioner Dan Saltzman, who stubbornly had been insisting on covering Portland's historic open reservoirs in the face of intense community opposition, said "politics can't get bogged 
down over process in every instance." He said "I think maybe part of the rub is we have a City Council now that seems to want to be particularly decisive." "There are a lot of people who are not accustomed to that" (Nkrumah and Stern. Oregonian, October 2, 2003).

Clashes between city council members and neighborhood leaders over many different projects and recent decreases in funding and ONI staff support for the neighborhood system threatened the health of Portland's long-standing culture of grass root activism and cooperation between city government and community members. One neighborhood activist said the city had lost "a 'shared vision' under which the council and neighborhoods would work together to solve issues...there was a value that was recognized in conducting the process that way, that you got a better decision if the citizens were involved" (Nkrumah and Stern. Oregonian, October 2, 2003).

Mayor Katz became particularly alarmed, in October 2003, when, Leonard, Saltzman, and Franesconi, joined forces to unilaterally change a proposed district plan for NW Portland, which had been negotiated with broad community involvement and input over a number of years. They chose to allow a prominent developer to build a number of parking garages over strong opposition of neighborhood activists. Mayor Katz, who had opposed allowing the garages, said that "special interests have won"" at the expense of the community. "I hope that we realized that the message that this sends to other neighborhoods is that they all are in peril" from this city council (Nkrumah. Oregonian, November 5,2003$).^{74}$

\footnotetext{
${ }^{74} \mathrm{NW}$ neighborhood leaders refused to agree to the changes in the NW District Plan. They showed their strong displeasure by organizing a parade of community members who marched down the street with a
} 
Leonard continued to argue said he'd had "hundreds of conversations" with Portlanders "who want better and more accessible city services in their neighborhoods"Portlanders who "may be too busy with family and work to attend neighborhood meetings but also deserve a voice." Leonard said "There are people who don't have time for process....They want results" (Stern. Oregonian, October 7, 2003).

New ONI Director Jimmy Brown, a former manager in the Multnomah County Department of Community Justice, began work in November 2003. Some neighborhood leaders soon began to complain that ONI leadership had stopped listening to the community and criticized Brown's effectiveness. Some community members reported that the ONA BAC, under Brown's leadership, no longer modeled inclusive and collaborative approaches to decision making and had become a "rubber stamp" for decisions by Leonard. Some community members praised Leonard for his leadership in championing changes to city code that strengthening the City's mechanisms to regulate liquor license establishments in Portland's neighborhoods. ${ }^{75}$

\section{$\underline{\text { Seltzer Sharpe Strachan Proposal-November 11, } 2003}$}

Many supporters of community and neighborhood involvement were becoming increasingly alarmed at the changes to the system under Commissioner Leonard and the increasing conflict between city leaders and agencies and neighborhood and community activists. In November 2003, three prominent community leaders called for a return to

copy of the NW District Plan and then ceremonially burned the document in front of a house designated for demolition to build one of the parking garages (Sieber. Conversation with Mark Sieber, October 17, 2013).

${ }^{75}$ Leonard lead the effort to have the City Council adopt Ordinance 178201 (substitute, as amended) on February 18, 2004, which adopted "time, place, manner" restrictions on liquor establishments and directed ONI Liquor License Notification Program (started in 2000) and the Portland Police to support the implementation of the new regulations. 
ONA/ONI's original focus on supporting community organizing and empowerment. The three included: former city commission Margaret Strachan, former city commissioner and author of the 1992 report on ONA; her husband Sumner Sharpe, a well known local planning consultant and founder of the urban planning program at Portland State University (PSU); and Ethan Seltzer, director of the PSU Toulan School of Urban Studies and Planning (and former land use staff person at Southeast Uplift in the 1970s!) (Seltzer, Ethan and Sumner Sharpe and Margaret Strachan. Imagine a City of Engaged, Articulate Citizens and Neighborhoods. November 11, 2003).

Strachan, Sharpe, and Seltzer charged that Portland's neighborhood program "once broadly recognized as a catalyst for civic innovation" had become "a shadow of its former self." They argued that ONI, "rather than promoting and sustaining neighborhood organizing as a means for ensuring a steady flow of new participants into neighborhood association activities, and articulate and empowered neighborhoods" had become "a topheavy bureaucracy intent on defining performance in institutional rather than grassroots terms." The three called for "a new commitment to neighborhood organizing, a willingness to define performance goals in terms of community needs and processes, and a refocusing of effort on neighbor-to-neighbor interaction."

Strachan et al argued that, in the 1970s the City Council had created ONA as a commitment " to supporting and sustaining neighborhood organizing in the belief that organized, articulate neighborhoods would be a key to Portland's future success even if, from time to time," neighborhood associations opposed the City Council. ONA's role was to efficiently pass "funds through to coalitions" whose role was to support 
organizing and provide "technical assistance at the grassroots level" and to help City agencies "listen more effectively to what citizens were talking about."

The three charged that the commitment to organizing and to a "limited role for ONA" had been "abandoned almost completely" and that ONI had become bloated and acted as an "adjunct of the city bureaucracy." "What was once a commitment to grassroots empowerment through organizing has been transformed into an ineffective central bureaucracy attempting to herd citizens through top-down devised processes."

The authors presented several principles that they believed were "essential for a healthy neighborhood system in Portland." The main themes of these principles included:

- Inclusive redefinition of neighborhoods to include "residents, business owners, tenants, land owners and anyone else engaged in the territory" of the neighborhood. They urged an end to "the parallel development of neighborhood and business associations" and suggested that neighborhood boundaries be redrawn "along more functional lines."

- Neighborhood associations as "vehicles for participation, not representation" to recognize the value of the results of participation, while also recognizing "it is not fair, just, or reasonable to expect neighborhood associations to carry the burden of representation" which is the role of elected officials and for which they should be held accountable.

- Recommitment of ONI to neighborhood organizing and to "grassroots empowerment through organizing "to ensure that "neighborhoods provide a vital forum for residents, and the vest avenue for the city to understand 
where local priorities lie;" they stressed that, done properly, this organizing would "incorporate new voices and new residents in an ongoing civic discussion" and would support the development of the leadership needed to neighborhoods develop and advocate for "an inclusive agenda of neighborhood concerns."

- Encouragement of and support for neighborhoods to solve their own problems, either through interaction with city agencies or through neighborhoods developing their own resources to meet their needs, and to "ensure that all neighborhoods have access to the tools they need to move their priorities forward."

- Refocusing of the role of district coalitions as "nonprofit organizations that receive base funding from the city to sustain organizing efforts in each of their member organizations," and to support "neighbor to neighbor communication," "technical assistance and training," and to "convene neighborhood associations to identify and act on common concerns or interassociation [sic] conflicts."

- Significant reduction in number of ONI staff that would limit ONI to "fewer staff positions that are found within any single district office....." and focus the agency on "helping city agencies understand the dialogue taking place at District meeting tables," and "training and technical 
assistance" to facilitate "more effective interaction between city staff and neighborhood associations....,76

- Crime prevention efforts that are part of a strategic community policing program and paid for with public safety funds and co-located with neighborhood district offices when both the districts and community policing leaders agree.

\section{- City investment in a neighborhood system that yields "organized} associations in every neighborhood," each with an "agenda or set of priorities," a "strategy for acting on those priorities," and a "commitment to involving all citizens in helping to frame those goals" success would be measured by "how well citizens interact with each other in neighborhoods..." (Strachan et al stress the point that "Making neighborhood associations or district offices into 'little city halls,' rhetorically or otherwise, only serves to define them from the top-down as adjuncts of the City, rather than as avenues for building community and empowering citizens."

Strachan et al recommended radically restructuring Portland's neighborhood association and neighborhood district system for Portland by dividing the city into eight to ten districts, each of which would provide "services to about 12 neighborhood

\footnotetext{
${ }^{76}$ At this time, Portland's neighborhood and community involvement system received primary support from only one staff person in the downtown ONI office. Of the $58 \mathrm{ONI}$ employee positions listed in the City of Portland FY 03-04 Approved Budget (425), ten worked in the Crime Prevention Program and about twelve supported housing and noise inspections. The 58 employees also included ONI staff at the north and east Portland neighborhood offices, and staff supporting other ONI programs, including liquor licensing, graffiti abatement, information and referral services, the Disability Program, and administration and support staff.
} 
associations." They recommended that each district receive adequate funding to support four positions: "a coordinator, an organizer charged with supporting communications efforts (publications, websites, etc.), one organizer to support planning efforts, and an office manager/information and referral position." The coordinator and two organizers each would be expected to directly support four neighborhood associations.

Strachan et al recommended that ONI be staffed by three employees: "a coordinator, an assistant for communications and technical assistance, and an office manager/information and referral position." They also recommended that ONI received $\$ 50,000$ each year to “provide mini-grants for 'civic microenterprises' aimed at furthering neighborhood organization, capacity, and cohesion." They estimated that this pared down ONI operation could be supported at an annual cost of $\$ 270,000$. They estimated that City funding required to support this pared down ONI operation and the neighborhood district offices at about " $\$ 2.8$ million per year." They claimed that this cost would be well within the level of City funding for ONI operations at the time.

Strachan et al asserted that the City needs to "recommit to tapping the wisdom of its citizens to create the next generation of civic innovation in Portland" ...re-establish Portland neighborhood system as a leader in the country...."Further, it can begin to build back the sense of community that so many citizens are seeking, but which has become confused in recent years with more bureaucratic efforts and imperatives."

Strachan et al called for neighborhood leaders to review their proposal and and recognized that the proposal would need to be "embraced broadly from the grassroots on up." They stated that "We are not interested in yet another top-down reformulation of 
Portland's approach to neighborhoods." They closed by offering their assistance, if after extensive community discussion "there is a desire to move changes like this forward" to support "a broad coalition with reformulating neighborhood associations to move Portland ahead as a model of civic innovation."

The Strachan, Sharpe and Seltzer proposal represented another strong call for ONI to return to ONA's original mission of community empowerment and a rejection of Commissioner Leonard's proposed shift for the of ONI and the district offices to being providers of city government services to the community. Strachan et al's vision for Portland's community and neighborhood involvement system included an increased number of neighborhood districts across Portland that would support neighborhood association communications, provide training and planning and technical assistance, and convene neighborhoods to discuss issues. This system would put most of its resources and activities out into the community and reverse the steady increase in the size and role of ONI-except for the administration of a new annual grant program. Strachan et al proposed measuring the performance and success of the system by the extent to which every neighborhood had an organized neighborhood association that identify the priorities of its neighbors through an inclusive process and then actively and successfully advocated for the achievement of those priorities.

\section{Election and Tom Potter-A Turning Point}

The 2004 city council and mayor elections became a turning point for community involvement in Portland. Neighborhood leaders, frustrated with their lack of success using the traditional avenues of Portland public involvement, turned to the political realm 
to try to achieve the change they sought. Tom Potter, former Portland police chief and the "father" of Portland's community policing program in the early 1990s, decided to enter the race for mayor, partly because of his alarm at what he saw as the growing disconnect between Portlanders and their city government.

Neighborhood Leaders Run Against Leonard: Neighborhood leaders were disappointed when no experienced local political figure stepped up to run against Randy Leonard, whose first, four-year term on the city council was coming to a close. Leonard was known as a very formidable candidate whose aggressive campaign tactics and strong union support made him difficult to beat. Neighborhood leaders began trying to recruit one of their own to run. Ultimately, a group of initially six, then eight, neighborhood activists from different parts of the city agreed to run as a group. They hoped to use their networks to collectively earn enough votes in the May 2004 primary election to force Leonard into a run-off. They agreed that, if they were successful, they would back whoever from their group earned the most votes. The neighborhood candidates met together often to discuss strategy and share information and advice. They participated as a group in the many candidate debates across the city and used their presence to raise their concerns about Leonard and to advocate for an alternative governance model in which city government and community members worked together as partners in local decision making.

Some neighborhood activists also joined together to form a political action committee, "Neighborhood PAC." They hoped that Neighbor PAC (NPAC) would give neighborhood activists a vehicle to have a greater voice in shaping the type of candidates 
that decided to run for the city council and who would win. They also hoped NPAC would give neighborhood activists a greater voice on city wide policy issues (similar to the PAN in the 1970s and APN in the 1980s). ${ }^{77}$

Ultimately the neighborhood candidates were not successful in forcing a run-off election. Leonard won a majority in the primary (52\%) and avoided a run off. In all, ten candidates ran against Leonard, nearly all of whom had never run for political office. Leonard's opponents together raise a total of $\$ 36,000$ in campaign funds, while Leonard raised $\$ 239,000$. Leonard said his victory vindicated him and showed that "a majority of people in Portland support my position that people in government should be accountable and tell the truth." One of the neighborhood candidates said "We've accomplished a moral victory." He noted Leonard's majority was very low for a sitting city commissioner and said "Commissioner Leonard knows the alarm bells are ringing" (Learn. Oregonian, May 19, 2004).

\section{Tom Potter's Background and the 2004 Mayoral Campaign: Tom Potter}

dramatically changed the dynamics of the mayoral election when he announced his candidacy for in the summer of 2003. Until Potter entered the race, sitting City Commissioner Jim Francesconi appeared to be the most likely next mayor of Portland. Francesconi had been campaigning aggressively and was strongly supported by the downtown business community. Francesoni diligently pursued donations and was well on his way to amassing the largest campaign war chest in Portland's local election history.

\footnotetext{
${ }^{77}$ NPAC did not become very active during the campaign, and the neighborhood leaders who created it choose not to keep it going after the 2004 election.
} 
Potter, long known for his deep commitment to community involvement and social justice, quickly drew strong grassroots support from neighborhood and community activists. Many leaders in communities of color and immigrant and refugee communities, who had worked with Potter when he was with the Police Bureau, also supported him. Other long-time champions of strong community involvement, like former Mayor Bud Clark and former City Commissioner Margaret Strachan, declared their support for Potter.

Potter brought a very unusual set of values and ideas about community and government to his run for mayor. Potter's values were rooted deep in his experiences as a young Portland officer in the 1960s. Potter said that when he first became a police officer in $1966^{78}$ a lot of tension existed between the police and the community. Crime was high, as was racial tension. Potter said that within a year of joining the police force, "we started having riots in Portland." "We would go into neighborhoods thinking we were going to protect a neighborhood without even knowing the neighborhood." "There were no gentle lessons here." "Like many police officers," Potter said, "I came in thinking that I was going to help" the community. "And yet, when I would go out, particularly in parts of northeast Portland, the acrimony was mind boggling...people hated you, and 'pig' was a very common word, plus a lot of other words...."

Potter said he started "looking and observing" and found that "the police, quite frankly, were the source of a lot of the problems. It really wasn't the community. It was the police and how we dealt with the community....we treated them in a very patronizing

\footnotetext{
${ }^{78}$ Carlin Ames, Sarah. Oregonian. October 25, 1990.
} 
manner." Potter had an early formative experience that he says had a major impact on him.

"... as a young police officer, one of the most telling events for me was that I was driving around [the] Sellwood [neighborhood] where I worked as a police officer..." Back then "Sellwood was a very poor neighborhood. It had gangs. There were drug problems." "When I went to the Police Academy, there was nothing that talked about engaging the community, because that just wasn't done. You were a law enforcement officer. You went out and enforced the law. And the community was the 'victim' or the 'suspect.",

"One day when I was driving around, this guy flags me down in my police car. I'm in uniform. I'm obviously out patrolling, and so he stops me and he says 'Officer, I know we've got some really serious problems here in Sellwood. Is there anything we can do, as a community, to help you? I was stunned. I didn't know what to tell the guy. I said, 'Well, I don't know.' I said 'I'll talk to my sergeant, then I'll get back to you. So, at the end of my shift, I go back, turn my car in, go to the sergeant, and I say 'Sarge, this citizen asked these questions. What do I tell him?' - and this is the classic definition of bureaucracy and 'we're the experts'-He said, 'Tell the guy to go back in his house. We'll take care of it." The belief was that there's no role for the public, "there's no value. In fact, there's no point in having them involved, because they'll just get in the way." Potter said that this is one of the classic characteristics of bureaucracy, "We're the experts and you're not." "I thought, "Boy, there's something really wrong here" (Potter. Conversation with Leistner, March 30, 2009).

Potter told the Oregonian how he opened up to a more "community-based"

problem solving approach to policing, as opposed to the traditional "arrest-based" approach. Potter says that "one of the first things he noticed on patrol were kids streaming into a storefront office of something called the Brooklyn Action Corps. He went in for a look himself." The Brooklyn Action Corp was one of Portland's early neighborhood associations. Local residents created the organization in 1962 and were very involved in revitalizing the neighborhood by working on urban renewal and social 
service issues. "They were doing exactly what I was doing, but I was doing it from a law enforcement standpoint. They were trying to make the neighborhood better." Potter told the Oregonian that a light went off in his head, and he saw the value of trying to solve community and social problems early on rather than relying on a reactive law enforcement strategy (Rollins. Oregonian, Nov. 18, 1990).

Portland Mayor Bud Clark came into office in the mid-1980s with a strong focus on neighborhoods. Clark decided to respond to the growing crime, drug, and gang problems in Portland partly by promoting a community policing strategy in which police worked with residents and that focused on crime prevention. Clark believed that “neighborhoods, schools, police and people throughout government need to work together to enforce community standards and find long-term solutions to the social problems that cause crime." Clark realized that community policing would require major changes within the Police Bureau. Clark assigned Potter, who was then a police captain, to lead the development of a new community policing strategy (Lane and Hallman. Oregonian, October 30, 1988).

Potter had led the Police Bureau's North Precinct. As precinct commander in this very diverse part of Portland, Potter had had the opportunity to try out his communityfocused approach by working with community member to solve a number of problems, one being community concern about drugs and prostitution centered on a strip of motels along Interstate Avenue (Hallman, Jr. Oregonian, January 17, 1989). As the Police Bureau's new point person on community policing Potter began to research and study up on community policing efforts in the U.S. and in other countries. 
In 1989, Mayor Clark, Police Bureau leadership, and Potter were ready to lead the bureau's transition to community policing. The basic concept was that police would not "simply react to crime" but would be "encouraged to deal with the symptoms of crime at its most basic level—the neighborhood. At the same time, citizens will be expected to work closely with police to come up with solutions to crime problems." Potter emphasized that "Partnership is the key word. Partnership will underscore everything we try to do." Potter had developed his community policing program in collaboration with “bureau commanders and representatives from the mayor's office and from neighborhood groups." Potter proposed to start by surveying community members and meeting with "neighborhood associations and ethnic groups" to find out what they wanted from the Police Bureau (Hallman, Jr. Oregonian, January 17, 1989). Many different neighborhood and community groups strongly supported Clark and Potter's new community policing strategy.

In 1990, Mayor Clark appointed Tom Potter to be Portland's new Chief of Police to replace retiring chief, Richard Walker. The Oregonian reported that Clark hoped that "Potter would convert the entire bureau to community policing" and quoted Clark as saying, "Nobody's as rabid about community policing as Captain Potter." The news of Potter's appointment was welcomed by many community members and people in local law enforcement. Potter emphasized his strong focus on problem solving when he told the Oregonian that "community policing was a commitment to find solutions with community help. Police officers need more time to work with citizens, but the approach can succeed even without extra time. 'When you take a call...and you're doing it as a 
problem solver, not just as a law enforcement officer, you have a better chance of solving that person's or that community's problem"' (Carlin Ames, Sarah. Oregonian. October $25,1990)$.

At Potter's swearing in as chief, he stressed his strong support for civil rights, inclusion, and social justice to a diverse group of hundreds of supporters. He challenged the Police Bureau to "create the safest neighborhoods in the nation, to have all citizens participate in shaping Portland's future, and to eradicate bigotry, sexism, racism and homophobia." "Rhetoric must be backed up by results....We must act boldly to begin to make our neighborhoods safe again. All people, all colors, must be our sisters and brothers." The Oregonian reported that Potter said that "arresting and locking up criminals wouldn't solve society's woes. For every dollar spent on enforcement...the community must spend at least as much to eradicate poverty, improve education, provide better-paying jobs and to rebuild families." Potter said, "We must reduce the gap between the haves and have-nots....We need each other. We need to stop looking for enemies and start looking for allies" (Carlin Ames, Sarah. Oregonian, November 20, 1990).

Potter showed his willingness to stand up for his beliefs when he became the first Portland Police Chief to ride, in uniform, in Portland's Gay Pride Parade. He rode in a red convertible with his daughter, Katie, also a Portland Police officer, who recently had come out as the first openly lesbian officer on the police force. Potter publicly supported gay and lesbian rights at the same time a conservative group in Oregon was promoting a statewide ballot measure to condemn and restrict rights for gays and lesbians. Potter soon became widely known for his support for "the rights of all citizens, including women, 
ethnic minorities and homosexuals" and for his belief that "It's important that both society and the police are free of sexism, racism and homophobia" (Rubenstein.

Oregonian, June 10, 1991; Filips. Oregonian, June 30, 1991).

Potter retired as chief in 1993, a year after Vera Katz became Portland's mayor. The Oregonian reported that while community members continued to appreciate Potter's openness and willingness to work with the community and support for civil and human rights, he was leaving a divided Police Bureau. A number of staff within the Police Bureau resented Potter's push for community policing at what they believed was the detriment of traditional police work. Some resented his support for diversity and gay rights and his efforts to promote woman and people of color within the bureau. Other Police Bureau staff strongly supported Potter's efforts (Rollins and Hallman, Jr. Oregonian, March 14, 1993).

After he retired, Potter consulted with police departments around the country on community policing, served for a short period of time as the director of New Avenues for Youth - a nonprofit organization that served homeless youth in Portland, served as the interim director for the state public safety training academy, and delivered meals to the elderly as a volunteer with a local non-profit organization.

In 2001, Potter resurfaced in the public eye when he wrote an op-ed piece for the Oregonian calling for the City of Portland to reconnect to community policing. In his oped, he stressed a number of democratic governance themes that would make up the foundation of his campaign to be mayor a few years later. These included: "community policing without the partnership and support of the community is not community 
policing;" "trust is the glue building community policing;" the City needs to commit to community policy in writing through a "written community policing plan;" and "a community must stay the course, stay involved and stay together" to ensure that the community and the policy achieve the goals of community policing.

Potter argued that the police could not solve the "serious crime and social problems" facing Portland without partnership with the community. He emphasized that a "true partnership requires the full involvement of both groups at every stage of the development and implementation." Potter argued that "trust isn't given; it must be earned" and described how police in the past had worked with citizens to "analyze problems and apply strategies" and had earned community trust by opening up the Police Bureau and working with community members to;v help reshape it." Potter said when the community and police work together to develop a written community policing plan, it gives both police and community members a "shared vision," helps them "stay on track," and "builds consensus between them"(Potter. Oregonian, August 8, 2001).

In July 2003, Mayor Katz announced she would not run for a fourth term as mayor. In September 2003, Potter formally announced that he would enter the race to replace her. Many Portland populists and neighborhood and community activists who had been increasingly frustrated with what they saw as a major disconnect between city government and the community quickly rallied to support Potters' candidacy. Some of his early supporters included former Mayor Bud Clark, former City Commissioner Margaret Strachan, community organizer and activist Joanne Bowman, and many Portland community and neighborhood activists. 
City Commissioner Jim Francesoni already had declared his run for the mayor's position. Political insiders saw Francesconi as the front runner. When Potter announced his run, Francesconi had a big lead in collecting important endorsements and had raised hundreds of thousands of dollars in campaign contributions. Most politics watchers in Portland thought Potter had little chance against Francesconi (Stern. Oregonian, September 4, 2003).

Potter defied the norms for mounting a serious run to be mayor in Portland. He did not attempt to raise $\$ 1$ million — an amount many political consultants said was needed to win. Instead Potter pursued a grassroots campaign in which he relied on his name recognition and strong community support from his community policing days. In contrast to Francesoni's aggressive pursuit of campaign donations, Potter chose not to do any traditional fund raising and actually imposed an upper limit on contributions to his campaign of $\$ 25$ per person in the primary. ${ }^{79}$

Francesconi's and Potter's campaign messages were very different. Francesoni stressed his experience on the city council, a "back to basics" approach that would "bring new accountability to city spending and reject misguided spending projects" and the familiar election rhetoric around "good paying jobs, strong schools, and safe neighborhoods." Francesconi claimed that he would be ready to "hit the ground running as mayor with a 100-day plan to get Portland moving again" Some of Potter's main campaign themes included getting citizens and government working together again, ensuring that the voices of community members would be heard at City Hall, and

\footnotetext{
${ }^{79}$ Potter also endorsed three of the neighborhood candidates running against Leonard—a risky move against such a strong political player.
} 
working with community members to "develop a vision for our city that reflects the priorities of all Portlanders, not just a few." Potter reminded Portlanders of his leadership role in bringing community policing to Portland and in hiring and promoting "women and minorities in the Police Bureau "so that the face of the Bureau reflected the faces of our community." Potter claimed he had the leadership and management skills to lead city government, "I know what it's like to hold people accountable, demand change and get it" (Multnomah County Online Voter's Guide: Nov. 2004 General Election-City of Portland Mayor. Web. < http://web.multco.us/elections/november-2004-general-electioncity-portland-mayor >).

Francesconi criticized Potter for talking about creating a vision for Portland with the community rather than providing specifics about what he would do if he were elected. Francesconi also noted that-unlike Francesconi, who had served on the City Council since 1997-Potter had not been involved in major issues in Portland for many years. Potter strongly criticized Francesconi for his aggressive pursuit of political contributions and questioned whether Francesconi would be focused on serving the interests of the community or his big money contributors. Potter also tied Francesconi to the city council's recent disconnect from, and conflicts with, community activists.

The primary election in May 2004 surprised many political insiders in Portland. Despite Francesconi's significant fundraising advantage over Potter, Potter lead the field of 23 mayoral candidate with 42 percent of the vote to Francesconi's much weaker showing of 34 percent. Potter's support and the energy around his candidacy continued to grow during the general election. Potter maintained his upper limit on contributions to his 
campaign but raised it to $\$ 100$ per person. Rather than spending a lot of money on television ads, the Potter campaign worked with community and neighborhood activists who blanketed many parts of the city with Potter campaign yard signs—a powerful visual symbol of Potter's strong community support. A number of misteps by Francesoni also shifted support to Potter. By October 2004, a poll commissioned by the Oregonian and KATU television showed Potter with a 35 percent lead over Francesconi.

In November 2004, Portlanders voted strongly in favor of Potter's outsider message of reconnecting the community with government and establishing a new vision for Portland over the insider candidate with the detailed list of proposed actions. (Potter received 61 percent of the vote to Francesconi's 38 percent.) (Multnomah. Election Archive. May 18, 2004 Primary Election. Web. < http://web.multco.us/elections/may-182004-primary-election> ;November 2, 2004 General Election. Web. < http://web.multco.us/elections/november-2004-general-election>). Potter's election would set the stage for a major course change by city government in its relationship with the community.

The next chapter describes the many reforms to Portland's community and neighborhood involvement system instituted during Potter's one term as Portland mayor (2005-2008).

Mayor's Budget Messages - Vera Katz - FY 2000-01 to 2004-05

Portland Mayor Vera Katz's city budget messages of her last years in office stress the difficulties of needing to cut the city budgets due to the national economic recession, the cost of complying with federal environmental mandates, and the aftermath of the 
terrorist attacks on September 11, 2001. She notes that many of Portland's jurisdictional partners-e.g. Multnomah County, local school districts, and the State of Oregon—also were struggling with budget cuts, which put additional strains on city services.

Katz continues to report budget priorities similar to those in her first two terms in office. She highlights the need to continue to provide city services that respond to critical community needs, maintain Portland's quality of life, and increase investments in “infrastructure and basic services." She continues to focus on increasing government efficiency and reducing the cost of administrative services, public safety, public schools, jobs and economic development” (Portland. "Mayor's Message." City Budget FY2002-03 4). She also highlights continuing efforts to "address environmental issues including the cleanup of Portland Harbor, our River Renaissance, protecting endangered species and promoting sustainable business practices"(12).

Community Involvement in the Budget Process: Katz briefly mentioned Your City, Your Choice (YCYC) and YCYC's community budget meetings and public opinion survey in her budget messaged in 2000 and 2002. In her last budget message in 2004, Katz reported that the city budget process that year was "exceptionally open" and attributes this openness to the role of the Portland Business Alliance (an association of downtown Portland businesses) in carrying out an "independent budget analysis with the full cooperation of the City" and Katz's appointment of "a four-member panel of citizens to observe and participate in the budget process this year." She reports that "One or more of the members of this panel attended virtually every budget meeting that I held. Their questions and observations were most helpful in developing this budget, and I thank them 
for their commitment to civic involvement" (Portland. "Mayor's Message." City Budget FY 2004-05 4).

Community Involvement and ONI: Katz referred to community involvement or to ONI only a few times in her last five budget messages. However, she did announce two policy changes that would significantly shift (at least temporarily) ONI's role and focus away from community empowerment and neighborhood support.

In 2001, Katz announced a policy decision to have ONI staff begin to provide direct community involvement support to city bureau projects and activities. Katz justified this shift by citing recommendations from the ASR to improve city government's involvement with community members through "more effective use of the expertise in the Office of Neighborhood Involvement." She noted that the "ASR recommendations directed City bureaus to expand their use of [ONI] to assist with public outreach and coordination of the multitude of meeting scheduled throughout the city." She added that she had reviewed the budget and believed that "ONI can provide these services within existing staff levels"'[emphasis added] (Portland. "Mayor's Message." City Budget FY 2001-02 9). It is important to note that adding extensive new duties to ONI without providing additional resources effectively required ONI staff to reduce their existing support for community empowerment and Portland's community and neighborhood involvement system to be able to take on these new duties.

In 2003, Katz reported another major shift in ONI's role and function. She reported that the City budget that year included funding to implement ONI Commissioner-in-Charge Randy Leonard's plan to relocate housing inspection staff and 
services from the Bureau of Development Services to ONI. Katz maintained that this change would "improve coordination and customer service in the neighborhoods." She added that "We hope to leverage this with the Planning Bureau effort to move some planners out into the neighborhoods as well" (Portland. "Mayor's Message." City Budget, FY 2003-04 7).

Katz also made a couple references to funding support for a few ONI programs. In 2000, Katz reported that the City budget included an additional $\$ 99,000$ for neighborhood services and mediation services and a modest increase to support ONI's graffiti abatement program. In 2002, Katz reported continued support for ONI crime prevention and neighborhood mediation services.

Katz's last budget message: In 2004, Katz presented her twelfth and final mayor's budget message. She used the opportunity to reflect on her time as mayor and what she saw as her major accomplishments. Katz emphasized that the FY 2004-05 City budget "provides basic services for our citizens, but it also invest in our promising future." She noted that this was the fifth in a row in which cuts were required to balance the City budget.

Katz identified four priority areas for her final budget—public safety, affordable housing, economic development, and infrastructure and capital needs (3-4). She also recognized the City's interest in environmental protection.

Katz chose to open her concluding remarks with a defense of city staff, who she characterized as "a wonderful group of dedicated City workers who strive every day to make this City a good place to live" against what she calls "the enduringly popular 
pastime of criticizing government..." (11).Katz wrote that she was proud that her 12 budgets as mayor had been "fiscally responsible" and "accountable to the needs of our citizens." She stated that she was “privileged to serve as Mayor during one of our City's most prosperous periods, and was challenged by "difficult fiscal challenges" during "the past five years." Katz stated that in both the good times and the challenging times her proposed budgets had "provided for the basic services expected by our citizens, but they have also sought to invest in our future" (11).

Katz closed her final budget message by saying that preparing the city budget "is not the 'sexiest' of tasks for a Mayor" but says that it is one of the "most important duties of an elected official. She goes on to state that "For where we spend our money says a lot about who we are and what we value." (11) This comment makes it particularly interesting to note that Katz does not mention community involvement or ONI anywhere in her final budget message.

Overall, Katz's twelve mayor's budget messages show her consistent focus on improving government efficiency and government service delivery and seeing community members as "customers" rather than "partners" in government decision making. During Katz's three terms as mayor, a number of long-time ONI programs ended (e.g., BACs, Neighborhood Needs, neighborhood planning). Commissions set up to give different communities a voice in decision making also were discontinued (Disability Commission and Metropolitan Human Rights Commission) or shifted to another jurisdiction (Youth Commission). No major advances were made in strengthening ONI's community involvement program during Katz's time as mayor, and, in the early 2000s, 
ONI's ability to support community and neighborhood empowerment was significantly weakened when the few ONI staff assigned to these activities were redirected to provide direct community involvement support and services to city bureaus.

\section{Lessons from the early 2000 s}

In the early 2000s, Portlanders engaged in deep, strategic thinking about two long-standing challenges for Portland's community and neighborhood involvement system-how to involve a greater diversity of the community and how to significantly improve city government community involvement. Many of the policy and program ideas generated during this period would be implemented during Mayor Potter's administration. The intense conflict between city leaders and community members during the early 2000s galvanized significant community support for a return to a more collaborative relationship between city government and community members. The loss or deterioration of many elements of the system in the 1990s and 2000s and the apparent ease by which elected officials had been able to undermine or redirect the system caused many people to seek ways to institutionalize and preserve key elements of Portland's “community governance" partnership.

The early 2000s offered a number of insights relevant to this study's primary research questions regarding important system elements, the reform process, and embedding advances toward greater participatory democracy.

System Elements: Many of the processes of the early 2000s either reinforced what earlier system reviews and processes had identified as important system elements or identified new elements. Key system elements identified during this time focused on: 
building capacity in the community, ensuring willingness and ability in city government to work with the community, and ONI's role.

Community Capacity: Different processes generated a number of recommendations for how to strengthen capacity in the community to be involved in and affect city decision making. The need for leadership and skill training for community members came up frequently, especially in Interwoven Tapestry, Southeast Uplift's DRC and DCLC, and the PITF. The processes called for an ongoing, citywide training program that would be available to a wide range of neighborhood and community activists. Suggested training topics included: City processes, neighborhood demographics (who's in the community), outreach strategies-especially outreach to historically underrepresented communities, issue and power analysis, mediation and negotiation skills, community organizing, diversity and privilege, advocacy, communications and organizational development.

The PITF, DRC and DCLC all recommended additional support for the creation of networks between neighborhood associations and other community-based groups. The PITF members argued that "increased relationships, communication and cooperation" between community groups would "build a stronger a more credible political voice" and identify broader, shared priorities in the community (PITF, 2006 13-14).

The ASR, PITF, and BOSG all called for improved community involvement in city government capital project priority setting, planning and implementation. One approach suggested was a return to some form of the earlier Neighborhood Needs process, through which neighborhood and community organizations could identify their 
needs and priorities, especially for capital projects, and have then reviewed and considered by city agencies and in the city budget process.

Many reviews of the system called for the creation of neighborhood grants program. A neighborhood grants program was seen as a way to give people a reason to get involved, help them develop fundraising and project management skills, develop partnerships with other community organizations, unleash community creativity, and leverage additional community resources. Interwoven Tapestry gave out small grants in the community as part of its three-year project. Other processes, including the PITF and BOSG also called for a neighborhood grants program. Commissioner Francesconi attempted to create a neighborhood grants program during his brief time as ONI Commissioner, and even received City Council approval to go ahead, but the program was not funded and implemented.

Another frequent recommendation was adequate funding of neighborhood district coalitions and other community groups to support community organizing. Some community activists also called for more equitable distribution of funding among the neighborhood district coalitions that would ensure minimum funding for each coalition to support a basic office and staff augmented by additional funding based on indicators of community need in each district—such as the number of neighborhood associations and different socio-economic factors.

The system reviews during the early 2000s continued to support having a citywide system of neighborhood associations, but also recognized the limitations of what volunteer-run community organizations could accomplish on their own. As Ahmed-Shafi 
said, if you want volunteer organizations to do more than they are choosing to do, you probably will need to provide staff support, training, and technical assistance to help them do it.

Nearly all the system reviews recognized the need to expand Portland's original neighborhood association system to include other types of community organizations. The failure of the 1998 ONI Guidelines to attract single request for formal recognition from a single business association or "ethnic-based community organization" showed the need for the City to work with the community groups it hopes to involve to ensure that, whatever relationship the City offers, is one that meets the goals and interests of these organizations and communities. Southeast Uplift's DRC and DCLC modeled the kind of inclusive, respectful, and collaborative process that could identify appropriate strategies for involving these groups. The DCLC went on to develop and advocate for a number of specific proposals to fund and involve under-represented groups in the system, some of which were funded and implemented during subsequent Potter administration.

City Government: The ASR and the PITF reinforced earlier calls for citywide standards, guidelines and policies to improve and better coordinate city government community involvement. The PITF, for the first time, laid out a comprehensive strategy — with detailed recommendations - to begin to change the culture of city government and to institute policy requirements and support for city staff to act on it. The PITF recommended that the City Council adopt the PITF public involvement principles and embed community involvement values and requirements in key government policy 
documents and structures. The PITF also recommended the development of best practices materials and training programs for city staff.

Other PITF recommendations focused on improving the quality and coordination of city government communications, events calendars, community contact lists, web access to city documents, public records request policies, information about capital projects. The PITF suggested training topics that included: culturally specific skills for reaching out to and involving diverse communities; electronic media strategies; database development and management; process design; customer service; public information; dealing with difficult people; and conflict resolution. The PITF also recommended a review and significant improvement in the City's formal notification system.

The PITF recommended the development of effective mechanisms by which the neighborhoods could identify and communicate to city goverment their needs and priorities for capital projects (similar to the earlier Neighborhood Needs process). The PITF also recommended improvements in community involvement in the City budget process. The BOSG recognized the need to develop different mechanisms to involve community members with different levels of knowledge and interest in the budget process, rather than just a "one-size-fits-all” approach.

The SWCP "Citizen Involvement" goal and policies called for community involvement in all phases of planning and implementing projects in Southwest Portland (a requirement echoed by Oregon State Planning Goal 1). Interwoven Tapestry, Strachan et al, and Tom Potter all called for a strong community policing program that worked in partnership with community members. (Potter raised significant concerns about the 
deterioration of Portland's community policing program in his 2001 Oregonian op-ed piece.)

The ASR and PITF identified the need for some entity in city government that would promote, support, and evaluate city government community involvement. The ASR recommended that ONI play much of this role. The PITF called for the creation of a Public Involvement Advisory Commission with staff support (funded by all city agencies through an overhead model) to lead this work.

$\underline{O N I}:$ ONI's appropriate role in Portland's system became a major question during the early 2000s. The ASR recommended that ONI become the central agency in city government responsible for coordinating, supporting, and evaluating community involvement by all city bureaus. Under Commissioner Saltzman, ONI staff began to shift their time and attention away from supporting the neighborhood system and began to provide direct community involvement support to specific city bureau projects.

Commissioner Leonard took this even further by announcing his desire to rename ONI as the "Office of Neighborhood Services," moving a significant number of neighborhood inspection and noise control staff into ONI, and proposing to turn the district coalition offices into "mini City Halls" that would provide city services in Portland's neighborhoods. In response, many community members called for ONI to return to its original role of supporting community organizing and the ability of neighborhood associations and community organizations to have a voice in city government decision making. 
During the early decades of Portland's community and neighborhood involvement system, Portland's neighborhood associations were seen by many City government leaders and staff and by many neighborhood activists as the primary formal mechanism for community input to the City. By the early 2000s, this model was being seriously challenged. Many city leaders and staff, as well as some community members, continued the long-standing complaint that neighborhood associations did not adequately represent the perspectives and priorities of the full diversity of people in their communities. Defenders of the system counted that neighborhood associations are "participatory" not "representative."

A number of review processes identified the need for Portland's system to expand to recognize, involve, and support other types of community organizations. The discussion began with Charles Shi's recommendations during the 1995-96 TFNI process that the City formally recognize ethnic- and culture-based organizations as "neighborhoods without borders." Shi recommended that the City give organizations that support a broad segment of a particular non-geographic community the opportunity to apply for formal city recognition as a "coalition," similar to a neighborhood district coalition. Rey España and the Southeast Uplift DRC argued that often individuals need to gather and organize with people in their own community first before they can connect with other types of community organizations (like neighborhood associations). España also recommended an approach that would meet groups where they were in the evolution of their community organizing and organizational capacity building and provide support that was appropriate to the stage of their organizational development. Rather than the 
“one-size-fits all” formal recognition opportunity offered to CBNBs in the 1998 ONI Guidelines, España advocated for a capacity-building approach that would help groups learn about their community, build relationships and social capital together, and learn about ways to effect change. Interwoven Tapestry offered a good example of this approach in the way it helped members of both the Slavic and African communities form organizations and begin to build organizational capacity.

This vision for an expanded system still included a strong role for geographic organizations, like neighborhood associations and business associations, but also would recognize and support capacity building in organizations that supported and served nongeographic communities.

Reform Process: The early 2000s, were a time of very creative strategic and policy thinking either in the community or in process in which city staff and community members worked together.

The Southeast Uplift DRC and DCLC became important community organizing and policy development vehicles that built alliances among community groups and developedn and advocated for, program and reform proposals. The story of the DRC and DCLC shows the importance of: leadership (i.e., Kennedy-Wong initiated of the DRC and continued support for the DRC and DCLC processes); processes that prioritized respect, relationship building and trust; effective staff support from people with strong social justice values and community organizing and group process skills; neighborhood and city staff allies who actively supported the goals of under-represented groups; a policy entrepreneur (i.e., España's significant impact on shifting the discussion from 
increasing funding to neighborhood associations, so they could reach out to underrepresented communities, to directly funding and supporting under-represented community organizations), and strong community organization strategies that allowed the process to evolve from the earlier DRC focus on community outreach to the proposal development and advocacy efforts of the DCLC.

The early 2000s, showed the value of a "political champion" in advancing reforms and preserving progress primarily through the example of how the lack of a strong political champion for community involvement on the City Council led to a significant deterioration of Portland's community and neighborhood involvement system. Mayor Katz viewed community members primarily as "customers" of government services not partners in governance. Many important community involvement programs, as well a number of community-focused city commissions, were ended during her time as mayor. The early 2000s also saw the negative impacts of attempts by Commissioners Saltzman and Leonard, who, instead of working collaboratively with community members and city staff to understand the system's challenges and develop ideas for moving forward, attempted to impose their own top-down solutions that generated intense controversy and did little to improve community involvement in Portland.

The early 2000s also showed the strategic importance of formal review processes and their reports on raising the visibility of policy issues and promoting policy changes. The ASR and PITF both provided useful analyses of city government community involvement strengths and weaknesses and proposed actions to improve city government community involvement. The proposals—especially those of the PITF—helped 
community activists and sympathetic city staff advocate for change and provided blue print for many of the reforms instituted under Mayor Potter.

Embedding: Since the founding of Portland's community and neighborhood involvement system in the 1970 s, community members had criticized city leaders and staff for not being interested in or skilled at involving the community, or giving "lip service" to community involvement. The partnership between community activists and city leaders and staff deteriorated even further during the early 2000s. Community involvement proponents were alarmed at the dismantling of important community involvement programs and the attempts to redirect ONI away from community empowerment and toward greater support of city bureau community efforts. The PITF report represented the first deeper analysis of how to embed community involvement values and best practices in city government policies, structures and daily work activities.

One of the PITF's most powerful proposed strategies was to insert community involvement values and requirements into formal city policy documents that carried the force of law or into requirements that would be enforced. PITF members created an updated set of public involvement principles to provide a framework for other policies and best practices. They recommended that the city council adopt the principles by ordinance - rather than by resolution as the city council had done with the 1996 public involvement principles. The PITF also recommended adding language to the City Charter-the City's highest level policy document--that would establish a clear role for community members in city governance. 
PITF members also recommended significantly strengthening the community involvement goal and policy language in the Comprehensive Plan (Comp Plan). City staff are required by law to write findings that explain how policy proposals and planning projects meet the goals and policies of the Comp Plan. Community members who feel that a City decision does not comply with Comp Plan goals and policies can appeal the decision to the Oregon State Land Use Board of Appeals (LUBA). This would significantly increase the incentive for city leaders and staff to ensure good community involvement—at least in City activities under the Comp Plan policy umbrella.

Another strategy to raise the priority of and incentives for good public involvement was the PITF's recommendations that the job descriptions of bureau directors and senior staff include public involvement skills and requirements and that effective public involvement become an element of city staff formal performance reviews. $^{80}$

Another PITF recommendation that sought to raise awareness and transparency of city government community involvement was the recommendation that the city council require every ordinance brought to city council for review and approval to be accompanied by a short report form that would describe any public involvement that had been done and the effect it had on the subject of the ordinance. PITF members also recommended that the City Council require city bureau directors to submit annual reports on their agency's community involvement activities.

\footnotetext{
${ }^{80}$ City public involvement staff often complained that, while they believed in good public involvement and tried to follow best practices in involving the community in the work of their bureau, senior management in their bureaus did not value or understand the nature of good public involvement or support it as an integral part of the bureau's work and projects.
} 
PITF members also sought to increase the quality and consistency of city bureau public involvement by recommending: the development of citywide community involvement guidelines and standards, the development of agency-wide community involvement policies by each city bureau, and formal written community involvement plans for specific types of city projects.

PITF members saw opportunities to leverage some enforcement of good community involvement through the City Ombudsman and City Auditor. The City Ombudsman could investigate complaints from community members who believed that a city bureau had not followed formal city community involvement requirements and procedures, and the City Auditor could audit the community involvement policies and practices of city bureaus and issue formal findings and recommendations for improvement.

The PITF also saw the value of establishing and staffing an ongoing formal city commission—versus periodic task forces—-that would advocate for implementation of the public involvement principles and other PITF recommendations. This formal body would raise the visibility and status of community involvement in city government and would provide ongoing capacity to review city government community involvement activities and advocate for improvements.

PITF members also recognized that one of their ultimate goals was to change the culture and behaviors of city leaders and staff within the city bureaus. To this end they made a number of recommendations intended to provide support and guidance to city staff to help them improve the way they involved the community in their work. These 
recommendations included the development of community involvement standards and guidelines, best practices materials, training for city staff, peer sharing and review of proposed public involvement plans. They also recommended regular evaluation of community involvement efforts to ensure that best practices could be identified and spread.

The early 2000s, despite, or maybe partly because of the high level of conflict between city leaders and the community, were a time of very creative and strategic thinking about how to broaden involvement in Portland's community and neighborhood system and to improve the willingness and ability of city government leaders and staff to work with the community. Many of the recommendations developed during this time would be implemented during Mayor Tom Potter's administration. The next chapter reviews the evolution of Portland's community and neighborhood involvement system from 2005 through 2013. 


\section{CHAPTER VII \\ REFORM AND REJUVENATION—2005 to 2013}

Portland Mayor Tom Potter (2005-2008) dramatically reversed the decline of Portland's community and neighborhood involvement system and instituted the most significant expansion of the system since the 1970s. The two mayors who followed Potter-Sam Adams (2009-2012) and Charlie Hales (who began his first term as mayor in 2013) — continued to support much of the increased funding and most of the programs begun under Potter. The system changes instituted during this period represent a major advance toward a more inclusive and vibrant participatory democracy culture in Portland and a more effective and lasting governance partnership between city leaders and staff and community members. This chapter examines the system reviews and key program changes during the time period from 2005 through 2013.

Mayor Potter came into office with a deep belief that governance should be a partnership between City government and the community. Potter brought to his administration his unusually high level of support for public involvement and his longstanding-standing and deep commitment to ensuring a voice for historically underrepresented groups—especially communities of color, immigrants and refugees, and youth. Potter used his position as mayor and the significant additional discretionary revenues available to city government during the good economic times of his administration to implement a wide range of processes and programs that put his values into action and implemented many recommendations of earlier system reviews. 
This chapter begins with a review of a system assessment prepared by neighborhood coalition leaders just prior to Potter taking office. The chapter also reviews early leadership and programmatic changes made by Potter at ONI and four of Potter's twenty bureau innovation projects (BIPs): BIP 1/visionPDX, an extensive and very inclusive community visioning process; BIP 9, which created a public involvement assessment tool for city staff; BIP 20/Charter Review Commission, which proposed amendments to Portland's City Charter, including one to change the form of city government (which voters rejected) and another that required the City Council to establish periodic community charter review commissions (which voters adopted); and BIP 8/Community Connect, the most comprehensive review of Portland's community and neighborhood involvement system since it was founded in the 1970s.

Community Connect established three primary goals and developed a "Five-year Plan to Increase Community Involvement" that charted a new and expanded course for Portland's community and neighborhood involvement system. Community Connect recommended that Portland community and neighborhood involvement system be expanded and formally recognize and support organizations representing non-geographic communities-e.g., communities of people drawn together by shared identity or life condition - in addition to the traditional neighborhood association system. Potter initiated a number of new programs in ONI and elsewhere that implemented Community Connect's broader and more inclusive vision for community involvement in Portland. This chapter describes these new programs. 
Neighborhood activists also continued to seek ways to develop city-wide bodies to allow them to work together on citywide policy issues. This chapter examines two of these bodies, one focused on land use issues and the other on park issues.

Mayor Sam Adams took office in January 2009. Adams assigned responsibility over ONI to long-time neighborhood activist and newly-elected City Commissioner Amanda Fritz. Adams and Fritz continued to support many of the new community and neighborhood involvement programs initiated by Potter and worked together to insulate ONI from many of the severe city budget cuts necessitated by the national and local economic recession.

Adams also initiated or supported the continued operation of number of important processes. This chapter examines: the re-establishment of required budget advisory committees (BACs) for city bureaus; the Portland Plan-Portland's broad strategic planning process that followed visionPDX - and its introduction of the concept of "equity" for city government; the work of the new Public Involvement Advisory Council (PIAC); the 2011 Charter Review Commission; the creation of Portland's Office of Equity and Human Rights, and the East Portland Action Plan.

Mayor Charlie Hales took office in January 2013. Hales had been a Portland city commissioner in the past and had been the city commissioner in charge of ONA during the 1995-96 TFNI. Hales choose to keep ONI and the new Office of Equity and Human Rights in his portfolio and, at least during his first city budget process, protected ONI from severe budget cuts that affected other parts of city government. This chapter provides some insights into Hales' priorities and his early discussions with ONI and 
neighborhood coalition leaders about the future of Portland's community and neighborhood involvement system.

The chapter also looks to the future and summarizes further system changes summarized by ONI staff and leaders of ONI's neighborhood and community partner organizations, to continue to expand and strengthen Portland's neighborhood and community involvement system. The chapter also includes summaries of the mayor's budget messages from Potter, Adams, and Hales and lessons learned from the 2005-2013 period relevant to this study's three primary research questions.

\section{Neighborhood Coalition Leaders' Strategic Assessment-December 2004}

Tom Potter's election as Portland's new mayor in November 2004 unleashed great expectations among neighborhood and community activists. The leaders of all seven of Portland's neighborhood district coalitions hoped that Potter would move quickly to reinvigorate and expand Portland's community and neighborhood involvement system. They wanted to jump start the process and help shape Potter's reform agenda. They worked quickly to prepare a document which identified what they saw as the system's strengths and challenges and their priorities and recommendations for reform. The neighborhood coalition leaders shared their document with Potter and his staff shortly after he took office in January 2005.

The neighborhood coalition leaders titled their document, "Portland's Neighborhood System: Government By and For the People.” Their report clearly reflects their years of frustration with the decline of the system, frequent criticisms of the system and of neighborhood volunteers by city leaders and staff, and unilateral, top-down 
attempts by individual city council members to redirect the system away from community empowerment and toward city service delivery.

In their report, the coalition leaders identified Potter's election as a "unique opportunity to incorporate new challenges and develop new assets related to public participation through Portland's 'neighborhood system.'” They clarified that by “neighborhood system” they meant the City’s broader community involvement structure, including "neighborhood associations, affiliated grass-roots programs, coalition offices, and City Bureaus including [ONI] administration as it impacts resident participation" (1).

The neighborhood coalition leaders stated their hope that their document would "lead to a complete review of 'the neighborhood system' and the creation of a strategic plan led by and develop by the community." They advocated for immediate implementation of "reforms dealing with the mechanics of the system." They suggested that reforms of the "intent and framework of the City of Portland's commitment to public participation" would "require a more detailed strategic planning process with the widest possible outreach" (1). This section describes the neighborhood coalition leader's assessment of the current system and their recommendations for short-term and long-term reform.

The “Current State of the 'Neighborhood System:"” The neighborhood coalition leaders began their document with a review of the system's origin and evolutions. They noted that, "Prior to the creation of Portland's neighborhood system in 1974, public participation was a rare animal in Portland.” Many barriers prevented community members from being involved in municipal government except for "local 
elites." "Structured communications between the people and their government was often reserved solely for elections" (2).

They reported that "For the first twenty years of its existence, the City of Portland's unique and innovative neighborhood system focused public participation through Neighborhood Associations." ONA had a small staff that worked with the staff of the neighborhood coalitions to support community involvement through: neighborhood associations; community input into city decision making through the BAC Program and the Neighborhood Needs process; and through community policing. They wrote that, "Neighborhood activism was focused on social services (model cities), housing (CDCs), land use (neighborhood planning program), public policy engagement and self-directed community development activity." They asserted that that "the system seemed most effective when citizens received the support to participate and when elected officials and staff were genuinely interested in authentic collaboration" (2).

The neighborhood coalition leaders reported that, over the previous ten years, "concerns with the effectiveness of the program and budget constraints" had led to changes in the neighborhood system. The focus shifted to "who wasn't at the table rather than who was." Elected city officials and staff and some in the broader community complained that that the neighborhood system "was not representative." "Concern began to grow not over access to the table, but who was sitting at the table." The demand that neighborhood associations be "representative" rather than "participatory" grew at the same time that policy, program, and budget changes "negatively impacted 'the neighborhood system"” (2-3). 
The neighborhood coalition leaders identified a number of changes that they believed had weakened the neighborhood system and community involvement in Portland. In 1983, the City of Portland and Multnomah County agreed to divide up their duties as a way to increase efficiency and reduce costs. The county took the lead in providing human services. The City took the lead responsibility for physical aspects of the community, such as land use planning and development, streets, sewer, water, police, fire, and parks. Neighborhood associations, which structurally were aligned with city government, became less involved in important human services issues. In the 1990s, the City discontinued its neighborhood planning program — a major focus of the early neighborhood system. The City ended the program in response to budget cuts and intense conflict between community activists and city planners over the Southwest Community Plan in the late 1990s. The City's Police Bureau, which had instituted a far-reaching community policing program in the early 1990s, by the mid 2000s had shifted away from "a partnership between police and community" and toward a more traditional model of policing. Portland's model BAC Program—which used to engage community members in the development of bureau budgets and the overall city budget (a program praised by the Tufts University researchers in the late 1980s) — had faded away. "Residents, once engaged at the beginning of the budget process, now found themselves reacting to a budget developed by the City administration" (3).

The neighborhood coalition leaders also noted that-in sharp contrast to Portland city government's strong support for community involvement in the 1970s and 1980sby the early 2000 s, city government had turned into "a bureaucracy that had learned how 
to manage public relations" in which public participation had "become more possible, yet often more frustratingly dysfunctional." ONI's focus and mission also changed over time. ONA had started out "nearly solely focused with supporting contracts to coalition offices." ONI, over time, grew into a "multifaceted agency" whose purpose and function shifted frequently_change often being driven more by political goals than careful strategic planning (3).

Portland's neighborhood system faced other challenges including: the relocation of crime prevention staff from of the coalition offices to the downtown ONI office; "Dramatic increases in insurance, mailing, printing, and other operational costs"-while city funding for the coalitions remained flat; and disparities between the salaries of nonprofit coalition staff and staff at ONI and the two city-run neighborhood district offices (3). ONI programs that supported elders and provided mediation services were spun off as independent, non-profit organizations. The Human Rights Commission and Metropolitan Human Relations Center were dissolved. ONI began to provide more direct services_-including the City/County Information and Referral Program and neighborhood inspections and noise control. The number of ONI "employees engaged in public service rather than public participation activity increased dramatically" (4).

Philosophy and Function: Neighborhood coalition leaders described their perspectives on the philosophy and functions of the neighborhood system and city government, as follows:

Neighborhood System: Portland's neighborhood system "is a participatory system. It informs, invites, and encourages neighbor participation in directing community 
decisions" and "provides linkages to improve [neighborhood] livability." Neighborhood coalition leaders asserted that "All of this participation and involvement means a lot more time and work" but "more cooperation and involvement can, in the end, lead to a better result, much happier 'customers,' and bureaus and their employees that are appreciated and respected." They concluded that the " "neighborhood system' is ideal for community building/organizing, developing community leaders, problem solving, recommending and prioritizing policy, visioning future neighborhood livability plans, generating self support, partnering with government, and providing constructive criticism” (4).

City Council and City Bureaus: The neighborhood coalition leaders argued that the “"neighborhood system' works best" when each city bureau includes in its core mission "a commitment to authentic cooperative, transparent public participation." They suggested that segregation of all city public participation functions into one agency (as was recommended by the ASR (200)) is less effective. They found that community members can provide a valuable resource that cannot be "duplicated or bought" for "budgeting, planning, and community development" when City leaders and staff "authentically" invite community members to participate" and do not consider community members "an enemy force." "Elected officials" also can help "make the neighborhood system work" by committing themselves to and supporting "authentic cooperative, transparent public participation" (4).

Neighborhood Associations: The neighborhood coalition leaders noted that neighborhood associations are "self-defined and self-directed." Neighborhood volunteers get involved because they want to "improve their community." They noted that capacity 
varies across neighborhood associations because they are "participant based and open to" everyone. A neighborhood association reflects the "personality, consistency, skills, and knowledge" of the volunteers involved. The neighborhood coalition leaders argued that neighborhood associations are effective, partly because of the "City of Portland's longtime commitment to recognize and support 'the neighborhood system"' and because the City works with neighborhood associations and provides them with financial support. Neighborhood coalition leaders maintained that neighborhood associations provide valuable "institutional memory" about their geographic community and "the systems that serve them" and "special knowledge" about and "pride" in their community (5).They also asserted that, to be effective, neighborhood associations need support, including "organizational development advice" in "leadership, facilitation, creativity community development activity, maintenance of the social fabric, and issues education." The need for support varies across neighborhood associations. Neighborhood coalition leaders suggested that City staff and others who work with neighborhood associations need to recognize and adjust to the reality that neighborhood association participants are volunteers and "have constraints on their time and capacity to be involved." Neighborhood leaders also asserted that neighborhood associations provide an ongoing structure that community members can use to "advocate, build on local assets, or respond to a crisis," and that neighborhood associations function best "when they have the organizational capacity to balance local interests, encourage a sense of fairness, and otherwise facilitate neighborhood advocacy" (5). 
What's Working: Coalition leaders identified a number of things that they believed were "working:"

- "The neighborhood system is an important foundation of government by and for the people."

- The City of Portland's strong commitment to the neighborhood system, compared to most other cities, and Portland's neighborhood is one of the strongest in the country.

- ONI's support to the neighborhood system.

- The role of the neighborhood system as an going structure community members can use to development their neighborhoods and respond to crises.

- Valuable institutional memory held by neighborhood volunteers.

- The neighborhood system, by assisting community members, helps reduce the burden on city council and staff and offers city council and staff a place to send communities members who come to them for help.

- Occasional shortages of neighborhood volunteers are not a "problem," but common experience of many volunteer organizations.

- Local community building efforts that have local buy-in are more effective.

- The effectiveness of the neighborhood system in networking with other community groups is increasing.

- Neighborhood system volunteers represent a "unique pool of educated facilitators" who help community members and city leaders and staff.

- Some neighborhood associations produce "great newsletters and websites." 
- Portland's mayor can change bureau attitudes toward "public participation and community policing" (5-6).

What's "Broke:" Coalition leaders also identified aspects of the system that they believed were "broken:"

- City bureaus and City Council are "less interested in listening and more interested in managing, directing or ignoring participation by neighborhood associations."

- City staff often are "defensive around neighborhood associations."

- Council often chooses to view neighborhood associations as "adversaries or allies" based on political considerations.

- City bureaus often engage in "'punch list" community involvement and try to engineer certain outcomes rather than engaging in "authentic collaboration""public relations" to manage the community instead of collaborative "public involvement."

- The quality of community involvement "varies from bureau to bureau."

- City leaders and staff often "blame the neighborhood system for not being inclusive but do not commit themselves or their resources to help solve a problem that is widespread in our society and city. (They added that blaming community volunteers "is as unlikely to improve inclusivity as ignoring it is.")

- The fragmentation and "silo mentality" of Portland's city government "impedes effective public participation." 
- The city budget development process "is missing a resource by not engaging" the community "through authentic, education, collaboration, and action through the Neighborhood Needs process and Bureau Advisory Committees."

- The City appears to be systematically trying to "avoid considering comment from neighborhood groups" in "land-use matters."

- Parts of the neighborhood system find reaching all their community members challenging, "not because of a lack of desire or knowledge, but because of time constraints, funding, and skill levels" (6).

- More resources are needed in the neighborhood system to support involvement on "high stakes issues." Resource distribution needs to respond to changing levels of need-i.e., more resources made available to neighborhoods in which a "community crisis" arises.

- Neighborhood district coalition capacity has been reduced because, while City funding support has "remained the same in dollars over the past decade," "operations costs have risen (e.g., "postage, printing, insurance, supplies, etc.)," crime prevention staff were moved out of the district offices and into the downtown ONI office; key partnerships with the City had ended, including “neighborhood planning, [Bureau of Environmental Services] neighborhood outreach [through the BES “Downspout Disconnect” community outreach program and other programs that had been housed at $\mathrm{ONI}$, and community policing. 
- The salaries of staff at the five non-profit neighborhood district coalitions have stagnated at that same time that the salaries of staff in the two city-run neighborhood offices increased "implying that [non-profit neighborhood coalition] staff are less significant."

Ideas for Immediate Reforms: Neighborhood coalition leaders recommended a number of immediate reforms intended to: increase inclusion of underrepresented groups, reduce operating costs for neighborhood coalitions, refocus the downtown ONI office, increase support for neighborhood communications, and improve and expand community involvement in the City budget process.

"Inclusion of Underrepresented Groups:" Neighborhood coalition leaders recommended that the City "Provide adequate support to promote meaningful involvement and leadership development for underrepresented groups in the neighborhood system." They suggested that ONI staff be assigned to work "directly with neighborhood associations and other community groups," and that "public participation" and "inclusivity" become priorities for all City bureaus. They also recommended "directing resources toward groups traditionally not participating in the neighborhood system" (7).

Operating Costs: Neighborhood coalitions traditionally had provided insurance coverage for neighborhood association boards, events, and projects. Given the increasing cost of insurance coverage, the neighborhood coalition leaders recommended that the City directly insure neighborhood associations for general liability and "maintain a legal defense fund" to assist neighborhood associations defend themselves against "spurious 
lawsuits." They recommended that the Portland Bureau of Transportation take over covering liability insurance for street closures for block parties and events, hanging street banners, and "approved neighborhood-based projects in the public right of way." Neighborhood coalition leaders also recommended that the City pay a consultant to help the neighborhood coalitions create a "centralized pool" for other non-liability insurance services, including "employee health insurance, workers compensation, etc.," and to help them create a "centralized cooperative purchasing authority in an effort to reduce costs through efficiency" (7-8). ${ }^{81}$

Downtown ONI Office: Neighborhood coalition leaders advocated for a shift of direct service functions-e.g., neighborhood housing and nuisance inspectors and noise control staff—out of ONI, "so that ONI can use its resources to become a stronger advocate for public participation." They suggested that ONI Crime Prevention staff and staff in ONI's Information and Referral Program be moved out of the downtown ONI office and into the neighborhood coalition offices to strengthen the capacity of these offices. They recommended that ONI staff be assigned to support "neighborhood associations and underrepresented groups to increase inclusivity in public participation." They asked that the monthly meetings of the Neighborhood Coalition Chairs and Directors with ONI staff encourage discussions of "big picture" issues instead of just focusing on "administrative detail" and reacting to issues that arise. They recommended

\footnotetext{
${ }^{81}$ These recommendations specifically applied to the five non-profit neighborhood coalitions. The City of Portland and ONI provide many administrative support services, free of charge, to the two city-run neighborhood offices_-including insurance coverage, IT support, financial services, personnel, etc. ONI's provision of these services has allowed these offices to direct time and resources they would have spent on these services to other priorities. This has been another aspect of the perceived inequities between the cityrun and the non-profit coalitions
} 
that, instead of directing these meetings, ONI staff should "support" the coalition directors and chairs in their discussions and work. ONI also should stop "blindsiding" neighborhoods and coalitions with "actions and decisions" and, instead, should involve "neighborhood associations and their neighborhood offices" in "decisions that affect the neighborhood system..." (8).

\section{Communication-Money/Resources: Neighborhood coalition leaders} recommended that the City increase "monetary, technical, and staff" support for strong communications in the neighborhood system. They advocated for adequate additional funding to "allow each residence in a Portland neighborhood to receive" a minimum of "two newsletters from their neighborhood association each year." They also asked the City to support neighborhood associations in "developing, hosting and support of a website on the City of Portland's server" and to expand "the evolvement program" citywide (8-9).

City Budget: Neighborhood coalition leaders repeated the often-heard recommendation that the City reinstitute some form of Neighborhood Needs process that would allow neighborhood associations to proposed capital projects for their neighborhoods. They suggested that the City designate a certain amount of funding to each neighborhood coalition and let each coalition determine the community-identified capital projects that would be funded (similar to the St. Paul model). They also reiterated recommendations to create a small grants program "to stimulate self-directed grass roots involvement (e.g., Savannah, Georgia model)" and to reinstitute the Bureau Advisory Committee (BAC) program. Neighborhood coalition leaders advocated for equalization 
of pay across the city-run and non-profit neighborhood coalition. They also recommended that the City convert as many as possible City bureau "public relations" staff positions to "public participation" positions. They encouraged City bureaus to consider affiliating their work with the neighborhood offices—as was done by BES when it funded the Downspout Disconnect Program at ONI- to support "public participation in the neighborhood system." They praised the Bureau of Planning's new district liaison planner program and encouraged the City to continue it.

Long-term Strategic Planning: Neighborhood association leaders also called for a strategic planning process to stop the "drift" of the neighborhood system and to establish a "specific philosophy and framework" for the system. They hoped that this would help maintain a consistent direction and mission for the system and insulate the system" against future attempts to redirect it." They advocated for regular, well-thoughtout reviews of the system—versus the "abrupt," top-down changes proposed and imposed during the early 2000s. They also called for stronger connections between neighborhood and schools, a review of the effects of the split of services between the City and County, and the identification of innovative community input strategies as alternatives to traditional public hearings. They argued that community members needed help to "understand the big picture implications of possible paths" and their benefits, costs, and tradeoffs.

The neighborhood coalition leaders raised familiar concerns about lack of adequate support for neighborhood and community involvement and lack of authentic interest on the part of City leaders and staff involving community members in City 
decision making. They recommended both immediate reforms - many of which had been recommended by early system reviews_-and also called for a more in-depth strategic planning process that would define a "consistent direction and mission for the system" and insulate the system against "future attempts to redirect it." Many of the neighborhood coalition leaders' concerns and recommendations would be taken up by a number of new processes initiated by Mayor Potter, starting in the spring and summer of 2005, and implemented through funding decisions Potter made during his time in office.

\section{Bureau Innovation Project-2005}

In January 2005, shortly after he took office, Potter took control of all the city bureaus. He retained control of all of city government for his first six months in office. ${ }^{82}$ Potter used this opportunity to reach out to all 8,000 city staff people through a citygovernment-wide survey to seek their help in identifying opportunities to "change how our City works - and make it work better." The survey was part of what Potter called the Bureau Innovation Project (BIP). The project goals included:

- "create a workforce that reflects the rich diversity and cultural awareness of our city;"

- "break down barriers between our bureaus and build a collaborative workforce with shared goals;"

- "make every customer our most important customer;", and

\footnotetext{
${ }^{82}$ Portland mayors have the authority to assign responsibility of bureaus to the other city council members. Portland mayors often take all the bureaus under their control for a short period of time during the budget development process.
} 
- “implement Managing for Results ${ }^{83}$ so we can make citywide decisions based on a shared set of goals" (Portland. Office of Mayor Tom Potter. Report on the Bureau Innovation Project. May 2005, cover letter).

About 2,000 city staff responded to the survey. Staff in the mayor's office also interviewed "bureau directors, senior management and key stakeholders in the community" and asked them about "best practices, new ideas directors would like to develop, and ideas once considered but never implemented. Mayor's staff also reviewed "past audits and efficiency reports" (Portland. Office of Mayor Potter. Report on the Bureau Innovation Project. i).

In May 2005, after consulting with the other city commissioners, Potter identified twenty major recommendations for further action. Mayor Potter established committees to work on each of the twenty recommendations. Sixteen of the recommendations focused internally on city government operations. Four recommendations focused externally on the City's relationship with the community. The four community-focused recommendations included:

\footnotetext{
${ }^{83}$ Managing for Results was a proposal developed by City Auditor Gary Blackmer in 2002 to "keep the City focused on its mission and goals, and to integrate performance information into decision-making, management, and reporting." Managing for Results required the City Council to set "clear long- and shortterm goals," keep "goals in mind when allocating resources," manage "government to achieve desired goals," and measure performance and report results to the public. Blackmer and Mayor Katz advocated for City Council adoption and implementation of the Managing for Results model to bring greater longer-term discipline and focus to City Council priority setting and subsequent policy and budget decision making (Portland. Office of the City Auditor. Managing for Results. December 2002 i). The "silo" structure of Portland's commission form of government does not encourage citywide strategic planning and action. City Council members usually gain political visibility from the actions of the bureaus under their control. Little incentive exists for City Council members to aggressively investigate or try to influence actions by bureaus in another City Council member's portfolio. It is not uncommon for a city commissioner who criticizes another city commissioner's bureaus, to find that the other commissioner retaliates by scrutinizing the initial commissioner's bureaus. Potter often expressed his impatience and frustration with Portland's commission form of government. The BIP project was part of Potter's broader effort to bring more strategic planning and central leadership and management to Portland's city government.
} 
- BIP 1: "Develop a Citywide Strategic Plan in Collaboration with a Community Visioning Process by March 2006." The BIP Report stated that his project was intended to "identify the shared values of all Portland citizens," and use the results of the process "as a platform to develop a citywide strategic plan." This "strategic plan" would include "a vision, mission, statement and goals for bureaus to link to and develop performance measures" and would provide a framework to "focus the work of the City," "provide a basis for measuring progress," and lead to "further organizational changes" within the City's "bureau structure" (2) .The resulting broad community visioning process became known as "visionPDX."

- BIP 8: "Redefine and Revitalize the Office of Neighborhood Involvement." The BIP Report stated that this project would "Conduct a complete assessment of ONI's mission, goals and organizational structure to reinvigorate citizen participation and involvement and supporting the City's goals of diversity and inclusiveness to build community capacity." (This was the "strategic review" of Portland's community and neighborhood involvement system requested by the neighborhood coalition leaders and others.)

- BIP 9: "Develop Improved Public Engagement Procedures." The BIP Report stated that his project would "Reconvene the [PITF] and move forward many of its recommended actions to develop improved citywide public outreach goals and strategies." The project also would ensure "coordinated public 
outreach" by city bureaus "for both project-specific and citywide work efforts." The project also was intended to "expand citizen involvement opportunities for appointment to City Boards and Commissions."

- BIP 20: Appoint a City Charter Review Commission by October 1, 2005. The Charter Review Commission would “Assess the City's charter to consider alternative governing structures and changes" that would "improve customer service, streamline government operations, offer more flexible hiring practices for bureaus, encourage better collaboration with PDC and update, simplify and clarify rules" that "no longer apply, are unclear, or could be accomplished more efficiently." (This project responded, in part, to Potter's often-stated desire to replace Portland's commission form of government with some sort of strong mayor system.)

BIP 1, later known as "visionPDX," would become the most open and inclusive public process ever undertaken by Portland city government. It would model many of the best practices for involving diverse and historically underrepresented communities. BIP 9 significantly narrowed its original focus, and, instead of reconvening the PITF, developed a public involvement assessment toolkit to help city staff determine when to involve the public and at what level. BIP 8, later known as "Community Connect," would develop a comprehensive five-year strategy to increase community involvement in Portland that would significantly shape the direction of ONI and the scope and activities of Portland's community and neighborhood involvement system. The BIP 20 Charter Commission proposed four ballot measures-one proposed regular review of the City Charter and 
another proposed to change Portland's form of government to a strong mayor form. Portland voters approved the first by 3 to 1 , and rejected the latter by 3 to 1 . All four of the BIP processes are described in more detail below.

$\underline{\text { visionPDX - Community Engagement Report }}$

BIP 1 was renamed "visionPDX" and became one of the signature achievements of Tom Potter's one term as mayor Portland. visionPDX was a community-led and city government supported process that asked Portlanders to share their "hopes, dreams and aspirations for the city." visionPDX modeled many best practices of inclusive community involvement and especially those that reach out to and involve individuals and communities that traditionally had not been involved in City processes before. The City of Portland "visionPDX" Community Engagement Report (October 2007) documented, in great detail, the visionPDX outreach strategies and methods, and the important lessons learned.

Mayor Potter early on asserted that visionPDX only would be successful "if a broad and diverse group of voices helped to shape it." When Potter launched visionPDX, he not only charged the Vision Committee with "creating a vision document," but "equally important" to Potter was "the process of engagement," which be believed was a "necessary component of effective community governance" (6).The Vision Committee Engagement Subcommittee was formed and charged with "ensuring that the multitude of people and cultures that make up Portland today were included from the beginning" because only through a gathering of diverse perspectives could Portlanders "begin to understand the complex opportunities and challenges before us as a community" (4). The 
Community Engagement Report documented primarily the work of and lessons learned by two of the Vision Committee subcommittees: the Engagement Subcommittee and the Grants subcommittee.

Mayor Potter intended that visionPDX would be followed by the Portland Plana strategic planning process that would move forward to implement the community's vision for Portland through the update of Portland's Comprehensive Plan, the Central City Plan, and other important city policy documents. The Community Engagement Report stated that "Community governance recognizes that ownership of community problems, solutions and opportunities (e.g., homelessness, drug crimes, development, schools, etc.) rests with the entire community - and that effective progress on these issues requires the cooperation of many stakeholders." The report notes that Potter "stressed that the future of Portland will depend on how well we cultivate and develop a communitygovernment partnership model that supports the goal of an intentional city" (6).

visionPDX "Five Elements": The final visionPDX report group the community's

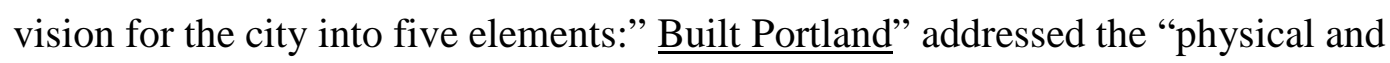
structure" aspects of the city and "how we our communities to look and feel...;"

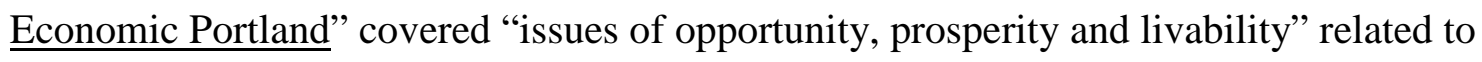
the economy and "the availability of meaningful work;" Environmental Portland" focused on "natural areas within and around Portland" and the City's commitment to "sustainability and environmental preservation;" "Learning Portland" focused on schools and on "practicing an ethic of life-long education;" "Social Portland" considered "individual and community health and well-being" and how community members "relate 
to one another; this element also covered "the civic life of Portland from processes for engaging community in public decision making to partnerships in public safety" (Portland. visionPDX website. The Five Elements. downloaded October 8, 2013).

"Social Portland" values and directions: The Social Portland element of visionPDX included community involvement values such as: community members caring about and committing to "individual and collective well-being;" viewing "diversity as a vital community asset;" facilitating "inclusion of all Portlanders in our democratic processes and in community decision-making;" and "Because we are actively engaged in the governance of our city, we have confidence that our leaders' decisions advance the common good" (Portland. Portland 2030: a vision for the Future. February 2008 25).

The "Social Portland" element also identified "directions" that describe what Portland would be like if the vision for "Social Portland" were realized. Some of the "directions" included: accessible community gathering spaces; encouragement of public deliberation and consideration of multiple viewpoints by the City; city government "civic engagement mechanisms that allow for broad participation;" strong voices for both neighborhood associations and for "identity-based groups;" reduced structural barriers to public involvement; and "accessibility and equity in all public programs." The "directions" also included meeting basic needs of community members, community and environmental health, available health care, a diverse and collaborative police force, "healthy, clean and crime free" communities, and "artistic and cultural activities" that showcase "our city's commitment to creativity and innovation." The full list of "Social Portland" "directions" is presented in Figure 4 below. 
Figure 4: visionPDX Visualizing Social Portland

Visualizing Social Portland:

1. The City of Portland has invested in accessible gathering spaces where its diverse community members can interact and communicate.

2. As in generations past, Portlanders find unique ways to solve problems collectively because the City of Portland encourages public deliberation and considers public decisions from multiple viewpoints.

3. Responding to the increasing diversity of its residents, the City of Portland has developed civic engagement mechanisms that allow for broad participation.

4. Neighborhood associations have a strong voice, as do identity-based groups whose members cross neighborhood boundaries.

5. Structural barriers to public involvement have been addressed and all Portlanders actively participate in civic life.

6. Government has ensured accessibility and equity in all public programs.

7. Basic needs of community members are met, allowing Portlanders the opportunity to succeed and to express their full ingenuity.

8. Individual, community and environmental health are among the highest in the nation because they are considered a public priority.

9. Heath care is available to all and Portland is committed to sustaining the adequacy, viability and excellence of local health care systems.

10. The police force is reflective of Portland's diversity and officers work collaboratively with the entire community to resolve conflicts and keep the city safe.

11. Both the urban core and our neighborhoods are healthy, clean and crime-free spaces to live, work and play.

12. The variety and breadth of artistic and cultural activities showcases our city's commitment to creativity and innovation.

(Portland 2030: a vision for the Future, February 2008 27.)

Community Involvement in visionPDX: The visionPDX Community

Engagement Report described visionPDX as a "city-initiated, community led project

developed to create a new vision" for Portland's city government and the community at 
large. The report states that visionPDX was lead by a "volunteer 40+ members Vision Committee" that included representation of "scores of community groups and individuals..." (6). The over forty people who served on the "Vision Committee" for the project divided into six subcommittees, each of which had some influence on the community outreach for the project. The outreach and involvement was designed and supported primarily by a very diverse group of community members and City staff, known as the Engagement Subcommittee. The Community Engagement Report primarily documented the work of the Engagement Subcommittee and the Grants Subcommittee and offered very interesting insights into which strategies and methods work best to reach diverse individuals and groups in the community, especially group's that historically have been underrepresented in Portland civic life and decision making (5).

visionPDX reached out to many groups that the City never had reached out to before. The report stated that visionPDX "sought input from key stakeholders such as neighborhood associations and business leaders while also ensuring that historically underrepresented groups" were consulted and had a voice as well (6). The report quotes the co-founder of the African Women's Coalition saying: "'I have lived in Portland for over 30 years, and this was the first time anyone asked my community how we envision the future'", (5)

The Community Engagement Report shared a number of lessons learned about “community visioning" and about community involvement. Community visioning lessons included: be clear about the purpose of visioning and recognize that the process is just as important as the product; "Engage communities early and often;" "Look for 
ways to collaborate" and "continue to expand the number of people and organizations" involved; "Remember that visioning is continuous" and incorporate the vision values every time the "community responds to change."

Community involvement lessons included:

- "Develop new leaders" by "actively engaging individuals and groups in the visioning goals" and making the development of new leaders a goal from the outset (8-9).

- "Provide skilled facilitators" who are "culturally competent, skilled at listening well and moving people respectfully through discussion;" "Rely on the expertise and existing relationships community partners have with their constituents."

- "Involve the community in developing tools" because outreach tools ("i.e., surveys, questionnaires, interview questions, etc.) that have been tested in the community for relevance often lead to create community ownership and support for the outreach content and methods.

- "Meet the basic needs of community members" by providing "food, child care, translation and other amenities" at outreach events to reduce what otherwise would be barriers to involvement for many community members.

- "Follow through on action items and specific feedback, and include the public in implementation" to break the common pattern of "public distrust and skepticism" because of past "promises not kept;" implementation and 
"concrete opportunities for change" will increase trust between community members and government.

- "Build ample cushion into your timeline" to allow the process to adjust to "unforeseen circumstances" and to ensure flexibility "while simultaneously moving toward a set of goals"- the Report emphasized that this is "extremely important."

- "Clearly delineate staff and volunteer roles" to ensure "efficient use of time and an easier path to your goal."

- "Create ways to evaluate your engagement" "in coordination with the community" to "measure the short-and long-term community impact of your project."

- "Take stock of your efforts periodically, looking for any possible mid-course corrections," such as sharing preliminary data and findings to identify "gaps and areas for improvement" in the process (9).

Key Outreach Strategies and Tools: The Community Engagement Report identified three key principles that guided the visionPDX community involvement efforts: "DEPTH—Create community ownership through meaningful process and outcomes;" "BREATH_-Involve as much of the public as possible;" and "SUSTAINABILITY-Maintain engagement over time" (12).

The Vision Committee's primary outreach tool was a community survey. The survey asked people what people they valued about Portland and why, what changes they would most like to see, what Portland would look like in 20 years if their hopes had been 
realized, and which actions would be most likely needed to achieve their vision for Portland (13). The Vision Committee received "13,000 completed surveys" and input from "an additional 2,000 people at small group discussions" (10).

Relationship building was important to many groups in the community. Members of the Engagement Subcommittee recognized that "many communities would not want to take a survey or hold a discussion group on these topics right away, without a former relationship having been established." To meet the needs of these communities and learn "how to better dialogue with diverse groups," subcommittee members focused on "having honest conversations"—-which they called "Engagement Interviews"—with individuals and small groups. These interviews focused first on "what engagement these communities were already doing, what worked and what didn't work well, and how to best reach out to their communities..." (13).

While each community faced some challenges specific to their group, recurring themes included the fact that "Many populations are focused on addressing basic needs (housing, health care, food) and aren't in a space to offer their perspective." Some community groups reported "their primary concerns" needed to be met before they could "engage on other issues." Some interviewees noted the importance to them that they see that their input was used by visionPDX "through continued engagement and tangible outcomes." "Many groups commented on the need to build relationships over time" (14). In addition to the survey and "engagement interviews," Vision Committee members also interviewed over 20 "key strategic partners and stakeholders" and asked them about their organization's vision, mission, and current goals, and how best to 
improve outreach to their communities. The Community Engagement Report noted that several of the groups interviewed recommended "'going where their constituents are'...to dialogue with them." They explained that this meant "both going to physical spaces community members frequent and coming prepared with the right outreach methods." Stakeholders also suggested: training community members "how to participate in local government, and the value of that participation;" developing "community-wide dialogues on diversity;" creating "real opportunities for decision-making on the local level (e.g., neighborhoods determining [City] capital investments);" and developing "relationships" with community groups and connecting "community groups to one another" (15). Vision Committee volunteers also attended and shared information at large community events around the city, e.g., Portland's annual Rose Festival and Cinco de Mayo celebration.

A major outreach innovation by visionPDX was the Community Grants Program. This grants program "comprised a large portion" of the overall visionPDX engagement effort and modeled strategies for reaching many groups in the community that the City had never reached effectively. The grant program pushed significant resources out into the community. It also "funded non-profit and community outreach organizations" to design and host community conversations and gather information from members of their communities. Led by Vision Committee volunteers, the Grants Subcommittee allocated $\$ 250,000$ in grants and chose 29 organizations from 143 applications."

The Community Engagement Report said the Community Grant Program “supported organizations' ability to talk to people they knew best: clients, community partners and people in their neighborhoods, to name a few." The Vision Committee 
trusted community-based organizations to implement strategies appropriate for the target populations they identified" (18-19). Grantees used a wide variety of creative outreach strategies including focus groups and small group discussion, one-on-one interviews at existing events and through door-to-door canvassing, house parties and celebratory events, community theater performances, an interactive, multi-media kiosk that was moved to locations around the city in which people could watch a video and then record their ideas for Portland, the City Repair mobile tea house, and a variety of video productions (16-27).

Barriers to Community Involvement: The Community Engagement Report identified "barriers" to effective community involvement that community members shared during visionPDX outreach activities. People who were struggling with unmet basic needs, such as housing, food security, transportation, and health care, did "not have the time or energy to participate in civic activities..." Some Portlanders live in isolation from their communities and from government and services, especially populations “experiencing high mobility and economic displacement. Lack of a social connection to "neighbors and other community members" was another barrier. Several organizations identified the "importance of relationship-building for the long-term, citing the lack of time as a major barrier to building trust and connection" (30).

“Cultural and language differences" kept several "populations from non-dominant cultures" from participating. Some communities brought a strong "Distrust of government and skepticism" with them from their countries of origin and would not stay involved because "they felt that promises made by politicians are often not kept." The 
disability community reported often experiencing "stigma and stereotypes that result in stress and a sense of being overwhelmed" making it difficult to voice their issues and participate effectively. Latino community representatives cited the "public's negative perception of Latinos" as a main barrier to their participation. Girls, Inc. reported that "many girls encounter barriers to participation because their families might be culturally patriarchal. Elders in Action reported that older adults often feel not recognized or valued, which impedes their effective participation. Similarly young people also felt that their age impeded their involvement. Young people often are not included in "adults venues, and when they are invited, can often feel intimidated to speak up" (31).

Other barriers included: "lack of adequate representation in existing civic participation systems" "Outreach volunteers and staff" who often do not "represent the diversity of the community they are working with;" adequate resources often are not provided to support "good involvement" (e.g., "materials, translation/interpretation, food, space, etc."); "Poor internal and external dynamics" often can "hinder engagement efforts;" and "'[I]nvolvement fatigue", from too many community involvement processes can lead Portlanders "to feel tired when asked to participate." Finally, a "Lack of strong leadership" that encourages people to become and stay involved also decreases participation (31-32).

Solutions to Improve Community Involvement: The Community Engagement Report identified a number of "solutions" to help improve community involvement.

- "Understand the community's needs" by thinking "through the specific needs and stories of the audience being reached." 
- "Provide skilled facilitators" who can help "produce safe and inviting public events," and who are "culturally competent and skilled at listening well and moving people respectfully through discussion."

- "Be proactive about building relationships" by allotting "time to build relationships" and not waiting "for a crisis," by bringing "people together with long-term collaboration in mind," and by encouraging collaborative practices to minimize "divisiveness and "internal squabbling'."

- "Involve community members in outreach to their constituents" because "it's best to work through the organizations and individual that already have connections with the communities that you want to get involved."

- "Follow through on action items and specific feedback, and include the public in implementation" to help overcome the "distrust and skepticism" that often is rooted in "promises not kept with the public."

- "Provide culturally relevant and informative education to the general public and leaders" to help the "larger community," "schools, community organizations, and institutions" learn how to be sensitive to and work with different communities.

- "Involve the community in developing outreach tools" because testing community involvement tools in the community can help outreach materials and approach be more relevant to different community groups and can give community members a greater sense of ownership over the content. 
- "Find and use community-specific media" and ensure that outreach messages "build on the issues" different community groups care about.

- "Make engagement convenient" because, for many people, "civic engagement is a luxury;" providing for "basic needs" by providing "food, child care, translation and other amenities as public outreach events facilitates involvement" (32-33).

“Lasting Impacts" of visionPDX community involvement: The visionPDX Community Engagement Report noted that, as "Portland grows more populated and more diverse, we will face new challenges that require cooperation among communities to solve." The report argued that "Our success in meeting these challenges will depend largely upon the effort invested in bringing people together, sharing experiences and building long-term relationships." The report asserted that "Community engagement efforts like visionPDX improve connections between individuals, community organizations, businesses and government, which has lasting impacts."

The Community Engagement Report stated that the extensive visionPDX community involvement efforts had a number of additional impacts. The report observed that "Throughout the visionPDX process, we saw an upsurge of civic engagement from individuals and organizations across Portland who were included and involved for the first time." Leaders of some historically under-represented groups reported that "more of their members and newly naturalized citizens are registering to vote. Organizations with very different missions have formed partnerships and new projects. Groups with very 
different constituencies are collaborating on [a] joint leadership development program"84 (35).

The report quoted Kayse Jama, executive director of the Center for Intercultural Organizing (CIO), who noted that "Before visionPDX, people of color weren't working together as much. Through visioning, we found out that immigrants, refugees, and longtime communities of color have a lot in common. That shared experience was very powerful" (35).

The report closed with the statement: "A clear message received during the vision project was “involve us"” (35)

visionPDX Follow up_Vision into Action: After visionPDX finished its work in 2007, the City Council "created the Vision into Action [VIA] Coalition to act as keepers of the vision. The City Council charged the new group with "oversight and communication regarding the status of vision implementation" and the supervision of the "Vision into Action community grants program" that the City Council had pledged to fund. The VIA Coalition initially was staffed by the Bureau of Planning. The group later created their own independent non-profit organization (Portland. City Council Resolution 36570, Jan. 16, 2008).

The VIA Coalition included a number of activists from community organization who had worked on and helped shape visionPDX's extensive and very successful community outreach and involvement. The coalition members described their purpose as being "a catalyst for concrete actions that will move us closer to realizing the future we

\footnotetext{
${ }^{84}$ The "leadership development program" referred to here was ONI's new Diversity and Civic Leadership Program, which is described in more detail below.
} 
want for ourselves and for future generations." They reported that they sought to accomplish this by "advocating for equity with the Portland Metro Area, supporting community projects that promote livability and realiz[e] community priorities" and by providing data and documentation to the community about the impact of community engagement processes and projects on realizing the [visionPDX] vision in the Portland Metro Area" (Portland. Vision into Action Coalition. Current Projects. [no date]).

The VIA Coalition also administered the VIA community grants program. The City Council provided the group with just over $\$ 100,000$ to give out in 2008 and another just over $\$ 100,000$ to give out in 2009 . The VIA coalition funded a wide diversity of community groups that carried out many different types of community projects-twelve projects in 2008 and eight projects in 2009 (Portland .City Council Resolution 182152. September 3, 2008; Portland City Council Resolution 182819. May 27, 2009). The VIA Coalition also distributed $\$ 10,000$ through the VIA Youth Grants Program to eleven youth-initiated, youth-led projects that implemented aspects of the Children's Bill of Rights and visionPDX (Portland. visionPDX. Vision into Action. 2008 Community Action Grants Program. [no date]).

VIA Coalition members also advocated for the implementation of the visionPDX values and goals during a number of different City processes. In 2007, a number of VIA Steering Committee members served on the 2005-07 City Charter Commission created by Mayor Potter (BIP 20). In 2008, the Bureau of Planning shifted its focus from the completed visionPDX project and began to work on the Portland Plan. During the administration of Mayor Sam Adams, VIA Coalition members served on the Portland 
Plan Equity Technical Advisory Group (Equity TAG), and participated in the discussions that led to Mayor Adams' creation of the City's new Equity Office in 2011 (Portland. Vision into Action Coalition. Current Projects. [no date]).. ${ }^{85}$

visionPDX represented a significant advance in community involvement practice for the City of Portland. A major change was that the process was much more genuinely community-led rather than lead or controlled by city staff. A great diversity of community members were involved as members of visionPDX committees and significantly affected the design and implementation of the community outreach and involvement. The process used a great variety of innovative involvement methods that were very attuned to the needs, cultures, and capacity of the groups they were trying to reach. The process showed many community members and city staff what really great community outreach could look like. As one of Mayor Potter's top priorities, the project also benefited from being well funded at over \$1 million. Unfortunately, while some city agencies adopted some of the model outreach strategies and practices in their subsequent processes, others did not, and continued to use more traditional approaches.

Two important lessons that would be taken up by other processes were the strategy of funding community groups to reach out to their own communities as part of a project's involvement strategy, and the concept of using community grants to involve community members, catalyze community creativity and leverage community resources to help meet a public purpose. The Vision into Action grant model would be replicated in by ONI's new Neighborhood Small Grants Program and soon thereafter the East Portland

\footnotetext{
${ }^{85}$ The VIA Coalition appears to have been active for a few years after the completion of visionPDX in 2007. In October 2013, the most recent post on the VIA Coalition website appeared to be from 2011 (http://www.visionpdx.com/).
} 
Action Plan community grants program, both funded during Mayor Potter's administration.

A number of the leaders from communities of color and immigrant and refugee communities who participated in visionPDX and Vision into Action also had participated in Interwoven Tapestry and/or the Southeast Uplift DRC and DCLC. Many had, through their participation in these other processes, developed relationships with each other and with ONI staff and with neighborhood leaders and leaders of other community organizations. Some of the organizations involved in these processes later became formal ONI community organization partners through their participation in ONI's Diversity and Civic Leadership Program. A few individuals also were active in Mayor Potter's concurrent major review of ONI and the neighborhood system, known as BIP 8, or "Community Connect."

\section{Bureau Innovation Project 9-"Develop Improved Public Engagement Procedures"}

The BIP Report (May 2005) identified the continuing need to develop "consistent standards and expectations" to guide city government's involvement of the community in City “decision-making processes.” The BIP Report stated goal for BIP 9 project as:

"To actively engage citizens at all levels of civic governance and provide greater opportunity and accessibility for all citizens to participate in city decision-making. To achieve greater transparency and consistency for citizens interested in becoming involved in city efforts."

The report noted that this effort would complement the BIP 8 review of Portland's neighborhood system. The BIP Report suggested that the BIP 9 project "Reconvene the Public Involvement Task Force" and bring the PITF's report "developed by more than 40 
community groups, city staff, and public involvement professionals forward to the City Council for discussion and implementation.”

In June 2005, the Mayor's office created a committee of city staff and community members to work on BIP 9. Eileen Argentina, a manager with the City of Portland Bureau of Transportation (BPOT) and Joanne Bowman (one of the three PITF co-chairs) co-chaired the BIP 9 Committee. Argentina and Bowman soon decided that the broad charge and scope originally envisioned for BIP 9 was beyond the capacity of the BIP 9 Committee. They decided instead to pursue a more narrow goal and implement one of the many PITF recommendations - the development of a toolkit to guide city staff in how to assess the level of public involvement appropriate for a particular project.

The BIP 9 committee worked from June 2005 to November 2006 and developed a simple and useful assessment tool, known for years afterwards as "the BIP 9 Toolkit." The committee members emphasized that the toolkit was intended to be "easy to apply to all city bureaus and create consistent expectations for the public, yet not limit the creativity or flexibility of public involvement staff" (Portland. Office of Mayor Tom Potter. Public Involvement Toolkit. November 2006 1).The tone and content of the toolkit attempted to be sensitive to concerns expressed by city staff during the PITF process about wanting avoid rigid "cookie cutter" process requirements. The Public Involvement Toolkit instead focused on providing strategic guidance that city staff could adapt to the varied work and wide range of projects carried out by different bureaus.

The committee members recognized that many city staff people who interact with the public may not have had formal community involvement training. The Public 
Involvement Toolkit presented information in simple and accessible formats to make it as "user friendly" as possible. The toolkit also provided a process flowchart and referred city staff to the City of Portland Outreach and Involvement Handbook for more guidance on general steps and public involvement techniques.

The Public Involvement Toolkit suggested that city staff, at a minimum, perform "an assessment of the project or initiative" being considered, that included the following:

- Environmental Scan: “An environmental scan for related mandates, plans, and other directives that may have bearing on the project.

- Initial Stakeholder Assessment: “An initial stakeholder assessment, including considering whether this project may disproportionately affect a particular community or traditionally underrepresented community."

- Goals and Purposes Review: "A review of the goals and purposes of public involvement for the project," and

- Evaluation of Available Resources: “An evaluation of resources available for the public engagement component of the project" (1).

After this preliminary review, the toolkit encouraged city staff to use the toolkit to "further define the public involvement approach most suited to the particular project" and to use the toolkit "multiple times throughout the span of a project to assess options in a project's phase or to reassess in the event that circumstances change or modifications are needed" (1).

The Public Involvement Toolkit suggested that city staff work with a "representative stakeholder group, to assess the optimal approaches and methods for 
engaging the public in a project or initiative" and to design the formal public involvement process. It emphasized that, not only can representatives of the proposed target stakeholders groups help improve the process design, involving them also "can help develop early public commitment to project success..." (2). The toolkit recommended that city staff work with the stakeholder group to: answer some basic scoping questions about the level of impact of the project; determine the level of public involvement that is appropriate to the project; and then identify tools and techniques that best fit that level of involvement. This approach embodied the early involvement called for by the PITF and implemented so effectively by the visionPDX process.

The toolkit also guided City staff in ranking the answers to the following "Level of Impact" questions from "very low" to "very high."

1. "What is the anticipated level of conflict, opportunity, controversy, or concern on this or related issues?"

2. "How significant are the potential impacts to the public?"

3. "How much do the major stakeholders care about this issues, project, or program?"

4. "What degree of involvement does the public appear to desire or expect?"

5. "What is the potential for public impact on the proposed decision or project?"

6. "How significant are the possible benefits of involving the public?"

7. "How serious are the potential ramifications of NOT involving the public?"

8. "What level of public participation does Council and/or bureau directors desire or expect?" 
9. "What is the possibility of broad public interest?"

10. "What is the probably level of difficulty in solving the problem or advancing the project" (Appendix B)?

The Public Involvement Toolkit provided a table that listed levels of public involvement—-inform," "consult," "involve," "collaborative," "and "decide" (based on the IAP2 Spectrum). The table described the "public participation goal" for each level and the simple description of what the City would commit to at that level of involvement (e.g. "Decide" - "Implement what the public decides." The table also suggested some basic categories of tools that are appropriate for each level (e.g. "Information/Notification," "Events/Meetings," "Community Education," "Committees," etc) (Appendix C). The toolkit also included a table that provided numerous tool options under each category (Appendix D).

While, the BIP 9 committee did not reconvene the PITF and move forward to implement all the PITF recommendations, the Public Involvement Toolkit did offer a valuable resource to help city staff think through some of the basic design issues for public involvement for their projects. It is not clear how many city staff use the Public Involvement Toolkit. In 2013, a few city bureaus strongly encourage or require their staff people to use the toolkit. Many city staff appear either to be unaware of the toolkit or not to use it regularly. ${ }^{86}$

Once it became clear that BIP 9 was not going to take up the broader work of the PITF (as initially proposed in the BIP 9 charge), some community members who felt

\footnotetext{
${ }^{86}$ In 2013, PIAC members, including Elizabeth Kennedy-Wong who was Mayor Potter staff person who oversaw the BIP 9 Committee's work, are reviewing and updating the BIP 9 Toolkit.
} 
strongly that the PITF work needed to continue complained to the mayor's staff about what they saw as the dramatically-reduced scope of the BIP 9 project. The mayor's staff consulted with the Mayor Potter and reported back that he was committed to creating a standing public involvement advisory commission to carry on the PITF work. (The PITF had recommended the creation of such a standing commission as one of the PITF major recommendations.)

Mayor Potter followed through on this commitment and in 2007 funded a position at ONI to helping create and coordinate the work of the commission and to reestablish and support the city public involvement staff peer networking group (CPIN). In 2008, the City Council formally established the ongoing Public Involvement Advisory Council (PIAC) to carry on the work of the PITF to establish guidelines and standards for city government community involvement. (See the description of PIAC below.)

\section{BIP 20-City Charter Commission}

The BIP Report (May 2005) recommended the appointment of a "City Charter Review Commission" to "consider alternative governing structures and changes." The BIP Report, stated the rationale for creating the commission, as follows:

"Portland's City Charter establishes the Commission form of government in which individually-elected Commissioners oversee a group of city bureaus, serving as both the chief administrator and 'Commissioner-incharge' for a portfolio of bureaus as well as serving in a legislative capacity as a member of the City Council. This creates a dynamic of competing interest, one to legislate for the benefit of the entire city, the other to administer for the benefit of one's particular portfolio." The report further states that "Many attribute the difficulty in collaborating across bureaus and working together as 'one city' to the Commission form of government." (Portland. Report on the Bureau Innovation Project 2005 28). 
The BIP Report suggested that the commission "Establish principles on which to base Charter Commission reform;" analyze alternative government structures; explore changes to the City Charter that would encourage better collaboration between the semiautonomous Portland Development Commission and other city bureaus; and to assess current civil service and human resources provisions in the City Charter.

The BIP Report suggested that the goal of the project would be to "improve customer service, streamline government operations, offer more flexible hiring practices for bureaus, encourage better collaboration with PDC and update, simplify and clarify rules which no longer apply, are unclear, or could be accomplished more efficiently."

The City Council created the Charter Review Commission and appointed its members in November 2005 (Portland .City Council Resolution Substitute 36346, November 9, 2005). The commission members heard testimony from current and former elected officials, city employees, "community organizations, neighborhood associations and other stakeholder groups and individuals." They also sought guidance from government and public administration experts, reviewed "academic and professional literature," and studied model charters and charter of "comparably-sized cities."

In January 2007, the commission members presented their report to City Council, titled “A City Government for Portland's Future." Commissioner members proposed that the City Council refer four measures to Portland voters. One measure updated and clarified civil service provisions in the City Charter. Another gave the City Council greater oversight over the Portland Development Commission and clarified the roles and responsibilities of the PDC and the City Council. The other two, described below, 
changed Portland's form of government and established periodic community charter review commissions.

Change the Form of Portland's City Government: The most controversial measure proposed by the Charter Review Commission replaced Portland's commissioner form of government with a form in which the City's Chief Administrative Officer (CAO) would responsible for overseeing and coordinating the "day-to-day management of the City's bureaus, operations and finances." The Mayor would appoint the CAO, subject to City Council confirmation. The CAO would be directly accountable to the Mayor. The Mayor would act as the "chief elected executive official of the City with ultimate authority and political accountability for City operations." The City Council members would focus on "legislative oversight of City operations and management, policy development, long-term strategic planning and constituent representation.” The City Council would continue to "play a quasi-judicial role in certain areas, primarily land use" (Portland. Charter Review Commission. January 2007 8).

Charter Review: The fourth measure was directly related to community involvement in city government decision making. The measure required the City Council to convene, "at least every six years," a citizens' Charter Commission (representative of the City as a whole) to review aspects of the City Charter and recommend Charter amendments to Council and the voters of the City." In 2007, the City Charter had no provision requiring regular review of the City Charter. The Charter Commission members identified some of the advantages of periodic charter review: 
- "Provides citizens an opportunity to periodically review the City Charter and gives all residents of the City an opportunity to consider fundamental issues of City structure and governance;"

- “Adheres to Portland's tradition of civic engagement by permitting citizens to independently examine the City's governing document from an impartial perspective;"

- "Composition of each Charter Commission promotes representation and inclusiveness;" and

- "Permits the Charter to evolve to reflect the changing face and needs of the City and its residents" (16).

Charter Commission members also emphasized that future charter commissions would "reflect Portland's residents, and will be cognizant of community issues. Members of the Charter Commission will listen to suggestions from all Portland residents, including elected officials [who were not allowed to be charter commission members], as to what should be investigated in the Charter and then select its highest priorities." The measure also proposed to allow the charter commission recommendations to go directly to the ballot. The measure required the first charter review commission to be established within two years.

Charter Commission members identified issues they believed deserved "urgent attention" during the first charter review process in two years. These issues included:

- Election and voting format for city council elections "(e.g. districts, at-large, hybrid formats)" 
- Number of positions on the city council

- "Alignment with visionPDX and Community Connect results"

- "Consider a Charter preamble to emphasize Portland's community values"

- 'Streamlining the Charter to a 'model charter' format" and removing language that more properly belonged in City Code or elsewhere.

Regular community charter review measure would have made it much easier to implement the PITF recommendation to place language in the City Charter that established governance values for "community governance" and formally established the role of community member in government decision making. The Charter Commission members also recognized the possible need to insert language to implement aspects of with visionPDX and Community Connect values and/or recommendations.

The City Council voted to forward all four measures, with some changes, to the May 15, 2007 election ballot. Voters approved the PDC measure by 53 percent, and the civil service reforms measure by 54 percent. Voters strongly approved the periodic charter review measure with a 76 percent "Yes" vote. The measure to change Portland's form of government, which Mayor Potter strongly supported, failed to passed-76 percent of Portland voters voted "No" (Multnomah County Elections. "Election Results and History," "May 15, 2007 -Election Results," http://web.multco.us/elections/may-152007-election-results, downloaded October 8, 2013).

The version of the charter review measure passed by Portland voters (Measure No. 26-89) included the following provisions: 
- Required the City Council to convene a Charter Review Commission at least every 10 years;

- Required the City Council to establish the first charter commission in two years;

- Required the commission to "reflect the diversity of the City and be made up of 20 residents"

- Required each city council member to "nominate four Charter Commission members, subject to confirmation by the Council"

- Allowed the Mayor and City Council to request that the commission members review "specific Charter sections," but allowed the commissioner members to choose to review other parts of the Charter if they chose to;

- Required the commission to provide written reports to the city council;

- Required the city council to forward to the ballot any City Charter amendment supported by at least 15 of the commission members;

- Allowed the city council to choose whether or not to refer charter amendments to the voters that were supported by a majority, but fewer than 15 , of the commission members.

This new formal requirement for periodic community review of the City Charter embedded a valuable recurring opportunity for community members to have direct access to changing the City's most fundamental governing document. Also, the measure's language ("at least" every ten years) allowed the City Council to establish a charter review commission at any time. 
Mayor Sam Adams would create the first charter review commission, as required by the measure, in $2011 .^{87}$ (See below for a description of the 2011 Charter Review Commission.)

\section{BIP 8/Community Connect}

The BIP 8 project—later knows as "Community Connect"—-significantly would expand and shift the focus of Portland's community and neighborhood involvement system.

Many people, for many years, had raised concerns about the representativeness and inclusiveness of Portland's neighborhood association system and the lack of an adequate voice in City decision making for many groups in the community. Tom Potter, during his campaign, had expressed his concern that many groups, including people of color and immigrants and refugees, did not feel that the neighborhood system welcomed their participation or worked on the issues they cared about. Community groups had asked for many years that Portland's community involvement system be expanded to include other types of community groups. City officials and others frequently criticized neighborhood associations for having low rates of involvement. Neighborhood association and neighborhood coalition leaders had been calling for many years for more resources and support for the system and for a longer-term definition of the purpose of the system and a strategic plan for broadening and improving community involvement in Portland.

\footnotetext{
${ }^{87}$ The Portland City Charter Section 13-301.Charter Commission states that even though the new charter section that includes the language passed by voters is dated May 15, 2007, the "effective date" is listed as "January 1, 2009.
} 
The BIP 8 project—later known as "Community Connect"—-would establish a broad and detailed strategic plan for reinvigorating and expanding Portland's community and neighborhood involvement system. This strategic plan significantly would influence reforms initiated under Mayor Potter and the continued evolution of the system through the time of this study in 2013.

BIP Report on BIP 8: The BIP Report (2005) titled BIP 8: "Redefine and Revitalize the Office of Neighborhood Involvement." The BIP Report stated that ONI's “mission and organizational structure" never had been analyzed or extensively evaluated. ${ }^{88}$ The BIP Report stated that ONI's mission and structure was "due for a comprehensive reassessment in order to fully harness the level of participation of Portland's citizen-activists." The report asserted that a "reorganization will reinvigorate citizen participation, allow for meaningful citizen contribution, and better organize the neighborhood system of 95 neighborhood associations and 7 district coalitions to ensure better citizen involvement." The report stated that "citizen participation in neighborhood associations has declined dramatically," partially because of "changing demographics, decreased support and resources, more time constraints on working families..." (Portland. Report on the Bureau Innovation Project. May 2005 14).

The BIP Report suggested that the BIP 8 project should "Bring together diverse community interests to determine what civic participation should look like in Portland, evaluating and modifying ONI's mission and structure to achieve those goals." The report directed ONI to "model the behaviors identified in the [PITF] guidelines for public

\footnotetext{
${ }^{88}$ It's not clear whether the mayor's staff who prepared this document were unaware of the 1995-96 Task Force on Neighborhood Involvement or did not think that review was "significant."
} 
engagement—openness, inclusion, and listening" in conducting "this redefinition and restructuring, and to "Work in partnership with the City's Visioning process to enhance and engage public involvement" (14).

The Community Connect Process: The BIP 8 process got off to a rocky start and would be plagued by process missteps for much of its existence. The mayor's office invited a large number of representatives from a wide array of neighborhood and community-based organizations to a kick-off meeting with Mayor Potter in June 2005. Many attendees were confused about whether or not the mayor was inviting them to serve on the committee itself. Mayor's staff had to let people know after the meeting that the Mayor's Office would select a smaller, but very diverse, group of individuals to serve on the committee.

The actual BIP 8 committee members met for the first time in early August 2005. They included a broad range of representatives from the neighborhood system, underrepresented communities and community organizations and different city bureaus. Elizabeth Kennedy-Wong, with Mayor Potter's office, and ONI Director Jimmy Brown introduced themselves as the co-leaders of the group. BIP 8 Committee members discussed the purpose of the group and chose five of their members to serve with Kennedy-Wong and Brown as a steering committee for the group. A staff person from the City's Office of Management and Finance had been assigned to take notes at the meeting. No other staff people or resources were provided specifically to support the BIP 8 project (Portland. Bureau Innovation Project 8.Meeting Notes August 3, 2005). 
During fall 2005, committee members met monthly and discussed strategies for how to reach out to and gather input from a broad range of community groups and perspectives. Kennedy-Wong withdrew from the process for a couple months while she was on maternity leave (Portland. Bureau Innovation Project 8.Meeting Notes October 21, 2005).

Kris Smock's advice to BIP 8: The BIP 8 steering committee invited local community organizing consultant Kris Smock to share her thoughts and advice with the group. Smock described the pros and cons of what she referred to as the "civic model" of community organizing, which includes traditional volunteer neighborhood associations. ${ }^{89}$ She suggested that the BIP 8 Committee members consider the drawbacks of the "civic model" as they designed their process. Smock identified four primary drawbacks:

- "Who gets involved." Smock noted that most of the people who get involved in neighborhood associations are "the people with the capacity and resources to enable them to respond to the opportunity." "Without more explicit methods for" reaching out to "other residents and building their leadership skills," "traditionally disenfranchised" residents will find it hard to get involved.

- "No real policy influence." Smock maintained that neighborhood association meetings tend to "serve as forums for airing problems and discussing ideas," and give residents an opportunity to interact face-to-face with "government employees." The meetings “don't really provide a way for residents to

\footnotetext{
${ }^{89}$ Smock describes the "civic model" and four other models of community organizing in her book, Democracy in Action: Community Organizing and Urban Change, 2004.
} 
influence policies or decisions"- except through "the initiative of volunteers who have the pre-existing skills to engage at that level."

- "Lack of structure" leads to "no voice for most." Smock discussed how "The lack of a more structured process for discussion and decision-making means that traditionally disenfranchised residents who do end up at the meetings often don't feel like they have a voice."

- "Self-reinforcing cycle." Smock added that neighborhood associations often are "seen as the legitimate voice for the whole community, so when government or private entities need the community's approval for something, they go to these groups." She cautioned that "without a more explicit effort to engage traditionally disenfranchised residents, the groups do not genuinely represent the community." She maintained that the "problem becomes selfreinforcing as disenfranchised residents start to see these groups as only representing the interests of a narrow segment of the community" (Smock. Comments to Bureau Innovation Team 8 October 19, 2005 1).

Smock suggested to the BIP 8 Steering Committee members that other community organizing models provide "a range of different methods and tools" that more effectively engage "historically disenfranchised residents in public life" and give "all residents a more genuine voice in decision-making" (1). Smock shared the following community organizing lessons she had identified through her research.

- Outreach Strategies: Smock said that neighborhood associations often put a notice in the paper and distribute flyers to invite community members to a 
meeting to comment on "planning or development projects in their neighborhood." Often, few community members show up, leading neighborhood association leaders to assume they "don't care" and do not want to be involved in the decision. Smock argued that, while this is a "typical response," it "ignores the basic tenets of outreach, which she identified as:

- "Flyers as reminders:" Flyers and written materials work best as reminders about something resident already are involved in, not to engage them initially.

○ "Relationships:" "To engage residents, you need to build one-on-one relationships with them."

- “One-on-ones:" To build these relationships, you need to go out and talk "to people about their issues and concerns," really listen to them, and then create a "meaningful process for those concerns to be incorporated into the group's work."

- "Trust and confidence in the process:" Once you have built a "genuine relationship of mutual trust and respect" and people are confident their concerns and interests will be incorporated into the process, "then you have a basis for inviting them to get involved."

○ "Landlords and developers:" Land lords and developers often come to meetings with a clear agenda and self interest, with existing relationships with the neighborhood leaders who organized the meeting, and they often have "paid staff with the time, skills, and experience to participate." 
- "Labor intensive:" This outreach process is very labor intensive and needs to be done "in a consistent way. Most organizing groups rely on paid staff to do the outreach." Smock suggested that neighborhood volunteers could be trained "to do door-to-door outreach or house meetings" but she cautioned that "it would need to be well-coordinated and organized" 90 (Smock2005 2).

- Leadership Development: Smock stated that the "assumption that people learn the skills of citizenship through experience (e.g. Putnam) only really holds true for people who start off with an existing base of education and skills...they can build on through experience." Smock argued that "leadership development needs to be intentional." People who "don't already have the skills and experience" need to be provided with "training and capacity building up front" to be able to participate on an equal footing with other players. They also need "ongoing coaching and staff support throughout the process." Smock noted that BIP 8 could draw from many models of leadership development, but she emphasized that these models require "staff support and significant time and resources." She also stated that these models "require one-on-one work with each resident," and that "Just setting up some group trainings is not enough" (2).

\footnotetext{
${ }^{90}$ BIP 8 Steering Committee members asked Smock how many paid staff would be needed to support this type of effort by all ninety-five neighborhood associations in Portland. Smock stated that she thought that one paid community organizer for each neighborhood association would be required to do it well. ONI funding at the time supported around thirty staff people across the seven neighborhood coalition officesnot all of these staff people were available to provide direct organizing support to neighborhood associations.
} 
- $\quad$ Structure and Process: Smock noted that "a big difference" exists between "seeking resident input and involving residents in decision-making in a genuine way." She said that neighborhood associations "typically provide a forum for individual residents to solve their problems by bringing them to the attention of city bureaucrats" and providing "input on specific decisions" that affect their neighborhood. They do not "usually create a way for residents to engage in broader city wide decisions over resource allocation and public priority setting." Smock argued that meaningful involvement of community members in those types of decisions would require the City to "give up control and to be open to what residents decide." She cautioned that that does not mean "the process should be unstructured" or completely controlled by the community. She maintained that "Government needs to create a very highly structured, controlled framework within which residents can have meaningful influence over the content of the decisions." Smock asserted that, contrary to some people's assumption that "the more unstructured and open-ended a process is, the more democratic it is," her research had suggested that the "opposite is actually true." "[H]ighly structured and aggressively facilitated" processes are most effective at "engaging diverse groups of residents in a meaningful way and giving a voice to the most disenfranchised residents...." Smock went on to caution that "The less structured the process is, the more likely it is that pre-existing power dynamics will be replicated in a community engagement process" and that the process will "end up providing an 
opportunity for the 'usual suspects' to have input in this decision."

Smock closed her comments on this topic by stated that BIP 8 needed to acknowledge "up front that different groups will come to the table with potentially conflicting interests." She noted the "tendency in Portland's political culture to emphasize consensus and partnership... and to gloss over the real differences in power and interests that groups come to the table with." Smock suggested one strategy to address this would be to "give each 'interest group,' particularly among the traditionally disenfranchised populations, a chance to meet on their own and work through the issues and develop their positions ahead of time" so they can "approach the process from a position of greater strength" (2-3).

Smock suggested that the BIP 8 Committee members reach out to the community to find out what is working and not working about the current system by starting with focus groups or one-on-one interviews with representatives of "groups that try to influence government decisions" including "citizen activists and experts." She suggested the group could use surveys to test out different possibilities. She cautioned the group to wait to engage people until they had something concrete in which people could "see the possibility of having input on things that affect their daily lives" rather than sharing "something abstract where the focus is on creating a process." If BIP 8 had greater "capacity and resources," Smock suggested that the group organize community forums around the city to share information from the surveys. She also suggested "grassroots

\footnotetext{
${ }^{91}$ Smock's contention would be supported by the turmoil and frustration that arose during the course of the BIP 8 process from the lack of clear direction from the Mayor's office regarding the mission, scope and purpose of BIP 8 and lack of skilled and effective facilitation and strategic support for much of the process.
} 
outreach prior to the meeting to introduce the ideas to people, get their general feedback, create a buzz, and start building relationships," possibly by training "neighborhood association leaders to do door-to-door canvassing" or partnering with "existing organizations to do house meetings." Smock suggested that the community meetings provide information "on the options and case studies/models from other communities," small groups discussions and responses, an opportunity for participants to "vote/prioritize/comment on the options," and "opportunities for people to sign up to get more involved." Smock closed by warning that "If you can't do meaningful outreach, you will replicate the existing problems" $(3-4) .{ }^{92}$

BIP 8 Struggles On: BIP 8 committee members continued to meet monthly and discuss outreach strategies. They also continued to wrestle with the lack of clarity about the group's charge. One community organization leader said the letter he received that invited him to serve on BIP 8 had said that the group was being asked to create the ideal system from scratch, then the group was told the process was to be about restructuring ONI—but it was not clear whether this meant the bureau or the entire community and neighborhood involvement system. Amalia Alarcón de Morris with ONI said the purpose was to identify the best mechanism to get people involved. ONI Director Jimmy Brown said BIP 8 committee members were supposed to build a process to gather information from citizens about what kind of system they wanted-not to development the system themselves. BIP 8 members asked for further clarification on the committee's charge (Portland. Bureau Innovation Project 8. Meeting Notes November 2, 2005).

\footnotetext{
92 visionPDX, with much more funding and staff capacity that BIP 8, was able much more closely to achieve the model of community outreach Smock described. However, BIP 8 ultimately would succeed in gathering input from a wide variety of groups and stakeholders in the system and the community.
} 
In January 2006, Mayor Potter appointed Alarcón de Morris as the new ONI Director. Brown left to work for the Water Bureau (Portland. Office of Mayor Tom Potter. Mayor Potter Appoints Interim ONI Director December 29, 2005).

More changes were on the way. In December, Alarcón de Morris emailed that group that the OMF staff person who had been taking notes was being reassigned to work on the city budget process. She reported that some representatives of communities of color and immigrant and refugee organizations were not coming to the BIP 8 meetings because they were not getting meeting notices or felt that the meetings were not a good use of their time. Some had told her they wanted to continue receiving meeting minutes and announcements, but preferred to share their issues and concerns in a single focused meeting (Alarcón de Morris. Email to Cece Hugley-Noel et al.RE: BIP 8 Contact Assignments December 29, 2005).

Mayor Potter attended the January 2006 BIP 8 meeting and shared his vision for BIP 8 and his "community governance" philosophy with the group. Potter described "community governance" as the community and government working together to solve the community's problems. Potter said his vision for the purpose of BIP 8 was to reach people who had not been reached by the current system, such as renters, immigrants, and people of color. Potter said he did not want to be too directive with the BIP 8 committee. He said "I'm willing to look at any system that will work better." Potter committed to implementing what the group developed. He told the committee members, "You interpret your charge." Potter shared with the group that he had told city bureaus that he would not look at their budget proposals unless they showed him that they had involved the 
community in developing them. Alarcón de Morris announced that an experienced facilitator would be brought in to facilitate future BIP 8 meetings (Leistner, Paul. Personal meeting notes. Bureau Innovation Project 8. January 4, 2006).

The February 2006 meeting was facilitated by Judith Mowry, an experienced facilitator with Resolutions NW and a long-time community activist. BIP 8 members also welcomed a university student intern, Alex Johnson, who had been recruited to help support the BIP 8 Committee by one of the BIP 8 members. BIP 8 members continued to discuss the group's charge. They determined that they needed more information on: 'What does ONI do now?;" models from other communities, and the state of the current neighborhood system. This information would allow them to go back out to the community with more refined questions. Group members also recognized a need to reengage BIP 8 members who had dropped off the committee (Portland. Bureau Innovation Project 8. Meeting Note. February 1, 2006).

In early March 2006, the Mayor's office advertized an outreach and engagement coordinator position that would provide support to BIP 8 through June 2006. The job announcement described BIP 8 as answering the questions: If we could create the ideal neighborhood system today, what would it look like? Who would participate? How would they participate? How do we overcome barriers to participation? What would need to be in place to inspire people to participate? How can we make participating in local government relevant to the community. ${ }^{, 93}$ By April 2006, the Mayor's office had hired

\footnotetext{
${ }^{93}$ Source; Email from Amanda Rhodes to Tracey Braden at PSU, Subject: Available: Outreach and Engagement Coordinator Position, March 16, 2006.
} 
Johnell Bell to fill the position, with the expectation that he would help with outreach to under-represented communities.

In May 2006, BIP 8 members proposed creating a number of sub-committees. The subcommittee tasks were to: assess the current neighborhood system, develop and implement outreach efforts, research models from other communities, and propose data analysis methods. Bell told the BIP 8 members that Mayor Potter wanted more coordination between BIP 8 and BIP 9 and visionPDX (Portland. Bureau Innovation Project 8. Meeting Notes May 3, 2006).

June 2006 Portland Tribune Article: In early June 2006, the Portland Tribune ran an article about BIP 8 that angered many neighborhood leaders across the city. The article identified Kennedy-Wong as Mayor Potter's coordinator of the BIP 8 project and characterized her as "someone willing to take on the city's neighborhood associations as the city's dominant citizen participation models." The article reported that KennedyWong was "bothered" that renters, new immigrants, the elderly and other "underrepresented" community members were not participating in neighborhood associations, which were supposed to be the "primary channels through which Portland citizens affect City Hall decisions.” The Tribune stated that it was Kennedy-Wong's job, through BIP 8 , to give these community members a voice. ${ }^{94}$ (Korn, Peter. June 2, 2006).

The Tribune reported that Kennedy-Wong believed that neighborhood associations did not carry the same weight at City Hall as they once did and had less power because of a shift in the way elected officials interacted with community members.

\footnotetext{
${ }^{94}$ Korn's Portland Tribune article also called "Bureau Innovation Project No. 8" a "bureaucratic sounding effort if ever there was one." The Mayor's office changed the name of BIP 8 to "Community Connect" a couple months later.
} 
Kennedy-Wong also maintained that the role of neighborhood associations was becoming less clear at the same time that the number other types of activist organizations in Portland had risen. The Tribune reported that the purpose of "Kennedy-Wong's project" was to "create formal new ways for people to participate in city government without relying on the neighborhood associations."

The Tribune warned that "any new model is going to have to deal with some skepticism from the neighborhood associations." Neighborhood leader and BIP 8 member Linda Nettekoven, according to the article, agreed "that the neighborhood associations could do a much better job of involving more people in their work," but she also said that this would take "more support from the city." Nettekoven stated, "I'm very concerned that people keep saying the neighborhood associations don't do a good enough job representing people. We have no mechanism for getting the word out except to go and put things on everybody's doorstep. You need more resources from some place if you're going to truly involve people." She also noted that volunteer neighborhood associations were facing an increasingly complex city government "with more meetings to attend, and more issues to follow" and that neighborhood associations needed help. The article quoted Nettekoven as saying "I don't think all the conversation about further decentralization of decision making is possible if we don't put more resources into whatever system we come up with."

The Tribune reported that Kennedy-Wong believed that, while "people in Portland are still politically active," they increasingly "don't see neighborhood associations as the places they want to invest their energy." Kennedy-Wong noted that at 
the same time neighborhood associations were feeling that City Council was not listening to them, City Council members were challenging neighborhood associations by asking "Who are you, and do you really represent the community?"

The Tribune article identified, 20-year old North Portland activist and BIP 8 member Charles McGee as the kind of person "Kennedy-Wong hopes to appeal to, and involve." The article reported that McGee believed that "despite good intentions, the project already is losing momentum: 'We started off with a group of fantastic individuals. But our numbers have dropped dramatically."' McGee agreed with Mayor Potter's desire to "change the citizen input model" in Portland, and noted that "For some people...neighborhood associations make no sense." McGee continued, "'I'm an African-American male, 20 years old, but I don't attend a neighborhood meeting. In my community that's not how we advocate. In our community we typically do it on an individual level or through various agencies or through the Urban League or churches. Not everybody goes down to City Hall and lobbies like people in Southwest Portland do." The article reported that "McGee says he's beginning to think that [BIP 8] will never come up with a practical model. The article quoted McGee as saying "The lack of overall direction from the mayor's office has really turned a lot of folks away from wanting to be part of this group....It's starting to look like a waste of taxpayer dollars.",95 The Tribune, at the end of the article, reported that Kennedy-Wong believed that BIP 8's work would not necessarily marginalize neighborhood associations. The article

\footnotetext{
${ }^{95}$ McGee had asked for a clear statement of BIP 8's charge at nearly every BIP 8 meeting he had attended to this point.
} 
quoted Kennedy-Wong as saying, "If the neighborhood associations use this process to their advantage, they can use it to increase their power."

After the article came out, many neighborhood leaders in Portland were very angry with Kennedy-Wong and even more worried than before that BIP 8 intended to replace or undermine the neighborhood system. It is somewhat ironic that KennedyWong's description of the weaknesses of neighborhood associations had been raised by many earlier reviews of Portland's community and neighborhood involvement system. Unfortunately, instead of a collaborative process that sought to make community involvement work better for all groups in the community—with significant levels of new resources-BIP 8 was portrayed as an attack on neighborhood associations and a search for a new community involvement model to replace-instead of build on-Portland's traditional neighborhood association system. Also, Smock's warning against having an "unstructured and open-ended" process was supported by McGee's criticisms and the departure from BIP 8 of many of the representatives of communities of color and immigrants and refugees and other community organizations.

Progress and more turmoil: The summer and fall of 2006 would see some progress for BIP 8 and more turmoil. Shortly after the Tribune article ran, the Mayor's Office advertised a staff support position for BIP 8. Mayor Potter also attempted to provide more direction to the group.

Mayor Potter, in a letter to BIP 8 members, dated June 20, 2006, attempted to clarify his charge to BIP 8. Potter wrote that "The relationship between citizens and government needs to be reevaluated. We need you to talk to people about what the model 
should be that effectively engages citizens in making decisions about the city. This is your charge as a group." Potter maintained that: "Citizens needs to be engaged to fix all problems;" "Citizen [sic] need to claim ownership of their government;" "Government needs to share power and the role of defining success;" "People need to relearn how to be neighbors and connect with one another;" and "People need to reclaim the greater role of community to care for each other."

On June 21, 2006, BIP 8 members gathered for a retreat at Portland's Forestry Center to take stock of their progress and develop workplans for the BIP 8 subcommittees. In July, BIP 8 members agreed to schedule separate workgroup meetings in addition to the full group's regular monthly meetings. In early July, Johnell Bell asked group members to suggest new, less bureaucratic, names for the group. In August, the Mayor's Office officially renamed the group "Community Connect."

At the August 24, 2006 meeting, Community Connect members discussed a very extensive proposed outreach and data gathering plan, developed by Sanj Balajee who had joined the Community Connect paid staff and who would support this effort. Balajee's plan proposed to reach out to neighborhood coalition boards and neighborhood association leaders, interview neighborhood coalition directors, and get input from city employees, city board and commission members, and the general public through a questionnaire available online and in hard copy. The plan also proposed reaching out to "Current system stakeholders" and "disengaged populations" through "mini grants, focus groups, Neighborhood association conversations, and questionnaires at community events, and online questionnaires." The plan targeted: 
- Previously Disengaged Populations (Mini-grants)

- Commissioners \& Staff (1-on-1 interviews)

- ONI Coalition Directors (1-on-1 interviews)

- ONI Coalition Boards/NA members (Hard copy surveys)

- Boards \& Commissions including BAC (online surveys)

- ONI, Coalition, City employees (online surveys)

- Internal Research (desk research)

- Misc. Research (visionPDX, tech/comm., Interviews \& prior surveys

- General Community (online survey)

- Bureau Mgmt (1-on-1 Interviews).

Outreach activities were scheduled to begin in September 2006 (Portland. Community Connect. Meeting Notes and meeting materials, August 24, 2006).

On September 16, 2006, Mayor Potter hosted a gathering for neighborhood leaders from neighborhood associations across Portland. The event was intended to give neighborhood leaders the opportunity to review and comment on the work of visionPDX, Community Connect, and the Charter Review Commission. Former Portland city commissioner and former ONA Commissioner in Charge Charles Jordan (1977-1984) welcome the neighborhood leaders. The event included overviews of the three projects and an explanation of the concept of "community governance." Participants broke up into small groups to discuss and comment on the projects.

At the end of the event, Mayor Potter spoke to the gathering. He recognized that neighborhood leaders had not been gathered together like this for a while and suggested 
scheduling annual meetings of the neighborhood association chairs from across the city. Potter stressed that "citizen participation is good government." He encouraged the participants to help decide what should be looked at, the kind of answers they wanted to see, and how to prioritize resources. Potter noted that the City Council would make the final decision on how to move forward and noted that "The city budget is the real policy maker of the City." Potter emphasized that he wanted to see more early, "front-end" public involvement. He also stressed that elected officials need to understand their role"It's the 'people's power' not their power." Potter reported that he wanted an outcomebased approach for government and community activities. Potter concluded by stating that "We need the fire of belief that we can get things done." He recognized that "neighborhood associations carry the weight of their neighborhood on their shoulders," and recognized that "it's hard." Potter urged neighborhood leaders to make Portland the most friendly place for people, not just jobs (Leistner. Personal notes on Neighborhood Association Leaders Event, hosted by the Office of Mayor Tom Potter on September 16, 2006).

In September 2006, the Community Connect Models Committee discussed "guiding values/principles" for and the "functions of an ideal community engagement system." The Outreach Committee had given out half of the funds available for minigrants to organizations to gather input from different communities in Portland. At the end of September, Community Connect members met the new Community Connect project coordinator-Mike McCormick—a long-time community organizer with decades of experience with community groups. Community Connect now was supported by five 
staff people. ${ }^{96}$ The workgroup developing a report on the current neighborhood system also had finished its work (Portland. Community Connect. Meeting Notes, September 28, 2006).

In October 2006, Community Connect members examined their progress to date and revised their workplan. They recognized that they needed more volunteers to help with outreach and analysis of the input and needed to give out the rest of the outreach mini-grants. Also, the expanded staff under McCormick's leadership had just begun its comprehensive coordination of the project. McCormick reported that in his initial conversations with the community members they had been skeptical about the City's seriousness about fixing "its neighborhood (or community engagement) system." McCormick reported that "They are tired and cynical of being asked what they think of the system, only to be left waiting for concrete change." Community Connect members agreed to extend their timeline to allow more time for relationship-building and communication, information gathering and analysis, and the design and presentation of their final findings and recommendations. The Models Workgroup argued that it did not make sense to move forward to develop the system proposal before they had finished their assessment of different models (Portland. Community Connect. Meeting Notes October 26, 2006).

In late November 2006, another Community Connect member, who lead a community organizing group in Portland, left the group. He said that, after a year of

\footnotetext{
${ }^{96}$ The Community Connect September 28, 2006 Meeting Notes report that the staff included: Michael McCormick, Sanjeev Balajee, Johnell Bell, Dana Gantz (intern), and Judith Mowry from Resolutions NW.
} 
work, he was not able to spend more time on the project. ${ }^{97}$ Bell left the staff to accept a position with Multnomah County Chair Ted Wheeler. Mowry was replaced as the group facilitator by Stuart Watson from Resolutions NW. Balajee and Bell reported that extensive input had been collected from eighteen different groups through sixty individual interviews and 1300 completed questionnaires. They also reported that common themes were emerging from different groups including the need to build trust and the desire to have a voice in decision making (Portland. Community Connect. Meeting Notes November 30, 2006).

The November 26, 2006 Community Connect meeting became very tense when McCormick criticized group members for not doing a better job of recruiting and involving people from under-represented communities in Community Connect's work. Kennedy-Wong also criticized the Model's Workgroup for consisting mostly of longtime neighborhood association leaders and said the group needed to add more people. A number of Community Connect members reacted angrily to the criticism. They argued that they had been doing a tremendous amount of work on the project. One group member said too much was being expected of them. Another said she was ready to quit. Another said they repeatedly had asked members of under-represented communities to get involved in Community Connect. She suggested that maybe McCormick and Kennedy-Wong needed to take a different approach to their coordination of the project. A

\footnotetext{
${ }^{97}$ Charles McGee--whom the Portland Tribune had quoted in its June 2, 2006 article--also resigned from Community Connect in early December for similar reasons.
} 
number of group members left the meeting very upset ${ }^{98}$ (Leistner. Personal notes on Community Connect meeting November 30, 2006).

A few days later, Community Connect members received an email letting them know that McCormick had asked the Mayor's Office to let the group take a pause to reassess its work and consider how to move forward. The message reported that the Mayor's Office had granted the request to allow for a review of Community Connect's "scope, timing and process" and "who needs to be involved in order to produce meaningful recommendations." McCormick also called each of the Community Connect members to apologize for the November 30 meeting. He said that he had been following instructions from Kennedy-Wong, and that it was out of character for him to criticize the work of committee volunteers. McCormick then issued an ultimatum to the Mayor's office saying that either Kennedy-Wong needed to be removed from her oversight over Community Connect and any other neighborhood system projects, or he would resign. The Mayor's Office shifted responsibility for Community Connect from Kennedy-Wong to Liesl Wendt, who had overseen the visionPDX project, but continued to have Kennedy-Wong work on other neighborhood system projects. McCormick resigned.

Community Connect forges ahead: The Mayor's Office invited Community Connect members to reconvene in later February 2007 and identified Liesl Wendt, who had oversee the visionPDX process, to be the point person for the Mayor's Office on Community Connect. At the meeting, Wendt reported that Community Connect member Colin McCormack would chair the group. Balajee would be the sole staff person and

\footnotetext{
${ }^{98}$ A number of Community Connect members began to refer to the November 26, 2006 meeting as the "meeting where people cried."
} 
would be assisted by a student volunteer from PSU to help with the analysis of all the input from the many different outreach efforts. Watson would continue to facilitate the meetings.

Wendt reported that Mayor Potter supported having the group take more time. "The mayor said he wanted the project to be successful, even if that meant spending more time together to get the project done right." She told the group not worry, they would not be starting over. Colin McCormack told the group that the mayor was more interested in an overall structure for community involvement that specific involvement tools (Portland. Community Connect. Meeting Notes, February 21, 2007; and Leistner personal notes on the same meeting).

A number of Community Connect members at the February 2007 meeting still were unsure of the group's charge. When one person asked how many people were confused about the group's charge, two-thirds of the group members raised their hands. Wendt said the mayor wanted the group to define its charge. Alarcón de Morris said she was glad the group was not starting over and reported that another group [Southeast Uplift's DCLC] was advocating, through the ONI BAC budget process, for a proposal to involve and support under-represented communities. Some Community Connect members were confused about the extent to which the Community Connect recommendations were supposed to inform the ONI BAC budget development process that year. Southeast Uplift Executive Director and Community Connect steering committee member Cece Hughley-Noel told the group that the task for Community Connect was just to tweak the current system and focus on addressing the immediate 
concerns in the system and to make sure that the group's recommendation could and would be implemented—not to create an ideal system (Portland. Community Connect. Meeting Notes, February 21, 2007; and Leistner personal notes on the same meeting).

Wendt reported that Balajee was working full time on gathering and analyzing the input data. Some group members volunteered to serve on a Data Analysis Work Group (DAWG) and agreed to help recruit other community members to help with the data analysis. Wendt reported that the Mayor's Office was thinking of hiring a consultant to help the group move forward (Portland. Community Connect. Meeting Notes February 21, 2007).

In March 2007, Balajee presented a draft report summarizing common themes from Community Connect's "19 data sources." These sources included:

- Under-represented Groups: Mini-grantees, visionPDX interviews.

- Community Data: General public survey, BIP 9, and visionPDX.

- Neighborhood and Community Leaders: Input from the September 16, 2006 gathering of neighborhood leaders, input from members of neighborhood associations and neighborhood coalition boards, members of city boards and commissions, and neighborhood coalitions directors.

- City Government Perspective: Conversations with City Council members, bureau director interviews, city public involvement employees.

- $\underline{\text { Other: }}$ Small business community, other jurisdictions (e.g., Metro, Tri-Met, Portland Public Schools, etc.), technology, and informally-generated ideas and comments. 
- Literature Review: Assessment of the current system, seventeen best practices and model, and a review of recent system reform efforts (Portland.

Community Connect. Summary of Research: Piecing Together Community Engagement in Portland July 2007 8).

Steering committee members reported that they had met with Mayor Potter, and that Community Connect no longer would focus on the neighborhood system structure but would focus on analyzing the input data to understand the community's needs. They also reported that the Community Connect recommendations would not be expected to influence the ONI Budget for FY 2006-07, but would be considered during the FY 200708 budget process. They also again reported that the Mayor's office was considering hiring a consultant to help the group finalize its recommendations and to define an outreach strategy (Portland. Community Connect. Meeting Notes March 22, 2007).

In May 2007, the DAWG members presented their report, which included 948 recommendations grouped into six broad categories: outreach and engagement, connections to government decisions makers, general structure and roles, communication, resources, and “other." Community Connect members also learned that the Mayor's office had hired Kris Smock and Dana Brown, based on their "professional background, proposed approach, familiarity with the community, and affordability," to help the group. Smock would meet one-on-one with Community Connect members to get their feedback on the process. Brown would develop the communication and outreach plan for the release of the draft and final project recommendations (Portland, Community Connect. Meeting Notes May 31, 2007). 
Smock and Brown moved quickly to help the Community Connect members focus and agree on a well-designed and supported process to produce the group's final goals, strategies, and recommendations. Smock and Brown introduced themselves to the Community Connect members at the group's June 21, 2007 meeting. Smock reported that she had 10 years of experience as an independent consultant on strategic planning in multi-stakeholder processes. She also had a strong background in community building and community organizing, organizational leadership and "voice"—especially for underrepresented communities. Brown reported that she had consulted with non-profit organizations and government agencies and had experience working in community engagement and community organizing. Smock and Brown asked each Community Connect member to share what passion has kept them involved. They also proposed ground rules for the committee's meetings (Portland. Community Connect. Meeting Notes June 21, 2007).

Hugley-Noel reported that Smock's and Brown's roles were to guide the workgroup through the process, to provide structure and a framework for the committee's work, to manage the project and to facilitate the group's meetings. The steering committee would keep the group on track. The Community Connect members would be the "work horse." She emphasized that the consultants, the steering committee, and the Community Connect members needed to pull together. The Community Connect recommendations would be based on the data collected and organized by the DAWG. Smock and Brown suggested that the group schedule two retreats. At the first retreat Community Connect members would: prioritize objectives for each goal, finalize 
criteria to evaluate strategies to achieve the goals, evaluate different strategies, and identify a short list of strategies with which to move forward. Smock would synthesize the group's work for the second retreat. At the second retreat, Community Connect members would identify potential structures as well as discuss, refine, and develop draft recommendations. Smock suggested creating an advisory committee of people who had served on Community Connect but who had left the committee to review the recommendations before they went public. Brown proposed a process to take the Community Connect draft recommendations out to the community.

Smock suggested three draft goals to serve as organizing categories for the menu of options based on the input data and the previous Community Connect work:

- "Engage the full diversity of our community (e.g. increase number and types of people involved);"

- "Strengthen community capacity (e.g. education, needs and asset identification, networks in and between communities, community problemsaving);" and

- "Increase community impact on public decisions (e.g. dialogue with decisionmakers, opportunities and mechanisms for input)." $" 99$

Group members discussed and agreed to these three goals. Smock then lead the group in a discussion of criteria to evaluate strategies that then would be turned into specific recommendations. The group members agreed to use the following criteria: viable, sustainable, broad impact responsive, inclusive, effective, asset-based, education,

\footnotetext{
${ }^{99}$ Smock's first and third proposed goals mirrored the "breadth" and "depth" elements of participatory democracy identified by Berry Portney and Thomson (1993).
} 
community action, community capacity, energizing/inspire, innovate, representative (Portland. Community Connect. Meeting Notes June 21, 2007).

Prior to the first retreat on July 21, 2007, Smock sent Community Connect members a "Draft Menu of Options," which presented ideas from DAWG, BIP 9, and other relevant sources, organized under the three goals. Community Connect members sent her comments, which she incorporated before the retreat. At the retreat, Smock led the group members through a dot exercise that identified ten priority strategies under each goal. Community Connect members then broke into small groups to discuss the three goals. They organized the review criteria into three categories-viable, impactful, strategic — and used these use these criteria to prioritize three top tactics for each objective (Portland. Community Connect. Retreat Summary July 21, 2007).

On August 4, 2007, Community Connect members met for their second retreat. They amended the main criteria categories to include: viable, impactful, strategic, and effective. Wendt recognized that Community Connect members remained unclear about what Mayor Potter wanted from them. She said he supported the direction they were headed under Smock and Brown's guidance. She emphasized that Potter particularly was interested in the engagement of under-represented groups and involving people in the general public who were not currently involved. Community Connect members then read and discussed options for the City's overall “community engagement structure.” These included: maintaining the existing neighborhood system structure with reforms to improve its effectiveness; restructuring the system to support a broader diversity of organizations, including geographic-based (neighborhood and business associations) and 
identity-based (communities of color, immigrants and refugees, youth, elders, homeless, etc.) organizations (Portland. Community Connect. Retreat meeting materials August 4, 2007).

On August 21, 2007, the broader Community Connect "Advisory Committee" (which included people who had served on Community Connect, but who had left the group) met to review the draft goals and recommendations. The participants represented a greater diversity of organizations and committees than usually participated in Community Connect meetings. Smock introduced the draft goals and recommendations. She recognized that it was a lot for people to wrap their heads around in one sitting. Wendt clarified that Community Connect had started out with a focus on ONI and the neighborhood system, but had expanded its focus to "building a healthy community and community capacity” (Leistner. Personal notes on Community Connect Advisory Committee meeting on August 21, 2007).

Smock reviewed the draft recommendations, and participants broke into small groups to discuss them. Smock emphasized that this was meant to be a five-year planthe expectation was not that all this would be "done tomorrow." She also emphasized that Community Connect would be asking the City to commit new resources to implement the recommendations_-not to divert existing resources. She noted that the recommendations envisioned expanding the existing neighborhood system to include non-place-based groups that would have to meet certain recommendations to receive funding.

Smock reported that Community Connect members had heard that a place-basedonly system was not working for many people. She shared that Mayor Potter wanted an 
inclusive structure — not to have ethnic groups competing against each other or against neighborhood associations. The goal is not to dilute the neighborhood system but to broaden it, to build capacity in groups, to ensure a city wide focus, and to provide leadership training, among other objectives.

Participants discussed the goals, objectives, and recommendations and identified a number of common themes, which included:

- Support for other types of community organizations, not just traditional neighborhood associations; the goal is not primarily to get people to go to neighborhood associations, but rather to help people in different communities get organized; for many, they're more likely to do that with people who share their identity or interests.

- Get funding out into the community — small grants are good for this.

- Door-to-door outreach is needed to help get people involved.

- Formal structures are needed to involve other communities-youth, ethnic communities, etc.-but not in a way that leads to competition vs. cooperation.

- More resources are needed to improve the system.

- Technology can help people get involved, if it's what people need and want and will use-not necessarily centralized.

- A variety of approaches is needed.

- Neighborhood coalitions should focus on community organizing and community building to help the many people who say they want to start groups and programs. 
- Every neighborhood coalition needs permanent structures that include ethnic groups, youth, etc. to help more groups connect to the existing system and have real power.

- Organizations need to reach out to each other and ask "what are your issues?" "how can we help?" and not compete with each other.

- Neighborhood coalitions need a critical mass of staff to be able to respond to the needs of different communities and organizations.

- Neighborhood coalitions cannot force neighborhood associations to changethey only can provide support to encourage them to change.

- Citywide community summit agendas should be determined by community members, not by ONI or the City; if an ongoing city-wide "peoples' council" existed, community summits would not be needed.

- The City should reestablish a human rights commission.

- Neighborhood associations should focus on being effective, not representative-on getting people together to work on things together and take action.

- Meetings need to be more inclusive-don't use Roberts Rules of Order.

- Neighborhood associations were created to focus on land use issues; underrepresented groups want to focus on gentrification, lack of jobs, etc.- - not land use. 
- The culture of City government needs to be open to engaging with the community (Leistner. Personal notes on Community Connect Advisory Committee meeting on August 21, 2007).

On August 23, 2007, Smock asked Community Connect members for their final feedback on the revised Community Connect document. Balajee reported that Mayor Potter overall supported the Community Connect draft goals and recommendations. Balajee reported that Potter supported creating and inclusive structure that allowed for a win-win scenario in which groups-place-based and non-place-based—would not complete against each other. This would broaden community power and avoid spreading resources too thinly across groups, which would dilute rather than strengthen community voice. It also would encourage a citywide perspective. This approach also would adapt to fit varying levels of capacity and readiness and not require all groups automatically to have to fit in to the neighborhood coalition model. Balajee reported that Potter was interested in aligning similar efforts, such as the Immigrant and Refugee Taskforce (the recommendations of which were expected in fall 2007), the Community Experience Partnership that was working on recommendation for elders, a citywide community leadership training "Citizen's Academy" proposal being developed for the Mayor's Office and ONI by PSU Professor Steve Johnson, the City's "eVolvement" online community involvement program, the Black Citizens' Coalition (which was asking to receive the same status and funding as a traditional neighborhood coalition), and the Children's Bill of Rights (Portland. Community Connect. Meeting Notes, August 23, 2007). 
During September 2007, Community Connect members hosted a couple "Connection Café" events in the community to share the group's draft goals and recommendations with community members and to get their feedback. Mayor Potter participated in one of these events. Wendt represented Potter at the other event.

In early October 2007, directors of a number of City bureaus sent Balajee a formal letter with their feedback on the draft Community Connect goals and recommendations. ${ }^{100}$ They all supported Community Connect's three goals and supported many of the recommendations. They supported creating "formal recognition and a seat at the table for organizations that represent people of color, immigrants, and other underrepresented groups." They agreed that the current neighborhood system did not adequately respond to the interests and reflect the voices of "large segments of our community," but requested greater clarity on the criteria that would be used to determine "which groups or organizations should be invited to the table" and what a "seat at the table" meant. They strongly supported recommendations that called on City bureaus to use best community involvement practices, but noted that "full implementation will probably require additional resources." They particularly supported the recommendation to create a "Strategic Community Involvement Think Tank" because "Providing best practices information" "could be particularly valuable to city bureaus." The bureau directors supported the recommendation to create new guidelines for Bureau Advisory Committees, but stated that these advisory committees "should be formed with the

\footnotetext{
${ }^{100}$ The directors that signed the October 11, 2007 letter represented; Portland Office of Transportation, Bureau of Planning, Bureau of Environmental Services, Office of Management and Finance, Portland Parks and Recreation, Bureau of Development Services, Portland Water Bureau, and the Bureau of Housing and Community Development.
} 
expectation they will advise bureaus and Council, not be given authority to make program or budget decisions." The bureau directors were open to the recommendation that City Council "delegate 'control over certain policy, planning and budgeting decisions to local communities"” but were concerned that the draft language was "unclear and appears to be a more open-ended grant of authority which could lead to conflicts with other City goals and objectives." They supported "the idea of setting aside a sum of money that can be used to support community priorities as determined by those groups," which could involve both "independent initiatives" and "moving City efforts forward on a faster timeline or at a larger scale than otherwise planned."

The bureau directors expressed some concern about the recommendation to amend the City Charter to "add a 'bill of rights' section dealing with community governance." They argued that some of Community Connect's innovative approaches could be implemented without amending the City Charter. This would allow city leaders and staff and community members to "adapt and be flexible to add to what works and stop doing what doesn't." They stated that amending the City Charter, "seems too prescriptive and restrictive at this early date." The bureau directors ended their letter by stating that "We are ready to help move this ambitious agenda forward, placing Portland in a national leadership position on community involvement" (Portland. Letter to Sanj Balajee from City of Portland Bureau Directors regarding Community Connect Draft Recommendations. October 11, 2007).

On October 25, 2007, Smock and Balajee reviewed, with Community Connect members, 530 responses from the general public , city employees, city commissioners, 
and city bureau directors on the draft goals and recommendations. They reported that the recommendations that received the most support from the community and city leaders and staff included:

\#2: Engage the full diversity of our community;

\#3: Promote effective communication;

\#5: Strengthen the community's capacity to take action (top strategies: small grants, targeted staff support, leadership skills, and reform of the district coalition system); and

\#7: Make public decision-making more responsive (top strategies: cmty needs process, making info accessible, creating formal liaison for communities, closing the loop).

Smock and Balajee reported that the city commissioners generally were supportive but wanted more details before they confirmed their support. Smock clarified that the final product would include: a Five-year Plan to Increase Community Involvement (similar to the draft) as well as a plan describing possible first-year implementation actions and additional strategies and actions for the subsequent second to fifth years (Portland. Community Connect. Meeting Notes October 25, 2007).

The Mayor's office hired Community Connect chair McCormack to serve as the mayor's new public involvement manager and appointed Southeast Uplift Neighborhood Coalition Executive Director Hughley-Noel as the new chair of Community Connect. In early November 2007, Community Connect members met and discussed which strategies to use to ensure implementation of the five-year plan even after Potter left 
office and what they could achieve with the current city council. Hughley-Noel suggested asking the city council to bless the three primary goals and then revisiting the details with them in the future. She suggested that "ONI will be the keeper of the flame." Community Connect members discussed creating a taskforce to study and flesh out a Bureau of Community Involvement" that would produce an annual report to keep focus on progress. Group members also discussed creating action teams to develop implementation plans for each of the key Community Connect recommendation areas, and to create a citywide leadership training program, and a "Think Tank/Resource Center" (Portland. Community Connect. Meeting Notes November 1, 2007).

Community Connect members met again a week later and reviewed the five-year plan, the first year implementation plan, and the final report. Group members agreed that the ONI BAC should be expanded to include new community organization partners rather than create a separate ONI advisory group for these communities. They also discussed the idea of changing ONI's name to the Bureau of Neighborhood and Community Involvement. Brian Hoop from ONI noted that a new ONI staff person had been hired to coordinate the creation of the new Diversity and Civic Leadership Program at ONI. He suggested that another new ONI position be created specifically to support implementation of new programs and support for the neighborhood association system. ${ }^{101}$

\footnotetext{
${ }^{101}$ The FY 2006-07 City Budget already had provided significant new funding to ONI for Portland's community and neighborhood involvement system, including funding for a new neighborhood grants program, additional funding to each of the seven neighborhood coalitions to support increased communications with the community, funds to create a Civic Leadership Academy for communities of color, and funding for Community Engagement Initiatives to support projects that bring together neighborhood associations and under-represented communities (Portland. City Budget. FY 2006-07 412).
} 
Community Connect members formally approved the "Five-year Plan to Increase Community Involvement" with some suggested edits that Smock agreed to make, and then celebrated their more than two years of hard work and struggle, which had produced what they saw as a significant step forward for Portland's neighborhood and community involvement system.

Final Community Connect Report and Recommendations (2008): Community Connect members identified their final report and "Five-year Plan to Increase Community Involvement" as a "comprehensive roadmap for strengthening Portland's civic life," and characterized their "three interdependent goal areas" as a "'three-legged stool' of effective community involvement" (Portland. Community Connect. A City for All of Us-More Voices, Better Solutions: Strengthening Community Involvement in Portland: Community Connect Final Report. January 2008 5).

Community Connect members asserted that "an effective and inclusive system of community involvement is essential for a healthy city, and a functioning democracy" (6). The report quoted Community-Connect chair Hughley-Noel as saying "Our recommendations build on the strengths of the existing neighborhood system while broadening the system to more fully involve the full diversity of our community" (6).

The report recognized that "significant improvements to our system of community involvement will require a serious commitment from the City," and clarified that the Community Connect recommendations assume that new programs and activities will be 
"funded with new resources when needed" and will not "divert resources from existing programs..." (6). ${ }^{102}$

Community Connect members found that Portland had grown and become more ethnically diverse over the previous ten years. They also found that “...many popular public participation programs that were launched during the neighborhood system's heyday in the 1970s and 1980s...have since been dismantled," Some Portlanders said “they don't feel welcome or that the neighborhood association doesn't represent their interests." Neighborhood leaders said they were frustrated by "inadequate funding and limited capacity" and "...not having enough of an impact on public decision making" (8).

Community Connect members found that “...many of the city’s diverse populations do not necessarily define their communities in geographic (i.e. neighborhood-based) terms." Instead, "For many Portlanders, the 'community' most important to them is based on their shared identity or shared interest with others." Community Connect members noted that some neighborhood associations had tried to reach out to these groups but with limited success. They reported that the result was that “... a growing number of Portlanders belong to groups which are under-represented in civic affairs." Community Connect members described "under-represented groups" as including, but not limited to: "people of color, immigrants and refugees, persons with disabilities, low-income families, youth, elders, renters, and people experiencing homelessness." They noted that "...like the neighborhood leaders" community members

\footnotetext{
${ }^{102}$ This statement responded to the strong fear among neighborhood leaders that the City intended to take funding away from neighborhood associations - who already felt they were underfunded — and give it to other community organizations that had direct relationships with under-represented communities.
} 
from under-represented groups "are concerned that their voices are not being heard within City government" (8).

The report stated that, to realize "A Community Involvement System for the $21^{\text {st }}$ Century," Portland's community involvement system needed to be updated through the development of "strategies to more effectively engage under-represented groups" (9). They asserted that "Full representation is the hallmark of a healthy democracy" and "of a healthy city," and "The inclusion of more voices will result in better decisions that have broader support" (8).

Community Connect members argued that creating a more inclusive city would require "deliberate strategies to make sure all Portlanders have the opportunity to be heard," including: support for "under-represented groups to overcome the barriers that have prevented them from getting involved in the past;" the provision to "neighborhood organizations and City agencies" of the tools and resources they need to more effectively reach out and build bridges with under-represented communities;" and support for "leadership development and organizing within under-represented communities to enable them to enter into civic life with a strong voice so that they can participate on an equal footing" (9).

The Community Connect members identified the principles they had used to guide themselves in their development of the "Five-year Plan," which included: "Strengthen the important work of neighborhood associations;" broadening "Portland's community involvement system beyond neighborhood boundaries to more fully engage our city's diverse communities;" "Reinvigorate how government works with the 
community;" and building on existing "innovative models" used by ONI, City bureaus, and local communities (10).

Community Connect members shared their vision of a city where: "People feel connected to one another, and to their communities;" "All Portlanders, regardless of their backgrounds, have the opportunity to be actively engaged in civic affairs;" "Government leaders are response and accountable to community input and priorities;" and "The inclusion of more voices in civic affairs results in a healthier and more vibrant city" (5).

They asserted that, If the Five Year Plan were fully implemented, "Portland will continue to set an example nationally as a city where the government and the community work in genuine partnership, and where everybody has a chance to be heard." Implementation of the plan also would give "Portland an opportunity re renew its commitment to community involvement by investing in strategies that will reinvigorate civic life in our $21^{\text {st }}$ century city" (6).

Three goals/Strategies: The Community Connect members presented three main goals. These included:

\section{Goal 1: "Increase the number and diversity of people involved in their}

communities." "The first step to an effective community involvement system is to engage the broad diversity of the community in civic life."

Goal 2: "Strengthen community capacity." "Once community members are actively engaged, they need the connections, skills, and tools to be able to work together effectively to solve problems and achieve their community aspirations." 
Goal 3: "Increase community impact on public decisions." "A world-class system of community involvement will only be effective to the extent that City leaders are responsive to the community's input. [This] third goal increases the community's ability to have an impact on local government policies and decisions" (5).

Community Connect members stated that, if the Five-year Plan were successfully implemented:

- "Portlanders will feel connected to one another and their communities;"

- "Members of the city's increasingly diverse populations will be more involved in civic affairs;"

- "When issues arise, Portlanders will be aware of the issues and opportunities for involvement, and will feel welcomed and supported in getting involved;"

- "Portlanders from a broad range of communities will have the capacity to solve problems that impact them;"

- "City government will develop more consistent, transparent, accountable, respectful, and informative processes to involve people in making decisions;“"

- "Both the community and government will experience satisfaction in the decision-making process;"

- "Greater community input at the front end will result in decisions that have wide public support, saving resources in the long run;" and

- "The inclusion of more voices will result in better outcomes for building a healthy and vibrant city." 
Community Connect members emphasized that their plan gave Portland an opportunity to make strategic investments that would "reinvigorate our civic life and build a genuine partnership between government and the community."

Recommendations and Strategies: Community Connect members presented eleven recommendations and numerous strategies that they believed would help achieve the three goals. These are described below.

\section{Goal 1: Increase the number and diversity of people involved in their}

\section{communities:}

- "Increase the power and voice of under-represented groups": Strategies included: "Create and fund leadership training for members of underrepresented groups;" "Provide support to grassroots organizations that represent Portland's diverse communities;" and "Provide formal access to City government" by formally recognizing and providing a "seat at the table" for organizations that represent under-represented groups (14).

- "Engage the full diversity of our community by addressing barriers to participation." Strategies included: "Make opportunities for participation more worthwhile, rewarding, and effective" by having clear agendas and effective facilitation, incorporating time for fun and relationship-building, focusing on issues to the community, and achieving "meaningful outcomes;" "Make meetings and events welcoming and accessible to all" by using "inclusive methods of dialogue and decision-making; enable 
under-represented groups to share their own unique ways of community building and decision-making; use culturally sensitive methods;" and “Overcome logistical barriers to participation" by providing child care, food, translation and transportation support for key meetings, holding events and meetings at times and locations easy for people to attend, and ensuring that events are physically accessible and that people with disabilities can fully participate (15).

- "Promote effective communication to keep the community informed about issues, opportunities for involvement, and ways to plug in." Strategies included: "Facilitate communication and information sharing" between neighborhood and community organizations; "Promote dialogue and communication through new technologies;" and "Promote culturally appropriate direct outreach and communications strategies" "including door-to-door and one-on-one relationship building, reaching out to different populations where they naturally gather, building on existing networks, using customized approaches for different communities, and providing translated materials as well as alternative communication methods (theater, popular education, etc.)" (17).

\section{Goal 2: Strengthen community capacity:}

- "Foster social ties and a sense of community identity: identify best practices and provide training and support to implement appropriate strategies such as: "Community building" through "block parties, community and multi-cultural 
fairs and festivals, and face-to-face relationship building to foster mutual understanding;" "Publicize neighborhood identities and assets" through welcome kits for new residents that tell them about their new community and street sign caps with neighborhood names; and "Create and preserve physical spaces and design features" that provide a focal point for communities and create welcoming and inclusive places where people can gather and interact (18).

- 'Support the community's capacity to take action to move forward its priorities." Strategies included: "Build leadership and advocacy skills" through a citywide leadership training program; "Provide small grants to community organizations;" "Provide targeted staff support to communities experiencing a high degree of development pressure or other major changes;" and "Provide evaluation and best practices information by creating a Community Involvement Resource Center" based in the community and facilitated by ONI or [Portland State University]...."

Community Connect members also recommended the promotion of "equity and accountability in ONI contracts" to ensure effective support for neighborhoods and communities throughout the City. They suggested requiring neighborhood district coalitions to provide "a minimum level of core services, the provision of adequate resources to neighborhood district coalitions and other contracted community organizations to enable them to meet the expectations of their contracts; equitable distribution of resources 
and services across neighborhood district coalitions; holding neighborhood district coalitions accountable to specific performance measures; and developing a consistent structure for all contracted organizations (such as requiring all of these organizations to be governed by a nonprofit board of directors) (19).

- "Foster networking and collaboration between neighborhood and business district associations and other local organizations and interest groups." Strategies included: "Promote opportunities for neighborhoods and other community to come together citywide," such as through an "annual citywide Community Assembly;" "Promote collaboration between organizations" by having ONI act as a convener, fostering partnerships through grants that encourage partnerships, and supporting ONI partner organizations to build "broad-based networks and partnerships with other groups;" and "Bring together different communities and interests to build shared understanding" through citywide dialogues on "controversial and divisive issues" and "study circles" (21).

\section{Goal 3: "Increase community impact on public decisions."}

- "Make public decision-making more responsive and accountable to community input." Strategies included: "Create a broad and inclusive City budgeting process" that includes early budget workshops in the community and easy to understand information; "Create an ongoing Community Needs Process;" Establish city government liaisons to different communities; "make 
information about government decisions easily accessible and transparent;" "Close the loop" with community members and explain government decisions, the rationale for the decisions, and how community input was used in making decisions; "Encourage City bureaus to create Bureau Advisory Committees (BACS) that would review and advise "bureau directors on budgets, key policies, and annual bureau work plans"-BAC members should be recruited "from a broad cross-section of the community" and should receive "adequate staffing and consistent training;" and "Give the community direct control over certain decisions" by "giving communities direct control over certain locally-specific projects or functions" and by empowering "the local community to make decisions about designated revenue pools or give the community priority input over certain locally-specific planning or development issues" (22).

- "Institutionalize the City's commitment to public involvement in decisionmaking." Strategies included: "Foster an internal culture within City government that supports a commitment to public involvement;"'Provide staff training and capacity building, and include quantifiable public involvement measurements in performance evaluations, particularly for upper management;" and involve community members in evaluating public involvement processes in which they participated.

Community Connect members also called for the creation of "comprehensive public involvement standards and guidelines" and the implementation of PITF 
and BIP 9 recommendations, including: Amending the City Charter to include language that commits the City to the "principles and values of community governance;" City Council adoption of community governance principles for city government by ordinance; requiring City bureaus to develop general formal written public involvement policies for their bureaus and written public involvement plans for certain types of major capital, policy and planning projects and budget decisions; ensuring the use of "culturally appropriate and effective strategies and techniques" to reach out to under-represented communities; the creation of a stable funding mechanism to support public involvement processes; and the establishment of a standing Public Involvement Standards Commission "to advise bureaus and hold the City accountable to adopted public involvement principles, standards, and guidelines" as well as the creation of a staff position to support the Commission (24).

- "Create the infrastructure to support the goals and recommendations in this Five Year Plan by updating [ONI's] internal structure." Strategies included: Renaming ONI to reflect its broader mission; strategic investments in neighborhood and community organizations; effective coordination and support for the decentralized neighborhood and community involvement system; support for strong collaboration and communication between community organizations; the provision of vehicles for neighborhoods, business, and other groups to work together on local and citywide issues; 
formal recognition and access to City government for diverse groups and organizations; assistance to city bureaus to help them access community input on government decisions.

Community Connect members also set out criteria to guide any ONI structural changes, which included: all new programs should be funded with new funding and should not divert funding from existing programs; requirements and expectations for ONI contract organizations only should be expanded if adequate resources and capacity are provided to enable the organizations to meet the new requirements; all ONI contract organizations should meet "certain common criteria" and be held accountable to "specific performance and outcome measures" defined in the contracts, and the bureaucracy that supports the system should be limited and streamlined (25).

\section{Community Connect-Some Lessons Learned: Community Connect is a} fascinating example of an initially very poorly designed and implemented process that ultimately produced a very valuable product.

Process: The Community Connect process suffered from the beginning from a lack of dedicated and skilled staff support and funding. Poor process design, leadership, and implementation and the lack of a clear charge (nearly throughout the process) led many group members from communities of color and community organizations to drop out of the process and frustrated those who remained. ${ }^{103}$

\footnotetext{
${ }^{103}$ One long-time and very respected neighborhood leader who participated in Community Connect continues to characterize Community Connect as the worst process in which she has ever participated, while strongly supporting the Community Connect final goals and recommendations.
} 
Potter played a positive role by strongly and consistently advocating for the broader purpose of the project, which was to giving more people a voice-especially historically under-represented communities in Portland. His strong support for community involvement and his public commitment to implement the group's recommendations encouraged many participants to stick with the process. Potter was not effective at hearing, understanding, and articulating the type of strategic direction Community Connect members were looking for from him. For much of the process, Potter directed the Community Connect members to develop their own charge.

The lack of clarity about the charge also was aggravated by unfortunate public comments and mixed messages. Sometimes the group was told Community Connect was about improving the existing system, while at other times Community Connect members were told to think about designing a new system from scratch. This might have made sense if the City were developing a system for the first time. However, Portland had a 40year-old community and neighborhood association system through which thousands of community members volunteered their time and energy and got things done. Negative comments about neighborhood associations during the process by staff from the Mayor's office during the process added to the problems. Greater sensitivity to this reality should have led the process to state definitively, early on, that it was intended to expand and strengthen the existing system, not replace it.

It is ironic that the BIP Report (2005) had directed ONI to "model the behaviors identified in the [PITF] guidelines for public engagement-openness, inclusion, and listening" in conducting the project. The Community Connect process showed that 
accomplishing this requires much more than simply inviting a diverse group to participate. It also relies on strong and effective process design and implementation and treating the participants with respect. Also, Smock, in October 2005, gave very direct advice to the Community Connect steering committee about how to design and implement the process. She warned against the very approach Community Connect took early on. She warned that an "unstructured" process was not effective at engaging diverse groups and the most disenfranchised people. Smock instead argued for a "highly structured and aggressively facilitated" process.

The Community Connect process improved later on through skilled leadership from Southeast Uplift Director Cece Hughley-Noel who served on the steering committee and later chaired the group. Her work behind the scenes with the mayor's staff helped move the project forward more productively. Strong staffing by Balajee was essential to the success of the wide-ranging data collection process and the analysis of all the resulting input. The decision to contract with Smock and Brown, also brought their very high level skills to the process of moving from data collection to the creation of a very well-received and influential final report. Their influence at the end of the processes raises the question of what might have happened if the Mayor's Office had invested in hiring Smock at the outset to design and lead the process. Her involvement, or involvement by someone with her skills and experience—might have saved the process a lot of time and significant frustration.

The overall lesson from the Community Connect process is that good process design, leadership, and implementation matters. Large community involvement processes 
that take up controversial topics and seek major change need to be well-designed, resourced, and staffed and led by individuals with a strong commitment to and skill at creating a welcoming and respectful environment and using people's time wisely and constructively. The poor design and implementation of Community Connect stands in sharp contrast to the much more inclusive and constructive process examples of Interwoven Tapestry, the Southeast Uplift DRC and DCLC, visionPDX, the Public Involvement Advisory Council, and the East Portland Action Plan (described below).

Clear Goals and Recommendations: One of the great lessons of the final Community Connect report and the "Five-year Plan to Increase Community Involvement" was the value of having a formal comprehensive and detailed report that accurately reflected the concerns, hopes and ideas of many communities and neighborhood and community organizations and that provided a clear vision of where the system needed to go and a comprehensive set of action items for how to get there.

One of the most important contributions of Community Connect was the finding that not everyone identifies their "community" through their geographic neighborhood. For decades, the primary focus of Portland's community and neighborhood involvement system had been trying to get people from historically under-represented groups to participate in neighborhood associations. The recognition of "communities beyond neighborhood boundaries" had started with Charles Shi and the 1995-96 TFNI. Community Connect formally established that non-geographic communities needed to receive City support and be included in the formal system on their own. 
Community Connect also drew attention to the need to get people more involved in their community through a wide variety of activities, events, and organizations as a first step to getting them involved in more formal policy processes and organizations. A system that only offered participation in formal groups, like neighborhood associations or other community organizations would miss the need for people to shift their thinking beyond themselves and their immediate families and friends and begin to make connections with other people in the community. This very much supports Putnam's work on the value and importance of developing "social capital"—-both "bonding" and "bridging" social capital.

Community Connect also highlighted the need for the City to invest in building capacity in the community through leadership training, organizational development, and helping different groups build relationships and work together. For 40 years, the City of Portland had been providing this type of support for the formal neighborhood association system. Community Connect insisted that other communities and groups in Portland needed similar support if their constituents were going to have a voice in local civic life and decision making.

Community Connect also reaffirmed the crucial need for a strategy to be implemented to ensure that city government leaders and staff were willingness and able to work collaboratively with the community. Community Connect re-emphasized many of the major recommendations made earlier by the PITF and the BIP 9 Committee.

Community Connect's Five-year Plan has been a great success in that it has dramatically changed the focus and functions of Portland's community and neighborhood 
involvement system. The next section describes the many changes at ONI implemented, partly in response to Community Connect's work, during the Potter administration.

\section{ONI Expansion and System Changes}

Mayor Tom Potter presided over the largest expansion of Portland's community and neighborhood involvement system since it was founded in the 1970s.

From the beginning of his term of office, Mayor Potter chose to keep ONI in his portfolio - unlike Mayor Katz, who gave responsibility for ONI to other city commissioners, none of whom were viewed as strong supporters of community involvement. In Portland, when a mayor retains a bureau in his portfolio, this usually signifies that the bureau and its work are important to the mayor. Being in the Mayor's portfolio often increases the likelihood that an agency's budget requests will be funded. The mayor develops the city budget and is better able to insert his priorities into the document than the other city council members. During his one term in office, Potter directed over \$3 million in new funds to strengthen and expand Portland community and neighborhood involvement system. Many of these system changes continue to be in place in 2013 .

Potter brought in new leadership for ONI. In January 2006, Potter replaced Jimmy Brown and appointed Amalia Alarcón de Morris as ONI director. Many neighborhood leaders had complained that Brown did not strongly advocate for ONI's community empowerment role (a difficult challenge given his original boss' (Commissioner Leonard's) focus on neighborhood services) and was not very effective at strategically designing and leading open and inclusive decision-making processes. Alarcón de Morris, 
at the time, was managing ONI's Neighborhood Resource Center. Prior to that, she had managed ONI's Metropolitan Human Rights Center and had overseen ONI's participation in the Interwoven Tapestry Project. Alarcón de Morris brought to her new role as ONI Director her strong political and strategic skills and background working with communities of color and her strong credibility in the community. ${ }^{104}$ Also, in contrast to Leonard's unilateral appointment of Brown as ONI Director without any input from the community, Potter provided opportunities for community members to meet and talk with the primary candidates for the ONI director position before he made his decision. $^{105}$

Alarcón de Morris quickly moved to revitalize the ONI Bureau Advisory Committee (BAC) and made it a central focus of community discussion and policy setting for the agency. During the FY 2007-08 budget process, the ONI BAC began using the three Community Connect goals and Community Connect's strong focus on increased the capacity and involvement of historically underrepresented groups to guide the group's policy and budget decisions (Portland. City Budget. FY 2007-08 397). The ONI BAC traditionally had been made up primarily of neighborhood system representatives, ONI's grant and contract organization partners, and community members. Alarcón de Morris and the BAC members expanded the group by inviting representatives of the organizations that participated in ONI's new Diversity and Civic Leadership Program to

\footnotetext{
${ }^{104}$ Alarcón de Morris continues to serve as ONI director at the time of this study in 2013. This makes her the longest serving director to date in ONA/ONI's history. Her long tenure as ONI Director has helped maintain ONI's focus on the values and direction for the agency established under Mayor Potter.

${ }^{105}$ Potter kept Jimmy Brown in his role as ONI Director during Potter's first year in office, despite some pressure from neighborhood activists who wanted Brown replaced as quickly as possible. In December 2005, Leonard, who was the City Commissioner in charge of the Water Bureau, announced that Jimmy Brown would move to the Water Bureau to manage the bureau's "community outreach and customer services group" (Oregonian, December 20, 2005).
} 
join the group—which they did. The participation of the representatives of all these organizations on the ONI BAC in the years since them has helped build relationships between ONI's growing number of community partner organizations (Alarcón de Morris and Leistner 2009 50).

Potter moved quickly to undo many of the changes Leonard had instituted at ONI and redirected ONI to its traditional role of empowering community members and groups and helping them have a voice in City decision making. Potter moved the Noise Control Program out of ONI and back to BDS in FY 2005-06. The following year (FY 2006-07), he moved the Neighborhood Inspections Program back to BDS. Potter's renewed community empowerment focus for ONI and his desire for all city bureaus to develop the capacity to involve community members in their work, led him also to end ONI's role in supporting BES projects. BES's Downspout Disconnect Program and Combined Sewer Overflow (CSO) outreach programs, some of which had been part of ONI since the mid 1990s, were moved back to BES (Portland. City Budget, FY 2007-08 398).

Over his four-year term as mayor, Potter funded a number of new positions at ONI to support expanded parts of the system. Hoop, who had been the sole staff ONI person dedicated to supporting the neighborhood system and other community involvement efforts, became the manager of the ONI Neighborhood Resource Center when Alarcón was made ONI Director. Five staff people were hired to coordinate and support new and existing programs, including: the Disability Program, the Diversity and Civic Leadership Program, Public Involvement Best Practices Program (which supports the PIAC and CPIN), the Effective Solutions Program (which supported high stakes 
conflict resolution processes), and the neighborhood system. ONI later changed the name of this group to the Community and Neighborhood Involvement Center (CNIC) to better reflect the broadened role of the group.

In 2005, Potter initiated the four Bureau Innovation Project projects described above-visionPDX, Community Connect, BIP 9, and Charter Review Commission. The recommendations of these projects—especially Community Connect and BIP 9 as well as the earlier PITF—would guide much of the expansion of ONI's program programs. This section reviews the primary program changes at ONI during the Potter administration.

ONI's Mission and Purpose: The ONI "Bureau Summary" in FY 2007-08 City Budget, identified, as "Significant Issues" for ONI, the difficulty the City had had in engaging underrepresented groups in City efforts and the need to increase capacity in the neighborhood system and to support the organizing effort of underrepresented communities. This new language read:

"The City of Portland has long had a goal of engaging more people in government. The City has also recognized that, collectively, we have had problems engaging underrepresented groups in City efforts (people of color, renters, people with low income, etc.). In an effort to explore lasting solutions to this problem, ONI is working to strengthen the existing neighborhood system's capacity to fully and meaningfully engage all neighbors, we well as to consistently support the organizing efforts of historically underrepresented communities. ONI is doing this by supporting the recommendations the communities make about which approach will most successfully engage their constituents." "This year ONI enters its second year of capacity building in the communities. The bureau, at the direction of its Bureau Advisory Committee, used a three-pronged approach:"

- "Build capacity and support self-determination in underrepresented groups."

- "Build capacity among neighborhood and coalition partners to conduct research and engage all neighbors." 
- "Build adequate infrastructure within ONI to support, measure, and evaluate these initiatives."

"This year's programs lay important groundwork for future efforts to bridge the gap between underrepresented groups and the City" (Portland. City Budget FY 2007-08 397).

The language in the City Budget that described ONI's role and purpose was updated in FY 2007-08 to reflect the Community Connect goals and to state clearly that ONI was pursuing a dual approach of building capacity both in the neighborhood system and supporting the organizing efforts of underrepresented groups as well. The new language read:

"Expanding Civic Engagement: The City of Portland has long had a goal of engaging more people in government. As Portland grows and becomes more diverse, ONI seeks to expand involvement and bring additional people and communities into the public dialogue. The City has also recognized that efforts to engage underrepresented groups (people of color, renters, people with low income, etc. ) in City initiatives have not been very effective. In exploring lasting solutions to this problem, ONI is working to strengthen the existing neighborhood system's capacity to fully and meaningfully engage all neighbors. The City has supported these efforts through funding for small grants, outreach, leadership training, and technical assistance. ONI also supports the organizing efforts of historically underrepresented communities, recognizing that it is critical to support groups developing their own civic capacity in their own cultural contexts. These two approaches of strengthening the neighborhood system and supporting underrepresented groups in their own organizing efforts are complementary" (Portland. City Budget FY 2008-09 395).

The "Strategic Direction" section also reported that ONI, "in partnership with its [ONI BAC]," used the Community Connect goals and Community Connect's "Five-Year Plan to Increase Community Involvement" to "develop a budget that supports the Community Connect implementation strategies. ONI's entire budget reflects these goals, 
which build on years of hard work by volunteers throughout the city." The section identified the Community Connect goals as:

- "Increase the number and diversity of people who are involved in their communities."

- "Strengthen community capacity."

- "Increase community impact on public decisions" (Portland. City Budget, FY 2008-09 396).

ONI and the ONI BAC continued the process of embedding the Community Connect goals into ONI's formal mission statement after Potter left office and Sam Adams became Portland's mayor. In 2010, ONI staff and the ONI BAC members worked together to develop a new mission, goals, and values for ONI that would further formalize community empowerment as ONI's primary purpose. The individuals involved in this effort saw this as an important strategy to help ward off any future attempts to redirect ONI's purpose. ONI's new mission, goals, and values focused on including the full community in civic life and city decision-making. The language of the mission, goals, and values is presented below in Figure 5 (additional detail included under each value statement has been omitted). 
Figure 5: Office of Neighborhood Involvement Mission/Goals/Values

\author{
Office of Neighborhood Involvement \\ Mission/Goals/Values
}

Adopted by the ONI BAC on April 12, 2010

Office of Neighborhood Involvement Mission: Promote a culture of civic engagement by connecting and supporting all Portlanders working together and with government to build inclusive, safe and livable neighborhoods and communities.

Office of Neighborhood Involvement Goals:

- Community Involvement: Increase the number and diversity of people who are involved and volunteer in their communities and neighborhoods.

- Capacity Building: Strengthen neighborhood and community capacity to build identity, skills, relationships and partnerships.

- Public Impact: Increase community and neighborhood impact on public decisions.

- Livability and Safety: Provide tools and resources to improve neighborhood and community livability and safety.

- Services: Provide accurate information and responsive and effective services to community members and organizations.

Office of Neighborhood Involvement Values:

- PREAMBLE: "The Office of Neighborhood Involvement (ONI) works towards a future where the community is a full and equal decision-making partner in all aspects of the City of Portland. We serve our increasingly diverse community through promoting collective civic engagement for all people in Portland, with a commitment to transparency, compassion, and relationship building. We strive to recognize and repair the disparities that exclude and harm the people of Portland. We strive to be authentic, accessible and accountable within government and the community. The values put forth here are intended as a guide and foundation for all our work."

- VALUES: "Inclusion - No one gets left out;" "Shared Power and Governance;" "Relationships—-the cornerstone of our work;" and "Social Sustainability— people are our most important resource."

(Portland. Office of Neighborhood Involvement. "Inside ONI," "Mission, Goals and Values." Web. Adopted April 10, 2010.

<http://www.portlandoregon.gov/oni/28363> . Downloaded October 20, 2013.) 
New ONI Programs: Potter significantly increased the number and scope of the ONI programs that supported community involvement in Portland. Potter began this expansion in FY 2006-07 with \$500,000 of funding. Potter continued to fund and support these programs throughout his administration. The new and expanded ONI programs are described below.

Table 2 below describes the major new ONI programs and staff positions created with the over $\$ 3$ million in new funding provided to ONI to support neighborhood and community involvement activities during the Potter administration. 
Table 2: Major New Funding for ONI under Mayor Potter (FY 2006-07, 2007-08, 2008-09)

\begin{tabular}{|c|c|c|c|c|}
\hline $\begin{array}{l}\text { ONI PROGRAMS AND } \\
\text { POSITIONS }\end{array}$ & FY 2006-07 & FY 2007-08 & FY 2008-09 & TOTAL \\
\hline $\begin{array}{l}\text { Additional Funding for } \\
\text { Neighborhood Coalitions-- } \\
\text { communications }\end{array}$ & $\$ 95,000$ & $\$ 95,000$ & $\$ 95,000$ & $\$ 285,000$ \\
\hline $\begin{array}{l}\text { Additional Funding for } \\
\text { Neighborhood Coalitions-- } \\
\text { organizer positions }\end{array}$ & & $\$ 350,000$ & $\$ 350,000$ & $\$ 700,000$ \\
\hline $\begin{array}{l}\text { Neighborhood Small Grants } \\
\text { Program (NSG) }\end{array}$ & $\$ 200,000$ & $\$ 200,000$ & $\$ 200,000$ & $\$ 600,000$ \\
\hline $\begin{array}{l}\text { Diversity and Civic Leadership } \\
\text { (DCL) Leadership Academy }\end{array}$ & $\$ 70,000$ & $\$ 70,000$ & $\$ 70,000$ & $\$ 210,000$ \\
\hline $\begin{array}{l}\text { Diversity and Civic Leadership } \\
\text { (DCL) Organizing Project }\end{array}$ & & $\$ 268,000$ & $\$ 299,000$ & $\$ 567,000$ \\
\hline $\begin{array}{l}\text { Community Engagement } \\
\text { Initiative }\end{array}$ & $\$ 45,000$ & $\$ 45,000$ & $\$ 45,000$ & $\$ 135,000$ \\
\hline $\begin{array}{l}\text { Fund for Accessible } \\
\text { Neighborhoods (FAN) }\end{array}$ & & $\$ 15,000$ & $\$ 45,000$ & $\$ 60,000$ \\
\hline $\begin{array}{l}\text { New Position: ONI Effective } \\
\text { Engagement Solutions }\end{array}$ & & $\$ 58,000$ & $\$ 95,142$ & $\$ 153,142$ \\
\hline $\begin{array}{l}\text { New Position: ONI } \\
\text { Neighborhood Program } \\
\text { Coordinator }\end{array}$ & & & $\$ 93,973$ & $\$ 93,973$ \\
\hline $\begin{array}{l}\text { New Position: ONI Public } \\
\text { Involvement Best Practices } \\
\text { Program Coordinator (PIAC } \\
\text { and CPIN) }\end{array}$ & & $\$ 75,000$ & $\$ 89,497$ & $\$ 164,497$ \\
\hline Small Business Support & $\$ 100,000$ & $\$ 50,000$ & $\$ 0$ & $\$ 150,000$ \\
\hline Performance Indicators Project & & $\$ 25,000$ & $\$ 25,000$ & $\$ 50,000$ \\
\hline Total & $\$ 510,000$ & $\$ 1,251,000$ & $\$ 1,407,612$ & $\begin{array}{r}\$ 3,168,6 \\
12\end{array}$ \\
\hline
\end{tabular}

(Kersting, Mike. ONI Financial Analyst, January 2009).

\section{Increased Resources to Neighborhood Coalitions and Neighborhood}

Associations: Potter implemented a number of the recommendations that previous system reviews had made to strengthen the neighborhood system. Most of these program 
expansions became an ongoing part of the funding for the neighborhood system (at least through 2013). Potter began investing in new programs and positions in FY 2006-07 and continued to increase funding to ONI to expand existing programs, create new programs, and hire additional staff in the following two budget years.

The ONI section of the FY 2008-09 City Budget described the Neighborhood Program as the "core of ONI's mission and historical charge to administer, promote, and advocate for Portland's neighborhood system" (Portland. City Budget, FY 2008-09 402). New funding for the Neighborhood Program, included:

- One-time infrastructure investments: $\$ 42,500$ for ONI infrastructure needs, including "improving connectivity to remote locations, safety upgrades for ONI offices, and continued support for" BIP 8. (Portland. City Budget, FY 2006-07 412)

- Communications: $\$ 95,000$ each year, distributed among the seven neighborhood coalitions to support increased neighborhood associations communications (the $\$ 95,000$ represented an average of $\$ 1,000$ for each of the 95 neighborhood associations intended to allow each neighborhood association to send out two neighborhood-wide communications each year).

- Insurance: $\$ 35,000$ "to mitigate rising insurance costs for coalitions and $\$ 5,000$ for ONI Neighborhood Legal Defense fund (Portland. City Budget, FY 2006-07 412). ONI would continue to provide funding to help neighborhood coalitions purchase directors and officers and general liability coverage for neighborhood and coalition boards, events, and activities. ONI also continued 
to build up the "legal defense fund" which, in 2013, was about $\$ 20,000$. (No neighborhood association in Portland has been sued in recent memory-but the funds are there just in case.)

- $\quad$ Neighborhood Coalition Staff: In both FY 2007-08 and FY 2008-09, ONI provided an additional $\$ 350,000$ funding to the seven neighborhood coalitions to allow each coalition to hire an additional staff person to improve outreach to historically under-represented community members (i.e., $\$ 50,000$ per coalition). These funds also were intended to support new fiscal management and technical assistance and administration neighborhood coalition management of the new Neighborhood Small Grants Program in each district (Portland, City Budget, FY 2008-09 396).

- ONI Staff person: The FY 2008-09 City Budget provided ONI with one-time funding to hire a staff person specifically to help implement Community Connect's "Five-year Plan to Increase Community Involvement." The position description included "managing dialogue between the many diverse ONI stakeholders, improving performance tracking and evaluation, and expanding capacity to coordinate neighborhood program recommendations related to leadership development, small grants, and communications." (Portland. City Budget, FY 2008-09 403) ONI filled the position in October 2009. The position later became part of ONI's “ongoing budget" and remains filled in 2013. 
Neighborhood Small Grants Program: A number system reviews since the 1970s had recommended the creation of a neighborhood grants program. Potter finally implemented this recommendation in FY 2006-07, when he provided ONI with funds to create the "Neighborhood Small Grants Program.” Potter provided ONI with $\$ 200,000$ each year for the FY 2006-07, FY 2007-08 and FY 2008-09 for the program. ONI worked with the neighborhood coalitions to develop the program. ONI coordinated the overall goals for the program, worked with the neighborhood coalitions to develop a generic grant application template and distributed grant funds to the neighbor coalitions. The neighborhood coalitions took the lead in administering the program including holding workshops to help community members and groups learn about the grant program, helping community members prepare their grant applications, setting up review committees of community member to review the applications and choose the grant recipients, and then working with grantee organizations to monitor their progress and then reporting to ONI on the outcomes of the projects. ONI allows neighborhood coalitions to retain up to 15 percent of their allotted grant program funds to cover their cost to administer the program. The program has been very popular in the community and has led neighborhood and community groups to design and implement hundreds of different types of community projects. The program continued to be funded until FY 2013-14. The ONI BAC decided to meet the budget cuts required by Mayor Hales partly by not funding the Neighborhood Small Grant program for that budget year. ONI and neighborhood and community advocates plan to advocate for restored funding for the program in FY 2014-15. 
Fund for Accessible Neighborhoods (FAN): ONI received funding over two years (\$30,000 in FY 07-08 (Portland. City Budget, FY 2007-08 398)and \$30,000 in FY 08-09 (Portland. City Budget, FY 2008-09 396)) to create the Fund for Accessible Neighborhoods (FAN). The FAN program was intended to help neighborhood coalitions reduce barriers to participation that had been identified in a number of earlier system reviews, including: translation/interpretation, child care, translation, transportation and ADA accessibility. ONI used the funds to pay for bus tickets, child care, interpretation and translation services, and services to accommodate the needs of some community members with disabilities. ${ }^{106}$

ONI and the neighborhood coalitions realized early on that child care could be delivered in two primary ways: providing child care at an event, and reimbursing community members for their cost to pay for a babysitting for their own children. Another issue was whether providing child care was intended to increase participation at a one-time meeting or event, or whether it was intended to increase participation in ongoing meetings—-such as regular neighborhood associations meetings or meetings of an ongoing or shorter-term advisory committee. In either case, community members needed to know that the service would be available consistently, and they needed to feel comfortable that their child would be safe. Some people preferred to arrange for and pay their own babysitter for their children and then get reimbursed. Requests for

\footnotetext{
${ }^{106}$ ONI also began to provide food for participants at major evening meetings, including the monthly meetings of the ONI BAC and the Public Involvement Advisory Council. A number of previous system reviews had emphasized that providing food was an important way to encourage participation and to show respect to community participants. Other City bureaus, such as the Bureau of Planning and Sustainability, have started to provide food at the evening meetings of their community advisory committees, as well. City of Portland policy requires that at least 50 percent of the participants at a meeting be community members to justify the use of City funds to provide food at the meeting.
} 
reimbursement came primarily from existing neighborhood association or neighborhood coalition board members, rather than new members. A question also arose about what kind of liability a neighborhood association or other community organization might be taking on when it provides child care. ONI staff and coalition staff recognized that these issues needed more research and that a well-thought-through guide to offering childcare for neighborhood associations and other community groups would be helpful.

The FAN Program also reimbursed neighborhood coalitions and associations for translation and interpretation costs. Some neighborhood groups used the funds but most did not. Again, it became clear that some strategic guidance was needed to help neighborhood groups understand how to use translation and interpretation services more effectively. A few years later, the City of Portland began working on a city-governmentwide set of guidelines to help city bureaus understand when and how to use translation and interpretation more strategically as part of a larger community outreach plan.

ONI staff also worked with neighborhood coalitions and associations to help community members understand that they have a right to ask for ADA accommodation and help neighborhood associations and coalitions know how to respond when a someone asks for accommodations. ONI has funded one neighborhood coalition (NWNW) at about $\$ 4,000$ per year to provide closed captioning at meetings for a community member who is sight and hearing impaired. Again, city government will needs to develop guidelines and a city-government-wide approach to advertizing, implementing, and funding ADA accommodations at city government meetings and events. The FAN program was ended as part of required ONI budget cuts. 
Neighborhood and Community Engagement Initiative (NCEI): ONI received $\$ 45,000$ each year for three years (FY 2006-07, FY 2007-08, and FY 2008-09) to fund a Neighborhood and Community Engagement Initiative (NCEI) (Portland. City Budget, FY 2006-07 412). The purpose of the NCEI was to "provide leadership opportunities for neighborhood and district coalition leaders to engage and build relationships with underrepresented groups towards creating a strong neighborhood system." ONI described the project as "the companion project to the Diversity and Civic Leadership Academy, which focuses more on engaging organizations of color to provide leadership training for and by leaders of color" (Portland. Office of Neighborhood Involvement. "Mayor's Memo," for "Ordinance Title: Approve three grant agreements for the $2^{\text {nd }}$ year of the Neighborhood and Community Engagement Initiative," September 18, 2007).

In 2007, Central NE Neighbors neighborhood coalition (CNN) partnered with the Native American Youth and Family Center (NAYA) on a NCEI project to reach out to and help organize area high-school students and provide networking opportunities with neighborhood associations in the CNN district. The East Portland Neighborhood Office (EPNO) partnered with Human Solutions (an agency that provides support services to low-income and homeless families and individuals) to reach out to low-income renters and recent immigrants and help them engage them with neighborhood association leaders on different community organizing issues (ONI, ordinance support materials_- "Mayor's Memo," for "Ordinance Title: Approve three grant agreements for the $2^{\text {nd }}$ year of the Neighborhood and Community Engagement Initiative,” September 18, 2007). 
In 2009, the Neighbors West/Northwest (NWNW) neighborhood coalition partnered with Sisters of the Road (a non-profit organization that organizes and empowers people who are experiencing homelessness) to host an "interactive community forum." The forum brought together newly-elected City Commissioner Amanda Fritz and community activists to learn about "diverse organizing efforts in housing rights, homelessness, and local livability issues" and participate in skill-building workshops on issues "ranging from advocating at city hall to community organizing" (Neighbors West Northwest. Community Advocacy in Action. Event flyer. March 31, 2009).

Another NCEI project was a two-year joint effort between two neighborhood coalitions (Southeast Uplift and Southwest Neighborhoods, Inc.) and the Somali Women's Association (SWA). The project included outreach by the SWA to Somali families in the Creston-Kenilworth Neighborhood in southeast Portland and the West Portland Park Neighborhood in southwest Portland. The SWA conducted door-to-door outreach to Somali families as part of an assessment of their needs. The SWA worked to "promote awareness of civic infrastructure and systems" available to support Somali families and developed resource guides for these families. The project also included "cultural awareness training about Somali culture and community" for neighborhood association members, social service providers, schools, and other relevant agencies identified through the needs assessment. The project culminated in a Community Engagement Fair that brought together Somali families, neighborhood associations, schools, and service providers to help them learn about "services, support and each 
other's cultures" (Portland. Office of Neighborhood Involvement. NICE project brochure, 2007).

ONI staff person Brian Hoop, remembered that ONI offered each of the seven neighborhood coalitions about $\$ 6,300$ to do a project each year. Hoop stated that about half did. Hoop reported that when neighborhood coalitions did not use the NCEI funds available to them, ONI shifted the unused funds to other neighborhood coalitions that were doing projects. ONI also used unused NCEI funds to assemble additional child care activity boxes and to purchase language translation headsets for use by ONI neighborhood and community organization partners (Hoop email to Leistner, October 21, 2013, 2:27 PM).

In some cases, neighborhood coalitions continued to work with community organizations they first partnered with on a NCEI project. Hoop remembered that Sisters of the Road applied for and received grants from the Neighborhood Small Grants Program funds administered by NWNW to document stories of individual experiencing homelessness in downtown and northwest Portland. Funding the NCEI was ended as part of the ONI budget cuts required in FY 2009-10 (Hoop email to Leistner, October 21, 2013, 2:34 PM).

Hoop reported that the NCEI projects were "some of the most innovative work [neighborhood] coalitions were doing out of the Five-year Plan [to Increase Community Involvement in Portland]." Hoop said the effort "was all a bit scattered and hard to keep track of since so many things were going on-hiring new [ONI] staff, getting the [Neighborhood Small Grants Program] going, and starting the [Diversity and Civic 
Leadership Program]." Hoop said that ONI did not have the capacity to track and evaluate all the NCEI programs - a common challenge for ONI (Hoop email to Leistner, October 21, 2013, 2:34 PM). The NCEI program was ended as part of required ONI budget cuts.

Diversity and Civic Leadership Program (DCL): The Diversity and Civic Leadership (DCL) Program is one of the most significant new community involvement programs initiated during the Potter administration. For the first time, communities of color and immigrant and refugee organizations had a formal place in Portland's community and neighborhood involvement system. The program initially was funded by Mayor Potter in response to lobbying by the Southeast Uplift DCLC and supported by the work of Community Connect.

In FY 2006-07, Potter included \$70,000 in ONI's for the program. ONI used the funds to hire Jeri Williams to work with community groups to develop the program. Williams brought to the position her strong background in community organizing and environmental justice, as well as her extensive experience working with communities of color, and the Native American community, of which she is a member. Williams continues to coordinate the DCL Program in 2013.

The DCL Program began as two programs—-the Cultural Organizing Project and the Leadership Academy. (The two programs later would merge.) This was the first time ONI had "dedicated funds specifically to build leadership capacity and community organizing among people of color and immigrants and refugees in Portland.” During Potter's administration, the Leadership Academy received $\$ 210,000$ over three years, and 
the Organizing Project received \$567,000 over two years (Alarcón de Morris and

Leistner, 2009 51).

Alarcón de Morris and Leistner (2009) described the DCL Program as follows:

"The Leadership Academy provided leadership training through local community organizing groups that work with people of color and immigrants and refugees. One of the Leadership Academy projects was the Pan-Immigrant Leadership and Organizing Training (PILOT) Program. The Center for Intercultural Organizing and Latino Network each lead about 15 participants through a series of training sessions over 12 months and then brought the groups together for additional crosscultural training. Training topics include: Basics of City Government, Introduction to Community Organizing, Meeting Planning, Turnout and Facilitation, Volunteer Recruitment and Base Building, Politics of Oppression (Poverty, Class, Gender, Immigration Status, Race, etc.), Power Analysis, Issue Selection \& Campaign Planning."

"The DCL Organizing Project included funding for community-based organizations that serve under-engaged groups and that traditionally have operated in more of a service provider model. The program seeks to develop the organizations' outreach and community organizing capacity and increase participation of their constituents in civic governance. The organizations include: The Urban League of Portland, Native American Youth and Family Center, Latino Network/Verde, and Immigrant Refugee Community Organization (IRCO). Engage '08 was IRCO's project under this initiative. Forty-one members of Portland's Slavic, African and Asian immigrant and refugee communities participated in civic workshops, visited City Hall and met with government leaders. The program focused on community organizing, helping participants feel more comfortable with government, and developing their leadership skills. Many participants had never engaged with government or thought they could. Program graduates now serve on city boards and commissions and budget workgroups, and actively are engaging with neighborhood associations and other community organizations" (51).

The DCL Program has been extremely successful at raising the visibility of ONI's DCL partner organizations and ensuring that they have a seat at the table. Just as city bureaus used to automatically reach out to neighborhood associations, most now know to reach out to the DCL partner organizations as well. Representatives of DCL partner 
organizations have served on many city boards and commissions and advisory committees, including the Planning and Sustainability Commission, the Human Rights Commission, the Public Involvement Advisory Council, the Portland Plan Equity TAG, and a number of Comp Plan Update policy expert groups.

Relationship building has been another benefit of the DCL Program. Individuals representing the different ONI DCL partner organizations have gotten to know each other better over time through the monthly DCL Program meetings convened by Williams at ONI. Organizations that used to see each other more as competitors for limited resources now work together regularly to advocate for issues that benefit some or all of them. DCL representatives and neighborhood coalition leaders also have developed stronger relationships through their service together on the ONI BAC and many other city government community involvement committees and processes, and their joint participation in advocating with City Council for funding for ONI and ONI's programs. The DCL partner organizations and neighborhood coalitions and neighborhood associations still do not work together very often, but they have started talking about ways to collaborate and build stronger understanding and relationships.

City Government Best Practices Program: Potter implemented a couple of the 2003-04 PITF recommendations when he funded a new Public Involvement Best Practices Program in FY 2007-08. This included a new staff position at ONI to create and coordinate a new Public Involvement Task Force and to rejuvenate and support the city government peer group of city bureau public involvement staff, known as the City Public Involvement Network (CPIN). 
ONI hired Afifa Ahmed-Shafi to fill this position. Ahmed-Shafi had been working at Southeast Uplift supporting the DRC and greater cultural competency among neighborhood associations. Ahmed-Shafi went on to help create and coordinate Public Involvement Task Force in 2008 (discussed in more detail below) and began coordinating regular CPIN meetings. Ahmed-Shafi helped arrange a number of CPIN meetings where DCL partners, people with disabilities, and neighborhood system representatives shared information with city staff about their communities and how best to reach out and work with them.

A few years later, Ahmed-Shafi's position began to be funded through the “overhead model”- - to which city all bureaus contribute—as suggested by PITF, because her position serves all of city government, not just ONI.

Disability Program: ONI hired Nickole Cheron in February 2006 to re-establish the Disability Program and to re-establish and support a disability advisory committee. Cheron later would help create and support the Portland Commission on Disabilities.

The FY 2006-07 ONI Budget described the role of the Disability Program as “Community organizing and public education on disability issues; Assisting City policy development related to general disability and ADA issues; Acting as a resource for disabled persons by providing information on disability services, organizations, providers, and legal rights" (Portland. City Budget, FY 2006-07 419). In FY 2008-09 the ONI Budget stated that "The Disability Program connects, supports, and encourages collaborative civic engagement among the disability community, neighborhoods, and City government through support for the Portland Citizens Disability Advisory 
Committee" (Portland. City Budget, FY 08-09 402). The ONI budget stated that the advisory committee "promotes the civil, social, economic, political, and legal rights of persons with disabilities" (396). The advisory committee evolved into an going formal city government commission in 2008 .

The Portland Citizens Disability Advisory Committee was re-established in November 2006 "to connect, support and encourage collaborative and inclusive engagement with all persons of the disability community, neighborhoods, and local government.

Mayor Potter and the City Council subsequently created the Portland Commission on Disabilities on December 17, 2008 after "extensive community input, a survey, focus group and research of successful local and national models" Potter intended that the commission would support people with disabilities in Portland and "improve intergovernmental collaboration with City bureaus and City Council” (Portland. City Council. Resolution 36658, December 17, 2008).

The commission's current mission is "to guide the City in ensuring that it is a more universally accessible city for all." To do this the commission broadens "outreach and inclusion of persons with disabilities in Portland;" represents "a wide spectrum of disabilities on behalf of the residents of the City of Portland; " and facilitates "increased collaboration and information exchange between persons with disabilities, City bureaus and City Council" (Portland. Commission on Disabilities. Our Mission. Web. [no date]. <http://portlanddisability.com/our-mission/> .Downloaded October 26, 2013). 
When the Office of Equity and Human Rights was created in 2011, responsibility for supporting the Portland Commission on Disability (and a support staff position) moved from ONI to the Office of Equity. The Disability Program and Cheron stayed with ONI.

Effective Engagement Solutions: Potter created the Effective Engagement Solutions Program at ONI in FY 2008-09. ONI hired long-time facilitator and community activist Judith Mowry to fill this position. Mowry's role was to support “communities experiencing a high degree of development pressure or other major changes;" bring “together different communities and groups to build shared understanding and to foster dialogue on controversial and potentially divisive issues;" and facilitate "high-stake, high-conflict community meetings" (Portland. City Budget, FY 2008-09 396). Mowry would go on to be seen by city commissioners as a "go-to" person to help them navigate controversies in the community and to help them design (and survive) community meetings on hot topics. Mowry also would help create and facilitate a much-respected community dialogue process on gentrification in Northeast Portland, known as the "Restorative Listening Project." Mowry and her program were transferred to the Office of Equity and Human Rights, in 2011.

Elders in Action: ONI also has for many years provided funding support to a private non-profit organization, known as Elders in Action. Elders in Action "advocates for the needs of seniors and helps seniors advocate for themselves" (Portland. City Budget, FY 2008-09 403). 
ONI's relationship with Elders in Action goes back to FY 1989-90 when Bud Clark shifted responsibility for the Metropolitan Youth Commission, the Metropolitan Human Relations Commission and the City/County Commission on Aging from the City's Human Resources Bureau to ONA. The ONA budget that year stated that "The youth, aging and human rights constituencies are a natural complement to the neighborhood network in that they serve as a vehicle for citizen participation and advocacy on social issues of concern to neighborhoods" (Portland. "Office of Neighborhood Involvement." City Budget. FY 1988-89 167). The Commission on Aging transitioned out of ONI and into a private non-profit_-Elders in Action-in 1997. ONI continues to partially fund Elders in Action each year through a contract.

Small Businesses: Potter initially sought to reestablish ONI's relationship with the business district associations and provided funding for a position at ONI to support these organizations. As discussed earlier, the 1995-96 TFNI had recommended expanding the ONI system to include business district associations, and the 1998 ONI Guidelines had provided a formal process by which business district associations could apply to ONI for formal recognition, although none ever did.

In FY 2006-07, Potter provided $\$ 100,000$ to ONI to hire a staff person and to support business district association recruitment and organizational capacity, and improve connections with ONI, neighborhood coalitions, neighborhood associations, business associations, and other community organizations (Portland. City Budget, FY 2006-07 412). In FY 2006-07, Potter gave ONI an additional $\$ 50,000$ one-time allocation to continue to fund "a full-time staff position to provide organizational support and capacity 
building for neighborhood business associations" (Portland. City Budget, FY 2007-08 398).

The next year, the ONI Budget included a budget note that stated that the Alliance of Portland Neighborhood Business Associations (APNBA) "will assume the neighborhood business district support starting in FY 2008-09" (Portland. City Budget, FY 2007-08 399). Future City funding support for neighborhood business district associations would flow through the Portland Development Commission. This funding would continue to support APNBA (later known as "Venture Portland") which provided business districts associations with similar support and services as a neighborhood district coalition office. Under Mayor Adams, PDC also would fund, and Venture Portland would administer, a small grants program for business district associations.

Performance Measurement: Proponents of community involvement long have sought ways to make the case to skeptical elected leaders, the media, and the public for the value of involving the community in decision making and the effectiveness of spending public funds on community involvement programs. However, it is much easier to measure activity (i.e., the number of people who attended a training) than the results (i.e., the effect the training had on a participants ability to effective organize and advocate for issues they care about).

ONI traditionally had required neighborhood district coalitions—as a condition of their ONI grant agreement— to submit regular performance reports. Neighborhood coalition reported to ONI the number of technical assistance contacts, community involvement projects, partner organizations, efforts to involve historically 
underrepresented groups, neighborhood and coalition meetings, meetings attended by coalition staff, community members who participate in leadership trainings, total attendance at neighborhood association and coalition meetings and the number of newsletters distributed in the community (Portland. Office of Neighborhood Involvement. Performance Indicators for District Coalition and Neighborhood Offices 2006).

This data often was not particularly very reliable or comparable. Each district coalition defined the categories differently (for example, one neighborhood coalition would list hundreds of partnerships in a reporting period, while another large coalition would list three or four). Neighborhood coalitions also varied in the rigor and consistency with which they gathered the information. The lack of consistency across the system made it difficult to aggregate the data into reliable citywide numbers.

During Mayor Potter's administration, staff from the mayor's office and ONI sought to improve the measurement of the system's performance. Potter allocated $\$ 50,000$ in one-time funding to ONI in FY 2007-08 to hire a consultant to work with ONI and community partners to develop performances measures (Portland. City Budget, FY 2007-08 398). ONI contracted with Sanj Balajee, who had staffed Community Connect's extensive data gathering and analysis work. Balajee worked with neighborhood coalition representatives over many months and developed a system of intake and reporting forms that measured a much broader range of activities and impacts than ONI's previous performance indicator system. 
ONI and neighborhood coalition leaders determined that implementation of Balajee's proposed system would require extensive additional staff resources at the neighborhood district coalitions and ONI to gather, report and analyze the data. While both City Commissioner Fritz, who was the commissioner in charge of ONI at the time, and Mayor Adams had asked for better measurement of the performance of ONI and the neighborhood system, they did not support committing significant additional resources to this purpose.

ONI staff abandoned Balajee's more complex measurement system and instead worked with neighborhood coalition leaders and staff to develop common definitions and a common set of Excel spreadsheets to improve the consistency and comparability of the more traditional quarterly "activity-based" tracking and reporting. ONI also asks neighborhood coalitions to share a few qualitative success stories each quarter to help illustrate the impacts of different neighborhood system programs and activities required in the ONI/coalition grant agreement. In 2013, ONI staff and neighborhood coalition leaders and staff talked about sharing their experiences with this relatively new performance measurement system and updating and revising the system, as needed.

Some people noted that ONI's performance measurement system only looked at what was happening within the neighborhood system, but did not provide any insights into that state of civic participation by the community at large. In the late 2000s, the City Auditor offered ONI an opportunity to include a couple questions in the Auditor's annual community survey that measured community attitudes about city government services. 
ONI staff developed two questions that the City Auditor has included in the annual survey since 2009. The questions include:

- "In the past 12 months, how often have you been involved in a community project or attended a public meeting?" (Options: "More than 10 times," "6 to 10 times," "3 to 5 times," "Once or twice," and "Never."

- "Overall, how to rate the quality of each of the following City services?" One of the fourteen serve areas options is: "Opportunities to influence government decisions."

The results over the four years of data available at the time of this study showed that:

- The percentage of people who were involved in a community project or attended a public meeting rose steadily from 36 percent in 2009 to 42 percent in 2012 and 41 percent in 2013.

- Community members who rated the City's opportunities to influence government decision making as "very good" or "good" started at 32 percent in 2009 and dipped to 26 percent in 2011 and rose again to 28 percent in 2012 and 2013 (Portland. Office of the City Auditor. Annual Community Survey Results, 2009 through 2013).

It is not clear how useful this information is, but at least it will allow ONI staff and others to identify any changes over time. 
Other Potter Innovations: Potter supported a number of projects and initiatives that sought to provide a greater voice for under-represented communities in Portland. Some of the most prominent are described below.

Children: During his mayoral campaign, Potter asserted his belief that the health and well being of children was a major benchmark of the health of the city as a whole. He "pledged to make children the center of his mayoralty" ("Creating a child-friendly city." Editorial. Oregonian 2 January 2005). Potter strongly supported children and children's rights throughout his term as Portland mayor. Potter argued that "Our children are suffering right now. They're sending messages to the adult population they need help. We tell them, it's not in the budget, it's not our responsibility" (Sarasohn. Oregonian, January 30, 2005). One way Potter drew attention to the condition of children in Portland was by starting every City Council meeting by "asking some version of the question 'How are the children doing?'” He also invited school children to testify at the beginning of city council meeting every week about their concerns and what they believed needed to happen—and many did (Griffin. Oregonian, March 6, 2005). ${ }^{107}$

Potter began championing the development of a "Children's Bill of Rights" at the start of his administration. The Oregonian quoted Potter as saying that this document would include "adequate housing, proper nutrition, adequate health care, adults in their lives who are nurturing, and access to excellent education." Potter asserted that public spending need to support this vision for children. His goal was to use "the Children's Bill

\footnotetext{
${ }^{107}$ The Oregonian reported that Potter tied "the tradition back to African tribesmen and women who great each other with the question, 'What about the children?' and use the health of a society's young people to gauge quality of life" (Griffin. Oregonian, August 16, 2006).
} 
of Rights to create a vehicle for community discussion" and to draw "attention to the issue and [create] a scenario for the change" (Sarasohn. Oregonian, January 30, 2005).

Potter and the Multnomah Youth Commission co-sponsored a "Bill of Rights Convention" in May 2006. Nearly 350 students participated in the event and overwhelmingly approved the "Our Bill of rights: Children and Youth" document. One of the students involved stated that "What we're hoping to have the Bill of Rights be is something to hold government and city officials accountable for decisions that they make that affect us, the youth.” The Oregonian reported that Elizabeth Kennedy-Wong with the mayor's office said the document was part of Potter's commitment to giving youth a strong voice in decision making (Nkrumah. Oregonian, June 2, 2006). The "Bill of Rights," written by a committee of more than 30 youth, was seen as being the first such document in for a major U.S. city that actually was written by youth themselves (Griffin, Oregonian, August 16, 2006). The Portland City Council formally adopted the "Bill of Rights" in August 2006, and the Multnomah County Commission did the same in May 2007 (Portland. City Council. Resolution 36432, August 16, 2006; Multnomah. County Commission. Resolution No. 07-102, May 22, 2007).

The "Bill of Rights" asserts that youth are "entitled to a voice and opinion in decision that will impact our lives," a "quality education," "physical, mental, and spiritual wellness," "the tools that will lead to a healthy and productive life, "loving care and a healthy environment at home," and "access to safe and clean recreational areas" (2006). The members of the Multnomah Youth Commission (all youth, ages 13-21) continue to use the Bill of Rights as a guiding document. The commission is the "the official youth 
policy body for both Multnomah County and the City of Portland" "that strives to provide a voice for youth in the County \& City's work" (Multnomah Youth Commission. "Home." Web. <http://web.multco.us/multnomah-youth-commission> .Downloaded October 27, 2013).

Potter also funded the creation of a Youth Planning Program at BPS (Portland. “Mayor's Message." City Budget, FY 2008-09 9). During the time the program was active—during both the Potter and early Adams administrations—young people involved in the program engaged in outreach to youth as part of the Portland Plan, helped manage Vision into Action Grants for youth projects and developed the "Youth Manual"—a very accessible and high quality manual for people who "want to engage youth in local government" (Portland. Bureau of Planning and Sustainability. Youth Manual. [ no date]. Web. < http://www.portlandoregon.gov/bps/article/436057> .Downloaded October 27, 2013). Funding for the Youth Planning Program ended during the Adams administration. Immigrant and Refugee Task Force: In October 2006, the City Council passed a resolution affirming its commitment to include "immigrants and refugees in civic and public life" in Portland. The city council also established a "short-term task force of immigrant and refugee community members, city representatives and other stakeholders to investigate barriers experienced by Portland's growing immigrant and refugee population, and identify possible solutions" and to report back to City Council (Portland. City Council. Resolution 36447, October 18, 2006).

The Immigrant and Refugee Task Force completed its review and submitted its report in December 2007. The task force recommended specific actions, which included: 
- Creation of an "office of immigrant and refugee affairs, with a multi-ethnic staff, that would serve as a bridge and facilitator between the immigrant and refugee community and City government."

- Establishment of "a multicultural community center that can house a variety of immigrant and refugee organizations, has space for large meetings and community gatherings, and offers opportunities for people of different ethnicities to mingle."

- Provision of "additional resources for immigrant and refugee organizations to train or support their constituents in civic engagement."

- Conduct of "a professional evaluation to (1) assess the City's current Human Resources (HR) policies and practices, and (2) recommend change that would result in the recruitment, hiring, and retention of multilingual and multicultural staff to serve Portland's fast-growing immigrant and refugee communities" (Portland. Immigrant and Refugee Task Force. New Portlanders Speak, December 2007).

Many of these recommendations would be taken up by the Office of Human Relations, created by Potter in 2008, and then the Office of Equity and Human Rights, created by Adams and Fritz in 2011.

Human Relations Office and Human Rights Commission: In 2006, Potter commissioned a study to recommend a framework to re-establish a human relations entity for the City of Portland. The resulting report, presented in January 2007, chided the City of Portland for having "no human rights entity that holds us accountable for fulfilling our 
commitments under the Universal Declaration of Human Rights.'The report noted that 2008 was the $60^{\text {th }}$ anniversary both the UN declaration and the formation of "Portland's first human rights entity—-the Portland Inter-group Relations Commission" (Portillo and Frederick, 2007 3). The report noted that this early group later became the "Portland Human Relations Commission," and then, in 1978, became the Metropolitan Human Relations Commission (MHRC). The report stated that "The MHRC saw its ups and downs until its final demise in 2003 when, as a program of [ONI] it was cut from the [City] budget." The report questioned how Portland- "the most populous city in the state"- could not have a human rights commission when so many other cities in the northwest did. The report proposed a framework for creating "a permanent entity that plays proactive role in affirming human rights and is charged with addressing discrimination and strengthening intergroup and interpersonal relation so that Portland can truly embody its values of diversity and inclusion" (4).

In January 2008, the City Council created the City of Portland Office of Human Relations. The city council stated that the office's mission would be to "create greater cohesion in our community by promoting mutual respect, dignity and open communication among all people." The city council stated that the "primary purpose" of the new office would be "to empower and serve the residents of Portland by advocating for the rights of all people and resolution to issues rooted in bias and discrimination through education, research, advocacy and intervention." The city council also directed the office to "staff a 15-member Human Rights Commission and the Racial Profiling 
Committee" and "implement the recommendations of the Immigrant and Refugee Task Force" (Portland. City Council. Resolution 36571, January 16, 2008). ${ }^{108}$

While all four city council members present for the vote, voted to create the Office of Human Relations, the Oregonian reported that some of the city commissioners "expressed concern about its broad mission." The Oregonian reported that City Commissioner Randy Leonard "said he wanted the group to actually reduce wrongs, such as job and housing discrimination, instead of just making recommendations.” The Oregonian reported that City Commission Dan Saltzman "said he worried about 'mission creep' and high budgets, noting the city already has staff focused on disability rights, police abuses and other issues" (Dworkin. Oregonian, January 17, 2008).

In March 2008, the City Council formally created the City of Portland Human Rights Commission. The City Council directed the new commission to "eliminate discrimination and bigotry, to strengthen intergroup relationships and to foster greater understanding, inclusion and justice for those who live, work, study, workshop, travel and play in the City of Portland." The City Council established the jurisdiction of the commission would include "all practices and incidents occurring in the City of Portland" that affected the people listed above, and authorized the commission to "address such practices and incidents through education, research, advocacy and/or intervention, but shall not have civil rights enforcement authority" (Portland. City Council. Ordinance 181670, March 19, 2008).

\footnotetext{
${ }^{108}$ Potter had created the Racial Profiling Committee to review concerns, especially from communities of color, of racial profiling by Portland police.
} 
In 2011, Mayor Adams and City Commissioner Amanda Fritz would lead an effort that would result in the City Council's creation of a new "Office of Equity and Human Rights." The Office of Human Relations would be folded into the new entity, which would support both the Human Rights Commission and the Portland Commission on Disability (Portland. City Council. Ordinance 184880 as amended, September 21, 2011).

Voter Owned Elections: In 2005, during Potter's administration, the City Council would approve a unique, but short-lived program that provided public funds to candidates running for city government offices. City Commissioner Erik Sten and City Auditor Gary Blackmer had begun advocating for the program a few years earlier. They believed the public funding of local campaigns would help respond to "public concerns about campaign spending in Portland." Sten and Blackmer warned that the "trend of escalating campaign spending" and the "strong influence of money on elections outcomes" had led to a "dominance of money" that "discourages many good leaders from running and changes the dynamics of voter-candidate relationships." They asserted that "A healthy elections system should ensure government is responsive to the voters. Yet market-tested sound bites cannot replace the political dialogue that bring out City voters and leaders together." Sten and Blackmer argued that public funding of campaigns would level "the playing field by giving candidates who demonstrate real grassroots support the financing they need to run an effective campaign." They asserted that the program would reduce the reliance of candidates, particularly incumbents, on "large contributions from a few contributors." They noted that similar public funding of campaign programs had been 
operating successfully in other parts of the country for over 20 years (Portland. Office of City Auditor Gary Blackmer and Office of City Commission Erik Sten. Publicly

Financed Campaigns in Portland. March 22, 2005 cover letter).

On May 18, 2005, the City Council approved the creation of a public campaign funding system for the "Auditor, City Commissioner and Mayoral elections." The City Council also directed the City Auditor to refer the system to the voters at the November 2010 election (Portland. City Council. Ordinance 179258 as amended, May 18, 2005). This was intended to give Portlanders an opportunity to see how the system worked for a few elections before they would be asked to vote on whether to continue the program. Potter strongly supported the creation of the new "Voter Owned Elections" system. ${ }^{109}$

The new "Voter Owned Elections" system had mixed results. The system functioned for three election cycles, and provided candidates with $\$ 1.76$ millionadministration of the system cost another $\$ 220,000$. Two of the nine candidates who participated won seats on the city council through the system-Erik Sten, an incumbent city commissioner who had been one of the authors of the system—and Amanda Fritz, a long-time neighborhood activist, who ran twice under the system and won on her second try—becoming the first and only non-incumbent to win election through the system. The system also experienced controversy. One publicly funded candidate misused the funds provided by the system and left the state still owing Portland taxpayers $\$ 90,000$. Another

\footnotetext{
${ }^{109}$ Some critics of the system argued that the fact that Potter-who limited his campaign contributions and did no traditional campaign fundraising - defeated Francesconi-who set a new record for money raised in a Portland mayoral election — showed that the system was not need. Proponents of the system said that Potter's election was an anomaly and that research showed that incumbent elected officials almost always won contest elections as did nearly every candidate who raised the most money.
} 
candidate was convicted of forging some of the signatures he gathered to quality for funding under the program (Schmidt. Oregonian, November 4, 2010).

In November 2010, Portlanders very narrowly voted to end the system- 50.3 percent against the system and 49.7 for it (Multnomah. Election Archive, November 2, 2010 General Election, Web, <http://web.multco.us/elections/november-2010-general$\underline{\text { election> }}$. Downloaded October 27, 2013).

The Oregonian suggested that while proponents of the system remained "more convinced than ever that the corrosive influence of money in politics must be addressed at all levels of government," opponents had been motivated by a number of factors. Some voters "objected to the basic premise of spending public money on political campaigns. Others resented that city politicians [had] implemented the program without initially referring it to voters;" some were reacting to the controversies that had occurred. The Portland Business Alliance (PBA) (Portland's influential downtown business association), which "largely funded the opposition campaign" asserted that "voter-owned elections was a solution in search of a problem" (Schmidt. Oregonian, November 4, 2010). Proponents of the system accused the PBA of opposing the system so aggressively because it reduced the influence of big downtown business people and the large campaign contributions they often made.

Elections in Portland have returned to the traditional campaign funding model. ${ }^{110}$

\footnotetext{
${ }^{110}$ It is interesting to note that Fritz was able to win reelection as a city council member against a wellfunded opponent in 2010 without the Voter Owned Elections system. However, like Potter had done, Fritz set upper limits on the size of the individual campaign contributions she would accept, but also spent about $\$ 250,000$ of her own money on her campaign, in effect self-funding her campaign (Schmidt. OregonLive, October 16, 2012).
} 
VOZ Day Laborer Facility: Potter had been "an outspoken advocate for the rights of immigrant workers" for many years. During his mayoral campaign in 2004, he spoke about creating a hiring center to support day laborers in Portland. The Oregonian quoted Potter as saying "This is one of our most vulnerable populations. These are people who are trying to do an honest day's work." Once in office, Potter created a committee to explore how to move forward on this goal. Community and immigrant activists supported the project. Some local business owners and anti-illegal immigration groups opposed it (Griffin. Oregonian, July 29, 2007). In March 2008, Potter led the City Council in approving \$200,000 grant to VOZ Workers’ Right Education Project “to operate a day labor hire site in Portland." The grant was intended to fund the "cost of the facility and a contract staff person" (Portland. City Council. Ordinance 181651, March 5, 2008). VOZ created the day laborer center on land owned by the Portland Development Commission (PDC) close to where day laborers traditionally had congregated. The City Council continued to provide funding to support the project. Five years later, in 2013, VOZ was still operating the day laborer center and was negotiating with PDC about the future of the center on that particular site. The Oregonian reported that "the center still has the city's support, according to aides in Mayor Charlie Hales' office and the [PDC[ leaders. But a permanent solution isn't any closer to becoming a reality" (Theen. Oregonian, October 27, 2013).

East Portland Action Plan: Another major innovative community involvement process begun during Mayor Potter's administration was the East Portland Action Plan. For many years, people in east Portland, a large area annexed by the City of Portland in 
the 1980s and 1990s, had complained that City Council and the city staff were not paying attention to their needs. Their area was shifting rapidly from its previous rural and suburban character and becoming more urbanized. Other issues included a significant shift of people with low incomes out of gentrifying northeast Portland to east Portland, new housing being built that was of poor quality and did not fit the character of existing development, a significant increase in the diversity of the community-especially the growth of immigrant and refugee communities, and a strong need for economic development and jobs. Mayor Potter joined with Multnomah County leaders and State Speaker of the House Jeff Merkley (whose district included east Portland) to initiate a broad and inclusive community strategic planning process for east Portland, known as the East Portland Plan. The EPAP Committee completed most of its work during 2008, Potter's last year in office.

Implementation of the EPAP action items, which began in 2009 , is being led by an EPAP Implementation Committee that represents a wide range of interests in the community and receives strong staff and funding support from the City to carry out its activities. The combination of strong community involvement in developing the EPAP and in the implementation of the plan is seen by many as a good model for a process that attracts and involves a broad spectrum of the community and implements actions that are important to the community. The EPAP Implementation Committee models many of the best practices learn in Portland over the last twenty years. (The EPAP is discussed in more detail below.) 
Mayor's Budget Messages - Tom Potter - 2005-06 to 2008-09

Potter's four-year term as Portland's mayor was characterized by a strengthening economy and high levels of discretionary one-time resources that allowed Potter to fund a number of new programs and projects. In his first mayor's budget message, Potter recognized that FY 2005-06 was "the sixth straight year" that the City Council needed to cut services "due to a recession" (FY 2005-06 3). By the next year (FY 2006-07), the economy began to recover ushering in three years of extra revenue beyond that needed to fund basic government services-over \$30 million in FY 2006-07 (8), \$37 million in FY 2007-08 (5), and \$33 million in FY 2008-09 (3).

Values and Priorities: Potter expressed consistent priorities and values throughout his four budget messages. Potter pledged to Portland's citizens to protect "frontline services" and support "innovation and efficiency" to "enhance customer service"...."and that citizens' concerns will be heard" (FY 2005-06 4).

Potter convened the city council members in fall 2005, and they identified "five focus areas" for the budget: "Building a Family-friendly City;" "Creating Sustainable Economic Development;" "Enhancing Public Safety \& Emergency Preparedness;" "Finding Energy Alternatives;" and "Rebuilding the City's Infrastructure" (FY 2006-07 3).

Potter also prioritized creating a city that cherished its children and protected vulnerable Portlanders. In FY 2005-06, he stated that "working with our citizens, we have delivered a budget that makes our community stronger, our children's futures brighter, and our most vulnerable residents more secure" (FY 2005-06 3) 
In his FY 2007-08 budget message, Potter stated that that year's budget "now presents us with an opportunity to restore, enhance and protect those basic services that the community looks to its government to provide." Among these basic services, Potter listed "green parks and safe neighborhoods, affordable housing and good roads, family wage jobs, and a healthy environment" (FY 2007-08 3).

Potter also pursued greater efficiency and transparency in government. In FY 2005-06 he stated his belief that "good government is possible at a reasonable cost" (FY 2005-06 3). In FY2006-07 Potter referred to the "20 Bureau Innovation Projects" that were "making our City more diverse, creating greater transparency and accountability, requiring collaboration between City bureaus and Portlanders, and providing effective use of taxpayer dollars" (FY 2006-07 3).

Potter's community visioning project—visionPDX — was part of his bigger effort to establish the community's vision for the city and then use that input to create a longterm strategic plan for City government. In FY 2006-07, Potter reported that the "Visioning Project is now engaging our community in a discussion about its aspirations for Portland's future." Potter then stated his plan is to use the community's vision to "shape our future through a strategic plan with the incremental steps necessary to achieve a better Portland for everyone" (FY 2006-07 3). In FY 2007-08, Potter noted that "In the months ahead, the work gathered from the Visioning Project will inform the creation of a strategic plan that will link the aspirations of Portlanders to the actions of future City Councils" (FY 2007-08 4). 
In his last budget message, for FY 2008-09, Potter presented what he believed were important "lessons learned" for "the next Council:"

- "The City must fix its aging infrastructure."

- "Core services must come first." Potter stressed that "core services" do not just include "public safety, roads, and parks" but "also the human infrastructure we have built over the last four years to invite more members of the community — and more diverse members of the community_into the decision-making process. We will open the doors of City Hall to more people through such acts as the Council's funding of a Human Rights Commission. Now they must remain open" (4) [emphasis added].

- "In Portland, of all places, we should save for a rainy day."

- " Our entire budget must be more transparent." Potter advocated for a budget that was more understandable to community members, and that clearly identified "shadow" obligations, including "one-time funded" programs that really are meant to be ongoing, and obligations, like Milwaukie light rail, for which future councils would need to provide matching funding (4).

- "The Council must share a strategic, long-range plan for Portland's future, and stick with it." Potter reported that "The City is developing new, comprehensive plans that should provide a guide to how our city grows for the next 20 years. These plans_-including an East Portland Plan—will also reflect the dreams of thousands of everyday Portlanders who shared their vision for their community's future during visionPDX." Potter stressed that "these plans 
will only matter if the Council not only shares the vision, but is able to work together on a common set of long-term goals and programs, making these the basis for future budget decisions" (FY 2008-09 5).

- "The City must form more public-private partnerships." "Government is not the solution to every problem. Our City must work more closely with our business and civic communities to find solutions" (5).

- "Portland must work more closely with its regional partners" (5).

Budget Process: Potter instituted a new approach to involving the community in the development of the city budget, which he used throughout his four years as Portland's mayor. In FY 2005-06, Potter announced that he had "formed two work teams made up of Commissioners and citizens to look at the City budget as a whole and make recommendations (FY 2005-06 3) Potter charged the two budget teams with "thinking more strategically" and placing the highest priority on "funding those programs that most closely match our community's needs and priorities" (3). Potter reported that these budget teams "collaborated in a transparent process, thinking strategically not just about the needs of individual bureaus, but about our City as a whole” (FY 2006-07 4).

In each of his budget messages, Potter recognized that the city budget was "the thoughtful product of many people within and outside Portland government." He always thanked "the City Commissioners, our citizen budget advisors, community budget forum participants" and different city staff people (FY 2006-07 3) Potter made a point of thanking "citizen advisors on these teams by name" each year. 
In his last budget message, for FY 2008-09, Potter again praised the work of the budget teams of City Commissioners and citizen budget advisors, and reported that "hundreds of citizens have directly participated in the development of this budget through work on bureau advisory committees and oral or written testimony" (FY 2008-09 3).

Potter also stated his belief that, with the help of the City Council "and the involvement of our citizens," the budget "charts a future for our city that keeps our neighborhoods strong, protects our children, and strengthens our economy" (FY 200607).

Budget Highlights: Potter chose to highlight many different community involvement programs and projects in his budget messages.

In FY 2005-06, Potter reported that "Community policing programs have been retained... and $\$ 1.0$ million in one-time funds is provided for problem-oriented policing strategies" and that all the City's community centers would remain open. However, Potter also announced that funding or some community centers would be reduced to 80 percent with the expectation that they would seek "new community sources of financial support and business partnerships." He reiterated one of his messages during the campaign: "Residents cannot continue to assume that government is the only solution for community needs" (FY 2005-06 5).

Potter also announced that "by trimming [ONI's] central administration" he was able to create a “ $\$ 500,000$ Community Investment and Empowerment account, designed to provide more direct funding and services to neighborhoods." (This funding was transferred to the mayor's office to support visionPDX in FY 2005-06.) Potter also 
reported that "Elders in Action and neighborhood mediation services" were funded, and that the budget supported "community gardens because citizens told us they are an important part of our neighborhoods" (FY 2005-06 6).

In addition to a description of the visionPDX project, Potter also announced that "a City Charter Review Commission will be appointed in the coming months" to assess "alternative governing structures or changes to the current structure that will improve customer service, streamline government operations, offer greater flexibility in hiring, and encourage better collaboration across City bureaus and with the Portland Development Commission” (FY 2005-06 6).

Potter focused on increasing workforce diversity and cultural awareness within city government. He reported that the "Council is firmly committed to increasing workforce diversity and cultural awareness." He noted that the budget includes funding for "a new Citywide training initiative" and that the Bureau of Human Resources "will work with every bureau to maintain aggressive recruitment efforts to bring qualified minorities and underrepresented classes into the City workforce" (FY 2005-06 7).

In FY 2006-07, Potter provided budget highlights in five priority areas identified by the City Council in fall 2005. Under the first priority--"Build a family-friendly city, where families can afford to live and children can be reared and educated in a supportive community," he asserted that the "City must step up its efforts to meet the needs of our most vulnerable citizens" (FY 2006-07 5). Under the second priority—“create a strong economy, planning for both the success of our business community and individual and family prosperity," he mentioned funding to "enhance graffiti abatement" and " $\$ 100,000$ 
for the Office of Neighborhood Involvement to work with the small business community" (6). Under the third priority, "enhance public safety and emergency preparedness by reviewing service delivery in the city, and with our regional partners, ensure a safe and peaceful community," Potter reported that the budget allocates " $\$ 509,000$ to "Strengthen community policing" by opening "precincts around the clock and on weekends" (6).

In FY 2007-08, Potter mentioned that much of the $\$ 23$ million in one-time money allocated by the council in November went to giving "an early start to programs that are part of a series of five Council-wide initiatives that we have inaugurated this year to help organize City priorities for investments, encourage collaboration among bureaus and agencies, and focus Citywide activities." Potter again mentioned his intention that "These initiatives will encourage the Council to continue collaborating on an integrated, strategic vision that informs all our spending decisions" (4). Among the community involvement initiatives, he mentioned:

- 'The Children and Youth Bill of Rights, sponsored by the Mayor's Office, educating Portlanders about the needs for, and availability of, services for children and how best to fill any gaps" (FY 2007-08 4).

- Initial funding to establish "a Human Relations Commission that will create greater cohesion in our community by promoting mutual respect and open communication" (FY 2007-08 4).

Potter again highlighted programs and projects that supported the City Council's five priority areas: stabilizing and restoring core services, rebuilding critical infrastructure, creating a vibrant business climate, striving to improve Portland's 
livability, and helping "the community engage their government and participate in civic life" (FY 2007-08 5-7).

Under "strive to improve Portland's livability," Potter noted that the budget includes $\$ 1.8$ million for the Bureau of Planning to complete visionPDX and continue to work on the Central Portland Plan and Comprehensive Plan update, to ensure that the growth in the city is smart and reflects the community aspirations" (FY 2007-08 7).

Under "help the community engage their government and participate in civic life," Potter highlights:

- " $\$ 125,000$ for the East Portland Action Plan, which will bring together neighborhood, business, and elected leaders with school officials, law enforcement, and City agencies to identify and prioritize short- and longerterm actions to improve livability in east Portland neighborhoods" (FY 2007$087)$.

- $\$ 200,000$ to start a Human Relations Commission that will provide a venue to address individuals' concerns of unfair treatment by local government because of their race, ethnicity, or culture" (7).

- “ $\$ 580,000$ for $[\mathrm{ONI}]$ to increase funding for each district coalition office for the first time in 15 years and to help underrepresented groups develop leadership and organizing skills to gain more access to government" (7). In his last budget message, for FY 2008-09, under his fourth goal—“"grow Portland's reputation as the nation's most livable city"-Potter highlighted: 
- $\quad$ \$1.8 million for the Bureau of Planning for the Central Portland Plan and Comprehensive Plan update. Funds will also be provided to enhance the Planning Bureau's district liaison program and support the Youth Planning program. All of these planning efforts are intended to ensure that the growth in the city is smart growth that reflects the community's aspirations" (FY 2008-09 9).

- " $\$ 500,000$ to implement the East Portland Action Plan, which has brought together neighborhood, business, and elected leaders with school officials, law enforcement, and City agencies to identify and prioritize short- and longerterm actions to improve livability in east Portland neighborhoods" (9).

- “ $\$ 125,000$ for additional small neighborhood grants to immediately fund planning projects to bring the Vision into Action" (9).

Under Potter's fifth goal_-“make Portland welcoming to every resident”-Potter highlighted:

- “ $\$ 377,000$ to create the Office of Human Relations and restore the City’s Human Rights Commission, which will provide a venue to address individuals' concerns of unfair treatment by local government because of their race, ethnicity, culture, immigration status, disability, or sexual preference" (Fy 2008-09 9).

- “ $\$ 103,250$ to further address issues specific to immigrant and refugee populations in Portland as part of the Office of Human Relations over the next two years" (9). 
- $\quad \$ 1.0$ million for the Office of Neighborhood Involvement (ONI) to enhance the capacity of district coalition office staffing; expand core ONI staff that can help neighborhoods resolve disputes; implement the recommendations of Community Connect, which will make government more accessible to residents; and assist underrepresented communities with finding their voice in the neighborhoods by giving them the organization and experience they need to make themselves heard" (9).

Closing Statements: Potter closed his budget messages by recognizing and celebrating the high levels of collaboration between city council members, city government staff, and community members in developing the city budgets. In FY 200506, Potter stated that the budget process "only becomes stronger the more we are able to involve Portland's citizens. Next year, I promise we will hear their voices earlier and even more often" (FY 2005-06 8) In FY 2006-07 Potter stated that he was "pleased" with the budget "because of the hard work and involvement of so many people." He reported that that year "we held more public workshops and held them earlier. Our five citizen advisors brought the critical eye of the private sector and important community questions to our process, often challenging how we were approaching decisions and helping to make them better. Our citizens' voices are clearly represented in this document" He also noted that the City had made a good started one of the previous year's goals "to begin building more effective partnerships between the City and its citizens, between the private sector and the public" (FY 2006-07 8). 
In FY 2007-08, Potter opened his concluding remarks again by celebrating the "unprecedented level of collaboration among the entire City Council, our staffs, and the community. He ended by stating: "I hope Portlanders will continue to participate in government as this budget is implemented over the next year, as so many of you participated in developing it. As always, we want to hear from you" (FY 2007-08 8).

In Potter ended his fourth and final budget message by stating that: "In my first Proposed Budget in 2005, I wrote that 'working with our citizens, we have delivered a budget that makes our community stronger, makes our children more secure, and protects those among us most in need of our help.' I believe this budget accomplishes those same goals. Thank you" (FY 2008-09 10).

Potter's budget messages reflect his strong commitment to community involvement in government decision making, government efficiency, strategic management of city government as a whole, and long-term strategic direction based on the community vision. Potter frequently mentions the valuable role he believes community member play in the budget process. He also makes a point of highlighting many programs and projects that expanded and strengthened Portland's community and neighborhood involvement system.

\section{Citywide Policy Bodies--Citywide Land Use Group and Citywide Parks Team}

Different system reviews and individual community activists have called for the creation of some sort of city wide body or vehicle that neighborhood and community activists could use to discuss citywide policy issues and organize themselves to take action. Citywide bodies have been created from time to time-i.e., the PAN in the 1970s, 
APN in the 1980s, and NPAC in the mid 2000s, but they each only were active for a short period of time.

As of 2013, Portland still does not have a formal citywide neighborhood or community council. One citywide body that has functioned for many years is the Citywide Land Use Group. Another similar body that was created in 2005 is the Citywide Park Team. Although the Citywide Park Team was only active for a few years, in 2013 City Commissioner Amanda Fritz called on each of the seven neighborhood district coalitions to create a Parks Committee, which might lead to the resurrection of this citywide committee.

Citywide Land Use Group: Neighborhood activists create the Citywide Land Use Group (CWLU) sometime in the 1990s. Neighborhood association leader Tom Badrick, chaired the CWLU early in its history. Badrick said the group already existed when he got involved with it in the mid 1990s. Bradick reported that, at the time, his neighborhood association just had won a land use case that prevented an electric utility company from locating a cell tower at a substation along an arterial in his neighborhood. Badrick remembered that "Like other future issues, it wasn't about yes/no, but isn't there a better way." He reported that his neighborhood association "worked with the cell provider to place antennas on roof tops to accomplish the same effect." A couple months later the same issue came up when a cell tower was proposed at a property across the street from Badrick's house along another arterial in the neighborhood. Badrick stated that 'it seemed like a topic NA's could work on together instead of fighting it one at a time in a void." 
Badrick remembered that he emailed the ONA director at the time, Diane Linn, about the issue. She invited him to come to a CWLU meeting to talk about it. Badrick made a presentation to the small group of people at the meeting and he "suggested the group could be helpful." He said the group's members politely listened to him and the meeting ended. When he came back the next month, none of the people who had been at the previous meeting were there, and Badrick agreed to chair the group to fill the leadership void. Badrick said that Linn helped him "connect to a few other people, and soon we built a larger group. We kept working the issues of helping each other." Badrick reported that participation in the group increased dramatically when the City "signed onto Metro's goals of accepting greater density and the upped the ante by agreeing to take more." Badrick remembered that the group went from a few attendees to "a meeting with 89 people from all over the city where David Knowles, then Planning Director explained and justified the city position." Badrick reported that, a few years later, when he was preparing to "retire" from the CWLU, he was watching Portland's local community access television channel and saw the director of the City's development and permitting bureau describing the community outreach her bureau had done on a project—- "top of the list was CWLU." Badrick said he was very gratified to realize that CWLU had developed enough clout "to matter." Badrick reported that he handed off the leadership of the group to "the most capable people one could find - three Spirit of Portland winners-Arlene Kimura, Bonny McKnight and Amanda Fritz"111 (Badrick email to Leistner, October 17, 2013).

\footnotetext{
${ }^{111}$ Kimura and McKnight are long-time neighborhood leaders from east Portland. Fritz is a long-time neighborhood activist from southwest Portland. Fritz served for seven years on the Portland Planning
} 
ONI staff person Brian Hoop remembers helping Badrick, in the early 2000s, develop a database of contacts for the CWLU and send out meeting announcements. Hoop reported that when McKnight took over as chair of the CWLU in 2003, she chose to end the group's relationship with ONI. McKnight has continued to chair the CWLU to the time of this study in 2013. McKnight prepares the meeting agendas, sends out meeting notices, and facilitates the CWLU meetings. The CWLU meetings continue to be a regular community outreach stop for city staff working on land use planning related projects. In 2013, some CWLU members discussed creating a new alternative city wide land use group that would have a more open and inclusive leadership structure and more open approach to setting the meeting agendas. They also discussed partnering with ONI again to strengthen the group's outreach and recruitment efforts and to expand online opportunities for community dialogue and information sharing on land use issues.

Citywide Parks Team: In the early 2000s, east Portland neighborhood activists Linda Robinson and Alesia Reese wanted to start an east Portland neighborhood “coalition-wide committee to address parks issues in East Portland." They reached out to southwest Portland neighborhood parks activist Amanda Fritz to learn more about a coalition-wide parks committee that they had heard that the southwest neighborhood coalition (SWNI) had created. In their conversations with Fritz, Fritz "mentioned her idea of forming an ad hoc citywide parks group, open to anyone interested in Portland parks," similar to the CWLU group led by Bonny McKnight (Robinson. Email to Leistner, October 20, 2013, 1:51 AM). 
Robinson, Reese, and Fritz went on to create the "Citywide Parks Team" in 2005.

Fritz chaired the group during its first year, and then Robinson took over. Fritz reports

that "We had people from all over, mostly from [park] Friends and NA groups" (Fritz.

Email to Leistner, October 17, 2013).

The Citywide Parks Team website identified the group's mission as:

"The Citywide Parks Team partnership brings together many special focus groups and individuals, such as Neighborhood Association and district/coalition parks committees, "Friends of..." organizations, businesses, and so on. It's also a place for people who don't otherwise participate in parks organizational discussions to add their voices -- for example, sports facility users, social and cultural service providers sharing building space, etc. And it provides opportunities for liaison with the Parks Bureau, Parks Board, Portland Parks Foundation, and other stakeholders. It's citizen-initiated, citizen-led, citizen-owned, and intended for all Portlanders who care about getting things done in and for parks in Portland" (Citywide Parks Team. Web. $<$ http://explorepdx.org/pcwpt.html> . Downloaded October 17, 2013).

Fritz shared her recollections about the original purpose and activities of the

group:

"I hoped it would help us organize and become more cohesive citywide, and it did. We had mostly presentations from Parks staff and other staff. Two meetings I particularly remember were one where we talked about fire hazards in relation to tree preservation and home safety which filled either Pettygrove or Lovejoy, [Rooms in City Hall] and another on community gardens which filled the Rose Room [in City Hall]. It was basically the only forum (then or since) where any interested citizen could show up and talk with staff and other citizens about the topic of the month. For the fire session, I got the impression the various bureau staff were talking to each other for the first time, too" (Fritz. Email to Leistner, October 17, 2013). 
Robinson reported that "Most meetings had a special topic, including a speaker on the topic and lots of time for discussion, but the dominating topic that we came back to, over and over, was equity—geographical equity, racial/ethnic equity, socioeconomic equity, etc" (Robinson. Email to Leistner, October 20, 2013, 1:51 AM).

Robinson stated that "One of the primary goals of the group was to increase/improve communication between [Portland Parks and Recreation (PP\&R)] and park advocates. While it was obvious people in Portland loved their parks, there was a lot of distrust of PP\&R itself. We were hoping to change that." Robinson continued, "My hope was that we could show PP\&R management that we could help them if they would share more information with us and involve us in projects at an earlier stage. I was convinced that we could become better advocates for the Bureau if we could establish a more collaborative relationship with them. They kept telling us how dependent they were becoming on park volunteers, but their immediate response to most suggestion from park advocates was, 'I don't think we can do that'” (Robinson. Email to Leistner, October 20, 2013, 1:51 AM).

Robinson recalled that the group initially met at City Hall, but then had to move the meetings to other locations when the rules for the use of after-hours meetings in City Hall changed. Robinson said the frequent changes of meeting location "did NOT work well," and attendance dropped off. Robinson stopped facilitating the meeting after she was appointed to the Portland Parks Board in late 2009. She recalled that last meeting of the Citywide Parks Team was in early 2010. Robinson said that, in early 2005, the group "set up an email listserv through Yahoo Groups—a list that still exists, though it's not 
used very much." Robinson says she still forwards PP\&R press releases to the listserv, and "occasionally someone else posts something." She thought "there are still 20 or 30 people in that group" (Robinson. Email to Leistner, October 20, 2013, 1:51 AM).

Fritz stated that she believed that the primary accomplishment of the Citywide Parks Team was to grow "friendships across the city" and to advance "knowledge and understanding," which she said she believed was "accomplishing a lot" (Fritz. Email to Leistner, October 17, 2013).

Robinson said, at some time before 2010, "Parks started tracking all the Friends groups that had formed over the years." She said the bureau "seems to be making an effort to work more collaboratively with them" (Robinson. Email to Leistner, October 20, 2013, 1:51 AM). Robinson also stated that, in her personal experience and the experience of several east Portland neighborhood activists, "there is MUCH MORE grassroots participation in Parks now than there was there was ten years ago, or even five years ago! A number of things have contributed to that-but I have to think that the Citywide Parks Team [made] a significant contribution, if nothing else" through the relationships developed through the group (Robinson. Email to Leistner, October 20, 2013, 10:06 AM).

Robinson reported that east Portland park activists went on to form the "East Portland Parks Coalition." She said that this group also has helped improve relations with PP\&R. Robinson stated that: "The fact that the [PP\&R] Zone Manager attends nearly every one of those monthly meetings has been a HUGE factor in making that group effective.” The zone manager often plays “a 'listening role,' getting a much better feel for 
the wishes and concerns of folks who are intimately involved with these parks." She reported that the zone manager, at other times, serves as a "great sounding board, giving valuable feedback as to what might (or might not) be possible and why — and when." Robinson noted that the zone manager "after hearing a consistent theme come up in the meetings," knows they "whole system well enough to realize there's an existing program that, with just a bit of tweaking, could provide the desired service-and they are in a position to connect the folks who can make it happen" (Robinson. Email to Leistner, October 20, 2013, 10:06 AM). ${ }^{112}$

Robinson noted that both the Citywide Park Team and the East Portland Parks Coalition "were set up as ad hoc groups_-open to anyone interested in participating. There are no specific representatives from each neighborhood association." Robinson reported that Alesia Reese, who facilitates the East Portland Parks Coalition meetings, regularly reports to the East Portland Neighborhood Office (EPNO) neighborhood association chairs group on the activities of the East Portland Parks Coalition. She also noted that when the East Portland Action Plan (EPAP) implementation committee established its subcommittees, the group "did NOT form a committee to deal with park issues (even thought parks are a big issue in the area) because they were all aware of the existence of the East Portland Parks Coalition. Robinson and EPAP co-chair Arlene Kimura, a long-time east Portland neighborhood activist, serve as the official EPAP representatives to the East Portland Parks Coalition and regularly report on the parks

\footnotetext{
${ }^{112}$ The regular participation of the Park Bureau zone manager in the East Portland Parks Coalition meeting, is a good example of a city staff person building a relationship over time with community members the benefits both his work and the work of the community members.
} 
coalition's "accomplishments, events and issues to the full EPAP group" (Robinson. Email to Leistner, October 20, 2013, 11:04 AM).

Fritz was elected to the Portland City Council in 2008 and re-elected to a second term on the city council in 2012. In July 2012, Mayor Charles Hales designated Fritz as the commissioner-in-charge of the City of Portland Parks and Recreation Bureau. In fall 2013, Fritz called on each of the seven neighborhood district coalitions to develop a "Parks Committee" to advise her how community members wanted the City to utilize $\$ 8$ million in revenue from systems develop charges, which was available to spend on the City's park system (Ashton. East Portland News. 2013). Fritz suggested that a new Citywide Parks Team could evolve out of the seven neighborhood coalition park committees, "in a year or two once the area parks committees get established, if the participants want to do that." She added that "I'd like to see a Citywide Transportation Committee and a Citywide Crime Prevention Committee run by grassroots activists, too" (Fritz. Email to Leistner, October 17, 2013).

Unlike the PAN from the 1970s and APN from the 1980s and the Citywide Parks Team of the mid 2000s, only the CWLU group has been able to sustain its activities over time (nearly twenty years by 2013). While individual community activists periodically see the value of creating a citywide group, the history of these groups appears to indicate that their continued existence depends heavily on ongoing support, either from one or more dedicated and skilled community members—like McKnight—or from a paid and skilled staff person assigned to support the group. District area subject committees-like the East Portland Parks Coalition_ - often are better able to sustain their focus and energy 
than a citywide committee. The East Portland Parks Coalition also benefits from its good relationship with the East Portland Action Plan, one of the most innovative and effective community organizing initiatives implemented in Portland. ${ }^{113}$

\section{Mayor Sam Adams and ONI Commissioner Amanda Fritz (2009-2012)}

Mayor Sam Adams took office in January 2009. Adams came in with a reputation for having lots of energy and lots of ideas. Adams also knew how city government worked. Adams had been Mayor Katz's chief of staff for her entire twelve years as mayor, and he had served one term as a city commissioner. Adams had not gotten along particularly well with Potter on the city council, and Potter actively campaigned for Adams' opponent in the mayoral race. Many community and neighborhood activists wondered whether Adams would continue to support the expansion of Portland's community and neighborhood involvement system implemented under Potter. ${ }^{114}$

One early sign of Adams' attitude toward ONI and community involvement was his decision to give responsibility for ONI to newly-elected City Commissioner Amanda Fritz. Fritz was a long-time neighborhood activist, had served for many years on the Portland Planning Commission, and was the first (and only) non-incumbent to win election through Portland's short-lived "Voter Owned Elections" program. During

\footnotetext{
${ }^{113}$ Robinson states that the East Portland Action Plan is "the BEST thing that has happened to East Portland in the nearly 40 years I've lived there!" (Robinson. Email to Leistner, October 20, 2013, 11:04 AM).

${ }^{114}$ Adams' effectiveness and focus initially was damaged by a sex scandal that broke only a few weeks after he took office. The Oregonian wrote at the end of Adams one term as mayor that he "survived a state criminal investigation and two recall attempts" but that "his reputation was so damaged" that he decided not to "seek a second term." The Oregonian also noted that "yet through sheer will and hard work Adams rammed through an ambitious priority list, easily eclipsing the record of predecessor Tom Potter. The scandal forced Adams to adapt, to become more collaborative and reliant on others." The Oregonian quoted Adams' former boss, Portland Mayor Vera Katz, as saying "I think he had an incredible four years. Had we not had this scandal, he would have run for re-election and he would have had an incredible legacy" (Schmidt. Oregonian, December 23, 2012).
} 
Adams' one term in office, he and Fritz often joined together to protect ONI and the ONI programs from the severe budget cuts being required of other General Fund supported city bureaus and programs during the Great Recession. Adams also became a major proponent of "equity" in Portland during his very hands on leadership of the City's strategic planning process known as the Portland Plan. ${ }^{115}$

During the four years that she was the ONI Commissioner, Fritz strongly advocated for funding for ONI and its programs and community partners and was a dependable and vocal advocate for community involvement in city decision making. She also spent a lot of time out in the community attending community events and meetings and stayed up late at night personally responding to emails from community members.

\section{City Bureau Budget Advisory Committees (BACs): City bureau budget} advisory committees (BACs) finally made a comeback in the FY 2009-10 budget process. Neighborhood and community activists had been asking for a reinstatement of BACs as part of the city budget development process since Mayor Katz had dissolved the program in the early 1990s. Mayor-elect Sam Adams came to the monthly meetings of the Public Involvement Advisory Council (PIAC) (only two days after his election) and announced that he was requiring each city bureau to create a Budget Advisory Committee (BAC) as part of the FY 2008-09 budget process. ${ }^{116}$ Adams told the PIAC members that bureaus would be required to evaluate and rank their programs against the program's

\footnotetext{
${ }^{115}$ A number of people believe some of Adams' support for "equity" in Portland was rooted in his experiences as a gay man and an advocate for gay rights and his experience growing up in a low-income family.

116 The formal "council budget direction" to bureaus stated that "Bureaus will be expected to form Bureau Budget Advisory Committees that include management, labor, customers, and internal and external stakeholders" (Portland. Office of Management and Finance. Memo from Casey Short and Andrew Scott to Bureau Directors et al. SUBJECT: FY 2009-10 Budget Approach and Process, October 17, 2008).
} 
relation to the bureau's core mission and against equity and social justice principles. Adams asked PIAC members for advice on the best ways to get community input for the budget process. Adams told PIAC members that he wanted to disable the existing dynamic of "who can stack the town hall meeting" in which groups that show up in the largest numbers get their requests met. PIAC members offered Adams a wide range of ideas and suggestions (PIAC Meeting Notes, November 6, 2008). PIAC members also created a workgroup that tracked activities of the BACs over the next few years and submitted a set of recommended guidelines for BACs that was adopted by the City Council in September 2012. (See below for a more detailed discussion of these BAC guidelines.)

ONI Budgets: During Adams' term in office, Portland and the nation were going through the Great Recession. As city revenues diminished, Adams' was forced to require city bureaus to cut their budgets. Every year, the ONI BAC members (often 50 to 70 people) engaged in an extensive series of meetings and identified program cuts that would meet the targets set by the mayor and the City's Office of Management and Finance. The ONI BAC members then would develop a counter proposal that they called the "Right Budget for ONI" that added back some of the funding. ONI BAC members argued that cuts beyond this point would cause significant damage to the progress that had been made in recent years in strengthening Portland's community and neighborhood involvement system and the system's ability to involve a broader spectrum of the community. City Commissioner Fritz worked with ONI BAC members to develop and implement a strategy that mobilized members of ONI's neighborhood and community 
partner organizations to advocate together for the "Right Budget for ONI." Because of the relationships that representatives of different neighborhood and community organizations on the ONI BAC had developed over the years of working together, each year they were able to pack the City Council chambers budget meeting on the ONI budget with a striking diversity of community members all supporting the "Right Budget for ONI." Adams and Fritz worked together every year of Adam's term as mayor and successfully protected ONI, its programs, and community partner organizations from more severe cuts, and, in some cases, were able to use one-time money to back fill much of what otherwise would have been lost.

A key strength of the ONI BAC process was that all the affected partners worked together over many meetings to understand each other's programs, set joint priorities, and agree to and implement a unified budget advocacy strategy. Most of the system advances made during the Potter administration remained in place.

Portland Plan: One of Adams' major accomplishments during his term as mayor was the completion of the Portland Plan. The Portland Plan initially was started under Mayor Potter following the completion of visionPDX and was intended to develop a strategic plan for the City that would implement the vision established by visionPDX. Adams, initially distanced himself from visionPDX and its association with Potter and expanded the scope of the Portland Plan to include more "visioning-like" outreach to the community and the involvement of more than twenty government and institutional partners in the Portland area. The final Portland Plan, adopted by the City Council in April 2012, defined itself as "a strategic plan to make Portland prosperous, healthy, 
educated and equitable. It provides a structure for aligning budgets and projects across numerous public agencies, guiding policies with an eye toward the year 2034, and a fiveyear action plan to get things started" (Portland. The Portland Plan: Summary, April $20121)$.

The Portland Plan had begun under Tom Potter after the completion of visionPDX in February 2008. Community members familiar with the very inclusive process used in visionPDX and the broad reaching Community Connect recommendations expected that the Portland Plan would implement many of the best practices identified by these processes to involve the community in the development of the Portland Plan. Instead the Bureau of Planning followed its more traditional policy (described by Hovey and Irazabal) of attempting to do much of the early work without the community. BOP set up a number of advisory committees to begin to research and establish the frame work for the Portland Plan. The committees were largely made up of city employees with few or no community members. When community members found out and asked to see lists of who was serving on these committees and to get copies of notes from the meetings, senior managers at BOP refused to share the information. In response to community concerns, BOP proposed what many community members saw as a very superficial community involvement process separate from the work of these substantive committees. Community members objected and charged that state planning goals required BOP to develop a complete community involvement plan before work started on the project. A small, diverse group of neighborhood and community leaders met with Gil Kelley to ask him to open up the process. He expressed concern that opening up the process would 
prevent BOP from completing the Portland Plan in a timely way. Some community members took their complaints about the process to the Oregon State Land Use Board of Appeals (LUBA). ${ }^{117}$ LUBA did not take any substantive action in response to the complaints. Community members also met with Mayor Potter to complain about lack of public involvement in the Portland Plan and to ask him to intervene. ${ }^{118}$ Potter promised to talk with BOP director Gil Kelley, but no subsequent changes in the process were implemented. ONI staff contacted BOP to offer assistance in helping design a good community involvement process. BOP senior management declined ONI's offer of assistance.

One of the key structural changes Adams made early in his term as mayor was to consolidate the City's Bureau of Planning (BOP) and the Office of Sustainable Development (OSD). The new Bureau of Planning and Sustainability (BPS) became the lead agency that would support the Portland Plan process. The new agency only needed one executive director. Adams choose to retain Susan Anderson, former director of OSD, to serve as the director of BPS. Gil Kelley subsequently left Portland city government service. This change in leadership created an opportunity to open up community involvement in the Portland Plan.

Portland Plan "technical advisory groups" (TAGs) —made up almost entirely of city staff-continued to meet to frame up issues and alternatives to take out to the community. One of these TAGs was the "Equity, Community Engagement, and Quality of Life" TAG (which later became known simply as the "Equity TAG.") The Equity

\footnotetext{
${ }^{117}$ Southeast Uplift Neighborhood Coalition. Testimony before Oregon State Land Conservation and Development Commission. May 1, 2008.

${ }^{118}$ Leistner personal notes on meeting with Mayor Tom Potter, April 18, 2008.
} 
TAG, initially was co-lead by Laurel Butman, with the Office of Management and Finance and former co-chair of the PITF. A number of staff people from different city bureaus who were involved in public involvement, including ONI, served on the TAG. Butman tightly controlled the agendas and conversations on the Equity TAG in an effort to meet the requirements and timelines set by BPS management.

In April 2010, Butman left her job with the City of Portland and went to work for Clackamas County. Mayor Adams assigned City Commissioner Fritz responsibility for overseeing "equity" in the Portland Plan. ONI Director Alarcón de Morris took over for Butman as co-chair of the Equity TAG (Portland. Butman. Email to ECEQL TAG members, April 23, 2010).

Alarcón de Morris moved quickly to get permission from BPS senior management to invite community members to join the TAG, and she advocated for other TAGs to do the same. Representatives of many of ONI's DCL partner organizations, other communities of color organizations, Vision into Action committee members, and PSU faculty, joined the group. The Equity TAG also began meeting out in the community at the office of the City's Office of Human Relations. Equity TAG members worked together to develop language around what equity meant and why it was important. Equity TAG members argued that "equity" should be an overarching theme for the Portland Plan. They generally asserted that aspects of who you are that are out of your control should not be predictors of your ability to fulfill your potential in Portland. Alarcón de Morris, through her status as a "TAG Lead" and a bureau director was able to share the message of equity with the other TAG leads, BOP senior management, and Mayor 
Adams and his staff, as well as advocating for greater inclusiveness and diverse participation the Portland Plan development.

The rapid rise of "equity" as a major theme for the Portland Plan largely grew out of the release of a number of studies showing that, while white, middle class Portlanders had done very well during the 1990s and 2000s, conditions for many people in communities of color in Portland had gotten worse. The most important of these studies was the Urban League of Portland's July 2009 study “The State of Black Oregon.” Another influential report was released in 2010 by the Coalition of Communities of Color and Portland State University, titled "Communities of Color in Multnomah County: An Unsettling Profile" (Curry-Stevens et al 2010). The Coalition for a Livable Future (CLF) also had published its influential "Regional Equity Atlas" in 2007. ${ }^{119}$ These studies documented significant race-and-ethnicity-based disparities in Portland. These studies were a wake-up call for many white progressive Portlanders and city leaders and staff. Mayor Adams soon became a strong "equity" champion. "Equity" also became the overall framework for Portland Plan's "three integrated strategies" ("Thriving Educated Youth," "Economic Prosperity and Affordability," and "Healthy Connected City") and its twelve success measures (Portland. The Portland Plan: Summary, April 2012 1). The Portland Plan's Equity Framework stated that "The City and Portland Plan partners will use the framework as a guide when they implement actions in other sections

\footnotetext{
${ }^{119}$ The CLF Regional Equity Atlas (2007) used "maps, policy analysis, community based research, and other tools" to "assesses how well different populations across the four-county Portland-Vancouver metro region" could "access key resources necessary for meeting their basic needs and advancing their health and well-being" (Coalition for a Livable Future website, "Regional Equity Atlas," http://clfuture.org/equityatlas, downloaded November 3, 2013).
} 
[of the Portland Plan] and develop their work plans to make the goals of the Portland Plan reality" (Portland. Portland Plan: A Framework for Equity, April 2012 17).

The Portland Plan Equity Framework defined "equity" as follows:

"Equity is when everyone has access to the opportunities necessary to satisfy their essential needs, advance their well-being and achieve their full potential. We have a shared fate as individuals within a community and communities within society. All communities need the ability to shape their own present and future. Equity is both the means to healthy communities and an end that benefits us all" (Portland. Portland Plan: A Framework for Equity, April 2012 18).

The Equity Framework also described an equitable community as follows:

"We make the promise of opportunity real when:"

- "All Portlanders have access to a high-quality education, living wage jobs, safe neighborhoods, basic services, a healthy natural environment, efficient public transit, parks and greenspaces, decent housing and healthy good."

- "The benefits of growth and change are equitably shared across our communities. No one community is overly burdened by the region's growth."

- "All Portlanders and communities fully participate in and influence public decision-making." [emphasis added]

- "Portland is a place where your future is not limited by your race, gender, sexual orientation, disability, age, income, where you were born or where you live."

- "Underrepresented communities are engaged partners in policy decisions" (Portland. Portland Plan: A Framework for Equity, April 2012 18)..

The definition and endorsement of "equity" as a primary goal for city government and other important government entities and institutions in Portland would lend significant momentum to further efforts to get city leaders and staff to think differently about their roles and responsibilities in increasing equity in Portland. The emphasis on meaningful community involvement for all community members—but especially 
"underrepresented communities_-further emphasized the need to preserve and build on the important reforms and expansion Portland's community and neighborhood involvement system implemented under Mayor Potter, and further embedded community involvement values in city government culture and practices.

Charter Commission 2011: In 2007, Portlander voters had approved Ballot Measure 26-98 - the measure proposed by the 2005-07 Charter Review Commission. Measure 26-98 required the Portland City Council regularly to establish commissions of community representatives to review the Portland City Charter. Mayor Potter and others saw mandatory regular community review of the city charter as an important strategy for ensuring greater community voice in shaping city government policies and structures. In spring 2010, ONI staff alerted the mayor's office that the deadline was approaching for establishing the first commission required by Measure 26-98.

Commissioner Fritz asked Mayor Adams if she could be in charge of setting up the charter review process. Fritz proposed a two-part process, which included setting up an initial charter review commission with a very limited scope and timeframe (to meet the requirement of Measure 26-98), followed, sometime later, by another charter review commission that would engage in a full review of the city charter. Fritz was concerned that 2010-11 was not a good time for a full charter review. The Portland Plan, which was using up a lot of city staff and resources at the time, still had a year to go until it would be completed. Fritz thought that this strategic planning process might generate ideas for charter changes that should not have to wait another ten years until another charter 
commission was created. ${ }^{120}$ Fritz also was concerned that, because of the economic recession and the tight city budget, the city did not have the resources to adequately fund and support a full charter review and community outreach process.

Fritz proposed that the first charter review commission meet for only six months and focus narrowly on identifying housekeeping changes in the city charter and designing a process and identifying possible issues for the second charter review commission. Fritz also sought to ensure that the people on the initial charter review commission would have the skills and experience to get up to speed quickly. She decided to recruit many of the commission members from the pool of individuals who already were serving on City board and commissions rather than the community at large.

City Council Resolution: In December 2010, the Portland City Council adopted a resolution that created the 2011 Charter Review Commission (Portland. City Council. Resolution 36836, December 15, 2010). The City Council recognized that it could not limit what the commission members chose to work on, but asked the group to complete three tasks:

- Identify "housekeeping amendments" to remove" offensive and outdated language from the Charter, while not making changes with greater policy implications" that would be placed on the ballot in May or November 2011;

- Recommend a process for setting up a second charter commission "soon after conclusion of the Portland plan" to "discuss and propose more extensive

\footnotetext{
${ }^{120}$ The actual language of Measure 26-98 allowed the City Council to establish a charter review commission at any time. The ballot measure language just required the City Council to convene a charter review commission "From time to time, but no less frequently than every 10 years...." (Portland. City Charter, Section 13-301. Charter Commission).
} 
policy changes based on wide public outreach and drawing from the conclusion reached in the Portland Plan...;"

- Prepare a list of policy issues for review by the next charter review commission.

The City Council declared that the charter review commission should convene in January 2011, and committed to funding the group for six months. ${ }^{121}$

The City Council members at the time also formally committed to "appointing a second Charter Commission soon after the Portland Plan is adopted.” This charter commission would be "encouraged and funded to address broad policy amendments to the Charter" and would be "informed by an extensive citywide public process and discussion." 122

Charter Review Commission Process: The charter review commission met monthly from January 2011 to February 2012.

At the Charter Review Commission's first meeting, former Mayor Potter told the group that, when he was mayor, he saw that no provision existed for periodic review of the City Charter. He said he felt that review of the charter "was an excellent forum for community engagement." He noted that the charter review commission was required to represented the "diversity of the city," and that the City Council was required to forward to the ballot any charter changes that at least fifteen commission members supported.

\footnotetext{
${ }^{121}$ The ordinance states that "the citywide outreach and input process leading to the 2007 Charter changes cost $\$ 600,000$ " and makes the case that the poor economy prevented city government from investing similar resources to ensure adequate funding and capacity for the extensive community involvement required for a meaningful and full charter review process.

${ }^{122}$ As of October 2013, the City Council has taken no action to prepare for or initiate a second charter review commission.
} 
Potter told the groups that "The Charter Commission is an opportunity for citizens to get their hands directly on the levers of power. Everything we do is impacted by the City Charter." Potter encouraged commission members to listen to their neighborhoods "to learn about issues facing the daily lives of Portland citizens." Robert Ball, who served on the 2005-07 Charter Review Commission, told the group that this earlier charter review commission was restricted to looking at only four topics. He said the 2005-07 Charter Review commission members saw many issues they would have like to consider. Ball said that was why they ensured that future charter review commissions would have the authority to look at any issue they chose to. Despite the City Council's request for the current charter review commission to limit its focus, Ball encouraged the commission members to "look at all aspects of the Charter, and to use their power to bring big ideas to the voters" (Portland. Charter Review Commission. Meeting notes. January 24, 2011).

Initially the commission was supported by a staff person assigned by Fritz. After the commission's six-month term ended, commission members told the city council they had not completed their work and asked for more time. Mayor Adams shifted responsibility for the commission to City Commissioner Dan Saltzman. Saltzman assigned a new staff member to support the commission. City Council also appointed new commission members to replace members who left because they had not planned on participating for more than six months.

Commission members made efforts to provide time for public comment at each of their meetings. They also did some community outreach at BPS Portland Plan open houses and held some community forums. Commission members also formed committees 
to explore charter amendments in areas identified through the outreach process, including a human rights commission, instant run-off voting, creation of an independent utility commission, and police accountability (Portland. Charter Commission. City of Portland Charter Commission Report [no date]).

The charter review commission members referred nine charter amendments to the City Council for referral to the May 2012 ballot. Each amendment had been approved by 15 or more commission members, which required the City Council to refer the proposed amendments to the ballot with any changes. Most of the measures corrected or removed outdated or offensive language. One of the measures established a two-year term for future charter review commission members. Portland voters approved all nine measures. $^{123}$

Findings/Recommendations: The commission's final report documented the group's process, listed topics for consideration by the next charter review commission, shares some of the commission members' frustrations with the process, and offered suggestions for how to improve the process for the next charter review commission. Some of the challenges with the process identified by commission members included:

- The significant time and energy needed to orient new commission members who replaced members who left in June 2011.

- The mid-stream change in staff supporting the commission and the second staff person's lack of knowledge of city government and lack of skill in supporting a formal group process.

\footnotetext{
${ }^{123}$ The nine measures passed with support ranging from 77 percent to 90 percent (Multnomah County Election Archives, May 15, 2012 Primary Election-Election Results).
} 
- The inability of the commission members to access and update the commission's website when one of the original commission members left and took the password for the site with him.

- Insufficient time and funding "for the in-depth study that proposals recommended and requested by the public deserved."

- Lack of support from city bureaus to help the commission carry out its work and investigations.

- Discovery toward the end of the process that "notices and announcements of meetings, public forums, and public hearings had not been forwarded through the [ONI] email list as thought, resulting in the loss of an important means of dissemination of information.

Recommendations: The commission members recommended changes in the process for the next charter review commission. These included:

- Appointment of charter members through an open and inclusive process (rather than the process used to select the members of this commission);

- "Appointment of commission members for a minimum of 2-year terms" (which Portland voters mandated through their passage of Measure 26-133 in May 2012);

- A clear understanding by, and recognition of, the role of the charter commission and commission members by City Council members;

- Early appointment of commission members to allow "sufficient time to study" the city charter and to prepare for the first commission meeting; 
- "Adequate funding to allow for in-depth study of issues...;"

- Staff support for the commission by "personnel with skills and knowledge necessary to keep minutes for all commission and committee meetings, public forums, and hearings" and to "manage the website site;"

- Support and cooperation from city bureaus and departments and "publication of commission functions on city calendars and email distribution lists;"

- Effective outreach to the community, including "publicizing meetings, hearings, and the work of the commission;"

- Scheduling of meeting dates so "all appointees are able to attend" at least half of the meetings;

- "Recognition of the importance of the City Charter to the function and future of the City of Portland and therefore the importance of the work of those who review and change it" (some commission members felt the city council did not respect their role or their work)

The experience of the 2011 Charter Review Commission illustrated some of the strengths and weaknesses of the charter review process established by Portland voters in 2007. The requirement that the City Council create a community charter review commission at least every ten years ensured that some level of community review of the city charter would take place periodically. Other strengths included the requirement that the group represent the diversity of the city, that the group can choose what it will work on, and the power the group has to send proposed amendments to the ballot without City Council being able to change the language. As Mayor Potter told the group, giving the 
community the opportunity to review and amend the City of Portland's most fundamental governing document, put a lot of power in the hands of community members.

Some of the weaknesses of the process included the reliance of charter review commissions on the city council for funding and staffing. Without strong staffing and support, future commissions will have difficulty functioning effectively and also adequately reaching out to and involving the community in their process. Effective community outreach is needed to help community members understand what the city charter is and how it works and how the city charter relates to and can affect issues their care about. Commission members also need to have enough time to do their work. Commission members solved this problem to some extent by getting voters to approve a City Charter amendment that established minimum two-year terms for future charter review commission members.

Comprehensive Plan-Community Involvement PEG: One of the high priority recommendations of the PITF (2003-2004) was to update and strengthen the community involvement goals and policies in Portland's Comprehensive Plan. The Comprehensive Plan (unlike the broader Portland Plan) establishes legally binding policies that apply to a large portion of the land use planning and capital improvement project activities of city government. The opportunity to implement this PITF recommendation arose when BPS completed the Portland Plan in early 2012 and began to work on updating Portland's Comprehensive Plan, which included developing new and revised goals and policies for the Comprehensive Plan and updating the Comprehensive Plan map, which sets the future direction for land use zoning across the city. 
BPS staff sought to improve involvement of the community in the development of the Comprehensive Plan and to involve the community earlier and more fully in the process than it had with the Portland Plan. BPS staff consulted with ONI staff on the process design. BPS created a number of "policy expert groups" (PEGs) to work on different parts of the plan. BPS included a diversity of community members, along with city staff and other stakeholders, on the PEGs from the outset of the process. They also hired independent, professional facilitators to facilitate the PEG meetings. Equity was a major theme and focus throughout the work of the PEGs. BPS formed the PEGS in May 2012. The PEGs began meeting in June 2012 and ended their work in June 2013. BPS staff prepared "summary memos" that reported on the work of each PEG and the PEGs recommendation new or updated goal and policy language (Portland. Bureau of Planning and Sustainability. Comprehensive Plan Update: Policy Expert Groups). <http://www.portlandoregon.gov/bps/58187, downloaded October 30, 2013). ${ }^{124}$

The Community Involvement PEG (CI PEG) was assigned to update the Comprehensive Plan's community involvement goal and policies. The CI PEG's work is described below as part of the description of the work of the Public Involvement Advisory Council.

\footnotetext{
${ }^{124}$ BPS designed the PEG groups to take a broader approach to the Comprehensive Plan update than the traditional land use planning focus on specific service areas such as transportation, land use, sewers, water, etc. The PEG groups included: Community Involvement, Economic Development, Education and Youth Success, Equity Work Group, Industrial Land and Watershed Health Working Group, Infrastructure Equity, Neighborhood Centers, networks, Residential Development and Compatibility, and Watershed Health and Environment (Portland. Bureau of Planning and Sustainability. Comprehensive Plan Update: Policy Expert Groups).
} 
$\underline{\text { Public Involvement Advisory Council (PIAC) (2008 to present) }}$

Mayor Tom Potter implemented one of the primary PITF recommendations when he supported the City Council's creation of the Public Involvement Advisory Council (PIAC) in February 2008. The City Council charged the PIAC to serve "as a standing body charged with developing recommendations to strengthen and institutionalize the City's commitment to public involvement through adopted principles, policies, and guidelines that assist City bureaus in creating consistent expectations and processes for public involvement activities..." The City Council also directed PIAC to "address recommendations raised by BIP 9, Community Connect, and draft recommendations of the Public Involvement Task Force” (Portland. City Council. Resolution 3658227 February 2008).

The PIAC was to be made up of half city staff and half community members. The "Preferred Qualifications for Membership" on the PIAC including: a commitment to the PIAC goals, representation from a "range of perspectives and experiences," diversity "in ethnic, age, gender, geographic and other demographics," experience "in public involvement or community outreach effort" either through work or leadership in a "neighborhood or community organization," and the ability to attend monthly meetings in the evening (Portland. City Council. Resolution 36582 Exhibit A).

ONI hired Afifa Ahmed-Shafi in 2007 to help create and coordinate the PIAC (and to reconvene the City public involvement staff peer support group — the City Public Involvement Network (CPIN)). Ahmed-Shafi brought to her work a strong commitment to social justice, her strong skills in process development and coordination, and her great 
commitment and sensitivity to ensuring that the PIAC members represented a wide diversity of communities and experiences, that they felt respected and listened to, and that PIAC meetings and processes were open, welcoming, and productive.

Once the City Council had formally established the PIAC, Ahmed-Shafi recruited a very diverse group of 34 individuals to serve on the body. The PIAC members included some individuals who had served on the PITF and BIP 9, representatives of ONI's DCL Program partner organizations, representatives from fourteen city bureaus, and community members representing a variety of communities, backgrounds, and perspectives. Ahmed-Shafi, over time, ensured that, unlike many other city boards and commissions, PIAC maintained strong and ongoing participation from its representatives from under-represented communities.

PIAC members first convened and began their work in fall 2008. Early on, Ahmed-Shafi led the group in an exercise in which group members reviewed, divided up and sorted all the recommendations from previous reviews of Portland's city government public involvement. Group members organized the recommendations on a "sticky wall" into three groupings. PIAC members created workgroups to further prioritize and work on these recommendations in each area—the workgroups included "Policy," "Process," and "Community." PIAC members have created a number of products since they began meeting in 2008. PIAC's major products are described below.

Public Involvement Principles (2010): One of the first tasks PIAC members worked on was to update the City's 1996 public involvement principles. PIAC members developed the updated principles after reviewing the 1996 principles, the principles 
developed by the PITF, and a number of other sets of public involvement principles developed by different organizations (e.g. National Coalition for Dialogue and Deliberation (NCDD), the International Association of Public Participation (IAP2), and others). PIAC members intended that the updated principles would clarify the fundamental elements of good public involvement and provide a strong foundation for their subsequent work. In August 2010, PIAC members brought their updated set of public involvement principles to the City Council for approval.

The updated principles included a preamble that established the value of a governance partnership between city government and the community and identified effective public involvement as "essential to achieve and sustain this partnership." The preamble made the case that "effective public involvement" ensures "better City decisions," leverages community energy and resources, engages the broad diversity of the community, increases community understanding and support for "public policies and programs," and increases "the legitimacy and accountability of government actions." The preamble described the principles "as a road map to guide government officials and staff in establishing consistent, effective and high quality public involvement across Portland's city government," and stated that the principles were intended to clarify what community members can expect from city government, "while retaining flexibility in the way individual city bureaus carry out their work."

The principles presented general values and expectations for public involvement under seven headings: "Partnership," "Early Involvement," "Building Relationships and Community Capacity," "Inclusiveness and Equity," “Good Quality Process Design and 
Implementation," "Transparency," and "Accountability." PIAC members recognized that many city staff people would be more likely to implement the principles if they had a better sense of what the principles looked like in operation and some of the positive outcomes of following the principles. To this end, PIAC members included with the principles a chart that identifies "indicators" for each principle that describes what would be happening if the principle were being followed and "outcomes" from following each principle.

The City Council adopted the new City of Portland Public Involvement Principles and the chart by resolution in August 2010 (Portland. City Council. Resolution 368074 August 2010). The City Council resolution formally replaced the City’s 1996 Public Involvement Principles with the new updated principles. (The full text of the Public Involvement Principles are inserted below.)

The City Council resolution also assigned to PIAC some follow up tasks. The City Council directed PIAC members to use the updated principles to develop a "a 'public involvement impact statement' modeled on the 'financial impact statement"' that bureaus were required to prepare and submit with any ordinances or resolutions they took to City Council. The City Council directed city bureaus to "complete and include this 'public involvement impact statement' with ordinances and resolutions proposed for Council action." The City Council also directed PIAC to "develop a "public involvement baseline assessment' questionnaire." The City Council required city bureaus to complete 
the questionnaire and return it to PIAC and required PIAC to review the information and report back to the City Council. ${ }^{125}$

City of Portland Public Involvement Principles Adopted by the City of Portland, Oregon on August 4, 2010

\section{Preamble}

Portland City government works best when community members and government work as partners. Effective public involvement is essential to achieve and sustain this partnership and the civic health of our city. This:

- Ensures better City decisions that more effectively respond to the needs and priorities of the community.

- Engages community members and community resources as part of the solution.

- Engages the broader diversity of the community-especially people who have not been engaged in the past.

- Increases public understanding of and support for public policies and programs.

- Increases the legitimacy and accountability of government actions.

The following principles represent a road map to guide government officials and staff in establishing consistent, effective and high quality public involvement across Portland's City government. These principles are intended to set out what the public can expect from city government, while retaining flexibility in the way individual city bureaus carry out their work.

\section{City of Portland Public Involvement Principles}

- Partnership: Community members have a right to be involved in decisions that affect them. Participants can influence decision - making and receive feedback on how their input was used. The public has the opportunity to recommend projects and issues for government consideration.

- Early Involvement: Public involvement is an early and integral part of issue and opportunity identification, concept development, design, and implementation of city policies, programs, and projects.

\footnotetext{
${ }^{125}$ Ahmed-Shafi and other PIAC members had prepared draft language for the resolution. They included language directing PIAC to create the public involvement impact form and baseline assessment in the draft resolution to give PIAC clear authority and direction from City Council to move forward to implement these two next steps and to ensure that city bureaus would be required to use the former and fill out and return the later to PIAC. City Council members reviewed and agreed to include this language in the final version of the resolution.
} 
- Building Relationships and Community Capacity: Public involvement processes invest in and develop long - term, collaborative working relationships and learning opportunities with community partners and stakeholders.

- Inclusiveness and Equity: Public dialogue and decision - making processes identify, reach out to, and encourage participation of the community in its full diversity. Processes respect a range of values and interests and the knowledge of those involved. Historically excluded individuals and groups are included authentically in processes, activities, and decision and policy making. Impacts, including costs and benefits, are identified and distributed fairly.

- Good Quality Process Design and Implementation: Public involvement processes and techniques are well - designed to appropriately fit the scope, character, and impact of a policy or project. Processes adapt to changing needs and issues as they move forward.

- Transparency: Public decision - making processes are accessible, open, honest, and understandable. Members of the public receive the information they need, and with enough lead time, to participate effectively.

- Accountability: City leaders and staff are accountable for ensuring meaningful public involvement in the work of city government.

Financial Impact and Public Involvement Statement (FIPIS): City staff, for many years, had been required to submit a "financial impact statement" as part of the packet of information that accompanied any ordinances or resolutions they took to the City Council for action. The PITF had recommended that city staff be required to fill out a similar form that would describe any public involvement done related to the item of the ordinance and any effect the public involvement had had on the subject of the ordinance. PITF members clarified that the purpose of the form "would be to encourage city staff to think about...public involvement needs" and to "provide the public and elected officials with evidence of the extent to which the public was involved" (Portland. Office of Neighborhood Involvement. Public Involvement Task Force Report. 2006 36).

PIAC members, supported by Ahmed-Shafi, carefully followed the new public involvement principles and modeled best practices of public involvement in the way they 
involved city staff — the affected "public" in this case — in the design and roll out of the new form. The 14 city bureau representatives on PIAC served as important early reviewers and offered very valuable feedback on the product and on PIAC's outreach to city bureaus, bureau directors, and city commissioners and their staffs. Some City Commissioners and city commissioner staff provided valuable input and said suggested additional questions for the form - they saw the proposed form as a valuable source of information that could give them a heads up on any potential conflicts with the community.

Early contacts with city staff had revealed that many city staff resisted the idea of having to fill out "another form." PIAC members listened and instead opted to add public involvement questions to the existing "financial impact form." Bureau staff already were used to filling out this form. PIAC members worked with the OMF financial analysts who used the existing form to develop a new, combined form. The OMF analysts saw this as an opportunity to update their part of the form. PIAC members and OMF staff tested out the form with a number of volunteer city staff to make sure the final version would be as understandable and easy for staff to fill out as possible.

PIAC members and OMF staff also worked together to provide extensive support to help city staff understand how to fill out the form. Some city staff members of PIAC volunteered to fill out the form for some of their projects to help create a set of real world examples other city staff could look to for guidance. Ahmed -Shafi and PIAC members also developed line-by-line guidance that walked city staff through the form. All this information was made available on the PIAC website. Ahmed-Shafi and other PIAC 
members also presented a number of trainings for city staff on how to fill out the form. About 300 city staff participated in the trainings. Many of these city staff were individuals who regularly prepared ordinances for their bureaus but had had little experience with public involvement processes. (This expanded involvement met one of the goals of the project, which was to broaden the awareness of public involvement throughout city government.

The final version, of what became known as the Financial Impact and Public Involvement Statement (FIPIS), asked some fairly basic public involvement questions. One new addition to the old financial impact form was a question about which geographic area or areas of the city the item affected or whether the item just affected internal city government services. The public involvement questions asked whether public involvement was included in the development of the item going before City Council, and if not, why not. If public involvement was done, the form asked what impacts the item was expected to have in the community, which community groups had been involved and how, what impact community input had on the development of the item going before city council, who designed and implemented the community involvement, and who to contact for more information about the public involvement done for the item. The form also asked whether any future community involvement was anticipated for the item and "why or why not." (The full set of FIPIS community involvement questions is provided in Figure 6 below.) The form also required bureau directors to sign off on the form to raise their awareness of community involvement and to ensure that they were aware of the bureau's answers to the questions. 
The FIPIS went into effect on July 1, 2011. The City Clerk had updated the City's instruction manual for submitting ordinances and resolutions to City Council with information about the FIPIS and a link to the form. Within a very short period of time, city staff began to fill out, not only the familiar financial impact questions, but also the public involvement questions.

Over the course of the year (July 1, 2011 to June 30, 2012) city staff submitted over a thousand FIPIS forms with items that went before the City Council. The forms provided interesting insights into scope of the work of city government and the different types of items that went before city council. The FIPIS responses also showed significant variation in responses across bureaus. Some answers were very brief, while other provided a lot of detail. Some bureaus assumed that no public involvement was needed for actions, for which other bureaus had chosen to involve the public.

Some of City Commissioners and their staff reviewed the FIPIS forms and asked city staff about their public involvement at public hearings. Some community members reviewed that forms, and, in some cases, challenged the city bureau's characterization of how their group had been involved and/or their level of support for the project.

In fall 2013, PIAC is considering updating the FIPIS questions and adding some “equity-focused" questions. At the same time, the city's Equity Office is considering seeking City Council approval to require bureaus to fill out a separate form with more indepth equity questions. The Title VI Civil Rights Program coordinator also is interested in adding Title VI-related questions to the FIPIS. 
The FIPIS form met its basic goals of raising awareness about public involvement across city government, generating a data stream of information about city bureau public involvement efforts, and providing increased transparency for the City's work. PIAC members found it challenging to enter and analyze all the data from the FIPIS forms. The full year's worth of data was finally entered into a spreadsheet with the help of a number of ONI interns and students from a Portland State University class. This highlighted for PIAC members that, as they implemented additional projects that would generate followup work assignments, PIAC would need additional capacity (e.g. staff or interns) to fulfill all the requirements of these projects.

\section{Figure 6: City of Portland Financial Impact and Public Involvement Statement (FIPIS)_Public Involvement Questions}

\section{PUBLIC INVOLVEMENT}

8) Was public involvement included in the development of this Council item (e.g. ordinance, resolution, or report)? Please check the appropriate box below:

YES: Please proceed to Question \#9.

NO: Please, explain why below; and proceed to Question \#10.

9) If "YES," please answer the following questions:

a) What impacts are anticipated in the community from this proposed Council item?

b) Which community and business groups, under-represented groups, organizations, external government entities, and other interested parties were involved in this effort, and when and how were they involved?

c) How did public involvement shape the outcome of this Council item?

d) Who designed and implemented the public involvement related to this Council item?

e) Primary contact for more information on this public involvement process (name, title, phone, email):

10) Is any future public involvement anticipated or necessary for this Council item? Please describe why or why not.

BUREAU DIRECTOR (Typed name and signature) 
Bureau Public Involvement Baseline Assessment: The next PIAC project was to develop a "baseline assessment" that would gather information on the public involvement policies and capacity of all the city bureaus. ${ }^{126}$ During the winter and spring of 2012, PIAC members again worked closely with city bureau representatives on PIAC to develop and field test the baseline assessment questionnaire. PIAC members also reached out to city bureau directors and city commissioners and their staff to keep them informed on the project and to ensure their buy-in and support. PIAC did not need to implement the same level of broad outreach with city staff as had been done for the FIPIS project, because only a few individuals in each bureau would be filling out the questionnaire.

PIAC members again tried to make the questionnaire as understandable and simple as possible to fill out. Most of the questions offered city staff a choice of possible answers to check off in addition to inviting their comments. The questionnaire was offered as a "fillable PDF" so staff could fill out and submit the completed questionnaire on line. The basic instructions that accompanied the questionnaire emphasized that PIAC was looking for "general information rather than a lot of detail." The instructions also stressed that “THERE ARE NO 'RIGHT' OR 'WRONG' ANSWERS” and that PIAC was simply gathering basic information about how different bureaus "manage and

\footnotetext{
${ }^{126}$ PIAC members patterned this "baseline assessment" on a similar survey of city bureaus that had been done by the City's internal Customer Service Advisory Committee. The CSAC had chosen to "simply gather information" on customer service policies and practices across city government. For city bureau leaders and staff this was less threatening than having the CSAC identify and target the city bureaus with the worst customer service. By gathering and presenting their information to city bureaus directors and the city council over a few years, they got to see what other bureaus were doing and by the end of the three years, most city bureaus were following at least basic best practices. PIAC members decided to follow this same strategy, which was in keeping with their "We're not the public involvement police; we're here to help you be more effective" approach.
} 
conduct their public involvement" to help PIAC identify "information, training and support that PIAC can provide to help bureaus involve the public more successfully." This was in response to fears expressed by some bureau directors and staff that PIAC and the City Council would be judging their bureaus based on their answers (Portland. Memorandum from Mayor Adams and City Commissioner to Bureau Directors \& Senior Bureau Managers. Announcing Implementation of the 'Bureau Public Involvement Baseline Assessment' Survey. June 25, 2012).

Mayor Adams and the City Commissioners announced the implementation of the baseline assessment in a memo to bureau directors and senior bureau managers in June 2012. Bureaus were required to fill out and return the questionnaire to PIAC by the end of July 2012.

The Baseline Assessment questionnaire included the following nineteen questions:

\section{Bureau Policies:}

1. Does your bureau have a written, overall public involvement policy/strategy/manual?

2. How does your bureau identify when it is appropriate to do public involvement (e.g. for a specific project) and, if so, the appropriate level of public involvement? (check all that apply);

3. Does your bureau create written public involvement plans as part of the development of its projects, programs, and policies?

\section{Staffing:}


4. Does your bureau have a designated lead staff person or manager who oversees public involvement for your bureau?

5. How does your bureau conduct its public involvement efforts? (check all that apply)

6. Does your bureau have FTE positions dedicated specifically to "public involvement/community outreach" or "public information" services? (check all that apply)

7. Does the formal job description for your bureau director include language that refers to the need to ensure the public is appropriately involved in the work of the bureau?

Training/Professional Development:

8. What public involvement training and/or mentoring opportunities does your bureau offer to regular bureau staff (vs. trained public involvement staff) who are asked to involve the public in their work or projects? (check all that apply)

\section{Evaluation:}

9. How does your bureau evaluate your public involvement processes? (check all that apply)

10. If your bureau evaluates its public involvement processes, how does your bureau use the information? (check all that apply)

Outreach/Communication:

11. What information does your bureau's website offer to help community members learn about your programs and projects? (check all that apply) 
12. Which avenues does your bureau offer to the public to comment on your bureau's activities and projects? (check all that apply)

13. What special strategies does your bureau use to involve historically underrepresented groups in the community? (e.g. communities of color, immigrants and refugees, people with disabilities, youth, renters, people who are homeless, elders, LGBTQ, and faith-based communities) (check all that apply)

\section{Advisory Committees:}

14. Does your bureau have one central committee (that includes volunteers, community members, and stakeholders) that provides ongoing review and input to the bureau and helps set priorities for your bureau?

15. What other types of advisory committees--with community member participation—does your bureau use?

16. How does your bureau recruit people to serve on its advisory committees? (check all that apply)

\section{Overall Assessment:}

17. What are three things your bureau feels it is doing well in involving the public?

18. What are three things your bureau finds most challenging in involving the public?

19. What information, technical assistance, training or other resources would help staff in your bureau involve the public more effectively? 
As of Fall 2013, PIAC committee members have compiled the bureau responses to the survey and are preparing a report on the baseline assessment for the City Council and discussing next steps to pursue. One next step being considering is to support an effort to get every city bureau to develop and adopt a bureau-wide community involvement policy and strategy.

Budget Advisory Committee (BAC) Guidelines: Mayor Sam Adams, as soon as he took office, required all city bureaus to create Budget Advisory Committees (BACs) with community members to advise them on the development of their bureau budget proposals. In September 2009, the PIAC Process Workgroup members held a focus group with ONI BAC members to get input on what improvements they would like to see in community involvement in the city budget process. The ONI BAC members indicated that their highest priority was to improve the quality and consistency of community involvement early in the process when individual bureaus were developing their own budget proposals (Portland. Public Involvement Advisory Council. Guidelines for public involvement in City of Portland Bureau Budget Advisory Committees (BACs), September 26, 2012 9).

PIAC Process Workgroup members “conducted an in-depth evaluation and review of City bureaus' BAC" processes. Workgroup members observed BAC meetings over a few years. They interviewed bureau "staff and community members and evaluated budget materials...to create guidelines that would improve future processes." PIAC members met with "each of the City Commissioners and/or staff representatives...to review and get their feedback." In June 2012, Process Workgroup members hosted a 
meeting with " 21 BAC coordinators and City Council staff representing 16 City bureaus" to review the workgroup's proposals and get their feedback (10).

In September 2012, the City Council formally adopted the PIAC "Guidelines for public involvement in City of Portland Bureau Budget Advisory Committees" and directed the City's Office of Management and Finance to "include these seven guidelines as part of its directions to city bureaus for their annual budget process. The City Council also adopted PIAC recommendations to: direct PIAC to "develop a best practices checklist" for BAC staff coordinators, direct PIAC to work with OMF and ONI and bureau BAC staff coordinators to convene community stakeholders after the completion of the City's budget process to debrief the public involvement in the process; and direct PIAC to work with ONI to advocate for funding for "diverse community organizations to deliver culturally specific engagement of the City's historically underrepresented populations in the City's budget process" (Portland. City Council. Resolution 3696026 September 2012).

The BAC guidelines developed by PIAC and adopted by the City Council covered seven topics described below.

Community and labor representation: This guideline required bureau BACs to include a "minimum of $50 \%$ community representation (non-City employees)" that would represent a "broad spectrum reflective of the community served...." This guideline allowed a city commissioner in charge of bureau to authorize exemptions to the BAC membership requirement if necessary and allowed bureaus "four years from Council adoption to build the capacity to meet these expectations" (3). 
Creation of bureau BAC budget process websites: This guideline required each bureau to make certain information available on its bureau budget website, including: "Information about BAC meetings, including dates, times, and locations;" "Meeting notices, agendas, and minutes" that are posted in a "timely manner;" "significant materials provided to BAC members in advance of meetings or within a reasonable period of time afterwards;" the list of BAC members, contact information for the BAC coordinator; information about how to become a BAC member, expectations for BACs members, and opportunities for public comment; links to significant budget documents, including the bureau's previous year budget and current requested budget, the Mayor's proposed budget, presentations to City Council, and any minority reports (3-4).

Maintenance of contact information list: This guideline required bureaus to "maintain a contact list where community members may sign-up to receive budget related information...."(4).

ADA and Limited English Proficiency accessibility: This guideline required bureaus to ensure adequate funding to comply with requirements to "reasonably modify policies and procedures and provide auxiliary aids/services" to enable people with disabilities to participate and to provide "reasonable interpretation and translation language services" to fully comply with "U.S. Title II of the Americans with Disabilities Act and Title VI of the Civil Rights Act" (4).

Handouts and presentation materials available to public: This guideline emphasized that all BAC meetings are public meetings. The guideline asserted that members of the public have the right to view documents provided to BAC members at 
the BAC meetings, and bureaus should have copies of "handouts and presentation materials" available for members of the public attending the meetings (4).

Public comment allowed at all meetings: This guideline required bureaus to provide an opportunity for public comment at every BAC meeting (5).

Minority budget reports: This guideline required bureaus to allow "two or more BAC members" to "write a minority report," which the bureau must include with the bureau's budget proposal (5).

The PIAC formal BAC guidelines document also described in more detail: the best practices checklist that PIAC was directed to develop; the recommendation that a minimum of $\$ 25,000$ be provided in future budget processes to fund ONI's DCL Program partner organizations and other ONI underrepresented community partner organizations to design and implement "culturally-specific strategies for engaging their constituencies in the City's budget development process;" and the recommendation to convene a community stakeholder meeting to provide advice to PIAC, OMF, ONI, and BAC bureau staff liaisons on "improving equitable engagement of different communities in the budget process, the development of tools to evaluate the effectiveness of community involvement in the "citywide budget process and individual bureau BACs, and improving "equitable community engagement" in the budget processes of individual city bureaus (5$6)$.

As of fall 2013, PIAC continues to work on implementing these final three recommendations. 
Comprehensive Plan-Community Involvement PEG: One of the PITF's high priority recommendations was to update the Portland Comprehensive Plan goals and policies on community involvement. The opportunity to implement this recommendation arose when BPS began to update the City's comprehensive plan in 2012 as the next step after the completion of visionPDX and the Portland Plan. ${ }^{127}$

BPS staff took a different approach to involving the community in the Comp Plan update than they had with the Portland Plan. BPS staff consulted with ONI staff on the process design. They went on to create a number of "policy experts groups" (PEGs) to work on different policy areas for the plan. The PEGs included, not only City staff, but also significant numbers of community members and stakeholders. BPS hired professional facilitators to facilitate the PEG meetings in the hope that this would improve the openness and functioning of these groups.

Some BPS staff acted as strong advocates for better process within the agency. Marty Stockton, who BPS originally hired to support public involvement in the Portland plan and who served on the Equity TAG, went on to support community involvement in the Comp Plan update. Stockton also was a PIAC member. Stockton and her supervisor Deborah Stein, who managed the BPS District Liaison Planning Program, acted as strong voices within BPS for opening up the process and applying lessons learned from the mistakes and successes of the Portland Plan. Senior management at BPS also appeared to be more open to community involvement after their experiences during the Portland Plan. The Portland Plan's major focus on equity helped raise awareness of disparities and the

\footnotetext{
${ }^{127}$ The Comprehensive Plan update, which began in 2012, was the first time Portland has engaged in a full review and revision of the city's comprehensive plan since the plan was first adopted in 1980.
} 
need to do a better job of involving historically under-represented communities in decision making. Mayor Adams also had required the BPS director and senior managers to participate in intensive equity trainings during the Portland Plan process.

One of the PEGs was dedicated to updating the "citizen participation" goal in the Portland Comprehensive Plan. This group — the Community Involvement PEG (CI PEG)_began meeting in June 2012. The majority of the CI PEG members were city staff and community members who also served on the PIAC Policy Workgroup. Stockton and an ONI staff person co-lead the group. (Both were PIAC members.) Stockton also recruited additional city staff, community members and a staff person with the Multnomah County Office of Citizen Involvement to serve on the group. The PIAC Policy Workgroup took on the Comp Plan update process as its primary function and changed its name to the "Comp Plan Workgroup." The members of this workgroup met in between the CI PEG meetings and served as a working committee to support the activities of the CI PEG.

The CI PEG members met monthly from June 2012 to June 2013. They reviewed many different documents that described community involvement principles and best practices. They developed a community survey that invited community members to share what they thought was working and not working about community involvement in land use planning and development review in Portland (Portland. Bureau of Planning and Sustainability. Community Involvement Policy Expert Group. Survey of Community Involvement in Portland's Planning and Development [fall 2012]).The CI PEG members also participated in community workshops hosted by BPS. 
The responses to the CI PEG survey revealed many themes and recommendations similar to those community members had offered over the previous 40 years. The most common themes called for "authentic" or "genuine" involvement that was "not just for show" and had an impact; accessible processes through the provision of child care, transportation, and convenient meeting times and locations; improved quality, consistency and coordination of community involvement across city government; improved city staff capacity and skills to design and implement community involvement processes and work effectively with community members and organizations; improved understanding, valuing of, and commitment to quality community involvement by city elected leaders, broader involvement of the range of communities and perspectives in Portland; more effective and varied outreach methods that are culturally appropriate and relevant to the communities being engaged and more fun; involvement of all affected people; the building of trust, relationships, and partnerships between city staff and community groups; and better use of Internet and web-based tools.

Survey responses also called for improved community involvement process design, which included: ensuring that processes are design to fit the particular need; adequate time for people to get up to speed and participate in a meaningful way; and advisory committees that have broad representation, are well supported, and have an impact. Respondents also called for early involvement of community members to give people the opportunity to be constructive versus adversarial; a role for the community setting priorities for city government budget allocations and projects; greater transparency regarding what community members can and cannot affect, accurate 
recording and reporting of community comments, clarity on who makes the decisions and how community input will be and is used; and education and support to strengthen community capacity to understand projects and the City's work and the needs and perspectives of other groups and interests in their community. ${ }^{128}$

CI PEG members used the information they gathered to begin to draft new goals and policies for community involvement. After BPS ended the work of the PEGs in June 2013, BPS agreed to let the PIAC Comp Plan Workgroup (which included a number of the most active CI PEG members) to continue to refine the goal and policy language during summer and fall 2013.

The CI PEG and PIAC Comp Plan Workgroup members developed a goal and policies intended formally to establish the "citizen participation program" required by Oregon State Planning Goal 1. They proposed that this language would be included in the Comprehensive Plan Chapter 8: Administration and Implementation. The group members also drafted new and expanded goals and policies for Chapter 1: Community Involvement. These goals and policies are described below.

\section{Community Involvement Program: CI PEG and PIAC Comp Plan Workgroup}

members determined that goal and policy language was needed to ensure that the City of Portland implemented the "citizen involvement program" required by Oregon State Planning Goal 1: Citizen Participation" since 1974. Their reading of Goal 1 was that the "program" needed to include: creation of a "community involvement committee," adoption of goals and policies related to community involvement, and the development

\footnotetext{
${ }^{128}$ The survey responses summarized above come from the responses to the CI PEG Survey, "Question 26: Changes needed: What could the city do to improve its community engagement approach?" compiled by CI PEG members in winter 2013.
} 
and maintenance of a community involvement manual to assist city staff in correctly complying with the community involvement goals and policies.

Stockton and other planning staff saw a strategic opportunity to place the goal and policy language related to the "community involvement program" in the Comprehensive Plan Chapter 8: Administration and Implementation, rather than the community involvement chapter. They felt that placing the language in this chapter would recast the creation of the "community involvement program" as an administrative requirement of the Comprehensive Plan and increase the likelihood that it would be implemented.

The workgroup members proposed the following draft goal to be included in

\section{Chapter 8:}

"Community involvement program. Require and implement a Community Involvement Program to provide an active, ongoing, and systematic process for community participation throughout planning and decision making. Enable community members to identify, consider, and act upon a broad range of issues within land use, transportation, parks, sewer and water systems, natural resources, and implementing measures."

Draft policies that accompanied this goal required the establishment and support of a "'committee for community involvement' [CIC] to: oversee the community involvement program;" ${ }^{129}$ develop and regularly review and update a "Community Involvement Manual;" review and provide "feedback to City staff on community

\footnotetext{
${ }^{129}$ PIAC Comp Plan Workgroup members strongly advocated for the CIC to be a separate committee. Oregon State Planning Goal 1 recommended that jurisdictions create a separate CIC but allowed jurisdictions to designate their planning commission or city or county council as the CIC. In the past, the Portland Planning Commission had played this role. Workgroup members argued that the Planning Commission had a conflict of interest in being able to fairly evaluate community involvement in planning activities because the commission was one of the decision-making bodies in the process. Planning Commission members also had many other duties and would be unlikely to have the capacity or expertise to carry out all the responsibilities of the "community involvement program." Workgroup members also argued that, if any jurisdiction in Oregon should have the capacity to create and sustain a separate CIC, it was Portland, the largest jurisdiction in the state.
} 
involvement processes for individual projects, before, during, and at the conclusion of a project;" and to periodically evaluate the "effectiveness of the Community Involvement Program."

Another draft policy required the City to "Ensure adequate funding and humans resources" that would be "sufficient to make community involvement an integral part of the planning process." This language reproduced similar language in Oregon State Planning Goal 1.

If this goal and these policies are adopted and implemented they significantly will increase the capacity of City government to involve the community in planning processes and decision making in many areas of city government. The creation of an ongoing CIC would provide another body within city government, in addition to PIAC, that would have the focus and expertise to review and advocate for improvements in community involvement.

Comp Plan Workgroup members also developed a number of goals and policies that were proposed as the content of a new Chapter 1: Community Involvement. CI PEG and Comp Plan Workgroup members had advocated for BPS to make the community involvement c chapter, "Chapter 1," to mirror the position of community involvement as Goal 1 among the state planning goals, and to symbolically raise the visibility and status of community involvement in the Comprehensive Plan. The CI PEG and Comp Plan Workgroup members decided to prepare a set of community involvement goals and then divide the policies into two groups: "on-going policies" and "project-specific policies." These are described below. 
Community Involvement Goals: The community involvement goals were intended to establish formal expectations for the values that would guide community involvement in planning and decision making related to the Comp Plan and the basic characteristics of community involvement processes. Some of the goals were familiar, such as:

"Community involvement as a partnership;" "Value of community wisdom and participation;" Transparency and Accountability;" Ongoing and diverse participation; and "Accessible and effective participation."

One of the goals focused on "Social justice and equity," inspired in part by the social justice elements of the AICP Code of Ethics ${ }^{130}$ and the Portland Plan overarching "equity" theme. The draft goal stated that "The City seeks social justice by working to expand choice and opportunity for all Portlanders, recognizing a special responsibility to involve underserved and historically underrepresented communities in planning. The City actively works to improve its policies, institutional practices, and decisions to achieve more equitable distribution of burdens and benefits."

A final goal focused on "Building strong civic infrastructure" and reinforced long-standing recommendations of the important of building the capacity of community members and organizations to participate. The draft goal stated that, "The City recognizes that it is essential to develop and support civic structures and processes that encourage active and meaningful community involvement and strengthens the capacity of individuals and communities to participate in planning processes and civic life in

\footnotetext{
${ }^{130}$ American Institute of Certified Planners. Code of Ethics and Professional Conduct. Revised October 3, 2009: A: Principles to Which We Aspire, 1. Our Overall Responsibility to the Public, f) "We shall seek social justice by working to expand choice and opportunity for all persons, recognizing a special responsibility to plan for the needs of the disadvantaged and to promote racial and economic integration. We shall urge the alteration of policies, institutions, and decisions that oppose such needs."
} 
Portland." This goal harkens back to the original creation of Portland's formal neighborhood system partly as an important means to help achieve orderly and effective land use planning.

In addition to these draft goals, the Comp Plan Workgroup members developed a number of more specific community involvement policies. They approached the development of these policies in a new way. In the past, most policies related to community involvement had focused on the characteristics of good community involvement for individual involvement projects. The Comp Plan Workgroup members determined that policies also were needed to ensure that a city bureau-especially BPSdeveloped and maintained ongoing organizational capacity and a culture that supported high quality community involvement across all individual community involvement projects. The workgroup members thus developed both "ongoing" policies and "projectspecific" policies. These are described below.

Community Involvement Policies-Ongoing: The workgroup members'six draft “ongoing" policies focused on: "Partners in decision making," "Early involvement," “Accountability, "Process assessment," "Community capacity building," and "Professional Development."

The partnership policy required city staff to "Enhance partnerships, coordination, and engagement of organizations, institutions, and agency partners." Sub-policies under this policy required city staff to "Continuously build and maintain partnerships" and coordinate with neighborhood and business associations, "underserved and historically underrepresented communities," and other governmental jurisdictions. 
The "early involvement" policy made a point of requiring improved “opportunities for interested and affected community members to participate early in planning and decision making." The policy language went on to specific that this included involving community members in process design and the identification of issues and opportunities, as well providing opportunities for community member to propose projects and helping prioritize which projects the City works on, and project implementation.

The "accountability" policy emphasized that city staff must "ensure" that community-contributed "ideas, preferences, and recommendations" shape "planning and decision making" in a meaningful way. Sub-policies also required that city staff "Document and conscientiously consider" community input and "Ensure that community members receive feedback from decision makers, including the rationale for decisions." A sub-policy also required the strengthening of communication "among City Council, the Planning and Sustainability Commission, City staff, and community members."

The "process assessment" policy required the City to continually assess and strive to improve the effectiveness of community involvement processes. This policy recognized that BPS staff often include some form of evaluation of their individual processes, but that no mechanism existed to look at all of evaluations to identify and share best practices or to identify areas in need of improvement.

The "community capacity building" policy sought to recognize that every time city staff involve the community in a project, they have the opportunity to build the skills and willingness of community members to participate in future community involvement 
processes. Conversely, poorly designed and implemented community involvement processes can discourage community members from participating other City processes in the future.

The "professional development" policy required the City to "Provide professional development opportunities to ensure staff have the tools, attitudes, skills, and experience needed to design and implement processes" that involve the full diversity of the community "in ways that are meaningful and appropriate to them." Workgroup members also discussed including policy language that would require the City to provide staff people with the time to meet with and develop longer-term understanding of and relationships and trust with different community groups.

Community Involvement Policies_-Project Specific: The workgroup members developed ten draft policies focused on individual community involvement projects. These included: "Representation," "Roles and responsibilities," "Transparency," "Process design," "Adaptability," "Accessibility," "Information for effective participation," "Data collection and analysis," "Process evaluation," and "Best practices and innovation."

Many of these policies repeated similar guidance from the past, with some exceptions. The "Representation" policy included language that requires city staff to research and identify the demographics, needs and priorities of, and trends affecting, the affected community. The "Data collection" policy required staff to "Actively involve community members in inventorying, mapping, data analysis, and the development of alternatives." The "Process evaluation" policy required city staff to evaluate each 
community involvement process "from both the City and participants' perspectives" and to "consider collected feedback and lessons learned in future involvement efforts."

The PIAC Comp Plan Workgroup members will continue to refine the language — with input from the full PIAC group — and will plan to submit their final proposed draft language to BPS in December 2013. BPS management and staff will edit this work and incorporate a final version into the public draft of the full Comp Plan update that will be shared with the community, most likely in winter 2014. Workgroup members will work with the full PIAC to develop PIAC's formal comments on the public draft to share with the Portland Planning and Sustainability Commission. A further revised version of the Comp Plan update then will be submitted to and reviewed by City Council.

Future PIAC activities: PIAC Comp Plan Workgroup members and other interested PIAC members have offered to help BPS and the members of whatever body is created or designated as the CIC to develop the community involvement manual. The manual is intended to provide guidance for city staff in how to meet the Comp Plan community involvement goals and policies. PIAC members anticipate that this manual could evolve into a manual that could serve all city bureaus. Comp Plan Workgroup members also have prioritized working with BPS to engage in a broad review of the City of Portland's formal public notification policies and practices—-something community members have been asking for since the 1970s.

Other future PIAC projects are likely to include: a strong focus on developing best practices materials and organizing ongoing community involvement trainings for 
city staff; support for each city bureau to develop a bureau-specific community involvement policy and overall strategy that fits the particular work, needs, and culture of their bureau; an update of the FIPIS form with additional "equity" questions; a follow-up survey to the Baseline Assessment to measure progress; and, possibly, a review of the City of Portland's boards and commissions system. PIAC members also have discussed developing the capacity to provide some consulting services to city bureaus on the design of their community involvement projects and to review and evaluate individual community involvement projects, after they are completed, to identify important "lessons learned," when requested to by city bureaus or community members.

The untimely and tragic passing of Ahmed-Shafi in late July 2013 has been a painful and significant setback for PIAC and the PIAC members. PIAC members quickly began to realize the full scope of how important Ahmed-Shafi's efforts were to ensure strong and compelling recruitment of new PIAC members. She spent a lot of time meeting with potential PIAC members-especially people from communities of color and other historically under-represented groups - to learn about their skills and interests and to help them feel listened to and respected. This extensive upfront work was crucial to convincing people that it would be worth their time to volunteer to serve on PIAC. She also ensured that PIAC meetings always were well designed, welcoming and productive. Ahmed-Shafi's wise and subtle strategic guidance helped the group sift through and move forward on good ideas. She also was very skilled at steering the group away from ideas and proposals that were not as constructive and less likely to help move PIAC 
toward achieving its greater long-term goals. She is deeply missed by PIAC members and ONI staff and many other people in City government and the community.

Lessons of PIAC: The PIAC has proved to be a very effective vehicle for implementing the recommendations of the PITF (2003-04) and for beginning to shift the City's community involvement, policies, structures, practices.

Ongoing, Formal Body: The PIAC has proved the PITF correct in its identification of the strong strategic value of an ongoing formal city board/commission with a clear mandate from the City Council. Whereas previous reviews of city government (ASR, PITF, BIP 9, and Community Connect) all were temporary committees that did their work, issued reports and then disbanded, PIAC's ongoing status allows PIAC members to devote the significant energy and time it takes to design, implement, and sustain the many different elements of the comprehensive PITF strategic plan. PIAC's ongoing status also allows PIAC members the time needed to develop the relationships, shared understanding, and trust needed to move ahead together. Past efforts have shown that making recommendations for change is not enough—somebody has to work on implementing the recommendations.

Strategic Approach: PIAC also has benefited greatly from the fact that the PITF and other studies already had laid out a comprehensive strategic plan and action steps for improving city government community involvement. PIAC has been able to focus most of its energy on designing, advocating for, and implementing policies and programs.

Broad and sustained change requires many different actions. PIAC members saw the public involvement principles as an important foundation for their work but 
recognized that much more needed to be done. The PITF recommended many different action items, some focused on changing policies and structures in city government, others on raising awareness and increased the willingness and capacity of city staff to work with the community, others focused on communication, accountability, and evaluation. PIAC's approach encompasses developing new policies and guidelines, best practices identification and development, training, data gathering, and evaluation.

Membership: PIAC's membership model of including half city staff and half community members also has proven to be very effective in allowing PIAC to serve as a forum for city staff and community members to build understanding, trust, and relationships over time. PIAC members have developed a shared understanding of each other's perspectives, hopes, values and aspirations related to community involvement and the work of individual city bureaus. PIAC serves as an important sounding board for ideas and an early testing ground for proposed policies and programs. PIAC's dual community and city government membership also gives the group's recommendations much greater credibility with City Council members, bureau directors, and community leaders-each can feel that someone who understands their interests has been part of the conversation.

PIAC membership also includes a number of individuals—-both community members and city staff_-who have served on past system reviews and bring valuable institutional memory to PIAC's work.

PIAC is unusual, for a city committee or body, in that participation by community members and representatives of historically under-represented communities has remained 
strong and consistent. This significantly contrasts with the more usual pattern in other city processes in which community members, especially from diverse communities, tend to drop off and stop participating over time.

Think Tank: PIAC also has provided, for the first time in Portland, a body that can act as the community involvement "think tank" recommended by Community Connect and supported by city bureau directors. PIAC members look for best practices from what Portland city bureaus already are doing and seek out additional good ideas from other jurisdictions in the region and around the country.

Staff Support: The PIAC experience again shows the importance of highly skilled and effective staff support. Ahmed-Shafi worked very effectively and strategically behind the scenes to recruit and support the ongoing participation PIAC's very diverse members. She guided and supporting the work of the PIAC steering committee, helped design and implement PIAC outreach and advocacy efforts around different PIAC products and initiatives, and generally empowered PIAC members so that they felt listened to and that their participation was making a difference.

Governance and Process Design: Ahmed-Shafi helped ensure that PIAC meetings always were open, inclusive, welcoming, and respectful, and modeled community involvement and process design best practices. PIAC members took the lead-with Ahmed-Shafi's support—in setting priorities for the group and in developing the group's products. The group's collaborative leadership model reinforced the sense of ownership PIAC members feel for the process. PIAC has no chair or co-chairs. AhmedShafi worked with the PIAC steering committee and the leads of the different PIAC 
workgroups to develop the PIAC meeting agendas. She facilitated the meetings in a very low-key style that emphasized workgroup reports, announcements, and leadership of group discussions by the PIAC members themselves and honored the energy and choices of the group. PIAC is not staff driven, but rather is group member driven and staff supported.

Helping vs. Judging: PIAC members have been careful and deliberate about framing their work as "helping" city staff and leaders learn the value of community involvement and how to work effectively with community members, rather than judging how well city bureaus are involving the community. PIAC members often say "We're not the public involvement police." "We're here to help city staff be more successful in doing their work." To the extent possible, PIAC members want city staff to see them as a resource rather than a threat.

PIAC members have chosen to leave the "judging" and enforcement to others, such as the Ombudsman and Auditor, individual community members and community organizations, city leaders, and peer pressure. PIAC has focused on identifying and advocating for best practices and increasing the transparency of city government community involvement.

Challenges: PIAC members always attempt to be sensitive to resistance from city staff and not to push hard enough to trigger a backlash. PIAC members listen to concerns expressed by city staff and make adjustments, while still moving forward on PIAC's overall strategic agenda. PIAC members also look for opportunities to collaborate with other efforts, such as the update of the Comprehensive Plan, the development of the City 
of Portland Title VI policy and program (which incorporated the PIAC public involvement principles and many other PIAC identified best practices) and the work of the city's Office of Equity and Human Rights, which also is advocating for city bureaus to develop equity policies and strategies and report on their equity efforts—which include better community involvement.

PIAC has identified as a major challenge the limited capacity of the group to expand its work without additional staff support. PIAC members all have other responsibilities either as community members or city staff. PIACs experience with the FIPIS and Baseline Assessment showed the need for people to enter data, analyze it, and develop reports that present out findings and recommendations. The development of a wide range of best practices materials and training also will require additional support.

The tragic and unexpected passing of Ahmed-Shafi in July 2013 poses a significant challenge for PIAC. Ahmed-Shafi played a major role in the creation and effective functioning of the group. In fall 2013, ONI is in the process of hiring someone to fill the Ahmed-Shafi's position. ONI did extensive outreach to PIAC members and others to get their feedback to better understand the particular skills Ahmed-Shafi brought to her work that helped maintain the group's high and very diverse participation and supported PIAC's strong productivity and effectiveness.

\section{Office of Equity and Human Rights}

The Portland City Council created the City of Portland Office of Equity and Human Rights in September 2011. The City of Seattle had created its "Race and Social Justice Initiative" in 2009. During the Portland Plan process, Equity TAG members and 
city staff from Commissioner Fritz's office, ONI, and other city bureaus, joined with representatives of the DCL Program organizations and other communities of color organizations and invited RSJI representatives to come to Portland to describe their program and work, and a number of Portlanders travelled to Seattle to participation in RSJI's annual conference. Many hoped that Portland could implement a similar program.

The RSJI website describes the initiative as follows:

"The Seattle Race and Social Justice Initiative (RSJI) is a citywide effort to end institutionalized racism and race-based disparities in City government. RSJI builds on the work of the civil rights movement and the ongoing efforts of individuals and groups in Seattle to confront racism. The Initiative's long term goal is to change the underlying system that creates race-based disparities in our community and to achieve racial equity" (Seattle. Race and Social Justice Initiative. About RSJI. Web. <http://www.seattle.gov/rsji/about.htm> .Downloaded October 24, 2013).

In January 2011, Mayor Adams proposed the creation of an Office of Equity in his annual State of the City address. Adams and Fritz convened a committee of community members and city staff to help develop a vision and overall workplan for the new office. The City Council formally created the Office of Equity and Human Rights in September 2011. The new office incorporated and staff of the Office of Human Relations created by Potter in 2008. The Oregonian reported that Adams and Fritz would "launch a search for a director for the office, which will have a \$1.1 million annual budget and seven to 10 staff members."

Not all the City Council members were enthusiastic about this new office. The Oregonian reported that "Commissioner Dan Saltzman, who had expressed reservations about the office, said he wants to see tangible results—not just 'brown bag lunches and film series.' 'Money does matter, Saltzman said. 'I'll be watching closely.'” 
Commissioner Randy Leonard, during the city budget process the previous spring, had made light of Adams proposal to create an Office of Equity and had suggested that he might create an "Office of Awesomeness" (Schmidt. Oregonian 4 May 2011). An Oregonian editorial during the budget process recognized that over $\$ 600,000$ of the proposed $\$ 1.1$ million in funding proposed for the new Equity Office was already budgeted for the Office of Human Relations, which would merge with the new Equity Office. The Oregonian wondered whether, instead of creating a new office, the City could team up with Multnomah that already had a similar equity office ("Watching each other's back." Oregonian. 9 May 2011).

Some ONI staff transferred to the new office, including Judith Mowry-along with her dispute resolution and high stakes meeting facilitation work, and Patrick Philpott—who staffed the Portland Commission on Disabilities. The new office also housed the Human Rights Commission, established under Potter. The director of the new office was hired in the in winter 2012, and a workplan for the new office was unveiled in July 2012.

The overall mission of the Office of Equity and Human Rights is to provide "education and technical support to City staff and elected officials, leading to recognition and removal of systemic barriers to fair and just distribution of resources, access and opportunity, starting with issues of race and disability." The Office of Equity and Human Rights reports that its objectives is to:

1. Promote equity and reduce disparities within City government; 
2. Provide guidance, education and technical assistance to all bureaus as they develop sustainable methods to build capacity in achieving equitable outcomes and service;

3. Work with community partners to promote equity and inclusion within Portland and throughout the region, producing measurable improvements and disparity reductions;

4. Support human rights and opportunities for everyone to achieve their full potential;

5. Work to resolve issues rooted in bias and discrimination, through research, education, and interventions (Portland. Office of Equity and Human Rights. About OEHR. Web. 〈http://www.portlandoregon.gov/oehr/62229> . Downloaded November 1, 2013).

Some community activists remained concerned about whether the Office of Equity and Human Rights would fulfill the full vision of what community activists hoped it would accomplish. The Urban League of Portland (which developed the very influential "State of Black Oregon" report) convened a "working group of city staff and community partners, including organizations of color, health advocates, and academics" in January 2011 — the "Partnership for Racial Equity"—which developed an independent "Racial Equity Strategy Guide.” The group intended this document as an "initial overview" for city bureaus and staff on "how to begin implementing a racial equity strategy." The guide included information on "What equity means in day-to-day practice;" "How to develop an equity lens and strategy;" "When to use important 
resources, such as the Office of Equity and Human Rights, Public Invovlement Advisory council and the Civil Rights Title VI program for technical assistance;" and "Examples of local and national model equity work" (Urban League of Portland. Racial Equity Strategy Guide. Web. <http://ulpdx.org/racialequitystrategyguide/> . Downloaded November 1, 2013).

In fall 2013, the Urban League is preparing to reconvene the Partnership for Racial Equity members and invite city leaders and staff from the Office of Equity and Human Rights, ONI, and the OMF Title VI program to report on how they are working together to achieve the goals of the Racial Equity Strategy.

Title II ADA and Title VI Civil Rights Program

The City of Portland's Title II and Title VI programs both are managed by the City's Office of Management and Finance. The City of Portland also took another important step toward improving equity and the involvement of under-represented communities in decision making when it adopted the City of Portland Title VI Civil Rights Plan in June 2013. The Title VI Plan incorporated the City of Portland Public Involvement Principles (developed by PIAC) and emphasized that "It is the policy of the City of Portland to involve the public in important decisions by providing for early, open and continuous public participation in and access to key planning and project decisionmaking processes." The Plan also stresses that city decision making processes need to be designed to "prevent disproportionate adverse human health and environmental effects, including social and economic effects, as a result of any City project or activity on 
minority and low-income populations" (Portland. Office of Management and Finance. 2013 City of Portland Civil Rights Title VI Plan. May 2013 3-4).

The City of Portland Title II ADA Program supports the City of Portland's efforts to "ensure that every program, service, benefit, activity and facility operated or funded by the City of Portland is accessible to people with disabilities" and "eliminate barriers that may prevent persons with disabilities from accessing our facilities or participating in City programs, services and activities (Portland. Office of Management and Finance.

Americans with Disabilities Act Title II Program. Web. <http://www.portlandoregon.gov/bibs/62112> . Downloaded November 1, 2013).

Both programs are backed up by strong legal requirements that provide added leverage to ensure that particular affected communities are considered and have a voice in decision making processes and that these processes are accessible.

\section{East Portland Action Plan}

The East Portland Action Plan (EPAP) offers a compelling example of how to create an inclusive process that involves a wide spectrum of community groups and interests in developing a district plan and then involve the community in advocating for and helping implement the plan. The EPAP models many of the principles and best practices of public involvement learned over many years in Portland.

The work of the EPAP Implementation Committee offers is an interesting model that is informing the discussion about the future form of district-level structures in Portland's community and neighborhood involvement system. 
The EPAP included two phases. In the first phase, City planners worked with a diverse committee of community members to create the plan, which included strategies and action items. In the second phase, these same community members decided to keep their group together to advocate for and assist with the implementation of the plan in their community.

Origin: East Portland encompasses a large area of land that the City of Portland annexed in 1980s and 1990s. East Portland has experienced rapid population grow and significant increases in racial, ethnic, and cultural diversity. The area also is transitioning from its previous "suburban and semi-rural form into an increasingly urban community" (Portland. Bureau of Planning and Sustainability. East Portland Action Plan. Adopted February 18, 2009 1). Community members in east Portland have long complained that the City of Portland and other government entities have not paid attention to their community's needs and challenges.

The EPAP project "was initiated following a meeting between staff from [the City of] Portland, Multnomah County and (then) State Speaker of the House Jeff Merkley." (Speaker Merkley's legislative district included the east Portland area.) ${ }^{131}$ Merkley "identified several livability issues that he believe were moving the [east Portland] community toward a 'tipping point' and warranted attention. Some of these issues included a shifting of poverty to the area, the quality and design of new housing, missed opportunities for economic development, a lack of investment, and concerns about public safety." At the time, the Portland Bureau of Planning was completing the East Portland Review, a study of the "area's demographic change, development trends, and community

${ }^{131}$ Oregonians elected Jeff Merkley to the U.S. Senate in 2008. 
issues." The review validated many of Speaker Merkley's concerns and those expressed by east Portland community for many years (Portland. Bureau of Planning and Sustainability. Memo from Susan Anderson to Mayor Adams and City Council. East Portland Action Plan Annual Report. April 2, 2010 1).

The East Portland Review found:

- "Population growth is increasing faster than the rest of Portland, with larger households than Portland on average but declining median incomes compared with Portland overall."

- "The area is becoming more ethnically and racially diverse compared to Portland overall and is expected to continue this trend."

- "The scale and appearance of new development is out of character with existing development."

- "The transportation network lacks connectivity as well as amenities for walking and biking, and is becoming congested in areas."

- "David Douglas School District, the largest of five school districts serving the area, is seriously over capacity and concerned about the strain on programs and facility capacity attributable to the continued influx of families to the area" (Portland. Bureau of Planning and Sustainability. Memo from Susan Anderson to Mayor Adams and City Council. East Portland Action Plan Annual Report. April 2, 2010 1).

EPAP process and plan: The EPAP process formally started in started in December 2007, when Portland Mayor Tom Potter, Multnomah County Chair Ted 
Wheeler and Speaker Merkley convened the first meeting of the EPAP Committee. The committee included a diverse group of 18 neighborhood association, community, and business representatives. The committee also included "elected officials and representatives from the City of Portland, Multnomah County, TriMet, the State of Oregon and Metro as well as school districts and key non-profit agencies working in East Portland." The committee was staffed by individuals from the City's Bureau of Planning and Sustainability and a consultant team. The committee met monthly from December 2007 to July 2008 (Portland. Bureau of Planning and Sustainability. East Portland Action Plan. 2009 7).

The EPAP Committee focused on identifying "gaps in policies, services and improvements in the area" and identified opportunities to bridge these gaps and improve the livability of east Portland (EPAP Feb 2009 2). The final EPAP document hundreds of "strategies and actions" intended to guide and direct "public agencies, non-profit organizations, and businesses and individuals" to address problems and move forward on opportunities in East Portland (Portland. Bureau of Planning and Sustainability. Memo from Susan Anderson to Mayor Adams and City Council. East Portland Action Plan Annual Report. April 2, 2010 1). The EPAP identified strategies and action steps in the following policy areas: Housing and Development Policy; Commercial and Mixed-Use Development; Transportation; Public Infrastructure and Utilities; Parks and Open Space, Natural Areas and Environmental; Economic Development and Workforce Training; Education Infrastructure and Programs; Public Safety; Safety Net Services and Housing 
Assistance; Community Building; and Equity (Portland. Bureau of Planning and Sustainability. East Portland Action Plan. 2009 12).

The Portland City Council adopted the final EPAP document in February 2009. The City Council also had “appropriated $\$ 500,000$ in its fiscal year 2008-09 budget" to support the implementation of the EPAP (Portland. City Council. Resolution 36682. 18 February 2009). ${ }^{132}$

East Portland Plan Implementation Committee: After the Portland City Council adopted the EPAP, community members who had served on the EPAP Committee agreed to keep working together to advocate for and assist in the implementation of the EPAP strategies and action steps.

One of the group's first actions was to support the hiring of Lore Wintergreen as the EPAP Advocate to support the work of the implementation committee. Wintergreen was an experienced community organizer and had worked extensively with underrepresented communities in Portland. She also brought to the position a strong passion for social justice and equity and strong skills in group process and policy advocacy. Wintergreen works out of the East Portland Neighborhood Office. Her official duties including convening and supporting the monthly general EPAP meetings; working with the EPAP Co-Chairs to "develop and distribute" monthly EPAP meeting agendas, reports, and background materials; preparing notes of the meetings; and developing "documents for review and comment" (East Portland Action Plan. Structure. [no date] 5).

\footnotetext{
${ }^{132}$ The Multnomah County Commission adopted the EPAP in July 2010 (Multnomah County Resolution 2010-211, July 22, 2010).
} 
EPAP Committee members established a structure for their work that included a general committee and many other committees focused on different elements of the EPAP. Committee members adopted guiding principles intended to ensure that the work of the EPAP Implementation Committee would be open and welcoming to the full diversity of people, groups, and communities in east Portland and would provide the structure and support needed to move the EPAP agenda forward.

The EPAP Implementation Committee adopted "guiding principles" that stated: "The EPAP is dedicated to:"

- "Value the past and consider the future in making decisions that contribute to improved livability in East Portland."

- "Build lasting community leadership and relationships as a means to laying the groundwork for successful implementation of the Action Plan."

- "Develop avenues for partnering by creating opportunities to bridge the work being done amongst EPAP commi8ttees and representatives, communities, and neighborhoods, thus building upon common values with respectful collaboration."

- "Openness of input and ideas and to respect and value differences of opinion, ideals, and time commitments with civility."

- "Ensure opportunities to participate are equitably provided across the spectrum of all interest groups and geographic areas, which may include the provision of translation, interpretation, and childcare."

- "Provide a hospitable and welcoming environment to all attendees." 
- "Prioritize the involvement of underrepresented communities."

- "Work towards the furtherance of actions and strategies as specifically described in the Action Plan” (East Portland Action Plan. Structure 1 ).

Participation on the EPAP General Committee and the other topic-related committees is "open to residents, Neighborhood Association members, business people, Business Association members, businesses, nonprofit organizations, special districts and service providers in the [EPNO] area." The EPAP General Committee meets monthly. An orientation session is offered at the end of each general monthly EPAP meeting to new participants learn about EPAP and the many committees working on difference aspects of implementing the strategies and action steps in the plan (East Portland Action Plan. Structure 1-2).

All meetings, including those of the General Committee and other committees are open to the public. "Committee and Subcommittee chairs are responsible for the scheduling of their respective...meetings and for keeping the EPAP Advocate informed of any schedule changes in a oversee and guide the process (East Portland Action Plan. Structure 2).

Anyone in the community can join one of the EPAP committees. Participants also have the opportunity to apply to sign a "Participant Agreement," after attending two EPAP meetings, which designates them as a "PA member." By signing the participant agreement, an individual commits to "make every effort to be present at meetings," and to participate actively in the EPAP work. PA members are expected to: 
- "Encourage broad and inclusive participation. Current PA members will consciously welcome and orient new people and ideas."

- "Interact with community members and partners to develop and promote interest and participation in implementing the Action Plan."

- "Share information with local organizations in which you are involved, and gather, synthesize, and convey information and perspective from those organizations."

- "Review background materials and monthly reports, so as to understand the issues and to gain familiarity with the array of actions and initiatives currently underway that may intersect with the work you are doing."

- "Provide a sounding board to ensure that a variety of data and viewpoints have been considered in the formulation of recommendations.

- "Advocate with agencies and service providers as determined by the group."

- "Voice concerns directly, promptly, and constructively with respect and civility."

- "Become familiar with EPAP guiding documents, such as the 'East Portland Action Plan',' Structure', 'Committees \& Representatives', and 'Principles for Improved Livability"” (East Portland Action Plan. Structure 3).

The EPAP group members elect "two PA members to act as general EPAP CoChairs." The Co-Chairs "facilitate and regularly attend EPAP meetings" and keep up to date on EPAP activities. The Co-Chairs are charged with establishing "a healthy and sustainable culture by keeping energy devoted to Relationships, Process, and Results in 
balance- - understanding that each of the three contribute to the health of the other two" (East Portland Action Plan. Structure 3) [emphasis in original].

The EPAP carries out it work through the General Committee, committees and subcommittees, and "representatives." All of these must serve "the operational functionality of the EPAP and implementation of the Action Plan" (East Portland Action Plan. Structure 3). Committees provide broader support for an EPAP topic area. Subcommittees "carry out specific [EPAP] strategies and action items." All committees and subcommittees are "established by consensus" by the general EPAP group and must have at least one active member who is a "PA member." Meetings must be open to the public and held in "mobility-device accessible locations" in east Portland. EPAP funds “childcare and interpretation as needed. Committees and subcommittees are required to submit "monthly reports to the EPAP Advocate one week prior to the monthly meetings" that identify the EPAP item the committee or subcommittee is working on, the group's goal, group participants, a statement of "relevant issues addressed and decisions made," and any request for "input or action from the EPAP" (East Portland Action Plan.

Structure 4). If a committee or subcommittee does not provide a "written and/or verbal report" for two "successive general [EPAP] meetings, the EPAP leadership and staff contact the group's chair or co-chairs to talk with them about "the viability of the" group and to let them know that if the group fails to submit a report at another EPAP general monthly meeting, EPAP may withdraw support to the group for getting out meeting notices as well as funding childcare and interpretation and can choose to dissolve the group (East Portland Action Plan. Structure 4). 
"Representatives" support EPAP advocacy by serving as a spokesperson and liaison on a particular aspect of the EPAP until "enough EPAP capacity" exists "to establish a Subcommittee." A "representative" must be a "PA member," must following the EPAP principles and work to further EPAP actions, and report "on significant activities and position statements on behalf of the EPAP at the general EPAP meetings" (East Portland Action Plan. Structure 4).

In 2013, the EPAP website listed sixteen EPAP committees and subcommittees. Committees that focused on EPAP organization and support include: EPAP General meeting, Co-Chairs, Communications, Grants Review, Operations, Representative Support Group, Structures, and the Technical Advisory Committee. Topic-focused subcommittees include: Bike, Brownfields, Civic Engagement, Economic Development, Education, Housing, Multi-Cultural Center, and Transit Rider. EPAP relies on the existing East Portland Parks Coalition to engage on parks issues and the EPNO Land Use and Transportation Committee on land use and transportation issues. The EPAP website also listed 25 individuals who represent EPAP to a wide range of community organizations, advisory committees, and projects (East Portland Action Plan. Committees and Representatives. [no date]).

EPAP Grant Program: Another very successful element of the EPAP implementation process has been the EPAP Grant Program. The City Council has approved funding for EPAP community grants every year since the beginning of the EPAP implementation phase (i.e. FY 2009-10, FY 2010-11, FY 2011-12, and FY 201213). 
The EPAP Grants Review Committee reviews grant proposals against the "Prioritization Criteria" EPAP established for the grant program in 2008. The criteria give special consideration to "Community building projects leading to more community involvement;"projects with low cost and high impact, that leverage "resources and partners involved in the EPAP process," broad visibility, and that are distributed throughout the geographic area of east Portland (Portland. City Council. Ordinance 183410, December 16, 2009; Ordinance 183748, May 5, 2010; and Ordinance 184430, February 23, 2011). In FY 2011-12, another criterion was added: the demonstration of an "ability to serve underrepresented populations" (Portland. City Council. Ordinance 18536630 May 2012).

EPAP staff extensively advertized the grant opportunity in the community. EPAP leaders and staff also designed the application requirements to try to make the applications as easy as possible to complete and submit to make the opportunity available to a wide diversity of east Portland community members. EPAP advertized the program through "web-site advertisement and email distribution lists." EPAP staff also [two] presubmittal workshops to help community members learn about the grant program and how to apply. The workshops were "located at a mobility devise accessible location" and "held on different days - one in the morning and one in the evening." Language interpretation was available at the workshops on request. Applicants were allowed to submit their grant applications in their first language (applications submitted in languages other than English were translated for the grant review committee members). EPAP staff 
provided applicants with access to a computer. They also accepted hand-written applications.

The City Council has consistently funded the grant program as part its broader funding of EPAP. The grant program was authorized to give out \$50,000 in FY 2009-10; $\$ 50,000$ in FY 2010-11; \$64,500 in FY 2011-12, and \$150,000 in FY 2012-13 - divided into \$52,600 for the EPAP “Civic Engagement Grant Program” and \$47,400 for the EPAP “ “General Grants Program.” In FY 2012-13 the EPAP General Committee decided focus particular on giving out grants to support civfic engagement. The EPAP “Civic Engagement Grant Program” was intended to "allow community members, neighborhoods, business associations, non-profits and other groups to implement [EPAP] Action Item 'Community Building.2.3. Develop and hold leadership and civic engagement classes/programs for East Portland citizens to build capacity for participating in lobbying, advocacy, board participation, partnership, etc.' with a focus on culturally specific communities in language appropriate ways." The "General Grants Program" was intended to allow the same types of groups to implement other EPAP Action items (Portland. City Council. Ordinance 18610719 June 2013).

During the first year (FY 2009-10), the EPAP grant program administered by ONI and overseen by BPS. ONI took over complete administration and oversight of the grant program in subsequent years.

Comments from Arlene Kimura, EPAP Co-Chair: EPAP Co-chair Arlene Kimura, a long-time and highly-respected neighborhood activist and chair of the Hazelwood Neighborhood Association, shared some of her thoughts about the EPAP 
Implementation Committee. Kimura had served on the committee that had developed the original East Portland Action Plan.

Kimura said the people who developed the original EPAP worked well together. She reported that the people involved in creating the original EPAP included government officials and bureau representatives, non-profit agencies, citizens, neighborhood groups, including representatives of non-geographic communities, mostly ethnic communities including communities of color and immigrant community mutual assistance associations (MAAs).

When the initial EPAP was completed, group members said "let's keep going" to make sure that the plan would be implemented. Kimura said people recognized that plans from the past often just sat on a shelf if resources were not provided to implement them (Kimura. Conversation with Leistner. October 22, 2013).

The City Council provided $\$ 500,000$ in FY 08-09 to support EPAP implementation. The asked the EPAP Implementation Committee "If you had money what part of the plan would you do first? One of the group's first actions was to hire hired Lore Wintergreen to serve as the EPAP Advocate and to staff the group.

Kimura noted that it was significant that the City allotted resources to implement the EPAP. Community members had seen many other plans they had worked on with the City sit on a shelf because no resources were available to implement them.

Kimura characterized EPAP as a special list of things people agreed needed to be done. Kimura said "You had something concrete to go for." She said "It's as though we all wanted to buy a car. We'd decided what kind of car. Now, how do you go about 
buying the car?" She said people who worked together on the plan also wanted to continue to foster the relationships that started with original EPAP group.

Some City elected officials and staff and some community members have looked at the broad participation in and energy and accomplishments of EPAP and have asked whether EPAP might be a better model for a district-level body than the more traditional East Portland Neighborhood Office. Kimura noted that EPAP and EPNO do different things. She asserted that the two organizations are complementary and have been very careful not to compete with each other. A number of neighborhood leaders serve on EPAP. The EPAP advocate is housed in and works out of the EPNO office.

Kimura described the different focuses and functions of EPAP versus the traditional neighborhood associations in east Portland. Kimura said neighborhood associations play an ongoing role, while EPAP is a very focused, short-term process. Kimura also noted that neighborhood associations have no specific charge. What they work on depends on the people involved in the neighborhood association. Neighborhood association members can work on some issues for years. EPAP has a clear charge and action items," and she said "EPAP has a beginning and an end." Kimura also noted that EPAP serves as an advocacy group for very specific actions. Neighborhood associations are more generalist. Kimura said that neighborhood associations "often respond to land use and plan revisions. EPAP doesn't do that."

Kimura suggested that a "transportation" issue offers a good example of the different roles. She noted that community members and city leaders have recognized for years that many areas in east Portland need sidewalks and safer streets. Kimura reported 
that getting sidewalks and safer pedestrian crossings is a part of the EPAP action plan. She said that neighborhood associations usually just say "we need sidewalks and better streets," but not every neighborhood association has a land use and transportation expert or committee that can advocate for the needed improvements. In contrast, EPAP representatives talked with PBOT and asked "What's your long-term plan" to increase the number of sidewalks over time?" EPAP also lobbied Metro, PBOT, and ODOT for funding. Kimura said neighborhood coalitions often do not have the "manpower" to do that. EPAP has a strong volunteer base of people who are passionate about transportation. Neighborhood coalitions rely more on paid staff. EPAP has no paid staff (other than the one position of EPAP Advocate), but it does have passionate volunteers who are able to send a more powerful message than paid staff. Kimura noted that some EPAP volunteers are focused on getting a sidewalk built in a specific location, while others focus on changing broader sidewalk and pedestrian safety policies.

Kimura also responded to the question: "Why is EPAP seen as much more inclusive than the neighborhood system?" She noted that neighborhood coalition committees tend to be "representative." For instance, neighborhood coalition land use committees tend to have one spot for each neighborhood association in the district. Kimura noted that "If you are a representative of the Tongan community, you have no representation on the neighborhood coalition land use committee." She said that, in contrast, the East Portland Parks Coalition operates differently-anyone who is interested in park issues can participate. 
Kimura described EPAP committees as being more informal. She said EPAP committee membership is self-selected. "If you are interested, you can participate. There's not a feeling of 'Who are you'" and who do you represent?" EPAP committees "set their own meeting schedule—it's not imposed on them." Committees are expected to get things done and help implement the EPAP action steps. The committees have to report back to the EPAP monthly general meetings at least once every three meetings of this larger group. They need to answer: "What did you do? Who are you engaged with?" Kimura reported that if a committee does not report back and meet the basic requirements of an EPAP committee, the general committee can withdraw the group's status as a recognized EPAP committee. It also can stop helping the group send out their meeting notices and stop paying for child care and interpretation at their meetings.

Kimura reported that community members new to EPAP often have an intense learning curve to figure out how EPAP works and how they can be involved. EPAP recognizes this and offers an orientation session at the end of every monthly general EPAP meeting. Kimura said the group has lots of young leadership. Some people, when they find out what is involved "say it's too much and leave-others stay."

EPAP also sets clear expectations for active participation on the general EPAP committee. Community members self-select to get involved. To become a formal member of the group (PA membership), they need to come to two meetings, commit to participating actively, and sign a membership agreement. Most EPAP general committee members also serve on one or more EPAP subcommittees. Kimura reported about 65 people currently are formal members of the EPAP General Committee. Arlene said that 
45 to 65 people regularly attend the EPAP General Committee meetings. Some meetings that focus on a particular issue of interest draw more people.

Kimura noted that "no one single system works for everybody." Arlene said that EPAP and the neighborhood system have some overlap, but they try never to be competitive. A number of neighborhood chairs serve on the EPAP committee. They work on issues that are near and dear to their hearts. She recommended maintaining EPNO and EPAP as separate organizations.

She emphasized that EPAP is "time limited" and specifically focused on implementing the EPAP action items. Kimura recognized that the original EPAP effort was "enormous and expensive." She suggested that EPAP, rather than being ongoing, should be revisited and updated periodically, e.g. every ten to fifteen years.

Kimura also recognized that different neighborhoods in east Portland have different circumstances and needs. She said many east Portland neighborhoods are not primarily residential and have recognized that they need to do things differently to involve their diverse community members. However, traditional volunteer neighborhood associations are not geared to do the kind of things that EPAP does- 'they do not have enough people involved." Many people in east Portland may work two or three jobs and feel they are too busy to come to neighborhood association board meetings. Kimura explained that EPAP committees meet during the day and on Saturdays to meet the needs of the participants. In some cases, a person may have a relative come in their place, even if the relative is not from the neighborhood. Kimura said a lot of people stay in touch by calling her. She has a distribution list that she uses to send out information. She said that 
attendance at meetings is only a small part of how effective participation should be measured.

Kimura says neighborhood associations and other community organizations need to tailor their processes to their communities. They need to understand who is in their community. Kimura stated that the traditional neighborhood structure needs to evolve somewhat. The more standard neighborhood association and neighborhood coalition approach works for some east Portland neighborhoods that are mostly residential, where the people all speak English, and where most are not the "working poor." She cited the example of the Glenfair Neighborhood Association, which produces flyers in Russian, Spanish and English to publicize its National Night Out event. Kimura stated that translating outreach materials "costs more" and neighborhood associations need funding to do this. She said the Glenfair Neighborhood Association applied for and received a Neighborhood Small Grant to help pay to have the flyers translated.

Kimura shared that her neighborhood includes a large number of non-Englishspeaking, Spanish speakers. Kimura said she makes a point of tabling at community events to share information about the neighborhood because "That's what people in my community come to." Kimura knows her neighborhood association has done a good job of outreach when these people come to neighborhood events. She said participation at her neighborhood association events is a good test of "who's heard us."

Kimura reported that EPAP will provide interpreters for a meeting or event, if a community members calls ahead. She stated that "Neighborhood associations don't have the resources to do this." EPAP builds funding for translation and children care into its 
budget. Kimura offered the example of the EPAP Brownfields Subcommittee, which includes a couple of group members who are from the Iraqi immigrant community. EPAP provides interpreters for them at each meeting. This costs around $\$ 300$ per meeting. Kimura said it is not clear that the City would fund this level of support for neighborhood associations and other community groups. Kimura reported that EPAP has some meetings where the participants mostly are Spanish speakers. These meetings are conducted in Spanish. Non-Spanish speakers use headsets to hear an English interpretation.

In response to a question about how the EPAP General Committee maintains its very diverse membership, Kimura said the EPAP Operating Committee regularly assesses the balance of people on the general committee. Rather than reserving designated spots for different communities, if certain groups are not well represented, the Operating Group will go out and actively recruit people from those groups or communities. For instance, Kimura said the group spent two years recruiting people from the African American community. Many African American people moved to east Portland when northeast Portland gentrified. Kimura said that now four or five people who are African American serve on the general committee. Some work on domestic violence issues. One focuses on youth employment. Kimura reported that EPAP also encourages public agencies to send representatives who are themselves from diverse communities and have the skills to work with different groups.

Kimura reported that EPAP developed this inclusive approach and process over time. The EPAP Operations Committee members recognized that their goal was to engage people in east Portland. She said they looked at "How do we do that?" and what 
creates a welcoming experience for people and what does not. Also, she noted that people can serve on one of the EPAP committees without becoming a formal member of the EPAP general committee. Each EPAP committee needs to have at least one EPAP general committee member. Anyone else can participate. They do not need to sign the participation agreement.

Kimura cited the flexibility in the EPAP Grant program application process as another example of how to reduce barriers to participation. Grant applicants are allowed to submit their applications in their first language, but they still need to provide all the required information. EPAP will have the application translated. Kimura also noted that EPAP subcommittees often provide a forum for non-English speaking community members to talk directly to City staff "without a filter." She said you need to help people feel comfortable enough to engage_- "and not worry that they will be deported."

Kimura emphasized that some of the key lessons from the EPAP experience are that doing good work often takes time and requires that people build relationships and trust to work together effectively. She noted that some EPAP results took two, three, or four years to achieve. She stressed that relationships evolved over that entire period of time. Kimura asserted that City leaders and staff need to understand that "Involvement is not a 'check list."” The City and community members need to invest in building longterm capacity to work together. While this is "very time consuming" the "rewards, longterm, are very substantial." She advised City bureaus to "give it time," and said that "Bureaus should not just translate a flyer and think they are done." She recognized that 
long-time City staff who have worked in the community over many years have more of an opportunity to develop relationships with community groups.

Kimura recognized that "Portland cares a lot about being a livability city." But, she cautioned, that if we just focus on a particular group—such as "young creative people"- "we' re missing the boat." She asserted that "We need to put out the same effort to involve non-English speakers and people with low incomes-the same effort for all groups."

Some Lessons from EPAP: EPAP offers Portlanders a very powerful example of what good public involvement could look like and insights into what it takes to achieve it. A large part of success of EPAP is that it involved a broad diversity of the people, groups, and interests in east Portland in defining what they believed needed to change in their community and action steps to achieve this change, and then provided the resources and support to allow community members to join together to advocate for and implement those changes. EPAP also benefits from having a clear purpose and scope for its workthe action items already are defined. Community members also have a strong sense that the process has a beginning and an end-unlike some processes which seem like openended commitments in which the ability to have an effect is unclear.

As shown in other processes-e.g. Interwoven Tapestry, the Southeast Uplift DRC and DCLC, visionPDX, and the Public Involvement Task Force—skilled staff support is a major element in EPAP's success. EPAP's one paid staff person, Wintergreen, like the people who staffed these other processes, has very strong social justice and inclusion values and very strong strategic and group process skills. She is very 
skilled at empowering community members and helping them be successful while guiding and supporting the process behind the scenes.

EPAP also focuses very much on the quality and inclusiveness of the "process" and building trust and strong relationships between people, not just focusing on the final product. EPAP has strong guiding principles that formally establish that inclusion, relationship building, trust and respect, are central elements of the process. One of the great achievements of EPAP is the strong relationships that have developed between individual EPAP participants, neighborhood and community organizations, different cultural and ethnic communities, non-profit agencies, and City staff and representatives of other jurisdictions.

The structure and operating culture of EPAP offers community members a lot of flexibility and is welcoming and accommodating to different needs, while still maintaining a strong focus on the purpose of the group to implement the EPAP action items and setting basic clear expectations for people's participation. The EPAP process models many of the welcoming behaviors and approaches that system reviews over many years have said are needed to reduce barriers to broad and diverse participation. These include flexible meeting times, accessible meeting locations, food, childcare, interpretation, and a strong commitment to treating people with respect and including them in ways in which they can have an impact.

EPAP leaders, in addition to having created an open and welcoming environment, make a point of assessing who is in the community and who should be involved and then actively reaching out and making sure they are involved. This is in contrast to the more 
traditional approach of many public involvement processes in Portland that are designed to meet the needs of certain interests and people (often pejoratively referred to as "the usual suspects"). When more diverse community members start dropping out of these processes, the standard response is to bemoan their departure but not to radically rethink the process to reengage them and make the process welcoming and relevant to them.

Mayor's Budget Messages - Sam Adams - 2009-10 to 2012-13

Adams opened his budget messages with references to the hard economic times during his four years in office. In 2005 and 2006, he reported that Portlanders were living "through the worst global recession in more than an generation." In 2007 and 2008, Adams reported that the City was beginning to recover. Unlike the extra city revenue available during Potter's administration, Adams required city bureaus to propose budget cuts every year during his four years as mayor.

Adams stated that his priorities were to "invest in a return to full prosperity;" the protection of "core City services essential to every resident of Portland; and to focus on "basic needs" to "keep all Portlanders safe and secure in their jobs, homes, and neighborhoods" (FY 2009-10 5), especially "the most vulnerable in our community" (FY 2010-11 5). Adams targeted "investments in housing, homelessness prevention, mental health, and addiction services" particularly to help these most vulnerable Portlanders (FY 2010-11 5).

In 2011-12, Adams referred to the City's increased "focus on equity to ensure that every Portlander has access to the most equal of opportunities." "Equity" had become the 
overarching theme for Portland's new strategic plan-The Portland Plan. Also in FY 2011-12, Adams identified "neighborhood nuisances and livability issues" as a major priority. He asserted that that he would hold city bureaus accountable for tracking these issues by geographic areas of the city and for addressing them (FY 2011-12 7).

In FY 2012-13, Adams again emphasized his priorities of "preserving front-line services," investing in "economic development," and continuing to provide services to support "the most vulnerable in our community." He also reported his continued "focus on equity." He summed up the focus of the City budget by stating that "Taken as a whole, this budget will make Portland's economy stronger and more resilient, our streets safer, our communities more equitable, and our government more responsive" (FY 2012-13 7).

Community Involvement in the Budget Process: Adams continued to expand the involvement of community members in the City's budget process. In his first year in office, Adams required each city bureau to rank each of its programs and services based on "its relationship to the bureau's mission and its support from the community" (FY 2009-10 6). Adams also directed every city bureau to form a Budget Advisory Committee (BAC) (for the first time since Mayor Katz had ended the previous BAC program). Adams directed bureaus to include on their BACs "management, labor, customers, as well as internal and external experts and stakeholders." Adams charged the BACS with reviewing " the bureau's draft budget request," weighing "in on the program and service rankings," and providing input on proposed budget cuts.

Adams also created a "citywide Budget Process Advisory Committee" that included "bureau management, labor, Council staff, employees, and citizens." He 
reported that this committee "met multiple times to provide direction on the City's approach" to the budget and suggested "ways to improve and rationalize the budget process." Adams held "three community forums, where we gathered specific input from Portland residents," which helped the city council members, "prioritize services," identify areas for improvement and areas to cut. Adams also reported that "We conducted an extensive public information and survey process...to validate the input...received at the community forums" (FY 2009-10 6)

Adams also required city bureaus to "put together a Bureau Baseline and Program Summary Template" to increase the transparency of bureau budgets to City Council and also to community members. He stated that "This is a first step to increasing transparency for our citizens of exactly what they are buying with their tax dollars and holding bureaus accountable for meting their goals" (FY 2009-10 8).

In 2010, Adams reported that, in addition to all the activities above, "Small groups, such as neighborhood coalitions and advocacy groups, were also given an opportunity to host Budget 101 sessions with their members, where members could both learn about the City budgeting process as well as provide feedback and input about the program that are most important to them" (FY 2010-11 6).

Although, Adams does not mention community involvement in the budget process in his FY 2011-12 or FY 2012-13 budget messages, he did continue to use the same processes during all four years of his mayoral administration.

Budget Focus: In 2009-2010, Adams identified "four key goals" that he used to build the city budget. These included: "Keep the city on a sound financial footing...," 
"Protect core services such as public safety and increase funding to human services programs...," "Make strategic investments in youth and local businesses...," and "Increase bureau accountability for service and performance improvement." Adams also announced that he would stop funding programs with "one-time" money that really were intended to continue from year to year. These programs would become part of a bureau's basic budget and would have funding priority, in the future, over one-time programs or projects. He mentioned in particular, that this would affect programs at "ONI and the Office of Human Relations” (FY 2009-10 6-7). In his FY 2010-11 budget message, Adams added an "equity" element to the same "four key goals" by stating that the "strategic investments" were to "fuel a more equitable economic recovery" (FY 2010-11 6).

In his FY 2011-12 budget message, Adams identified "five key goals," which included returning the "City to full prosperity" and investing in a stronger, more resilient City;" helping "those hit hardest by the recession" and providing "support to the most vulnerable in our community;" protecting "public safety services;" increasing "the City's focus on equity to ensure that every Portlander has access to the most equal of opportunities;" and identifying "neighborhood nuisances" and ensuring "more responsive City services" (FY 2011-12 8). In his FY 2012-13 budget message, Adams reported that he focused on "four interlocking goals for the City taken from the Portland Plan: Prosperous, Healthy, Educated, Equitable" (FY 2012-13 8).

Budget Highlights: Adams highlighted a number of community-involvementrelated programs and expenditures in his budget messages. 
In FY 2009-10, Adams included funding for community gardens as part of core services that supported vulnerable populations (FY 2009-10 7-8). Under "strategic investments" he reported budgeting \$137,000 to continue the Youth Planning Program. He also reported $\$ 290,495$ in funding for the Association of Neighborhood Business Districts (APNBA) as a continued investment in "small and local businesses" (8). (This continued support for business district associations that had shifted from ONI to PDC.)

Adams also reported his decision to consolidate the Bureau of Planning and the Office of Sustainable Development into one agency — the Bureau of Planning and Sustainability (BPS) (FY 2009-10 9). (This consolidation allowed Adams to remove Portland Planning Director Gil Kelley, which created an opportunity to open up and increase community in the Portland Plan process.)

In FY 2011-12, under the category "Creating a Fair and Equitable Portland" (one of Adams' five key goals for that year), Adams recognized that "In Portland, inequities exist across racial, geographic, and socio-economic lines." Adams asserted that "We need to address this, and ensure that all Portlanders have access to equal opportunity." Adams reported that "This budget addresses these inequities by providing over $\$ 1$ million to create an Office of Equity, and continuing funding for programs that support education and academic achievement." Adams also highlighted "\$279,692 in funding for the East Portland Action Plan” (FY 2011-12 10). (The East Portland Action Plan, in part, was intended to help remedy long-standing complaints from east Portlanders that city government paid little attention to their needs and those of their growing and increasingly diverse communities.) 
In FY 2011-12, Adams reported that he had directed staff to "create a survey asking Portlanders to report specific nuisances, irritations, or infrastructure issues in their neighborhoods and throughout the City. More than 5,000 responded." He noted that the city budget directed one-time resources to "some of these high priority annoyances" (FY 2011-12 10). Adams also reported that the "City conducted a separate phone survey, where over 16 percent of respondents cited "more or better community gardens" as a high priority. Adams reported that his budget that year invested "in the construction of up to 10 additional Community Gardens...." (11).

In 2012-13, in the "Prosperous" goal area, Adams emphasized that increased economic development would generate "resources to increase our outreach to vulnerable communities." Adams highlighted that the budget included $\$ 4.8$ million of one-time funding for "shelter services, rent assistance, and housing access services" to "protect our city’s most vulnerable citizens" and keep "our safety net” (FY 2012-13 8-9). Under the "Healthy" category, Adams noted that one of the City focuses had "been on healthy, connected, complete communities" where "Portlanders have access to what they want and need to thrive." Adams highlighted that, while " $\$ 99,318$ in on-going funds" had been cut from ONI’s Neighborhood Small Grants Program, he had budgeted “ $\$ 93,855$ in onetime funds" for the grant program. He also reported that "The East Portland Action Plan is again receiving a one-time infusion of $\$ 279,692$ for an advocate position and grants to the community. This budget action will help the residents of East Portland to be more actively engaged in the City's affairs, helping to fulfill the Portland Plan's goal to improve involvement" (FY 2012-13 10) 
In 2012-13, in the "Equitable" focus area, Adams stated that "For the city to succeed, all Portlanders—regardless of race, gender, sexual orientation, ability, neighborhood, age, income of where they were born—must have access to opportunities to advance their well-being and achieve their full potential. Equity not only makes individual lives better, it lifts up the whole city. Despite a tough budget year, I have kept equity at the forefront." Adams went on to highlight some specific budget decisions, including: "The Office of Equity budget was spared reductions, which reflects the City's commitment to moving a meaningful equity agenda forward in FY 2012-13 and beyond." Adams noted that the funding supported "the Portland Plan's equity framework and the action items related to closing gaps, engagement, partnering, racial issues, disability issues, and City accountability" (FY 2012-13 11).

Closing Statements: Adams closed his budget messages with very similar statements each year. Adams consistently commended "all the hardworking Portlanders—citizens and City employees alike" who participated community budget forums, employee budget forums, on bureau and the citywide budget advisory committees, and other outreach efforts, and who filled out "a Curbsider survey." Adams stated that this input enabled the City Council to focus the city budget "on the programs and services that matter most to you."

Adams stressed that, while Portland was positioned to "lead the nation in the green revolution and reap the economic rewards... of our sustainability leadership," "we will only be able to lead if we continue to support all our citizens in their individual efforts to make a better life for themselves" He asserted that "sustainability is about the 
environment and the economy, but it is also about equity." He wrote that each of his city budgets go "to the heart of equity" and were guided by both "empathy and common sense." He noted that "By investing in programs that most serve those with the greatest need, we are looking out for our most vulnerable neighbors-resident, business owner, or student. These basic needs are at the core of this budget."

Adams closed his final budget message, in 2012, by thanking the other city council members for helping him "adopt a final budget that makes Portland "a more prosperous, healthy, educated, and equitable place" (FY 2012-13 12).

Observations: Adams' four budget messages provide some interesting insights into his priorities and values as Portland's mayor. "Equity" is a dominant theme in Adams' four mayor's budget messages. He makes a point of recognizing the inequities that exist in Portland "across racial, geographic, and socio-economic lines.” He also repeatedly emphasized the need to make a special effort to support the most community's most "vulnerable" members.

He also makes a point of highlighting the creation of the City's new Equity Office and his decision to hold the office harmless from budget cuts to support its ongoing development. He also highlights his funding of the East Portland Action Plan implementation efforts which included hiring an advocate to support a committee of individuals represented diverse community interests responsible for overseeing the implementation of the plan. The funding also included resources to fund projects that implement elements of the plan and to give out community grants to encourage community involvement and build community capacity. 
Adams' budgets generally protected most of the expanded community involvement capacity that Potter had created at ONI and its community partner organizations_-especially the DCL Program organizations_-from debilitating budget cuts. He also supported moving many of ONI's new positions and programs from “onetime" funding status to "ongoing," which automatically made them part of ONI's base budget each . This shift was especially symbolic for DCL Program, because it signified that the DCL Program was an ongoing part of the ONI system and served as another indication of the system's shift from a solely geographic-based structure.

Adams continued to build on the expansion of community involvement in the city budget process initiated by Potter. For the first time in over 15 years, Adams required all city bureaus to create a BAC. He also expanded the citywide budget advisory committee. This was a major step toward recapturing and building on the valuable community involvement BACs brought to the city budget process under Goldschmidt. This time the BACs were supported by the Public Involvement Advisory Council (PIAC), which monitored the BAC process and supported the process by identifying ways to improve the process and by helping the city staff that coordinated the BACs to share information and best practices. Many hope these "budget advisory committees" will evolve into yearround "bureau advisory committees" for many bureaus. Year-round committees would allow community members to become more familiar with a bureau's programs, opportunities, and constraints, and to provide deeper guidance on the bureau's priorities and major policy decisions. 
Adams also provided the opportunity for community groups to design and hold their own Budget 101 workshops. This was a valuable strategy that implemented past recommendations that processes are most effective when they are relevant and accessible to the communities they seek to involve and when they are developed and presented in partnership with organizations those community members know and trust. (The City's Office of Management and Finance provided $\$ 300$ mini-grants to the organizations to help pay for their expenses related to the workshops.)

Adams also required city bureaus to begin to track the delivery of city services by neighborhoods and neighborhood districts in Portland. Adams initiated processes by which community members could contact the city and identify particular infrastructure and service needs in their neighborhoods. While this was not as comprehensive as the more formal Neighborhood Needs process of the past, it did provide a vehicle for community members to share their needs and priorities with city bureaus.

\section{$\underline{\text { Mayor Charlie Hales (2013) }}$}

Where will Portland's new mayor, Charlie Hales, take Portland's community and neighborhood engagement system in the coming years? Charlie Hales began serving as Portland mayor in January 2009. He brought to the role of mayor his past experience with city government as a Portland City Council member (1993 to 2002). ${ }^{133}$ While a city commissioner, Hales had been known for his efforts to reorganize Portland's planning

\footnotetext{
${ }^{133}$ Hales served as a Portland city commissioner from January 1993 until he resigned in May 2002, a little over a year into his third term (City of Portland, City Auditor website, "Directory of Current and Past Elected Officials," http://www.portlandonline.com/auditor/index.cfm?c=27134\&a=4937, downloaded October 15, 2013). Hales left the City Council and joined the engineering and consulting firm HDR, Inc. He spent the next "10 years traveling the country to promote streetcars and light rail as a project manager" (Oregonian, October 7, 2012).
} 
and development system to focus more on permitting and less on long-range planning and for having championed the development of Portland's streetcar system. Hales also served as the Commissioner-in-Charge of ONA for nearly six years (May 1993 through Dec. 1998).

During his time on the city council, Hales became familiar with Portland's neighborhood system in place at that time. Hales had a reputation among neighborhood activists as not being a strong supporter of public process who preferred instead to make a decision and move forward to implement it. Hales also was the commissioner-in-charge of ONA during the 1995-96 TFNI. He had directed the TFNI to thoroughly examine ONI and the neighborhood system and to look for "opportunities to make significant improvement in citizen participation." Hales also directed the TFNI to "Look beyond the current ONA structure to find opportunities to broaden citizen involvement and to encourage participation by the full diversity of our communities" (TFNI Report 1996 1).

After Hales' election as mayor in 2012, some community and neighborhood activists were a little leery that Hales would come into office still thinking about the neighborhood system at is was in the 1990s and not recognizing the many changes made since that time. Others thought that Hales' familiarity with the neighborhood system and his past interest in improving community involvement could be an advantage.

One of Hales early actions as mayor was to take all city bureaus into his portfolio during the first six months of his administration and to develop the city budget for FY 2013-14. During this time neighborhood and community activists and ONI staff wondered (and fretted over) which city commissioner Hales would assign to be the 
commissioner-in-charge of ONI and what this decision would portend for the future of ONI and the community and neighborhood involvement system.

Hales 2013 Budget Message: Hales' first mayor's budget message, unlike those of his predecessors, made no mention of community involvement in the budget process. His message also did not mention community involvement in general or say anything about the role of community members in city decision making.

Hales opened his budget message by noting that, when he entered office in January 2013, the city faced a “deficit for 2013-14 at \$25 million.” He stressed that his budget attempted to recognize the "human cost" of budget reductions and that he "tried to cut with as little harm as possible." Hales also reported that he was pleased that the City Council members "came together" in the budget process and "looked at the city as a whole" rather than a "bureau-by-bureau approach" (7).

Hales listed a number of "programs that remain fully or partially funded under my budget." Community members and community organizations had advocated for many of these programs during city community budget meetings. Hales included in the list continued implementation of the East Portland Action Plan and City support for the Multnomah County Youth Commission.

Hales also indicated some of his priorities by stating that one of his goals in cutting staff at the Police Bureau had been "to make sure the bureau did not simply lay off the youngest, least experienced officers" many of whom had been hired to improve diversity within the bureau and to reinvigorate a the community policing focus of the 
agency. ${ }^{134}$ Hales also noted the budget's continued support for the VOZ Day Labor Center, which first had been funded under Mayor Potter.

Hales' concluding remarks did not mention community members or community involvement. Hales emphasized his hope that the budget "reflects the reality of our times," is "transparent and easily readable," and "shares difficult decisions evenly across bureaus." The final comment in his message noted that the budget vastly reduced “increases for water and sewer.” (Portland. "Mayor's Message.” City Budget, FY 201314 3-10).

ONI 2013-2014 Budget: As Hales indicated in his budget message, the City of Portland faced a $\$ 21$ million shortfall at the beginning of the FY 2013-14 budget development process. Hales initially asked ONI and other city bureaus to identify 10 percent cuts for FY 2013-14 to make up the shortfall. The ONI BAC members, as they had in past years, joined together to comply with the mayor's request and develop alternative proposals. They determined that, after "several years of deep cuts to the [ONI's] programs," "there was no room to make additional cuts without impacting services in every program area." The ONI BAC members sent the mayor a proposal for across the board cuts to all ONI General Fund programs and for ONI's community partner organizations. The proposed cuts also provided no funding for the Neighborhood Small Grants Program in FY 2013-14 (Portland. City Budget. FY 2013-14 420). ONI BAC members and community partners then organized their constituents to lobby the

\footnotetext{
${ }^{134}$ In 2012, a U.S. Department of Justice investigation had found that the Portland Police Bureau had "engaged in an unconstitutional pattern or practice of excessive force against people with mental illness." The US DOJ and the City of Portland had entered into a formal agreement filed with the court to "make changes to Portland Police Bureau policies, practices, training and supervision" to remedy the problem (U.S. Department of Justice, Press Release, September 13, 2012).
} 
Mayor and City Council to restore some funding to ONI and not to accept the proposed full 10 percent cuts.

Mayor Hales partially restored about two-thirds of the proposed ONI budget cuts in the final budget adopted by City Council. The restoration of funding allowed Elders in Action to retain volunteer engagement staff, retained funding for neighborhood coalition communication and outreach staff, and funded continued outreach capacity for the Disability Program. The final budget also funded continued implementation of the East Portland Action Plan (EPAP) and retained the EPAP coordinator/advocate position and funded EPAP operating expenses, community grants and priority projects" (Portland. City Budget, FY 2013-14 420).

In the ONI section of the FY 2013-14 City Budget, ONI continued to assert that its mission and budget were grounded in the Community Connect goals and sought to implement the Five-year Plan to Increase Community Involvement. ONI continued to focus on promoting "a culture of civic engagement by connecting and supporting all Portlanders working together and with government to build inclusive, safe, and livable neighborhoods and communities." (417) ONI emphasized its continued commitment to supporting and strengthening Portland's neighborhood system and to building, supporting and expanding civic engagement among under-represented groups (418).

Hales, at the very end of the city budget process, announced some surprise program changes at ONI. He moved the Noise Control Program from BDS to ONI. He also shifted responsibility for supporting the Multnomah County Youth Commission from BPS to ONI. Mayor Hales saw the Noise Control Program as a good fit with ONI's 
other livability programs (i.e., Liquor Licensing and Graffiti Abatement). ${ }^{135}$ The Youth Commission originally was intended to be supported by both Multnomah County and the City of Portland. Multnomah County had funded a full-time position that provided nearly all of the commission's coordination and support. On the City side, some past mayors had designated one of their staff people as a liaison to the commission. In more recent years, the Youth Planning Program at BPS had become the City's main connection to the commission, but then the Youth Planning Program was defunded. Multnomah County had complained for some time that the City was not fulfilling its responsibility to support the Youth Commission. The Youth Commission mission of empowering youth and giving them a voice in decision making is a good fit with ONI's overall mission and ONI's goal of serving under-represented groups in the community. The City of Portland City Budget for FY 2013-14 did not provide ONI with additional funding to take on this new role. ONI chose to shift funding within its budget to free up resources to hire a youth program coordinator. The position is scheduled to be filled in late 2013.

Hales takes ONI: In June 2013, when he was assigning city bureaus to the city commissioners, Hales decided to take ONI and the Equity Office away from Commissioner Fritz and include them in his own portfolio. The Oregonian reported that Hales hoped that ONI and the Equity Office would "fit well with the Police Bureau" (which Hales also retained). "Blending those efforts strengthens each...It creates a nexus

\footnotetext{
${ }^{135}$ This move of the Noise Control Program to ONI harkens back to Goldschmidt's original recognition of the need to support both community empowerment (ONA) and to address livability issues in Portland's neighborhoods (Bureau of Neighborhood Environment). Hale's move also brings to mind Leonard's more recent, although short-lived, shift of neighborhood nuisance inspections and noise control from BDS to ONI. Leonard's action was part of his bigger strategy to transform ONI into a Bureau of Neighborhood Services. Hales' goals for moving noise control to ONI appear much more limited. Neither ONI staff or community members have expressed concern that Hales' decision will undermine or detract from ONI's overall mission of community empowerment.
} 
of community empowerment. Plus, it elevates their profile" (Kost. Oregonian, June 4, 2013).

Neighborhood and community activists and ONI staff wondered whether Hales had any particular ideas or strategies he wanted to pursue (as had many other city commission in the past), or whether he would try to learn about the current system and work collaboratively with community members to pursue opportunities to improve and strengthen the system.

Initially, in the absence of any concrete information about Hales' intentions, rumors began to circulate. Some community activists reported that they had heard Hales say at different public functions that he wanted to "revitalize" the neighborhood system and "tweak" the DCL program. Some neighborhood and community activists became concerned that Hales would try to impose "fixes" to the system without consulting with neighborhood and community groups (similar to efforts by previous city commissioners in charge of ONI-Kafoury, Saltzman, and Leonard).

Alarcón de Morris later met with the mayor to talk about his plans for ONI. Alarcón de Morris reported back to ONI staff and ONI's community partners that Hales had said he had no fixed ideas he wanted to implement. He told Alarcón de Morris that he wanted to hear from neighborhood and community activists and ONI about opportunities to make Portland's community and neighborhood involvement system work better.

\section{October 2013-Hales meeting with Neigh Coalition Dir and Chairs:}

Neighborhood coalition leaders got their first chance to meet face-to-face with Hales when Hales attended one of the monthly meetings of the neighborhood coalition directors 
and board chairs in October 2013 at the East Portland Neighborhood Office. The discussion at the meeting offered interesting insights into Hales' priorities and interests and the system improvements neighborhood coalition directors hoped he would support (Leistner. Personal meeting notes. October 10, 2013).

A few days prior to the meeting, the City Council received some good budget news, in the form of $\$ 11$ million in unanticipated revenue. City bureaus had the opportunity to proposal ways to spend portions of the money. Alarcón de Morris shared with neighborhood coalition leaders at the meeting that ONI considering asking for $\$ 14,000$ for to provide community members with scholarships to attend the Neighborhoods USA conference in Eugene in Spring 2014. She also reported that ONI would request $\$ 140,000$ to restore the Neighborhood Small Grants Program.

Alarcón de Morris also had let neighborhood district coalition directors know that the Mayor wanted to start holding his monthly check-in meetings with Alarcón de Morris regarding ONI out in the community. (Hales and Alarcón de Morris met regularly because ONI was in the mayor's portfolio of city bureaus.) Hales said he wanted to hold the meetings at different neighborhood district coalition office each time (as well as DCL Program and other ONI partner organizations) and invite the organization director and one or two organization staff people to participate.

In October2013, Hales met with the directors of all seven neighborhood coalitions and three coalition board chairs and a number of community members and ONI staff. Hales told the group he wanted to keep getting out "in the field" and asked them to let him know about community events and meeting he could consider attending. He also said 
he was looking forward coming out to the different neighborhood coalition offices for his monthly check-ins with Alarcón de Morris and the individual coalition directors.

Hales shared that his priorities during the first part of the year had been working with the Police Bureau on a return to community policing and improving how the police interact with people with mental illness. Hales notes that it takes awhile to "turn the ship" and emphasized actions he had already taken to increase diversity on the Police Bureau's command level. Hales identified school funding and the city budget as other important priorities for the earlier part of the year. Hales reported that his priorities in the coming months would be the future of the Portland Development Commission (which had experienced significant loss of tax increment financing revenues), homelessness in Portland, and the Willamette River Superfund site. Hales reported that he was working with Commissioner Steve Novick (commissioner in charge of the Portland Bureau of Transportation) to find new revenue for street maintenance-which could help the City respond to requests from neighborhoods for street paving and traffic and pedestrian safety improvements.

Alarcón de Morris asked Hales what he wanted to hear during the monthly checkins at the coalition offices. Hales replied that he wanted to hear about "what's working and what isn't" in the community involvement system. He said he also wanted to know "How are city bureaus working the neighborhood system and the DCL organizations?" Hales said the economy was improving, and the City likely would have more funding available in the future. He said he wanted to know what coalition leaders thought about how to use these additional resources. Hales told the group that he is an "iterative 
learner" and that his understanding evolves through multiple conversations. He said he believes in the Socratic process of asking questions and encouraged the group members to argue with him—-"that's how I learn."

One of the neighborhood coalition directors asked Hales what differences he sees in the neighborhood system from when he was the ONA Commissioner in the 1990s. Hales told the group that "it's a different Portland." He noted that many young creative people are moving to Portland. He asked "How do we involve them in civic life in Portland?" Hales also emphasized his belief in the need to balance "innovation" versus "restoration." "Sometimes we need to go back and restore what's been lost versus pressing forward." Hales noted that sometimes the City had "drifted away" from doing things that worked in the past. For example, he stated that he needed to tell bureaus, "No, city bureaus, you actually have to listen to the community." He also stated that the City had drifted away from community policing and said "We need to get back to it." Hales also said that if we want community members to get involved "They need to have some influence and power"- their involvement should not just be a "box [for city bureaus] to check." Hales said part of his task as ONI Commissioner will be to "try to sort out what drifted. Where do we need fundamental change versus where did we drift away from something we were doing right? Where do we need to go back to it?"

Hales asked group members to share their thoughts on what was working and what was not. Group members asked about his hopes for the update of Portland's Comprehensive Plan. Hales said he wanted to see zoning changed where it needed to be-he wanted results that would make a difference in the community. A number of 
group members complained that city bureaus often did not do a good job of coordinating their work. One East Portland neighborhood activist noted a "fundamental disconnect between BPS and PBOT" on the update to the Comprehensive Plan. While BPS had done significant outreach to the community on the Comp Plan project, PBOT, which was in charge of developing the City's Transportation Services Plan (TSP, a part of the Comp Plan) had only one staff person assigned to community outreach and that PBOT had done little to involve the community in the development of the TSP. Hales said that Commissioner Novick (commissioner in charge of PBOT) is interested and engaged and noted that PBOT has a new director, from Chicago, who still needs to learn about Portland's neighborhood system and how it works.

Another neighborhood coalition director noted a disconnect between BPS and neighborhood associations over recent years because of the loss of the neighborhood planning program. "Now BPS [only] comes out when they want to do a plan for a specific site." The coalition director reported that neighborhood associations, in some cases, are bypassing BPS and building relationships and working directly, usually with larger and more sophisticated developers who see the value of building relationships and learning to work with the communities in which they pursue their projects. This individual asserted that city bureaus also need to build long-term relationships with community groups.

An ONI staff person reported that the updated Comp Plan chapter on community involvement included policies that directed city bureaus to gather information about local communities and to allow city staff to devote time to building relationships with the 
communities they work in. He urged Hales to support relationship building by bureau staff.

A long-time and very involved north Portland neighborhood activist said PBOT needs to create a common community outreach office in the agency to improve its collaboration with ONI and community organizations. She also stressed that city staff need to reach out to and collaborate with community members early in process "before arguments develop." For instance, she urged city bureaus to invite community members to participate in "pre-application" meetings for projects. Hales noted that the commission form of government makes it difficult to coordinate public outreach and information efforts across city bureaus. He reported that Alarcón de Morris had been a good resource to other bureau directors. He also noted that his "PIO" (public information officer) in the mayor's office is attempting to increase cross-bureau coordination and show bureaus that "he's more of a resource than a threat." The north Portland activist emphasized that better coordination also is needed between bureau public information officers and other bureau staff and decision makers working on projects to ensure that community input gets to the right people and has an impact.

Another neighborhood coalition director urged Mayor Hales to remind city bureaus leaders and staff that Portland has invested millions of dollars over 40 years to develop and support Portland's neighborhood system. He asked Hales to tell bureaus, We've invested in the neighborhood system—use it!" A different neighborhood coalition director noted that neighborhood coalition offices often act as valuable liaisons between city bureaus and community members. 
Another neighborhood coalition director identified the Neighborhood Small Grants program as "as the most exciting program ever developed in the system." "It fulfills all of the goals of the [Community Connect] Five-year Strategic Plan." She said that community grantees have been very effective at leveraging additional business and city bureau contributions and resources. She asked the Mayor to restore funding to the grant program "if at all possible." Another neighborhood coalition director added the grant program helped her coalition build relationships with other community organizations. She said coalition office and the organizations continue to collaborate on events and projects.

Hales noted that New York City has lots of businesses who contribute to civic projects, while Minneapolis has a lot of foundation funding. He recognized that in Portland "We don't do a good job on philanthropy." He asked the group whether the Neighborhood Small Grants program should be funded out of the City's General Fund or by local foundations. Alarcón de Morris said both should be involved. One of the neighborhood coalition directors stated that foundations often are not familiar with "community activism" and are unaware of its nature and value. He asked Hales to help raise the visibility of community activism with foundations as something worthy of their support.

An ONI staff person reported that, since the 1970s, people have been calling for the development of a strong, citywide leadership training program for community members, and suggested that this would be valuable ongoing addition to Portland's community involvement system. Hales said leadership development was something he 
wanted to do "on this tour of duty." Alarcón de Morris emphasized that a similar ongoing community involvement training program was needed for city staff as well.

A number of group members said that too often city bureaus are disconnected from each other, and identified this as an ongoing problem for community members. One said bureaus need to talk to each other, not just say "It's not our responsibility" and send community members to a different agency. She said that city bureaus need to improve their communications and take responsibility to make things work, not force community members to chase down all the entities involved in a project or problem and figure out themselves how to get them to work together. Hales said "I want to work on this." Alarcón de Morris noted that disconnects between bureaus also occur when city commissioners in charge of bureaus do not work well together.

A neighborhood activist from east Portland asked Hales for his thoughts on the future of the three entities serving the community in east Portland: the East Portland Neighborhood Office (EPNO), the East Portland Action Plan (EPAP) implementation committee, and East Portland Neighbors (EPN), the non-profit partner organization to the city-run EPNO office. Hales said one of his goals, for whatever structure is developed in the future to serve east Portland, was to retain EPAP's formal involvement of nongeographic communities and issue-based groups. Hales also recognized that EPAP had shown that more people will choose to be involved If incentives exist, "like grants" and "real power" to accomplish things.

After Hales left the meeting, the neighborhood coalition directors agreed to note down and share with each other what was discussed at the monthly check-in meetings 
with the mayor. One director noted that they had forgotten to bring up with the mayor their concerns about inadequate notice by city bureaus and the need for a comprehensive review of City government public policies.

The group members generally found that the meeting with the mayor had gone well and many were hopeful that the mayor would listen to and work with them to continue to improve community involvement in Portland.

\section{Looking to the Future-What Comes Next?}

What's next for Portland's community and neighborhood involvement system? How will the system continue to evolve and move Portland toward greater participatory democracy? In 2013, five years have elapsed since the release of the Community Connect report and the "Five-year Plan to Increase Community Involvement." Many Five-year Plan recommendations have been implemented-others still remain to be implemented. ONI and its neighborhood and community organization partners have identified their own highest priority "next steps." This section describes current priorities for the overall ONI community and neighborhood involvement system and some of the individual programs within the system.

ONI-Broader System Approaches: Major priorities for nearly everyone in the system are to maintain the advances achieved in recent years, restore funding lost during the recent recession (for instance, restored funding for the Neighborhood Small Grants Program), and continue expansion of system funding and resources.

A major strategy being discussed by ONI and its neighborhood and community organization partners is the further expansion of the number and types of community 
organizations formally recognized as part of the system. The system has moved away from its long-time focus on geographic neighborhood associations as the primary vehicles for community involvement with city government, toward a sense of the community as a "fabric" of many different neighborhood and other community organizations.

Geographic organizations-i.e., neighborhood associations and business district associations_continue to be major parts of the larger system, with ONI supporting the neighborhood system and PDC supporting business district associations. In the early 2010s, an owner of a floating home marina approached ONI and Commissioner Fritz in an effort to organize new entity that would represent people who live in floating home communities and work on the Willamette and Columbia Rivers. The river community fits within a defined geographic boundary, could meet the requirements of a traditional neighborhood association, and easily could be served through the City's existing land use notification system. The river community organizer wanted her community to be visible to city leaders and staff and included in decision making. ONI staff considered proposing an amendment to city code and to the ONI Standards to allow the creation of a new category of "special geographic communities." Questions arose of how to negotiate the boundaries of this new entity with the twenty-six neighborhood associations whose boundaries include segments of Portland's rivers. ONI has deferred further discussion of creating a new category for "special geographic communities" until the next review and update of the ONI Standards. 
Non-geographic communities are the most promising and compelling area for expansion of the system. The DCL Program started the process by funding and supporting five community organizations that serve different communities of color and immigrant and refugees. ONI also has formal programs that serve the communities of elders and people with disabilities (i.e., Elders in Action and the Disability Program). Mayor Hales in 2013, also establish a formal role for ONI in working with youth, by establishing ONI as the city agency responsible for fulfilling the City's obligation to support the Multnomah Youth Commission. ONI's role with the Youth Commission easily could expand to encompass broader strategies related to involving youth in civic life and decision making.

ONI staff have begun considering what other communities might be added to the formal system. The most obvious place to start would be with the list of "underrepresented communities" referred to in many different ONI and City government documents. ONI's overall mission directs ONI to support people in these communities to get involved in civic life, build capacity among their leaders and organizations and network with other groups, and help them have a voice and impact in local decision making that affects them.

ONI, in the past, had offered "communities beyond neighborhood boundaries" and "business district associations" the opportunity to meet certain requirements and then be recognized formally by the City, be listed in the ONI directory, and receive land use and other city government formal notices-basically viewing them through a “neighborhood association lens." None of these organizations ever applied to ONI for 
formal recognition. The DCL Program was developed by ONI staff working with representatives of communities of color and immigrant and refugee communities to make sure that the program both served ONI's mission and goals while offering something that these organizations wanted and valued.

In 2012, ONI staff reached out to a number of individuals and organizations from different under-represented communities to find out what kind of support they most needed and wanted. These groups represented: renters, people with disabilities, people experiencing homelessness, youth, the river/water community, and a number of different community organizing and advocacy groups. Nearly all the groups said what they needed and wanted most was leadership training, organizational funding, technical support, and some form of formal status with city government that would give their organizations and community greater visibility and clout with city government leaders and staff. A number of groups said their top priority was to get funding to allow them to provide direct services (e.g., housing, health care, food, etc.). ONI's mission encompasses the former training and capacity building support, but does not include funding direct services (Portland. Office of Neighborhood Involvement. Communities Beyond Neighborhood Boundaries: Themes emerging from community interviews, October 23, 2012).

ONI staff also looked at different levels of relationship and support ONI could offer community organizations. ONI staff developed the following list of possible options: 
- “Acknowledgement:" ONI would include the organization in the list of community organizations it shares with city agencies, the media and other community organizations.

- “Formal Notification:" ONI would include the organization's contact information in the ONI Directory, which city bureaus use to send out formal notices regarding land and other policy issues as required by City Code.

- CCommunity Project Partner:” ONI would fund organizations to implement short-term, smaller-scale community projects through small grant programs, such as the Neighborhood Small Grants Program. Funding levels could range from $\$ 0$ to $\$ 20,000$.

- CCommunity Program Partner:” ONI would negotiate formal grant agreements that would fund (e.g., $\$ 20,000$ to $\$ 100,000$ ) organizations to provide specific services to specific, target, identity-based communities-similar to the funding ONI provides to its DCL Program partner organizations to provide leadership training and organizing support to their communities. Program partner organizations would participate on the ONI BAC and would be encouraged to partner with other ONI partner organizations. ONI funding likely only would be a portion of the partner organization's overall funding and activities.

- “Community Association Partner:” This category would allow ONI to formally recognize organizations that work to help some segment of the community engage in civic issues, often as part of a larger coalition of organizations. Association partners would receive formal standing with ONI and the City and formal notices from 
city agencies, and technical assistance and possibly some minimal funding ( $\$ 0$ to $\$ 2000$ ) through ONI coalition partner organizations. Association partners would be required to meet certain minimum requirements related to openness, transparency, accountability, and outreach to and representation of their particular community. (This model is based on the current status and role in the system of a traditional neighborhood association.)

- CCommunity Coalition Partner:” A coalition partner would be an umbrella organization for a group of community organizations (similar to the role of a neighborhood coalition to its member neighborhood associations). A coalition partner would have a long-term grant relationship with ONI (\$100,000 and up) and would provide a wide range of technical assistance and support to its member organizations and their communities, including training, communications, community organizing, fiscal sponsorships, insurance, etc. Coalition partners would need to comply with ONI reporting requirements and formal ONI standards.

• “Limited Duration Action Committee:” This category represents committees or groups that include representation from a wide range of community organizations and interests and are focused on the implementation of a clear set of action goals_-similar to the role of the East Portland Action Plan Implementation Committee. Annual funding might range from $\$ 200,000$ to $\$ 350,000$, and would be used to pay for staff support and a community small grants program.

- “ONI/City Program:” ONI, or other bureaus in city government, could establish programs to support community involvement in particular communities. Examples of these types of programs include: ONI's Neighborhood Program, DCL 
Program, Disability Program, and BPS's Youth Planner Program. City staff would provide a range of support and coordination services to organizations and individuals in the target communities.

- “City Board or Commission:” The City Council would create a formal, ongoing board or commission that would advocate for the needs and priorities of a particular community. Examples include, the Portland Commission on Disability, the Human Rights Commission, the Multnomah Youth Commission (Portland. Office of Neighborhood Involvement. Draft-Overview of Types of Partnerships available with ONI. October 18, 2012).

Other major, system-wide priorities include:

- $\quad$ Funding Equity Across ONI Partners: The City of Portland has been funding the neighborhood coalitions for forty years. ONI's DCL Program organizations have advocated for increased funding to their organizations to help achieve more equitable funding across different communities in the system.

- $\quad$ City Wide Leadership Academy: Systems reviews back to the 1970s have called for an ongoing, robust, citywide leadership training program. All of ONI's neighborhood and community partner organizations, as well as other community groups ONI has interviewed, support the development of such a leadership training system as an important element in ONI's overall strategy of building capacity for involvement and action in the community.

- $\quad$ More Inclusive District Bodies: Different efforts have been made over time to expand participation on neighborhood coalition boards to include representation 
of business and other community organizations, usually with only temporary success. In 2013, east Portland neighborhood and community activists, ONI staff, and Mayor Hales all are interested in exploring lessons learned from recent collaboration between the East Portland Neighborhood Office, East Portland Neighbors (the EPNO non-profit organization partner) and the East Portland Action Plan. EPAP is a short-term focused process that has involved a wide spectrum of the community. EPNO is an ongoing support structure that focuses primarily on serving east Portland's neighborhood associations. An opportunity exists in east Portland to develop and try out a new district governance and involvement model that could inform the next generation of district bodies for Portland's other six neighborhood district coalitions.

- $\quad$ Increased cooperation between ONI and Office of Equity and Human

Rights: ONI and the Office of Equity and Human Rights both have an interest in increasing equity and ensuring under-represented communities are involved in civic life and have voice in local decision making. In late October 2013, staff from the two offices met to begin to develop a shared vision for the City's equity work and the roles each agency will play in this work. Other entities that also have a stake in equity work within City government include: the OMF Title II ADA and Title VI Civil Rights programs, PIAC, the Portland Commission on Disabilities, and the Human Rights Commission.

Program-Specific Next Steps: Starting in 2011, ONI partner organizations began to discuss and identify their own priorities for the next five years under Community Connect. 
- Neighborhood System: The most immediate priorities for the neighborhood coalitions is to preserve recent additional funding for the neighborhood system and to restore recent cuts in funding — especially for the Neighborhood Small Grants Program. Other priorities include: updating the process and formula for allotting available ONI funding across the neighborhood district coalitions, with a greater emphasis on population and need; development of the city-wide, ongoing leadership training program, mentioned above; preparation of a wide range of "best practices" guides for neighborhood associations - on topics including organizational governance, communications, community outreach, dispute resolution, neighborhood visioning, fundraising, land use, issues advocacy, etc.; and negotiation of the next five-year ONIneighborhood coalition grant agreement to reflect new thinking about broader community involvement and include requirements more clearly tied to an updated performance measurement system (Portland. Office of Neighborhood Involvement. Overview of Neighborhood District Coalition 5-year Strategic Budget Proposal and Priorities Revised September 13, 2011).

- $\quad$ DCL Program: DCL Program partner organizations are seeking increased funding from ONI for each DCL Program partner organization (i.e., $\$ 100,000$ to $\$ 250,000$ each). This funding would allow each DCL Program partner organization to hire two to three staff to support training, organizing, and technical assistance to people and organizations in their communities. ONI and its DCL partners also want to expand the number of community organizations in the program and build and expand relationships with specific ethnic/multiethnic communities in Portland. (ONI staff have 
long considered included the Asian Pacific American Network of Oregon (APANO) as the sixth DCL Program partner organization). The DCL Program partners also would like funding for their own small grants program (Portland. Office of Neighborhood Involvement. DCL Partners-5-Year Strategic Priorities Discussion, August 22, 2011).

- Disability Program: ONI Disability Program Coordinator Nickole Cheron hopes to help the "Connecting Communities Coalition" of people with disabilities develop its capacity and evolve into a "coalition-level" ONI partner and to improve leadership training opportunities for people with disabilities in Portland (Cheron. Conversation with Leistner October 31, 2013).

- $\quad$ Public Involve Advisory Council: The PIAC members hope to receive funding to hire more staff to support PIAC members in their work.

Lessons of the Potter and Post Potter era - 2005 to 2013

The period from 2005 to 2013 represented the greatest expansion of Portland's community and neighborhood involvement system since the system was founded in the 1970s. This section identifies lessons learned related to the three primary research questions of this study:

4. What structures, program elements, policies, and practices did Portlanders find over time are necessary to encourage and support greater community involvement in local decision making and civic life?

5. What dynamics helped or hindered the evolution of Portland's community and neighborhood involvement system? 
6. What does the Portland experience tell us about what it takes to sustain and preserve the advances toward greater participatory democracy?

System Elements: During the period described in this chapter, Potter and Adams restored a number of the system elements that had been lost, and implemented many other long-standing recommendations for the first time.

Community Connect's three goals asserted that any successful neighborhood and community involvement system needs to work to achieve three primary purposes: getting more people involved and connected with each other and the civic life of the community, building capacity in the community in leaders and organizations and helping organization network with each other; and increasing the willingness and capacity of city government to work with community members to ensure that they will have a voice and be able to affect issues and decisions they care about.

Community Connect found that not everyone finds their strongest sense of community through shared geography. Community Connect argued that Portland's system needed to move away from its traditional focus on geographic neighborhood associations as the primary vehicle for community involvement with city government and embrace the concept that many people are more likely to become involved through participation in groups and organizations of people who share their identity, life circumstances, or interest. Community Connect asserted that ONI and the City should support capacity building in and work with all of these different organizations. Traditional neighborhood associations are still very important community organizing 
vehicles but they need to be viewed as elements within a broader and more diverse "fabric" of communities and community organizations.

The importance of ONI's original mission of community empowerment was reaffirmed and reestablished. ONI's capacity to support its mission was greatly enhanced through the hiring of a number of new staff people to support involvement by different groups in the community and by significant additional resources to support ONI's neighborhood and community partner organizations.

Effective community involvement requires adequate funding and support. During the 1990s and early 2000s, neighborhood leaders complained that, city leaders and staff were criticizing neighborhood associations for not involving a greater diversity of their community members, they also were not providing the additional funding and support these volunteer-run organizations needed do this.

A number of system reviews had recommended pushing resources out into the community to help fund community-identified priorities and projects and had recommended that the City fund some sort of neighborhood grant program. Potter funded the establishment of ONI's Neighborhood Small Grants program, which catalyzed tremendous creativity in the community and leveraged substantial community energy and resources. The City also funded community grant programs through Vision into Action and the East Portland Action Plan, which also were very effective tools for involving community members, building capacity and relationships in the community, and achieving community goals. 
Many system reviews also called for formal processes to involve community members in key decision making processes including: the development of the city budget, priority setting for capital improvement projects, and the development of longrange land use plans for the community. Mayor Adams reinstated the bureau budget advisory committees (BACs) and, through OMF, invited community groups to design their own processes to inform and involve their community members in the city budget process. Despite, repeated recommendations for reinstatement of some sort of Neighborhood Needs process, no process has been created to give community members a voice in helping the city identify its priorities for capital improvement spending and projects. Neighborhood planning did not make a comeback, but BPS established the District Liaison Planner Program, which assigned planners to work with communities in different parts of Portland. These district planners have become familiar with the cultures, needs, and priorities of different communities and have helped BPS follow through with planning projects that respond to some community-determined needs. In lieu of a formal neighborhood planning program supported by BPS staff, staff at some of the neighborhood coalition offices have been assisting neighborhood associations and their community members to implement their own visioning processes and to develop actions plans for their own neighborhoods.

Neighborhood and community activists continue to see value in having citywide bodies or mechanisms that allow them to gather, share information, and work together on policies and projects with a citywide focus. The Citywide Land Use Group (CWLU) is the only body that has been able to sustain involvement over a long period of time. The 
monthly meetings of the neighborhood coalition directors and chairs provide some opportunity for neighborhood coalitions to share information and work together but do not provide an opportunity for in-depth policy research and advocacy. The ONA BAC monthly meetings similarly provide an opportunity for representatives of neighborhood coalitions and associations and other ONI community partner organizations to get to know each other and identify issues they might want to work on, but the ONI BAC focuses primarily on policy issues that affect ONI's programs or budget. The monthly meetings of the ONI DCL Program partners have helped them strengthen their relationships and plan some strategic initiatives. Representatives of the DCL Program organizations also participate in the Coalition for Communities of Color, which has been very effective as researching policy issues and advocating for change with the City of Portland and Multnomah County. Community Connect and other system reviews also have recommended holding annual citywide neighborhood and community summits or gatherings to help people connect and identify needs and opportunities to work together. ONI has not organized a citywide neighborhood or community summit since 2004.

The experiences of the later 2000s and early 2010s also emphasized the importance for effective community involvement of skilled staff and good process design. Processes that are very successful at involving community members usually have staff people with strong community involvement values and skills supporting them. Community involvement successes and failures also support the importance of good process design, in all its many aspects. Although, Community Connect produced an important and influential product by the end, the poor process design and implementation 
repeatedly undermined and nearly ended the project. Other processes—-such as, visionPDX, PIAC, and the East Portland Action Plan—show how well-designed processes - that are open, accessible, well-funded, and that treat people with respect, and use approaches and methods tailored to meet the cultures and needs of different communities — are much more likely to be satisfying and productive and encourage community members and city staff to work together in the future. As Mayor Hales noted, EPAP had shown that more people will choose to be involved If incentives exist, "like grants" and "real power" to accomplish things.

Since the founding of Portland's community and neighborhood involvement system, neighborhood and community activists have called on the City to provide timely and relevant notification to affected neighborhood and community members and organizations regarding proposed city government decisions, policies, and programs. They have asserted repeatedly that this "early warning" system is crucial to the ability of individuals and organizations to get involved early when they can have the most impact. Many of the complaints about the City's notification system echo the same complaints made by neighborhood activists in the 1970s. The PIAC Comp Plan Workgroup has identified the need for a major review and update of the City's formal notification system as an important implementation step to follow the adoption of the updated Comprehensive Plan.

The importance of effective leadership training, similarly, has been identified by system reviews throughout the history of the system and was repeated by Community 
Connect and other processes. It appears that Mayor Hales may support the development and implementation of a citywide ongoing community leadership program.

Community Connect, the PITF, and many other system reviews emphasized the need to ensure that city leaders and staff are willing and able to work effectively and constructively with community members and organizations. The PITF recommendations provided a valuable, comprehensive, strategic plan for achieving this goal. The creation of PIAC has provided an strong ongoing body that is developing and advocating for the implement of these recommendations.

Reform Process: Mayor Potter presided over the most significant reform and expansion of Portland's community and neighborhood involvement system since its founding in the 1970s. These changes stand in stark contrast to the neglect and decline of the system under Mayor Katz. The Potter/Adams/Hales period offers interesting insights into factors that set the stage for and allowed these important changes to move forward.

Mayor Potter showed the significant effect a strong political champion, especially a mayor, can have on a City's progress toward greater participatory democracy and a “community governance" culture. Potter used his power as mayor and his influence over the city budget (and the availability of lots of discretionary one-time city revenue) to initiate and support many review processes (e.g. visionPDX, Community Connect, the Charter Review Commission, etc.) that raised attention to and provided important credibility and support for the implementation of many different program and policy initiatives. Potter steered millions of dollars of funding to community involvement projects and programs. He also strengthened the system for the future by establishing 
formal bodies - the Portland Commission on Disabilities, the Human Rights Commission, PIAC, and the Human Relations Office-to carry on this important work after he left office.

Mayors Adams and Hales have continued to support the system and both have played important roles in ensuring that the ONI Commissioner in Charge understands and supports community involvement and have helped soften the negative impact of required budget cuts on ONI programs and ONI's community partner organizations.

"Policy entrepreneurs" within city government and in the community continued to play an important role, both in re-introducing good ideas from the past and developing new ideas as processes moved forward. Many of them served as the work horses behind the many processes during this time period that helped map out needed reforms. Most of the reforms instituted by Mayor Potter had been developed by policy entrepreneurs during earlier processes. One of Potter's primary contributions was to “open the policy window" that allowed these reforms to be implemented.

The role of key studies in shifting public priorities and reframing issues also was very evident during this time period. The Urban League "State of Black Oregon" report and similar reports developed by the Coalition for Communities of Color and PSU served as a strong "wake-up call" for progressive Portland leaders and community members and illustrated the severe disparities many communities of color faced in Portland. The release of these studies during the development of the Portland Plan allowed the Equity TAG members and Mayor Adams to make "equity" the overarching theme and framework of this broad strategic planning process. These studies, as well as reports like 
Community Connect, also were valuable because they helped define problems and mapped out what it would take to solve them. These studies and reports served as valuable resources for policy entrepreneurs who wanted to push these agendas forward.

Embedding: The decline of Portland's community and neighborhood system under Mayor Katz, and City Commissioner Randy Leonard's unilateral attempt to refocus the system on "neighborhood services," were "wake-up calls" for many community members who realized they needed to embed the system's values, structures, and programs more deeply into city government and in the community to protect them in the future.

ONI attempted to "embed" its core mission of community empowerment by revising its mission and goals to reflect the Community Connect goals and values. While Potter funded many of the new programs at ONI through "one-time" funds, ONI staff, ONI BAC members and Commissioner Fritz worked hard to shift many of these programs to "on-going" status so they would become a more permanent feature of ONI's budgets.

As mentioned earlier, Potter helped embed many of his values more deeply into city government's structure by establishing new city commissions and the new Office of Human Relations. Mayor Adams and the Equity TAG members helped embed "equity" as a important policy goal in the Portland Plan policy document adopted by City Council. City staff and community members have worked hard to ensure that equity continues to be a driving force in the development of additional city policies, such as the city's Comprehensive Plan and the city's new Title VI Civil Rights Plan. The creation, by 
Mayor Adams and Commissioner Fritz, of the Office of Equity and Human Rights, the mission of which is to promote equity in city government and the community, established important capacity within city government to keep advocating for and assisting in the implementation of change in city government policies, practices and culture.

PIAC has been the source of some of the most comprehensive and effective efforts to embed community involvement values, policies, and practices in city government. The PITF recommendations provided a valuable strategic plan for this effort. PIAC successfully advocated for the City Council's adoption of the Public Involvement Principles and then moved strategically to incorporate these principles into other policy documents like the Comprehensive Plan and Title VI Civil Rights Plan. PIAC's work on the community involvement chapter of the Comprehensive Plan also will, for the first time in Portland's history, ensure the development of ongoing capacity in BPS to support, review and evaluate community involvement processes and will establish legally-binding requirements that city staff follow basic best practices for community involvement.

Portland's path to participatory democracy has never been more firmly rooted in Portland's city government—and the roots are still growing. 


\section{CHAPTER VIII}

\section{ANALYSIS}

Portland's forty-year effort to increase community involvement in civic life and local decision making offers a rich and valuable case study of how a community can move toward greater participatory democracy. This final chapter circles back to what Thomson (2001) identified as a central question for academics and practitioners who are seeking to bolster civic society: "[W]hat forms of organizations and activities have the potential to bridge the yawning gap between citizens and their governments..." (Thomson 20012 ).

This section answers this study's three primary research questions based on the Portland experience:

1. What structures, program elements, policies, and practices did Portlanders find over time are necessary to encourage and support greater community involvement in local decision making and civic life?

2. What dynamics helped or hindered the evolution of Portland's community and neighborhood involvement system?

3. What does the Portland experience tell us about what it takes to sustain and preserve the advances toward greater participatory democracy?

The overall finding of this study is that a significant advance toward greater participatory democracy and community governance in a community requires a comprehensive strategy that involves many more people in civic life in their community, that builds community capacity to organize and be involved in local decision making, and 
changes local government culture to significantly improve the willingness and ability of city leaders and staff to work in partnership with community members and organizations.

Structures, program elements, policies, and practices: Portlanders, in the 1970s, decided that the minimum community involvement required by law-i.e., formal public notices and public hearings—was not adequate. A number of Portland city leaders and staff and community members had a vision in which city government, neighborhood associations, and community members would work together as partners to shape Portland's future. They created Portland's formal, citywide neighborhood association system, supported it through ONA, and instituted bureau budget advisory committees (BACs), the Neighborhood Needs Process, and a neighborhood planning program to give community members a voice in major city government decisions. To increase the likelihood that neighborhood associations could help shape city government decisions, city agencies were required to give neighborhood associations 30-days notice of city decisions that affected their communities. Portland's community and neighborhood involvement system became nationally known through the work of the Tufts University research team in the late 1980 s. Despite the loss of some of these programs in the 1990s and early 2000s, Portland's neighborhood association system and the city office created to support it-ONA/ONI- endured. Over the decades during which the system has been in place, Portlanders have come to expect that city government (and other local institutions) will make some effort to involve the community in important decisions. Even though Portland has involved the community at higher levels than most cities, Portland neighborhood and community activists, for years, have complained that 
city leaders and staff do not genuinely involve the community in ways in which the community significantly can affect the outcome of processes, that the city does not involve community members early enough, and that city community involvement processes too often are not well designed and implemented and are not effective at reaching out to and involving a broad diversity of people in Portland-especially people from historically under-represented groups.

Two important review processes_-2003-04 Public Involvement Task Force (PITF) and 2005-08 Community Connect - together established an overall strategic plan that finally has provided a road map for significantly improving participatory democracy and community governance in Portland. The PITF focused on what it would take to improve the quality and consistency of city government community involvement. Community Connect took a broader view and identified three primary goals: to involve more, and more diverse, community members in civic life, build community organizing and involvement capacity in the community, and ensure that community members have an impact on local government decision making. Community Connect reinforced a number of the PITF recommendations under its "Goal 3."

Portland's experience reflects many of the academic theories found in the literature and shows how these different theories need to be combined in a larger strategic effort to achieve greater participatory democracy. Key elements needed to move toward greater participatory democracy are described below.

Increase "breadth" and "depth": Berry et al established a basic framework for participatory democracy that includes two key elements: breadth and depth. They suggest 
that "The breadth of a participation effort is the extent to which an opportunity is offered to every community member to participate at every stage of the policy making process," and that "he depth of a participation effort is the extent to which the citizens who choose to participate have the opportunity to determine the final policy outcome by means of the participation process." (54-55). These elements are very much at the heart of the PITF recommendations and the Community Connect goals of involving more people and ensuring they have a greater impact on decision making.

Build Social capital: Putnam and Feldstein make the case that increasing social capital is vital to expanding local democracy..."interpersonal connections and civic engagement among ordinary citizens" are "essential to making participatory democracy work." They also assert that a community needs both "bonding" social capital within groups and "bridging" social capital between groups. These concepts are central to Community Connect Goal One which focuses on getting more people involved in the civic life of the community in a variety of ways - not just forcing them to go to a neighborhood meeting or serve on a city task force. Community Connect recognized that getting people connected to other people in their community is an important gateway to their possible future involvement in community organizing and projects and more structured involvement activities. Putnam and Feldstein's concepts also are reflected in the shift in the Portland system to supporting people organizing with other people with whom they have a shared sense of community or identity (bonding social capital) and then helping neighborhood and community groups network and work together (bridging social capital). Mayor Potter sought to improve basic involvement by community 
members through funding to support expanded neighborhood association communications and especially the creation of the Neighborhood Small Grants Program. The Neighborhood Small Grants Program pushes resources out into the community and gives community members a reason to get organized and work on something they care about. Participation in the program builds awareness and relationships in the community and has led to a number of subsequent partnerships between community organizations that first got to know each other through the grant process.

Support Different Types of Organizations: Warren also argues for the need to build social capital and strengthen the social fabric of local communities by starting with whatever institutions exist in each community, then bridging social capital across communities, and then developing "mediating institutions capable of intervening successfully in politics and government" (19-20). Warren's argument is reflected in the approach developed by Interwoven Tapestry in the early 2000s and the Southeast Uplift DRC and DCLC, in which different groups in the community are supported in organizing within their communities, building on existing structures (like immigrant and refugee "mutual assistance associations"), and developing strength within their own organizations before linking up with other neighborhood and community organizations.

Chaskin argues that "neighborhood governance" requires "the engagement of neighborhood-level mechanisms and processes to guide civic participation, planning, decision making, coordination, and implementation of activities within the neighborhood, to represent neighborhood interests to actors beyond it, and to identify and organize accountability and responsibility for action undertaken." He further argues that individual 
neighborhood associations and other community-based organizations "operate within a local ecology of organizations and inter-organizational relationships" and that a range of associations and organizations may claim to speak for parts of the community. Smock asserts that different community organizing models (including the traditional neighborhood association "civic model") each have their strengths and weaknesses. She argues that one size or type of community organizing model will not work for everyone and in every situation. Chaskin's and Smock's arguments are reflected in the significant shift in Portland's community and neighborhood association system away from the traditional model centered on neighborhood-associations to a system that recognizes and works with a broad array of neighborhood and community organizations that fit the needs, culture, and capacity of the communities they serve.

Build and sustain a city wide system of community organizing vehicles: Berry et al state that a citywide system of neighborhood associations advances participatory democracy by providing community organizing vehicles that community members can use when an important issue or crisis arises. The Portland experience has shown the value of a city-wide system of independent, community-controlled organizing bodies. Participation in individual Portland neighborhood associations ebbs and flows according to the energy and needs of each neighborhood over time, but having established community organizing bodies provides a forum for community members to come together to discuss issues and to organize themselves to take action. ONI is now expanding this concept to ensure similar ongoing organizing capacity for non-geographic communities as well. 
Support community organizing: Most community members do not have the experience, skills, and confidence that would help them effectively engage in local decision making processes. Neighborhood activists long have asserted that they need more support if they are going to expand their outreach to the community and ensure that volunteer-run neighborhood associations are open, welcoming, and effective. Community Connect Goal 2 identifies the need to build capacity in the community by supporting the development of strong community leaders, healthy, well-functioning community organizations and linking community groups together to increase their power and effectiveness.

Smock describes the value of the traditional community organizing approach in which organizing staff reach out to community members and help them develop leadership skills and other skills of effective advocacy. Since the founding of Portland's community and neighborhood involvement system in the 1970s, different system reviews have recognized the need for leadership training and technical assistance to help build strong leaders and effective neighborhood and community organizations. Early on, ONA supported leadership training and technical assistance to neighborhood associations through its contracts with the neighborhood district coalitions. ONA/ONI staff also at different times provided training workshops directly to community members. A central aspect of the DCL Program is leadership training for people of color and immigrants and refugees. Over the years, a number of system reviews have called for the development of an ongoing, robust, community leadership training program-e.g., a Citizen's Academy —in Portland. ONI and its neighborhood and community partner 
organizations_-with apparent support from Mayor Hales—plan to develop a city-wide leadership training program that would be open to community members from all of Portland's different geographic and non-geographic communities.

Portland's experience has shown the importance of ensuring that community leaders and organizations receive support in many areas including, outreach, community organizing, visioning, fundraising, meeting management, advocacy, and dispute resolution. ONI, in 2013, is working with the neighborhood district coalitions and other groups to develop best practices materials in all of these areas. These materials also will provide valuable material from which to design training workshops. ONI is beginning to provide similar support to other non-geographic communities and community organizations.

Establish a multi-tier structure of community organizations: Putnam and Feldstein emphasize the need for people to be able to come together in organizations that allow them to have face-to-face communication with other community members. They also advocate for an approach in which smaller groups are "nested" together in larger organizations or coalitions to help them share information and ideas and build their power.

Portland's experience has shown the value of a multi-tiered structure in which independent neighborhood associations are grouped together in districts which are served by neighborhood district coalition offices. The neighborhood district coalitions provide a forum for neighborhoods to come together and share information and work on issues that transcend the boundaries of any one neighborhood association. 
The 1972 DPO Task Force members discussed the idea of creating a citywide tier that would allow neighborhood associations to come together to work on citywide issues. Thomson advocated this idea again during the 1993 Neighborhood Congress. A city-wide tier never has been implemented in Portland. The felt need continues to exist, however, and over the decades, neighborhood activists have attempted to create citywide bodies to work on policy issues a number of times - the Citywide Land Use Group (CWLU) is the only one that has endured. In lieu of creating a formal citywide body, neighborhood activists often organize temporary ad hoc groups to advocate on citywide issues. Community organizations that serve and advocate for non-geographic communities in Portland naturally tend to organize at a citywide level and, while they still have the challenge of reaching out to and including different sub-groups within their broader community, their basic organizational focus already is citywide.

Many system reviews have emphasized the value of periodically convening community and neighborhood activists from across the city to give them the opportunity to develop relationships and share information. ONA/ONI has organized neighborhood association summits in the past, but not since 2004. Community Connect recommended convening regular neighborhood and community summits that would bring together the full spectrum of community organizing efforts in Portland.

Support a central agency to coordinate and support the system: Portland's experience has shown the value of having an agency within city government that is dedicated to community empowerment and that serves as a bridge between city government and community groups. Attempts to redirect ONI's focus away from 
community empowerment and toward the delivery of human services or other city services has shown the importance of formally establishing and protecting the community empowerment focus of this entity. Adequate funding of this agency and the overall system also is very important. During the 1990s and early 2000s, when funding for ONI and the system stagnated, little progress was made in evolving the system. The significant new resources dedicated to ONI and its neighborhood and community partner organizations under Mayor Potter, showed that major advances require a commitment of adequate resources to get the job done. The ONA/ONI experience also has shown the important role of staff people with strong social justice and community process skills in ensuring that the system stays true to its values and fulfills its potential.

Support Government Capacity and Culture Change: Leighninger found that democratic governance efforts generally take two forms: permanent neighborhood structures, and temporary organizing efforts that include "citizen involvement" and "public engagement processes such as visioning processes, community budgeting, deliberative dialogues, and advisory groups. Sirianni and Friedland argue that "deliberative democracy" depends on city leaders and staff and community members "deliberating about public problems and solutions under conditions that are conducive to reasoned reflection and refined public judgment."

The Portland experience has shown the importance of establishing clear principles and policy requirements in city government that identify community involvement as important and an integral part of the work of city government. The PITF and Community Connect highlighted the need for programs dedicated to involving the community in 
certain important government decisions, including the city budget process, capital improvement project identification and implementation, neighborhood planning, and community policing. PITF also emphasized the importance of effective community process design and implementation and evaluation and sharing of lessons learned to improve community involvement across city government over time.

Create a "Think Tank" to Identify and Advocate for Best Practices: The PITF and Community Connect recommended the creation of a body that would think strategically about community and neighborhood involvement and would share best practices and advocate for reforms and improvements. This body could be within city government, or a local foundation, or university. The City Council's creation of PIAC in 2008, for the first time, established in Portland an ongoing body with the charge and capacity to examine community involvement practices in city government and to develop proposals for improvement. Many past recommendations to improve city government community involvement now are moving forward because of PIAC. In the past, an attempt was made to create a "Center for Public Participation" at Portland State University, but the effort failed when ongoing funding could not be found. PIAC's status as an independent board/commission within city government and the funding of staff support for PIAC through the City's "overhead" model makes it likely that PIAC will continue to play an active role in improving city government community involvement.

Value of an Overall Strategic Plan: The significant changes in Portland's community and neighborhood involvement system that currently are underway are due in great part to the clear vision and guidance provided by Community Connect and the PITF 
report. These documents represent much of the important learning about effective community involvement Portlanders have achieved over the past forty years. These documents attempt to cover all the important elements needed to move Portland's community and neighborhood involvement system toward greater participatory democracy and strong community governance. These documents continue to guide progress toward achieving that vision through clear and comprehensive goals, strategies, and action steps. The PITF and Community Connect carry added weight because they were developed through open, inclusive, and credible processes that included both city staff and community members.

Cities that implement some of the elements described above-such as creating a system of neighborhood associations, or implementing a creative community budgeting process, offering a citizen academy, or implementing occasional innovative community involvement processes - are likely to see improvement in some aspects of their community involvement. However, Berry et al warn that city leaders who open up their processes to greater community involvement sometimes leave community members more dissatisfied rather than less. Exposing community members to some open and inclusive decision making processes can raise their expectations that most of city government should function in the same way. That certainly has been the case in Portland. Over the last forty years, despite all of Portland city government's effort to involve the community, repeated reviews of the Portland's community and neighborhood involvement system have documented neighborhood and community activists continuing to call for better quality and more consistent community involvement. 
The consistency of the complaints over the years indicate that Portland was stuck at an intermediate level on the path to greater participatory democracy. Portland had implemented a citywide neighborhood association structure, required basic formal public notification of public decisions, and offered many different community involvement opportunities. However, many people in Portland—especially people from historically underrepresented communities-were not involved in the basic civic life of their communities and not involved in the neighborhood system or other formal community involvement processes. Neighborhood associations and other community groups varied tremendously in their ability to and interest in reaching out and involving more people in their communities. Community and neighborhood activists continued to feel that the City was not involving them early enough in priority setting and decision making processes and not ensuring that they had an impact on the outcomes of these processes. The quality and consistency of community involvement processes across City government also varied dramatically from processes that were showcases of community involvement best practices to other processes that represented the very top-down and closed processes that Portland had been trying to overcome when it created its community and neighborhood involvement system in the 1970 s.

The comprehensive strategy embodied in Community Connect and the PITF have provided Portland city leaders and staff and community members with a clear path to a higher level of participatory democracy and community governance. The coming years will show whether city leaders and staff and community members can work together and continue to ensure that Portland will be a leader in the nation in community involvement. 


\section{Dynamics that helped or hindered the evolution of Portland's System:}

Kingdon's "multiple streams" theory of public agenda setting explains many of the factors that influenced the original creation of Portland's community and neighborhood involvement system in the 1970s, the stagnation and decline of the system in the 1990s and early 2000s, and the dramatic reform of the system after 2005.

Kingdon asserts that three separate "streams" flow through the government agenda setting system-problems, policies, politics. When these streams come together, problems are more likely to be addressed or proposals moved forward. Policy entrepreneurs and elected officials can play important roles in either creating or taking advantage of open policy windows and moving changes forward.

Problems: Problems are identified through indicators, focusing events, feedback on existing programs, and redefinition of conditions as problems. The frequent studies of Portland's community and neighborhood involvement system played an important role in identifying, repeatedly, what was working and not working in the system. In some cases, studies were done but did not lead to change_-such as Strachan's 1992 report and the subsequent 1993 Neighborhood Congress-because they did not cross other "streams" at the time.

Other studies did lead to changes. In the 1980s, the committee that studied challenges in the functioning of neighborhood associations led to the development of the first formal ONA Guidelines for neighborhood associations. Portland Future Focus early on identified the need to increase the involvement of historically under-represented groups. The 1995-96 Task Force on Neighborhood Involvement set the stage for the 
renaming of ONA to ONI, called for the formal acceptance of alternative district structures, and initiated early efforts to recognize "communities beyond neighborhood boundaries." The Public Involvement Task Force (PITF) developed a broad strategy for increasing the quality and consistency of community involvement by city government, which the Public Involvement Advisory Council (PIAC) now is implementing. Community Connect established a broad strategy for the entire system that helped shape the reforms under Potter and that continues to guide the system's expansion today. The Urban League's "State of Black Oregon" report was one of a number of studies that showed significant evidence of disparities between white Portlanders and Portlanders of color. These studies helped make "equity" the major framework for the Portland Plan and continue to influence the update of Portland Comprehensive Plan and the development of the City's Title II ADA and Title VI Civil Rights plans. Many studies—even if they did not have an effect at the time—-served as background for future studies that often raised similar issues.

Other "focusing events" like the intense conflict over a number of City projects in the late 1960s and early 1970s and again in the late 1990s and early 2000s gave city elected leaders and staff a strong incentive to find better ways to work with the community. The earlier conflicts led to the creation of Portland's neighborhood system and ONA. The latter conflicts led to the creation of the PITF and Community Connect processes and set the stage for Potter's election as mayor and the many system reforms he implemented. 
$\underline{\text { Policies: }}$ Kingdon asserts that loosely knit communities of specialists, including researchers, analysts, and academics, often identify, raise, test, and refine policy alternatives. They engage in a process of "softening up the system" before moving forward. In Portland, these roles often have been played by neighborhood and community activists and sympathetic city staff people. For example, the idea for a neighborhood grants program repeatedly was recommended by different studies of the system over many years before Potter funded the Neighborhood Small Grants Program. Neighborhood and community activists and city staff kept bringing up the idea and researched similar programs in other cities to provide examples of how the program might work. Charles Shi brought up the idea of "communities beyond neighborhood boundaries" during the 1995-96 TFNI process. The Southeast Uplift DRC and DCLC discussed and evolved the concept over a number of years in the early 2000s. The Southeast Uplift DCLC developed and advocated for a number of different policy proposals to provide formal status and support for historically under-represented communities. ONI and the PIAC continue to develop, propose, refine, and advocate for different policies that implement the Community Connect goals and strategies.

$\underline{\text { Politics: }}$ Kingdon noted that elected officials often are more important than any other players inside or outside government at moving policy proposals forward. Other elements that affect the "politics" stream including arrival of a new administration, changes in community mood, and visible players—such as politicians and high level appointees — and hidden players — such as academic specialists, career bureaucrats, and government staffers. 
Many of the greatest advances in the evolution of Portland's system are tied to this "politics" stream. Goldschmidt's election as mayor in 1972 allowed him to support the creation of Portland's formal neighborhood system, ONA, the bureau budget advisory committees, the Neighborhood Needs Process, and neighborhood planning. Potter's election in 2004 gave him the opportunity to implement many important, long-standing recommendations for improving the neighborhood system. Potter created new programs at ONI, established the Human Relations Office, and created a number of commissions. Potter's signature project—visionPDX — involved many groups that had never been involved with the City before and set a new standard for what good, diverse community outreach looked like. Adams' decision to assign responsibility for ONI to Commissioner Fritz, a strong supporter of neighborhood associations and community involvement helped protect many of the advances achieved under Potter. Adams also became a major champion of "equity" in City government policy and programs.

The Portland experience also shows that political leaders can use their political influence to prevent further evolution of the system or actually roll back previous advances. Katz, during her twelve years as mayor, allowed the system to drift and stagnate and dismantled parts of it. She also assigned responsibility over ONI to city commissioners who were not strong supporters of community involvement, and, in the case of Randy Leonard, were actively hostile to ONI's traditional community empowerment role.

Portland neighborhood and community activists have recognized the tremendous importance of having a political champion for community involvement on the city 
council. In 2004, the Neighborhood PAC attempted, unsuccessfully, to organize to give neighborhood a greater voice in the political process. In 2012, a very diverse group of representatives of ONI's neighborhood and community partner organizations and other community activist groups gathered for a facilitated discussion to identify the skills and abilities they all wanted to see in city council members. Participants still plan to use the input from this meeting to develop a candidate questionnaire that they will ask all mayoral and city council candidates to complete. They then will make the results public to help community members consider which candidates best understand and support effective community involvement. ${ }^{136}$ Other neighborhood and community activists have talked about developing a training or briefing they could provide to newly elected city officials to help them learn about community governance concepts and the City's community involvement policies and best practices.

\section{Policy entrepreneurs: Kingdon asserts that policy entrepreneurs "play a major} role in drawing attention to and defining problems." They work to advance their issues, concerns, and pet projects higher on the government agenda. They often work to "soften up the system" to make it more receptive to their ideas and look for opportunities to turn "problems" into "opportunities." Policy entrepreneurs both in the community and in city government have played a major role in shaping some major aspects of Portland's system. For example, in the 1970s, Mary Pederson played a major role in shaping the role of ONA, particularly in advocating for a role for district neighborhood coalition offices in

\footnotetext{
${ }^{136}$ The representatives of the different neighborhood and community organizations that participated in this event, had met and gotten to know each other through their participation on the ONI BAC and other ONI and City advisory committees and project. This event was a good example of how naturally and easily very diverse neighborhood and community groups could come together around a topic they all cared about: having a voice in local decision making.
} 
providing organizing and other technical support to neighborhood associations (despite the fact that the City Council had dropped the district tier from the ordinance that created the early neighborhood system). Margaret Strachan led the focus group review of the neighborhood system in 1992 and then went on to advocate for and help organize the 1993 Neighborhood Congress. Rey España played a major role in seeding the idea that non-geographic communities need to be supported in organizing themselves first rather than forcing them to work through the existing neighborhood association system. España strongly influenced the development of what became ONI's DCL Program and ONI's current effort to seek to understand better and support other non-geographic communities as well.

Portland's experience has shown the value of frequent studies and evaluations to draw attention to what is working and what is not about community involvement in a community, the importance of having political champions on the city council, and the importance of giving policy entrepreneurs opportunities to share their ideas in settings in which people are likely to listen to them and help advocate for the implementation of their ideas.

Sustaining and Preserving Advances: Portland's experience also shows the importance of embedding advances toward greater participatory democracy to reduce the chance that they will be rolled back. Cooper (2011) notes that the long-standing cultural tradition in public agency leaders and staff is that the public has a fairly limited role in policy development and the day-to-day operations of government. Leighninger (2006) refers to this model as an "adult-child" relationship between government and the 
community. The National League of Cities asserts that "Ensuring the effective governance of the community...requires different skills and attitudes than the ones taught in most public administration schools." Gibson argues that a shift to more "citizen-based approaches" to governance needs to focus "primarily on culture change."

Gibson argued that the challenge is to inculcate a "deeper and more firmly entrenched cultural ethos of civic engagement." Cooper (2011) states that a more "citizen-centered" governance approach requires moving away from an emphasis on "particular participatory techniques, specific projects, and particular problems" and toward a broader "citizen-centered approach" that includes an adequate culture of engagement to "sustain and effectively employ" community involvement best practices. Stone (1998) argues that the culture reform requires altering subsystem relations and establishing" and "institutional legacy" to ensure that changes last. He argues that the inner core of a subsystem rarely reforms itself and requires outside pressure to achieve and sustain reform.

On one level, embedding greater participatory democracy in a community involves raising the expectations of both community members and city leaders and staff for what good community involvement looks like. Portland for years has been known as a city that values public process-but complaints also arise that there is too much process or that processes are not well designed or implemented. In any case, Portlanders expect some level of community involvement in important decisions. Even critiques of Portland's process-heavy culture chastise outsiders who run into trouble for not adequately involving the community, and for not understanding "the Portland way" of 
doing things. Community members' perception that city council members had violated "the Portland way" and had stopped listening to the community helped fuel the strong community support for Tom Potter's successful run for mayor.

Community involvement practices, in addition to being embedded in general community and government expectations, need to be embedded in the policies, structures, and daily practices of city government leaders and staff. Fernandez and Rainey (2006) identified seven elements required to achieve lasting reforms in public sector agency organizational culture: Ensure the need, Provide a Plan, Build Internal Support for change and Overcome Resistance, Ensure top-management Support and Commitment, Build External Support, Provide Resources, Institutionalize Change, and Pursue Comprehensive Change. PITF recommended and PIAC is implementing many of these strategies for change.

Portland was successful early on in embedding aspects of its community and neighborhood involvement system in city government through the adoption of the 1974 and 1975 ordinances that established the formal neighborhood system and ONA, and established roles and responsibilities for neighborhood associations, city agencies and ONA. Important early community involvement programs like the BACs, Neighborhood Need Process, and neighborhood planning, although referred to in the early ordinances, all functioned for a time but then were discontinued. The City Council's adoption, in 1996, of the Public Involvement Principles and city government Outreach Handbook, had little effect on improving city government because no follow up occurred to be sure that they were used widely and consistently. Commissioner Leonard's unilateral effort to 
refocus ONI on delivery of city services in neighborhoods led to ONI BAC's later revision of the ONI mission and goals to reflect the Community Connect goals.

PITF saw that the need to embed community involvement values and practices more deeply into city government was a major priority. PITF recommended a number of actions that later were recommended again by Community Connect. Some PITF recommendations focused on embedding community involvement in city government structures and policies. One was the creation of, and staff support provided for, PIAC as an ongoing body charged with improving the quality and consistency of city government. PIAC developed and the City Council later adopted new, revised community involvement principles for city government. PIAC members are working with BPS staff to develop new community involvement goals and policies for Portland's Comprehensive Plan that city staff would be required to follow. PIAC members plan to advocate for the City Council to require each city bureau to develop an overall community involvement policy that fits their particular bureau's work. The prominent role that "equity" played in the Portland Plan provided another important policy support for improving city government community involvement. The City of Portland Title II ADA plan and Title VI Civil Rights plan are examples of other legally binding policies that have a strong community involvement component. The adoption of community involvement values and best practices into formal city policy documents also has provided an opportunity for the City Ombudsman and the City Auditor to respond to and investigate complaints from community members and organizations about poor community involvement by city agencies. 
The PITF also recognized the importance of inserting community involvement into the priorities and incentives for city employees. The PITF called for community involvement requirements to be included in the job descriptions of all city bureau directors and senior staff and that these requirements would be part of their performance reviews. PIAC members also began to institute measures to raise awareness of and track community involvement activities of city bureaus through the FIPIS form that city staff need to complete with every item going to City Council for approval. The PITF also began documenting city bureau community involvement policies, capacity, and practices through the Baseline Assessment survey.

In addition to embedding community involvement in policies and performance tracking, PIAC members recognized the importance of understanding and providing city staff with the support they need to be able to better involve the community in their work. PIAC members are beginning to develop best practices materials, including the Comp Plan community involvement manual, and plan to develop and offer a number of training workshops for city staff on different aspects of community involvement. The need to build skills and confidence in city staff, mirrors the similar need on the community side to provide community involvement best practices guidance and leadership training to community and neighborhood leaders.

PIAC also is fulfilling the role of the community involvement "think tank" that the PITF and Community Connect recommended. PIAC will be able to track and evaluate progress toward changing the culture and practices of city government and will be able to 
continue to develop new policy and program proposals and advocate for their implementation to ensure that progress continues.

Future Research: Portland's ongoing efforts to support and expand community and neighborhood involvement offers many opportunities for additional research and learning. Some interesting possible study topics include:

- The ONI DCL Program is five years old. What has the program revealed about involving communities of color and immigrant and refugee communities in civic life and local decision making? How will the program evolve to include more groups or expand that funding and support ONI's DCL Program partner organizations provide to their community members?

- ONI is starting to learn about the needs of other non-geographic communities in Portland—-such as youth, homeless, LGBTQ, renters, disability, and elders. What particular needs do these groups have regarding community organizing and engaging in local decision making? What capacity do they already have? What organizations or structures already exist to support them? What additional support might ONI provide that would help these communities become more organized and effective?

- The Public Involvement Advisory Council (PIAC) is a very unusual body and process that offers significant promise of achieving the deeper city government culture change that many researchers have said is needed to advance toward greater participatory democracy. A study of PIAC's role 
in and effect on city government attitudes toward and practice of community involvement would be valuable, as would studies of different PIAC initiatives such as (1) the proposed new community involvement goal and policy language for Portland's Comprehensive Plan; (2) the implementation of PIACs recommendations for bureau budget advisory committees, (3) PIAC's effort to support all city bureaus to develop a public involvement policy, and (4) PIAC efforts to track and report on community involvement activities across city government.

- The Neighborhood Small Grants Program has been very popular in the community and appears to have catalyzed significant community creativity and build capacity in individuals and community organizations and encouraged the development of new relationships between community groups. A study that would document the effects and value of this program would help city leaders and community members judge the program's value and its long-term effects on individuals and organizations that have participated in the program.

- The East Portland Action Plan is viewed by many in city government and the community as one of the most inclusive and effective community involvement processes in Portland's history. A study of the process, impacts, and lessons learned from EPAP would be very helpful.

- East Portland neighborhood and community activists, ONI, and the City Council all are interested in exploring whether the experience with the 
EPAP, EPNO, and EPN bodies in east Portland could lead to the development of a new, more inclusive and effective district-level entity that could serve as a model for the next generation of district level bodies in Portland's community and neighborhood involvement system.

Documentation of this process and an evaluation of its outcome would be valuable. 


\section{REFERENCES}

Abbott, Carl. Portland: Planning, Politics and Growth in a Twentieth-Century City. Lincoln, NB: University of Nebraska Press, 1983.

Adler, Sy and Gerald F. Blake. "The Effects of a Formal Citizen Participation Program on Involvement in the Planning Process: A Case Study of Portland, Oregon." State and Local Government Review, 22.1, Winter 1990. 37-43.

Alarcón de Morris, Amalia. Office of Neighborhood Involvement. Email to Cece HugleyNoel et al.RE: BIP 8 Contact Assignments December 29, 2005

Alarcón de Morris and Paul Leistner. "From Neighborhood Association System to Participatory Democracy: Broadening and Deepening Public Involvement in Portland, Oregon." National Civic Review. (Summer 2009): 47-55.

American Institute of Certified Planners. Code of Ethics and Professional Conduct. Revised October 3, 2009.

Barber, Benjamin. Strong Democracy: Participatory Politics for a New Age. Berkeley, CA: University of California Press, 1984.

Berry, Jeffrey M., Kent E. Portney, and Ken Thomson. The Rebirth of Urban Democracy. Washington, D.C.: The Brookings Institution, 1993.

Boyte, Harry C. Everyday Politics: Reconnecting Citizens and Public Life. Philadelphia, PA: University of Pennsylvania Press, 2004.

---. The Citizen Solution: How You Can Make a Difference. St Paul, MN: The Minnesota Historical Society Press, 2008.

---. "We the People” Politics: The Populist Promise of Deliberative Public Work. Dayton, OH: Kettering Foundation, 2011.

Chaskin, Robert J. "Fostering Neighborhood Democracy: Legitimacy and Accountability Within Loosely Coupled Systems." Nonprofit and Voluntary Sector Quarterly, 32.2, (June 2003), 161-189.

Citywide Parks Team. Web. 〈http://explorepdx.org/pcwpt.html> . Downloaded October 17, 2013.

Coalition for a Livable Future. Regional Equity Atlas. 2007. Web. <http://clfuture.org/equity-atlas $>$. Downloaded November 3, 2013. 
Cooper, Terry L, Thomas A Bryer and Jack W. Meek. "Citizen-Centered Collaborative Public Management." Public Administration Review Special Issue (December 2006): 76-88.

Cooper, Terry L. "Citizen-Driven Administration: Civic Engagement in the United States." The State of Public Administration: Issues, Challenges and Opportunities. Ed. Donald C. Menzel and Harvey L. White. Armonk, NY: M. E. Sharpe, Inc., 2011, 238-256.

Curry-Stevens, A. and A Cross-Hemmer and Coalition of Communities of Color. Communities of Color in Multnomah County: An Unsettling Profile. 2010. Portland, OR: Portland State University.

De Tocqueville, Alexis. Democracy in America. Ed. Richard D. Heffner. New York: Penguin Books USA, 1956.

Diers, Jim. Neighborhood Power: Building Community the Seattle Way. Seattle, WA: University of Washington Press, 2004.

East Portland Action Plan. Structure. [no date]. Web. <http://eastportlandactionplan.org/sites/default/files/2013.02.20\%20EPAP\%20Gr oup\%20Structure.pdf $>$. Downloaded October 23, 2013.

---. Committees and Representatives. [no date]. Web. $<$ http://eastportlandactionplan.org/sites/default/files/2013.12.02\%20Committees\% 20\%26\%20Representatives_0.pdf> . Downloaded October 23, 2013.

Evans, Sara M. and Harry C. Boyte. Free Spaces: The Sources of Democratic Change in America. Chicago: The University of Chicago Press, 1992 ed.

Fagotto, Elena and Archon Fung. Sustaining Public Engagement: Embedded Deliberation in Local Communities. East Hartford, CT: Everyday Democracy, 2009.

Fernandez, Sergio and Hal Rainey. "Managing Successful Organizational Change in the Public Sector.” Public Administration Review 66.2 (March 2006): 168-176.

Fisher, Robert. Let the People Decide: Neighborhood Organizing in America. Updated ed. New York: Twayne Publishers, 1994.

Fung, Archon. Empowered Participation: Reinventing Urban Democracy. Princeton, N. J.: Princeton University Press, 2004. 
Gastil, John and Peter Levine. The Deliberative Democracy Handbook. San Francisco: John Wiley \& Sons, Inc., 2005.

Gibson, Cynthia M. "Citizens at the Center: a new approach to civic engagement." Case Foundation. 2006.

Grossman, Susan and Gumz, Edward. "Majority-Based Neighborhood Organizing and Its Role in Contemporary Community Practice." Journal of Community Practice, 112 (2003): 47-65.

Hovey, Bradshaw. "Making the Portland Way of Planning: The Structural Power of Language." Journal of Planning History, 2.2 (2003): 140-173.

Irazábal, Clara. City Making and Urban Governance in the Americas: Portland and Curitiba. Burlington, V.T.: Ashgate Publishing Company, 2005.

Johnson, Steven Reed (2002). The transformation of civic institutions and practices in Portland, Oregon, 1960--1999. Ph.D. dissertation, Portland State University, United States -- Oregon. Retrieved May 28, 2012, from Dissertations \& Theses @ Portland State University. (Publication No. AAT 3119017).

Kingdon, John W. Agendas, Alternatives, and Public Policies. Boston: Little, Brown and Company, $2^{\text {nd }}$ ed. 1995.

Kretzmann, John P and John L McKnight. Building Communities from the Inside Out: A Path Toward Finding and Mobilizing a Community's Assets. Chicago, IL: ACTA Publications, 1993.

Leighninger, Matthew. The Next Form of Democracy: How Expert Rule is Giving Way to Shared Governance... and Why Politics Will Never be the Same. Nashville, TN: Vanderbilt University Press, 2006.

Leighninger, Matt and Bonnie C. Mann. Planning for Strong Local Democracy. Washington, D.C.: National League of Cities, 2011.

Mathews, David. Politics for People. $2^{\text {nd }}$ ed. Urbana, IL: University of Illinois Press, 1999.

Migration Policy Institute. Building the New American Community. 2004.

---. Building the New American Community. [no date]. Web. <http://www.migrationpolicy.org/news/BNAC_REPT_SUM.pdf> . Downloaded on May 28, 2013. 
---. Press Release. "Immigrant Integration Project Shows Promising Results." December 9, 2004.

Multnomah. County Commission. Resolution No. 07-102 22 May 2007.

---. Elections. Election Results and History. May 15, 2007 -Election Results. Web. 〈http://web.multco.us/elections/may-15-2007-election-results > . Downloaded October 8, 2013.

---. Election Archive. May 18, 2004 Primary Election. Web. < http://web.multco.us/elections/may-18-2004-primary-election> .

---. Election Archive. November 2, 2004 General Election. Web. < http://web.multco.us/elections/november-2004-general-election> .

---. Election Archive, November 2, 2010 General Election. Web. <http://web.multco.us/elections/november-2010-general-election> . Downloaded October 27, 2013.

---. Election Archive, May 152012 Primary Election-Election Results. Web. http://web.multco.us/elections/may-15-2012-primary-election .

---. Multnomah Youth Commission. "Home." Web. <http://web.multco.us/multnomahyouth-commission> .Downloaded October 27, 2013.

---. Online Voter's Guide: Nov. 2004 General Election-City of Portland Mayor. Web. <http://web.multco.us/elections/november-2004-general-election-city-portlandmayor $>$.

Morse, Ricardo S. "Citizens Academies: Local Governments Building Capacity for Citizen Engagement." Public Performance \& Management Review, 36.1 (September 2012): 79-101.

National League of Cities. "The Rise of Democratic Governance: How Local Leaders are Reshaping Politics for the $21^{\text {st }}$ Century." Washington, D.C.: National League of Cities. [no date].

Neighbors West Northwest. Community Advocacy in Action. Event flyer. March 31, 2009.

Oregon. Statewide Planning Goals and Guidelines, Goal 1: Citizen Involvement. Oregon Administrative Rules, OAR 660-015-0000(1), December 1974. 
Pedersen, Mary. A Five-year Evaluation of Portland's Neighborhood and Citizen Participation Program. Office of Neighborhood Associations, October 1979.

Pedersen, Mary. Neighborhood Organization in Portland, Oregon: First Annual Report. Portland. Office of Neighborhood Associations, August 1974.

Perlman, Lee. Welcome to Portland, A Neighborhood Unfriendly City. 1998

Portillo, Frances and Lew Frederick. A Framework for Action: Findings and Recommendations: Creation of a Human Relations Entity for the City of Portland. January 3, 2007.

Portland Future Focus. Portland Future Focus Strategic Plan. August 1991.

Portland's Neighborhood System: Government By and For the People. [Directors and chairs of Portland's neighborhood district coalitions.] January 13, 2005.

Putnam, Robert D. Bowling Alone. New York: Simon \& Schuster, 2000.

Putnam, Robert D. "E Pluribus Unum: Diversity and Community in the Twenty-first Century: The 2006 Johan Skytte Prize Lecture." Scandinavian Political Studies 30.2 (2007): 137-174.

Putnam, Robert D. and Lewis M. Feldstein, with Don Cohen. Better Together: Restoring the American Community. New York: Simon \& Schuster, 2003.

Rhodes, Amanda. Email from Amanda Rhodes to Tracey Braden at Portland State University. Subject: Available: Outreach and Engagement Coordinator Position. March 16, 2006.

Seattle. Race and Social Justice Initiative. About RSJI. Web. <http://www.seattle.gov/rsji/about.htm> . Downloaded October 24, 2013.

Seltzer, Ethan and Sumner Sharpe and Margaret Strachan. Imagine a City of Engaged, Articulate Citizens and Neighborhoods. November 11, 2003.

Shi, Charles. "Breaking the Cycle of Victimization." Task Force on Neighborhood Involvement, Briefing Book, Section 11: Charles N.C. Shi: Comments on Working with Immigrant Families. December 1994.

---. "Neighborhood Without Border (for New Immigrant/Refugee Community.)"Breaking the Cycle of Victimization." Task Force on Neighborhood Involvement, Briefing Book, Section 11: Charles N.C. Shi: Comments on Working with Immigrant Families. November 1994. 
Sirianni, Carmen. Investing in Democracy: Engaging Citizens in Collaborative Governance. Washington, D.C.: The Brookings Institution, 2009.

Sirianni, Carmen and Lewis A. Friedland. The Civic Renewal Movement: Community Building and Democracy in the United States. Dayton, OH: Charles F. Kettering Foundation, 2005.

---. Civic Innovation in America: Community Empowerment Public Policy, and the Movement for Civic Revival. Berkeley, CA: University of California Press, 2001.

---. "Deliberative Democracy." Civic Dictionary. Civic Practices Network. [no date]. Web. <http://www.cpn.org/tools/dictionary/deliberate.html>. Downloaded 10 November 2013.

Skocpol, Theda and Morris P. Fiorina, eds. Civic Engagement in American Democracy. Washington, D.C.: The Brookings Institution, 1999.

Smock, Kristina. Democracy in Action: Community Organizing and Urban Change. New York: Columbia University Press, 2004.

---. Comments to Bureau Innovation Team 8. 19 October 2005.

Somerville, Peter. "Community Governance and Democracy." Policy \& Politics 33.1 (January 2005): 117-144.

Southeast Uplift. Board of Directors. Minutes June 3, 2002.

---. A Brief History of the DRC [prepared by Lisa Laurenceau] [no date].

---. DCLC working draft proposal. [dcl_pilot_jan_19.doc, saved on January 19, 2005].

---. Diversity and Representation Committee.

---. ---. Guiding Principles January 28, 2003

---. ---. Make Your Voice Heard! Report October 2002.

---. ---. Meeting Notes June 25, 2002.

---. ---. Meeting Notes June 24, 2003.

---. ---. Meeting Notes, August 26, 2003. 
---. ---. Memo to GREAT Committee on Communities Beyond Neighborhood Boundaries, October 10, 2003.

---. ---. Proposal for Community Outreach 8 October 2003.

---. “diversity_project_summ_draft.doc”[saved June 24, 2004].

---. The Homelessness Work Group: Summary Report, August 2004.

---. Hoyt memo to DCLC members, April 26, 2004.

---. Kennedy-Wong memo to Mayor Katz, March 24, 2004.

---. Project Concept \#1. [people_of_color_acad.doc”, saved February 2, 2005].

---. Project Concept \#2. [2_system_imprv.doc, saved April 27, 2005].

---. Project Concept \#4. [4_Academy_Broad.doc, saved January 20, 2005].

---. Testimony before Oregon State Land Conservation and Development Commission. May 1, 2008.

Stewart, Phil. "Self-Organizing and Community Politics." Connections. Dayton, OH: Kettering Foundation, 2008, 25-26.

Stone, Clarence, ed. Changing Urban Education. Lawrence, KS: University Press of Kansas, 1998.

Strachan, Margaret. Strengthening Citizen Participation through Neighborhood Associations: Future Focus Goals. Prepared by the Portland Office of Neighborhood Involvement. October 30, 1992.

Thomson, Ken. From Neighborhood to Nation: The Democratic Foundations of Civil Society. Hanover, NH: University Press of New England, 2001.

Urban League of Portland. Racial Equity Strategy Guide. Web.

<http://ulpdx.org/racialequitystrategyguide/> . Downloaded November 1, 2013.

---. The State of Black Oregon. July 2009.

United States. Department of Justice. Press Release. Justice Department and the City of Portland, Ore., Reach Preliminary Agreement on Reforms Regarding Portland Police Bureau's Use of Force Against Persons with Mental Illness. September 13, 2012. 
Warren, Mark R. Dry Bones Rattling: Community Building to Revitalize American Democracy. Princeton, N. J.: Princeton University Press, 2001.

Witt, Matthew Thomas (2000). Dialectics of control: The origins and evolution of conflict in Portland's Neighborhood Association Program. Ph.D. dissertation, Portland State University, United States -- Oregon. Retrieved May 28, 2012, from Dissertations \& Theses @ Portland State University.(Publication No. AAT 9987137).

\section{City of Portland}

Portland. Bureau Innovation Project 8.Meeting Notes 3 August 2005.

---. ---. Meeting Notes 21 October 2005.

---. ---. Meeting Notes 2 November 2005.

---. ---. Meeting Notes 1 February 2006.

---. ---. Meeting Notes 3 May 2006.

---. Bureau of Planning. Southwest Community Plan: Vision, Policies, and Objectives. July 2000.

---. Bureau of Planning and Sustainability. Community Involvement Policy Expert Group. Survey of Community Involvement in Portland's Planning and Development [fall 2012]

---. ---. Comprehensive Plan Update: Policy Expert Groups. Web. <http://www.portlandoregon.gov/bps/58187. Downloaded October 30, 2013.

---. ---. East Portland Action Plan. Adopted February 18, 2009.

---. ---. Memo from Susan Anderson to Mayor Adams and City Council. East Portland Action Plan Annual Report. April 2, 2010.

---. ---. Youth Manual. [ no date]. Web. <http://www.portlandoregon.gov/bps/article/436057> .Downloaded October 27, 2013.

---. Butman, Laurel. Email to ECEQL TAG members, April 23, 2010. 
---. Charter Commission. City of Portland Charter Commission 2011 Report [no date].

---. City Budget. FY 1973-74 to FY 2013-14.

---. Citizens Commission on Homelessness. Home Again: A 10-year plan to end homelessness in Portland and Multnomah County. December 2004.

---. City Charter.

---. City Commissioner Charles Jordan. Letter to Robert Butler 2 August 1979.

---. ---. Memo from Peter Engbretson to Chris Thomas 28 January 1980.

---. City Commissioner Dan Saltzman. Press release. "Saltzman Announces New Neighborhood Focus" 7 March 2001.

---. City Council. Ordinance 1378167 February 1974.

---. ---. Ordinance 14090526 November 1975.

---. ---. Ordinance 15992829 July 1987.

---. ---. Ordinance 1744103 May 2000.

---. ---. Ordinance 17466713 July 2000.

---. ---. Ordinance 17633620 March 2002.

---. ---. Ordinance 17688412 September 2002.

---. ---. Ordinance 179258 as amended 18 May 2005.

---. ---. Ordinance 1816515 March 2008.

---. ---. Ordinance 18167019 March 2008.

---. ---. Ordinance 1821523 September 2008.

---. ---. Ordinance 18281927 May 2009.

---. ---. Ordinance 18341016 December 2009.

---. ---. Ordinance 1837485 May 2010. 
---. ---. Ordinance 18443023 February 2011.

---. ---. Ordinance 184880 as amended 21 September 2011.

---. ---. Ordinance 18536630 May 2012.

---. ---. Ordinance 18610719 June 2013.

---. ---. Public hearing minutes 7 February 1996.

---. ---. Resolution 3531819 October 1994.

---. ---. Resolution 3532227 October 1994.

---. ---. Resolution 354947 February 1996.

---. ---. Resolution 356677 January 1998.

---. ---. Resolution 3611013 November 2002.

---. ---. Resolution 363469 November 2005.

---. ---. Resolution 3657016 January 2008.

---. ---. Resolution 3658227 February 272008.

---. ---. Resolution 3665817 December 2008.

---. ---. Resolution 3643216 August 2006.

---. ---. Resolution 3644718 October 2006.

---. ---. Resolution 3657116 January 2008.

---. ---. Resolution 3668218 February 2009.

---. ---. Resolution 368074 August 2010.

---. ---. Resolution 3683615 December 2010.

---. ---. Resolution 3696026 September 2012.

---. Citywide Administrative Service Review. Framework Plan: Public Information/Public Involvement 1 February 2001. 
---. Charter Review Commission. A City Government for Portland's Future: Charter Review Commission Report to City Council. January 18, 2007.

---. Charter Review Commission. Meeting notes. January 24, 2011.

---. Commission on Disabilities. Our Mission. Web. [no date].

<http://portlanddisability.com/our-mission/> . Downloaded October 26, 2013.

---. Community Connect. A City for All of Us-More Voices, Better Solutions:

Strengthening Community Involvement in Portland: Community Connect Final Report. January 2008.

---. ---. Meeting Notes and meeting materials 24 August 2006.

---. ---. Meeting Notes 28 September 2006.

---. ---. Meeting Notes 26 October 2006.

---. ---. Meeting Notes 30 November 2006.

---. ---. Meeting Notes 21 February 2007.

---. ---. Meeting Notes 22 March 2007.

---. ---. Meeting Notes 31 May 2007.

---. ---. Meeting Notes 21 June 2007.

---. ---. Meeting Notes 23 August 2007.

---. ---. Meeting Notes 25 October 2007.

---. ---. Meeting Notes 1 November 2007.

---. ---. Retreat Summary July 21, 2007.

---. ---. Retreat materials August 4, 2007.

---. ---. Summary of Research: Piecing Together Community Engagement in Portland July 2007

---. District Planning Organization Task Force. Task Force Report. December 28, 1972. 
---. Immigrant and Refugee Task Force. New Portlanders Speak, December 2007.

---. Project Interwoven Tapestry. Receiving Community Retreat, Saturday, August 25, 2001, “Tapestry Community Group Recommenations.doc" [saved September 17, 2001].

---. ---. Accomplishments 2001-2003,"“Accomplishments 4.10.03.doc” [saved on April 22, 2003]).

---. Letter to Sanj Balajee from City of Portland Bureau Directors regarding Community Connect Draft Recommendations. October 11, 2007.

---. Memo from Commissioners Francesconi, Leonard, and Saltzman to City Bureau Directors et al. Citywide Public Involvement Standards Taskforce. April 2, 2003

---. Memo from Mayor Adams and City Commissioner to Bureau Directors \& Senior Bureau Managers. Announcing Implementation of the 'Bureau Public Involvement Baseline Assessment' Survey. June 25, 2012.

---. "Mayor's Budget Message." City Budget. [for each year from FY 1973-74 to FY 2013-14].

---. Office of Equity and Human Rights. About OEHR. Web. <http://www.portlandoregon.gov/oehr/62229> . Downloaded November 1, 2013.

---. Office of Neighborhood Associations. BAC information sheet. [no date-appears to be from the mid 1980s].

---. ---. Guidelines for Neighborhood Associations, District Coalition Boards, and the Office of Neighborhood Associations. April 1987.

---. ---. Guidelines for Neighborhood Associations, District Coalition(s), and the Office of Neighborhood Associations. January 1992.

---. ---. Memo from Diane Linn to Sam Adams 18 February 1994.

---. ---. ONA Review Committee. Final Report. February 25, 1980.

---. ---. ---. Hearing November, 7, 1979, meeting notes 3-4; from Carl Abbott personal file; and notes from Jacobsen interview and meeting with area coordinators.

---. ---. Overview of Neighborhood District Coalition 5-year Strategic Budget Proposal and Priorities Revised September 13, 2011. 
---. ---. Report and Recommendations of the Task Force on Neighborhood Involvement. February 7, 1996.

---. ---. The Top 10 Resolutions from the 1993 ONA Neighborhood Congress. [no date].

---. Office of Neighborhood Involvement. Administrative Services Review Team-Public Involvement and Public Information. Meeting Summary 27 September 2000.

---. ---. An Outreach and Involvement Handbook for City of Portland Bureaus. First Edition. Fall 1995.

---. ---. Communities Beyond Neighborhood Boundaries: Themes emerging from community interviews. [Prepared by Brian Hoop]. October 23, 2012.

---. ---. DCL Partners-5-Year Strategic Priorities Discussion. August 22, 2011.

---. ---. Draft-Overview of Types of Partnerships available with ONI. [Prepared by Brian Hoop], October 18, 2012.

---. ---. Elizabeth Kennedy-Wong. Memo to coalition directors and David Lane, June 13, 2001.

---. ---. Email from David Lane to Elizabeth Kennedy-Wong and others, March 52001.

---. ---. Email from Elizabeth Kennedy-Wong, SE Uplift executive director to David Lane and others, March 5, 2001.

---. ---. Evaluation Report: City Wide CIP Open House: Fall 2001 December 2001

---. ---. Guidelines for Neighborhood Associations, District Coalitions, Neighborhood Business Associations, Communities Beyond Boundaries, Alternative Service Delivery Structures, and the Office of Neighborhood Involvement. January 1998.

---. ---. "Inside ONI," "Mission, Goals and Values." Web. Adopted April 10, 2010. <http://www.portlandoregon.gov/oni/28363> . Downloaded October 20, 2013.

---. ---. Interwoven Tapestry Project Monthly Update. December 2002.

---. ---. Joleen Classen. “overview of R\&R spring 2001” [saved June 7, 2001].

---. ---. "Mayor's Memo," for “Ordinance Title: Approve three grant agreements for the $2^{\text {nd }}$ year of the Neighborhood and Community Engagement Initiative," September 18, 2007. 
---. ---. NICE project brochure, 2007.

---. ---. Performance Indicators for District Coalition and Neighborhood Offices, 2006.

---. ---. Public Involvement Task Force Report: A Strategic Plan for Improving Public Involvement in the City of Portland. October 2006.

---. ---. Standards for Neighborhood Associations, District Coalitions, Business District Associations, and the Office of Neighborhood Involvement. July 13, 2005.

---. ---. Public Involvement Task Force. Public Involvement Task Force-2003-04. Web. www.portlandonline.com/oni/index.cfm?c=29118 . [Downloaded October 17, 2013]).

---. ---. ---. Who is on the Task Force? 2004. Web. <www.portlandoregon.gov/oni/article/122082> . [Downloaded October 17, 2013].

---. ---. ---. Workgroup Descriptions and Documents for Public Involvement Task Force. Web. <222.portlandonline.com/oni/index.cfm?c=31198> . Downloaded October $27,2013]$.

---. Office of the City Auditor. Drafting Manual: Ordinances, Resolutions, Reports, May 2013.

---. ---. Managing for Results. December 2002.

---. ---. Urban Services Policy and Resolution A. March 2013.

---. ---. Annual Community Survey Results [for years 2009, 2010, 2011, 2012, and 2013].

---. Office of City Auditor Gary Blackmer and Office of City Commission Erik Sten. Publicly Financed Campaigns in Portland. March 22, 2005.

---. Office of City Commissioner Jim Francesconi. Press release. Francesconi Announces Effort to Develop Citywide Public Involvement Standards Taskforce including citizens and city staff will make recommendations to Council. October 20, 2002.

---. Office of Management and Finance. Budget Outreach Options \& Analysis: Report of the 2004-05 Budget Outreach Study Group. September 2005.

---. ---. Bureau of Internal Business Services. 2013 City of Portland Civil Rights Title VI Plan. May 2013. 
---. ---. ---. Americans with Disabilities Act Title II Program. Web. <http://www.portlandoregon.gov/bibs/62112> . Downloaded November 1, 2013.

---. ---. Memo from Casey Short and Andrew Scott to Bureau Directors et al. SUBJECT: FY 2009-10 Budget Approach and Process, October 17, 2008.

---. Office of the Mayor. Memo from Mayor Bud Clark to Bureau Managers. RE: Neighborhood Recognition Week May 6-10, 1985. 8 March 1985.

---. Office of the Mayor. Memo from Mayor Bud Clark to city commissioners. RE: Neighborhood Recognition Week Events-May 6-10. 26 April 1985.

---. Office of Mayor Tom Potter. Report on the Bureau Innovation Project. May 2005.

---. ---. The Mayor's Bureau Innovation Project \#9: Public Involvement. Public Involvement Toolkit. November 2006.

---. ---. Mayor Potter Appoints Interim ONI Director. December 29, 2005.

---. Planning Commission. Proposal for a City Policy Statement on District Planning. April 14, 1971.

---. The Portland Plan: Summary, April 2012.

---. The Portland Plan: A Framework for Equity, April 2012.

---. Public Involvement Task Force. Guidelines for public involvement in City of Portland Bureau Budget Advisory Committees (BACS). Adopted by the City Council on September 26, 2012.

---. ---. Accessibility Workgroup Priority Recommendations. November 17, 2003.

---. Task Force on Neighborhood Involvement. Report and Recommendations, 7 February 1996.

---. visionPDX. Community Engagement Report. October 2007.

---. ---. The Five Elements. visionPDX. [no date]. Web. Downloaded October 8, 2013. $<$ http://www.visionpdx.com/reading/visiondocument/five_elements.html $>$.

---. ---. Portland 2030: a vision for the future by the people of Portland, Oregon. February 2008. 
---. ---. Vision into Action. 2008 Community Action Grants Program. Web. [no date]. < http://www.visionpdx.com/action/grants.php> .

---. Vision into Action Coalition. Current Projects. [no date]. Web. Downloaded Oct 6, 2013.< http://www.visionintoaction.org/?page_id=14> .

\section{$\underline{\text { Newspaper Articles }}$}

Ashton, David. "New Parks Commissioner Outlines Plans.” East Portland News. 2013. Web. <http://eastpdxnews.com/general-news-features/new-parks-commissioneroutlines-plans/> . Downloaded October 18, 2013.

Bailey, Matt. “Convenience store guidelines criticized.” Oregonian 27 August 1986.

“Booming start set for festival's Starlight Parade.” Oregonian 31 May 1985.

Carlin Ames, Sarah. "Potter appointment hailed by police, people." Oregonian. October 25, 1990.

---. "Potter takes oath as new police chief." Oregonian. November 20, 1990.

Christ, Janet. "Neighborhoods Report Leaves System Intact.” Oregonian, 13 November 1995.

---. "Panel Wants to Put More Cash in Coalitions." Oregonian, 4 December 1995.

Chuang, Angie. "Coalition Promotes Community Involvement." Oregonian. 17 February 2004.

“Citizen concerns object of 'City Listens’ program.” Editorial. Oregonian 29 April 1986.

“Citywide group 'official.’” Oregonian 30 March 1984.

“Citywide neighborhood picnic on tap." Oregonian 21 August 1984.

“Community Calendar.” Oregonian 26 June 1984.

“Council ceremony to honor volunteers." Oregonian 10 May 1987.

“Council modifies neighborhood association law.” Oregonian January 25, 1974.

“Creating a child-friendly city.” Editorial. Oregonian 2 January 2005. 
Dolan, Mike. "Festival to focus on Southeast community." Oregonian 25 August 1981.

Dworkin. Andy. "Portland sets up Office of Human Relations." Oregonian 17 January 2008.

Ellis, Barnes. “Katz Produces 'Transitional' Budget for Portland.” Oregonian 10 April 1993.

Erickson, Steve. "Pied Piper opens fair to children.” Oregonian 23 July 1986.

Falk, Susan. “Community history, symbolism unfurl.” Oregonian 9 May 1985.

---. "Refugees get banners of ground." Oregonian 2 May 1985.

Filips, Janet. "Potter \& daughter.” Oregonian, June 30, 1991.

Fitzgibbon, Joe. "Neighborhood association leaders share experiences at assembly." Oregonian 5 March 2001.

Gilbert, Holly. "KGW Cancels Portland Neighborfair.” Oregonian 3 February 1990.

Goetze, Janet. "Biggest block party in the U.S. blends cultures, cuisines." Oregonian 17 July 1981.

---. "City neighborhood agency embattled with defenders, foes." Oregonian, 9 November 1975.

---. "Fun, food, fellowship on tap at Neighborfair.” Oregonian 20 July 1979.

---. "Neighborhood agency loses bureau status." Oregonian, 14 November 1975.

---. "Praise, criticism leveled at neighborhood agency." Oregonian, 6 November 1975.

---. "Streamers mark start of festivities at Neighborfair." Oregonian 19 July 1979.

---. "Waterfront Park backers 'vindicated' by Neighborfair." Oregonian, 1 August 1976.

Griffin, Anna. "Portland children write own bill of rights. Oregonian 16 August 2006.

---. "Where to put day laborers." Oregonian 29 July 2007.

---. "Young voices counsel council on big issues.” Oregonian 6 March 2005. 
Hallman, Tom, Jr. "City commitment to community policing means change for both officers, citizens." Oregonian. January 17, 1989.

Hayakawa, Alan. "Clark victory boosts “Expose Yourself' sales.” Oregonian 17 May 1984.

Hortsch, Dan. "Neighborfair draws thousands to party alongside river." Oregonian 16 July 1982.

“Keep Grass Roots Green.” Editorial. Oregonian 10 February 1993.

Kiyomura, Cathy. "Council OKs Neighborhood Association Study." Oregonian 20 October 1994.

---. "Panel Finalized Portland Strategy." Oregonian 3 August 1991.

Korn, Peter. "Neighborhood Activism: Triumph of the past, hope for the future." Portland Tribune. 2 June 2006.

Kost, Ryan. "Hales shuffles city bureaus.” Oregonian 4 June 2013.

Lane, Dee and Tom Hallman, Jr. "Clark, still focus on crime fight." Oregonian, October 30, 1988.

Learn, Scott. "Neighborhood Coalitions: No to Saltzman.” Oregonian 20 April 2001.

---. "Leonard wins a second term.” Oregonian, May 19, 2004.

---. "Saltzman Backs Off Proposal to Open Bids on Neighborhood Services." 9 May 2001.

---. "Workers Air Grievances over Reductions on the Portland Budget at a Neighborhood Meeting." Oregonian 30 April 2001.

"Learn to talk to your city." Editorial. Oregonian 25 April 1985.

“Maintain neighborhood focus.” Editorial. Oregonian 28 March 1984.

Mazza, Patrick. "What's happened to the neighborhood movement?" NW Examiner, October 1993.

Mitchell, S. Renee. “Three wrong votes don't make City Hall right.” Oregonian, September 12, 2003. 
---. "You can’t Speak for Us Unless You Talk to Us.” Oregonian 2 May 2001.

“Neighborhood banners.” Oregonian 2 March 1985.

"Neighborhood groups sew up banner designs." Oregonian 26 November 1984.

“Neil Goldschmidt for Portland's mayor.” Editorial. Oregonian 7 May 1972.

Nkrumah, Wade. "Students ratify youth rights agenda." Oregonian 2 June 2006.

---. "City likely to add northwest garage sites." Oregonian 5 November 2003.

Nktumah, Wade and Henry Stern. "Leonard, activists clash over vision for participation." Oregonian 2 October 2003.

“Nourish Grass Roots." Editorial. Oregonian 7 October 1993.

Oliver, Gordon. "Convenience store 'epidemic' subject of meeting." Oregonian 26 September 1984.

---. "Planners support store plan." Oregonian 24 September 1986.

Olmos, Robert. "Neighborfair: Food, fun highlight day.” Oregonian 19 July 1976.

"Open house drill welcomes neighborhood associations to firehouse offices." Oregonian 9 April 1985.

Painter, John, Jr. "Clark 'people' strategy credited with Ivancie ouster." Oregonian 17 May 1984.

---. "Forum planned for City Council candidates." Oregonian 7 September 1984.

---. "Inaugural ball takes on regal proportions." Oregonian 3 January 1985.

Pihl. Melvin. Letter to the editor. Oregonian 25 July 251976.

Potter, Tom. Op Ed. "In my opinion: City must reconnect to community policing." Oregonian, August 8, 2001.

Rollins, Michael. “Standing Tall.” Oregonian, November 18, 1990.

Rollins, Michael and Tom Hallman, Jr. Oregonian. March 14, 1993.

Rubenstein, Sura. "Groups cite more clout against OCA.” Oregonian. June 10, 1991. 
Ruble, Web and Leverett Richards. "Neighborfair: Rain can't dampen spirit.” Oregonian 18 July 1977.

Sarasohn, David. “On Portland children, Potter means it.” Oregonian 30 January 2005.

Schmidt, Brad. “A fight to the finish.” Oregonian 23 December 2012.

---. "Portland Commissioner Amanda Fritz approaches $\$ 250,000$ in self-funding for reelection bid," OregonLive, Web. October 16, 2012 at 3:45 PM.

---. "Vote ends trial run of publicly funded campaigns." Oregonian 4 November 2010.

---. “What's cut in budget?” Oregonian 4 May 2011.

"Schnitzer chosen as trustee; neighborhood flags to unfurl." Oregonian 23 August 1985.

“Schrunk appoints 16 to aid area plans.” Oregonian 27 January 1972: 24.

“Starlight parade to kick off with six-gun salute.” Oregonian, 29 May 1986.

Stern, Henry. "City Matters: Tardy Council hears a word from mayor." Oregonian, September 26, 2003.

---. “City’s neighborhood office adds duties.” Oregonian, July 22, 2003.

---. "Leonard rankles a few bureau chiefs at City Hall." Oregonian, December 24, 2002.

---. "Neighborhood involvement director resigns.” Oregonian, September 22, 2003.

---. "Portland former police chief enters mayoral race." Oregonian, September 4, 2003.

---. "Resistance greets push to expand crime prevention." Oregonian, October 7, 2003.

Stickel, Bridget. "Ethnic fare, sunshine draw thousands to Neighborfair." Oregonian 20 July 1981.

“Strachan got start in Northwest.” NW Examiner. October 1993.

Theen, Andrew. "Day laborer advocates seek permanent site." Oregonian 27 October 2013.

Tomlinson, Stuart. “Who’s Who at Bud's Ball.” Oregonian 8 February 1986. 
“Watching each other's back.” Editorial. Oregonian 9 May 2011.

Werneken, John. "In my opinion: Association to serve neighborhood groups." Oregonian 24 April 1984.

$\underline{\text { Unpublished Meeting Notes, Interviews and Personal Communications }}$

Ahmed-Shafi, Afifa. Conversation with Leistner, March 15, 2011.

Alarcón de Morris, Amalia. Conversation with Leistner. March 6, 2011.

---. Conversation with Leistner. June 32013.

---. Conversation with Leistner, June 12, 2013.

Badrick, Tom. Email to Leistner, October 17, 2013.

Butman, Laurel. Email to Leistner, June 10, 2013.

Cheron, Nickole. Conversation with Leistner, October 31, 2013.

España, Ray. Conversation with Leistner, June 22, 2013.

Fritz, Amanda. Email to Leistner, October 17, 2013.

Hoop, Brian. Conversation with Leistner, July 11, 2008.

---. Email to Leistner, December 2, 2010.

---. Email to Leistner, October 21, 2013, 2:27 PM.

---. Email to Leistner, October 21, 2013, 2:34 PM.

---. Conversation with Leistner, February 16, 2011.

---. Conversation with Leistner, December 3, 2012.

---. Conversation with Leistner, May 292013.

Hoyt, Steve. Email to Leistner, June 6, 2013.

Kennedy-Wong. Elizabeth. Conversation with Leistner, February 17, 2010. 
Kimura, Arlene. Conversation with Leistner, October 22, 2013.

Lane, David. Email to Leistner, July 18, 2008.

Leistner, Paul. Personal notes. Bureau Innovation Project 8. January 4, 2006.

---. Personal notes. Neighborhood Association Leaders Event hosted by the Office of Mayor Tom Potter. September 16, 2006.

---. Personal notes. Meeting with Mayor Tom Potter. April 18, 2008.

---. Personal notes. Community Connect. November 30, 2006.

---. Personal notes. Community Connect. February 21, 2007.

---. Personal notes. Community Connect Advisory Committee. August 21, 2007.

---. Personal notes. Neighborhood District Coalition Directors and Chairs Group. October 10, 2013.

Nettekoven, Linda. Email to Leistner, June 5, 2013.

Odell, Julie. Email to Leistner, June 11, 2013.

Perlman, Lee. Conversation with Leistner. February 13, 2013.

Potter, Tom. Conversation with Leistner. March 30, 2009.

Robinson, Linda. Email to Leistner, October 20, 2013, 1:15 AM.

Robinson, Linda. Email to Leistner, October 20, 2013, 10:06 AM.

Robinson, Linda. Email to Leistner, October 20, 2013, 11:04 AM.

Sieber, Mark. Conversation with Leistner. March 16, 2012.

---. Conversation with Leistner, October 17, 2013. 


\section{APPENDIX}

PORTLAND MAYORS, ONA/ONI COMMISSIONERS IN CHARGE, AND ONA/ONI DIRECTORS-1973 through 2013

Name:

File type:

Size:

Required application software
Portland Mayors, ONA/ONI Commissioners in Charge, and ONA/ONI Directors (1973 through 2013)

PDF

$108 \mathrm{~KB}$

Abode Reader 